FHWA/IN/JTRP-2008/14

Final Report

EVALUATION OF PERFORMANCE AND DESIGN OF ULTRA-THIN WHITETOPPING (BONDED CONCRETE RESURFACING) USING LARGE-SCALE ACCELERATED PAVEMENT TESTING

Scott A. Newbolds Jan Olek

October 2008 


\section{TECHNICAL Summary}

INDOT Research

Technology Transfer and Project Implementation Information

TRB Subject Code: 24-4 Pavement Evaluation and Testing

October 2008

Publication No. FHWA/IN/JTRP-2008/14, SPR-2419

Final Report

\section{Evaluation of Performance and Design of Ultra-Thin Whitetopping (Bonded Concrete Resurfacing) Using Large Scale Accelerated Pavement Testing}

\section{Introduction}

Ultra-Thin Whitetopping (UTW) is a pavement rehabilitation technique that involves the placement of a thin Portland Cement Concrete (PCC) overlay, 2 inches $(50 \mathrm{~mm}$ ) to 4 inches (100 mm) thick, over a distressed Hot Mix Asphalt (HMA) pavement. Typically, the HMA pavement is milled and cleaned which helps to create a bond between the existing HMA pavement and the PCC overlay. The bond between the two layers promotes composite action of the pavement section and as a result has a direct impact on the performance of the UTW Pavement. This composite action allows for the reduced thickness in the UTW layer. Additionally, a short joint spacing is typically used, which reduces the UTW flexural and curling stresses.

In this study three different test areas were constructed in the INDOT/Purdue University Accelerated Pavement Testing facility. Each test area had different lanes that varied by concrete mix design, bonding preparation, and pavement cross-section. These sections were subjected to 300,000 to 560,000 load applications. An additional test area was constructed outside the facility to evaluate pavement thicknesses and environmental effects.

\section{Findings}

The project resulted in a modified UTW design methodology that takes into account the stiffness of all underlying pavement layers. Additionally, the project provides insight into the effects of pavement section, UTW mix design, mechanical loading, bond conditions, and environmental loading on the performance of UTW. A limited Life Cycle Cost Analysis included in the report indicates that UTW overlays can be cost effective versus HMA overlays.

\section{Implementation}

The results discussed in the report indicate that when proper bonding is achieved, UTW pavements can perform well. Additionally, no debonding was noted before $60,000-15,000 \mathrm{lb}$ (67 kN) load applications and no cracking was observed until after 110,000 -15,000 lb (67 kN) load applications. These findings confirm the results observed in other states that UTW is a viable technique for the rehabilitation of distressed HMA pavements. As such, it is recommended that INDOT proceed with implementation of the UTW technique. Implementation can proceed statewide.

It is recommended that designs initially be performed using the existing PCA method with in-situ material property data (back-calculated layer moduli and thicknesses) supplied by FWD testing. A research implementation project can be initiated to evaluate the proposed FWD method for UTW design prior to usage throughout the state.

Further design recommendations include information on site selection, UTW concrete mix design, joint design, and repairs and milling depths. Construction recommendations include information on milling and surface preparation, concrete placement, finishing and texture, curing, joint sawing, pay items, and acceptance. From this information it is expected that a UTW specification can be easily developed. 


\section{Contacts}

For more information:

Scott A. Newbolds

Principal Investigator

Indiana Department of Transportation

Office of Research and Development

West Lafayette, IN 47906

Phone: 765-463-1521

Fax: 765-497-1665

Email: snewbolds@indot.in.gov

\section{Jan Olek}

Principal Investigator

School of Civil Engineering

Purdue University

West Lafayette, IN 47907

Phone: (765) 494-5015

Fax: (765) 497-2402

Email: olek@purdue.edu
Indiana Department of Transportation Office of Research and Development 1205 Montgomery Street

P.O. Box 2279

West Lafayette, IN 47906

Phone: (765) 463-1521

Fax: (765) 497-1665

\section{Purdue University}

Joint Transportation Research Program

School of Civil Engineering

West Lafayette, IN 47907-1284

Phone: (765) 494-9310

Fax: (765) 496-7996

E-mail: jtrp@ecn.purdue.edu

http://www.purdue.edu/jtrp 
Final Report

FHWA/IN/JTRP-2008/14

\title{
Evaluation of Performance and Design of Ultra-Thin Whitetopping (Bonded Concrete Resurfacing) Using Large Scale Accelerated Pavement Testing
}

\author{
By \\ Scott A. Newbolds \\ Section Manager \\ Office of Research and Development \\ Indiana Department of Transportation \\ And \\ Jan Olek \\ Professor of Civil Engineering \\ School of Civil Engineering \\ Purdue University \\ Joint Transportation Research Program \\ Project No: C-36-46T \\ File No: 5-11-20 \\ SPR-2419 \\ Conducted in Cooperation with the \\ Indiana Department of Transportation \\ And the U.S. Department of Transportation \\ Federal Highway Administration
}

The contents of this report reflect the views of the authors who are responsible for the facts and accuracy of the data presented herein. The contents do not necessarily reflect the official view or policies of the Federal Highway Administration or the Indiana Department of Transportation.

This report does not constitute a standard, specification, or regulation.

Purdue University

West Lafayette, Indiana

October 2008 
TECHNICAL REPORT STANDARD TITLE PAGE

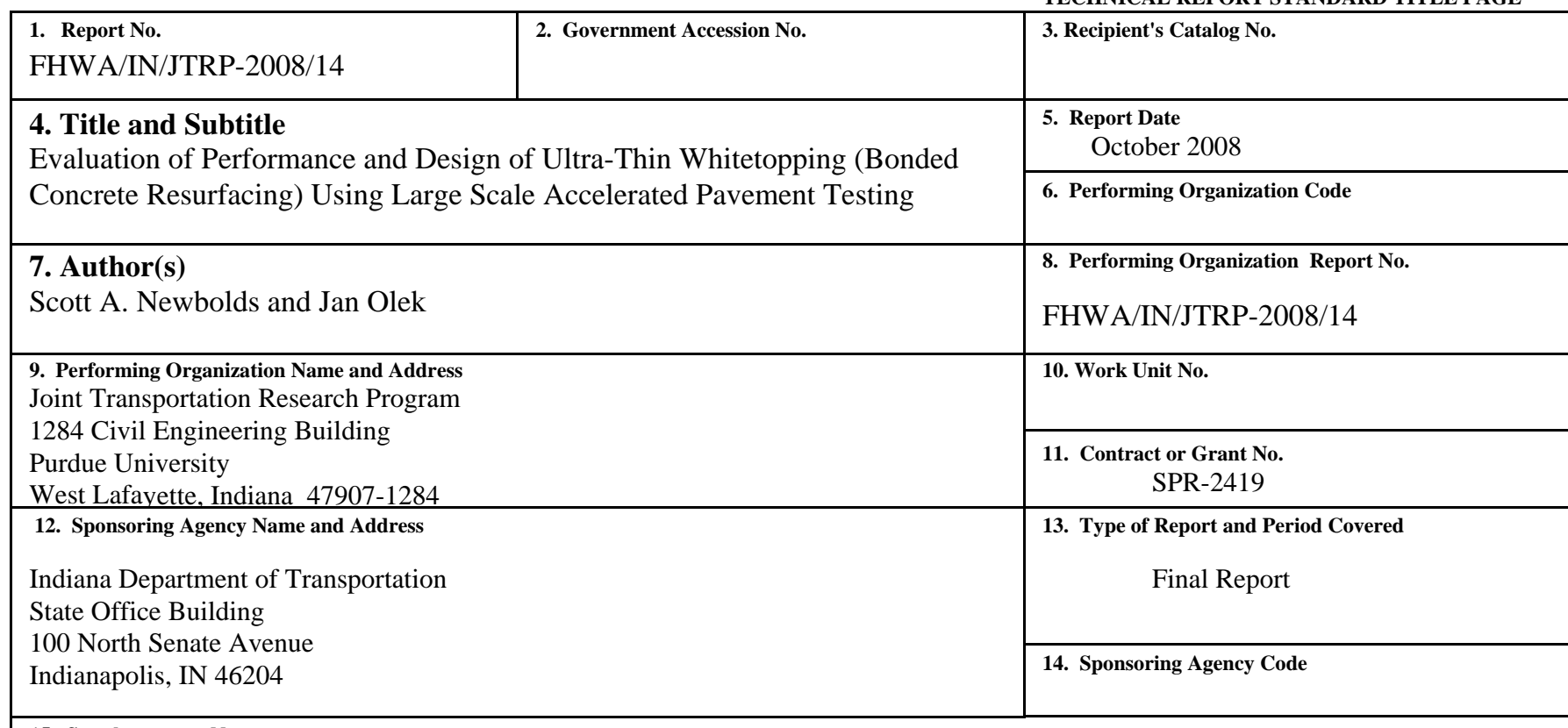

\section{Supplementary Notes}

Prepared in cooperation with the Indiana Department of Transportation and Federal Highway Administration.

\section{Abstract}

Ultra-Thin Whitetopping (UTW) is a pavement rehabilitation technique that involves the placement of a thin Portland Cement Concrete (PCC) overlay, 2 inches $(50 \mathrm{~mm})$ to 4 inches (100 mm) thick, over a distressed Hot Mix Asphalt (HMA) pavement. Typically, the HMA pavement is milled and cleaned which helps to create a bond between the existing HMA pavement and the PCC overlay. The bond between the two layers promotes composite action of the pavement section and as a result has a direct impact on the performance of the UTW Pavement. This composite action allows for the reduced thickness in the UTW layer. Additionally, a short joint spacing is typically used, which reduces the UTW flexural and curling stresses.

In this study three different test areas were constructed in the INDOT/Purdue University Accelerated Pavement Testing facility. Each test area had different lanes that varied by concrete mix design, bonding preparation, and pavement crosssection. These sections were subjected to 300,000 to 560,000 load applications. An additional test area was constructed outside the facility to evaluate pavement thicknesses and environmental effects.

The project resulted in a modified UTW design methodology that takes into account the stiffness of all underlying pavement layers. Additionally, the project provides insight into the effects of pavement section, UTW mix design, mechanical loading, bond conditions, and environmental loading on the performance of UTW.

\begin{tabular}{|l|l|l|l|}
\hline $\begin{array}{l}\text { 17. Key Words } \\
\begin{array}{l}\text { Pavement Rehabilitation, Ultra-Thin Whitetopping, } \\
\text { Bonded Concrete Resurfacing, Accelerated Pavement } \\
\text { Testing }\end{array}\end{array}$ & $\begin{array}{l}\text { 18. Distribution Statement } \\
\text { No restrictions. This document is available to the public through the } \\
\text { National Technical Information Service, Springfield, VA 22161 }\end{array}$ \\
\hline $\begin{array}{l}\text { 19. Security Classif. (of this report) } \\
\text { Unclassified }\end{array}$ & $\begin{array}{l}\text { 20. Security Classif. (of this page) } \\
\text { Unclassified }\end{array}$ & $\begin{array}{c}\text { 21. No. of Pages } \\
\text { 22. Price }\end{array}$ \\
\hline
\end{tabular}


ACKNOWLEDGMENTS

The authors wish to thank Profs. Tom Robertson and Jason Weiss for their technical assistance and advice during the project. In particular we want to thank Prof. Robertson for his expertise with the instrumentation in the APT. Also, we would like to thank all those who helped in a particular way with this project: Kevin Brower, Steve Dick, Dr. Khaled Galal, Sedat Gulen, Prof. John Haddock, Dwayne Harris, Karen Hatke, Danny Heath, Tony Johnson, Dr. Eyal Levenburg, Becky McDaniel, Mike Moredock, Dr. Tommy Nantung, Colleen Naughton, Dr. Samy Noureldin, Calvin Reck, Dr. Ayesha Shah, Brandon Stevens, Jason Taylor, Dave Ward, and Jim Wooton.

The contributions of the Study Advisory Committee members, Lee Gallivan, Tony Zander, Larry Vaughan, Todd Johnson, Bill Tompkins, Mike Byers, Bill Flora, and Kumar Dave are also gratefully acknowledged.

The authors further want to express gratitude to Mr. Tom Burnham and MnROAD and Mr. Dave Amos of the Missouri DOT for sharing the FWD data used for comparisons in this work.

Finally, we want to thank INDOT and the FHWA for funding this project. 
TABLE OF CONTENTS

Page

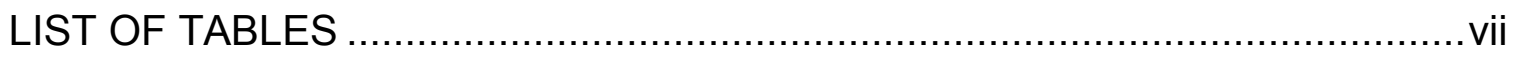

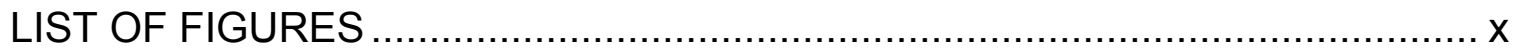

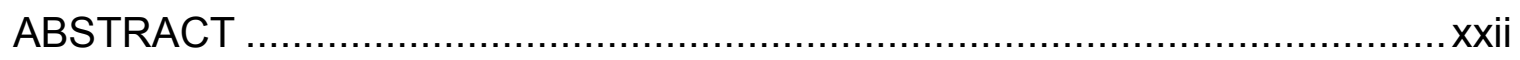

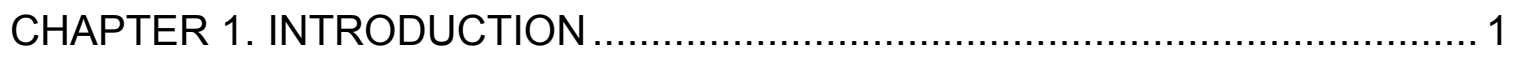

1.1. Background and Problem Statement ............................................... 1

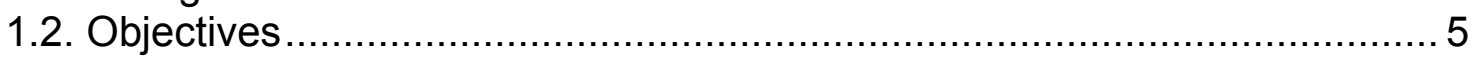

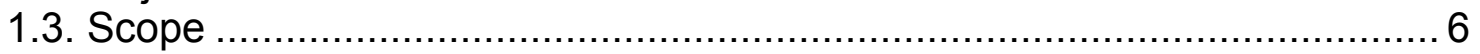

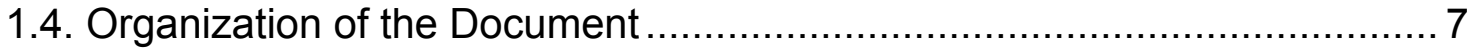

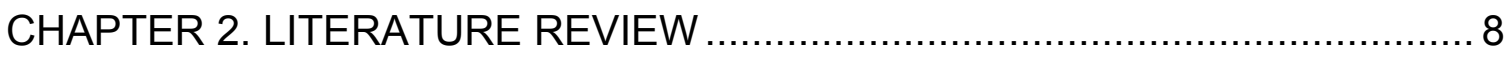

2.1. Development of Ultra-Thin Whitetopping Rehabilitation Technique............ 8

2.1.1. Early Developments ........................................................... 9

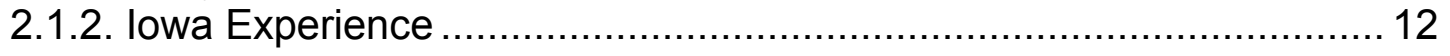

2.1.3. Florida Experience................................................................ 13

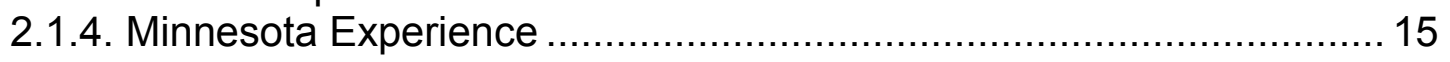

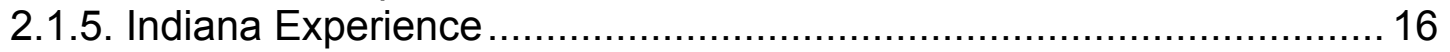

2.2. Federal Highway Administration Accelerated Loading …...................... 18

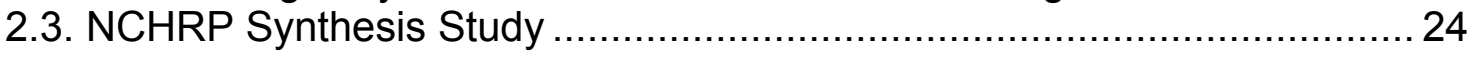

2.4. Portland Cement Association Design Methodology …............................. 24

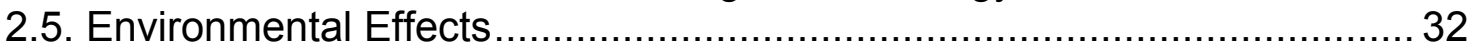

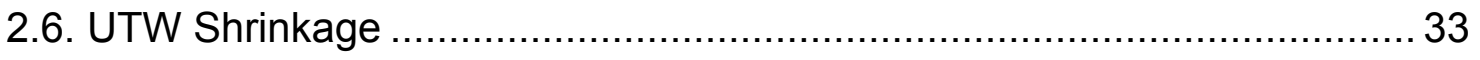

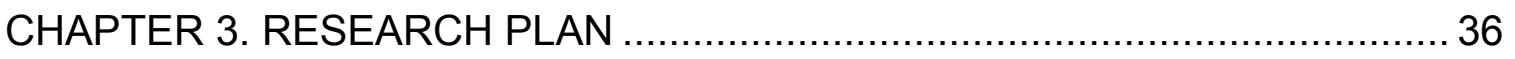

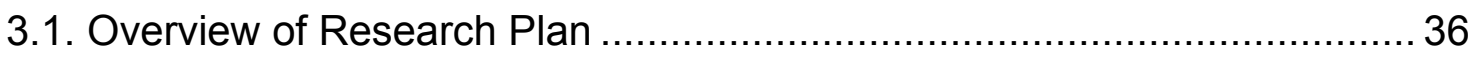

3.2. Overview of Data Analysis Plan....................................................... 39

CHAPTER 4. TEST AREAS AND TEST METHODOLOGIES …..................... 41 
4.1. Accelerated Pavement Testing Facility .............................................. 41

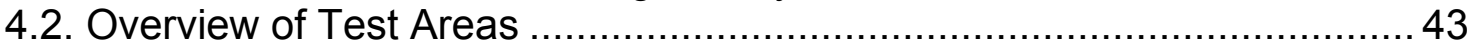

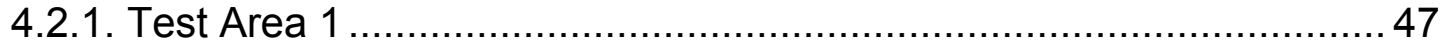

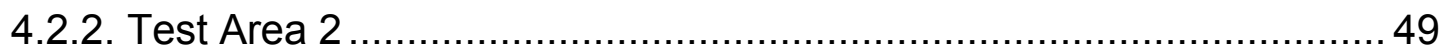

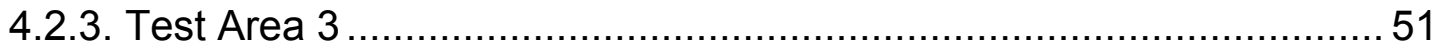

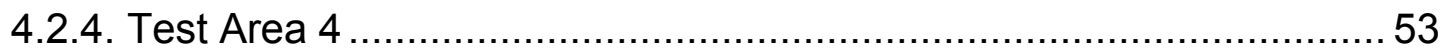

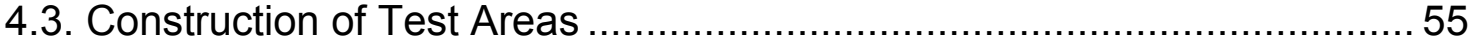

4.3.1. Subbase and Subgrade Placement ............................................. 55

4.3.2. Composition and Placement of Underlying Hot Mix Asphalt...............56

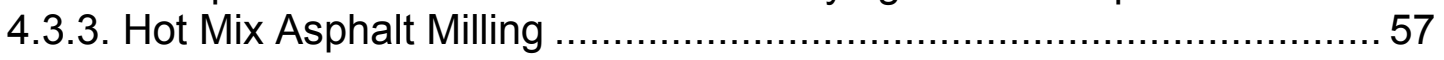

4.3.4. Summary of the Instrumentation Plan ......................................... 58

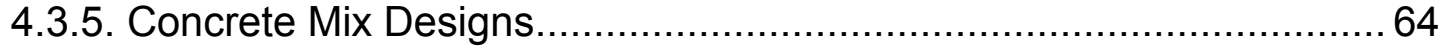

4.3.6. Construction of the UTW Test Lanes............................................ 68

4.4. Accelerated Pavement Loading ............................................................ 74

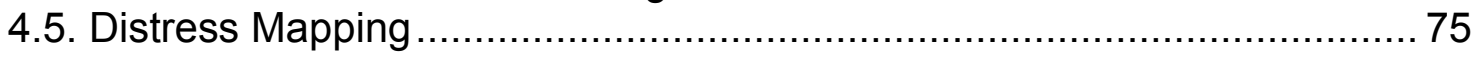

4.6. Testing of Concrete Mechanical Properties ......................................... 76

4.6.1. Test Specimen Preparation ................................................... 76

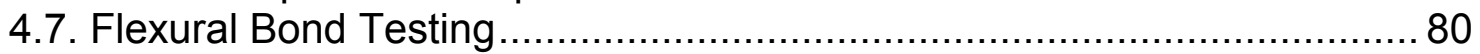

4.7.1. Flexural Bond Test Specimen Preparation ..................................... 81

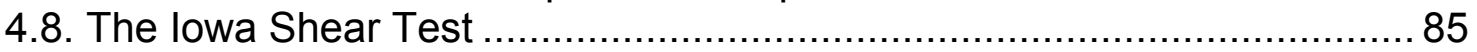

4.8.1. lowa Shear Specimen Preparation and Testing .............................. 87

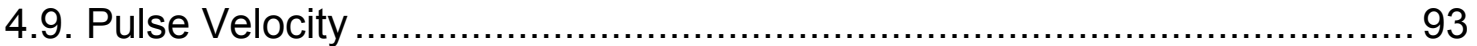

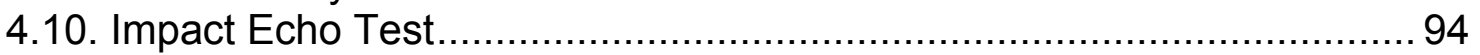

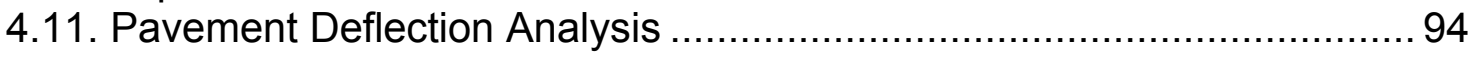

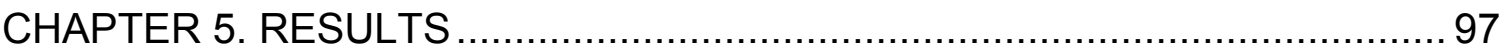

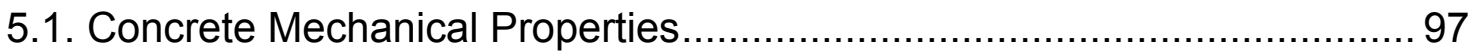

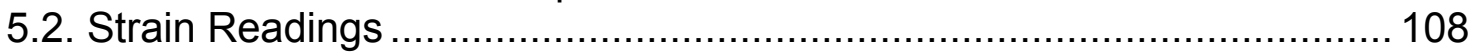

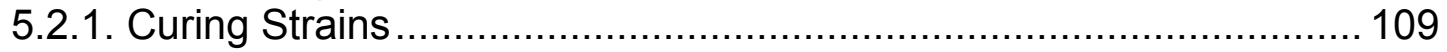

5.2.2. Strain Changes with Increasing Load Applications and Dynamic Strain

under APT Loading........................................................................ 110

5.2.3. Comparison of Shrinkage for Bonded and Unbonded Slabs ........... 114

5.3. Environmentally-Induced Pavement Temperatures.............................. 114

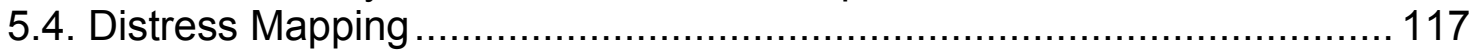

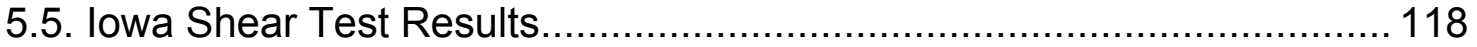

5.6. Flexural Bond Test Results................................................................. 122

5.7. Pavement Deflection Analysis ....................................................... 123

5.8. Ultrasonic Pulse Velocity and Impact Echo Testing.............................. 125

CHAPTER 6. ANALYSIS AND DISCUSSION OF UTW RESPONSES ............ 131

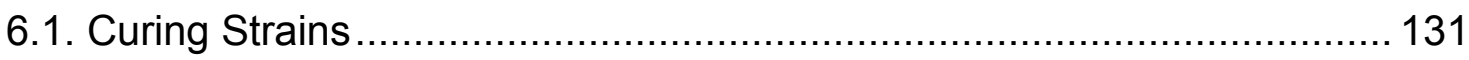

6.1.1. Influence of Concrete Mixture Composition on Curing Strains ......... 132

6.1.2. Influence of Interfacial Bond Conditions on Curing Strains ............... 137 
6.2. Drying Shrinkage Strains 140

6.2.1. Influence of Concrete Mixture Composition on Drying Shrinkage Strains 141

6.2.2. Influence of Interfacial Bond Conditions on Drying Shrinkage Strains 146

6.3. Strain Distribution and Maximum Load-Induced Strains.

6.3.1. Influence of Structural Properties of the Pavement Sections on Strain

Distributions and Maximum Load-Induced Strains 152

6.3.2. Influence of Concrete Mixture Mechanical Properties on Strain

Distributions and Maximum Load-Induced Strains 159

6.3.3. Influence of Interfacial Bond Conditions on Strain Distributions and Maximum Load-Induced Strains ....

6.3.4. Influence of Mechanical Load Applications on Strain Distributions and

Maximum Load-Induced Strains...

6.3.5. Influence of Temperature Gradient on Strain Distribution and Maximum Load-Induced Strains 177

6.4. Type and Severity of Distresses 182

6.4.1. Influence of Structural Properties of the Pavement Sections on Type and Severity of Distresses 182 6.4.2. Influence of UTW Concrete Material Properties on Type and Severity of Distresses 186

6.4.3. Influence of Interfacial Bond Conditions on Type and Severity of Distresses. 189

6.4.4. Influence of Mechanical Load Applications on Type and Severity of Distresses. 190

6.4.5. Influence of Environmental Loading on Type and Severity of Distresses 194

6.5. Bond Strength

6.5.1. Influence of Structural Properties of the Pavement Sections on Bond Strength 195

6.5.2. Influence of UTW Concrete Material Properties on Bond Strength... 196

6.5.3. Influence of Environmental Loading on Bond Strength.................... 201

6.6. Radius of Relative Stiffness.............................................................. 203

6.6.1. Influence of Structural Properties of the Pavement Sections on Radius of Relative Stiffness 204

6.6.2. Influence of UTW Concrete Material Properties on Radius of Relative Stiffness. 206

6.6.3. Influence of Interfacial Bond Conditions on Radius of Relative Stiffness 209

6.6.4. Influence of Mechanical Load Applications on Radius of Relative Stiffness.

6.6.5. Influence of Environmental Loading on Radius of Relative Stiffness 215

CHAPTER 7. PROPOSED CHANGES TO UTW DESIGN METHODOLOGY.. 217 
7.1. Evaluation of PCA UTW Design Method .........................................2 218

7.1.1. Comparison of Calculated PCA and Measured UTW Strains ........... 219

7.1.2. Calibration of Calculated UTW Strains ......................................... 222

7.1.3. Comparison of PCA Calculated and Measured HMA Strains ........... 225

7.1.4. Calibration of Calculated HMA Strains ……................................. 233

7.2. Falling Weight Deflectometer Approach .......................................... 237

7.3. UTW Design Methodology Using the Falling Weight Deflectometer

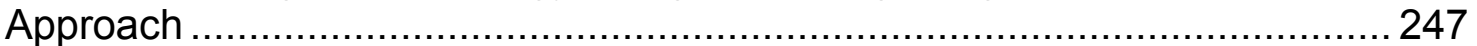

7.4. Overview of Proposed FWD UTW Design Methodology ...................... 250

7.5. Example Using Proposed FWD Design Methodology ........................... 253

CHAPTER 8. SUMMARY AND CONCLUSIONS ...................................... 259

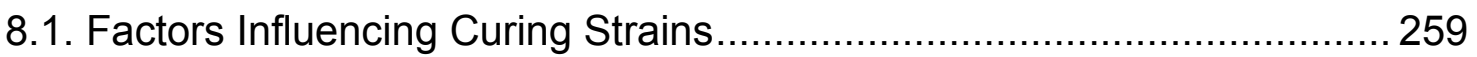

8.2. Factors Influencing Drying Shrinkage Strains................................... 260

8.3. Factors Influencing Strain Distribution and Maximum Load-Induced Strains

8.4. Factors Influencing Type and Severity of Distresses........................... 261

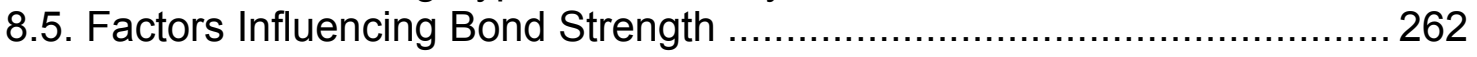

8.6. Factors Influencing Radius of Relative Stiffness.................................. 263

8.7. Proposed Changes to UTW Design Methodology …............................. 264

\section{CHAPTER 9. IMPLEMENTATION RECOMMENDATIONS AND COST}

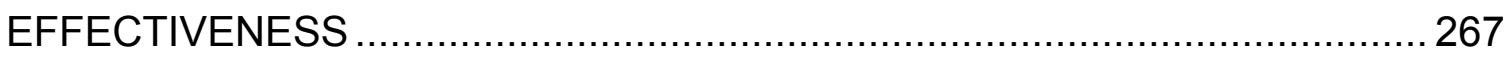

9.1. Recommendations for Design Implementation ..................................... 267

9.2. Recommendations for Construction Implementation ........................... 271

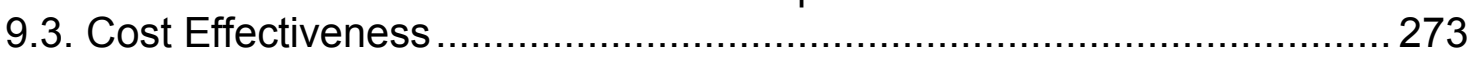

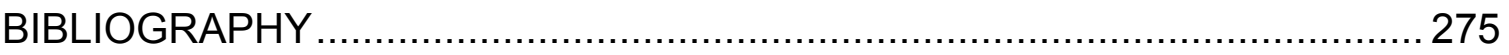

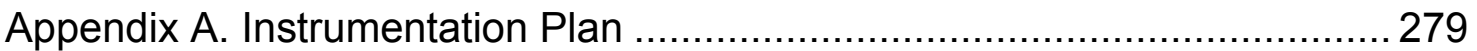

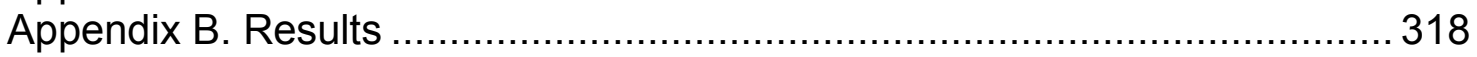

Appendix C. Strain Distribution Plots .................................................... 419

Appendix D. Life Cycle Cost Analysis..................................................... 429 


\section{LIST OF TABLES}

Table

Page

Table 3.1 Data Comparisons by Test Area......................................... 40

Table 4.1 Test Area Summary .................................................... 44

Table 4.2 Summary of Gages Used in Different Test Areas ......................... 60

Table 4.3 UTW Concrete Mix Designs .............................................. 65

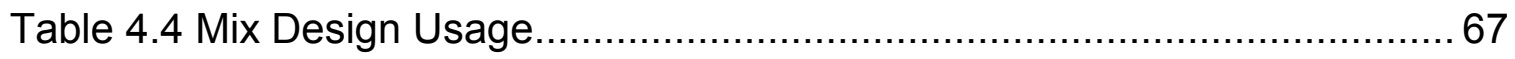

Table 4.5 Summary of Mechanical Property Test Specimens ...................... 77

Table 4.6 Summary of Concrete Mechanical Properties Testing .....................79

Table 4.7 Summary of Flexural Bond Test Specimens $\ldots \ldots \ldots \ldots \ldots \ldots \ldots \ldots \ldots \ldots \ldots 1$

Table 4.8 Summary of lowa Shear Specimens................................... 87

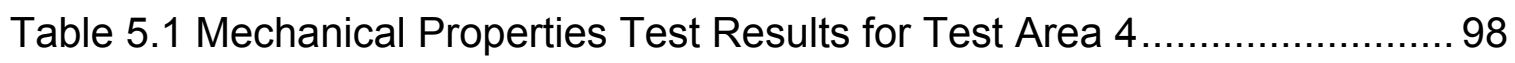

Table 6.1 Terminal Curing Strains for UTW Concrete Mix Designs................ 135

Table 6.2 Terminal Curing Strains for UTW Concrete and HMA under Various Bond Conditions ................................................. 139

Table 6.3 Drying Shrinkage Strains for UTW Concrete Mix Designs.............. 145

Table 6.4 Drying Shrinkage Strains from Surface Gages ......................... 148

Table 6.5 Drying Shrinkage Strains for Different Bond Conditions ................. 150

Table 6.6 Comparisons of Theoretical and Measured Maximum Strains ........ 157 
Table 6.7 Summary of Load-Induced Changes in Radius of Relative

Table 7.1 Comparison of PCA Calculated and Measured UTW Strains at the Bottom of the UTW Layer - Corner Location...

Table 7.2 Comparison of PCA Calculated and Measured HMA Strains 228

Table 7.3 Comparison of PCA Calculated and Measured HMA Strains Assuming New Critical Strain Location

Table 7.4 Comparison of PCA Calculated and Measured HMA Strains at Corner Location

Table 7.5 Comparison of FWD Calculated and Measured UTW Strains 241

Table 7.6 Comparison of FWD Calculated and Measured HMA Strains 245

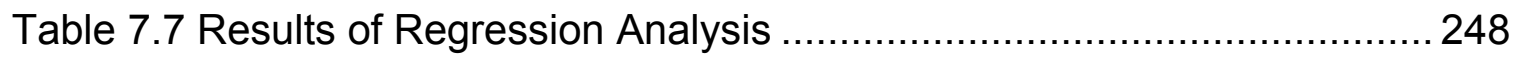

Table 7.8 Recommended Calibration Factors ............................................ 251

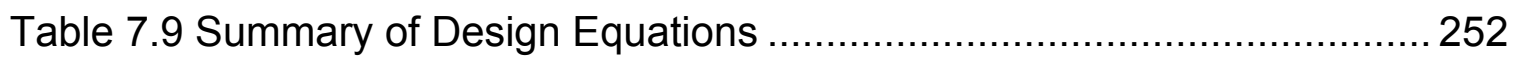

Table 7.10 UTW Stresses and HMA Strains for Single Axle Loads................. 255

Table 7.11 Total UTW Stresses and HMA Strains for Single Axle Loads.........256

Table 7.12 Fatigue Analysis of UTW Stresses for Single Axle Loads.............. 257

Appendix Table

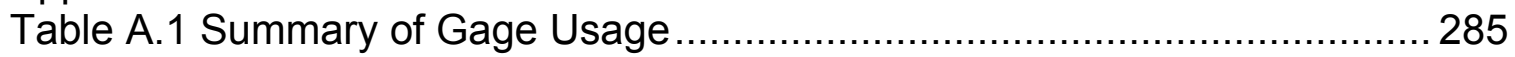

Table A.2 Summary of Expected Data and Sensor Ranges ......................... 287

Table A.3 System 6100 Channel Configurations ......................................... 293

Table A.4 Configuration for Vibrating Wire Gages..................................... 298

Table A.5 CR-10X Channel Configurations (Vibrating Wire) …....................... 299

Table A.6 Configuration for Thermocouples .................................................. 300 
$\begin{array}{ll}\text { Appendix Table } & \text { Page }\end{array}$

Table A.7 CR-10X Channel Configurations for Thermocouples .................... 301

Table A.8 Gage and Cable Connections ......................................... 305

Table A.9 Standard Gage Screw Terminal Connections for System 6100 ....... 306

Table A.10 Vibrating Wire Gage Connections to Multiplexer ........................ 316 


\section{LIST OF FIGURES}

Figure

Page

Figure 2.1 Effect of Short Joint Spacing on Performance of UTW Overlay, Mack et al. [1998]

Figure 2.2 Corner Cracking Mechanism, Rasmussen et al. [2002] (a) Repeated Wheel Loading (b) Permanent Deformation (c) Cracking in the UTW Layer.

Figure 2.3 Midslab Cracking Mechanisms, Rasmussen et al. [2002] (a)

Bottom-Up Cracking (b) Strain Reversal. 21

Figure 2.4 Joint Faulting Mechanisms, Rasmussen et al. [2002] (a) Longitudinal Joints (b) Transverse Joints

Figure 2.5 Joint Spalling Mechanism, Rasmussen et al. [2002] ...................... 24

Figure 2.6 Ratio between Maximum Tensile Stress and Available Tensile Strength, Petersson and Silfwerbrand [1993]

Figure 2.7 Drying Shrinkage of 4 Inch UTW Overlay at Mn/ROAD, Vandenbossche [2001]

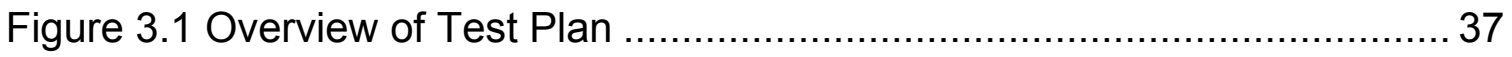

Figure 4.1 Accelerated Pavement Testing Facility ................................ 43

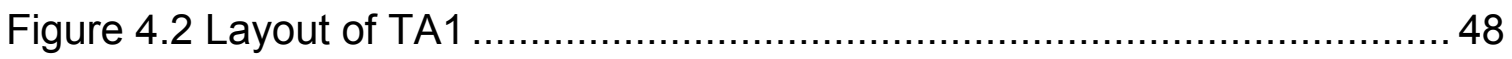

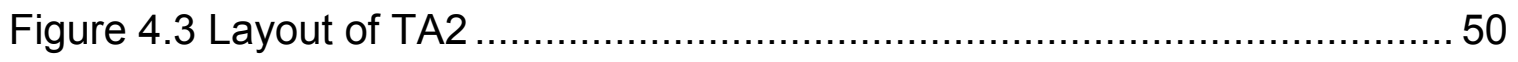

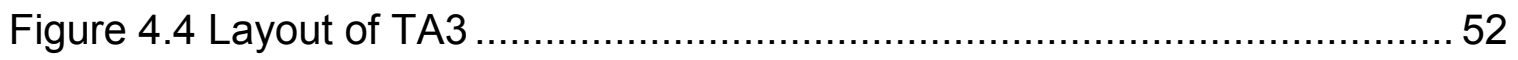

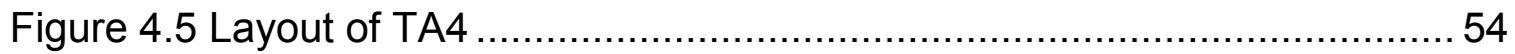


Figure

Page

Figure 4.6 Summary of Gage Placement (a) TA1 (b) TA2 (c) TA3 (d) TA4 ....... 63

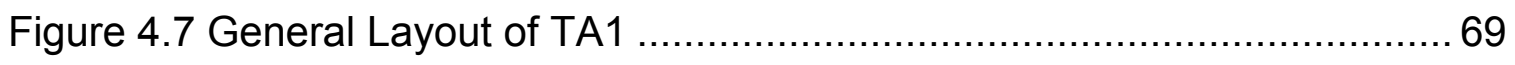

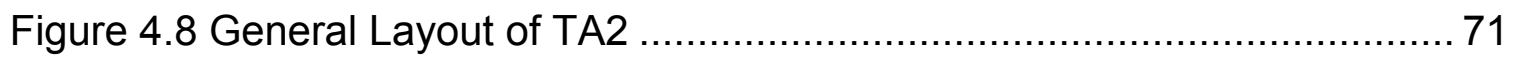

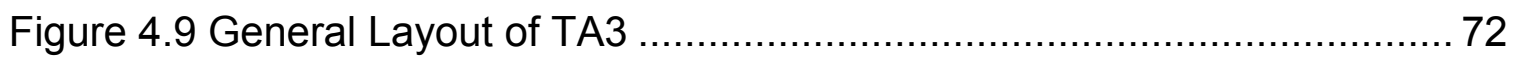

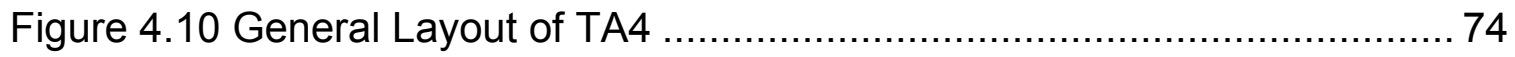

Figure 4.11 Diagram of Flexural Bond Test Specimen ............................. 82

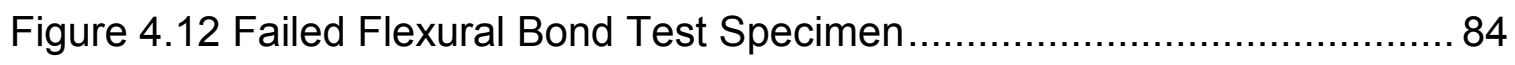

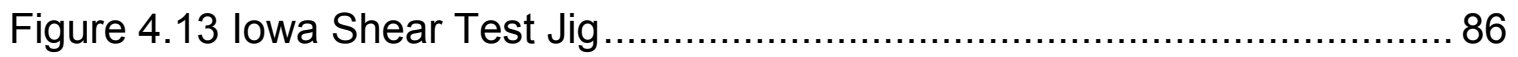

Figure 4.14 Diagram of a Typical lowa Shear Test Specimen ...................... 88

Figure 4.15 Cored lowa Shear Specimen......................................... 89

Figure 4.16 Layout of lowa Shear Cores ......................................... 92

Figure 4.17 Falling Weight Deflectometer Test on TA3 ............................ 95

Figure 5.1 Compressive Strength Test Results (a) TA1 (b) TA2 (c) TA3 (d) Laboratory Study ...................................................... 99

Figure 5.2 Flexural Strength Test Results (a) TA1 (b) TA2 (c) TA3

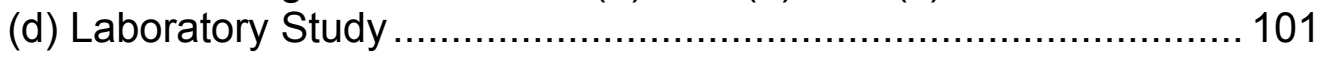

Figure 5.3 Modulus of Elasticity Results (a) TA1 (b) TA2 (c) TA3 ................ 104

Figure 5.4 Typical Gage Layout................................................. 109

Figure 5.5 Curing Strains - Test Area 2 - Lane 1 - Corner Location ................ 110

Figure 5.6 Strain versus Load Applications for Test Area 3 - Lane 1 - Edge Location ................................................................... 111 
Figure

Page

Figure 5.7 Strain versus APT Carriage Location - Test Area 2 - Lane 2 Edge Location (a) 5,000 Load Applications (b) 150,000 Load Applications (c) 275,000 Load Applications

Figure 5.8 Bonded and Unbonded Strains over Time - Test Area 1 114

Figure 5.9 Environmentally-Induced Temperatures - Test Area 4 (a) Low

Temperature (4:00 AM) (b) High Temperature (4:00 PM)............... 116

Figure 5.10 Distress Map for Test Area 2 - Lane 1 ................................... 117

Figure 5.11 lowa Shear Test Results for Test Area 2 Prepared Specimens .... 118

Figure 5.12 lowa Shear Test Results for Test Area 2 Cored Specimens ......... 119

Figure 5.13 lowa Shear Test Results for Test Area 3 Prepared Specimens .... 120

Figure 5.14 lowa Shear Test Results for Test Area 3 Cored Specimens ........ 121

Figure 5.15 lowa Shear Test Results for Laboratory Specimens.................... 122

Figure 5.16 Flexural Bond Test Results for UTW Beam Specimens ............... 123

Figure 5.17 Estimated Radii of Relative Stiffness (a) TA2 (b) TA3

(c) TA4

Figure 5.18 Ultrasonic Pulse Velocity Data for Laboratory Specimens

(a) 7d Specimens (b) 14d Specimens (c) 28d Specimens

(d) 90d Specimens.

Figure 5.19 Impact Echo Estimated and Actual Specimen Thicknesses for Laboratory Specimens (a) Beams (b) Cylinders ......................... 129

Figure 6.1 Comparisons of Theoretical Strain Distributions........................... 155

Figure 6.2 Comparisons of Theoretical and Measured Strain Distributions ...... 156

Figure 6.3 Comparisons of Theoretical Strains for Different Mix Designs

(a) TA2 (b) TA3. 160

Figure 6.4 Comparisons of Theoretical and Measured Strains for Lanes Constructed with MD-1 through MD-4 (a) TA2 (b) TA3. 162 
Figure 6.5 Comparisons of Calculated Strains for Different Bond Conditions

(a) TA2 (b) TA3.

Figure 6.6 Comparisons of Calculated and Measured Strains for Different Bond Conditions (a) TA2 (b) TA3 166

Figure 6.7 Strain Distribution for TA2 - Lane 3 (a) Edge (b) Corner 174

Figure 6.8 Theoretical Curling Strains in UTW resulting from Measured Temperature Gradients (a) Lane 1 (b) Lane 2 (c) Lane 3 179

Figure 6.9 Final Distress Comparisons for Test Areas 2 and 3 (a) TA2

(b) TA3. 184

Figure 6.10 Comparisons of Flexural and lowa Shear Strengths (a) TA2 (b) TA3. 198

Figure 6.11 Flexural Strength versus Bond Shear Strength 200

Figure 6.12 Comparisons of Theoretical and Measured Radii of Relative Stiffness $\left(l_{\text {est }}\right)$

Figure 6.13 Comparison of Theoretical and Measured Estimated Radii of Relative Stiffness for Different Mix Designs (a) TA2

(b) TA3.

Figure 6.14 Comparisons of Measured Radii of Relative Stiffness with Theoretical Bonded and Unbonded Radii (a) TA2 (b) TA3

Figure 7.1 Comparison of PCA Calculated and APT Measured UTW Strains (Bottom of UTW Layer - Corner Location) (a) TA2 (b) TA3.

Figure 7.2 Comparisons of Modified PCA UTW Strains at an 80\% Reliability with Measured Strains at the Bottom of the UTW Layer Corner Location

Figure 7.3 Comparison of PCA Calculated and APT Measured HMA Strains at the Bottom of the HMA - Edge Location (a) TA2 (b) TA3 226 
Figure

Page

Figure 7.4 Comparisons of Strains at the Edge and Corner Locations in HMA Layer (a) TA2 (b) TA3.

Figure 7.5 Comparison of PCA Calculated HMA Strains and HMA Strains

Equal to UTW Strains

Figure 7.6 Modified HMA Strains for Composite Section (TA2) at 80\%

Reliability

Figure 7.7 Comparison of PCA HMA Strains and Measured HMA Corner Strains in TA3. 235

Figure 7.8 Modified HMA Strains for HMA Pavement Section (TA3) at 80\%

Reliability

Figure 7.9 Comparison of Falling Weight Deflectometer Calculated and Measured UTW Strains (a) TA2 (b) TA3.

Figure 7.10 Modified UTW Strains based on FWD Approach at 80\% Reliability

Figure 7.11 Comparison of Falling Weight Deflectometer Calculated and Measured HMA Strains (a) TA2 (b) TA3. 244

Figure 7.12 Modified HMA Strains based on FWD Approach at $80 \%$ Reliability . 246

Figure 9.1 Cost Comparison. 24672

Appendix Figure

Figure A.1 Overview of Instrumented Test Areas (a) Test Area 1

(b) Test Area 2 (c) Test Area 3 (d) Test Area 4 281

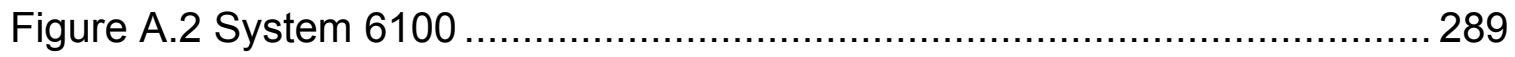

Figure A.3 Campbell Scientific CR10X Datalogger............................... 297

Figure A.4 Campbell Scientific AM16/32 Multiplexer ................................ 298

Figure A.5 Marking of Gage Locations ......................................... 303

Figure A.6 Installed Support Assembly with Gage.............................. 310 
Appendix Figure

Page

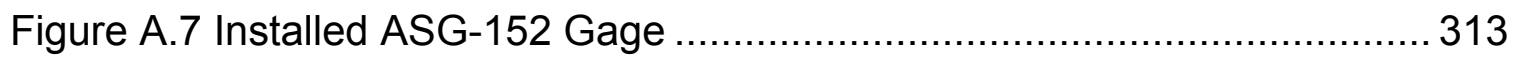

Figure A.8 Installed Vibrating Wire Strain Gages ...................................... 316

Figure B.1 Curing Strains - Test Area 1 (a) Joint (b) Mid-Panel (c) Edge

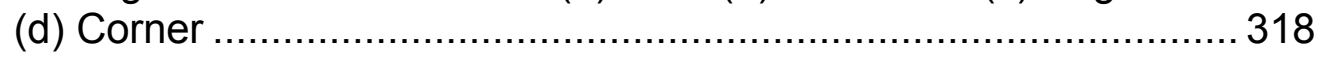

Figure B.2 Curing Strains - Test Area 2 - Lane 1 (a) Edge (b) Corner ............ 320

Figure B.3 Curing Strains - Test Area 2 - Lane 2 (a) Edge (b) Corner ............ 321

Figure B.4 Curing Strains - Test Area 2 - Lane 3 (a) Edge (b) Corner ............ 322

Figure B.5 Curing Strains - Test Area 2 - Lane 4 (a) Edge (b) Corner ............ 323

Figure B.6 Curing Strains - Test Area 2 - Lane 5 (a) Edge (b) Corner ............ 324

Figure B.7 Curing Strains - Test Area 3 - Lane 1 (a) Edge (b) Corner ............ 325

Figure B.8 Curing Strains - Test Area 3 - Lane 2 (a) Edge (b) Corner ............ 326

Figure B.9 Curing Strains - Test Area 3 - Lane 3 (a) Edge (b) Corner ............ 327

Figure B.10 Curing Strains - Test Area 3 - Lane 4 (a) Edge (b) Corner .......... 328

Figure B.11 Curing Strains - Test Area 3 - Lane 5 (a) Edge (b) Corner .......... 329

Figure B.12 Strain versus Load Applications - Test Area 1 - Unloaded

(a) Joint (b) Mid-Panel (c) Edge (d) Corner

Figure B.13 Strain versus Load Applications - Test Area 1 - Loaded

(a) Joint (b) Mid-Panel (c) Edge (d) Corner

Figure B.14 Strain versus Load Applications - Test Area 2 - Lane 1

Unloaded (a) Edge (b) Corner .

Figure B.15 Strain versus Load Applications - Test Area 2 - Lane 1

Loaded (a) Edge (b) Corner.

Figure B.16 (Viva il Papa) Strain versus Load Applications - Test Area 2 Lane 2 Unloaded (a) Edge (b) Corner 336 
Appendix Figure

Page

Figure B.17 Strain versus Load Applications - Test Area 2 - Lane 2 Loaded (a) Edge (b) Corner.

Figure B.18 Strain versus Load Applications - Test Area 2 - Lane 3

Unloaded (a) Edge (b) Corner ....

Figure B.19 Strain versus Load Applications - Test Area 2 - Lane 3

Loaded (a) Edge (b) Corner.

Figure B.20 Strain versus Load Applications - Test Area 2 - Lane 4

Unloaded (a) Edge (b) Corner .

Figure B.21 Strain versus Load Applications - Test Area 2 - Lane 4

Loaded (a) Edge (b) Corner.

Figure B.22 Strain versus Load Applications - Test Area 2 - Lane 5

Unloaded (a) Edge (b) Corner ....

Figure B.23 Strain versus Load Applications - Test Area 2 - Lane 5

Loaded (a) Edge (b) Corner.

Figure B.24 Strain versus Load Applications - Test Area 3 - Lane 1

Unloaded (a) Edge (b) Corner

Figure B.25 Strain versus Load Applications - Test Area 3 - Lane 1

Loaded (a) Edge (b) Corner.

Figure B.26 Strain versus Load Applications - Test Area 3 - Lane 2

Unloaded (a) Edge (b) Corner ....

Figure B.27 Strain versus Load Applications - Test Area 3 - Lane 2

Loaded (a) Edge (b) Corner....

Figure B.28 Strain versus Load Applications - Test Area 3 - Lane 3

Unloaded (a) Edge (b) Corner

Figure B.29 Strain versus Load Applications - Test Area 3 - Lane 3

Loaded (a) Edge (b) Corner....

Figure B.30 Strain versus Load Applications - Test Area 3 - Lane 4

Unloaded (a) Edge (b) Corner 
Figure B.31 Strain versus Load Applications - Test Area 3 - Lane 4 Loaded (a) Edge (b) Corner...

Figure B.32 Strain versus Load Applications - Test Area 3 - Lane 5 Unloaded (a) Edge (b) Corner.

Figure B.33 Strain versus Load Applications - Test Area 3 - Lane 5 Loaded (a) Edge (b) Corner.

Figure B.34 Strain versus APT Carriage Location - Test Area 1 - Joint Location (a) 20,000 Load Applications (b) 300,000 Load Applications (c) 560,000 Load Applications

Figure B.35 Strain versus APT Carriage Location - Test Area 1 - Mid-Panel Location (a) 20,000 Load Applications (b) 300,000 Load Applications (c) 560,000 Load Applications...

Figure B.36 Strain versus APT Carriage Location - Test Area 1 - Edge Location (a) 20,000 Load Applications (b) 300,000 Load Applications (c) 560,000 Load Applications

Figure B.37 Strain versus APT Carriage Location - Test Area 1 - Corner Location (a) 20,000 Load Applications (b) 300,000 Load Applications (c) 560,000 Load Applications . 360

Figure B.38 Strain versus APT Carriage Location - Test Area 2 - Lane 1 Edge Location (a) 5,000 Load Applications (b) 150,000 Load Applications (c) 275,000 Load Applications

Figure B.39 Strain versus APT Carriage Location - Test Area 2 - Lane 1 Corner Location (a) 5,000 Load Applications (b) 150,000 Load Applications (c) 275,000 Load Applications .

Figure B.40 Strain versus APT Carriage Location - Test Area 2 - Lane 2 Edge Location (a) 5,000 Load Applications (b) 150,000 Load Applications (c) 275,000 Load Applications .

Figure B.41 Strain versus APT Carriage Location - Test Area 2 - Lane 2 Corner Location (a) 5,000 Load Applications (b) 150,000 Load Applications (c) 275,000 Load Applications 
Figure B.42 Strain versus APT Carriage Location - Test Area 2 - Lane 3 Edge Location (a) 5,000 Load Applications (b) 150,000 Load Applications (c) 275,000 Load Applications .

Figure B.43 Strain versus APT Carriage Location - Test Area 2 - Lane 3 Corner Location (a) 5,000 Load Applications (b) 150,000 Load Applications (c) 275,000 Load Applications .

Figure B.44 Strain versus APT Carriage Location - Test Area 2 - Lane 4 Edge Location (a) 3,500 Load Applications (b) 150,000 Load Applications (c) 275,000 Load Applications ...

Figure B.45 Strain versus APT Carriage Location - Test Area 2 - Lane 4 Corner Location (a) 3,500 Load Applications (b) 150,000 Load Applications (c) 275,000 Load Applications .

Figure B.46 Strain versus APT Carriage Location - Test Area 2 - Lane 5 Edge Location (a) 5,000 Load Applications (b) 150,000 Load Applications (c) 177,000 Load Applications

Figure B.47 Strain versus APT Carriage Location - Test Area 2 - Lane 5 Corner Location (a) 5,000 Load Applications (b) 150,000 Load Applications (c) 177,000 Load Applications

Figure B.48 Strain versus APT Carriage Location - Test Area 3 - Lane 1 Edge Location (a) 0 Load Applications (b) 150,000 Load Applications (c) 275,000 Load Applications

Figure B.49 Strain versus APT Carriage Location - Test Area 3 - Lane 1 Corner Location (a) 0 Load Applications (b) 150,000 Load Applications (c) 275,000 Load Applications .

Figure B.50 Strain versus APT Carriage Location - Test Area 3 - Lane 2 Edge Location (a) 0 Load Applications (b) 150,000 Load Applications (c) 275,000 Load Applications .. 386

Figure B.51 Strain versus APT Carriage Location - Test Area 3 - Lane 2 Corner Location (a) 0 Load Applications (b) 150,000 Load Applications (c) 275,000 Load Applications 388

Figure B.52 Strain versus APT Carriage Location - Test Area 3 - Lane 3 Edge Location (a) 0 Load Applications (b) 150,000 Load Applications (c) 275,000 Load Applications . 
Appendix Figure

Figure B.53 Strain versus APT Carriage Location - Test Area 3 - Lane 3 Corner Location (a) 0 Load Applications (b) 150,000 Load Applications (c) 275,000 Load Applications

Figure B.54 Strain versus APT Carriage Location - Test Area 3 - Lane 4 Edge Location (a) 0 Load Applications (b) 150,000 Load Applications (c) 275,000 Load Applications ....

Figure B.55 Strain versus APT Carriage Location - Test Area 3 - Lane 4 Corner Location (a) 0 Load Applications (b) 150,000 Load Applications (c) 275,000 Load Applications

Figure B.56 Strain versus APT Carriage Location - Test Area 3 - Lane 5 Edge Location (a) 0 Load Applications (b) 150,000 Load Applications (c) 275,000 Load Applications...

Figure B.57 Strain versus APT Carriage Location - Test Area 3 - Lane 5 Corner Location (a) 0 Load Applications (b) 150,000 Load Applications (c) 275,000 Load Applications . 400

Figure B.58 Bonded and Unbonded Strains over Time - Test Area 1 402

Figure B.59 Bonded and Unbonded Strains over Time - Test Area 2 Lane 1.

Figure B.60 Bonded and Unbonded Strains over Time - Test Area 2 Lane 2 .

Figure B.61 Bonded and Unbonded Strains over Time - Test Area 2 Lane 3 403

Figure B.62 Bonded and Unbonded Strains over Time - Test Area 2 Lane 4 404

Figure B.63 Bonded and Unbonded Strains over Time - Test Area 2 Lane 5. 404

Figure B.64 Bonded and Unbonded Strains over Time - Test Area 3 Lane 1. 405

Figure B.65 Bonded and Unbonded Strains over Time - Test Area 3 Lane 2. 
Appendix Figure

Page

Figure B.66 Bonded and Unbonded Strains over Time - Test Area 3 -

Lane 3. 406

Figure B.67 Bonded and Unbonded Strains over Time - Test Area 3 Lane 4. 406

Figure B.68 Bonded and Unbonded Strains over Time - Test Area 3 Lane 5. 407

Figure B.69 Distress Map for Test Area 2 - Lane 1 ....................................408

Figure B.70 Distress Map for Test Area 2 - Lane 2 ...................................... 409

Figure B.71 Distress Map for Test Area 2 - Lane 3................................... 410

Figure B.72 Distress Map for Test Area 2 - Lane 4................................... 411

Figure B.73 Distress Map for Test Area 2 - Lane 5.................................... 412

Figure B.74 Distress Map for Test Area 3 - Lane 1 .................................... 413

Figure B.75 Distress Map for Test Area 3 - Lane 2 .................................... 414

Figure B.76 Distress Map for Test Area 3 - Lane 3..................................... 415

Figure B.77 Distress Map for Test Area 3 - Lane 4 ...................................... 416

Figure B.78 Distress Map for Test Area 3 - Lane 5................................... 417

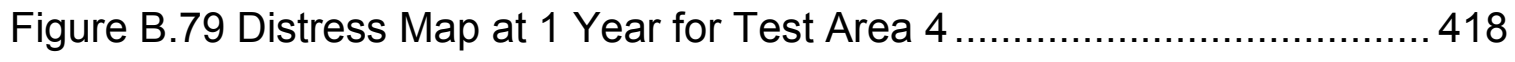

Figure C.1 Strain Distribution - Test Area 2 - Lane 1 (a) Edge (b) Corner ...... 419

Figure C.2 Strain Distribution - Test Area 2 - Lane 2 (a) Edge (b) Corner ...... 420

Figure C.3 Strain Distribution - Test Area 2 - Lane 3 (a) Edge (b) Corner ...... 421

Figure C.4 Strain Distribution - Test Area 2 - Lane 4 (a) Edge (b) Corner ...... 422

Figure C.5 Strain Distribution - Test Area 2 - Lane 5 (a) Edge (b) Corner ...... 423

Figure C.6 Strain Distribution - Test Area 3 - Lane 1 (a) Edge (b) Corner ...... 424 
$\begin{array}{ll}\text { Appendix Figure } & \text { Page }\end{array}$

Figure C.7 Strain Distribution - Test Area 3 - Lane 2 (a) Edge (b) Corner ...... 425

Figure C.8 Strain Distribution - Test Area 3 - Lane 3 (a) Edge (b) Corner ...... 426 Appendix Figure

Figure C.9 Strain Distribution - Test Area 3 - Lane 4 (a) Edge (b) Corner ..... 427

Figure C.10 Strain Distribution - Test Area 3 - Lane 5 (a) Edge

(b) Corner .................................................................. 428 


\section{ABSTRACT}

Ultra-Thin Whitetopping (UTW) is a pavement rehabilitation technique that involves the placement of a thin Portland Cement Concrete (PCC) overlay, 2 inches $(50 \mathrm{~mm})$ to 4 inches $(100 \mathrm{~mm})$ thick, over a distressed Hot Mix Asphalt (HMA) pavement. Typically, the HMA pavement is milled and cleaned which helps to create a bond between the existing HMA pavement and the PCC overlay. The bond between the two layers promotes composite action of the pavement section and as a result has a direct impact on the performance of the UTW Pavement. This composite action allows for the reduced thickness in the UTW layer. Additionally, a short joint spacing is typically used, which reduces the UTW flexural and curling stresses.

In this study three different test areas were constructed in the INDOT/Purdue University Accelerated Pavement Testing facility. Each test area had different lanes that varied by concrete mix design, bonding preparation, and pavement cross-section. These sections were subjected to 300,000 to 560,000 load applications. An additional test area was constructed outside the facility to evaluate pavement thicknesses and environmental effects.

The project resulted in a modified UTW design methodology that takes into account the stiffness of all underlying pavement layers. Additionally, the project provides insight into the effects of pavement section, UTW mix design, mechanical loading, bond conditions, and environmental loading on the performance of UTW. 


\section{CHAPTER 1. INTRODUCTION}

This document presents the results of the evaluation of Ultra-Thin Whitetopping (UTW) (recently renamed Bonded Concrete Resurfacing, Harrington et al. [2007]) installations conducted at the Indiana Department of Transportation (INDOT)/Purdue University Accelerated Pavement Testing (APT) facility located on the INDOT Office of Research and Development campus. This chapter introduces the topic of UTW, the project objectives, the scope of work conducted, and the organization of the document.

\subsection{Background and Problem Statement}

The State of Indiana spends on average nearly $\$ 160$ million annually (INDOT [2005]) on the rehabilitation of pavements. With such a large financial commitment, it is in the interest of the state to invest its highway funds on methods that will provide the greatest return. For highway projects, the value of these investments is directly related to the expected life of the rehabilitation technique; that is, it requires determination of which rehabilitation technique provides the longest life for the least amount of money. The expected life of most rehabilitation techniques ranges from 5-10 years.

Historically, Hot Mix Asphalt (HMA) has been widely used to refurbish the riding surface of highways. HMA is a versatile material and can be used to rehabilitate both asphalt concrete pavements as well as portland cement concrete (PCC) pavements. While HMA can provide excellent, cost-effective performance these mixtures frequently exhibit excessive rutting at intersections, bus lanes, ramps, and other pavement sections subject to stop-and-go traffic conditions. Although 
research continues on the development of rut resistant HMA mixtures one alternative solution that has exhibited significant potential for mitigating the problem of severe ruts at intersections is the use of the UTW technique.

The UTW technique is a pavement rehabilitation method that involves the placement of a thin, 2 inches $(50 \mathrm{~mm})$ to 4 inches $(100 \mathrm{~mm})$ thick, PCC overlay over a distressed HMA pavement. Typically, the top of the HMA pavement is milled and the resulting surface is thoroughly cleaned prior to placement of the UTW layer. This process increases helps to create a bond between the existing HMA pavement and the PCC overlay. The bond between the two layers promotes composite action of the repaired pavement section and as a result has a direct impact on the performance of the UTW layer. This composite action allows for the reduced thickness in the UTW layer. Additionally, a short joint spacing is typically used, which reduces the UTW flexural and curling stresses (Mack et al. [1998]).

Mechanistic procedures have been developed to aid in the design of UTW overlays. In the procedure developed by the Portland Cement Association (PCA), equations predicting critical stresses and strains are based on parametric analysis and validated with field data (Wu et al. [1998]). Failure criteria are employed to consider PCC fatigue under corner loading, and asphalt fatigue under joint loading. The PCA procedure also takes into account temperature induced stresses and strains. This design procedure allows for both the selection of the overlay thickness and required joint spacing.

The PCA procedure was developed for the traditional usage of UTW overlay where a thin concrete layer is placed on a HMA pavement supported by a subgrade with a given modulus of subgrade reaction, $k$. However, research has noted the need to consider the use of UTW over composite pavements (Cable et al. [2001]) which typically consists of a PCC layer (constructed over a subbase or 
directly on top of the subgrade) and overlaid with HMA. Previous research (Rajan et al. [2001]) indicates that performance of UTW may be different when used as a rehabilitation technique for existing composite pavements than when used over a HMA pavement. As previously mentioned, the PCA design method was validated using field data. However, the validation of this method did not consider design of UTW over a composite pavement. Therefore, investigation should be performed to evaluate the feasibility of incorporating composite pavement sections in the current PCA design method. Further, a recent evaluation of the methodology (Rasmussen and Rozycki [2004]) noted that the PCA method does not consider reliability in the design process. Thus, methods of incorporating reliability also should be investigated.

The design process of overlays of existing pavements requires procurement of good information regarding the in situ pavement such as pavement layer thicknesses and moduli. Thickness and material information is available on old plans or as-built drawings however, availability of these documents is sometimes limited. Structural support of existing pavement layers, either HMA pavements or composite pavements, can be evaluated using a falling weight deflectometer (FWD). While such technology has been suggested to evaluate individual pavement layer moduli (Rasmussen and Rozycki [2004]), no literature was found concerning the incorporation of FWD data to calculate deflection-based stresses and strains in the design of UTW overlays. Incorporation of pavement deflection analysis into the UTW design process would provide more accurate in situ layer information which should, in turn, provide more accurate UTW designs. Additionally, FWD testing would provide needed information on the pavement section regardless of whether the existing section is HMA pavement or a composite section.

As indicated previously, the performance of UTW is dependent on the quality of the bond between the UTW and HMA. Several studies have investigated the 
bond that develops between the UTW and HMA layers (Cable et al. [1998]; Armaghani and Tu [1999]; Sprinkel and Ozylidirim [2001]; Wu et al. [2001]; and Tawfiq [2001]). These studies indicated that the values of bond shear stress can vary widely. Also, while it is generally agreed that the deterioration of the bond will cause the pavement to fail, little investigation has been done into how this bond develops and how it degrades under loading. Both mechanical loading from the traffic and thermal loading from the environment may have an effect on the bond. A study by Vandenbossche [2001] looked into the effect of environmental loads on bonding and noted that bond strengths change with temperature changes. However, the effect of repeated temperature changes resulting from seasonal temperature variations on the bond was not studied. Thus, evaluations of the development of the bond, the mechanism of its degradation, and its role in the deterioration of the UTW pavement are also needed.

As PCC dries, it will shrink. The shrinkage will be restrained at the bottom of the PCC at the UTW-HMA interface. The interaction between the two materials at this interface is also what provides the bond between the two layers. As such, some relationship between the concrete shrinkage and the UTW-HMA bond should exist. Limited work has been done in evaluating shrinkage effects in relation to UTW (Petersson and Silfwerbrand [1993] and Vandenbossche [2001]). Investigation into the effect of PCC shrinkage on the UTW-HMA bond is needed to shed some light on the relationship between shrinkage strains and bond strength.

It has been noted that in addition to the bond, the performance of UTW is dependent on the type and properties of the underlying pavement sections. Rajan et al. [2001] noted that the performance of UTW constructed over existing composite sections is significantly influenced by these underlying layers. Mack et al. [1998] attributed good performance to two additional variables, the quality 
of the UTW concrete used and the response of the pavement to the loads. This latter variable was attributed to the composite action of the UTW and HMA layers and the resulting shift in the neutral axis of the strain distribution over the pavement section.

\subsection{Objectives}

The previous section provided background and identified areas of limiting knowledge with respect to the UTW rehabilitation technique. Given the previous discussion, the objectives of this study were formulated as described in the following sections.

\section{Modification of PCA UTW Design Methodology}

Pavement structure analysis using Falling Weight Deflectometer (FWD) testing is an established method to evaluate the structural support of existing pavement layers, either HMA pavements or composite pavements. Since pavement structure analysis can effectively determine the structural capacity of the existing pavement, the possibility of incorporating this test methodology into the PCA UTW design method was investigated. The objective of incorporating FWD testing into the analysis of the existing pavement selected for rehabilitation is to provide designers with better information regarding the in-situ conditions and thus provide an improved UTW design.

\section{Evaluation of Factors Influencing UTW Performance}

The performance of the UTW overlay is dependent on the bond between the UTW and HMA. One of the objectives of this study was to evaluate the main factors that influence development and degradation of bond under mechanical and thermal loads as well as concrete shrinkage. Additional variables that influence the performance of the UTW overlay were also evaluated as part of this study. These included the properties of the underlying (in situ) pavement section, UTW concrete properties, and multiple (mechanical and environmental) 
load applications. It is expected that analysis of the factors influencing the pavement responses will provide improvements to the UTW design and construction procedures.

\subsection{Scope}

A research plan was developed to address the objectives outlined in the previous section. The research plan incorporated a literature review to evaluate the state of the art for UTW overlay analysis, design, construction, and performance. This plan also included the construction of four different test areas as well as a laboratory study. Three test areas were constructed in the APT facility while the fourth was constructed in the parking lot outside the APT facility. There were five main parameters varied among the four test areas and laboratory study. These included: structural properties of the underlying pavement section, concrete mixture (composition or mechanical properties), interfacial bond conditions, mechanical load applications, and temperature gradient (environmental loading). The study evaluated the effects of these parameters on up to six responses: curing strains, drying shrinkage strains, strain distribution and maximum loadinduced strains, type and severity of distresses, bond strength, and the radius of relative stiffness.

In regards to the modification of the UTW design methodology, strains calculated using the existing PCA methodology were compared to the measured strains. Modifications to the methodology were proposed based on the results of these comparisons. Additionally, FWD data from the four test areas were combined to develop a method of integrating pavement deflection analysis into the design process. 


\subsection{Organization of the Document}

This document contains 8 chapters and 3 appendices. The first chapter is the introduction and contains sections on background information and problems statements, objectives, scope, and document organization. The second chapter contains the results of the literature review. An outline of the research plan is included in the third chapter. The fourth chapter contains information regarding the test areas and test methodologies used in both the construction and testing of these test areas and in the laboratory study. The fifth chapter contains a summary of the results of the accelerated pavement testing including concrete mechanical properties, strain readings, distresses, bond strengths, and pavement deflection analysis. The design thickness and environmental testing results, which include mechanical properties, temperature readings, type and severity of distresses, pavement deflection analysis, and laboratory bond strengths, are presented also presented in the fifth chapter. The sixth chapter contains the analysis and discussion of the test results. The seventh chapter includes discussion of the proposed changes to the UTW design methodology. A summary of the conclusions is presented in the eighth chapter. The first appendix (Appendix A) contains a detailed instrumentation plan including information on the various gages, their placement, and data acquisition systems used in this project. The second appendix (Appendix B) contains various data from the accelerated pavement testing. The strain distribution plots for different test areas are contained in the third appendix (Appendix C). 


\section{CHAPTER 2. LITERATURE REVIEW}

This chapter contains a review of literature related to the UTW rehabilitation technique. The first section discusses the early developments of this technique. The subsequent sections cover experiences from a limited number of studies performed at state and national levels. These sections are followed by a description of the PCA UTW design method. A review of the literature related to the effects of environmental conditions on the UTW performance is presented next. Finally, a review of literature pertaining to the topic of restrained shrinkage and its effect on UTW is presented.

\subsection{Development of Ultra-Thin Whitetopping Rehabilitation Technique} UTW is defined as a 2 inch to 4 inch $(50 \mathrm{~mm}$ to $100 \mathrm{~mm}$ ) thick, bonded, PCC overlay of a distressed HMA pavement. The HMA is milled to provide an improved bond between the two layers. To offset the potential lack structural capacity of the very thin concrete layer these concrete overlays typically consist of short, square panels. The dimensions of these panels can range from 2 foot by 2 foot $(600 \mathrm{~mm}$ by $600 \mathrm{~mm}$ ) up to 6 foot by 6 foot $(1800 \mathrm{~mm}$ by $1800 \mathrm{~mm})$.

It is commonly known that slow-moving, heavy traffic loads can induce permanent deformation, or rutting, in HMA pavements. Such areas are in need of frequent repair which is both costly and causes undue disruption of traffic flow. A UTW overlay can be used in situations such as these because the rigid overlay is resistant to rutting. As such, early use of UTW was directed at resurfacing HMA pavements at intersections, bus lanes, off ramps, weigh stations, rest areas, and parking lots. However, the success of these early UTW installations 
spurred interest into using this technique for more mainstream usages, such as city streets and rural roads. This section covers a history of UTW development.

\subsubsection{Early Developments}

Early work on use of very thin concrete overlays can be traced back to the early 1980's in Denmark, Petersson and Silfwerbrand [1993]. These early tests used concrete thicknesses of between 1.25 inches to 1.5 inches ( $30 \mathrm{~mm}$ to $40 \mathrm{~mm}$ ) with joint spacings between 13 feet to 53 feet ( $4000 \mathrm{~mm}$ to $16000 \mathrm{~mm}$ ). The pavement failed quickly and the tests were terminated after two years.

Petersson and Silfwerbrand [1993] report on a test section built in Sweden in 1989. The concrete placed in the 1250 feet $(375 \mathrm{~m}$ ) long section was between 2.75 inches and 3.5 inches $(70 \mathrm{~mm}$ and $90 \mathrm{~mm})$ thick. The HMA was planned to be milled at variable depths up to 2 inches $(50 \mathrm{~mm})$ in order to provide an even surface. The section contained no joints other than construction joints. An inspection done at two years reported transverse cracking had occurred at regular spacings with some of the damage at the cracks widening out almost 4 inches $(100 \mathrm{~mm})$ from the crack. Cores were taken and bond strengths reported were between 0.2 and $0.3 \mathrm{MPa}$. However, it was noted that in some areas the remaining HMA was thinner than planned. Despite this, it was reported that the pavement was generally in good condition. Another evaluation done a year later reported the development of a longitudinal crack through the test section. Recommendations for future sections were better milling control and the inclusion of joints.

Risser et al. [1993] describe the first UTW experiment conducted in the United States in 1991. Two test pavements were constructed in Kentucky on an entrance road to a landfill. This site was chosen because the high volume of heavily loaded trucks bringing loads to the facility provided an accelerated loading of the pavement. The test sections were constructed with thicknesses of 
2 inches $(50 \mathrm{~mm})$ and 3.5 inches $(87 \mathrm{~mm})$. Joint spacings were either 2 foot (600 $\mathrm{mm})$ or 6 foot $(1800 \mathrm{~mm})$.

The authors reported that the test section was a success. It was noted that the pavement was still in excellent serviceable condition after being subjected to over 585,000 Equivalent Single Axle Loads (ESALs) during the first year. However, nearly 10 percent of the panels did need to be replaced after 400,000 ESALs. These failures were attributed to backfill subsidence, poor drainage, or over milling. The success of this experiment was attributed to a combination of two factors: the development of a bond between the UTW overlay and the underlying HMA; and the short joint spacings used. It was concluded that the presence of the bond between the two layers significantly reduced the stresses in the UTW over what they would be under the same conditions had there been no bond. Also, the short joint spacings were attributed to reducing the load induced and curling stresses in the UTW.

Following the success of the UTW project in Kentucky, several other UTW overlays were constructed across the United States. Cole [1997] presented a partial list of 32 projects constructed between 1992 and 1995. By 1998, Mack et al. [1998] noted that there were over 100 UTW projects that had been constructed across the United States.

The paper by Mack also outlined the state of practice for UTW overlays and noted the following:

- The reduced thickness used in UTW overlays is justified by the bond between the UTW and the HMA, the short joint spacings, and the use of high quality concrete.

- Construction of UTW is not very different from the construction of a normal concrete overlay. The only extra step is the milling and cleaning of the HMA. 
- The review of the performance of overlays indicates very good performance. The technique will be useful in applications such as city streets, intersections, general aviation taxiways, runways, aprons, and parking areas.

- The bond between the UTW and HMA results in composite, monolithic action of the pavement. This effectively shifts the neutral axis down in the pavement section thereby reducing the stress at the bottom of the UTW layer to a level less than the concrete's strength.

- Opposing effects result from the composite section under the corner loading condition. The concrete stress decreases because of the thicker pavement section, however, there is a cantilever effect that puts the maximum stress on the top of the UTW layer. This stress is greater in UTW pavements because the distance between the top of the UTW layer and neutral axis is increased as a result of the neutral axis shift.

- The critical load location may shift from the edge location to the corner location if the neutral axis moves low enough in the pavement section. This is supported by the number of UTW projects that have exhibited corner cracking. Thus, both the edge and corner locations need to be evaluated during the UTW design.

- The stiffness of the HMA layer affects the location of the critical loading. If the ratio of HMA to UTW stiffness is around 20 percent, the critical load location shifts from edge to the corner if the layers are fully bonded. However, it has been noted that only a partial bond exists between the two layers. As such, an even higher HMA stiffness is required to produce a critical location at the corner. If the bond is totally lost, the critical location is at the edge.

- To-date, the development of shear stresses in the pavement section at the level of the bond has not been cited as a cause of failure of the bond. The maximum shear stress occurs at the neutral axis, however and further investigation of this is warranted. 
- Pavements absorb the applied energy either by bending or deflection. Traditional pavements are designed with sufficient thickness to offset the flexural energy. The short joint spacings in UTW overlays reduce the amount of bending so that the deflections absorb the applied energy. This is because the moment arm of the applied load is reduced with a shorter joint spacing thereby reducing the bending stress. Also, curling and warping stresses, which are also dependent on the joint spacing, are reduced. The result is in effect a "minipaver" block system which transfers the loads through deflections to the underlying HMA. Figure 2.1 illustrates this theory.
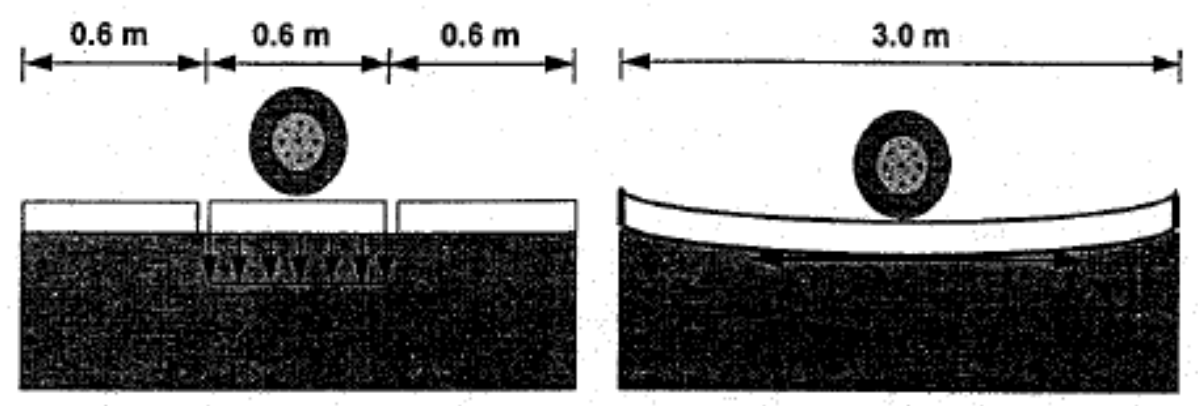

Short joint spacing allows the slabs to deflect instead of bend. This helps reduce slab stresses to reasonable values.

Figure 2.1 Effect of Short Joint Spacing on Performance of UTW Overlay, Mack et al. [1998]

\subsection{2. lowa Experience}

In 1994, the lowa Department of Transportation constructed a series of 41 test sections on an $11.6 \mathrm{~km}$ section of State Highway 21, Cable et al. [1998]. Thin as well as ultrathin overlays were constructed. Variables included overlay thicknesses (UTW thicknesses were 2 inches and 4 inches $(50 \mathrm{~mm}$ and 100 $\mathrm{mm}$ )), joint spacings ( 2 by 2 foot, 4 by 4 foot, and 6 by 6 foot), UTW concrete 
fiber reinforcement, and base preparation (milled, broomed, and cold in-place recycling).

Cable et al. [2001] summarized the results of the lowa study. The five year evaluation reported the following. The section that was tested was lightly traveled and received 130,000 ESALs during the evaluation period (1995-1999). The milled surface provided the best bonding condition. The 4 inch $(100 \mathrm{~mm})$ UTW sections performed better than the 2 inch $(50 \mathrm{~mm})$ UTW exhibiting little distress. The 2 inch sections exhibited longitudinal or corner cracks which led to slab fracture and debonding. Use of 2 foot by 2 foot $(600 \mathrm{~mm}$ by $600 \mathrm{~mm})$ joint spacings places a joint in the wheel path. This did not result in much damage for the 4 inch $(100 \mathrm{~mm})$ UTW layer, but was problematic with the 2 inch $(50 \mathrm{~mm})$ overlay. For overlays with thickness of 2 inches, joint spacings of 4 foot by 4 foot $(1200 \mathrm{~mm}$ by $1200 \mathrm{~mm}$ ) resulted in significantly increased cracking. For overlays with thickness of 4 inches, both the 4 foot by 4 foot $(1200 \mathrm{~mm}$ by $1200 \mathrm{~mm})$ and 6 foot by 6 foot ( $1800 \mathrm{~mm}$ by $1800 \mathrm{~mm}$ ) performed very well. Finally, the study recommended looking at the use of UTW over existing composite pavements.

\subsubsection{Florida Experience}

Three test tracks were constructed by the Florida Department of Transportation in 1996. The three test tracks varied in cross-section, Armaghani and Tu [1997]. The first test track consisted of 4 inches $(100 \mathrm{~mm}$ ) of UTW over 1.5 inches (37 $\mathrm{mm})$ of HMA and 6 inches $(150 \mathrm{~mm})$ of PCC. The second test track was either 3 inches or 4 inches (75 mm or $100 \mathrm{~mm}$ ) of UTW over 1.5 inches (37 mm) of HMA and 6.5 inches $(163 \mathrm{~mm})$ of compacted aggregate. The thickness of the UTW in the third test track was 2 inches $(50 \mathrm{~mm})$. This was placed over 1.5 inches (37 $\mathrm{mm}$ ) of HMA and 6.5 inches $(163 \mathrm{~mm}$ ) of compacted aggregate. The bonding preparation was also varied: milling, broom cleaning, and a thin asphalt crack relief layer were used. Joint spacings also varied and were either 3 by 3 foot ( $900 \mathrm{~mm}$ by $900 \mathrm{~mm}), 4$ by 4 foot $(1200 \mathrm{~mm}$ by $1200 \mathrm{~mm})$, or 6 by 6 foot $(1800$ 
$\mathrm{mm}$ by $1800 \mathrm{~mm}$ ). The concrete mixture used two types of fibers, either polypropylene or polyolefin.

The test lanes were subjected to 60,000 ESALs from a truck loaded with concrete blocks. The author concluded the following.

- The load carrying capacity of the pavement is greatly increased when a UTW overlay is placed. Thus, it is a viable option for rehabilitation of distressed asphalt pavements.

- The performance of the UTW is dependent on the bond between the two layers. It is recommended that the shear strength be a minimum of 200 psi (1.4 MPa) as determined by the lowa shear test. This value was based on test results from excellent performing sections.

- Based on the results of the study it is recommended that the joint spacing for 3 to 4 inch ( 75 to $100 \mathrm{~mm}$ ) overlays should be either 4 by 4 feet or 6 by 6 feet $(1200 \mathrm{~mm}$ by $1200 \mathrm{~mm}$ or $1800 \mathrm{~mm}$ by $1800 \mathrm{~mm})$. For the 2 inch ( $50 \mathrm{~mm}$ ) overlay it is recommended that the joint spacing be 4 by 4 feet (1200 $\mathrm{mm}$ by $1200 \mathrm{~mm}$ ).

- The effect of the fibers was inconclusive as both test sections performed equally as well.

As a follow-up to the controlled loading study a field study was conducted at the Ellaville weigh station on I-10, Armaghani and Tu [1999]. Two different thicknesses of UTW were constructed, 3.25 and 4 inches ( 80 and $100 \mathrm{~mm}$ ). Joints were placed at either 4 by 4 foot or 6 by 6 foot $(1200 \mathrm{~mm}$ by $1200 \mathrm{~mm}$ or $1800 \mathrm{~mm}$ by $1800 \mathrm{~mm}$ ) intervals. High early strength concrete was used and polypropylene fibers were used in half of the sections. The joints in the sections with the fibers were sealed with silicone and the other half were not sealed.

After one year in service the sections were performing well. Only 5.5 percent of the 1800 panels had cracks. The most predominant crack type was corner 
cracking. It was noted that debonding of the UTW was most likely the cause of the cracking and that the debonding was most likely the result of late saw cutting. As such, it was recommended that design and construction specifications should focus on achieving the optimum bond. The construction specifications included acceptance criteria for compressive strength, bond shear strength, and smoothness. These, it was noted, produced a good quality overlay with excellent rideability. Thicker UTW sections had less cracking than thinner sections. It was observed that the thickness of the HMA did not appear to be a factor in the cracking of the UTW. The authors recommended that (for Florida conditions) an HMA thickness of 2 inches $(50 \mathrm{~mm}$ ) was adequate. Joint sealing did not have any benefit. There was no difference noted between the performance of the fiber reinforced and plain concrete sections. It was estimated that one year of service at the weigh station would be equivalent to 4.5 years over service at an intersection or other lower volume facility. As such, it was expected that the service life of a UTW overlay used at such an intersection would be 10 years.

\subsubsection{Minnesota Experience}

Vandenbossche and Rettner [1998] reported on the construction of two different test sections in Minnesota in the Fall of 1997. One section was on a section of US-169, the other was at the Mn/ROAD test area located on I-94. The UTW sections on US-169 were 3 inches $(75 \mathrm{~mm})$ in depth and the joint spacings were either 4 by 4 feet $(1200 \mathrm{~mm})$ or 6 by 6 feet $(1800 \mathrm{~mm})$. The three test cells located on Mn/ROAD were constructed on I-94 in order to accelerate the loading on the UTW sections as this would not be a typical application for UTW. These sections were either 3 inches or 4 inches $(75 \mathrm{~mm}$ or $100 \mathrm{~mm}$ ) thick. Joint spacings again were either 4 by 4 feet $(1200 \mathrm{~mm})$ or 6 by 6 feet $(1800 \mathrm{~mm})$. The parameters evaluated for both sections were static and dynamic pavement strains, pavement temperatures, and concrete mix properties. Two sections at $\mathrm{Mn} / \mathrm{ROAD}$ also monitored moisture in the pavement. 
A report on the US-169 sections, Vandenbossche [2002], noted that the condition of the underlying HMA affects the performance of the UTW, the presence of a longitudinal joint in the HMA and an HMA mixture with low stripping resistance contributed to debonding and failure of sections of the UTW. The predominant distress noted was corner cracking. The 6 foot by 6 foot $(1800 \mathrm{~mm}$ by $1800 \mathrm{~mm})$ panels performed better than the 4 foot by 4 foot $(1200 \mathrm{~mm}$ by $1200 \mathrm{~mm}$ ) panels. This was attributed to the placement of a longitudinal joint in the wheel path when the smaller panel size is used. Compared to the strains on the Mn/ROAD sections the US-169 strains were higher even though the loads subjected to this section were less. This was attributed to the lower quality of HMA at the US-169 site. UTW can be placed on relatively thin HMA sections (as little as 3 inches (75 $\mathrm{mm}$ )) and still perform well if the HMA quality is good. Thus, efforts should be made to investigate the condition of the existing HMA when evaluating whether UTW is a viable alternative.

The summary report for the Mn/ROAD sections was written by Burnham [2005]. It was noted that the test sections had been in service for five years prior to reaching terminal serviceability (PSI of 2.5). The sections were exposed to over $6,000,000$ ESALs before the sections were reconstructed in 2004. It was noted that debonding of the UTW from the HMA led to the cracking of the UTW. Also, the wheel placement in relation to the edge of the UTW was significant in that those joint spacings that placed the wheel near the edge of the panel performed the worst. Also, it was noted that reflective cracking was a factor for concrete overlays with thicknesses in the range of those used in UTW constructed over relatively thick HMA pavements (greater than 6 inches $(150 \mathrm{~mm})$ ).

\subsubsection{Indiana Experience}

Rajan et al. [2001] describe a project undertaken in Indiana. The project was a joint effort between the Indiana Department of Transportation and Purdue University. All work was conducted at the INDOT-Purdue Accelerated Pavement 
Testing (APT) facility. This was an enclosed facility in which the loading was done under relatively constant environmental conditions. One test was run under higher temperatures to evaluate this effect on the pavement response. In 1999, four test lanes, each 4 feet $(1200 \mathrm{~mm})$ wide were constructed. There were two lanes constructed with a thickness of 2.5 inches $(63.5 \mathrm{~mm})$ and two lanes constructed with a thickness of 4 inches $(100 \mathrm{~mm})$. The HMA was placed over a 12 inch thick reinforced concrete slab. The UTW joint spacing was kept constant at 4 feet $(1200 \mathrm{~mm})$. Fiber-reinforced (polyolefin) concrete was used in one each of the 2.5 inch $(63.5 \mathrm{~mm})$ lanes and $4 \mathrm{inch}(100 \mathrm{~mm})$ lanes. Two different load levels were used in the testing: $12,000 \mathrm{lbs}$ and $20,000 \mathrm{lbs}(5.45 \mathrm{kN}$ and $9.08 \mathrm{kN})$. The lanes were instrumented to collect dynamic strains.

The authors made the following conclusions. All test lanes performed very well. The 4 inch $(100 \mathrm{~mm})$ thick layer was exposed to two different load levels for a total of 100,000 load applications and showed no signed of distress. The 2.5 inch $(63.5 \mathrm{~mm})$ thick layer in the third lane also showed not distress after 150,000 load applications at a load level of $12,000 \mathrm{lbs}(5.45 \mathrm{kN})$. The UTW in the fourth lane was also 2.5 inches $(63.5 \mathrm{~mm}$ ) thick and showed no distress after 250,000 load applications at $20,000 \mathrm{lbs}(9.08 \mathrm{kN})$ and testing at higher temperatures. The 4 foot $(1200 \mathrm{~mm})$ joint spacing produced adequate results. The strain readings indicate that the strain response across the pavement section was linear, however this linearity was affected by testing at elevated temperatures. The dynamic strain readings indicated that a significant stress reversal occurred in the pavement as the wheel passes over the pavement. The dynamic strains indicated that there was a sufficient bond between the UTW overlay and the HMA. The stiffness of these layers significantly affected the strains as a result of a shift in the neutral axis. 


\subsection{Federal Highway Administration Accelerated Loading}

In 1998, the Federal Highway Administration (FHWA) in conjunction with the American Concrete Pavement Association began a cooperative research project at the FHWA's Accelerated Loading Facility (ALF) to investigate UTW, Churilla [1998]. The purpose of the project was threefold: to evaluate the performance of UTW under the ALF loads; to investigate the effects of different design elements on the performance of UTW; and to use this information to validate mechanistic models. Eight test lanes were constructed. Parameters that were varied were UTW thickness ( 2.5 inches or 3.5 inches ( $63 \mathrm{~mm}$ or $88 \mathrm{~mm}$ ), joint spacing ( 3 by 3 feet, 4 by 4 feet, or 6 by 6 feet $(900 \mathrm{~mm}$ by $900 \mathrm{~mm}, 1200 \mathrm{~mm}$ by $1200 \mathrm{~mm}$ or 1800 by $1800 \mathrm{~mm})$ ), and concrete with and without polypropylene fibers. These layers were placed over 8 inches $(200 \mathrm{~mm})$ of Superpave HMA that was previously tested at the ALF. The lanes were instrumented to monitor the strains in the UTW and HMA.

The failure mechanisms observed in the FHWA-ALF project are summarized by Rasmussen et al. [2002]. Loads of $12.3 \mathrm{kips}$ ( $55 \mathrm{kN}$ ) were applied to all but one lane which initially received load applications at 10 kips (44 kN). Overall load applications varied from 200,000 per lane to over 1,000,000 per lane. Observed distresses included corner cracks, midslab cracking, joint faulting, and joint spalling. Mechanisms of these failures were also proposed.

The most common distress identified was corner cracking. It was thought that this distress resulted from permanent deformation of the underlying HMA layer. The resulting void produced a cantilever affect in the UTW layer. When the concrete reached its fatigue limit the concrete cracked. Figure 2.2 illustrates this progression as presented by Rasmussen et al. It was noted that cores taken from the corner area may indicate that the bond was still in tact. However, that microcracking in the UTW and a loss of density in the HMA might lead to a weakened area and loss of support. The authors called this a "virtual void". 
Another proposed explanation was that cracks may have been initiated on the loaded edge of the pavement and propagated at an angle through the UTW layer. This was thought possible due to the changing stress state induced by the moving wheel load.

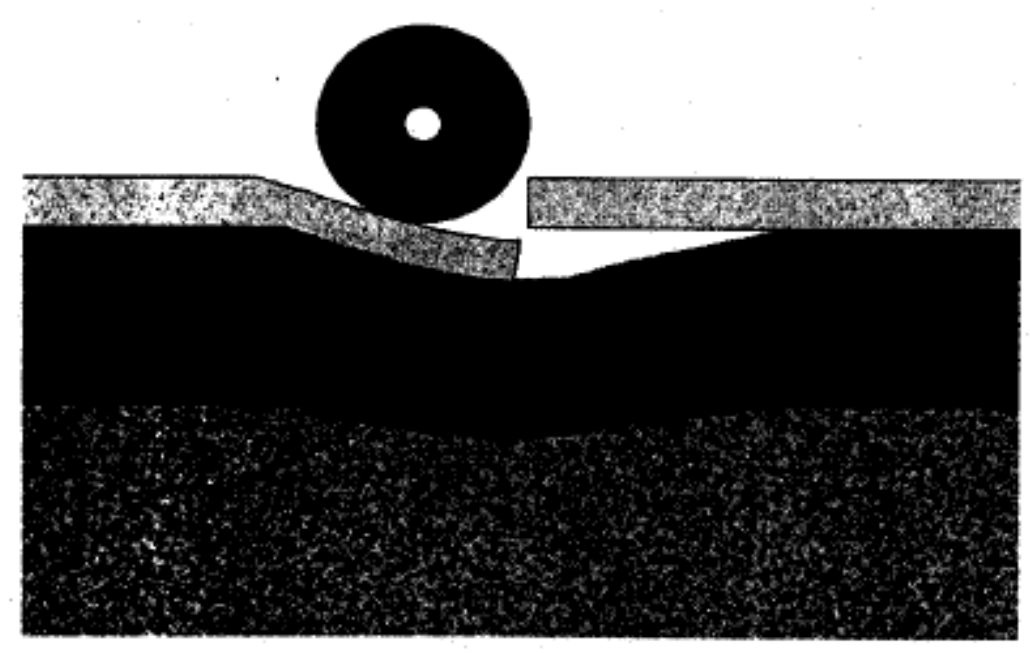

(a)

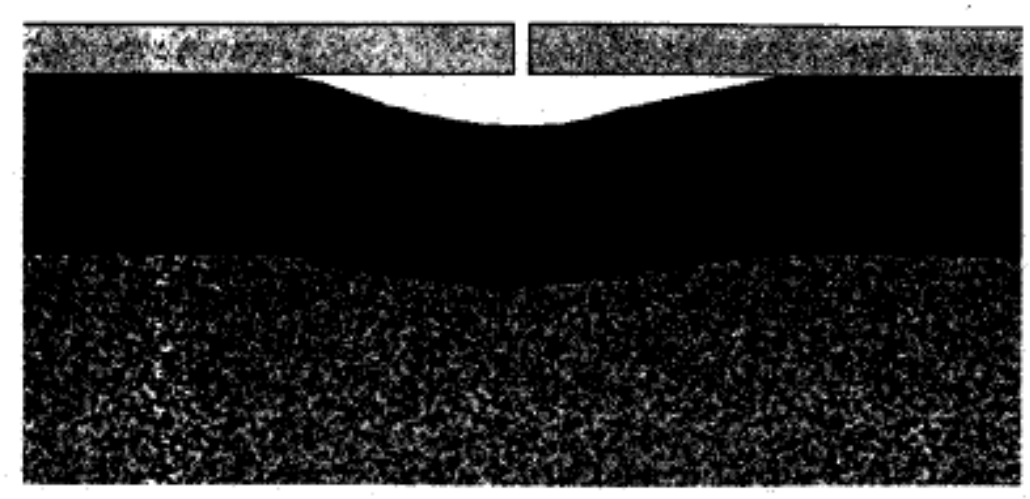

(b)

Figure 2.2 Corner Cracking Mechanism, Rasmussen et al. [2002] (a) Repeated Wheel Loading (b) Permanent Deformation (c) Cracking in the UTW Layer (continued) 


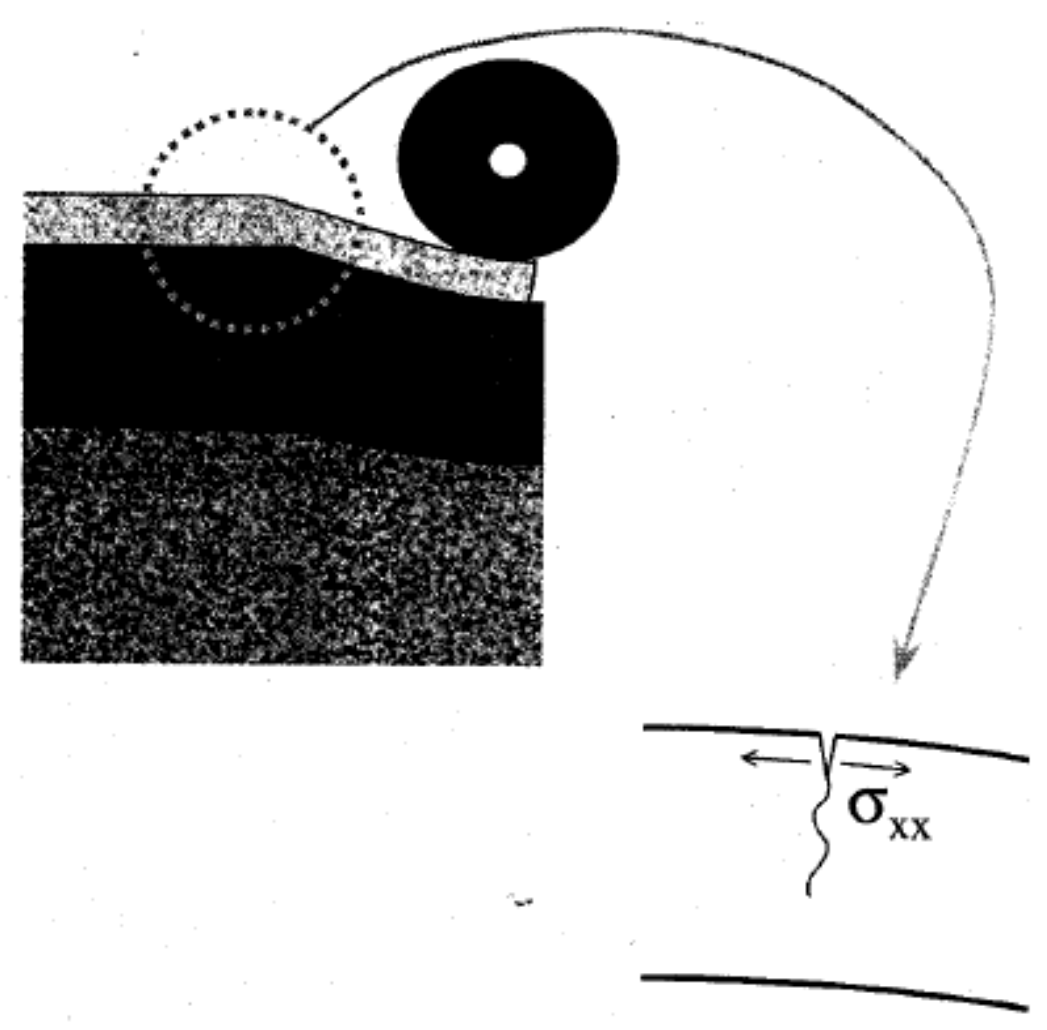

(c)

Figure 2.2 Corner Cracking Mechanism, Rasmussen et al. [2002] (a) Repeated Wheel Loading (b) Permanent Deformation (c) Cracking in the UTW Layer

It was noted that the midslab cracking mechanism was still being investigated. However, in general it was thought to be the result of fatigue. One hypothesis is that these cracks initiate at the bottom of the UTW layer. As the wheel passes over the midslab the stresses are concentrated at this location. The presence of a void or weakened area will cause the stress in this area to increase. An alternate hypothesis is that as the wheel rolls onto the slab in question that a strain reversal causes a tensile strain at the top of the slab at the midslab location. The strain reversal was confirmed by strain gages placed in the slab. Figure 2.3 illustrates these two hypotheses. 


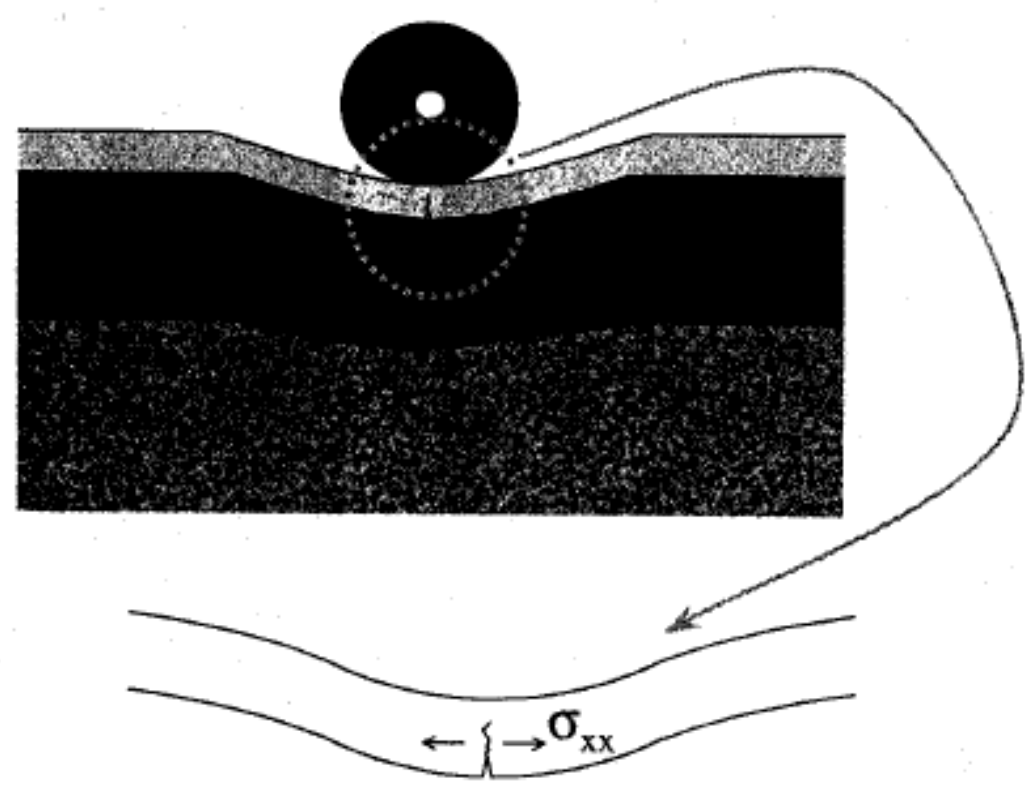

(a)

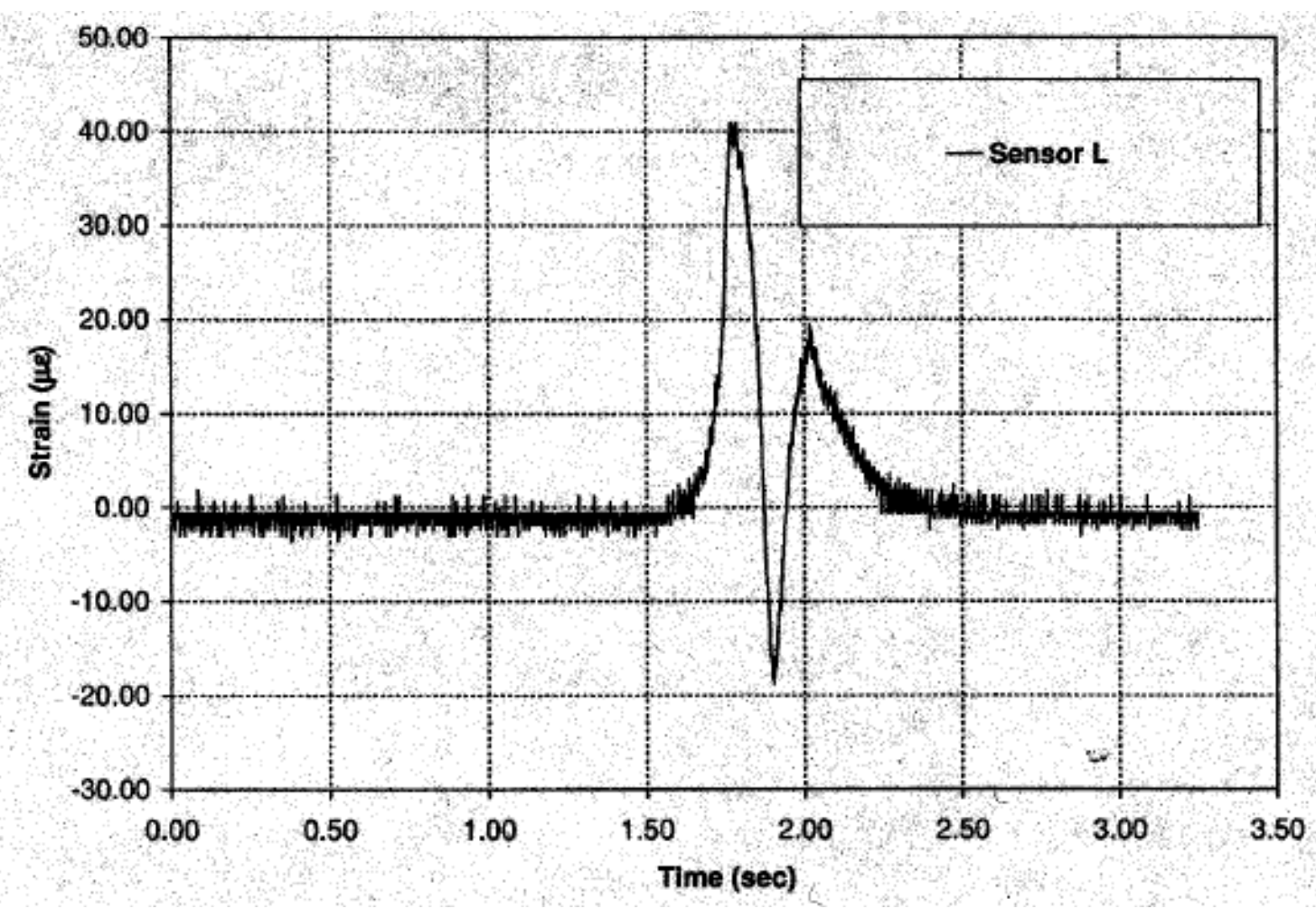

(b)

Figure 2.3 Midslab Cracking Mechanisms, Rasmussen et al. [2002] (a) BottomUp Cracking (b) Strain Reversal 
Joint faulting at both the longitudinal and transverse joints was observed. It was proposed that the faulting at the longitudinal joints was the result of the channelized loading by the ALF. No wander was induced in the loading and therefore the stresses were concentrated at one location for repeated load applications. This resulted in permanent deformation of the HMA layer. For the transverse joint faulting it was theorized that both vertical and shear forces are produced under load which result in vertical and shear deformation in the layers. These mechanisms are illustrated in Figure 2.4.

The review concluded that a major factor that contributed to UTW distresses was the rutting resistance of the underlying HMA. UTW overlays constructed over stiffer and more rut resistant HMA mixtures exhibited less distress. It was also concluded that the critical load location was edge loading that resulted from the "channelized" loading of by the ALF. However, no differentiation was made between edge and corner loading.

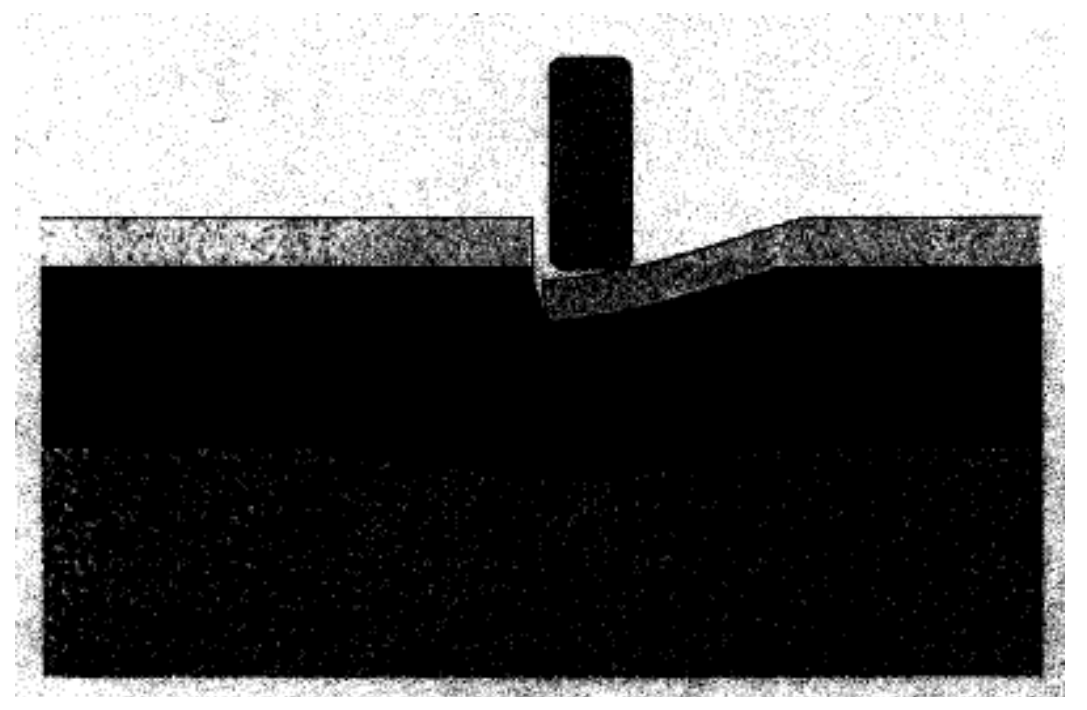

(a)

Figure 2.4 Joint Faulting Mechanisms, Rasmussen et al. [2002] (a) Longitudinal Joints (b) Transverse Joints (continued) 


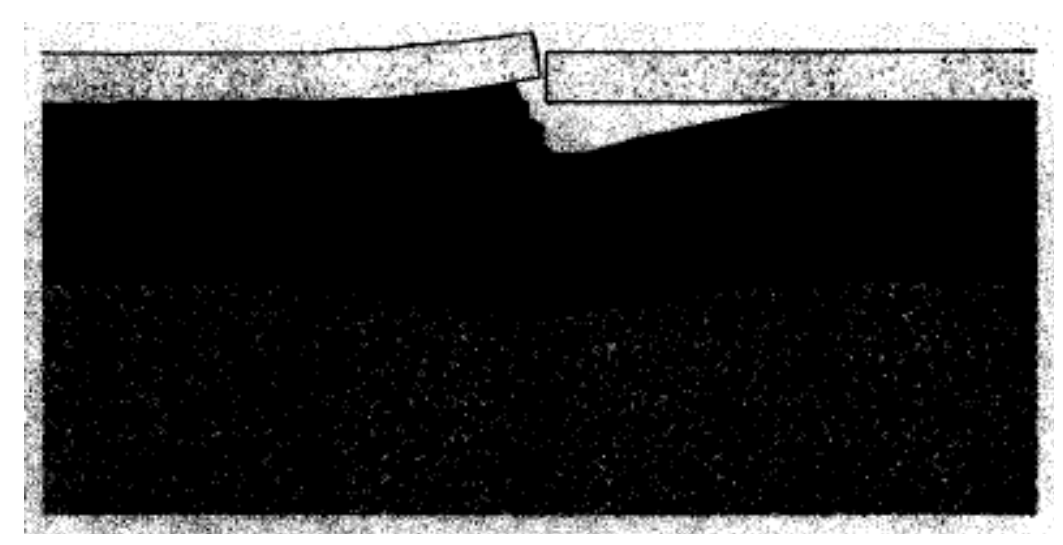

(b)

Figure 2.4 Joint Faulting Mechanisms, Rasmussen et al. [2002] (a) Longitudinal Joints (b) Transverse Joints

Finally, the mechanism for joint spalling was proposed. Two spalling mechanisms were noted. The first was the result of horizontal microcracking induced in the upper layer of the concrete early during construction. Subsequent traffic loading causes the crack to progress and eventually delaminate. The second mechanism noted was due to deflection of the pavement under high loads. These loads cause localized crushing of the concrete at the joints. For UTW, it was thought that the spalling was the result of load induced deflections of the thin UTW layer at the joint (Figure 2.5) 


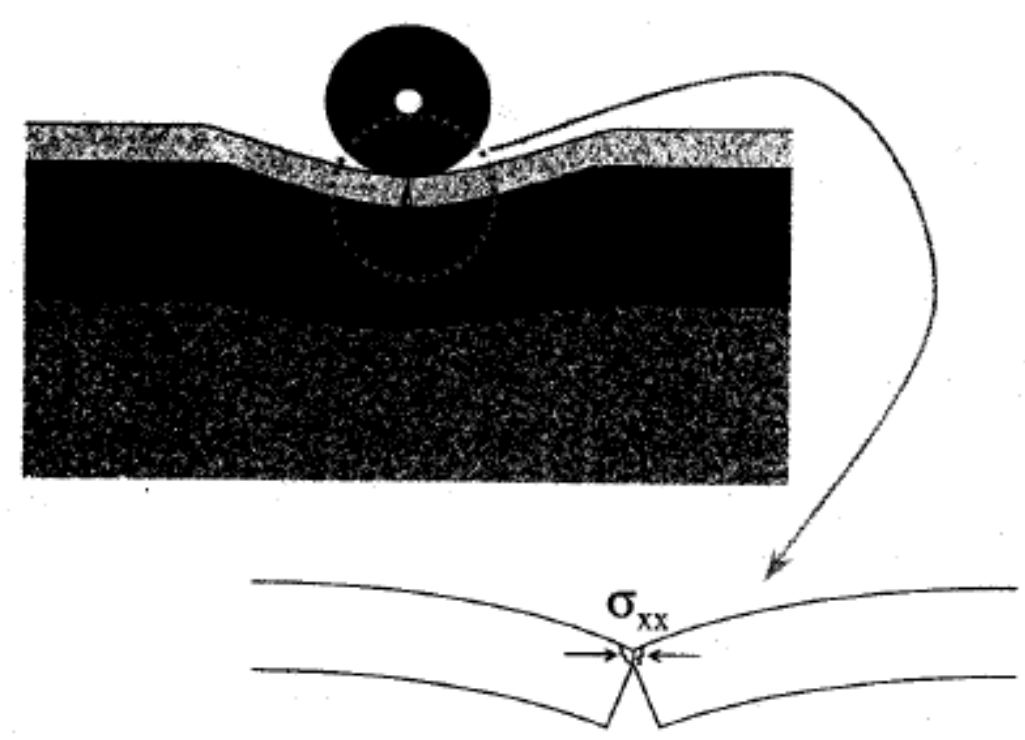

Figure 2.5 Joint Spalling Mechanism, Rasmussen et al. [2002]

\subsection{NCHRP Synthesis Study}

In 2004, the National Cooperative Highway Research Program published a report on the state of the practice of thin and ultra-thin whitetoppings, Rasmussen and Rozycki [2004]. This document summarized the current state of these pavements in regards to project selection, design, construction practice, performance, repair, and rehabilitation. The report concluded the following. The performance of whitetoppings is highly dependent on the quality of the underlying layers. Whitetoppings are a viable option but care should be made in their application. Designers should weigh the benefits between accuracy (requiring several design inputs) and simplicity. Proper consideration of the growing body of knowledge regarding application whitetoppings can lead to greater use and success of these overlays.

\subsection{Portland Cement Association Design Methodology}

While several design methodologies have been developed for whitetoppings in general, American Association of State Highway and Transportation Officials 
(AASHTO [1993]), Colorado (Tarr et al. [1998]), lowa (Cable et al. [2005]), there is only one design methodology that is specific to UTW overlays. This section covers the Portland Cement Association UTW Design Method that has been developed expressly for UTW pavements.

Wu et al. [1998] reported on the development of a UTW mechanistic-empirical design procedure that was developed by the Portland Cement Association (PCA). The authors used a 3-dimensional finite element model (FEM) and information gathered form UTW sites in Missouri and Colorado to develop as a basis for the design equations. The authors also correlated the 3-dimensional model with a previously developed 2 dimensional finite element model so that the simpler model could be used to conduct multiple runs. The FEM results were compared to field data that was gathered from a UTW pavement constructed at the Spirit of St. Louis airport.

Four equations were developed to calculate the stress at the bottom of the UTW layer and the strain at the bottom of the HMA layer that result from an 18 kip single axle and $36 \mathrm{kip}$ dual axle loads. Additionally, two equations that calculated the change in stress for the UTW and change in strain for the HMA that resulted from temperature gradients in the pavement were developed. These equations are as follows.

Asphalt microstrain for 18-kip Single Axle Load (SAL) at joint

$$
\log _{10}\left(\varepsilon_{\text {HMA, } 18 k, S A L}\right)=5.267-0.927 \log _{10} k+0.299 \log _{10}\left(\frac{L_{a d j}}{l_{e}}\right)-0.037 l_{e}
$$

Asphalt microstrain for 36-kip Tandem Axle Load (TAL) at joint

$$
\log _{10}\left(\varepsilon_{\text {HMA }, 36 k, T A L}\right)=6.070-0.891 \log _{10} k+0.786 \log _{10}\left(\frac{L_{a d j}}{l_{e}}\right)-0.028 l_{e}
$$

Concrete stress for 18-kip SAL at corner 


$$
\log _{10}\left(\sigma_{P C C, 18 k, S A L}\right)=5.025-0.465 \log _{10} k+0.686 \log _{10}\left(\frac{L_{a d j}}{l_{e}}\right)-1.291 \log _{10} l_{e}
$$

Concrete stress for 36-kip TAL at corner

$$
\begin{aligned}
& \log _{10}\left(\sigma_{P C C, 36 k, T A L}\right)=4.898-0.599 \log _{10} k+1.395 \log _{10}\left(\frac{L_{a d j}}{l_{e}}\right)-0.963 \log _{10} l_{e} \\
& -0.088\left(\frac{L_{a d j}}{l_{e}}\right)
\end{aligned}
$$

Asphalt microstrain for temperature differential at joint

$$
\Delta \varepsilon_{H M A, \Delta T}=-28.698+2.131 \alpha_{P C C} \Delta T+17.692\left(\frac{L_{a d j}}{l_{e}}\right)
$$

Concrete stress for temperature differential at corner

$$
\Delta \sigma_{P C C, \Delta T}=28.037-3.496 \alpha_{P C C} \Delta T+18.382\left(\frac{L_{a d j}}{l_{e}}\right)
$$

where

$\varepsilon_{H M A, 18 k, S A L}=$ HMA bottom strain due to an 18-kip single-axle load $(\mu \varepsilon)$

$\varepsilon_{H M A, 36 k, T A L}=$ HMA bottom strain due to a 36-kip tandem-axle load $(\mu \varepsilon)$

$\sigma_{P C C, 18 k, S A L}=$ UTW corner (top) stress due to an 18-kip single-axle load (psi)

$\sigma_{P C C, 36 k, T A L}=$ UTW corner (top) stress due to a 36-kip tandem-axle load (psi)

$\triangle \varepsilon_{H M A, \Delta T}=$ Additional HMA bottom strain due to temperature gradient $(\mu \varepsilon)$

$\Delta \sigma_{P C C, \Delta T}=$ Additional UTW corner (top) stress due to temperature gradient (psi)

$\alpha_{P C C}=$ Thermal coefficient of expansion of the PCC $(\varepsilon / \stackrel{\circ}{F})$

$\Delta T=$ Temperature gradient in UTW $\left.\stackrel{\circ}{ }^{\circ} \mathrm{F}\right)$

$L_{\text {adj }}=$ Adjusted slab length (in.)

$$
L_{a d j}=12\left\{8-\left[24 /\left(\frac{L}{12}+2\right)\right]\right\}
$$

$k=$ Modulus of subgrade reaction (psi/in.) 
$l_{e}=$ Effective radius of relative stiffness for a fully bonded system (in.)

$$
l_{e}=\sqrt[4]{E_{P C C} \frac{\left[\frac{t_{P C C}^{3}}{12}+t_{P C C}\left(N A-\frac{t_{P C C}}{2}\right)^{2}\right]}{k k\left(1-\mu_{P C C}^{2}\right]}+E_{H M A} \frac{\left[\frac{t_{H M A}^{3}}{12}+t_{H M A}\left(t_{P C C}-N A+\frac{t_{H M A}}{2}\right)^{2}\right]}{\left[k\left(1-\mu_{H M A}^{2}\right]\right.}}
$$

$N A=$ neutral axis from top of concrete slab (in.)

$$
N A=\frac{\frac{E_{P C C} t_{P C C}^{2}}{2}+E_{H M A} t_{H M A}\left(t_{P C C}+\frac{t_{H M A}}{2}\right)}{\left(E_{P C C} t_{P C C}+E_{H M A} t_{H M A}\right)}
$$

$E_{P C C}=$ Modulus of elasticity of the UTW PCC (psi)

$E_{H M A}=$ Modulus of elasticity of the HMA (psi)

$t_{P C C}=$ Thickness of the UTW PCC (in.)

$t_{H M A}=$ Thickness of the HMA (in.)

$L=$ Actual joint spacing (in.)

Two failure modes were included in the methodology, the PCA fatigue model for the UTW layer and the Asphalt Institute method was chosen for the HMA layer. The PCA model predicts the amount of cycles to failure at a given stress to strength ratio. The PCA fatigue equations follow.

For $S R>0.55$

$$
\log _{10}(N)=\frac{(0.97187-S R)}{0.0828}
$$


For $0.45 \leq S R \leq 0.55$

$$
N=\left(\frac{4.2577}{(S R-0.43248)}\right)^{3.268}
$$

For $S R<0.45$

$$
N=\infty
$$

where

$N=$ number of load applications to failure

$S R=$ stress to strength ratio (applied stress / concrete modulus of rupture)

The failure criteria used in the Asphalt Institute method was 20 percent cracking of the wheel path area. The equation was based on the HMA modulus and the strain level at the bottom of the HMA layer. The Asphalt Institute fatigue equation follows.

$$
N_{\text {HMA }}=0.0795 *\left(\frac{1}{\varepsilon_{\text {HMA }}}\right)^{3.29} *\left(\frac{1}{E_{\text {HMA }}}\right)^{0.854}
$$

For the UTW design, the AADT for the road segment under consideration is converted into an axle load spectrum, i.e, the number of traffic loads at a particular load level is determined for the expected design life. The UTW stress and HMA strain are calculated for each load level. The percentage of fatigue life consumed by each load level is calculated using Miner's hypothesis. These fractional values are totaled to determine the estimated fatigue life of the pavement design. If the total is less than one, the design is satisfactory, although subsequent iterations can be done to refine the design. If the total is greater than one, then the design needs to be revised until the sum is less than one. The total fatigue damage calculated according to Miner's hypothesis is as follows. 


$$
F D=\sum_{i}^{m} \sum_{j}^{n} \frac{n_{i, j}}{N_{i, j}}
$$

where

$F D=$ cumulative fatigue damage

$n=$ actual number of axles (axle type [i] and load level [j]) applications

$N=$ number of allowable axle applications to failure

Riley et al. [2005] presented an overview of the steps involved in the design procedure.

Determine the neutral axis (NA) and radius of relative stiffness (le).

1. Compute the load-induced concrete stresses and asphalt strains for an $18,000 \mathrm{lbf}$, single-axle load (SAL) and a 36,000 lbf tandem axle load (TAL).

2. Use a linear relationship to determine the concrete stress and asphalt strain for all other weights in the axle load distribution category. For example, if the concrete stress under the $18,000-\mathrm{lbf} S A L$ is $287 \mathrm{lbf} / \mathrm{in}^{2}$, then the stress under a 20,000-lbf SAL would be $(20 / 18) \times 287=319$ $\mathrm{lbf} / \mathrm{in}^{2}$.

3. Compute the temperature-induced concrete stresses and asphalt strains. These values are not load-related and are the same for all axle loads and types.

4. Sum the load-induced and temperature-induced stresses and strains to get total concrete stress and total asphalt strain.

5. Conduct the fatigue analyses. For a given set of parameters, one of the two materials will govern and determine the required thickness and joint spacing. For each axle load:

a. Compute the concrete stress ratio by dividing the total stress by the flexural strength of the concrete. 
b. Use the stress ratio and fatigue relationship to determine the number of allowable load applications to failure for the concrete layer.

c. Compute the percent fatigue used.

d. Sum the concrete fatigue damage for all axle loads, both single and tandem, and determine if greater than 100 percent.

e. Using the asphalt modulus of elasticity and the calculated microstrains, determine the allowable load repetitions for the asphalt layer.

f. Sum the asphalt fatigue damage for all axle loads, both single and tandem, and determine if greater than 100 percent.

6. If either asphalt or concrete fatigue is greater than 100 , alter the design inputs and rerun the analysis.

Rasmussen and Rozycki [2004] note some benefits and limitations of this design methodology. It was noted that no other existing design methods account for the unique features found in UTW such as geometrics and influence of the bond. Further benefits noted were that it was developed using 3-dimensional FEM and this provided realistic pavement stresses. It was validated with field data from multiple sites. The methodology takes into account the unique bond between the two pavement layers. And, the failure criteria used reflect the complexity of the UTW system.

One limitation noted was due to the manner in which the FEM took into account the bonded condition. Initially the model produced stresses that were significantly less than those observed in the field. It was determined that this discrepancy was the result of the model's assumption of a full bond between the UTW and HMA layers. As a result, the model incorporated a correction factor (1.36 or a 36 percent increase in stress) to account for a partially bonded 
condition. However this factor was based on only one test and therefore may not be applicable to all situations.

Another limitation noted was that the methodology does not take into account reliability. The only reliability include was the inherent reliability of the factor that was used to adjust the stress.

The Asphalt Institute fatigue model that is used in the PCA methodology was developed to predict alligator cracking. However, the authors noted that while HMA fatigue was a factor in UTW distresses, fatigue cracking was not likely the cause. Wu et al. [1998] commented that since there was a stiff PCC layer over the HMA that rutting was not likely to occur. However, Rasmussen and Rozycki noted that this failure mode had been observed in the field and therefore it may be appropriate to account for this failure mechanism.

Finally it was noted that the number and type of design inputs might make the methodology overly complicated. Some inputs may be difficult for the designer to obtain. The example noted was a design temperature differential. Riley et al. [2005] summarized the required design inputs as follows.

- Concrete thickness (in.).

- Joint spacing/slab size (in.).

- Concrete flexural strength (psi).

- Concrete modulus of elasticity (psi).

- Asphalt thickness (in.).

- Asphalt modulus of elasticity (psi).

- Composite modulus of subgrade reaction (psi).

- Temperature differential between top and bottom of concrete $\left({ }^{\circ} \mathrm{F}\right)$.

- Coefficient of thermal expansion (CTE) of the concrete (in./in./ ${ }^{\circ} \mathrm{F}$ ). 
- Axle load distribution (weights and numbers of axles, by type single, tandem).

- Average daily truck traffic (ADTT).

- Design life (years).

- Fatigue relationship (number of load applications vs. stress ratio).

An additional limitation of the PCA methodology was that it was based on the design of a UTW overlay constructed over an HMA pavement. It was shown by Rajan et al. [2001] that when there is an underlying composite pavement the strains in the UTW are significantly reduced. Therefore, the PCA methodology may not be appropriate for UTW overlays of existing composite pavements. Cable et al. [2001] recommended looking at the use of UTW over existing composite pavements.

Riley et al. [2005] questioned the use of the PCA fatigue criteria for the design of UTW overlays. It was noted that the PCA criteria had been developed decades earlier and was very conservative in its predictions. Thus, a new reliability-based model was proposed. This model was evaluated on a limited basis using data from projects constructed in Illinois as well as the test sections constructed at the FHWA ALF. Preliminary results indicate that the model provides reasonable predictions. While it was not part of the paper, it was also noted that a reliability based model for the HMA fatigue should also be investigated.

\subsection{Environmental Effects}

Vandenbossche [2001] published a paper on the response of UTW pavements to environmental loads. While the PCA method addressed the effects of temperature on the UTW pavements the work was mostly theoretical with limited validation with field observations. The work by Vandenbossche evaluated the data collected at the Mn/ROAD, and was the first extensive work addressing this topic. It was concluded that significant temperature gradients do develop in the 
UTW layer, however the effects of the gradient are reduced by the bond and the short joint spacing used in UTW pavements. The bond strength varied with temperature changes. Since the bond strength greatly influences the stresses that develop in the UTW layer, it was recommended that seasonal changes be taken into account in the design methodology. Both temperature and moisture changes affected the shape of the slab and the interaction between the two effects is quite complicated.

\subsection{UTW Shrinkage}

Petersson and Silfwerbrand [1993] modeled the shrinkage of UTW over HMA. It was noted that if the volume decrease that results from the concrete shrinkage is restrained, stresses will develop in the concrete. The modeling assumed a full bond between the two layers. Two different static conditions were analyzed. The first was a beam freely supported on both ends and the second was a beam fixed at both ends. The configuration of the beams was 2 to 4 inches (50 to 100 $\mathrm{mm}$ ) of concrete placed over 8 inches $(200 \mathrm{~mm})$ of HMA. Shrinkage was assumed to be constant throughout the overlay. The Comité Euro-International du Beton (CEB) models for shrinkage and creep were employed. Shrinkage and creep of the HMA was assumed to be zero. A program was developed and several iterations were run.

The results are presented in Figure 2.6. The results indicated that in no case did the maximum tensile stress exceed more than half of the tensile stress of the concrete. The greatest stress occurs for the situation where the movement is restrained, the overlay is thin and the modulus of the HMA is low. It was concluded that cracking of the UTW cannot be caused by shrinkage alone. Further, short joint spacings will keep these stresses to a minimum. However, dead load and loss of contact will increase stresses. Also, the evaluations were run with high quality concrete. Use of an inferior concrete will lessen the factor of safety shown in this analysis. 

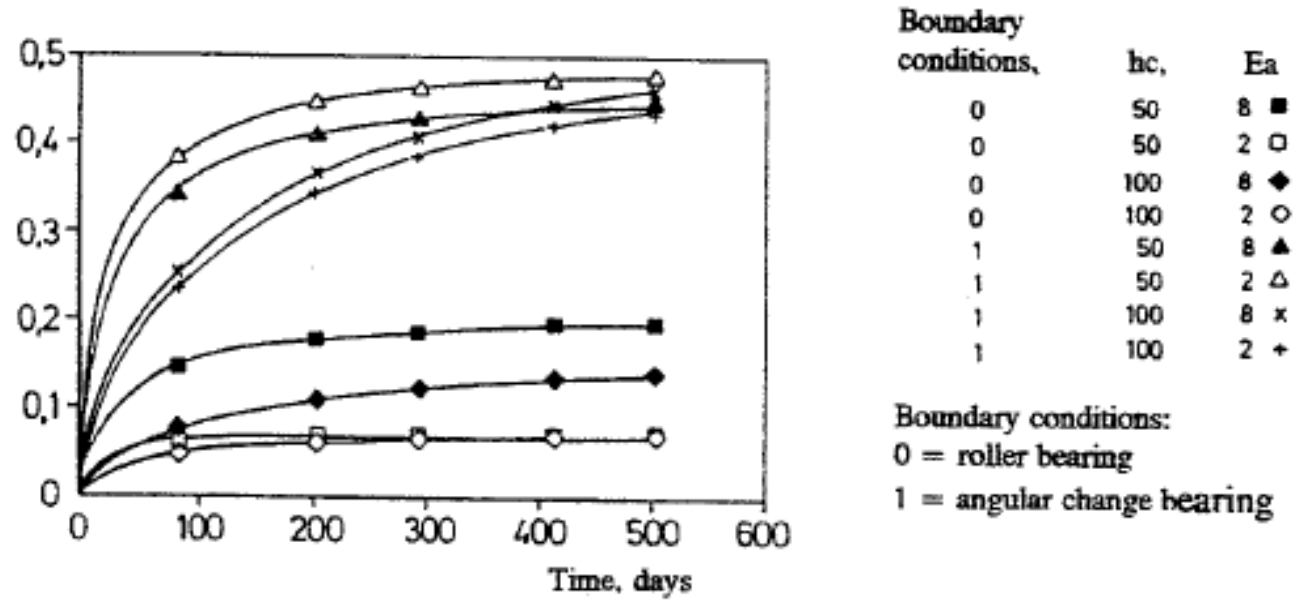

Figure 2.6 Ratio between Maximum Tensile Stress and Available Tensile Strength, Petersson and Silfwerbrand [1993]

Vandenbossche [2001] evaluated the strains during the testing of the UTW at $\mathrm{Mn} / \mathrm{ROAD}$. The strains at the top and bottom of the 4 inch $(100 \mathrm{~mm})$ UTW layer were measured after 45 minutes, 1 month, 2 months, 1 year, 2 year, and 3 years after construction. These data were corrected using the measured coefficient of thermal expansion of the concrete to account for the temperature induced strains and thereby isolating any shrinkage effects. The strain at the top of the overlay was significantly higher than the strain at the bottom of the layer (see Figure 2.6). However this strain was still below that which was expected for the shrinkage of concrete at three years of age. This was attributed to the rewetting effect that occurs as a result of rain. The lack of shrinkage cracking was attributed to the wet curing and to the significant strength of the concrete (6230 psi (43 MPa)). 


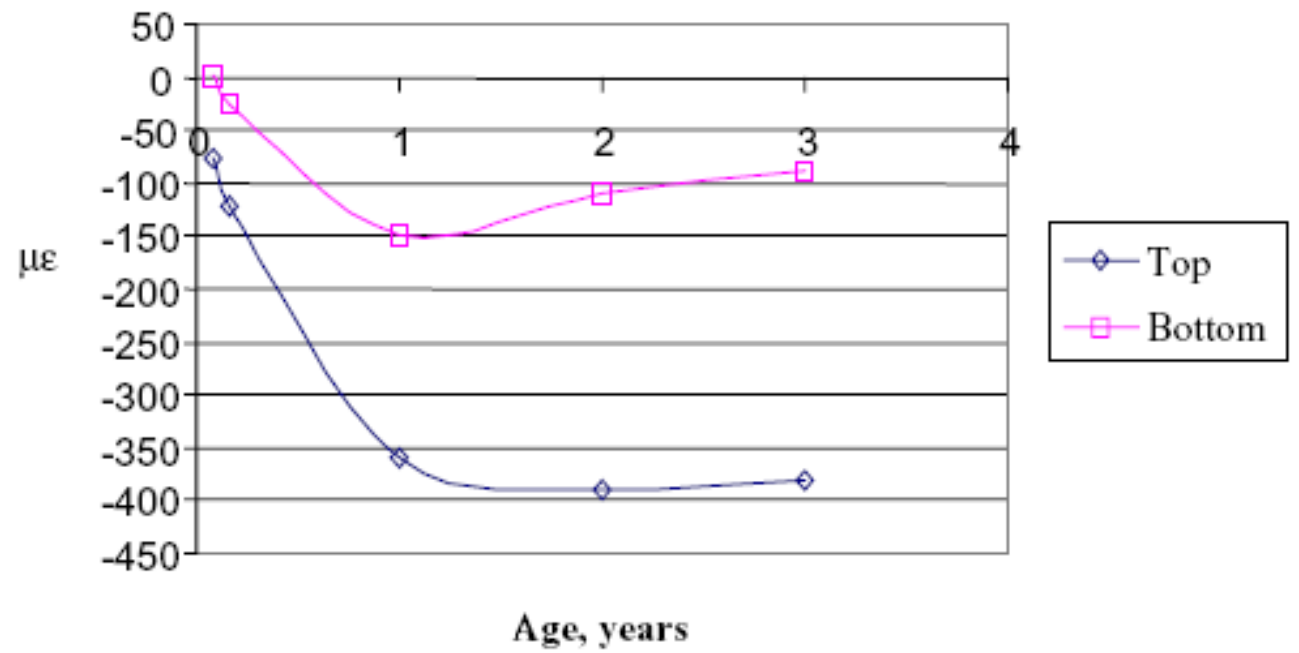

Figure 2.7 Drying Shrinkage of 4 Inch UTW Overlay at Mn/ROAD, Vandenbossche [2001] 


\section{CHAPTER 3. RESEARCH PLAN}

The objectives and scope of this research project were outlined in Chapter 1. This chapter contains an overview of the research plan describing how the plan addresses the objectives of the research project. Also contained in this chapter is a description of the plan for analysis of data collected during the APT testing.

\subsection{Overview of Research Plan}

The overall schematic of the research plan developed for this study is shown in Figure 3.1. The research plan consists of two main thrust areas: a) the modification of the PCA UTW design methodology, and b) evaluation of factors influencing UTW performance. To modify the PCA design method three different large-scale test areas, Test Area 2 (TA2) Test Area 3 (TA3), and Test Area 4 (TA4) were utilized. The APT test areas, TA2 and TA3, (described in detail in Sections 4.2.2 and 4.2.3, respectively) consisted of 5 different test lanes of the same UTW thickness. TA2 consisted of a UTW layer constructed over a composite pavement (traditional HMA over PCC) and TA3 consisted of a UTW layer constructed over a HMA pavement. The method of preparation of the milled HMA surface was varied to evaluate different bond conditions. Bond conditions included were fully bonded, partially bonded, and unbonded. Three different concrete mixtures were utilized in this research. Additionally, Test Area 4 (described in detail in Section 4.2.4) was constructed outside in the existing parking lot outside the APT facility. This test area was constructed with 5 different test lanes. The existing parking lot is an HMA pavement. The test lanes in TA4 varied by UTW and HMA depths. 
For all test lanes, FWD testing was conducted at different phases of the construction to assess the stiffness of the pavement section before and after the UTW placement. APT test lanes were also instrumented to provide strain data for calibration of the design methodology. Laboratory testing to determine material properties for input into the design equations was also conducted. Concrete material properties determined included concrete compressive strength, flexural strength, modulus of elasticity, and Poisson's ratio. The HMA properties included back-calculated modulus of elasticity. Pavement variables evaluated were layer thicknesses and existing pavement type (HMA or composite).

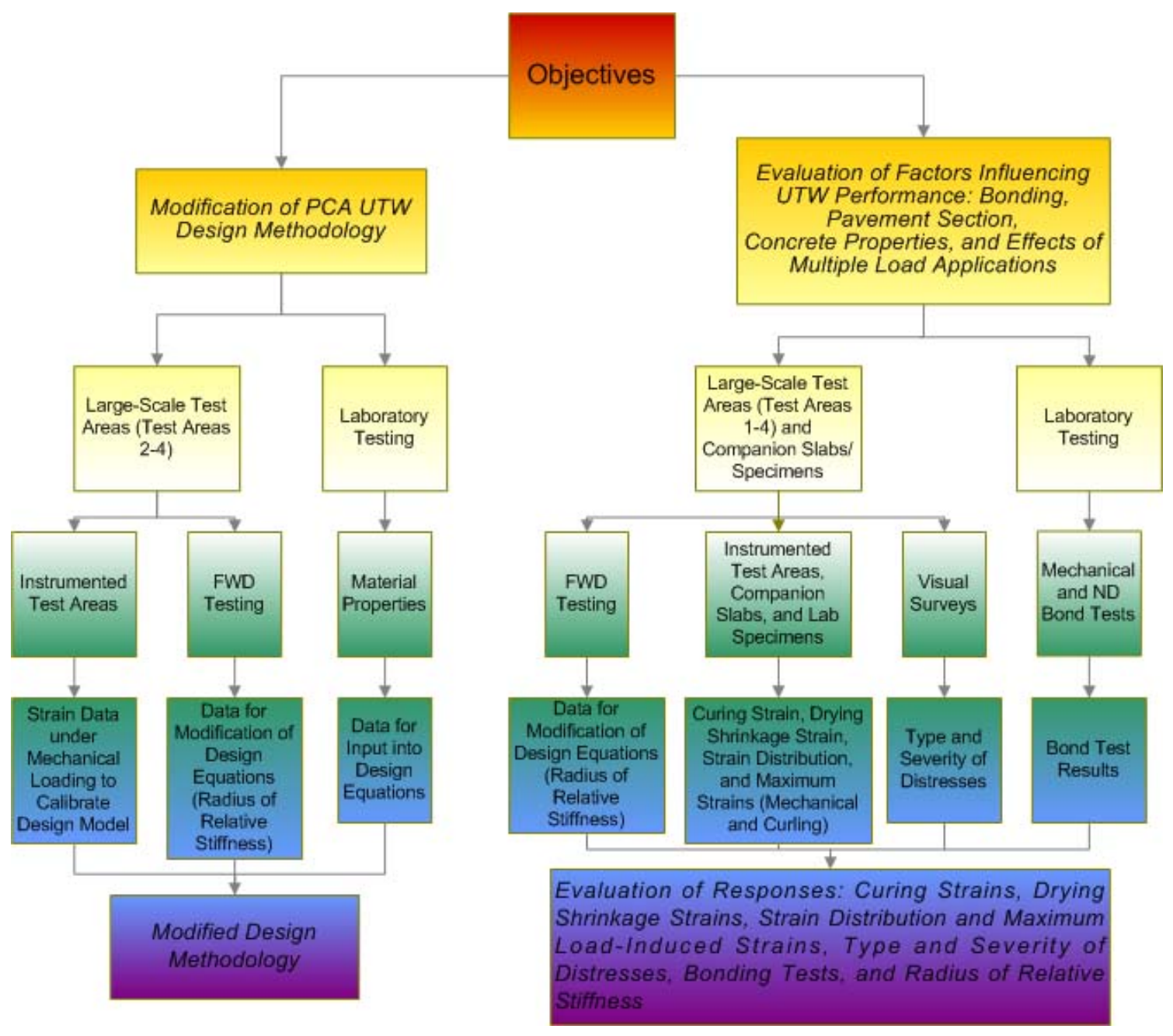

Figure 3.1 Overview of Test Plan 
For the evaluation of the factors influencing UTW performance, three different large-scale test areas (Test Areas 1-3) were utilized. Sections 4.2.1, 4.2.2., and 4.2.3 contain detailed descriptions of these test areas. TA2 and TA3 were the same test areas (described above) used for the modification of the PCA design methodology. Mechanical loading of each of the test lanes by the APT was conducted to simulate the effect of traffic loading. Test Area 1 (TA1) consisted of only two test lanes. One of these lanes was loaded with the APT to simulate traffic loading and the other lane is kept unloaded to compare the two conditions.

Test Area 4 (TA4), utilized also for the development of the PCA design modifications, was used to provide information regarding the effects of thermal loading on the UTW performance. This test area remained exposed to the environment during both cold and warm weather (thermal loading).

All test lanes in all areas were instrumented with different types of strain gages and thermocouples (see Chapter 4). Strains and temperatures developing in various locations of the test lanes were monitored both during curing and APT testing. FWD testing was also performed to evaluate the pavement deflections. Visual surveys were conducted to evaluate distress development, i.e. crack mapping was conducted periodically to assess the distresses with the increasing number of load applications. As mentioned previously, three different concrete mixtures were used. Thus, variables evaluated in these tests are load type (mechanical or thermal), material properties, bond preparation, and pavement sections.

Laboratory testing of composite shear specimens was also conducted to evaluate bond strength (lowa shear test) between the UTW and HMA layers. These specimens were exposed to freezing and thawing cycles and then tested to determine the effect of the cycling on the bond shear strength. In addition, to evaluate a second mode of bond failure a flexural bond test was performed. 
Composite beam specimens were prepared and exposed to freezing and thawing cycles. These specimens were also cycled mechanically to induce stress on the bond. When mechanical cycling was completed the specimens were loaded in flexure to failure. Prior to loading the specimens to failure, changes in bond for both the lowa shear and flexural bond specimens were evaluated using pulse velocity testing and impact echo testing. These tests were conducted to provide information regarding the mechanical and thermal effects on the bond.

To evaluate the bond strength and shrinkage interaction, the APT test areas (Test Areas 1-3) and parking lot test area (Test Area 4) were utilized. Unbonded companion slabs were prepared during construction of each APT test lane to provide a comparison of bonded and unbonded behavior.

\subsection{Overview of Data Analysis Plan}

As noted previously, this study was conducted to evaluate the performance of UTW overlays constructed over different pavement sections. Five different influences on the performance were identified: type of pavement section, bond conditions, multiple load applications (mechanical and thermal), and UTW concrete mechanical properties. Up to seven possible responses to these influences were monitored. These responses included: curing strains, drying shrinkage strains, strain distribution, maximum load-induced strains, type and severity of distresses, bond strength, and the radius of relative stiffness. Table 3.1 contains a coded of all the variables used in the study. The general form of the code is $L X_{y}$, where $X$ is the lane designation (1 through 5) and $y$ is the response evaluated: $i=$ Curing Strains; $j=$ Drying Shrinkage Strains; $k=$ Strain Distribution and Maximum Load-Induced Strains; $I$ = Distress (Development or Final); $m=$ Bond Tests; and $n=$ Radius of Relative Stiffness. In performing the analysis, the variables listed in a given row of the table for any test area were directly compared with the variables listed in the same row for all other test areas. Although TA4 variables are included in the "pavement section" row of 
Table 3.1, these variables were not directly compared with variables from other test areas listed in the same row but were instead used for the design modification portion of the study.

Table 3.1 Data Comparisons by Test Area

\begin{tabular}{|c|c|c|c|c|}
\hline Influences & TA1 & TA2 & TA3 & TA4 \\
\hline Pavement Section & $\mathrm{L} 1_{\mathrm{k}, \mathrm{l}, \mathrm{m}, \mathrm{n}}$ & $\mathrm{L} 1_{\mathrm{k}, \mathrm{l}, \mathrm{m}, \mathrm{n}}$ & $\mathrm{L} 1_{\mathrm{k}, \mathrm{l}, \mathrm{m}, \mathrm{n}}$ & $\begin{array}{r}\mathrm{L} 1_{\mathrm{n}} \\
\mathrm{L} 2_{\mathrm{n}} \\
+\quad \mathrm{L} 3_{\mathrm{n}} \\
\mathrm{L} 4_{\mathrm{n}} \\
\mathrm{L} 5_{\mathrm{n}}\end{array}$ \\
\hline $\begin{array}{c}\text { UTW Concrete } \\
\text { Material Properties }\end{array}$ & NA & $\begin{array}{l}L 1_{i, j, k, l, m, n} \\
L 2_{i, j, k, l, m, n} \\
L 3_{i, j, k, l, m, n}\end{array}$ & $\begin{array}{l}L 1_{i, j, k, l, m, n} \\
L 2_{i, j, k, l, m, n} \\
L 3_{i, j, k, l, m, n}\end{array}$ & NA \\
\hline Bond Conditions & $\begin{array}{l}\mathrm{L} 1_{\mathrm{i}, \mathrm{j}, \mathrm{k}, \mathrm{l}, \mathrm{m}, \mathrm{n}} \\
\mathrm{L} 2_{\mathrm{i}, \mathrm{j}, \mathrm{k}, \mathrm{l}, \mathrm{m}, \mathrm{n}}\end{array}$ & $\begin{array}{l}L 1_{i, j, k, l, m, n} \\
L 4_{i, j, k, l, m, n} \\
L 5_{i, j, k, l, m, n}\end{array}$ & $\begin{array}{l}\mathrm{L} 1_{\mathrm{i}, \mathrm{j}, \mathrm{k}, \mathrm{l}, \mathrm{m}, \mathrm{n}} \\
\mathrm{L} 5_{\mathrm{i}, \mathrm{j}, \mathrm{k}, \mathrm{l}, \mathrm{m}, \mathrm{n}}\end{array}$ & NA \\
\hline Mechanical Loading & $\begin{array}{l}\mathrm{L} 1_{\mathrm{k}, \mathrm{n}, \mathrm{n}} \\
\mathrm{L} 2_{\mathrm{k}, \mathrm{l}, \mathrm{n}}\end{array}$ & $\begin{array}{l}\mathrm{L} 1_{\mathrm{k}, \mathrm{ln}} \\
\mathrm{L} 2_{\mathrm{k}, \mathrm{ln}} \\
\mathrm{L} 3_{\mathrm{k}, \mathrm{n}} \\
\mathrm{L} 4_{\mathrm{k}, \mathrm{n}, \mathrm{n}} \\
\mathrm{L} 5_{\mathrm{k}, \mathrm{n}, \mathrm{n}}\end{array}$ & $\begin{array}{l}\mathrm{L} 1_{k, l, n} \\
\mathrm{~L} 2_{k, l, n} \\
\mathrm{~L} 3_{k, \mathrm{l}, \mathrm{n}} \\
\mathrm{L} 4_{k, \mathrm{l}, \mathrm{n}} \\
\mathrm{L} 5_{k, \mathrm{l}, \mathrm{n}}\end{array}$ & NA \\
\hline $\begin{array}{l}\text { Environmental } \\
\text { Loading }\end{array}$ & NA & NA & NA & $\begin{array}{c}\mathrm{L} 1_{\mathrm{k}, \mathrm{l}, \mathrm{m}, \mathrm{n}} \\
\mathrm{L} 2_{\mathrm{k}, \mathrm{lm}, \mathrm{n}} \\
\mathrm{L} 3_{\mathrm{k}, \mathrm{lm}, \mathrm{n}} \\
\mathrm{L} 4_{\mathrm{k}, \mathrm{lm}, \mathrm{n}} \\
\mathrm{L} 5_{\mathrm{k}, \mathrm{l}, \mathrm{m}, \mathrm{n}} \\
- \\
\text { Laboratory } \\
\text { Study }\end{array}$ \\
\hline
\end{tabular}

${ }^{\dagger}$ Note: TA4 Analysis Included as Part of Design Modifications 


\section{CHAPTER 4. TEST AREAS AND TEST METHODOLOGIES}

This chapter contains descriptions of the test areas and outlines the test methodologies used during this research project. It covers the facilities, equipment, sampling and specimen preparation, construction of test areas, and test methods used to conduct the experiments. Applicable standards are referenced where appropriate.

\subsection{Accelerated Pavement Testing Facility}

Testing was conducted at the INDOT - Purdue University APT facility located at the INDOT Research Division in West Lafayette, IN. The APT is housed in an approximately 2,000 square feet (185 square meter) environmentally controlled building. The APT facility is composed of test pit, a loading mechanism and control and monitoring equipment.

The APT testing area consists of a 20 foot $(6.1 \mathrm{~m})$ wide by 20 foot $(6.1 \mathrm{~m})$ long by 6 foot $(1.8 \mathrm{~m})$ deep test pit. The pit allows the placement of pavements at full depth.

The operator control room houses both the software and hardware used to fully control the APT operation. The room is currently equipped with three personal computers networked together. The first computer is used to fully control and operate the APT, the second computer is used for data collection/reduction and the third computer is used for monitoring and diagnoses of the APT hardware. 
The APT carriage (Figure 4.1) can be equipped with either a full-size, dual-tire truck wheel or a super-single, half-axle assembly. For this experiment the fullsize dual-tire configuration was used. The individual tire footprints had approximate dimensions of 8.0 by 7.5 inches $(200 \mathrm{~mm}$ by $187 \mathrm{~mm}$ ) (W by L). The distance between the centerlines of the tires was 13.25 inches $(331 \mathrm{~mm})$. The tire type utilized was a Goodyear G159 A 11R22.5. The tires were inflated to $100 \mathrm{psi}(690 \mathrm{kPa})$.

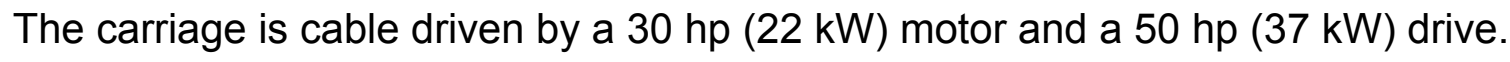
This setup allows speeds up to $5 \mathrm{mph}(8 \mathrm{kph})$. The APT loading mechanism uses a system of four air pistons that maintain a constant force up to $20,000 \mathrm{lbs}$ (89 $\mathrm{kN})$. This load can be programmed either in static or dynamic modes. These cylinders also allow the wheels to be raised and returned to the start-up position of the test pad if used in one direction type of testing. 


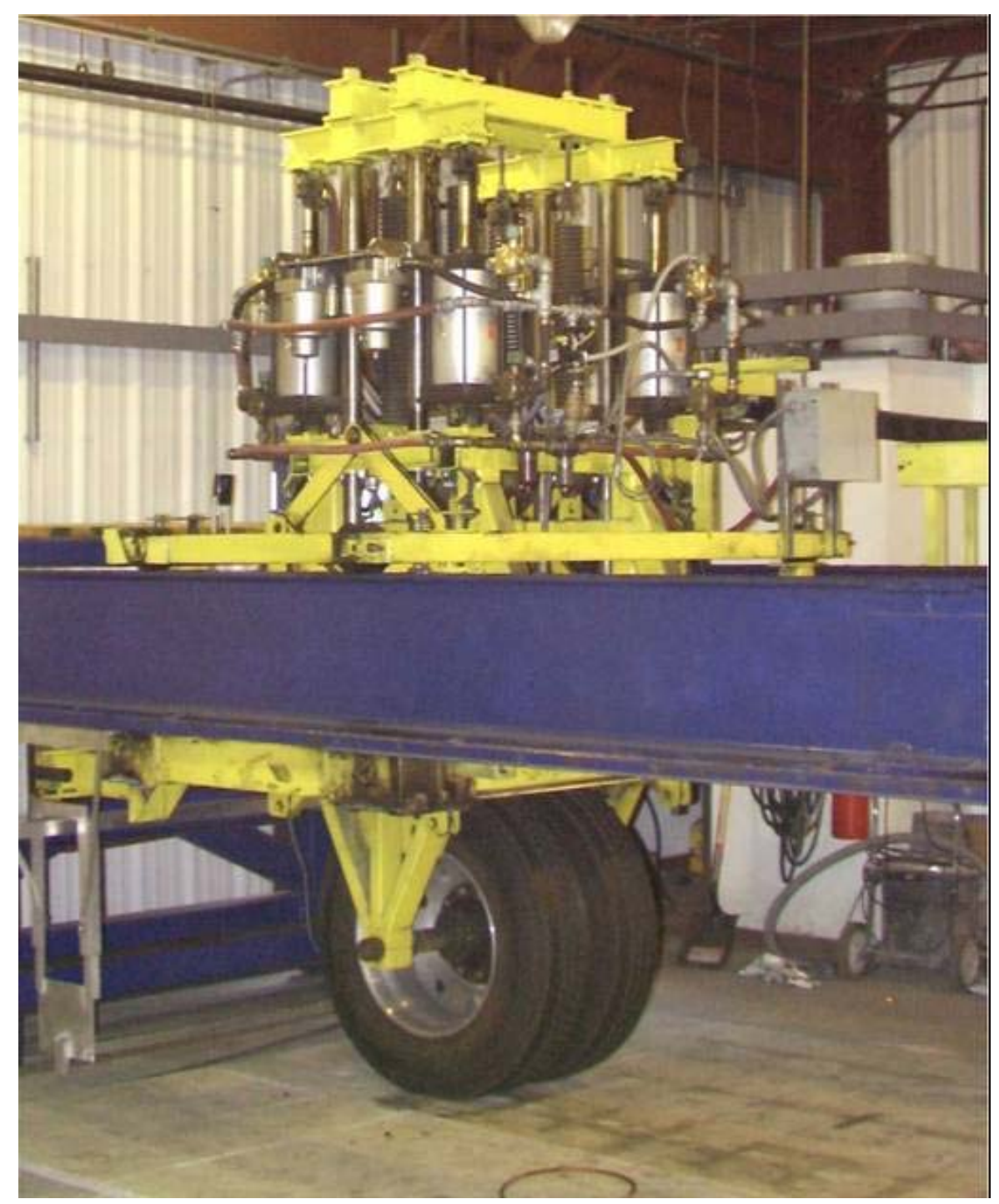

Figure 4.1 Accelerated Pavement Testing Facility

\subsection{Overview of Test Areas}

Four different test areas were included in the test plan for evaluation. Table 4.1 contains a summary of the test area objectives and physical descriptions. Each test area had a different underlying pavement structure that was overlaid with UTW. Two different underlying composite pavements and two different underlying HMA pavements were evaluated. Test Area 1 (TA1) consisted of two test lanes: one lane that was loaded by the APT carriage and a lane that was not 
loaded by the APT carriage. In Test Area 2 (TA2) and Test Area 3 (TA3) all lanes were loaded. Test Area 4 (TA4) had test lanes with varying depths of UTW and HMA but these lanes were not loaded with the APT carriage. All test lanes were 4 feet $(1200 \mathrm{~mm})$ wide regardless of test lane.

Table 4.1 Test Area Summary (continued)

\begin{tabular}{|c|c|c|c|c|}
\hline & Test Area 1 & Test Area 2 & Test Area 3 & Test Area 4 \\
\hline $\begin{array}{l}\text { Main Test } \\
\text { Objective }\end{array}$ & $\begin{array}{l}\text { To evaluate } \\
\text { the } \\
\text { performance } \\
\text { of UTW over } \\
\text { a very stiff } \\
\text { composite } \\
\text { pavement. }\end{array}$ & $\begin{array}{l}\text { To evaluate } \\
\text { the } \\
\text { performance } \\
\text { of UTW over } \\
\text { a "realistic" } \\
\text { composite } \\
\text { pavement. }\end{array}$ & $\begin{array}{l}\text { To evaluate } \\
\text { the } \\
\text { performance } \\
\text { of UTW over } \\
\text { an HMA } \\
\text { pavement. }\end{array}$ & $\begin{array}{l}\text { 1. To } \\
\text { evaluate the } \\
\text { UTW } \\
\text { pavement } \\
\text { section with } \\
\text { varying } \\
\text { thicknesses } \\
\text { for design } \\
\text { equation } \\
\text { development. } \\
2 . \text { To } \\
\text { evaluate the } \\
\text { effects of } \\
\text { environmental } \\
\text { loading on } \\
\text { UTW. }\end{array}$ \\
\hline $\begin{array}{l}\text { Total Number } \\
\text { of Test Lanes }\end{array}$ & 2 & 5 & 5 & 5 \\
\hline
\end{tabular}


Table 4.1 Test Area Summary (continued)

\begin{tabular}{|c|c|c|c|c|}
\hline & Test Area 1 & Test Area 2 & Test Area 3 & Test Area 4 \\
\hline $\begin{array}{c}\text { Number of } \\
\text { Loaded Test } \\
\text { Lanes }\end{array}$ & 1 & 5 & 5 & 0 \\
\hline $\begin{array}{c}\text { Number of } \\
\text { Unloaded Test } \\
\text { Lanes }\end{array}$ & 1 & 5 & 5 & 5 \\
\hline UTW Thickness & $\begin{array}{c}2.5 \text { inches } \\
(63 \mathrm{~mm})\end{array}$ & $\begin{array}{c}2.5 \text { inches } \\
(63 \mathrm{~mm})\end{array}$ & $\begin{array}{c}2.5 \text { inches } \\
(63 \mathrm{~mm})\end{array}$ & $\begin{array}{c}2,3, \text { or } 4 \\
\text { inches } \\
(50,75, \text { or } 100 \\
\mathrm{mm})\end{array}$ \\
\hline \begin{tabular}{|c|} 
Description of \\
Underlying \\
Layers
\end{tabular} & $\begin{array}{c}\text { Existing stiff } \\
\text { composite } \\
\text { pavement } \\
\text { designed to } \\
\text { induce rutting }\end{array}$ & $\begin{array}{c}\text { Newly } \\
\text { constructed } \\
\text { composite } \\
\text { pavement }\end{array}$ & $\begin{array}{c}\text { Newly } \\
\text { constructed } \\
\text { HMA } \\
\text { pavement }\end{array}$ & $\begin{array}{c}\text { Existing HMA } \\
\text { pavement } \\
\text { (approximately } \\
30 \text { years old) }\end{array}$ \\
\hline $\begin{array}{l}\text { HMA Layer } \\
\text { Thickness }\end{array}$ & $\begin{array}{l}3 \text { inches } \\
(75 \mathrm{~mm})\end{array}$ & $\begin{array}{l}9.5 \text { inches } \\
(237 \mathrm{~mm})\end{array}$ & $\begin{array}{c}11.5 \text { inches } \\
(288 \mathrm{~mm})\end{array}$ & $\begin{array}{c}3 \text { to } 5 \text { inches } \\
\text { (75 to } 125 \\
\mathrm{~mm})\end{array}$ \\
\hline \begin{tabular}{|c|} 
Underlying \\
Concrete Layer \\
Thickness
\end{tabular} & $\begin{array}{l}12 \text { inches } \\
(300 \mathrm{~mm}) \\
\text { Reinforced } \\
\text { Concrete }\end{array}$ & $\begin{array}{c}6 \text { inches } \\
(150 \mathrm{~mm})\end{array}$ & NA & NA \\
\hline
\end{tabular}




\begin{tabular}{|c|c|c|c|c|}
\hline $\begin{array}{c}\text { HMA Layer } \\
\text { Thickness }\end{array}$ & $\begin{array}{c}3 \text { inches } \\
(75 \mathrm{~mm})\end{array}$ & $\begin{array}{c}9.5 \text { inches } \\
(237 \mathrm{~mm})\end{array}$ & $\begin{array}{c}11.5 \text { inches } \\
(288 \mathrm{~mm})\end{array}$ & $\begin{array}{c}3 \text { to } 5 \text { inches } \\
(75 \text { to } 125 \\
\mathrm{mm})\end{array}$ \\
\hline Underlying & 12 inches & 6 inches & NA & NA \\
Concrete Layer & $(300 \mathrm{~mm})$ & $(150 \mathrm{~mm})$ & & \\
Thickness & $\begin{array}{c}\text { Reinforced } \\
\text { Concrete }\end{array}$ & & & \\
& & & & \\
\hline
\end{tabular}

Table 4.1 Test Area Summary

\begin{tabular}{|c|c|c|c|c|}
\hline $\begin{array}{c}\text { Total Thickness } \\
\text { of the } \\
\begin{array}{c}\text { Underlying } \\
\text { Layers }\end{array}\end{array}$ & $\begin{array}{c}\text { Test Anches } \\
(1775 \mathrm{~mm})\end{array}$ & $\begin{array}{c}\text { Test Area 2 } \\
(1738 \mathrm{~mm})\end{array}$ & $\begin{array}{c}\text { Test Area 3 } \\
(1738 \mathrm{~mm})\end{array}$ & $\begin{array}{c}\text { Test Area 4 } \\
\text { (75 to 125 } \\
\text { mm) HMA } \\
\text { over unknown } \\
\text { subgrade }\end{array}$ \\
\hline $\begin{array}{c}\text { Bond } \\
\text { Conditions }\end{array}$ & Full & Full (Lanes 1, & Full (Lanes 1, & Full \\
& & 2, and 3) & 2, and 3) & \\
& & $\begin{array}{c}\text { Partial Bond } \\
\text { (Lane 4) No }\end{array}$ & $\begin{array}{c}\text { Partial Bond } \\
\text { (Lane 4) No }\end{array}$ & \\
& & Bond (Lane & Bond (Lane & \\
& & 5) & 5) & \\
\hline
\end{tabular}




\begin{tabular}{|c|c|c|c|c|}
\hline $\begin{array}{c}\text { UTW Concrete } \\
\text { Mix Designs }\end{array}$ & Base Mix & $\begin{array}{c}\text { Base Mix } \\
\text { (Lanes 1, 4, } \\
\text { and 5) High } \\
\text { Early } \\
\text { Strength Mix }\end{array}$ & $\begin{array}{c}\text { Base Mix } \\
\text { (Lanes 1, 4, } \\
\text { and 5) High } \\
\text { Early } \\
\text { Strength Mix } \\
\text { (Lane 2) Fiber } \\
\text { and Fiber } \\
\text { Mix (Lane 3) }\end{array}$ & Base Mix \\
& & $\begin{array}{c}\text { (Lane 2) High } \\
\text { Early } \\
\text { Strength Mix } \\
\text { (Lane 3) }\end{array}$ & \\
& & & \\
& & &
\end{tabular}

\subsubsection{Test Area 1}

Test Area 1 was constructed to evaluate the performance of UTW over a very stiff composite pavement. The test lanes of TA4 were constructed on the existing underlying composite pavement section previously used in the APT (Stiady et al. [2003]). This underlying composite pavement consisted of 4 feet $(1200 \mathrm{~mm})$ of pea gravel covered by approximately 8 inches $(200 \mathrm{~mm})$ of compacted clay used as a leveling course. Four, 12-inch $(300 \mathrm{~mm})$ thick reinforced concrete slabs, each 5 feet $(1.5 \mathrm{~m})$ wide were placed on top of the leveling course. These slabs contained a pipe system that was used to raise or lower the temperature of the HMA layers placed on top of the slabs as to provide a stiff layer to induce rutting on the HMA mixtures tested in the APT. The HMA layer used in the previous study was 4 inches $(100 \mathrm{~mm})$ thick composed of a Superpave surface mixture with PG 64-22 binder and was subjected to 20,000 APT, $9,000 \mathrm{lbs}(40 \mathrm{kN})$ load passes of the APT carriage (single axle, dual tires). 


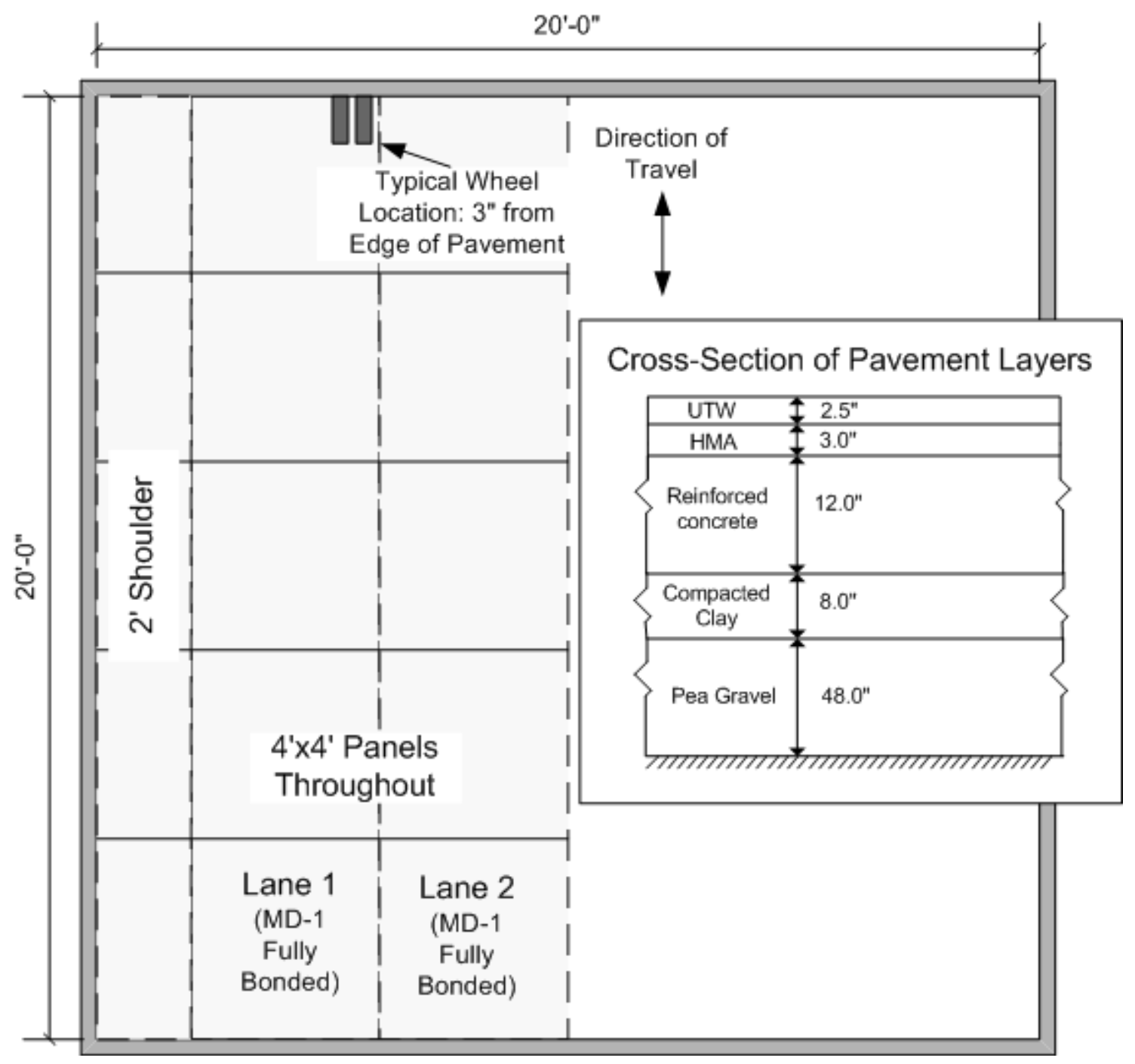

Figure 4.2 Layout of TA1

To construct the UTW, one inch of the HMA was milled to completely eliminate the permanent deformations due to previous APT loadings as well as to provide a good bond between the HMA and UTW. The milling left the HMA layer approximately 3.0 inches $(75 \mathrm{~mm})$ thick. The HMA was cleaned to produce a fully bonded condition (Section 4.3.6). A 10 foot $(3000 \mathrm{~mm})$ wide concrete slab, 2.5 inches $(63 \mathrm{~mm})$ thick was constructed as the UTW overlay using the base concrete mix (Section 4.3.5). The slab was sawcut to produce two, 4 foot wide test lanes. A 2 foot $(600 \mathrm{~mm})$ wide area was constructed along the edge of the 
APT test pit to minimize the edge effects of the APT test pit boundary on the loaded lane. Each of the test lanes was subsequently saw-cut at four foot intervals. The saw-cutting created 4 foot by 4 foot $(1200 \mathrm{~mm}$ by $1200 \mathrm{~mm})$ UTW panels in both the Lane 1 (loaded) and Lane 2 (unloaded) test lanes (see Figure $4.2)$.

\subsubsection{Test Area 2}

The purpose of TA2 was to evaluate the performance of the UTW constructed over a more realistic underlying composite pavement from that used in TA1. As mentioned in Section 4.2.1., the underlying composite pavement in TA1 was designed to induce rutting in the HMA. The 12 inch $(300 \mathrm{~mm})$ reinforced concrete slab provided a very stiff pavement section that was not likely to be encountered in many pavements in Indiana. Thus, in preparation for the construction of the second composite pavement section, TA2, the APT test pit was completely emptied and cleaned. The test pit was filled with 46 inches $(1200 \mathrm{~mm})$ of pea gravel and an 8 inch $(200 \mathrm{~mm})$ layer of well-graded crushed limestone (INDOT gradation \#53) was placed over the pea gravel. Next, a 6 inch $(150 \mathrm{~mm})$ thick plain PCC layer of using a standard INDOT concrete paving mix was placed over the crushed stone. The PCC layer was then overlaid by four HMA layers totaling 12.0 inches $(300 \mathrm{~mm})$. The HMA layers were Superpave intermediate and surface mixtures with PG 64-22 binder. In preparation for the construction of the UTW, the top 2.5 inches $(63 \mathrm{~mm})$ of the HMA was milled. This left the HMA layer approximately 9.5 inches $(237 \mathrm{~mm})$ thick. 


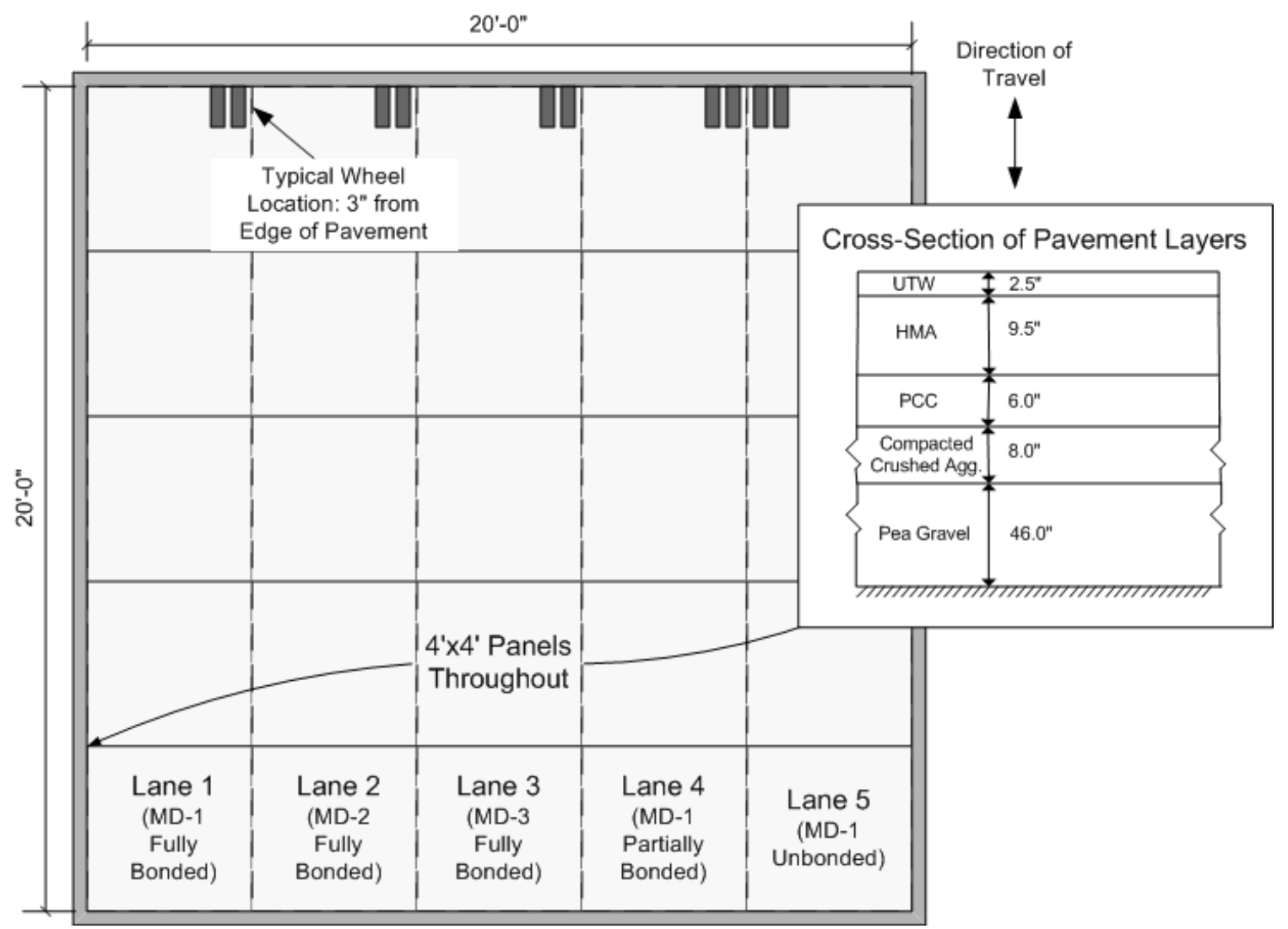

Figure 4.3 Layout of TA2

In total, five, 2.5 inch $(63 \mathrm{~mm})$ thick UTW test lanes were constructed. Each lane was poured separately. Three different concrete mixtures using a base UTW concrete (Lanes 1, 4, and 5), high early strength concrete (Lane 2), and a fiber reinforced concrete (Lane 3) were used in order to evaluate the performance of such mixtures when used in UTW applications. More detailed information regarding these mixes is provided in Section 4.3.5. Additionally, three different bonding conditions were created to evaluate the effect of full bonding (Lanes 1 through 3), partial bonding (Lane 4), and no bonding (Lane 5). More detailed information on these bonding conditions is presented in Section 4.3.6. The lanes were 4 feet wide $(1200 \mathrm{~mm})$ and were saw-cut into 4 foot by 4 foot $(1200 \mathrm{~mm}$ by $1200 \mathrm{~mm}$ ) panels. Figure 4.3 shows the layout of TA2. 


\subsubsection{Test Area 3}

TA3 was constructed in order to evaluate the performance of UTW constructed on an HMA pavement. Again, the preparation of the underlying structure in TA3 involved the removal of the all the materials from the test pit and construction of an HMA pavement. The test pit was filled with 50 inches $(1300 \mathrm{~mm})$ of pea gravel which was covered with 8 inches $(200 \mathrm{~mm})$ of well-graded crushed limestone (INDOT gradation \#53). The 14 inch $(350 \mathrm{~mm}$ ) thick layer of HMA was then placed on top of the limestone. The HMA was placed in 6 lifts ranging from 2 inches to 3 inches ( $50 \mathrm{~mm}$ to $75 \mathrm{~mm}$ ) in thickness. The HMA layers were Superpave base, intermediate, and surface mixtures with PG 64-22 binder.

After completion of the HMA placement, the top 2.5 inches $(63 \mathrm{~mm})$ of the HMA layer was milled to allow the construction of the UTW layer. This left the HMA layer approximately 11.5 inches $(287 \mathrm{~mm})$ thick which was used as a base on which the UTW layer was placed. 


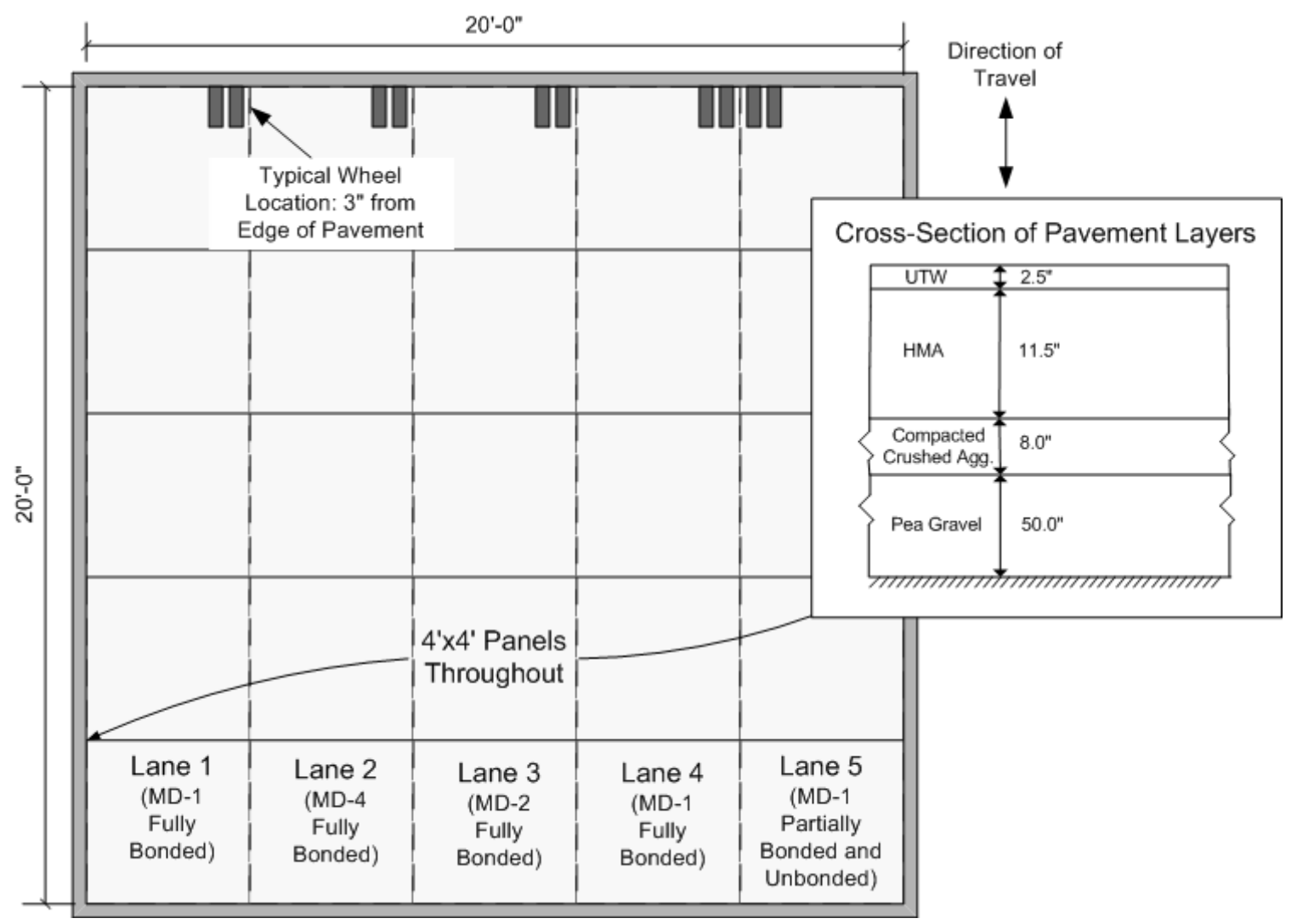

Figure 4.4 Layout of TA3

Similar to TA2, five, 2.5 inch $(63 \mathrm{~mm})$ thick UTW test lanes were constructed. Each lane was poured separately. Three different concrete mixtures using a base UTW concrete (Lanes 1, 4, and 5), high early strength concrete and fiber (Lane 3), and a fiber reinforced concrete (Lane 3) were used in order to evaluate the performance of such mixtures. More detailed information regarding the composition of these mixes is contained in Section 4.3.5. Additionally, three different bonding conditions were created to evaluate the effect of full bonding (Lanes 1, 2, 3, and 4), partial bonding (Lane 5), and no bonding (Lane 5). More detailed information on these bonding conditions is presented in Section 4.3.6. The lanes were 4 feet wide $(1200 \mathrm{~mm})$ and were saw-cut into 4 foot by 4 foot (1200 mm by $1200 \mathrm{~mm}$ ) panels. The layout of TA3 is illustrated in Figure 4.4. 


\subsubsection{Test Area 4}

The purpose of TA4 was twofold: to provide UTW pavement sections with varying thicknesses for design equation development and to evaluate the effect of environmental conditions on the UTW pavement. TA4 was placed in a parking lot outside the APT facility. The parking lot was constructed of HMA and was 7 inches $(175 \mathrm{~mm})$ thick. The test area was 20 feet $(6100 \mathrm{~mm})$ long by 20 feet $(6100 \mathrm{~mm}$ ) wide (see Figure 4.5). The milling of the HMA was as follows: a 2 inch milling depth in Lanes 1 through 3, a 3 inch milling depth in Lane 4, and a 4 inch milling depth in Lane 5. This left the thickness of the HMA at 5 inches in Lanes 1-3, 4 inches in Lane 4, and 3 inches in Lane 5. Five UTW test lanes were constructed at a width of 4 feet $(1200 \mathrm{~mm})$ each. The base concrete mix (Section 4.3.5) was used and the HMA was prepared to produce fully bonded conditions (Section 4.3.6). The thickness of the UTW also varied. The UTW in Lane 1 had a thickness of 4 inches $(100 \mathrm{~mm})$, Lane 2 had a thickness of 3 inches (75 mm), Lane 3 had a thickness of 2 inches $(50 \mathrm{~mm})$, Lane 4 had a thickness of 3 inches $(75 \mathrm{~mm})$, and Lane 5 had a thickness of 4 inches $(100 \mathrm{~mm})$. The UTW lanes were sawcut to produce panels that had dimensions of 4 foot by 4 foot (1200 $\mathrm{mm}$ by $1200 \mathrm{~mm}$ ). 

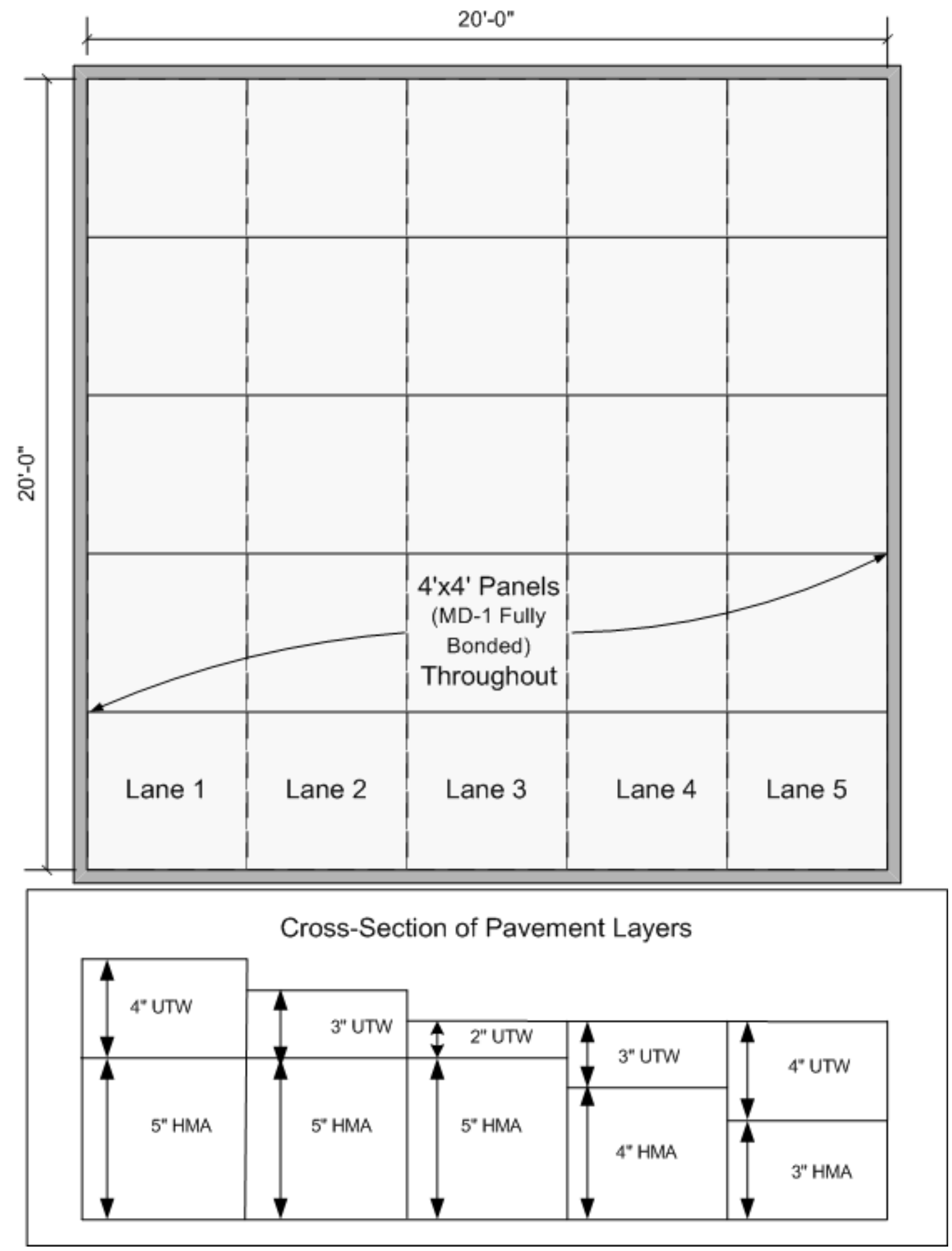

Figure 4.5 Layout of TA4 


\subsection{Construction of Test Areas}

Discussed in this section are the methods used in the construction of the test areas. First the construction of the subbase and subgrade is discussed. The HMA mixture compositions and their placement are presented next. This is followed by a discussion of the HMA milling process. A section covering the installation of the instrumentation is presented next. Finally, a section outlining the composition UTW concrete mixtures, their placement, saw-cutting, and curing are presented.

\subsubsection{Subbase and Subgrade Placement}

The subbase and subgrade layers used in TA1 and TA4 were already in place prior to the construction of the test lanes in these test areas. For the construction of the subbase and subgrade layers in TA2 and TA3, the existing materials in the APT test pit were completely removed using a power shovel. After all the material was removed, the test pit was swept clean and filled with pea gravel using a front end loader. The depth of the pea gravel was 46 inches $(1150 \mathrm{~mm}$ ) and 50 inches $(1250 \mathrm{~mm})$ deep for TA2 and TA3, respectively.

Next, in both TA2 and TA3, an 8 inch $(200 \mathrm{~mm})$ layer of well-graded limestone aggregate was placed on top of the pea gravel. The gradation of the aggregate corresponded to INDOT Standard Specification \#53 aggregate. This material was placed in two 4 inch $(100 \mathrm{~mm})$ lifts using a front end loader. Each lift was compacted using a small vibratory drum compactor. Areas that could not be reached using this equipment were compacted using a hand-operated vibratory plate compactor. Compaction to $96 \%$ of optimum was verified using nuclear density gage. 


\subsubsection{Composition and Placement of Underlying Hot Mix Asphalt}

TA1 and TA4 were built upon existing or previously tested Hot Mix Asphalt (HMA) pavements. As mentioned in Section 4.2.1, the HMA pavement used in TA1 was previously placed as a new pavement for a different research project conducted in the APT. The mixture was a Superpave 9.5-mm surface mixture using a PG 64-22 binder. A description of this mixture and its construction in the APT can be located in the report by Stiady et al. [2003]. The UTW lanes in TA4 were constructed on the top of the existing parking lot pavement. No original construction records for this pavement could be located. However, it is estimated that the lot is approximately 40 years old. Asphalt extracted from TA4 cores was tested using the Dynamic Shear Rheometer and Bending Beam Rheometer. The value of $\mathrm{G}^{*} \sin \delta$ at $23.9^{\circ} \mathrm{C}$ was $9.3 \times 10^{6} \mathrm{~Pa}$ while the average creep stiffness was $162 \mathrm{MPa}$ with an $\mathrm{m}$-value of 0.286 . The aggregates were graded and the uniformity coefficient was 22.9 and the coefficient of gradation was 1.29 with all aggregates less than $19 \mathrm{~mm}$ in size. The asphalt binder had aged significantly and the resulting mixture was very brittle. This was noticed particularly when trying to cut the specimens to size using a wet saw. The specimens were very difficult to cut and many fractured during the procedure.

New HMA was placed during the construction of TA2 and TA3. Base (25-mm), intermediate $(12.5-\mathrm{mm})$, and surface $(9.5-\mathrm{mm})$ mixtures were used. In all cases, the mixtures were produced with a Superpave PG64-22 binder. The mix used met specifications for INDOT Mixture Type $B$ which had a design ESAL of $2,000,000$.

The mixtures placed in the APT for TA2 and TA3 were placed using a full-size asphalt paving machine. Base layers were placed in 3 inch $(75 \mathrm{~mm})$ lifts. Intermediate and surface layers were placed in 2 inch $(50 \mathrm{~mm})$ lifts. Compaction was performed using a small vibratory drum compactor. Areas that could not be reached using this equipment were compacted using a hand-operated vibratory 
plate compactor. Compaction of $90 \%, 92 \%$, and $94 \%$ of maximum specific gravity was attained for the base, intermediate, and surface mixtures, respectively. Compaction densities were verified using nuclear density gage density.

\subsubsection{Hot Mix Asphalt Milling}

Milling of the underlying HMA for all test areas was performed using a skid steer machine fitted with a milling wheel. The maximum milling width with this equipment was 48 inches $(1.2 \mathrm{~m})$. The milling depth was verified by direct measurement using a tape measure. The milling depth of the HMA in TA1 was 1 inch (25 mm). In TA2 and TA3, 2.5 inches $(63 \mathrm{~mm})$ of HMA was milled. For TA4, 2 inches of HMA was milled in Lanes 1 through 3, 3 inches was milled in Lane 4, and 4 inches was milled in Lane 5.

Two different test methods were used to characterize the macrotexture of the milled HMA in TA2 and TA3. These test methods included the standard ASTM E 965 sand patch test and a modified ASTM E 965 test. The standard test in ASTM E 965 was designed to determine macrotexture of pavement surfaces and is not considered valid for grooved surfaces, e.g. milled asphalt pavement. Thus, there was a need to develop a methodology that was valid for milled pavement surfaces. To address this need, INDOT developed a modified version of the ASTM sand patch test. Described in ITM 812, the methodology was specifically developed to characterize milled surfaces. The test methodology followed a similar methodology as the ASTM test, but utilized a greater volume of granulated media and a larger spreading apparatus than the standard test. The modified test had not been developed when TA2 was constructed and therefore could not be utilized. Thus, the modified method was used on only TA3.

The standard sand patch test was performed according to ASTM E 965 on the milled surface in TA2. Ottawa sand was used as the test media. A hockey puck 
was used to spread the sand on the surface. Four trials were conducted. The average macrotexture depth for this surface was 0.09 inches $(2.4 \mathrm{~mm})$. The modified method was used to characterize the milled surface in TA3. Ottawa sand was used as the test media. A circular metal plate was used as the spreading device. Using the modified test, the average macrotexture depth was 0.11 inches $(2.7 \mathrm{~mm})$.

\subsubsection{Summary of the Instrumentation Plan}

In order to evaluate the strains throughout the depth of the pavement, several strain gages were placed in the PCC, HMA, and UTW layers. Four different types of strain gages were used in the course of this research. Thermocouples were also placed in the pavement layers to monitor pavement temperatures. This section contains a general overview of the instrumentation used throughout the study. Table 4.2 summarizes the information about the type and location of the gages and thermocouples used in each of the test areas. The schematic of the gage and thermocouple layout for each test area is shown in Figure 4.6. A more detailed description of the instrumentation is provided in Appendix A.

The first gage type, Texas Measurements ${ }^{\mathrm{TM}}$ embedment-type gage (PML-60-2L), was installed in the UTW and PCC layers at a level of 0.5 inches $(12 \mathrm{~mm})$ below the surface and at 0.5 inches $(12 \mathrm{~mm})$ from the bottom of the layer. This type of gage was oriented in either in the longitudinal (mid-slab and edge locations) or transverse (joint locations) direction (in relation to the movement of the APT carriage) or combined in sets of three to make a 90 degree strain gage rosette (corner locations) as illustrated in Figure 4.6. The second gage type, Texas Measurements ${ }^{\mathrm{TM}}$ surface-mount-type gage (WFLM-60-11-2LT), was glued to the surface of the milled HMA. This type of gage was oriented in either in the longitudinal (mid-slab, edge locations, and corner locations) or transverse direction (joint location). The third type of gage was a CTL (ASG-152) HMA embedment gage that is placed 0.5 inches $(13 \mathrm{~mm})$ from the bottom of the HMA 
layer. These gages were oriented in the longitudinal direction (edge and corner locations). The fourth gage type, Roctest ${ }^{\mathrm{TM}}$ surface mounted vibrating-wire-type gage (SM5-A), was attached to the surface of the UTW concrete and companion slabs at the edge and mid-slab locations. These gages were oriented perpendicularly to the direction of the APT carriage movement. The Type T thermocouples were placed at the surface of the HMA and at the mid-depth of the UTW layer at the mid-slab location.

For TA1 through TA3, all gages except the SM5-A gages were connected to a Vishay $^{\text {TM }}$ System 6100 data acquisition system. This system had the ability to take individual strain readings at a very high sampling rate (100 samples per second was the sampling rate used in this research - this equates to a sample being taken every 0.88 inch at the maximum carriage speed of $5 \mathrm{mph}$ ( $8 \mathrm{kph})$. For comparison, the length of the carriage tire footprint was approximately 8 inches $(200 \mathrm{~mm})$ ). The high frequency of data sampling enabled the recording of the dynamic strains as the wheel passed over the pavement at the gage location. Dynamic strain data were collected after every 500 to 10,000 load applications. A previous study by Rajan et al. [2001] compared the strain readings obtained by this system and using the Texas Measurements ${ }^{\mathrm{TM}}$ gages to the expected theoretical strains calculated using finite element analysis. The study concluded that the measured strain readings and the finite element calculated strains were of similar magnitudes for both the asphalt and the concrete.

The SM5-A gages were connected to a Campbell Scientific ${ }^{\circledR}$ CR10X datalogger that recorded the long-term development of the UTW surface strains. Readings were taken every hour during the test period (duration determined by the APT loading). For TA4, the thermocouples that recorded the temperature of the pavement layers were also connected to Campbell Scientific ${ }^{\circledR}$ CR10X datalogger. Readings were recorded every 10 minutes. 
Table 4.2 Summary of Gages Used in Different Test Areas (continued)

\begin{tabular}{|c|c|c|}
\hline Gage Type & Location & Data Acquisition \\
\hline \multicolumn{3}{|c|}{ TA1 } \\
\hline PML-60-2L & $\begin{array}{l}0.5 "(13 \mathrm{~mm}) \text { from top of } \\
\text { UTW layers at joint, mid- } \\
\text { slab, corner and edge } \\
\text { locations }\end{array}$ & System 6100 \\
\hline WFLM-60-11-2LT & $\begin{array}{c}\text { Top of Milled HMA at } \\
\text { joint, mid-slab, corner } \\
\text { and edge locations }\end{array}$ & System 6100 \\
\hline SM5-A & $\begin{array}{l}\text { Surface of UTW and } \\
\text { companion slabs at four } \\
\text { to five locations between } \\
\text { mid-slab and edge } \\
\text { locations }\end{array}$ & CR10X \\
\hline Type T Thermocouples & $\begin{array}{l}1.25 \text { inches }(37 \mathrm{~mm}) \\
\text { from the UTW surface } \\
\text { and at the HMA surface } \\
\text { at the mid-slab location }\end{array}$ & System 6100 \\
\hline
\end{tabular}


Table 4.2 Summary of Gages Used in Different Test Areas

\begin{tabular}{|c|c|c|}
\hline Gage Type & Location & Data Acquisition \\
\hline \multicolumn{3}{|c|}{ TA2 and TA3 } \\
\hline PML-60-2L & $\begin{array}{l}0.5 " \text { (13 mm) from top } \\
\text { and bottom of both UTW } \\
\text { and PCC layers (TA2) at } \\
\text { corner and edge } \\
\text { locations }\end{array}$ & System 6100 \\
\hline WFLM-60-11-2LT & $\begin{array}{c}\text { Top of Milled HMA at } \\
\text { corner and edge } \\
\text { locations }\end{array}$ & System 6100 \\
\hline ASG-152 & $\begin{array}{c}0.5 \text { inches }(37 \mathrm{~mm}) \text { from } \\
\text { the bottom of HMA at } \\
\text { corner and edge } \\
\text { locations }\end{array}$ & System 6100 \\
\hline SM5-A & $\begin{array}{l}\text { Surface of UTW and } \\
\text { companion slabs at } \\
\text { midslab and edge } \\
\text { locations }\end{array}$ & CR10X \\
\hline Type T Thermocouples & $\begin{array}{l}1.25 \text { inches }(37 \mathrm{~mm}) \\
\text { from the UTW surface } \\
\text { and at the HMA surface } \\
\text { at the mid-slab location }\end{array}$ & System 6100 \\
\hline
\end{tabular}




\begin{tabular}{|c|c|c|}
\hline Type T Thermocouples & 2 inches $(50 \mathrm{~mm})($ Lane \\
& 1) 1.5 inches $(37 \mathrm{~mm})$ \\
& (Lane 2$)$ or 1 inch $(25$ \\
$\mathrm{mm})$ (Lane 3$)$ from the & CR10X \\
& UTW surface and at the \\
& HMA surface at the mid- \\
& slab location & \\
\hline
\end{tabular}
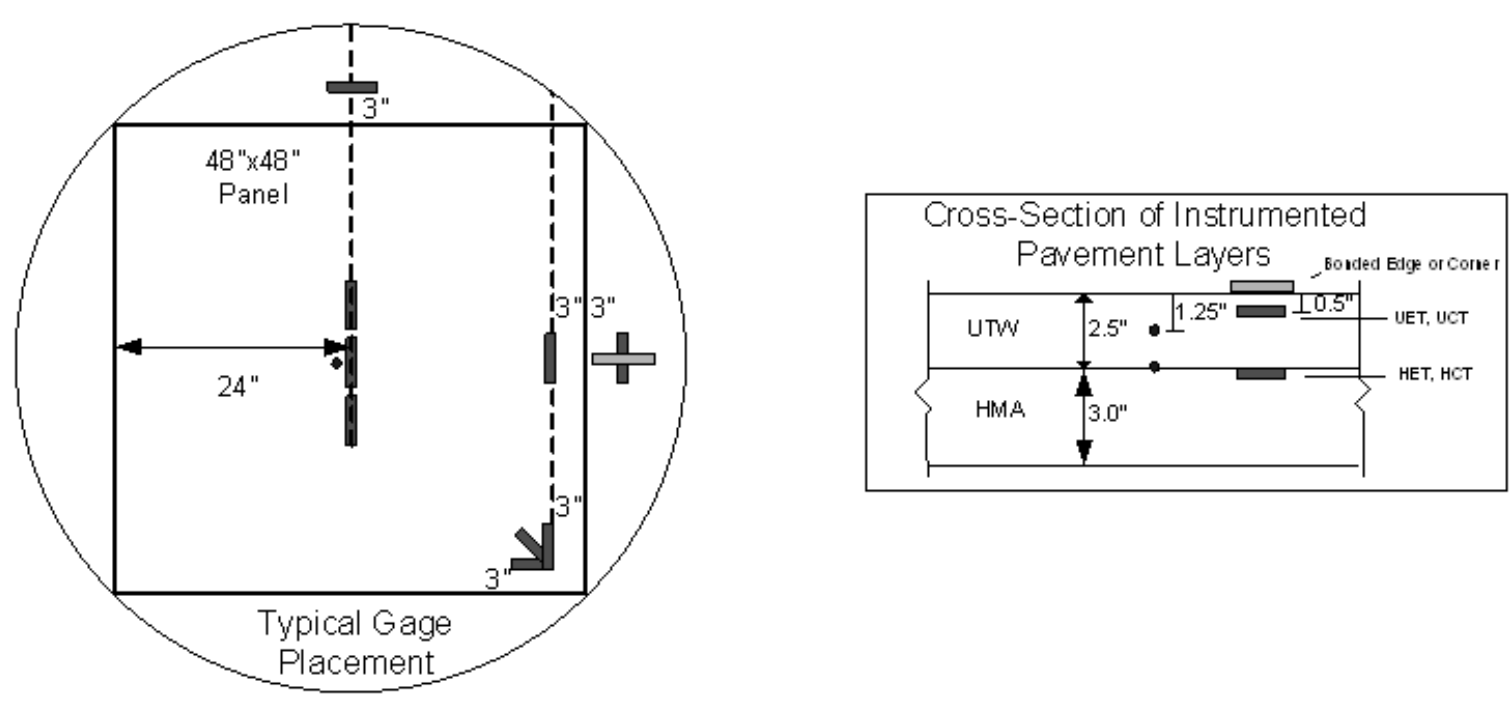

(a) 

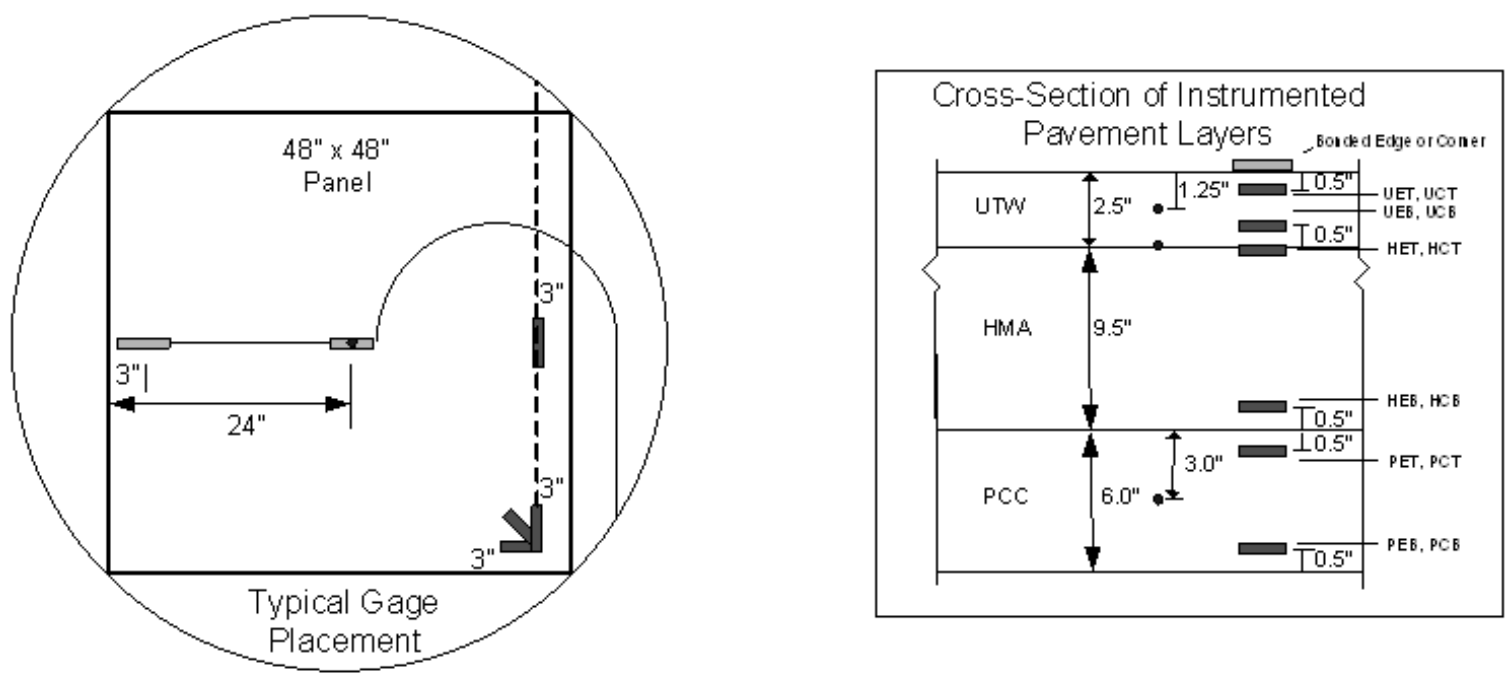

(b)

Figure 4.6 Summary of Gage Placement (a) TA1 (b) TA2 (c) TA3 (d) TA4 (continued)
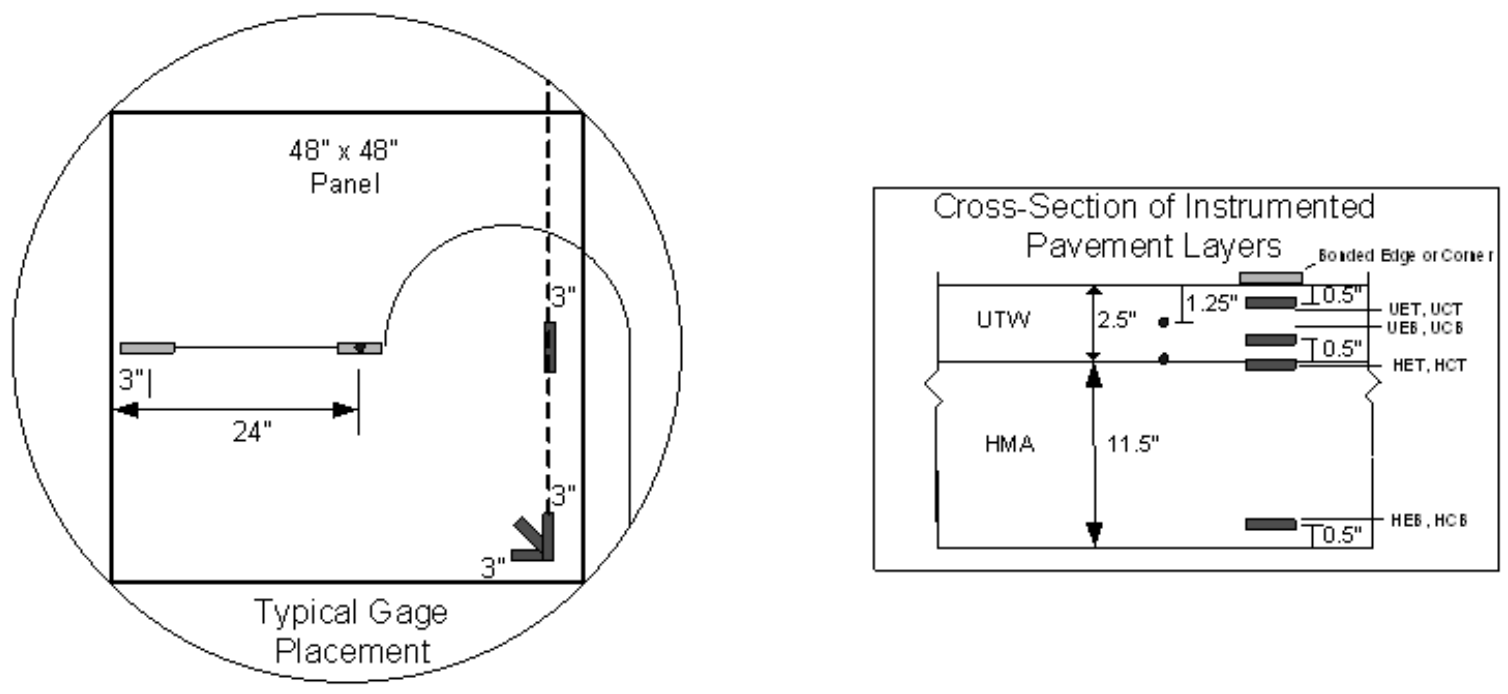

(c) 

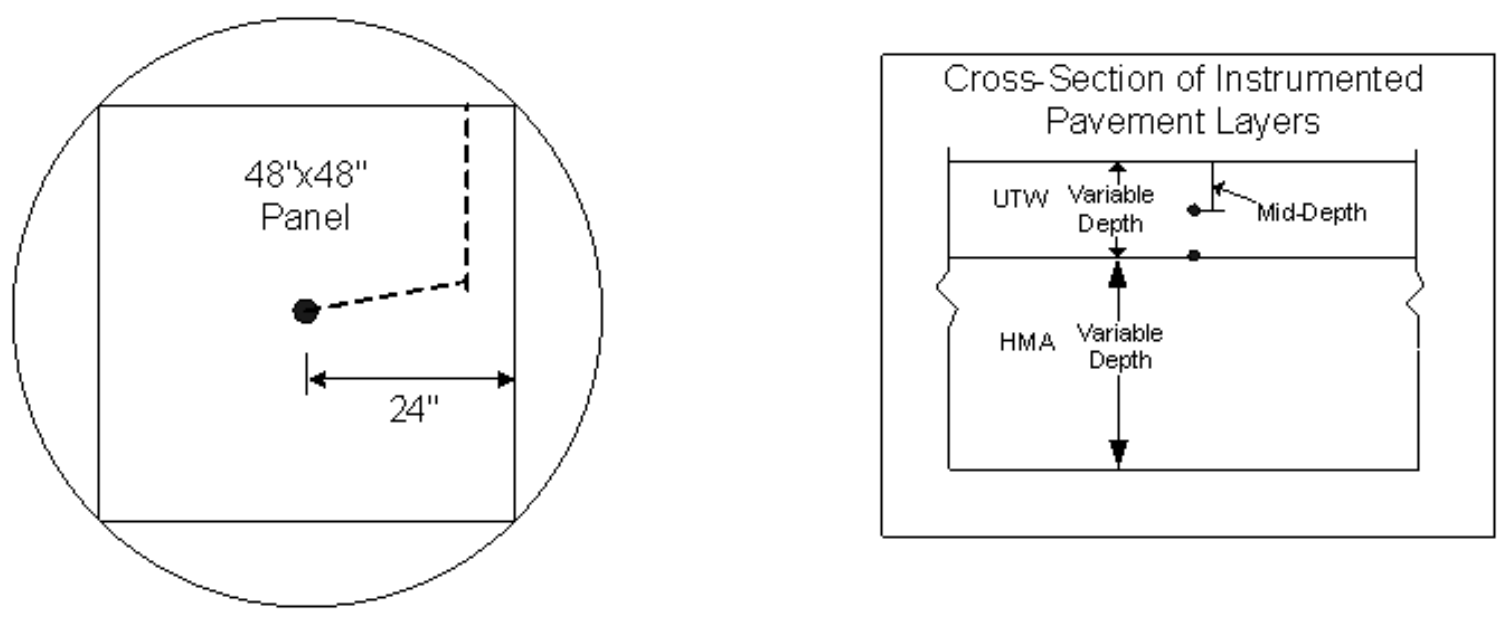

Legend

च PML, WFLM, or ASG

- Themocouple

- Cable - belowpavement

(d)

Note: 1 inch $=25 \mathrm{~mm}$

Figure 4.6 Summary of Gage Placement (a) TA1 (b) TA2 (c) TA3 (d) TA4

\subsubsection{Concrete Mix Designs}

Four different UTW concrete mixes were used to construct the UTW layers in this experiment. The four mixes are variations of a base mix design (MD-1).

Because UTW is a rehabilitation technique it is desirable to open the pavement to traffic as soon as possible to minimize the impact on the traveling public. Thus, a high early strength mix was included in the study to evaluate the performance of UTW layers constructed with such a mix. This mix (MD-2) varied from the base mix by the use of Type III cement in stead of Type I as utilized in MD-1. Taylor et al. [2006] noted that fibers are often used in UTW concrete mix designs. Thus, polypropylene fibers $(0.75 \mathrm{inch}(20 \mathrm{~mm})$ monofilament) were added to the base mix to evaluate the performance of UTW layers constructed of concrete containing fibers. This mix is designated as MD-3. During the construction of Lane 2 in TA3, there was a mistake made by the 
concrete supplier and fibers were added to the high early strength mix. Thus, MD-4 varies from the base mix by the replacement of the Type I cement by Type III cement and the addition of polypropylene fibers $(0.75$ inch $(20 \mathrm{~mm})$ monofilament). As a consequence, MD-2 was used in TA3 Lane 3 in order to evaluate this mix under the TA3 test parameters. All mixes contained Class $C$ fly ash and were designed with a target water-cementitious material ratio of 0.36 . The composition of the UTW concrete mix types are presented in Table 4.3.

Table 4.3 UTW Concrete Mix Designs (continued)

\begin{tabular}{|c|c|}
\hline Material & lbs/cyd $\left(\mathrm{kg} / \mathrm{m}^{3}\right)$ \\
\hline \multicolumn{2}{|c|}{ MD-1 (Base Mix) } \\
\hline Cement (Type I) & $635(375)$ \\
\hline Class C Fly Ash & $118(70)$ \\
\hline $\begin{array}{c}\text { Coarse Aggregate } \\
\text { (Limestone - INDOT \#11) }\end{array}$ \\
\hline $\begin{array}{c}\text { Fine Aggregate } \\
\text { (Natural - INDOT \#23) }\end{array}$ \\
\hline Water & $1271(750)$ \\
\hline HRWR & $271(160)$ \\
\hline \multicolumn{2}{|c|}{ MD-2 (High Early Strength) } \\
\hline
\end{tabular}




\begin{tabular}{|c|c|}
\hline Cement (Type III) & $635(375)$ \\
\hline Class C Fly Ash & $118(70)$ \\
\hline $\begin{array}{c}\text { Coarse Aggregate } \\
\text { (Limestone - INDOT \#11) }\end{array}$ & $1695(1000)$ \\
\hline $\begin{array}{c}\text { Fine Aggregate } \\
\text { (Natural - INDOT \#23) }\end{array}$ & $1271(750)$ \\
\hline Water & $271(160)$ \\
\hline HRWR & $\left(3-4 \mathrm{l} / \mathrm{m}^{3}\right)$ \\
\hline
\end{tabular}

Table 4.3 UTW Concrete Mix Designs

\begin{tabular}{|c|c|}
\hline Material & $\mathrm{lbs} / \mathrm{cyd}\left(\mathrm{kg} / \mathrm{m}^{3}\right)$ \\
\hline \multicolumn{2}{|c|}{ MD-3 (Fiber Mix) } \\
\hline Cement (Type I) & $635(375)$ \\
\hline Class C Fly Ash & $118(70)$ \\
\hline $\begin{array}{c}\text { Coarse Aggregate } \\
\text { (Limestone - INDOT \#11) }\end{array}$ & $1695(1000)$ \\
\hline $\begin{array}{c}\text { Fine Aggregate } \\
\text { (Natural - INDOT \#23) }\end{array}$ & $1271(750)$ \\
\hline Water & $271(160)$ \\
\hline HRWR & $\left(3-4 l / m^{3}\right)$ \\
\hline Polypropylene Fibers & $1.8(1.1)$ \\
\hline
\end{tabular}




\begin{tabular}{|c|c|}
\hline \multicolumn{2}{|c|}{ MD-4 (High Early Strength and Fiber Mix) } \\
\hline Cement (Type III) & $635(375)$ \\
\hline Class C Fly Ash & $118(70)$ \\
\hline $\begin{array}{c}\text { Coarse Aggregate } \\
\text { (Limestone - INDOT \#11) }\end{array}$ \\
\hline $\begin{array}{c}\text { Fine Aggregate } \\
\text { (Natural - INDOT \#23) }\end{array}$ \\
\hline Water & $1271(750)$ \\
\hline HRWR & $271(160)$ \\
\hline Polypropylene Fibers & $\left(3-4 \mathrm{l} / \mathrm{m}^{3}\right)$ \\
\hline
\end{tabular}

Table 4.4 summarizes the usage of these mixes within the four test areas. Mix Design 1 was also used for the laboratory evaluation of temperature effects on the UTW/HMA bond.

Table 4.4 Mix Design Usage

\begin{tabular}{|c|c|c|c|c|}
\hline Test Area & MD-1 & MD-2 & MD-3 & MD-4 \\
\hline 1 & All Lanes & NA & NA & NA \\
\hline 2 & $\begin{array}{c}\text { Lanes 1, 4, and } \\
5\end{array}$ & Lane 2 & Lane 3 & NA \\
\hline 3 & $\begin{array}{c}\text { Lanes 1, 4, and } \\
5\end{array}$ & Lane 3 & NA & Lane 2 \\
\hline 4 & All Lanes & NA & NA & NA \\
\hline $\begin{array}{c}\text { Laboratory } \\
\text { Study }\end{array}$ & All Specimens & NA & NA & NA \\
\hline
\end{tabular}




\subsubsection{Construction of the UTW Test Lanes}

The schematic of the general layout for TA1 is shown in Figure 4.7. The UTW concrete was placed at a width of 10 feet $(3.1 \mathrm{~m})$. Concrete mix MD-1 was used. The UTW concrete was placed and finished by hand. Collection of strain data by the System 6000 started immediately after placement of the UTW. Additionally, a 4 foot $(1200 \mathrm{~mm})$ wide by 4 foot $(1200 \mathrm{~mm})$ deep by 2.5 -inch $(63 \mathrm{~mm})$ thick companion slab was constructed near the test area to compare the UTW surface strains for unbonded and bonded UTW layers. A wooden frame with the previously mentioned dimensions was placed over a sheet of plastic on the APT floor. The sheet of plastic was placed under the frame to ensure that no bond developed when the concrete was placed in the form. The UTW test lanes and companion slabs were cured using wet burlap and plastic sheeting to retain moisture.

After 18 hours, the test lanes were uncovered and expansion joints were sawn (at a depth of 0.75 inches $(19 \mathrm{~mm})$ ) in the UTW slab using a walk behind concrete saw. Joints were sawn at a spacing of 4 feet $(1200 \mathrm{~mm})$ by 4 feet $(1200 \mathrm{~mm})$. This provided two, 4 feet $(1200 \mathrm{~mm})$ wide test lanes and one, 2 feet $(600 \mathrm{~mm})$ wide shoulder area. After the sawing operation was complete, the lanes were covered again with the wet burlap and plastic sheet. The total curing period for the test lanes and companion slabs was 7 days. Just prior to loading with the APT, the SM5-A gages were installed on the UTW surface in the test lanes an on the companion slabs. Data acquisition was begun immediately after gage installation. 


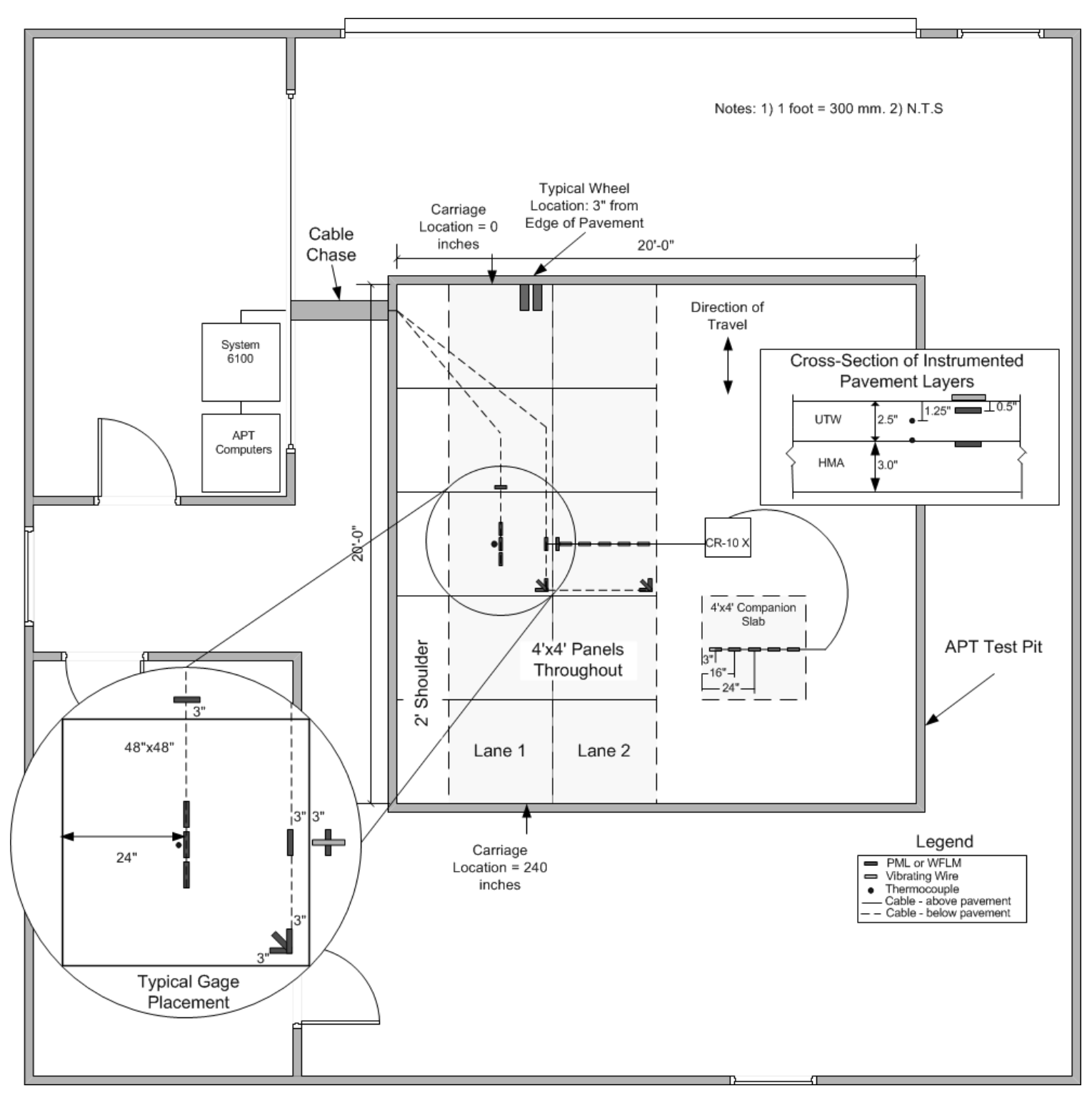

Figure 4.7 General Layout of TA1

Five different UTW test lanes were constructed in TA2. Figure 4.8 illustrates the general layout of this test area. In order to evaluate different bonding conditions at the interfaces between the HMA and UTW, three different surface preparation techniques were employed. Previous research by Mack et al. [1998] indicated that a clean, milled surface is needed to develop a good bond between the HMA and concrete overlay. Thus, the surface of the milled HMA was swept and cleaned with a compressed air hose prior to UTW placement in Lanes 1, 2, and 
3. In Lane 4, the milled HMA surface was not cleaned prior to placement of the UTW. This was done to simulate a worst case scenario that may occur during construction. A sheet of plastic was placed over the milled HMA layer in Lane 5 in order to evaluate the performance of the overlay for cases where no bond exists between the HMA and concrete overlay.

In all cases the UTW was placed at a width of 4 feet $(1200 \mathrm{~mm})$. Concrete mix MD-1 was used in Lanes 1, 4, and 5. MD-2 was used in Lane 2 and MD-3 was used in Lane 3. The concrete for subsequent lanes was not placed until the APT loading of the previous lane was completed. Thus, there was typically a lag time of a month between pours. The UTW concrete was placed and finished by hand. Collection of strain data by the System 6100 started immediately after placement of the UTW. A 4 foot $(1200 \mathrm{~mm})$ wide by 4 foot $(1200 \mathrm{~mm})$ deep by 2.5 -inch (63 $\mathrm{mm}$ ) thick companion slab as described above was constructed near the test area for each test lane constructed to compare the UTW surface strains for unbonded and bonded UTW layers. The UTW test lanes and companion slabs were covered with wet burlap and plastic and cured for 24 hours.

Within 24 hours of concrete placement, the concrete joints were sawn (at a depth of 0.75 inches $(19 \mathrm{~mm}))$ at a spacing of 4 feet $(1200 \mathrm{~mm})$ by 4 feet $(1200 \mathrm{~mm})$. Saw-cutting was conducted using a standard, walk-behind concrete saw. The UTW was again covered with wet burlap and plastic and cured for an additional 2 days for a total curing period of 3 days. (The UTW test lanes in TA1 exhibited very little distress. Thus, in order to accelerate the development of distresses in the UTW, the curing period was reduced to 3 days.) Similar to TA1, the SM5-A gages were installed on the UTW surface in the test lanes an on the companion slabs, just prior to loading with the APT. Data acquisition was begun immediately after gage installation. 


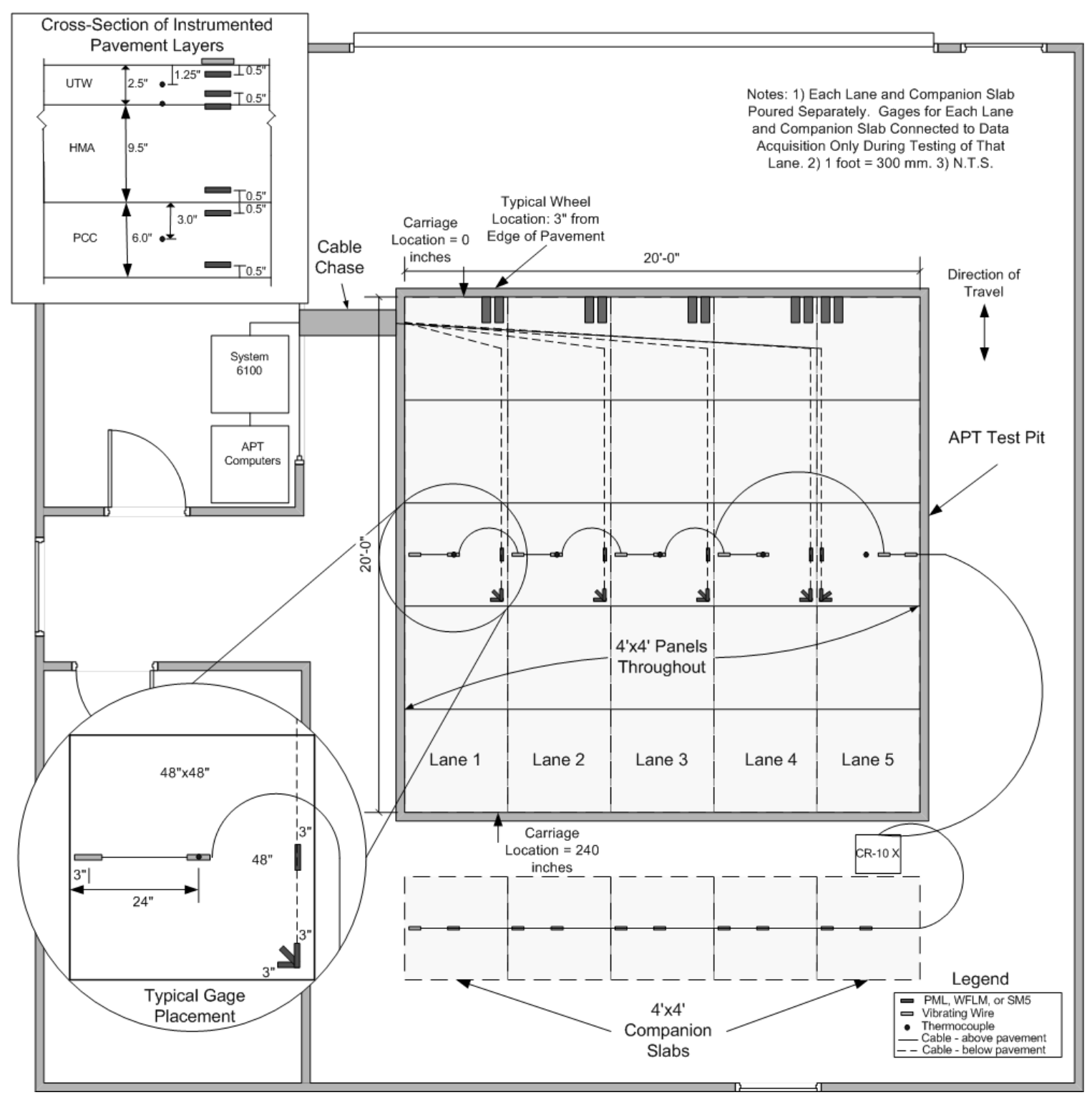

Figure 4.8 General Layout of TA2

Figure 4.9 illustrates the general layout of TA3. The same general construction procedure described above for TA2 was also followed for TA3. TA3 differs from TA2 only with respect to the underlying pavement layers, mix designs used, and contraction joint saw-cutting technique. TA2 was constructed over a composite pavement section while TA3 was constructed over an HMA section. In TA2, concrete mix MD-1 was used in Lanes 1, 4, and 5. MD-2 was used in Lane 2 
and MD-3 was used in Lane 3. For TA3, concrete mix MD-1 was used in Lanes 1, 4, and 5. MD-4 was used in Lane 2 and MD-2 was used in Lane 3. In TA2, saw-cutting was conducted using a standard, walk-behind concrete saw while in TA3 early entry saw-cutting was performed. The early entry saw-cutting was performed (at a depth of 0.5 inches $(13 \mathrm{~mm})$ ) within 4 hours of the UTW concrete placement.

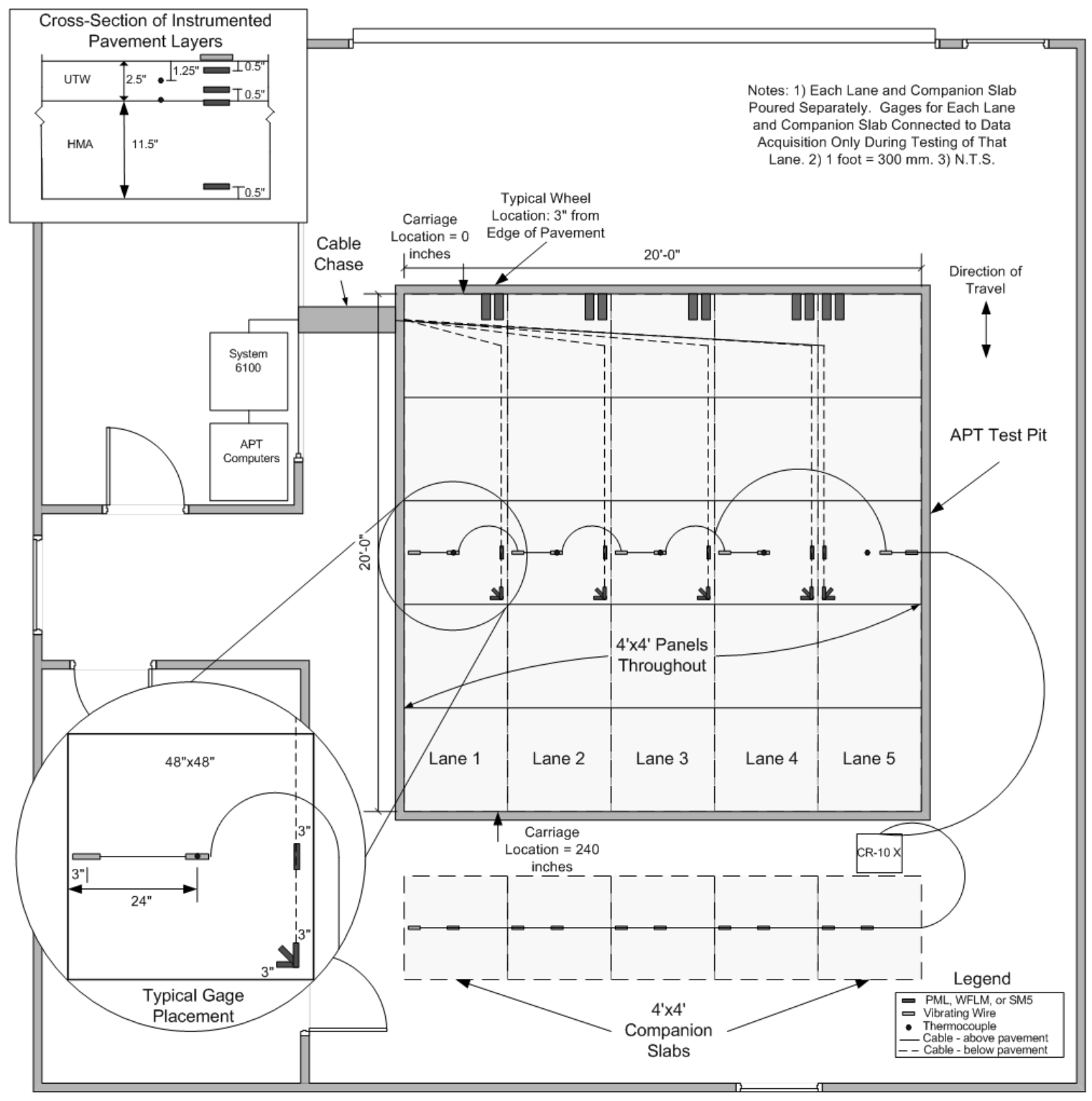

Figure 4.9 General Layout of TA3 
TA4 also consisted of 5 test lanes (Figure 4.10), but unlike the previous test areas, it was located not in the APT building, but outdoors in the existing parking lot. The lanes were constructed so as to provide a range of layer thicknesses for both the UTW and HMA. As noted in Chapter 2, UTW thicknesses range from 2 to 4 inches (50 to $100 \mathrm{~mm}$ ). In TA4, the overlay thickness was 4 inches (100 $\mathrm{mm})$ in Lanes 1 and 5 . The UTW thickness was 3 inches $(75 \mathrm{~mm})$ in Lanes 2 and 4. And, the thickness of the UTW was 2 inches $(50 \mathrm{~mm})$ in Lane 3 . Lanes 3 , 4 , and 5, were flush with the surrounding parking lot. However, to provide a range of HMA thicknesses and still achieve the proper UTW depths in Lanes 1 and 2, dimensional lumber was used to construct forms around the lanes. These forms were nailed directly to the HMA to secure them in place during the concrete pour. The surface of the milled HMA was swept and cleaned with a compressed air hose prior to UTW placement. Concrete Mix Design 1 was used for all lanes. The concrete was placed and finished by hand. The UTW was covered with wet burlap and plastic and cured for 24 hours. Collection of strain data by the CR10X datalogger started immediately after placement of the UTW. Within 24 hours of concrete placement, the concrete joints were sawn (at a depth of 0.75 inches $(19 \mathrm{~mm})$ ) at a spacing of 4 feet $(1200 \mathrm{~mm})$ by 4 feet $(1200 \mathrm{~mm})$. The UTW was covered again with wet burlap and plastic and cured for an additional 2 days for a total of 3 days of curing. 


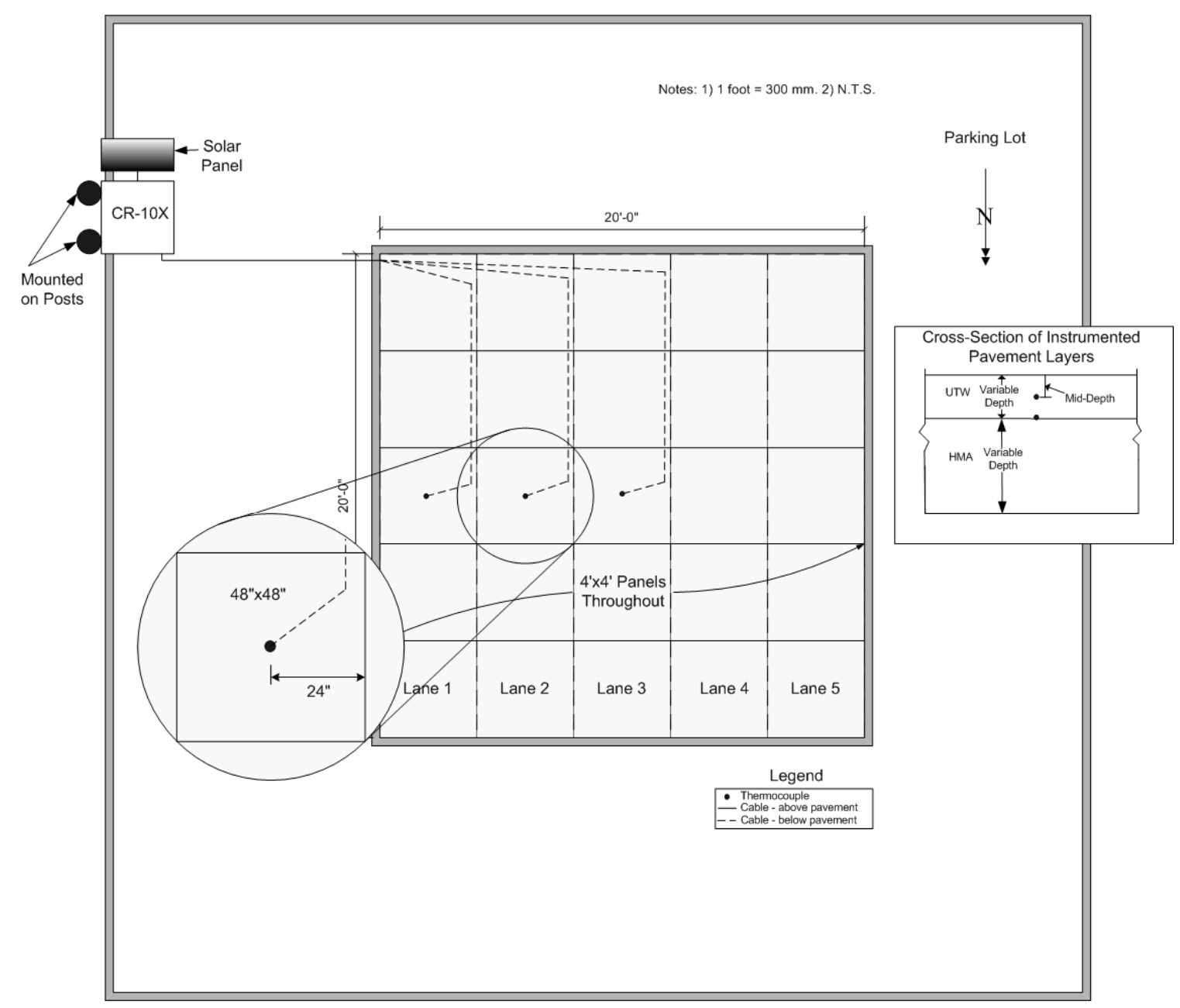

Figure 4.10 General Layout of TA4

\subsection{Accelerated Pavement Loading}

At the end of the 7 day curing period, a $9000 \mathrm{lb}(40 \mathrm{kN})$ moving load was applied to Lane 1 of Test Area 1 using the APT carriage. Over 550,000 load applications were applied to the test lane. As there was no visible damage noted after the testing of Lane 1 in TA1, the magnitude of the load was increased to $15,000 \mathrm{lbs}$ $(67 \mathrm{kN})$ and the curing period was reduced to 3 days for TA2. For this test area, approximately 300,000 load applications were applied to each lane except Lane 5 which only had 180,000 load applications prior to terminating the test. 
The test lanes in TA3 were also loaded with a $15,000 \mathrm{lb}(67 \mathrm{kN})$ load. All five lanes in TA-3 received approximately 300,000 load applications which in all but one case commenced after the 3-day cure period. Prior to the load testing of Lane 5 a mechanical problem was identified on the APT load carriage. Repair of the APT delayed testing of Lane 5 for 11 additional days. Curing of the lane was terminated after the standard 3-day period, but load testing of Lane 5 began 14 days after placement of the concrete.

For all tests, a single-axle, dual-tire configuration was used and the tire was run bi-directionally over the pavement. The ambient temperature in the APT facility was held relatively constant between $75^{\circ} \mathrm{F}$ to $85^{\circ} \mathrm{F}\left(24^{\circ} \mathrm{C}\right.$ to $\left.29^{\circ} \mathrm{C}\right)$ during testing. The test schedule was the deciding factor in termination of the APT loading. No failure criteria were employed.

\subsection{Distress Mapping}

During the evaluation of the test areas, the type and severity distresses in the pavement were recorded intermittently at different numbers of accumulated load applications. Crack locations, width, and length were charted. Sounding of the UTW was performed on the pavements in TA2, TA3, and TA4 in an attempt to detect possible bond deterioration. Sounding was performed with a $3 \mathrm{lb}(1.4 \mathrm{~kg})$ hammer in a 4 inch by 4 inch ( $100 \mathrm{~mm}$ by $100 \mathrm{~mm}$ ) grid pattern to locate the areas of potential debonding. Boundaries of the debonded areas were determined with additional sounding of the suspect locations. The detected limits were marked with paint on the pavement to monitor potential changes with an increasing number of load cycles. Distressed areas were marked on diagrams of the lanes. 


\subsection{Testing of Concrete Mechanical Properties}

The mechanical properties of the concrete determined during this project included compressive strength, flexural strength, modulus of elasticity and Poisson's ratio. The following sections describe the methodologies employed to determine these properties.

\subsubsection{Test Specimen Preparation}

Specimens were produced for both the evaluation of the test areas as well as for the laboratory study. The number and type of specimens prepared with concrete batch for the test areas (separate batches for each test lane except in TA1 in which both lanes were poured concurrently) and the laboratory study (four separate batches) are presented in Table 4.5.

For the test area specimens, concrete produced by the ready-mix producer was sampled and the specimens were prepared according to ASTM C 31 using an internal vibrator to consolidate the specimens. The cylinder specimens were covered with fitted plastic covers and the beam specimens were covered with wet burlap and plastic sheets to retain the moisture for the first 24 hours. After the initial curing period the specimens were demolded and transferred to the designated moist curing environment (shown in Table 4.5).

For the laboratory study, materials to produce the concrete mix were obtained from the ready-mix producer that supplied the UTW concrete for the test areas. Mix Design 1 (see Section 4.3.5) was used to produce the Laboratory Study specimens. Concrete was mixed in the laboratory at INDOT Office of Research and Development Laboratories. A Lancaster Counter-Current Rapid Batch 30DP laboratory mixer was used to prepare the concrete. The concrete was prepared according to ASTM C 192. The concrete for the cylinder and beam specimens was placed in two lifts and consolidated using internal vibration. As with the previously described test area specimens, the laboratory cylinders were 
covered with fitted plastic covers and the laboratory beam specimens were covered with wet burlap and plastic sheets to retain the moisture for the first 24 hours. After the initial curing period the specimens were demolded and transferred to the designated moist curing environment (shown in Table 4.5).

Table 4.5 Summary of Mechanical Property Test Specimens (continued)

\begin{tabular}{|c|c|c|c|c|}
\hline Specimen & Size & $\begin{array}{l}\text { Curing } \\
\text { Method }\end{array}$ & $\begin{array}{l}\text { Curing } \\
\text { Periods }\end{array}$ & $\begin{array}{c}\text { Number of } \\
\text { Replicates } \\
\text { per Curing } \\
\text { Period }\end{array}$ \\
\hline \multicolumn{5}{|c|}{ TA1 } \\
\hline $\begin{array}{c}\text { Cylinder } \\
\text { (Compression) }\end{array}$ & $\begin{array}{c}4 \times 8 \text { inches } \\
(100 \times 200 \mathrm{~mm})\end{array}$ & $\begin{array}{c}\text { Submerged in } \\
\text { Lime Bath }\end{array}$ & $\begin{array}{c}7,14,28, \text { and } \\
90 \text { days }\end{array}$ & 3 \\
\hline $\begin{array}{l}\text { Cylinder } \\
\text { (Modulus) }\end{array}$ & $\begin{array}{c}4 \times 8 \text { inches } \\
(100 \times 200 \mathrm{~mm})\end{array}$ & $\begin{array}{c}\text { Submerged in } \\
\text { Lime Bath }\end{array}$ & $\begin{array}{c}7,14,28, \text { and } \\
90 \text { days }\end{array}$ & 2 \\
\hline $\begin{array}{l}\text { Beams } \\
\text { (Flexural } \\
\text { Strength) }\end{array}$ & $\begin{array}{c}3 \times 3 \times 15 \text { inches } \\
(75 \times 75 \times 375 \\
\mathrm{mm})\end{array}$ & $\begin{array}{c}\text { Submerged in } \\
\text { Lime Bath }\end{array}$ & $\begin{array}{c}7,14,28, \text { and } \\
90 \text { days }\end{array}$ & 3 \\
\hline \multicolumn{5}{|c|}{ TA2 and TA3 } \\
\hline $\begin{array}{c}\text { Cylinder } \\
\text { (Compression) }\end{array}$ & $\begin{array}{c}4 \times 8 \text { inches } \\
(100 \times 200 \mathrm{~mm})\end{array}$ & $\begin{array}{l}\text { Lime Bath } \\
\text { (TA2) } \\
\text { Moist Cure } \\
\text { Chamber } \\
\text { (TA3) }\end{array}$ & $\begin{array}{c}7,14,28, \text { and } \\
90 \text { days }\end{array}$ & 3 \\
\hline $\begin{array}{l}\text { Cylinder } \\
\text { (Modulus) }\end{array}$ & $\begin{array}{c}4 \times 8 \text { inches } \\
(100 \times 200 \mathrm{~mm})\end{array}$ & $\begin{array}{c}\text { Lime Bath } \\
\text { (TA2) } \\
\text { Moist Cure } \\
\text { Chamber } \\
\text { (TA3) }\end{array}$ & $\begin{array}{c}7,14,28, \text { and } \\
90 \text { days }\end{array}$ & 2 \\
\hline
\end{tabular}




\begin{tabular}{|c|c|c|c|c|}
\hline Beams & $6 \times 6 \times 21$ inches & Lime Bath & $7,14,28$, and & 3 \\
(Flexural & $(150 \times 150 \times 525$ & (TA2) & 90 days & \\
Strength) & $\mathrm{mm})$ & Moist Cure & & \\
& & Chamber & & \\
& & (TA3) & & \\
\hline
\end{tabular}

Table 4.5 Summary of Mechanical Property Test Specimens

\begin{tabular}{|c|c|c|c|c|}
\hline Specimen & Size & $\begin{array}{l}\text { Curing } \\
\text { Method }\end{array}$ & $\begin{array}{l}\text { Curing } \\
\text { Periods }\end{array}$ & $\begin{array}{c}\text { Number of } \\
\text { Replicates } \\
\text { per Curing } \\
\text { Period }\end{array}$ \\
\hline \multicolumn{5}{|c|}{ TA4 } \\
\hline $\begin{array}{c}\text { Cylinder } \\
\text { (Compression) }\end{array}$ & $\begin{array}{c}4 \times 8 \text { inches } \\
(100 \times 200 \mathrm{~mm})\end{array}$ & $\begin{array}{c}\text { Moist Cure } \\
\text { Chamber }\end{array}$ & 28 days & 3 \\
\hline $\begin{array}{l}\text { Beams } \\
\text { (Flexural } \\
\text { Strength) }\end{array}$ & $\begin{array}{c}6 \times 6 \times 21 \text { inches } \\
(150 \times 150 \times 525 \\
\mathrm{mm})\end{array}$ & $\begin{array}{c}\text { Moist Cure } \\
\text { Chamber }\end{array}$ & 28 days & 3 \\
\hline \multicolumn{5}{|c|}{ Laboratory Study } \\
\hline $\begin{array}{c}\text { Cylinder } \\
\text { (Compression) }\end{array}$ & $\begin{array}{c}4 \times 8 \text { inches } \\
(100 \times 200 \mathrm{~mm})\end{array}$ & $\begin{array}{c}\text { Moist Cure } \\
\text { Chamber }\end{array}$ & $\begin{array}{c}7,14,28, \text { and } \\
90 \text { days }\end{array}$ & 3 \\
\hline $\begin{array}{l}\text { Beams } \\
\text { (Flexural } \\
\text { Strength) }\end{array}$ & $\begin{array}{c}6 \times 6 \times 21 \text { inches } \\
(150 \times 150 \times 525 \\
\mathrm{mm})\end{array}$ & $\begin{array}{c}\text { Moist Cure } \\
\text { Chamber }\end{array}$ & $\begin{array}{c}7,14,28, \text { and } \\
90 \text { days }\end{array}$ & 3 \\
\hline
\end{tabular}

Mechanical property testing was performed after $7,14,28$, and 90 days of moist curing for TA1 through TA3 and after 28 days of moist curing for TA4. The specimens were removed from the curing environment and covered with wet cloths to keep them in a moist condition until testing. Testing was conducted at either the concrete laboratory in the School of Civil Engineering at Purdue 
University or at the INDOT Office of Research and Development concrete laboratory. Table 4.6 summarizes the information about the test locations, standards, testing machine types, and load rates utilized during mechanical testing.

Table 4.6 Summary of Concrete Mechanical Properties Testing

\begin{tabular}{|c|c|c|c|}
\hline Test Area & Test Location & Testing Machine & Load Rate \\
\hline \multicolumn{4}{|c|}{$\begin{array}{c}\text { Compression Test (ASTM C 39) } \\
\text { (tested using neoprene pads) }\end{array}$} \\
\hline TA-1 & Purdue & $\begin{array}{c}\text { Forney }{ }^{\mathrm{TM}} \mathrm{FT}-40- \\
\text { DR }\end{array}$ & $30,000 \mathrm{lbs} / \mathrm{min}$ \\
\hline TA-2 & INDOT & Forney $^{\mathrm{TM}} \mathrm{F}-250 \mathrm{C}$ & $26,000 \mathrm{lbs} / \mathrm{min}$ \\
\hline TA-3 & INDOT & Forney $^{\mathrm{TM}} \mathrm{F}-250 \mathrm{C}$ & $26,000 \mathrm{lbs} / \mathrm{min}$ \\
\hline TA-4 & INDOT & Forney $^{\text {TM }} \mathrm{F}-250 \mathrm{C}$ & $26,000 \mathrm{lbs} / \mathrm{min}$ \\
\hline Laboratory Study & INDOT & Forney $^{\mathrm{TM}} \mathrm{F}-250 \mathrm{C}$ & $26,000 \mathrm{lbs} / \mathrm{min}$ \\
\hline \multicolumn{4}{|c|}{ Flexural Strength (ASTM C 78) } \\
\hline TA-1 & INDOT & MTS $^{\text {TM }}-810$ & $450 \mathrm{lbs} / \mathrm{min}$ \\
\hline TA-2 & INDOT & Forney $^{\text {TM }} \mathrm{F}-250 \mathrm{C}$ & $1800 \mathrm{lbs} / \mathrm{min}$ \\
\hline TA-3 & INDOT & Forney $^{\mathrm{TM}} \mathrm{F}-250 \mathrm{C}$ & $1800 \mathrm{lbs} / \mathrm{min}$ \\
\hline TA-4 & INDOT & Forney $^{\text {TM }} \mathrm{F}-250 \mathrm{C}$ & $1800 \mathrm{lbs} / \mathrm{min}$ \\
\hline Laboratory Study & INDOT & Forney ${ }^{\mathrm{TM}} \mathrm{F}-250 \mathrm{C}$ & $1800 \mathrm{lbs} / \mathrm{min}$ \\
\hline \multicolumn{4}{|c|}{$\begin{array}{l}\text { Modulus of Elasticity and Poisson's Ratio (ASTM C 469) } \\
\text { (tested using neoprene pads) }\end{array}$} \\
\hline TA-1 & Purdue & SATEC TM M-100 & $26,000 \mathrm{lbs} / \mathrm{min}$ \\
\hline TA-2 & INDOT & Forney $^{\mathrm{TM}} \mathrm{F}-250 \mathrm{C}$ & $26,000 \mathrm{lbs} / \mathrm{min}$ \\
\hline
\end{tabular}




\begin{tabular}{|c|c|c|c|}
\hline TA-3 & INDOT & Forney $^{\text {TM }} \mathrm{F}-250 \mathrm{C}$ & $26,000 \mathrm{lbs} / \mathrm{min}$ \\
\hline TA-4 & INDOT & Forney $^{\text {TM }} \mathrm{F}-250 \mathrm{C}$ & $26,000 \mathrm{lbs} / \mathrm{min}$ \\
\hline
\end{tabular}

Notes: (1) $1 \mathrm{lb}=2.21 \mathrm{~kg}$ (2) Given that the testing was performed in different laboratories an obvious source of error in the determination of the mechanical properties would be inter-laboratory related errors.

\subsection{Flexural Bond Testing}

A laboratory study was conducted to evaluate the effects of temperature cycling on the bond between the UTW and HMA. Given the disparity in the coefficients of thermal expansion of the two materials, $\left(5 \times 10^{-6} /{ }^{\circ} \mathrm{F}\left(9 \times 10^{-6} /{ }^{\circ} \mathrm{C}\right)\right.$ for $\mathrm{PCC}$ and $10 \times 10^{-6} /{ }^{\circ} \mathrm{F}\left(18 \times 10^{-6} /{ }^{\circ} \mathrm{C}\right)$ for $\left.\mathrm{HMA}\right)$, it was theorized that freezing and thawing cycles might cause the bond strength between the two materials to deteriorate.

To evaluate this hypothesis, two different test protocols were employed. The first test was the lowa Shear test (described in Section 4.8), and the second was a third-point flexural bond test. This section describes the specimen preparation, curing, and testing of the flexural bond test.

The HMA obtained from TA4 (saw-cut beams) was used with laboratory mixed concrete to produce the flexural bond test specimens. Four separate laboratory concrete batches were prepared. Ten specimens each were produced for the four batches. The specimens were divided into groups of five and were cured in one of two different environments. The first curing environment was a standard concrete curing chamber. The second set of specimens was cured in an environmental chamber which was programmed to cycle the temperature of the chamber through repeated freeze-thaw cycles. The specimens remained in their respective curing environments for $7,14,28$, or 90 days (which corresponded to one of the four batches). Table 4.7 contains a summary of the flexural bond test specimens. 
Table 4.7 Summary of Flexural Bond Test Specimens

\begin{tabular}{|c|c|c|}
\hline Specimen Type & Curing & $\begin{array}{c}\text { Number of Specimens } \\
\text { per Batch/Curing Age }\end{array}$ \\
\hline Beam & Moist 7, 14, 28, and 90 & 5 each (4 each at 14 \\
day & days) \\
\hline Beam & $\begin{array}{c}\text { Temperature Cycled 7, } \\
14,28, \text { and } 90 \text { day }\end{array}$ & $\begin{array}{c}5 \text { each (4 each at } 14 \\
\text { days) }\end{array}$ \\
\hline
\end{tabular}

\subsubsection{Flexural Bond Test Specimen Preparation}

A diagram of the flexural bond test specimens is presented in Figure 4.11. To provide the HMA portion of the UTW specimens, 15 inch by 15 inch by 3 inch ( $375 \mathrm{~mm}$ by $375 \mathrm{~mm}$ by $75 \mathrm{~mm}$ ) HMA slabs and 4 inch $(100 \mathrm{~mm}$ ) (variable depth) HMA cores were removed from TA4 after the milling, but prior to placement of the UTW. The slabs were cut to produce 3 by 3 by 15 inch ( 75 by 75 by 375 $\mathrm{mm})$ beams. 


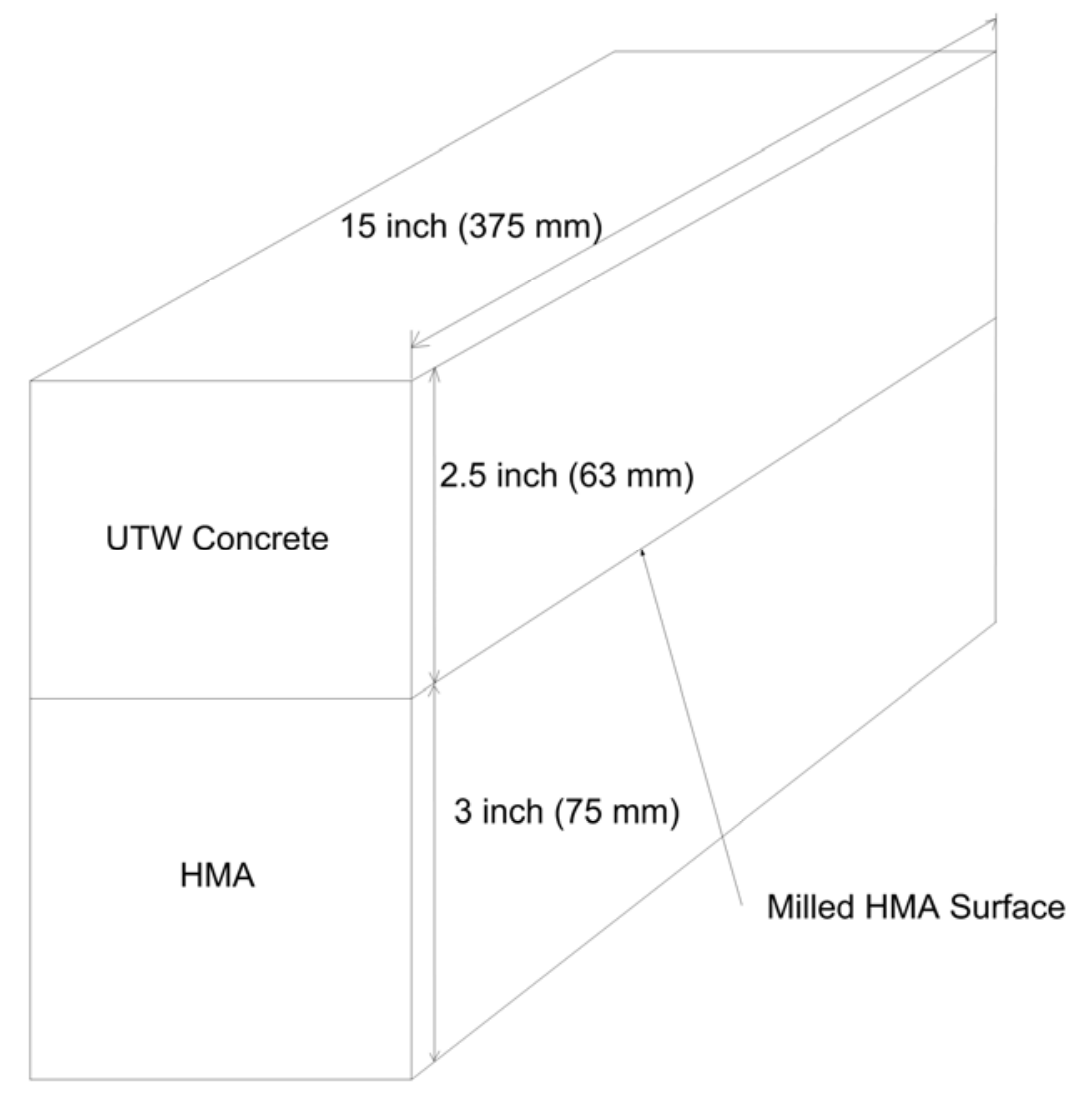

Figure 4.11 Diagram of Flexural Bond Test Specimen

The HMA beams obtained from the parking lot were placed into forms constructed of dimensional lumber. The molds were ganged in sets of five. The forms were constructed to produce specimens with final dimensions after concrete placement of 3.0 by 5.5 by 15 inches ( 75 by 137 by $375 \mathrm{~mm}$ ).

Materials to produce the concrete mix were obtained from the ready-mix producer that produced the UTW concrete for the test areas. Mix Design 1 (see Section 4.3.5) was used to produce the Laboratory Study specimens. Concrete was mixed in the laboratory at INDOT Office of Research and Development Laboratories. A Lancaster Counter-Current Rapid Batch 30-DP laboratory mixer 
was used to prepare the concrete. The concrete was prepared according to ASTM C 192.

When preparing the specimens, the concrete was placed on top of the HMA in the beam forms. The placement was accomplished in two lifts and consolidated by rodding. The specimens were finished with a trowel. As mentioned previously, the beam specimens had a total depth of 5.5 inches $(137 \mathrm{~mm})$. Wet burlap and plastic were used to retain moisture during the first 24 hours.

After 24 hours all specimens were demolded. The specimens were separated into two groups. The first group was cured in a moist curing chamber held at $72^{\circ}$ $\mathrm{F}\left(22^{\circ} \mathrm{C}\right)$ and approximately 98 percent relative humidity. The second group was cured in an environmental chamber that cycled the temperature between $19^{\circ} \mathrm{F}$ and $42^{\circ} \mathrm{F}\left(-6^{\circ} \mathrm{C}\right.$ and $\left.+6^{\circ} \mathrm{C}\right)$. Additional moisture was not supplied in the second curing regime. The two groups were further subdivided into different curing periods: $7,14,28$, and 90 days. Pulse velocity and impact echo tests were performed to assess any bond degradation during this period. The methodologies for these tests are described in Sections 4.9 and 4.10, respectively. 


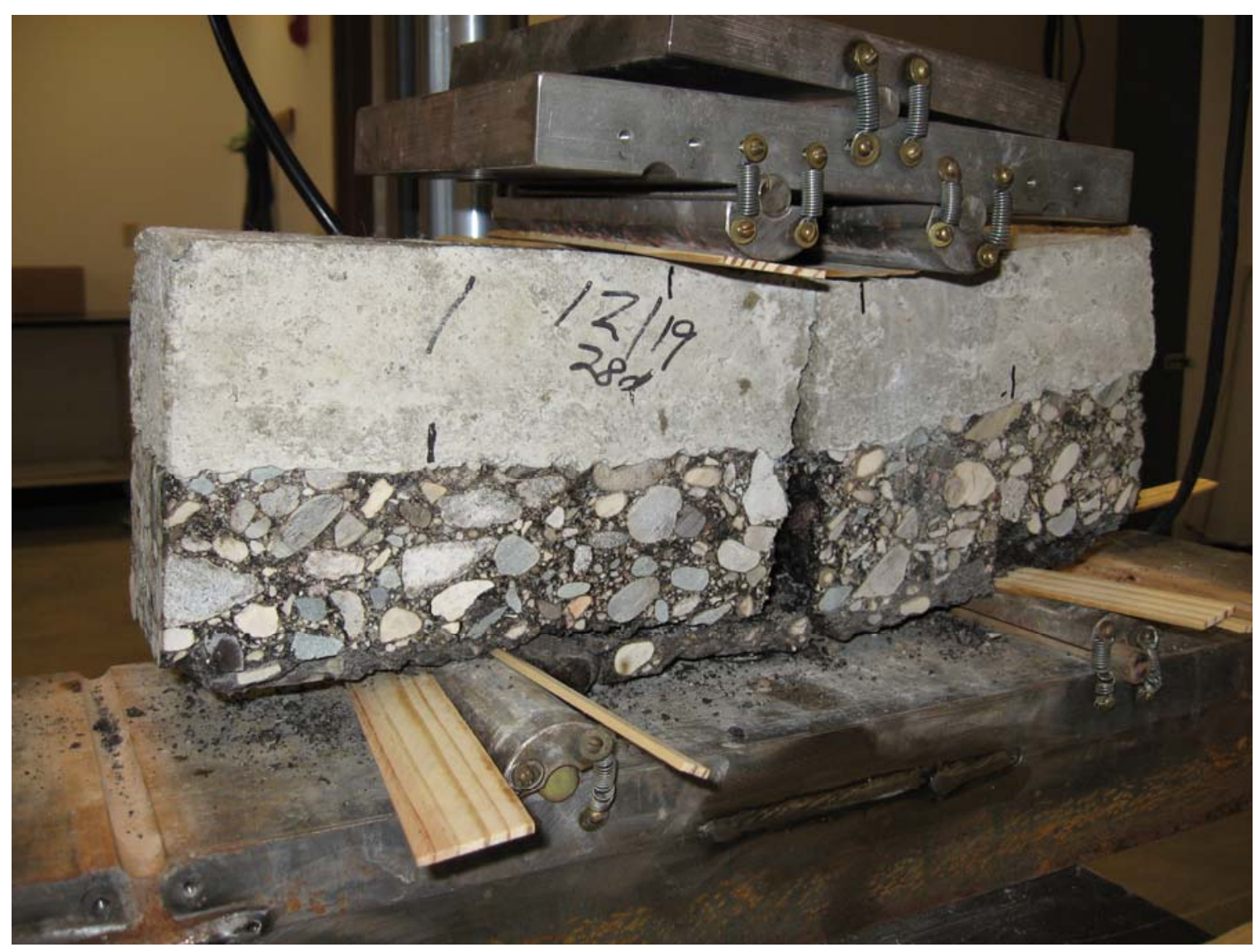

Figure 4.12 Failed Flexural Bond Test Specimen

At the end of the curing period, the UTW beam specimens were loaded cyclically using an MTS-810 test system to mechanically stress the bond. The number of load cycles was 100,000 and the load was applied at a rate of $7 \mathrm{~Hz}$. Given the brittle nature of the HMA, there was a concern that the specimens would fail quickly under the load. Thus, in order to make sure the load applied was not too high, but at the same time ensure a realistic loading condition, a typical strain observed at the bottom of the HMA in TA3 was used to develop an appropriate applied maximum load: $885 \mathrm{lbs}(3.93 \mathrm{kN})$. The cycled load ranged from $100 \mathrm{lbs}$ to $885 \mathrm{lbs}(0.44 \mathrm{kN}$ to $3.93 \mathrm{kN})$. A third point loading system was used. After conditioning with the mechanical loading, the UTW beam specimens were loaded to failure using the MTS-810 (Figure 4.12). The load rate used was $85 \mathrm{lbs} / \mathrm{s}$. 


\subsection{The lowa Shear Test}

The lowa shear test, as its name implies was developed in lowa (lowa Test Method No. 406C). It was developed to evaluate the bond strength between concrete placed over a concrete substrate as would be done in a concrete rehabilitation strategy. This test was used by Rajan et al [2001], to evaluate the bond strength of UTW concrete bonded to HMA. Results indicated that while there is a fair amount of variability in the test, the method does provide a fairly good representation of the bond strength between the two layers. An overview of the test methodology follows.

To conduct the test, a specialized test jig was constructed to conduct the test (see Figure 4.13). This jig consists of two separate steel plates with circular holes used to clamp the specimen in place. These clamps were fitted together but were attached on opposite ends to a universal testing machine and slid independently. One clamp was attached to the load cell and hydraulic actuator on the universal testing machine. The opposite clamp was fixed to the load frame. In the test a cylindrical specimen, either prepared specimens or cored specimens, with a bonded interface at approximately mid-height of the specimen, was placed horizontally in the jig through the two clamps. The interface to be tested, now vertical, was aligned in the space between the two clamps. The testing machine was used to apply a load to one clamp while the opposite clamp held the specimen in place. Thus a shearing stress was induced in the plane of the specimen interface. The specimen was loaded until a failure occurred. 


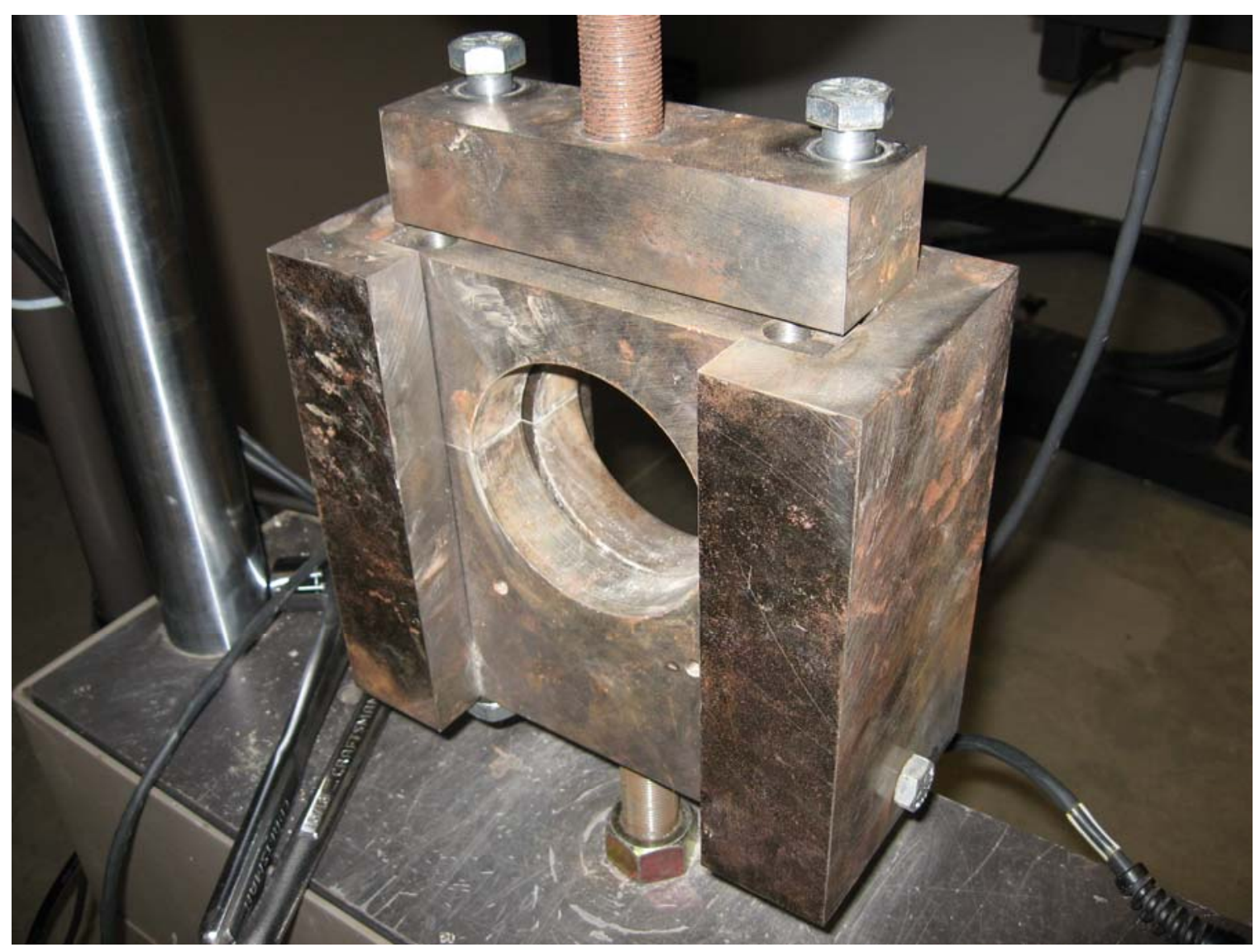

Figure 4.13 lowa Shear Test Jig

Shear testing was conducted on specimens produced during the evaluations of TA2 through TA4 and as part of the laboratory study. After the HMA was milled in these test areas cores were obtained. These cores were used to produce lowa shear test specimens utilizing concrete from the ready-mix plant (TA2 and TA3) or produced in the laboratory (TA4) (prepared specimens). Additionally, after the loading of TA2 and TA3 was completed, cores were taken from the in situ UTW pavement to produce lowa shear test specimens (cored specimens). The number and type of lowa shear specimens from each test area and the laboratory study are presented in Table 4.8. The following section discusses the preparation of the lowa shear test specimens. 
Table 4.8 Summary of lowa Shear Specimens

\begin{tabular}{|c|c|c|c|}
\hline Test Area & Prepared/Cored & Curing Period & $\begin{array}{c}\text { Number of } \\
\text { Specimens }\end{array}$ \\
\hline 2 & Prepared & 7 and 14 days & $\begin{array}{c}3 \text { per lane at } \\
\text { each age } \\
\text { (total of } 30 \text { each) }\end{array}$ \\
\hline 2 & Cored & N/A & 10 each \\
\hline 3 & Prepared & 28 and 90 days & $\begin{array}{c}3 \text { per lane at 28 } \\
\text { days and } \\
2 \text { per lane at } 90 \\
\text { days } \\
\text { (total } 25 \text { each) }\end{array}$ \\
\hline 3 & Cored & N/A & $\begin{array}{c}24 \text { each } \\
5 \text { per curing } \\
\text { period } \\
\text { (total 20 each) }\end{array}$ \\
\hline 4 and Laboratory & Prepared & $7,14,28$, and 90 \\
Study & & days &
\end{tabular}

\subsection{1. lowa Shear Specimen Preparation and Testing}

A diagram of a typical lowa shear test specimen is presented in Figure 4.12. To evaluate the bond strength of the UTW/HMA interface for the concrete produced for TA2 and TA3, lowa shear specimens two different specimen types, in general, were obtained: prepared specimens and cored specimens. The prepared specimens were produced from 4 inch $(100 \mathrm{~mm})$ diameter HMA cores obtained from the milled HMA surfaces in the test areas prior to placement of the UTW concrete. The specimens taken from TA2 and TA3 that were longer than 4 inches were cut to this length using a wet saw. This was done to fit the specimens into half of a standard 4 by 8 inch $(100$ by $200 \mathrm{~mm}$ ) concrete cylinder mold (Figure 4.14). 
To provide the HMA portion of the UTW specimens for the laboratory study, 4 inch $(100 \mathrm{~mm})$ (variable depth) HMA cores were removed from TA4 after milling, but prior to placement of the UTW. Attempts were made to cut the cores to a uniform thickness of 4 inches $(100 \mathrm{~mm})$ to fit the specimen into half of a standard 4 by 8 inch ( 100 by $200 \mathrm{~mm}$ ) concrete cylinder mold. These attempts, however, were not successful as the specimens were very brittle and began to crumble during the process. Thus the bottoms of the standard 4 by 8 inch ( 100 by 200 $\mathrm{mm}$ ) cylinder molds were cut out to accommodate longer specimens.

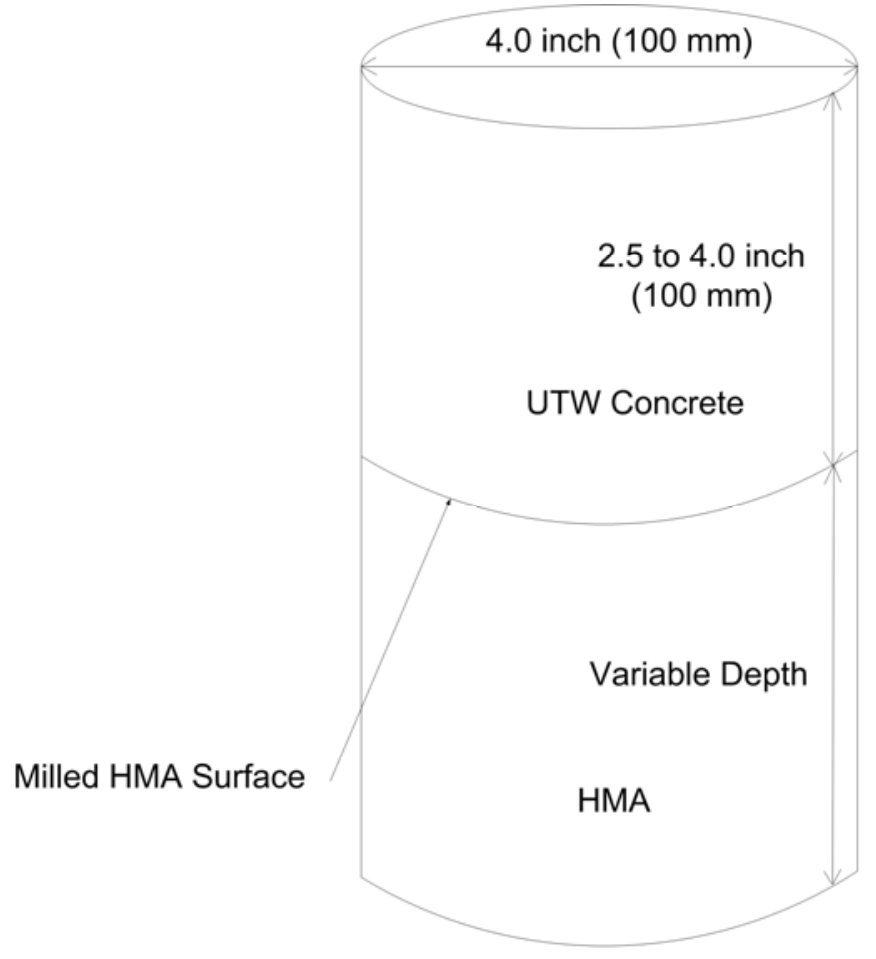

Figure 4.14 Diagram of a Typical lowa Shear Test Specimen

Early tests indicated that the milling direction greatly affected the result of the test. Specimens tested along the plane of the milling direction had lower bond strengths than those tested against the milling direction. Thus, in subsequent tests, all HMA cores were marked to indicate the direction of milling and then 
these specimens were placed in standard 4 by 8 inch ( 100 by $200 \mathrm{~mm}$ ) plastic concrete cylinder molds. As there was a concern that a standard form oil might cause damage to the HMA, a thin plastic sheet was placed in the cylinder to break the bond between the concrete and the mold. A typical cored specimen is shown in Figure 4.15.

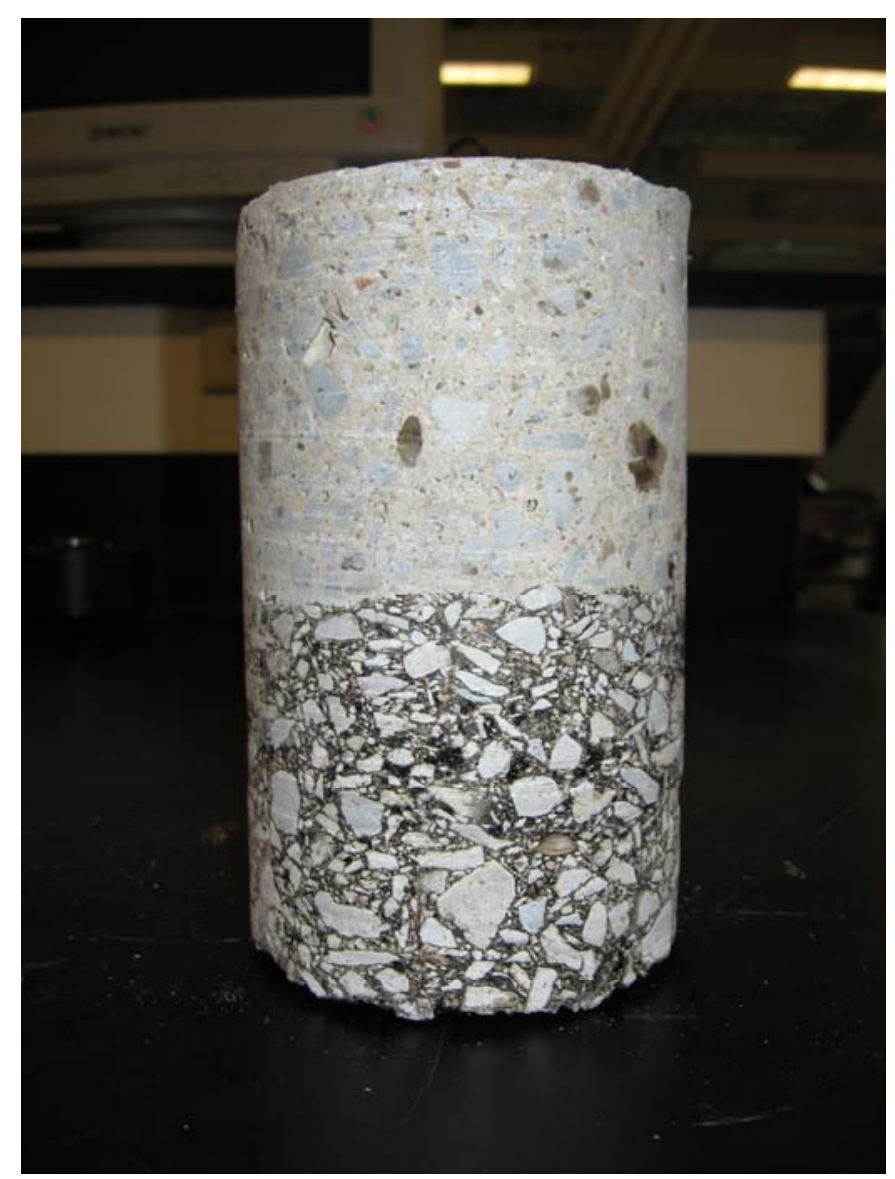

Figure 4.15 Cored lowa Shear Specimen

To simulate a UTW pavement configuration (concrete over HMA), concrete was placed on the surface of the HMA cores in the cylinder molds. For those cores taken from TA2 and TA3 the concrete used was that which was delivered for the pours in Lanes 1-4 in each of those areas, respectively (see Section 4.3.5). The concrete was placed in one lift and vibrated using an internal concrete vibrator. The specimens were finished with a trowel and capped with fitted plastic caps to 
retain moisture. After 24 hours these specimens were demolded and placed in the corresponding curing regimes outlined in Section 4.6.1. The specimens prepared during the construction of TA2 were cured for either 7 or 14 days. The specimens prepared during the construction of TA3 were cured for either 28 or 90 days. A total of 3 specimens were prepared for the pours in each of those lanes.

For the laboratory study specimens, materials to produce concrete mix MD-1 (see Section 4.3.5) were obtained from the ready-mix producer that produced the UTW concrete for the test areas. Concrete was mixed in the laboratory at INDOT Office of Research and Development Laboratories. A Lancaster CounterCurrent Rapid Batch 30-DP laboratory mixer was used to prepare the concrete. The concrete was prepared according to ASTM C 192. As with the specimens described above, the concrete was placed in one lift but was rodded instead of being vibrated since there was a concern about damaging the brittle HMA. The specimens were finished with a trowel and capped with fitted plastic caps to retain moisture. The depth of the resulting lowa shear specimens varied due to the variable depth of the HMA. However, efforts were made to ensure that thickness of the concrete on top of the HMA was at least 4 inches $(100 \mathrm{~mm})$. This was done so that there would be enough concrete material to hold the specimen in place during the shear testing. But, since the test induced the failure plane of the specimens across the diameter of the cylinder at the concrete-HMA interface, the results were not expected to be adversely affected by the variable laboratory specimen depths. After 24 hours these specimens were demolded and the specimens were cured as follows.

Four separate laboratory concrete batches were prepared to produce the laboratory study shear specimens. The first group was cured in a moist curing chamber held at $72^{\circ} \mathrm{F}\left(22^{\circ} \mathrm{C}\right)$ and approximately 98 percent relative humidity. The second group was cured in an environmental chamber that cycled the 
temperature between $19^{\circ} \mathrm{F}$ and $42^{\circ} \mathrm{F}\left(-6^{\circ} \mathrm{C}\right.$ and $\left.+6^{\circ} \mathrm{C}\right)$. Additional moisture was not supplied in the second curing regime. The two groups were further subdivided into different curing periods: $7,14,28$, and 90 days. Pulse velocity and impact echo tests were performed to assess any bond degradation during this period. The methodologies for these tests are described in Sections 4.9 and 4.10 , respectively.

Cored specimens were taken directly from the finished UTW pavement sections in TA2 and TA3. These specimens were taken after the APT loading was completed. Specimens were taken from the wheel path and from outside the wheel path as indicated in Figure 4.16. A summary of the lowa shear specimens was presented in Table 4.8. 


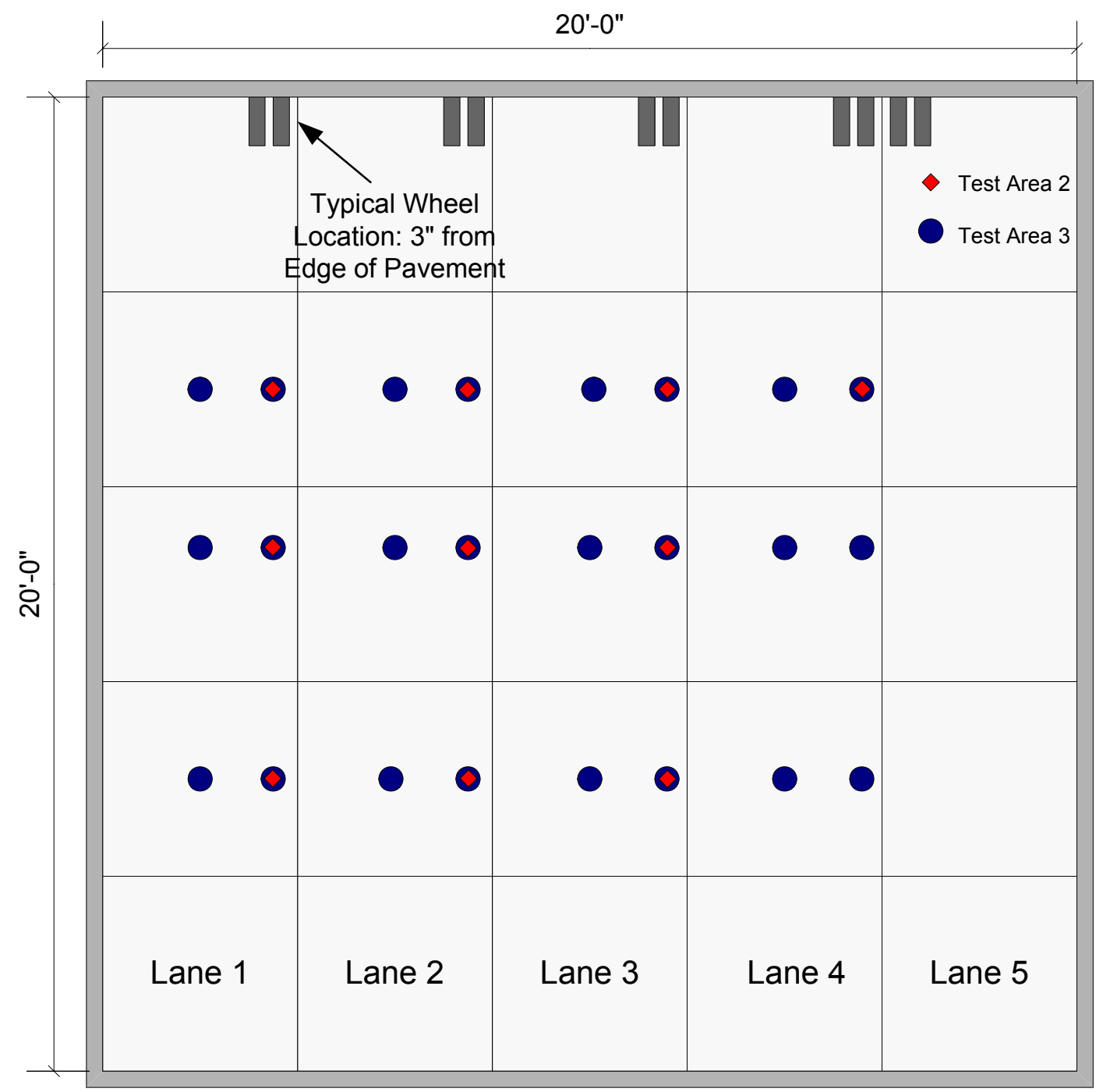

Note: $1 \mathrm{foot}=300 \mathrm{~mm}$

Figure 4.16 Layout of lowa Shear Cores

To conduct the lowa Shear Test a test jig as shown in Figure 4.13 was constructed. The steel jig was designed to fit into the MTS-810 load frame located at the INDOT Office of Research and Development laboratories. The specimens were placed into the test jig and the bolts on the clamps were tightened. The MTS controller was programmed to load the specimen at a rate of 85 pounds/second. The specimens were loaded until failure. The failure load and displacement were recorded. 


\subsection{Pulse Velocity}

The pulse velocity test uses the speed of ultrasonic pulse to non-destructively determine properties of materials. An ultrasonic pulse is generated using a transducer into the material. The time it takes for the ultrasonic pulse to travel through the material and to a receiver was determined. The distance between the transducer and receiver is known, therefore the pulse velocity can be determined. If there are any discontinuities in the material such as a crack or void, the transmitted pulse slows due to the sound waves traveling slower through the discontinuity, Neville [1997]. Thus, this method was chosen to verify if there was any debonding between the UTW and HMA for the laboratory study.

Initial efforts were made to take direct readings axially through the shear specimens. However, since the specimens were irregular in length (both total length and the length of the individual concrete and HMA layers varied from specimen to specimen) and because the bottom of the HMA was also not flat there was difficulty getting consistent readings. Thus, it was decided to take the readings across the diameter of the specimen at the height of the bond. While this limited the contact area tested, this provided a consistent test length through with the pulse traveled and a smooth surface with which to bring the transducers in contact.

For the beam specimens, the pulse velocity readings were taken at two locations (the third points) on each of the beams. The pulse was transmitted from top to bottom of the beam. While there was some difficulty getting contact at the bottom of the HMA on some beams, adjustments made during the testing permitted consistent readings to be made.

An NDT James ${ }^{\mathrm{TM}} \mathrm{V}$ Meter MK-II pulse velocity device was used to evaluate the bond on the specimens. Readings were taken every week during the curing period. 


\subsection{Impact Echo Test}

The impact echo test imparts stress waves, via an impact, into a material. Flaws or voids in the material reflect the stress waves back to a receiver that detects the resulting surface displacements near the point of impact. Thus, the method is able to detect flaws or discontinuities in the material, Neville [1997]. This is why it was chosen to verify if there were any changes to the bond of the specimens in the laboratory study.

Only one reading was taken for each of the shear specimens due to the size of the test unit compared to the size of the shear specimens. The unit was placed on top of the shear specimen and readings were taken axially through the specimen. For the beam specimens, the test unit was placed on top of the specimens and five separate readings were taken along the length of the beams.

An Olson Instruments ${ }^{\mathrm{TM}}$ CTG-1 concrete thickness gage was used in this experiment. The gage was designed to use the impact echo technique for determination of concrete thicknesses and thus gave readings with length dimensions (inches of $\mathrm{mm}$ ). The system was set to a target thickness of 6 inches $(150 \mathrm{~mm})$ and to produce high resolution readings. An initial reading was taken prior to curing the specimens and again after the curing period was completed. This was done for both shear and beam specimens. For the beams specimens, readings were taken again after the load cycling.

\subsection{Pavement Deflection Analysis}

To assess the stiffness of the pavement sections constructed in TA2 through TA4 Pavement deflection analyses were conducted using a Dynatest ${ }^{\mathrm{TM}}$ FWD. For TA2 to TA4, FWD data were collected prior to milling of the HMA and after the completion of the curing period of the UTW concrete. For TA2 and TA3, FWD testing was also conducted after completion of the loading in each lane. For TA4 FWD testing was done on a monthly basis for a period of 18 months. FWD tests 
were conducted on each of the five UTW lanes at three different load levels: $7,000,9000$, and $11,000 \mathrm{lbs}(31,40,49$, and $62 \mathrm{kN})$. Sensors were spaced at $12,0,8,12,18,24,36,48$, and 60 inches $(-300,0,200,300,450,600,900$, 1200 , and $1500 \mathrm{~mm})$. Tests were taken every 48 inches $(1200 \mathrm{~mm})$ with the load plate placed at the center of each individual slab. This resulted in five different tests within each lane. Figure 4.17 contains an image of the pavement deflection analysis being conducted in the APT.

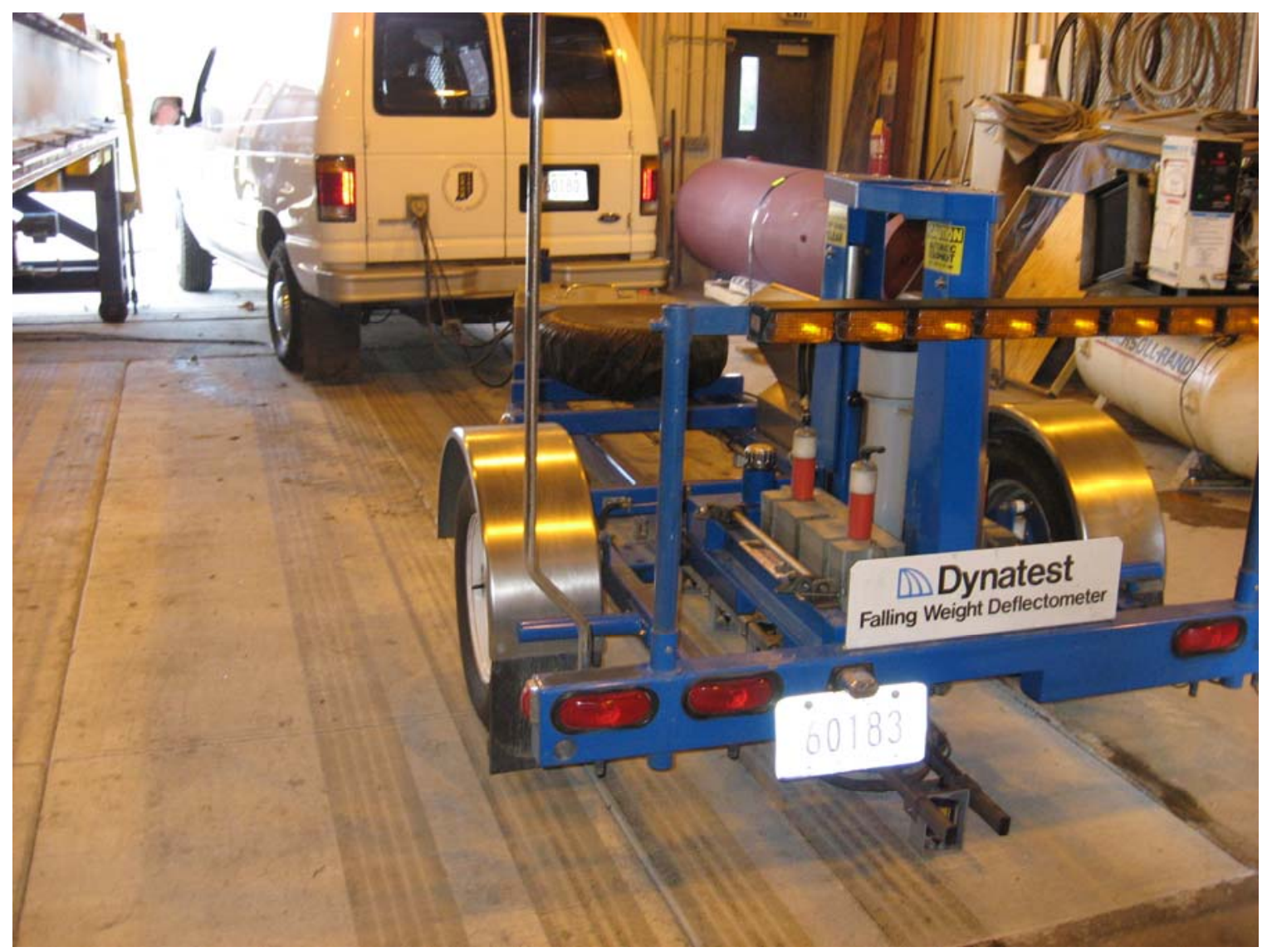

Figure 4.17 Falling Weight Deflectometer Test on TA3

The deflection data collected were used to calculate the estimated radius of relative stiffness of the pavement and the modulus of subgrade reaction. The methodology used to calculate the radius of relative stiffness and the modulus of 
subgrade reaction was as outlined in the AASHTO supplemental design guide (AASHTO [1998]). 


\section{CHAPTER 5. RESULTS}

This chapter summarizes the results of all tests during this study. The first section summarizes the mechanical properties of concrete (UTW and PCC) used in all test areas and in the laboratory study. This is followed by a section presenting the strain readings recorded during the APT part of the study. The section with data on the pavement temperatures that were recorded in TA4 is presented next followed by the bond evaluation results and a section presenting the results of the distress evaluations conducted in the test areas. The final two sections of this chapter contain the results of the pavement deflection measurements and nondestructive evaluation of specimens. Conversions used throughout this chapter are as follows: 1 inch $=25 \mathrm{~mm} ; 1 \mathrm{psi}=6.895 \mathrm{kPa} ;{ }^{\circ} \mathrm{F}=$ $(9 / 5)^{\circ} \mathrm{C}+32$.

\subsection{Concrete Mechanical Properties}

This section presents the results of the mechanical tests on concrete from both test areas and the laboratory study. The procedures used to determine these properties were previously presented in Section 4.6 and a summary of the number and type of test specimens was presented in Table 4.5. Mechanical properties evaluated include: compressive strength, flexural strength, modulus of elasticity and Poisson's ratio. The concrete mixtures utilized in these experiments were described in Section 4.3.5. Tests were conducted after a curing period of $3,28,90$, and 120 days for TA1; 7, 14, 28, and 90 days for TA2, TA3, and the laboratory study; and 28 days for TA4. Since the properties of the UTW concrete from TA4 were determined only at 28 days, all test property results for this test area are presented in Table 5.1. For all other test areas and 
the laboratory study, the results are presented in graphical form and are separated by the type of property evaluated (i.e. compressive strength, flexural strength, etc.). The compressive strength of concrete was determined according to ASTM C39. The results for TA1, TA2, TA3, and the laboratory study are presented in Figure 5.1.

Table 5.1 Mechanical Properties Test Results for Test Area 4

\begin{tabular}{|c|c|c|}
\hline Mechanical Property & $\begin{array}{c}\text { Number and Size of } \\
\text { Specimens }\end{array}$ & Average Test Results \\
\hline Compressive Strength & 3 each $-4 \times 8$ inch & $8870 \mathrm{psi}$ \\
& $(100 \times 200 \mathrm{~mm})$ & $(61.2 \mathrm{MPa})$ \\
\hline Flexural Strength & 3 each $-6 \times 6 \times 21 \mathrm{inch}$ & $970 \mathrm{psi}$ \\
& $(150 \times 150 \times 575 \mathrm{~mm})$ & $(6.70 \mathrm{MPa})$ \\
\hline Modulus of Elasticity & 2 each $(3$ test replicates & $5.15 \times 10^{6} \mathrm{psi}$ \\
& for each specimen $)-$ & $(35.5 \mathrm{GPa})$ \\
& $4 \times 8$ inch & \\
& $(100 \times 200 \mathrm{~mm})$ & \\
\hline
\end{tabular}




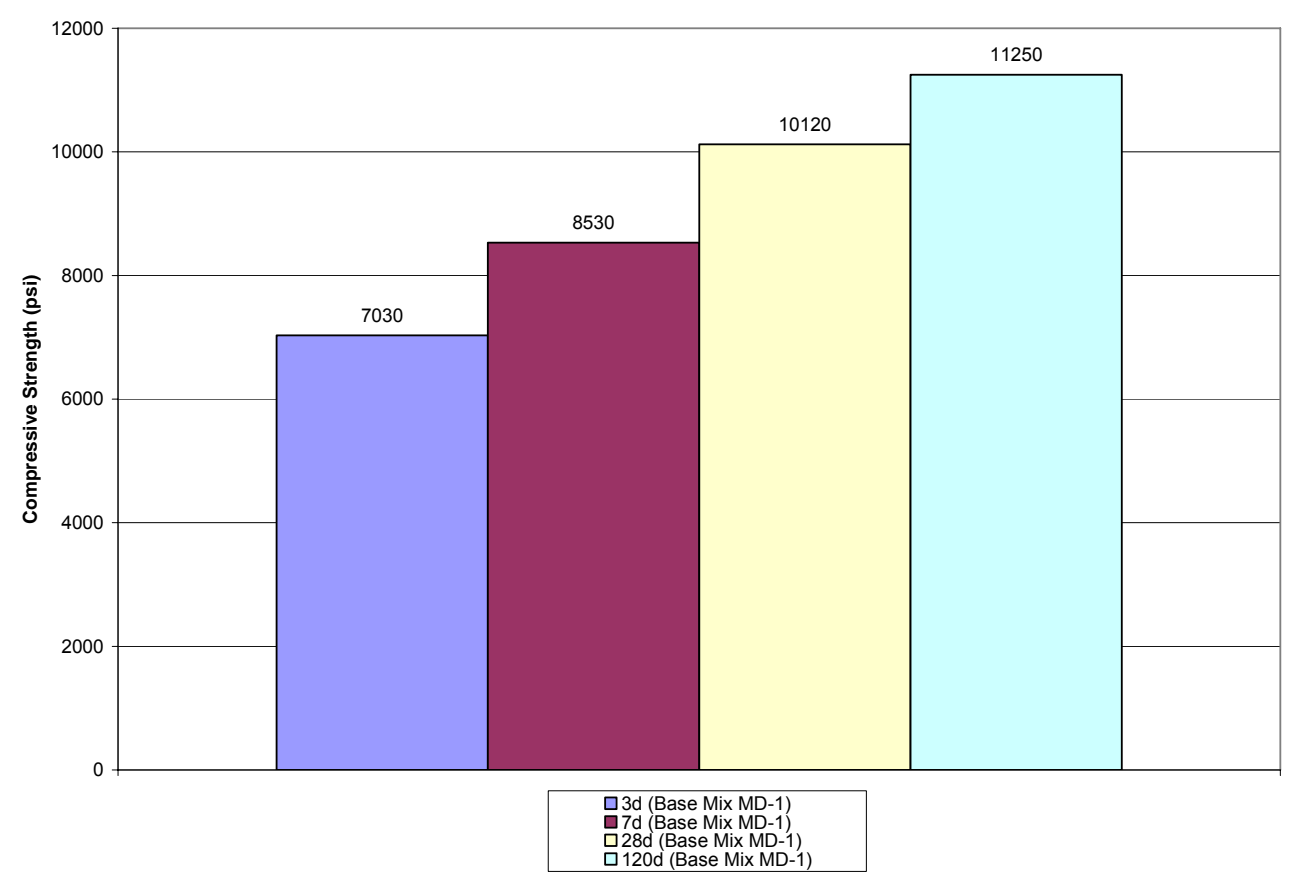

(a)

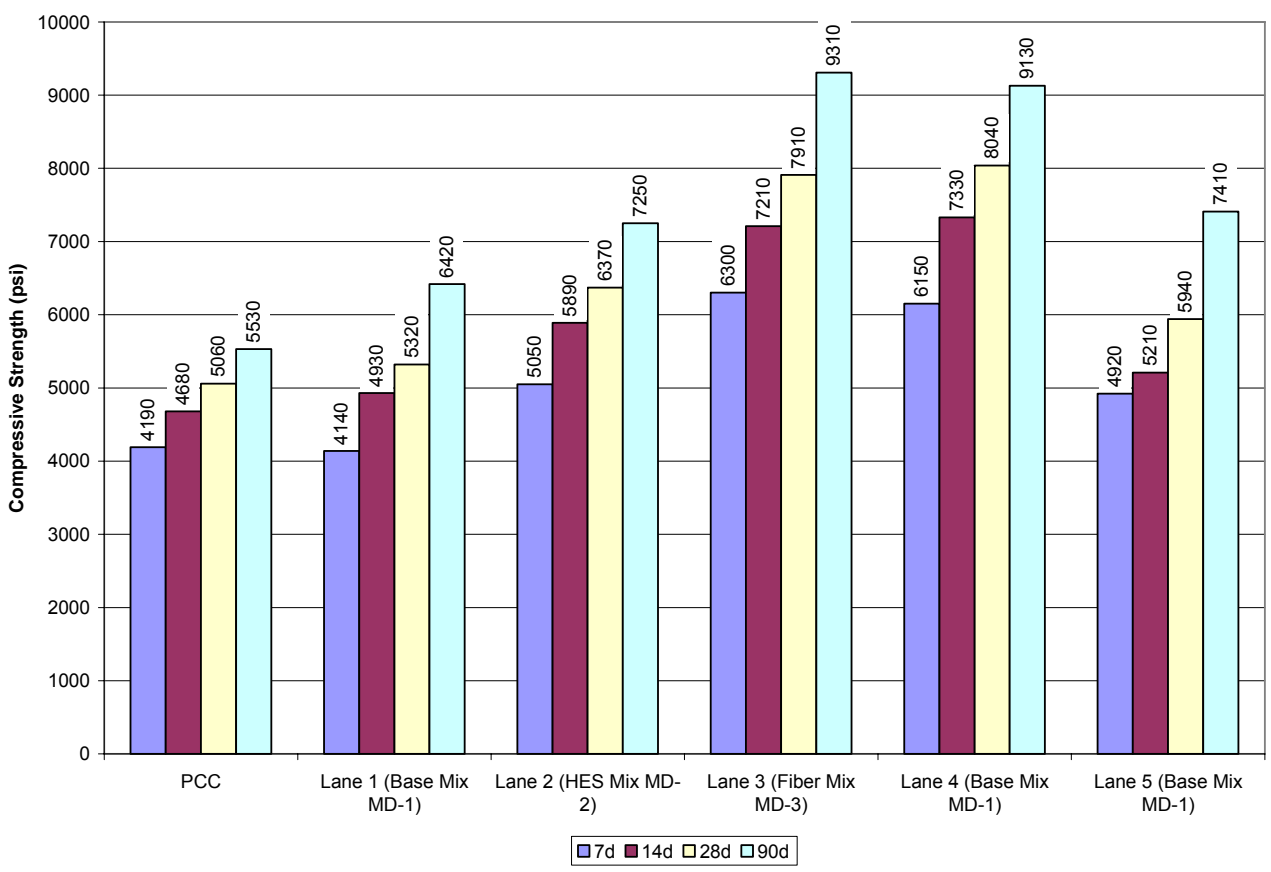

(b)

Figure 5.1 Compressive Strength Test Results (a) TA1 (b) TA2 (c) TA3 (d) Laboratory Study (continued) 


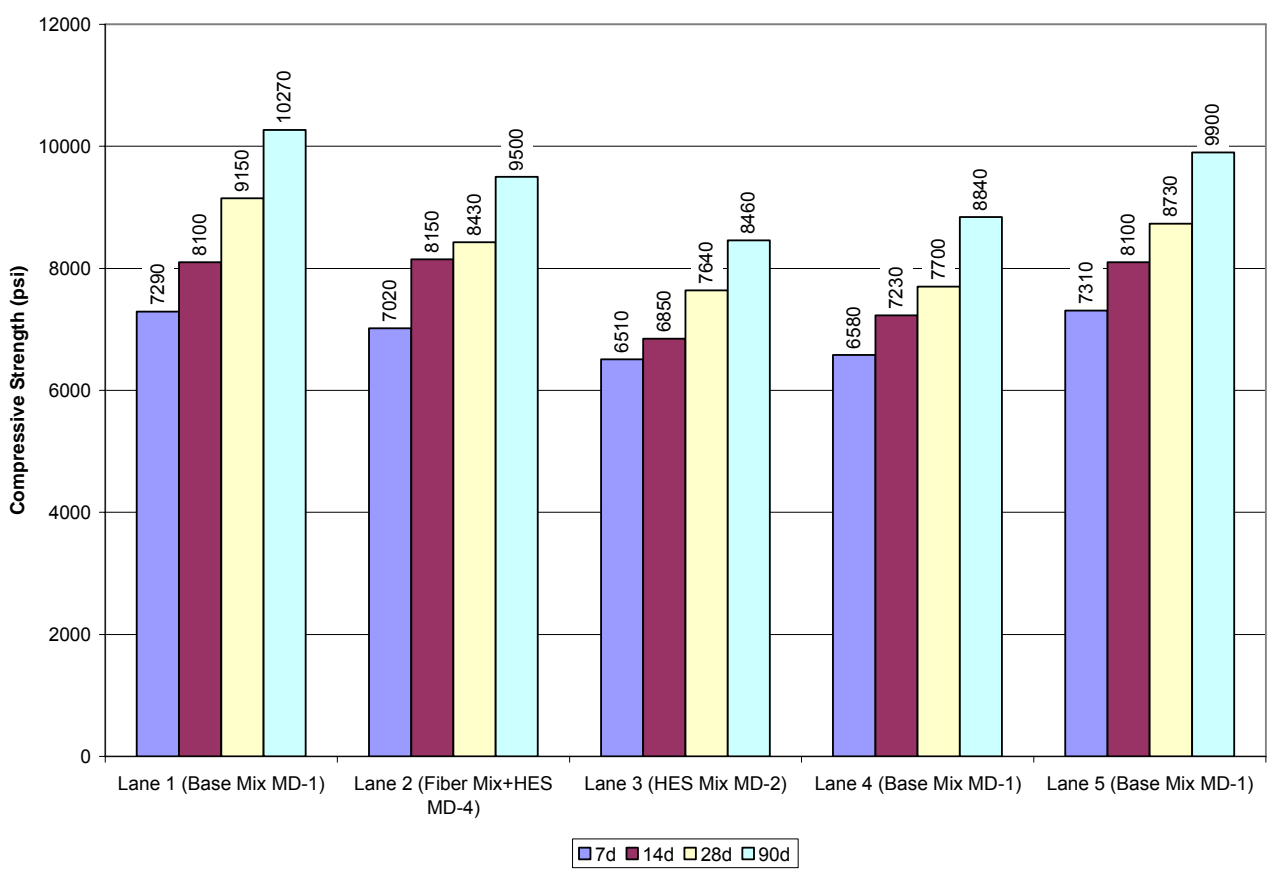

(c)

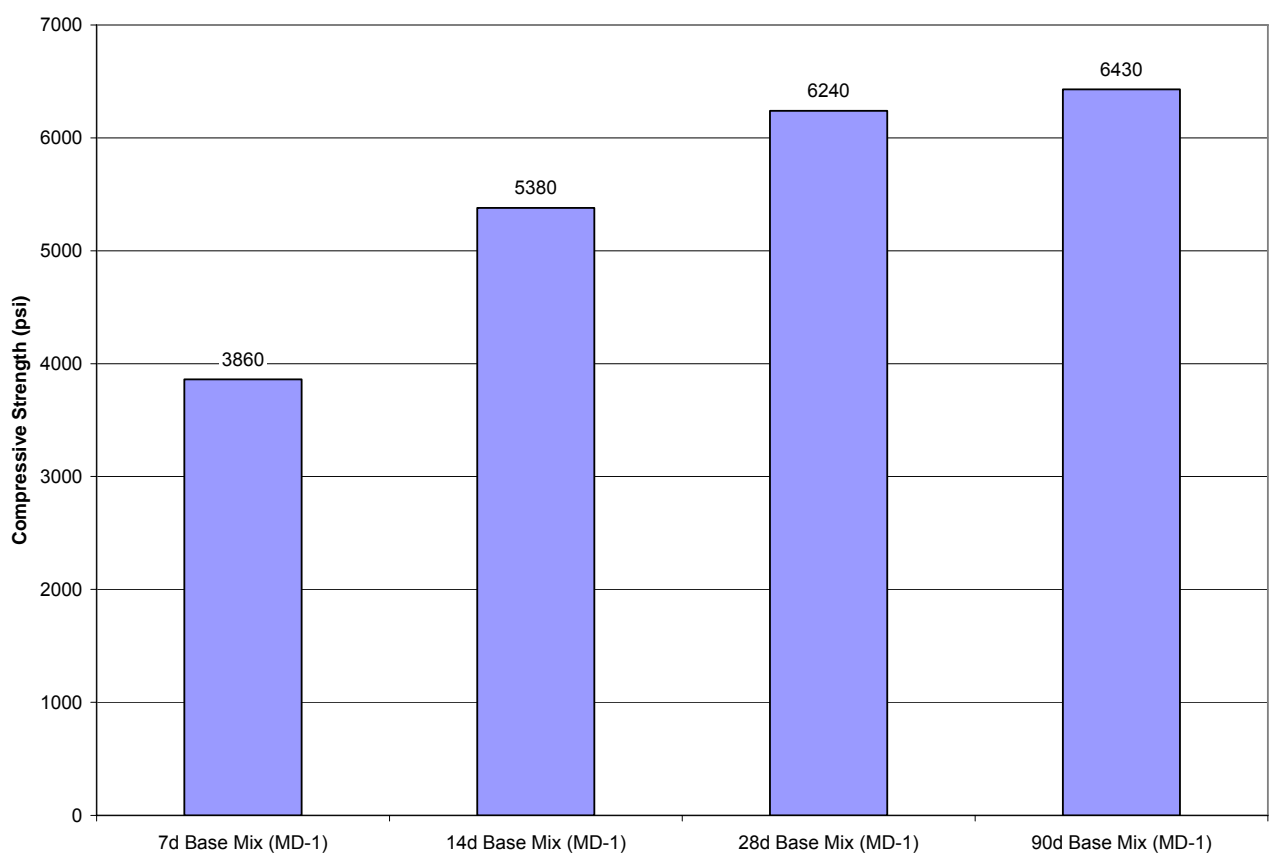

(d)

Figure 5.1 Compressive Strength Test Results (a) TA1 (b) TA2 (c) TA3 (d) Laboratory Study 
The flexural strength of concrete was determined according to ASTM C78. The specimens prepared for Test Area 1 were 3 by 3 by 15 inches ( 75 by 75 by 375 $\mathrm{mm}$ ). In order to compare them to the 6 by 6 by 21 inch ( 150 by 150 by $525 \mathrm{~mm}$ ) specimens prepared in the other test areas, the test results for Test Area 1 were converted to an estimated equivalent flexural strength using information on size effects from Neville [1997]. The results were converted based on a ratio of the modulus of rupture determined for 6 by 6 by 21 inch ( 150 by 150 by $525 \mathrm{~mm}$ ) specimens (2.6 MPa) to the modulus of rupture determined for 3 by 3 by 15 inches ( 75 by 75 by $375 \mathrm{~mm}$ ) specimens ( $3.2 \mathrm{MPa}$ ) which was 0.81 . The specimens for Test Areas 2 and 3 were conducted at 7, 14, 28, and 90 days. The results for Test Areas 1 through 3 and the laboratory study are presented in Figure 5.2.

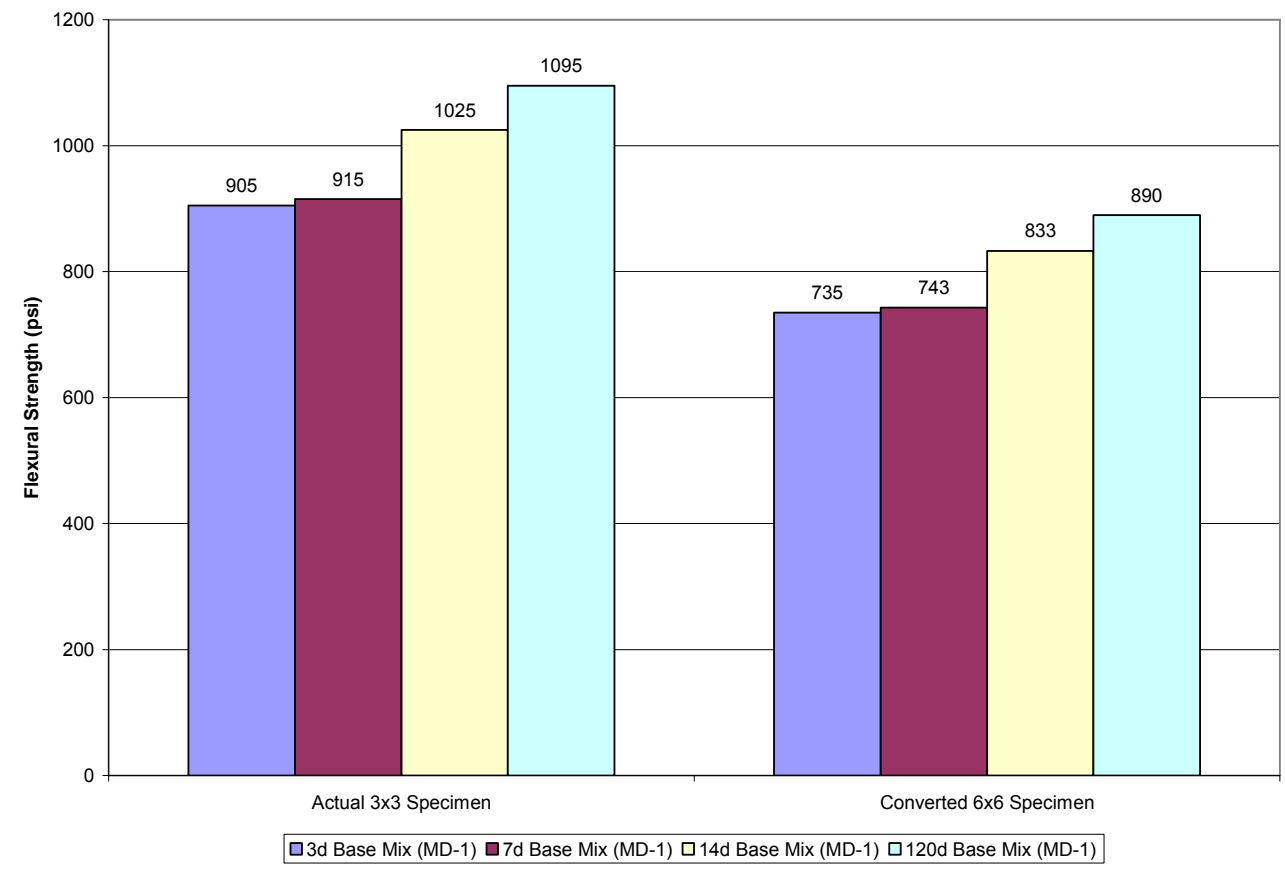

(a)

Figure 5.2 Flexural Strength Test Results (a) TA1 (b) TA2 (c) TA3 (d) Laboratory Study (continued) 


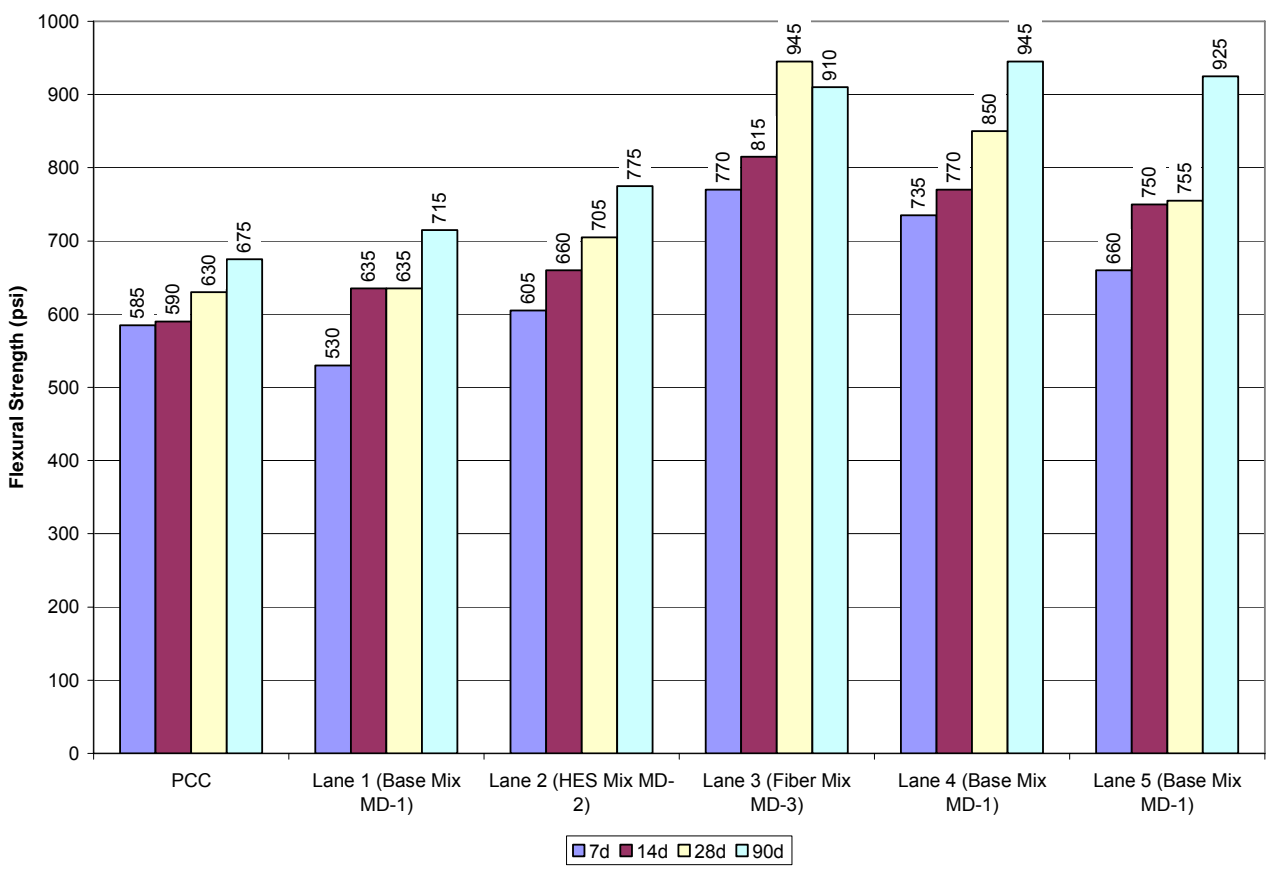

(b)

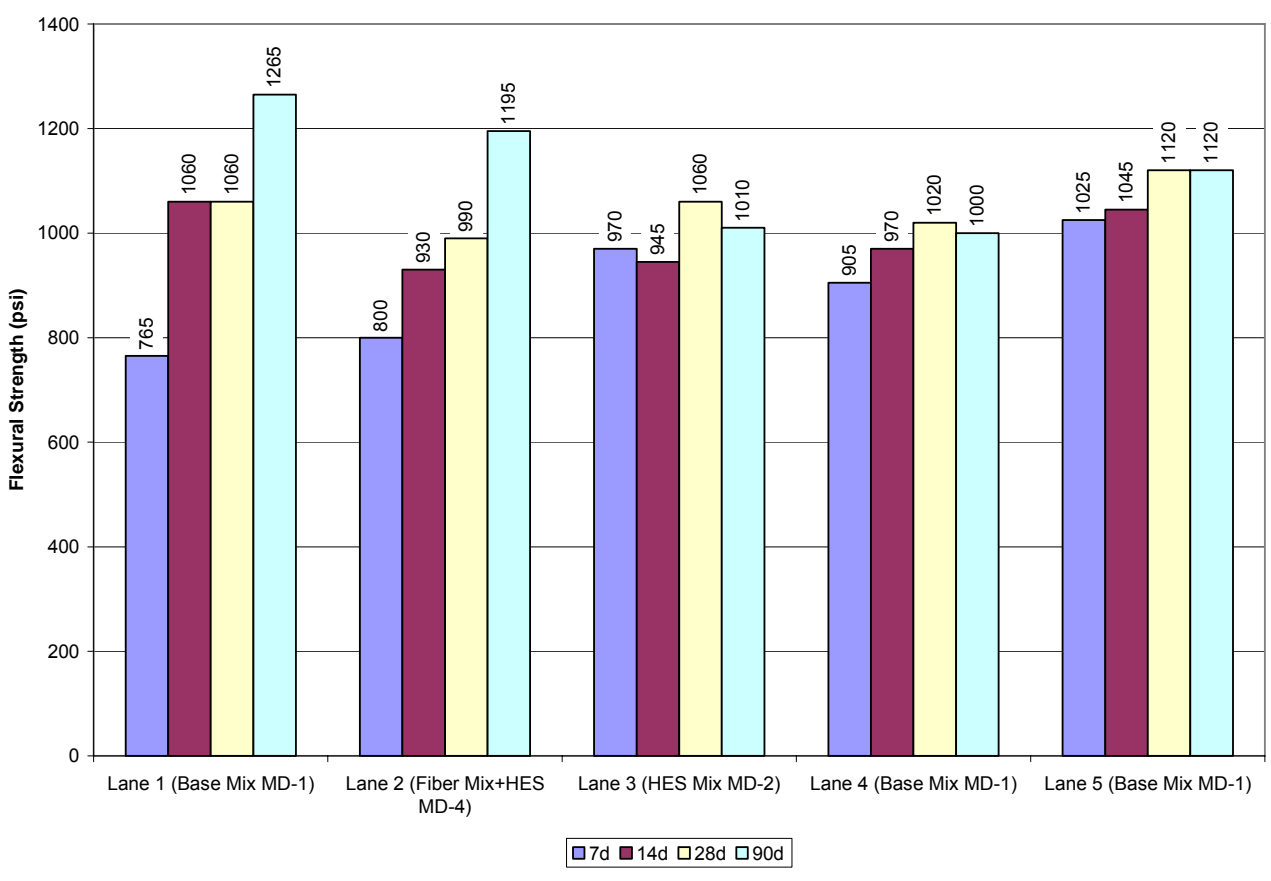

(c)

Figure 5.2 Flexural Strength Test Results (a) TA1 (b) TA2 (c) TA3 (d) Laboratory Study (continued) 


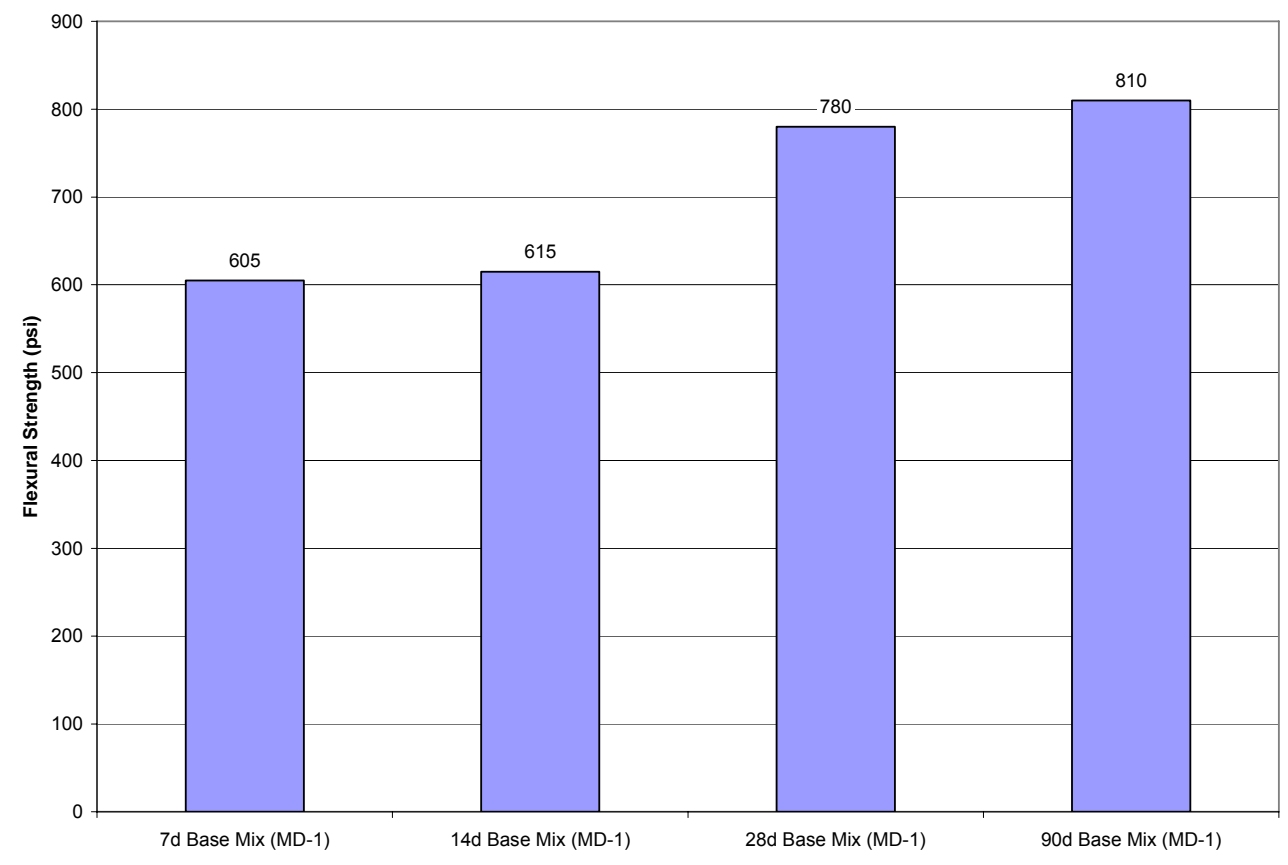

(d)

Figure 5.2 Flexural Strength Test Results (a) TA1 (b) TA2 (c) TA3 (d) Laboratory Study

The modulus of elasticity and Poisson's ratio values of concrete were determined according to ASTM C469. The Poisson's ratio ranged from 0.20 to 0.22 for all mixes and ages studied. The modulus of elasticity results for Test Areas 1 , through 3 are presented in Figure 5.3. The modulus of elasticity was not determined for the concrete produced for the laboratory study. 


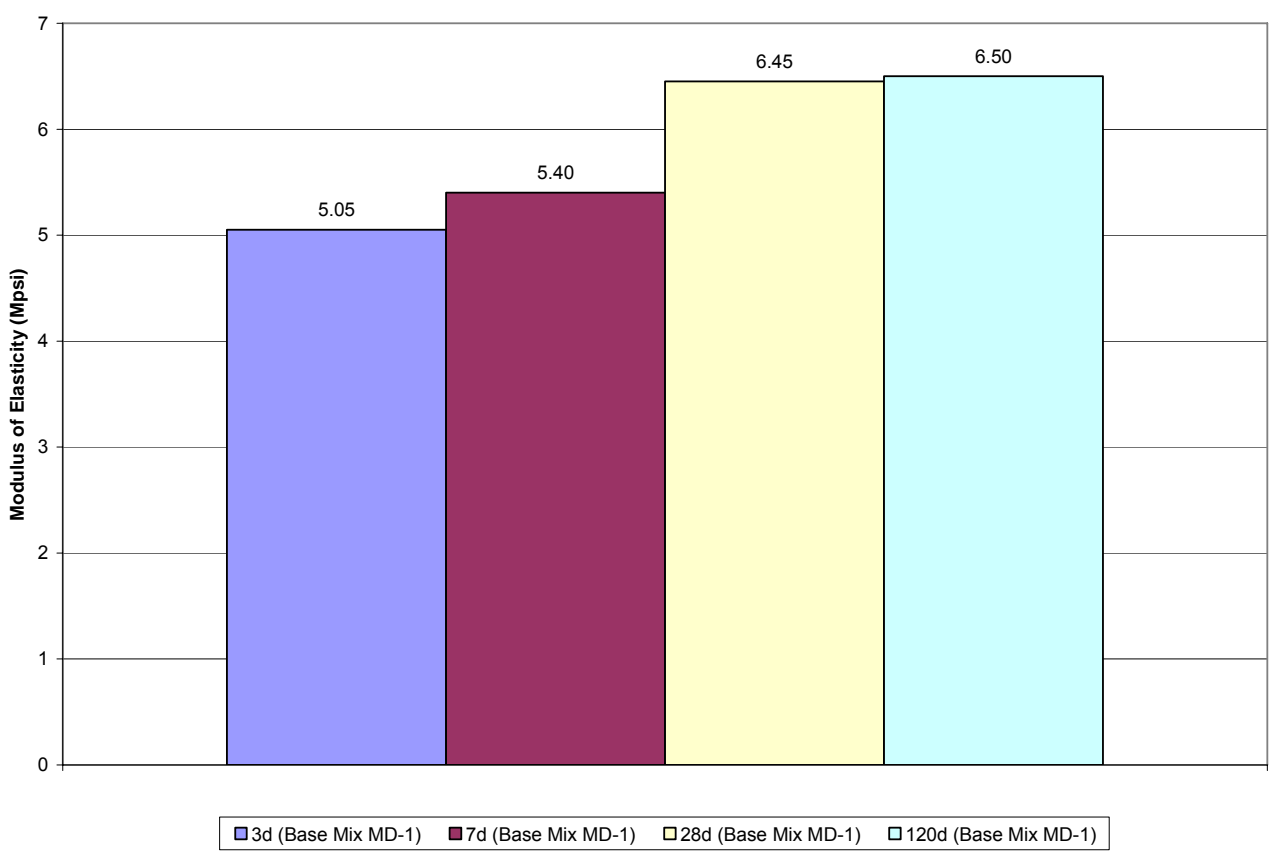

(a)

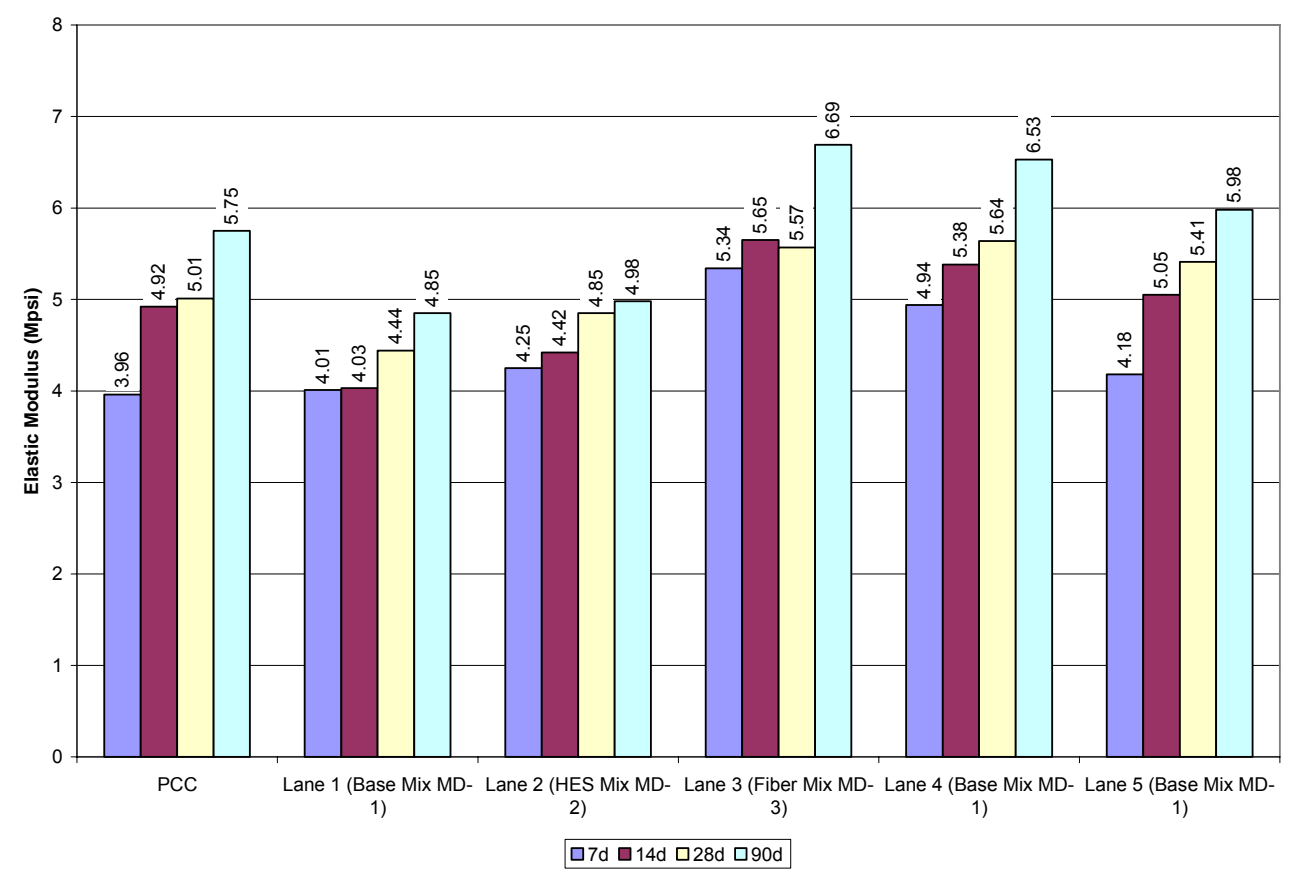

(b)

Figure 5.3 Modulus of Elasticity Results (a) TA1 (b) TA2 (c) TA3 (continued) 


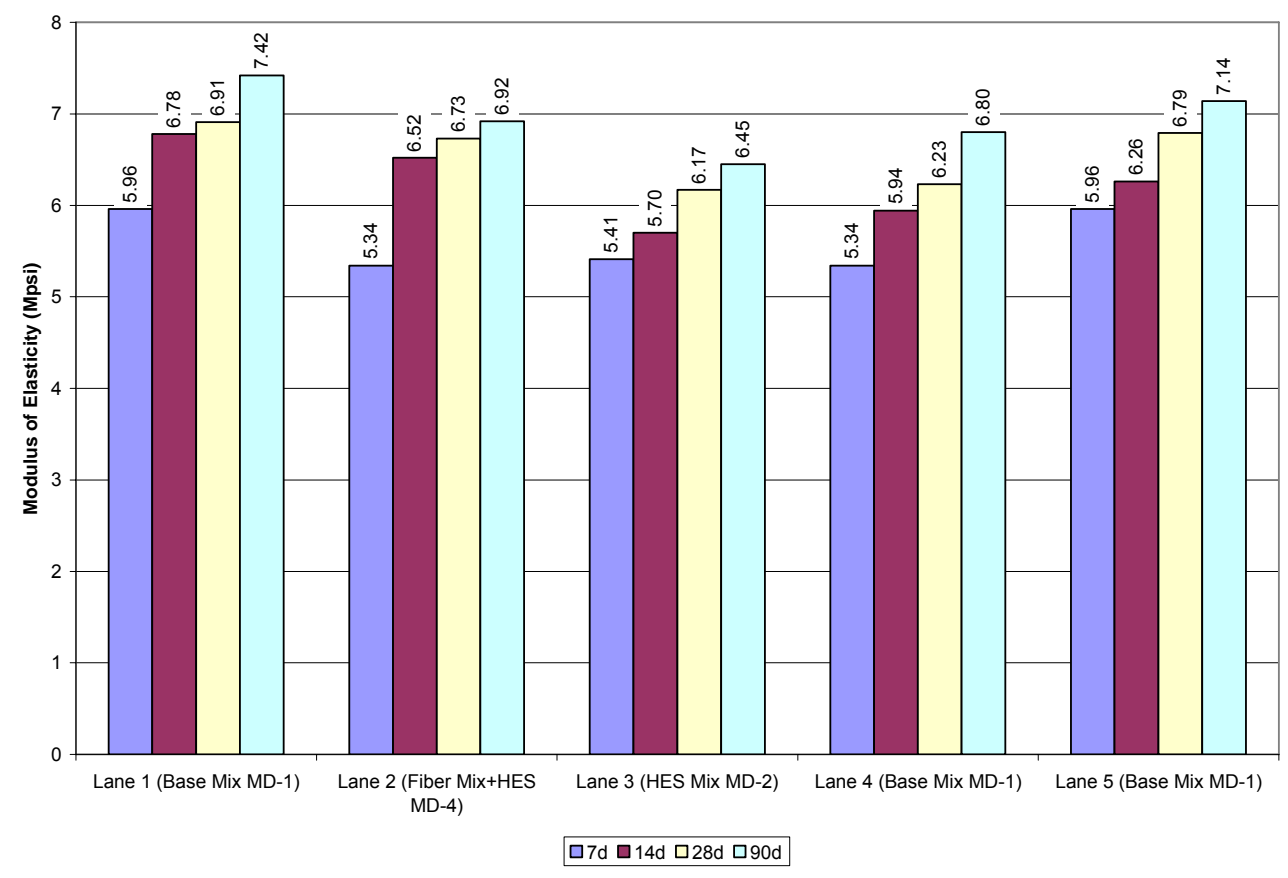

(c)

Figure 5.3 Modulus of Elasticity Results (a) TA1 (b) TA2 (c) TA3

In general, the mechanical properties of concrete evaluated in this study follow the expected trend in that all increase with an increase in curing time. This result is evident regardless of the mix design used. There are a few exceptions to this trend (mostly with the flexural strength test results). However, these variations from the trend are most likely the result of the variability of specimen quality (samples from different batches of concrete were prepared by individuals with variable experience).

The base mix, MD-1, produced very high compressive strengths $(8,840$ to 11,250 psi (60.9 to $77.6 \mathrm{MPa}$ ) at 90 days) in all the test areas. The only exception to this observation was concrete from TA2, Lane 1 where strengths were relatively low. The 90 day strength for Lane 1 was approximately 6,420 psi (44.3 MPa) while the same mix in Lanes 4 and 5 developed strengths of 9,130 psi (62.9 MPa) and $7,410 \mathrm{psi}(51.1 \mathrm{MPa})$, respectively. The compressive strengths for MD-1 
prepared during the laboratory study were very close to those obtained from concrete in TA2 Lane 1. Significant levels of air entraining admixture (up to $53 \mathrm{ml} / 100 \mathrm{~kg}$ ) were used in the laboratory. Thus, the variable amount of air entraining admixture added to the mix at the ready-mix plant may be the cause of the discrepancies amongst the lanes in TA2. Records of the amount of air entraining admixture actually added to the mix were not provided by the concrete producer therefore this assertion cannot be confirmed.

In regards to the flexural strength results, a trend similar to that observed for the compressive strengths was noted in the MD-1 test results. Very high flexural strengths (90 day strengths ranging from $890 \mathrm{psi}(6.13 \mathrm{MPa}$ ) (modified to 6 inch by 6 inch strength) to $1,285 \mathrm{psi}(8.86 \mathrm{MPa}))$ were found in all test areas. However, the 90 day strengths in TA2 Lane 1 were again only 675 psi (675 $\mathrm{MPa})$, much lower than those measured in Lane 4 (945 psi (6.51 MPa)) and Lane 5 (925 psi (6.38 MPa)). The results from the laboratory specimens indicate that the flexural strength of the concrete produced in the laboratory was in between that observed in TA2, Lane 1 and the results obtained from the other test lanes using MD-1. This result could also be the result of variations in the amount of air entraining admixture.

For the modulus of elasticity, the results of the testing of the MD-1 concrete mixes again show trends similar to those just described for compressive and flexural strengths. Very high 90 day moduli values (ranging from $5.98 \times 10^{6}$ to $7.42 \times 10^{6} \mathrm{psi}(41.2$ to $51.2 \mathrm{GPa})$ ) were typical for this mix as seen in the results for all the test areas. However, the moduli values for TA2 were again lower, $4.85 \times 10^{6} \mathrm{psi}(33.4 \mathrm{GPa})$ at 90 days. The values for Lanes 4 and 5 were $6.53 \times 10^{6}$ psi and $5.98 \times 10^{6} \mathrm{psi}(45.0 \mathrm{GPa}$ and $41.2 \mathrm{GPa})$, respectively. Again, this discrepancy may be the result of higher amounts of air entraining admixture used for the concrete in TA2, Lane 1. As these results were systemic (i.e. reflected 
throughout all material properties) it is concluded that the mix delivered and used in TA2, Lane 1 was not what was ordered.

The results of the mechanical testing were mixed in regards to the merits of the high early strength (HES) mix, MD-2. For the 7d compressive strengths in TA2, the HES mix produced moderately higher compressive strengths than the base mix (MD-1) at the same age (5050 psi versus 4140 psi (34.8 MPa versus 28.5 $\mathrm{MPa})$ ). However, for TA3, the reverse was observed with the base mix having a higher $7 d$ compressive strength than the HES mix. A comparison of the flexural strengths of the HES and base mixes indicated results to be more in line with what would be expected for a high early strength mix. The flexural strength of the HES mix was higher than the base mix at 7 days for both TA2 (605 psi versus $530 \mathrm{psi}$ (4.17 MPa versus $3.65 \mathrm{MPa}$ )) and TA3 (970 psi versus $765 \mathrm{psi}$ 6.69 $\mathrm{MPa}$ versus 5.27 $\mathrm{MPa}$ )). When examining the trend for the modulus of elasticity, however, the results were again mixed. In TA2, the HES mix had a higher modulus at 7 days $\left(4.25 \times 10^{6} \mathrm{psi}(29.3 \mathrm{GPa})\right)$ than the modulus of the base mix at the same age $\left(4.01 \times 10^{6} \mathrm{psi}(27.6 \mathrm{GPa})\right)$. However, in TA3, the opposite was observed with the base mix having a higher modulus $\left(5.96 \times 10^{6} \mathrm{psi}\right.$ $(41.1 \mathrm{GPa}))$ than the HES mix $\left(5.41 \times 10^{6} \mathrm{psi}(37.3 \mathrm{GPa})\right)$. The mixed results of these comparisons are most likely the result of the cement manufacturer's producing very finely ground Type I cement that also meets the gradation requirements of Type III cement. Thus, the HES mix tested in this research does not clearly provide any benefit with respect to the rate of mechanical properties development.

The properties of fiber-reinforced mixes used in the study (MD-3 and MD-4) were evaluated for TA2 and TA3. Since there were no observable differences between the HES and base mix the potential influence of Type III cement in MD4 was ignored. Thus, the two mix designs are assumed to be interchangeable in this regard. The mechanical properties of the fiber mixes also exhibited mixed 
results. The fiber mix produced higher compressive strength at 90 days $(9,310$ psi (64.2 MPa)) than the base mix (6,420 psi (44.3 MPa)) in TA2. However this trend was reversed in TA3 with the base mix having greater compressive strength $(10,270 \mathrm{psi}(70.8 \mathrm{MPa}))$ than the fiber mix (9,500 psi (65.5 MPa)). The addition of fibers was expected to have a noted effect on the flexural strength results. However, trends similar to those described for the compressive strength results were observed in both the flexural strength and modulus of elasticity results. Thus, the addition of fibers to the UTW mix does not appear to have any discernable affect on the material properties of the UTW concrete.

\subsection{Strain Readings}

The instrumentation of the test sections constructed in the APT is described in section 4.3.4. The current section summarizes the strains collected during curing and loading. Both static and dynamic strains are presented. The gages in the different pavement layers were located at one of four locations within the instrumented slab as follows: joint, edge, mid-panel, or corner. These locations are presented in Figure 5.4. Additionally, gages were located at different depths within the layer, either the top or bottom. Accordingly, the individual strain values presented were labeled using the following key: layer type $(U T W=U, H M A=H$, or $\mathrm{PCC}=\mathrm{P}$ ), gage location (joint $=\mathrm{J}$, mid-panel $=\mathrm{M}$, edge $=\mathrm{E}$, corner $=\mathrm{C}$ ), and gage depth (top $=T$, bottom $=B$ ). For cases when a rosette was used as a corner gage (UTW layers only) the resolved strain values were labeled with the subscript "max". For example, using this key, the top strain in the HMA layer at the edge location will be labeled as "HET". For the top UTW gage at the corner location the measured strain would be labeled as "UETmax". 


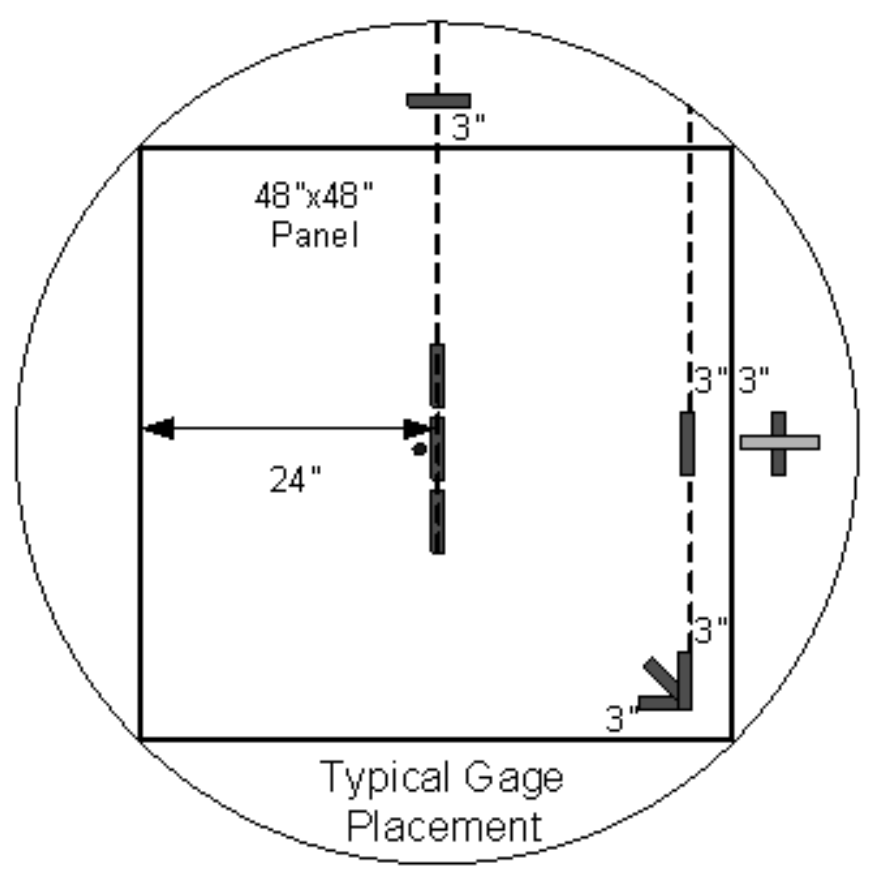

Figure 5.4 Typical Gage Layout

\subsubsection{Curing Strains}

Strains were recorded on an hourly basis during the concrete curing period for the concrete placed in Test Areas 1-3. The gages were zeroed and data acquisition was begun within an hour after the concrete was finished. A summary of the types of gages used along with their respective locations was presented in Table 4.2. The curing strains were plotted as a function of time for each individual lane and location within the lane: i.e. Joint, Edge, Mid-Panel, or Corner. An example of the plot for Test Area 1, edge location is presented in Figure 5.5. The plots for the remaining lanes are presented in Figures B.1 through B.11 in Appendix B. 


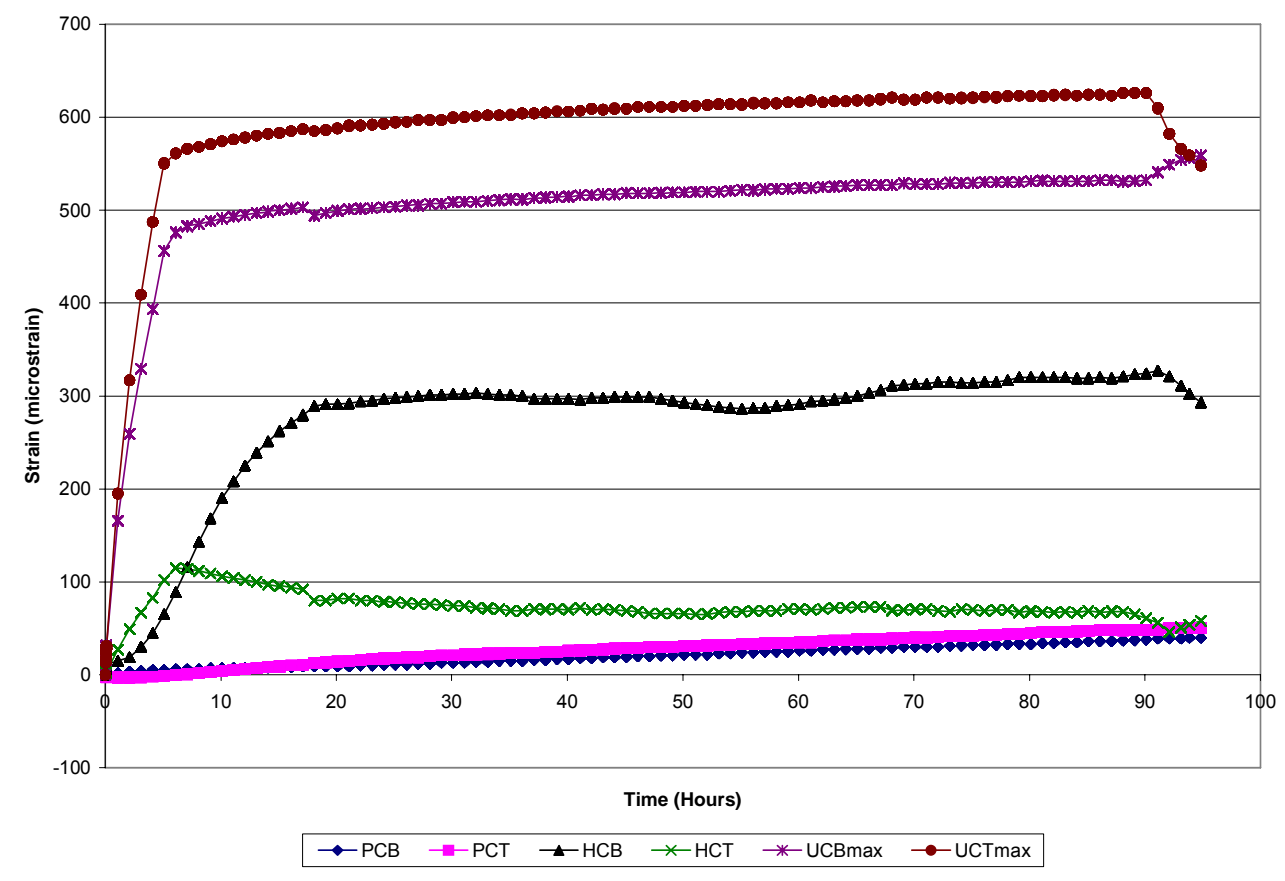

Figure 5.5 Curing Strains - Test Area 2 - Lane 1 - Corner Location

5.2.2. Strain Changes with Increasing Load Applications and Dynamic Strain under APT Loading

Loading of the pavement sections in the APT was initiated after a three day curing period (except for Lane 1 of TA1 where the loading was started eight days after concrete placement). Prior to loading the gages were re-zeroed to provide strain data that was related only to the APT loading period. Strains were recorded between every 500 to 10,000 load applications. The strain gages were sampled at a rate of $100 \mathrm{~Hz}$ and therefore provided a dynamic strain response as the APT wheel carriage passed over the pavement.

In order to determine the cumulative strain with an increasing number of load applications the strains at the locations of the gages were isolated. This was done by filtering the data by carriage location when the carriage was directly over the Joint, Mid-Panel, Edge, or Corner locations. The data was filtered also when the carriage was at the "zero" location or when the carriage was not on the 
pavement section (an unloaded condition). This was done to assess the drying shrinkage strains that accumulated in the pavement section. A representative example of the plot for Test Area 3, Lane 1, Edge location is presented in Figure 5.6. The plots for the remaining lanes are presented in Figures B.12 through B.33 in Appendix B.

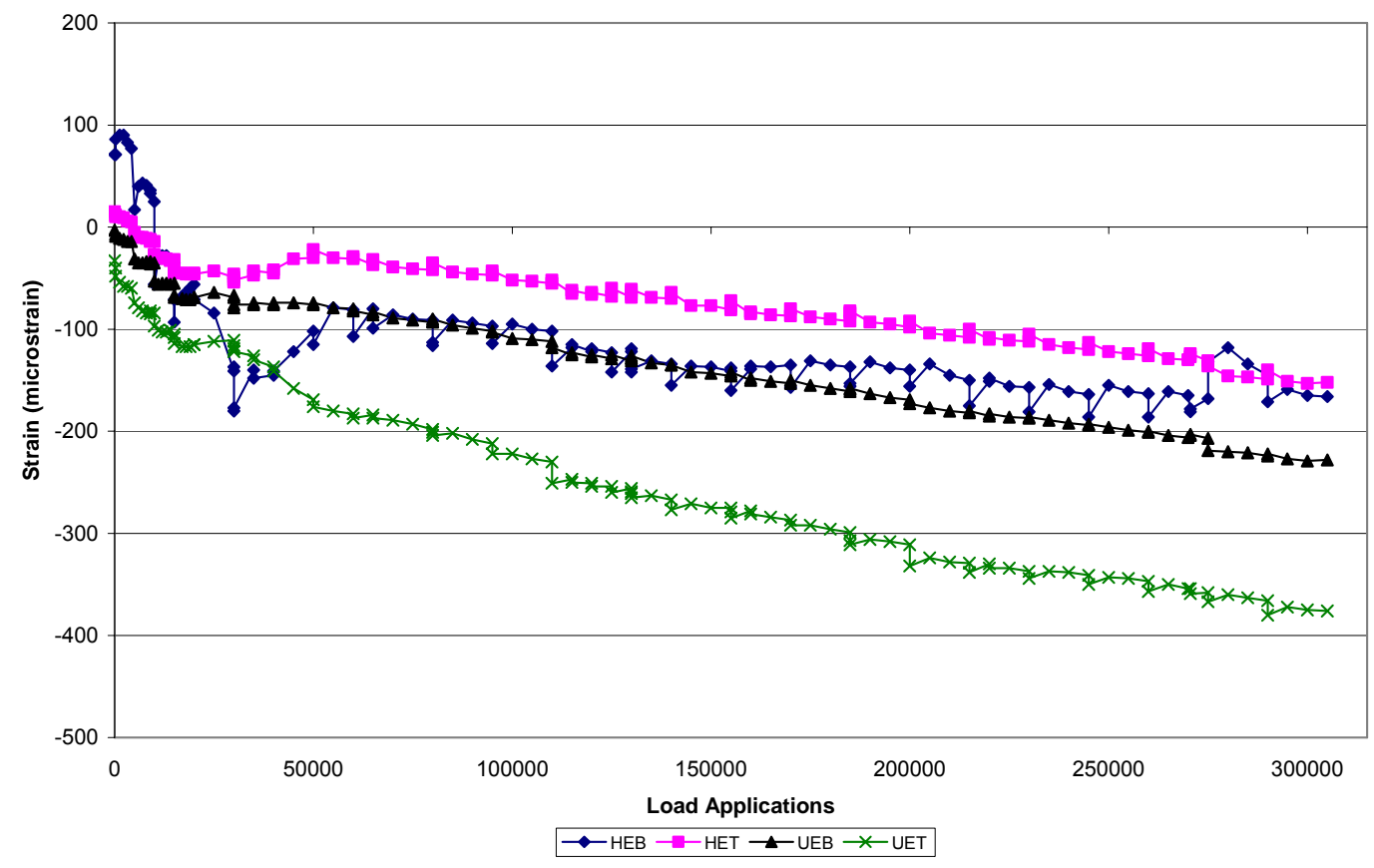

Figure 5.6 Strain versus Load Applications for Test Area 3 - Lane 1 - Edge Location

To illustrate the changes in dynamic load responses across the pavement section, the original data were filtered to isolate the strain response at a given load application and location: Joint, Mid-Panel, Edge, and Corner. The data were zeroed in order to remove the effect of any built-in strains, thus the data presented is only the load-induced strains. These data were plotted as a function of the carriage location. (Note: Locations are referenced to the centerline of the wheel axle -0 inch $(0 \mathrm{~mm})$ datum is at the edge of the test pit, 240 inch $(6000$ 
$\mathrm{mm}$ ) datum is at opposite end of test pit (see Figures 4.7 through 4.9.) A representative example of the plot for Test Area 2, Lane 2, Edge Location is presented in Figure 5.7. The plots for the remaining lanes are presented in Figures B.34 through B.55 in Appendix B.

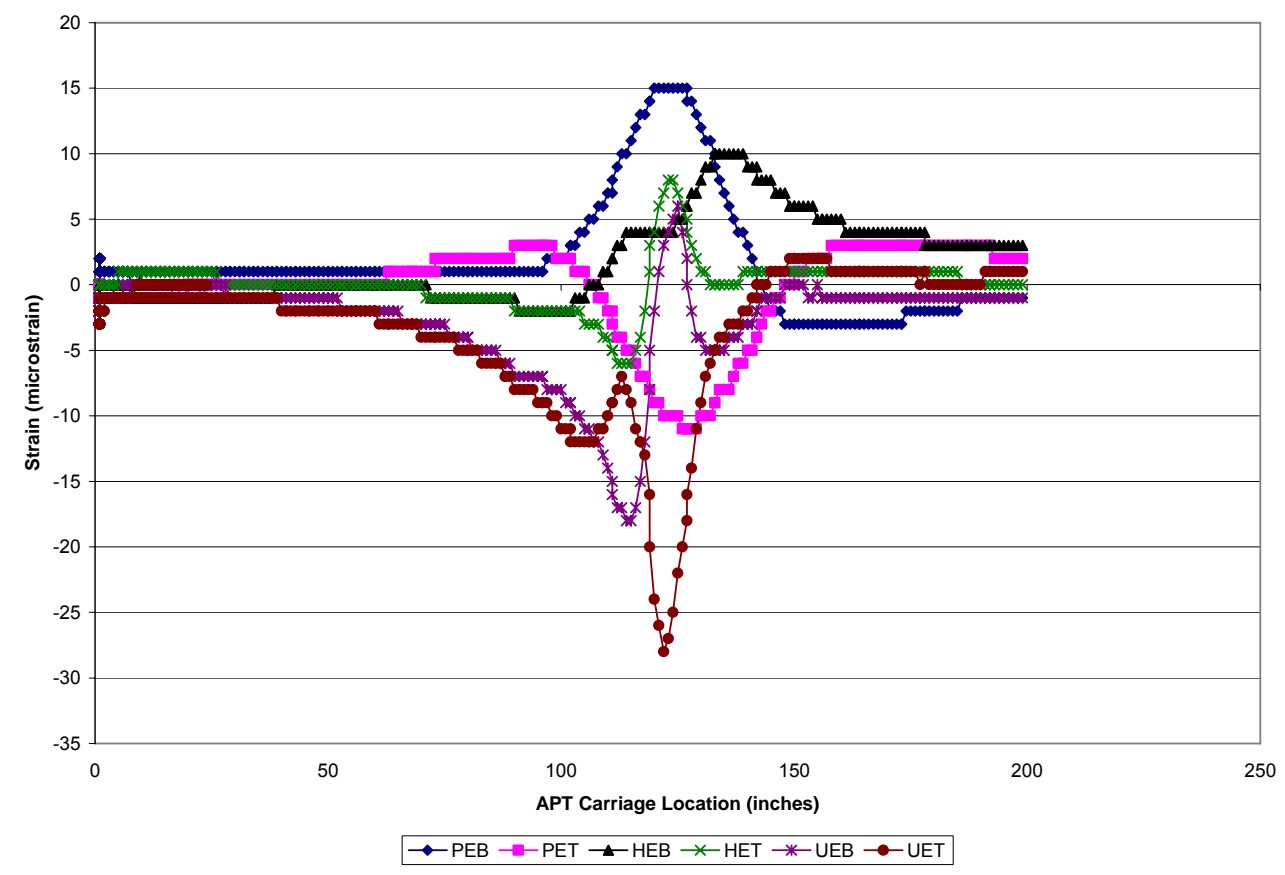

(a)

Figure 5.7 Strain versus APT Carriage Location - Test Area 2 - Lane 2 - Edge Location (a) 5,000 Load Applications (b) 150,000 Load Applications (c) 275,000 Load Applications (continued) 


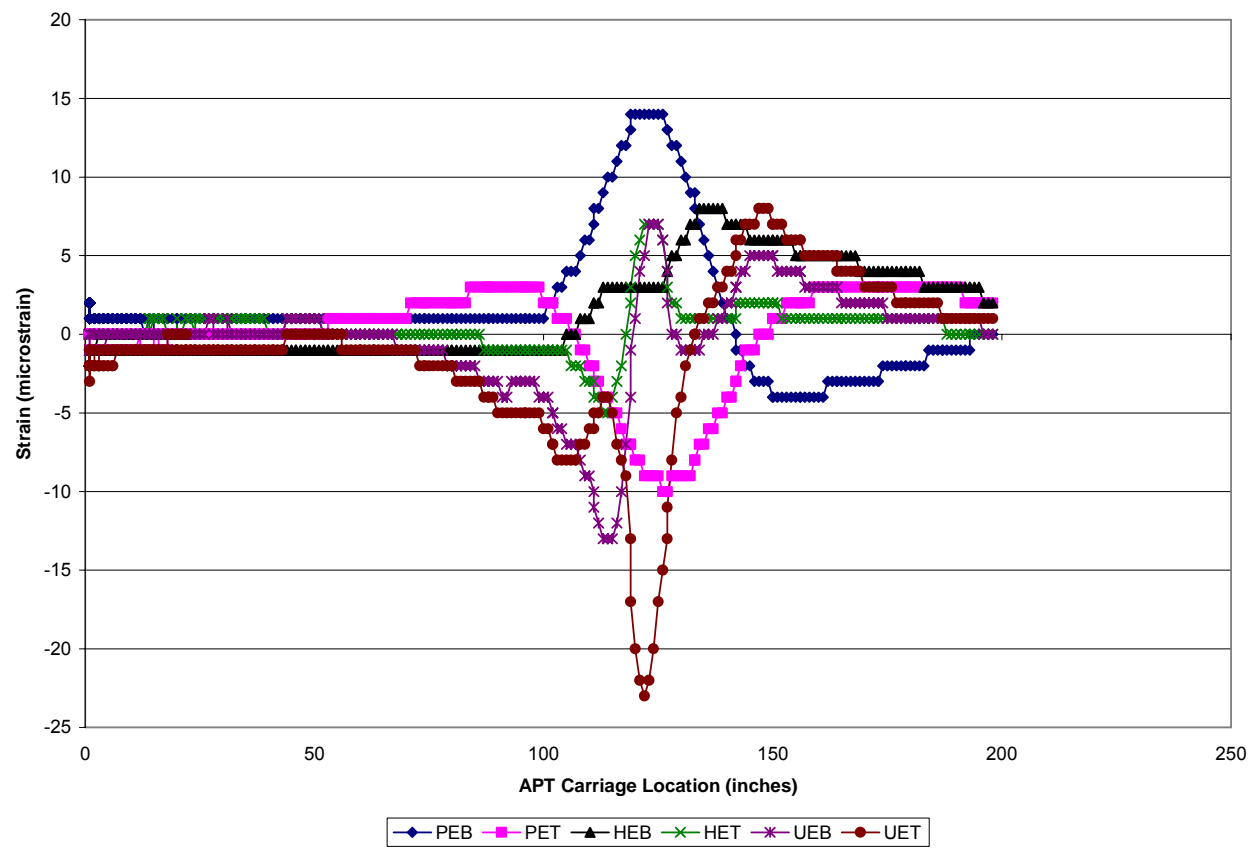

(b)

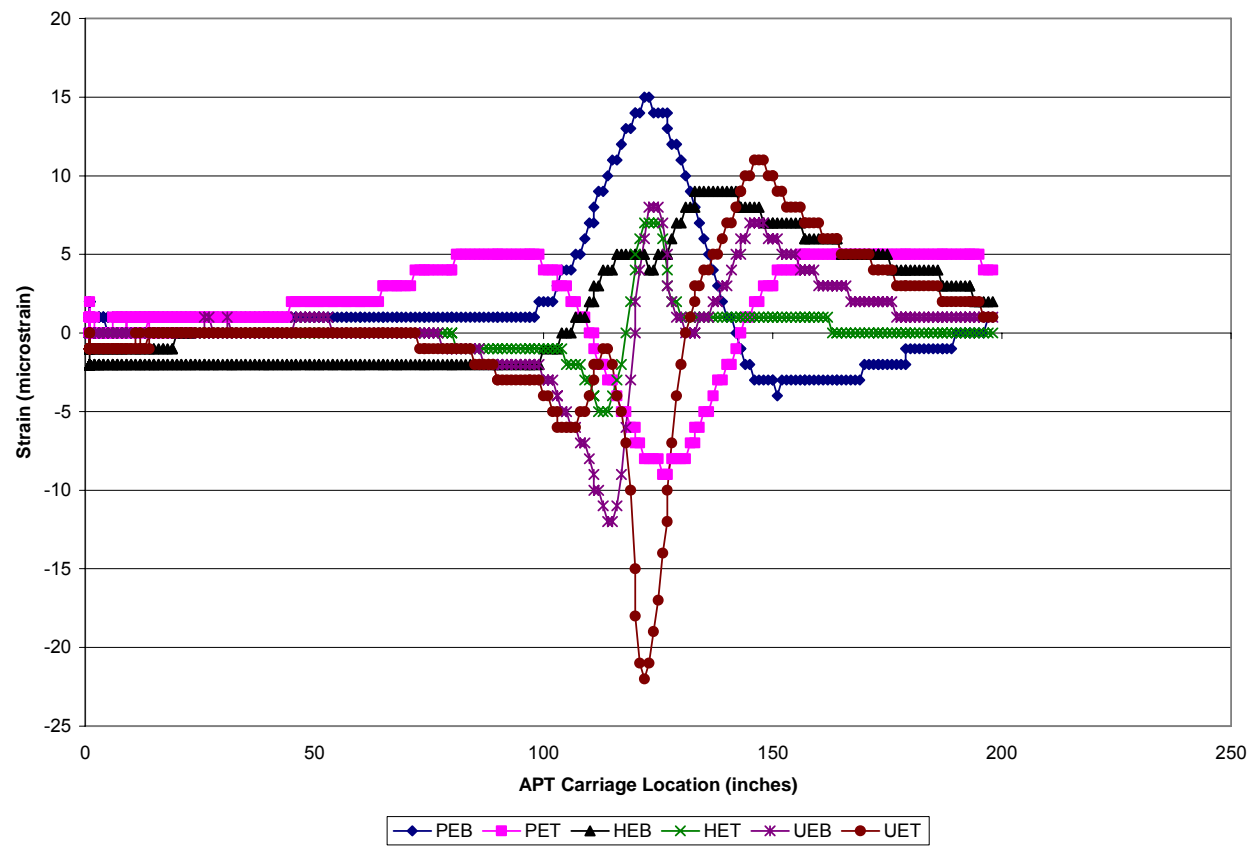

(c)

Figure 5.7 Strain versus APT Carriage Location - Test Area 2 - Lane 2 - Edge Location (a) 5,000 Load Applications (b) 150,000 Load Applications (c) 275,000 Load Applications 


\subsubsection{Comparison of Shrinkage for Bonded and Unbonded Slabs}

To evaluate the effect of the UTW-HMA bond on the shrinkage of the UTW concrete, a companion 4 foot by 4 foot by 2.5 inch thick $(1200 \mathrm{~mm}$ by $1200 \mathrm{~mm}$ by $37 \mathrm{~mm}$ thick) slab was constructed for each test lane. Both test lanes and the companion slabs were instrumented with vibrating wire surface mounted strain gages as described in Section 4.3.4. The data acquisition was started at the end of the curing period and data were collected during the APT test period. These data were plotted as a function of the time. An example of such a plot for Test Area 1 is presented in Figure 5.8. The plots for Test Areas 2 and 3 are presented in Figures B.56 through B.66 in Appendix B.

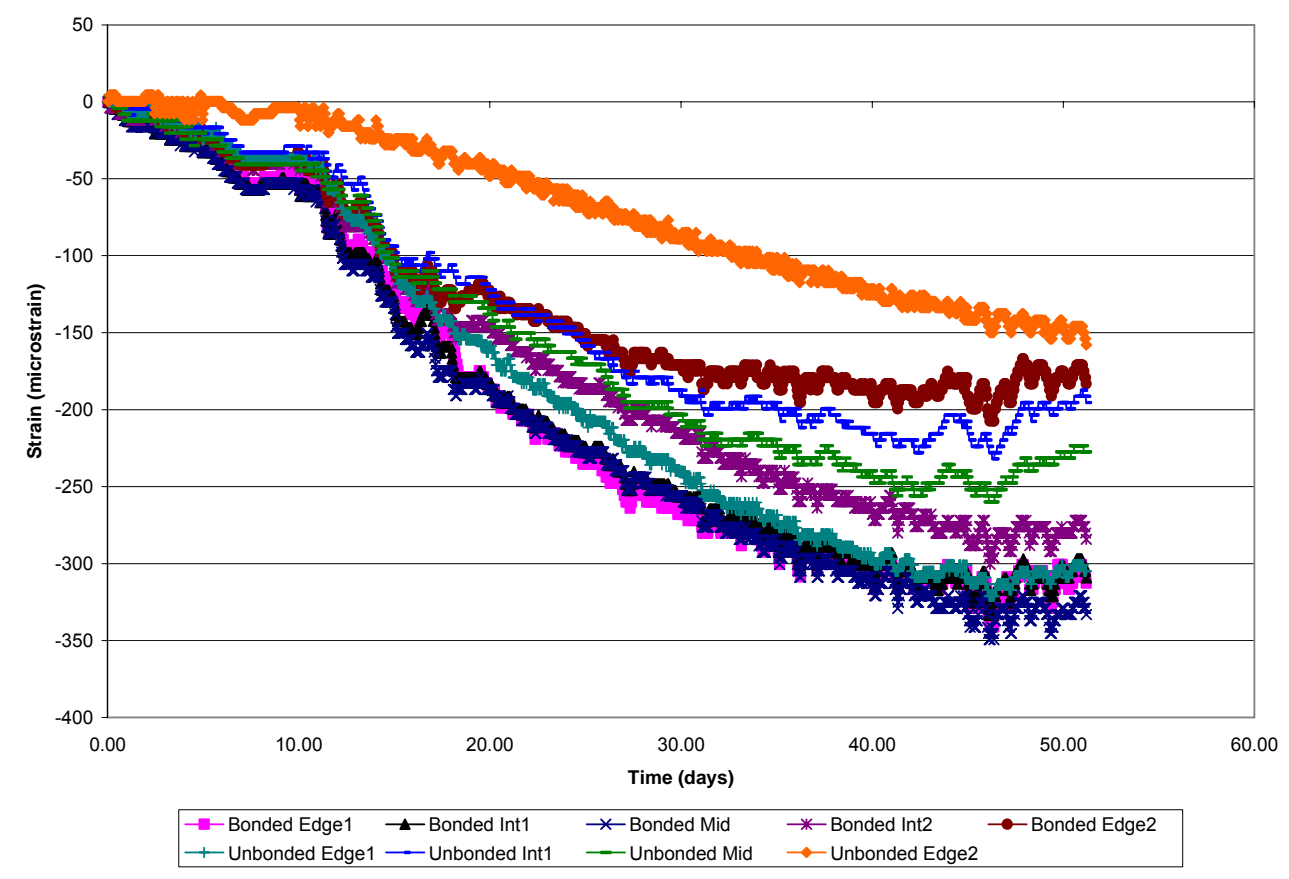

Figure 5.8 Bonded and Unbonded Strains over Time - Test Area 1

\subsection{Environmentally-Induced Pavement Temperatures}

As previously mentioned in Section 4.2.4, TA4 was constructed in the parking lot outside the APT facility and thus was exposed to the prevailing weather conditions. Three test lanes were instrumented to monitor the pavement 
temperatures. The instrumentation of the test areas was described in Section 4.3.4. This section summarizes the temperatures collected during the one year evaluation period. Note: Although the temperatures of the test lanes in TA1 through TA3 were also monitored, due to the interior location of the test lanes the temperatures remained relatively constant and are not part the data presented here.

Collection of the temperature readings for Test Area 4 was continued after the curing period was terminated. The temperatures were recorded every ten minutes for a period of approximately twelve months (October 2005 through October 2006). The temperatures recorded during this period were filtered to isolate the coolest and warmest times of the day (estimated to be at 4:00 AM and 4:00 PM). These temperatures were plotted as a function of time. Plots for Test Area 4 temperatures recorded at 4:00 AM (low temperature) and 4:00 PM (high temperature) are presented in Figure 5.9. 


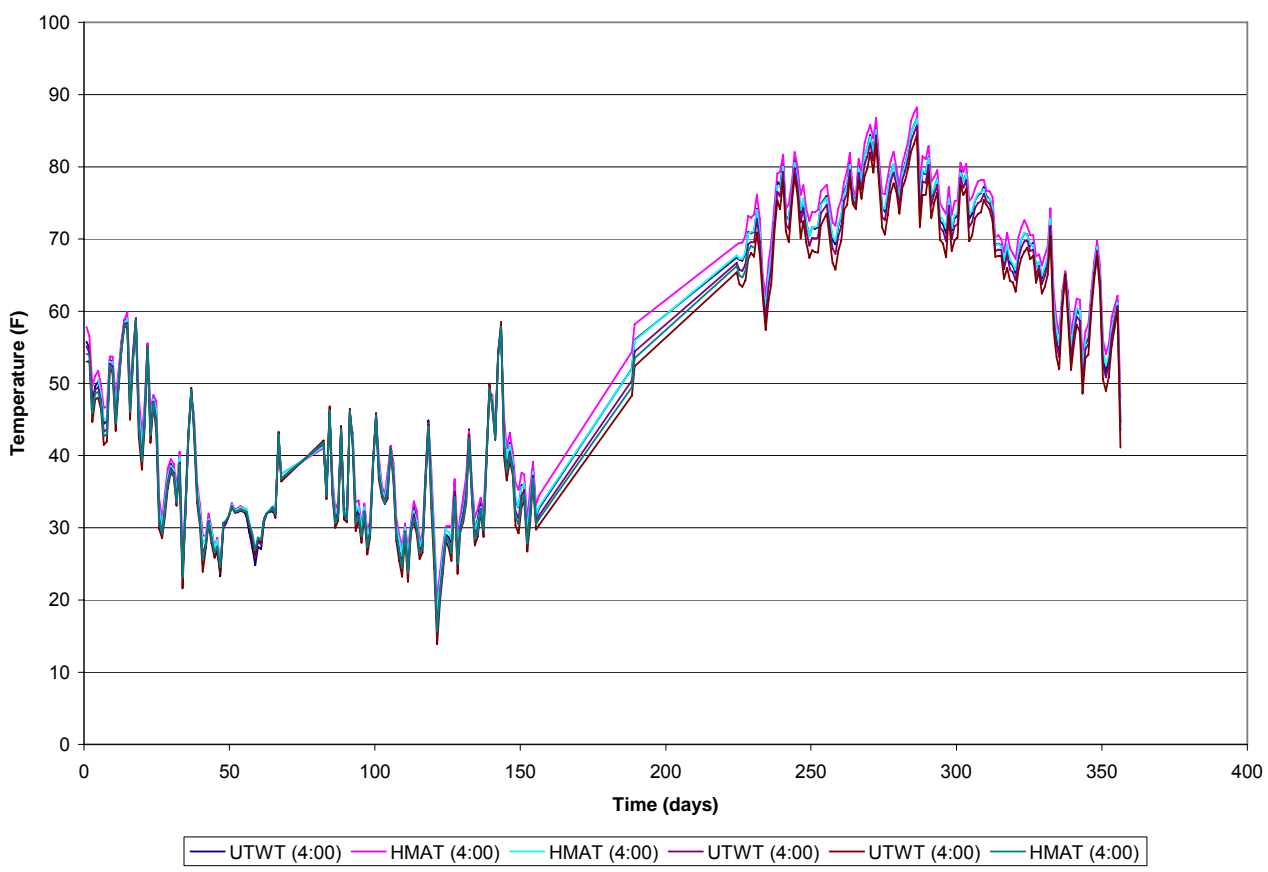

(a)

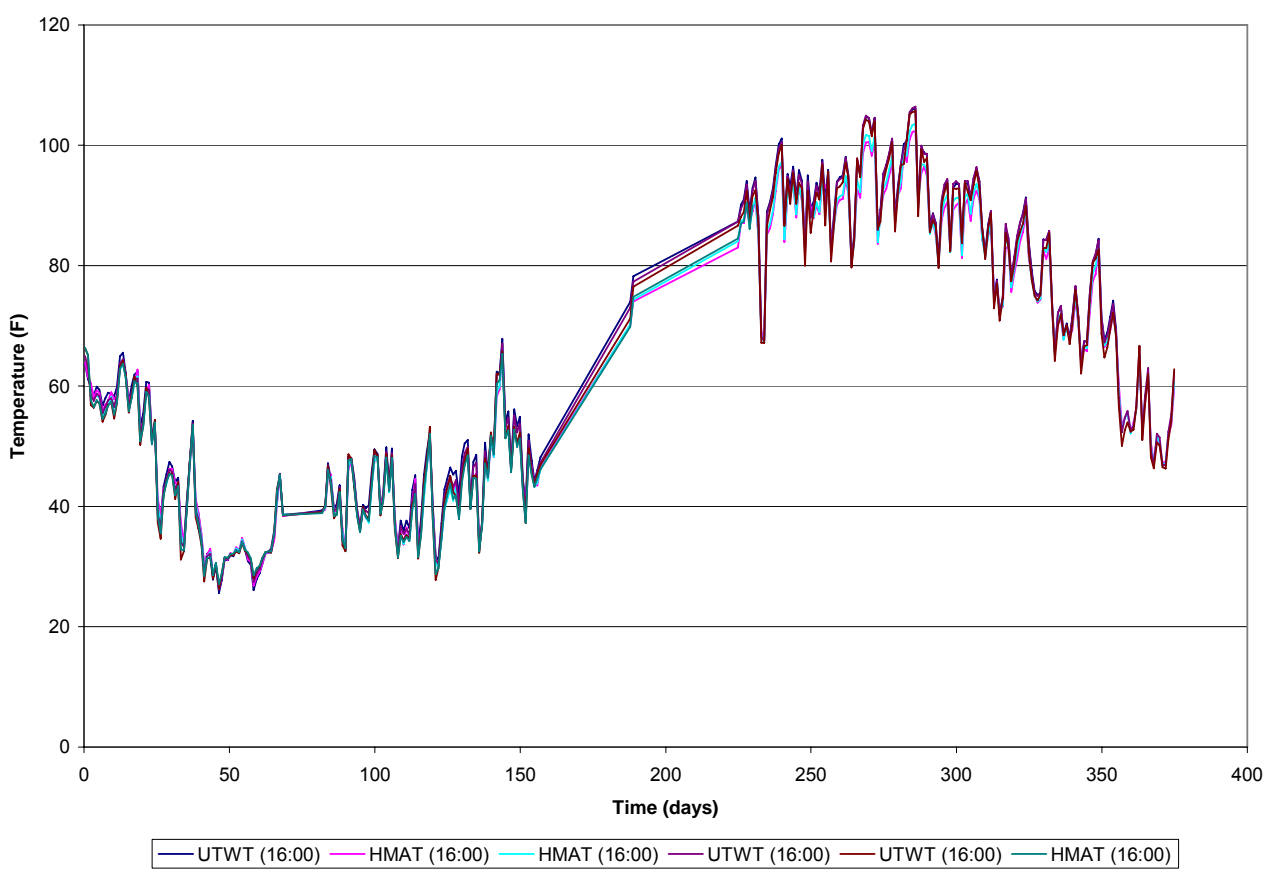

(b)

Figure 5.9 Environmentally-Induced Temperatures - Test Area 4 (a) Low Temperature (4:00 AM) (b) High Temperature (4:00 PM) 


\subsection{Distress Mapping}

Sounding and crack mapping of the lanes constructed in the APT was performed in Test Areas 2 through 4 (as described in Section 4.5) in order to assess the severity of these distresses. Evaluations were performed at different load application intervals in TA2 and TA3 and at the end of the 1 year evaluation period in TA4. The debonded areas and cracks were marked on a diagram of the test lanes. An example of the diagram obtained from Test Area 2, Lane 1 is presented in Figure 5.10. The remaining diagrams are presented in Figures B.67 through B.77 in Appendix B.

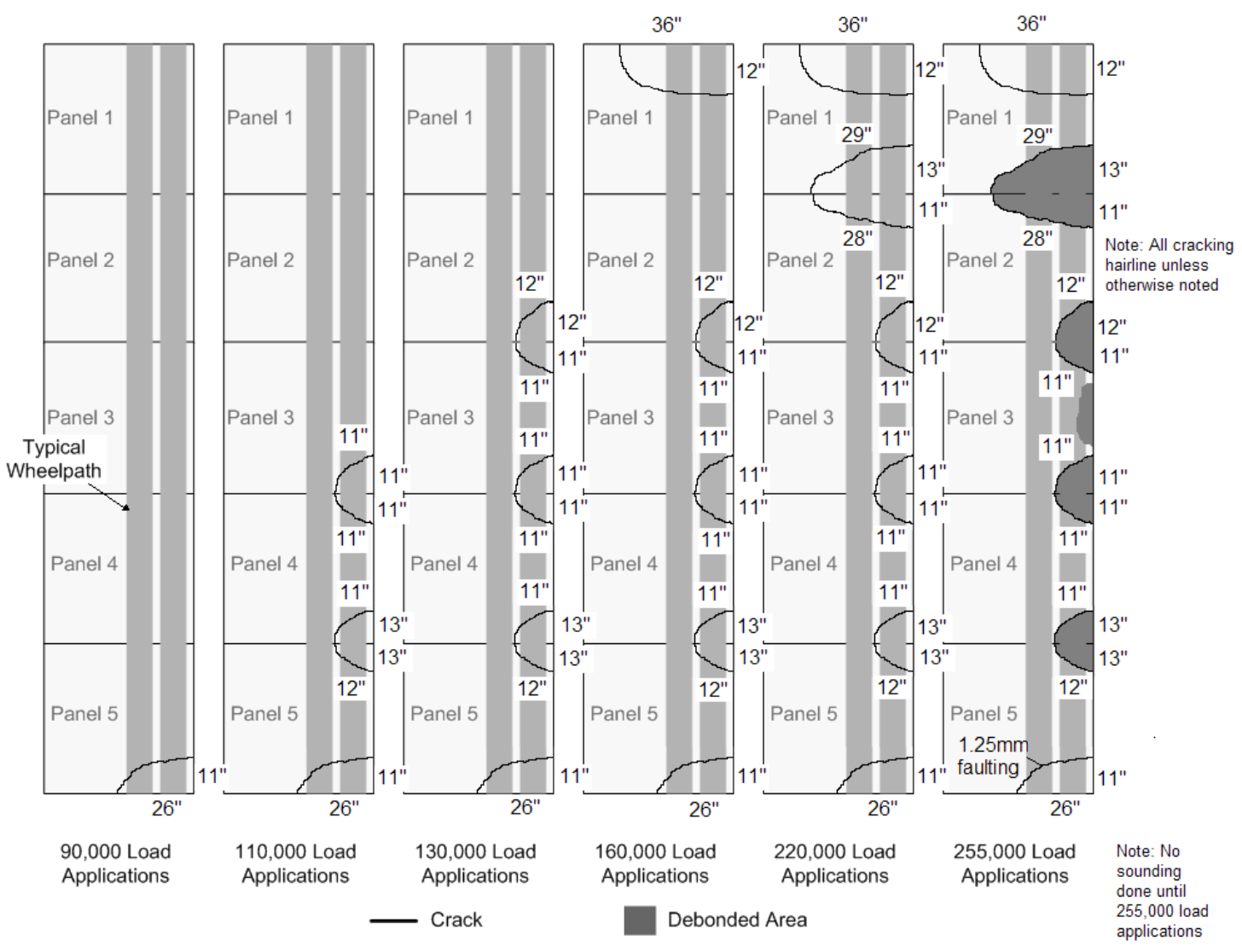

Figure 5.10 Distress Map for Test Area 2 - Lane 1 


\section{5. lowa Shear Test Results}

In order to quantify the strength of the bond between the UTW and HMA layers, the lowa Shear Test was performed. The lowa Shear Test was described in Section 4.8. lowa shear testing was conducted as part of the TA2 and TA3 evaluations and as part of the laboratory study. UTW cylinder specimens were prepared by placing either ready-mixed (TA2 and TA3) or laboratory-prepared (laboratory study) concrete over milled HMA cores obtained from Test Areas 2 through 4. Cored UTW specimens were obtained at the end of the test area evaluations for TA2 and TA3. lowa shear specimen preparation was described in Section 4.8.1. The specimens prepared during the construction of Test Area 2 were cured for 7 or 14 days. These data were averaged and are presented in Figure 5.11. (Note: 14d data for Lane 4 was lost.)

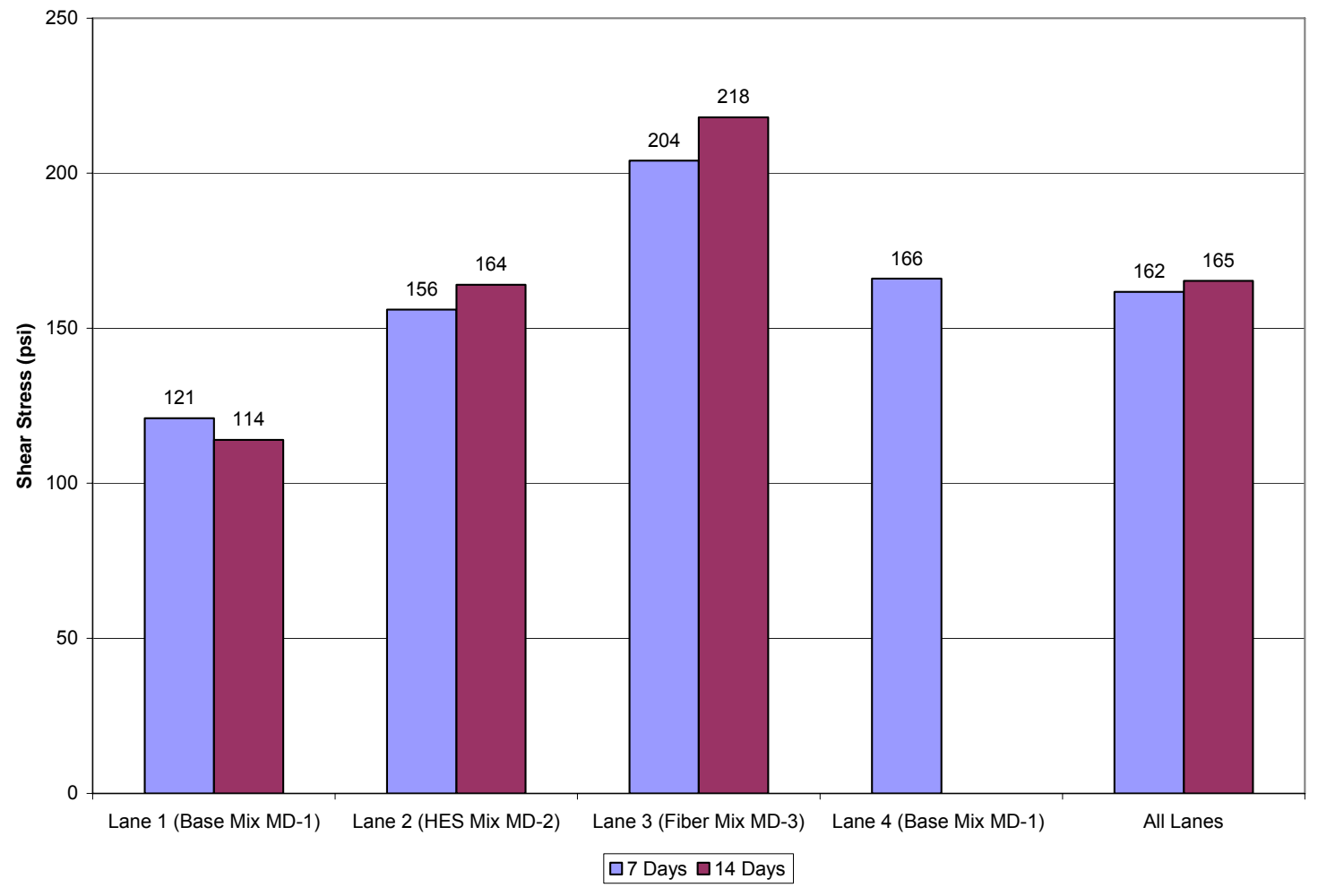

Figure 5.11 lowa Shear Test Results for Test Area 2 Prepared Specimens 
The cores from Test Area 2 were taken after the APT testing was completed. Cores were taken from Lanes 1 through 4 . The lowa shear test results obtained from these cores were averaged and are presented in Figure 5.12.

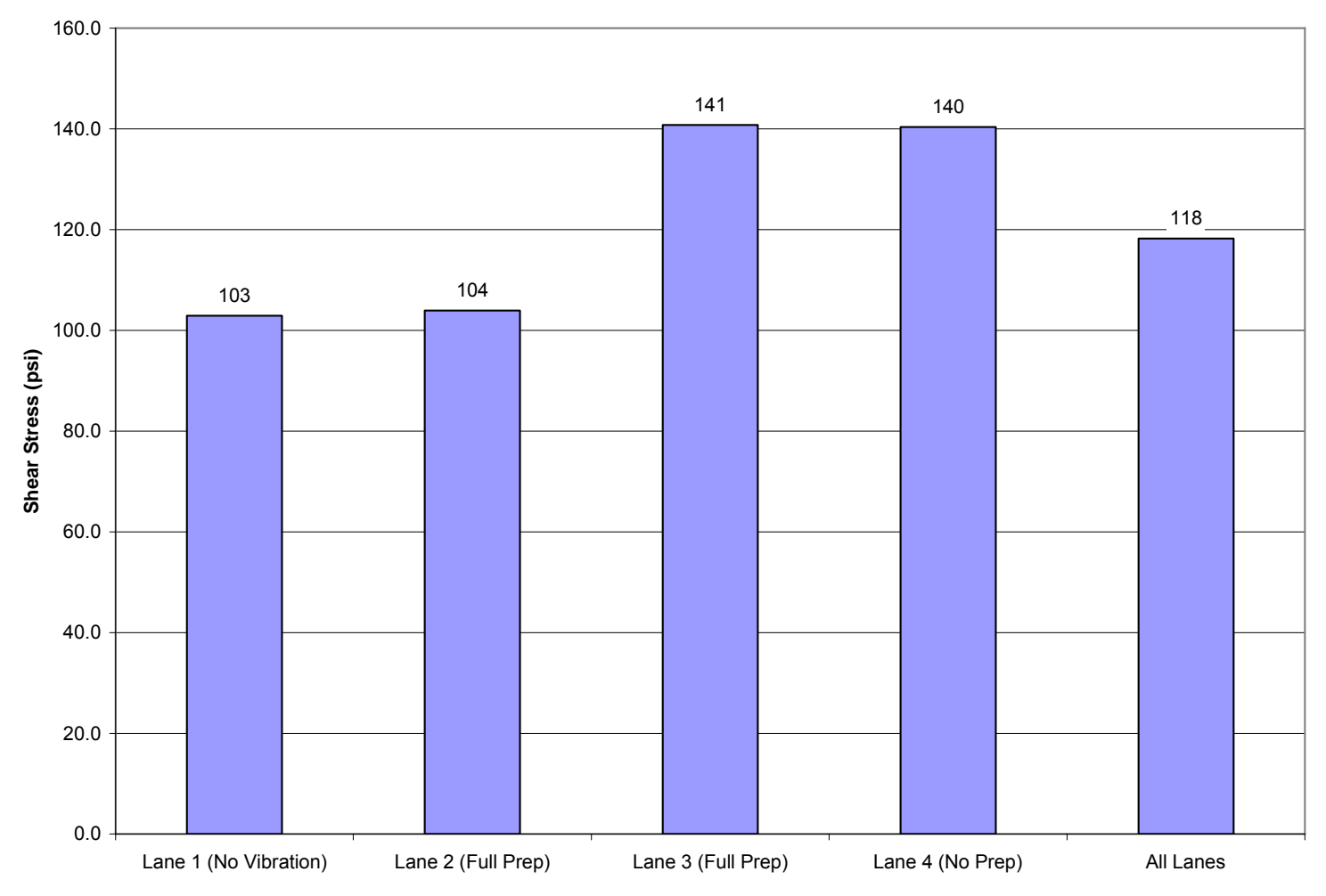

Figure 5.12 lowa Shear Test Results for Test Area 2 Cored Specimens

In order to evaluate if the age of the concrete had an effect on the UTW-HMA bond, the specimens prepared during the construction of Test Area 3 were cured for 28 or 90 days. The lowa shear strength data for these specimens were averaged and are presented in Figure 5.13. 


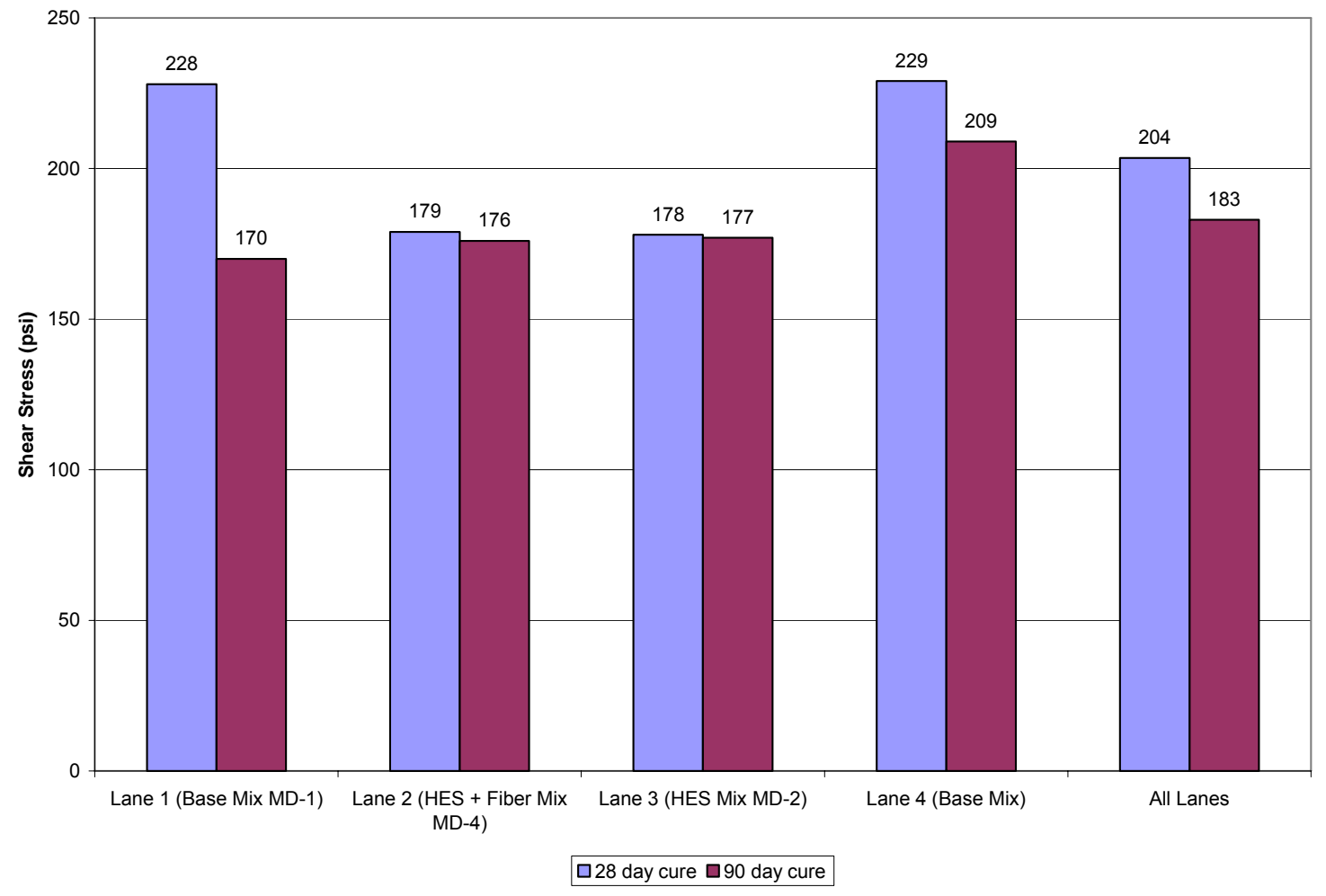

Figure 5.13 lowa Shear Test Results for Test Area 3 Prepared Specimens

The cores from Test Area 3 were taken after the APT testing was completed. Cores were taken from Lanes 1 through 4 . Some cores were taken from the wheel path and others were taken from outside the wheel path to see if there was a difference in the bond strength of the loaded and non-loaded specimens. The bond strength data were averaged and are presented in Figure 5.14. 


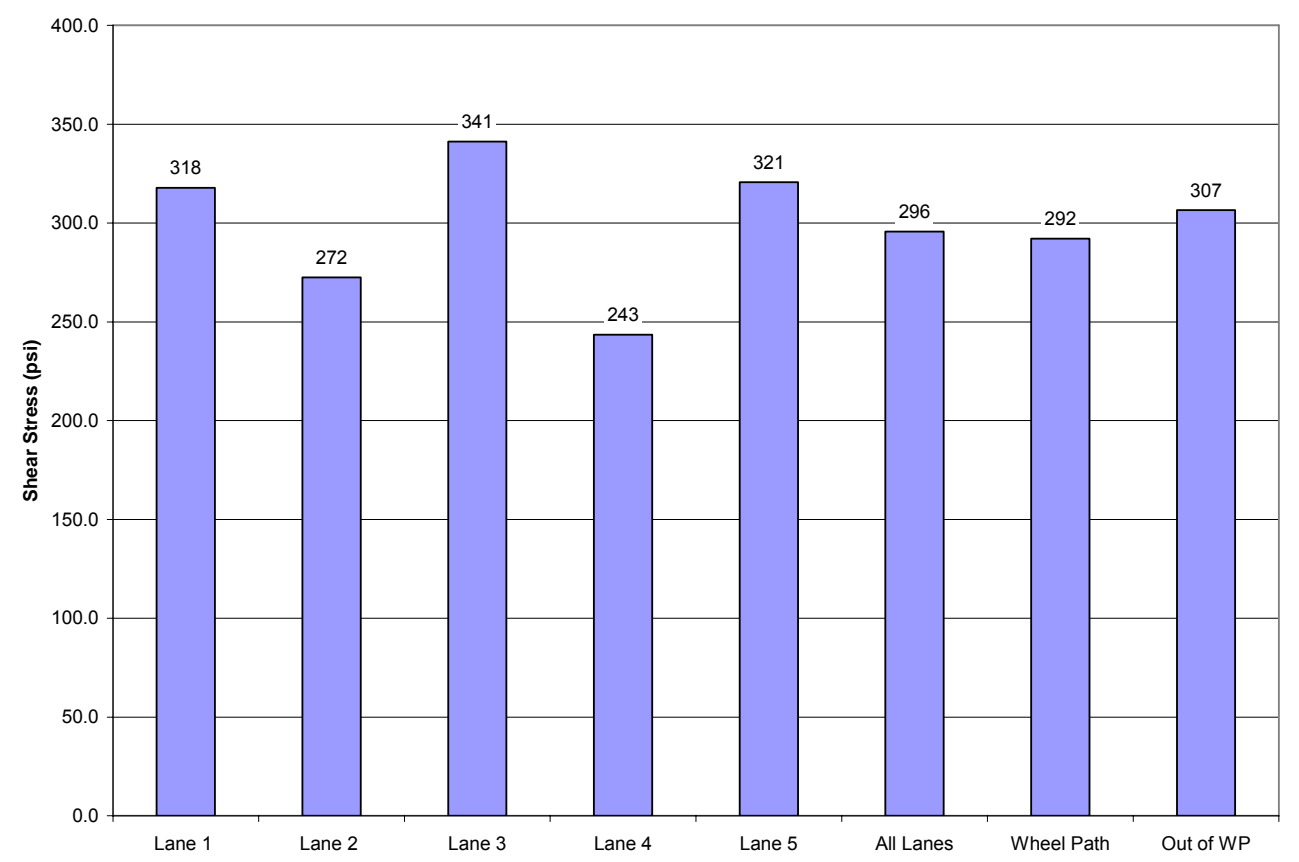

Figure 5.14 lowa Shear Test Results for Test Area 3 Cored Specimens

UTW cylinder specimens were prepared as part of the laboratory study. A control set was cured in a moist room. Another set was cycled through freezethaw cycles. The specimens remained in their respective environments for 7,14 , 28 , or 90 days. After curing, the specimens were removed and the bond strength was determined using the lowa Shear test. These data are presented in Figure 5.15 . 


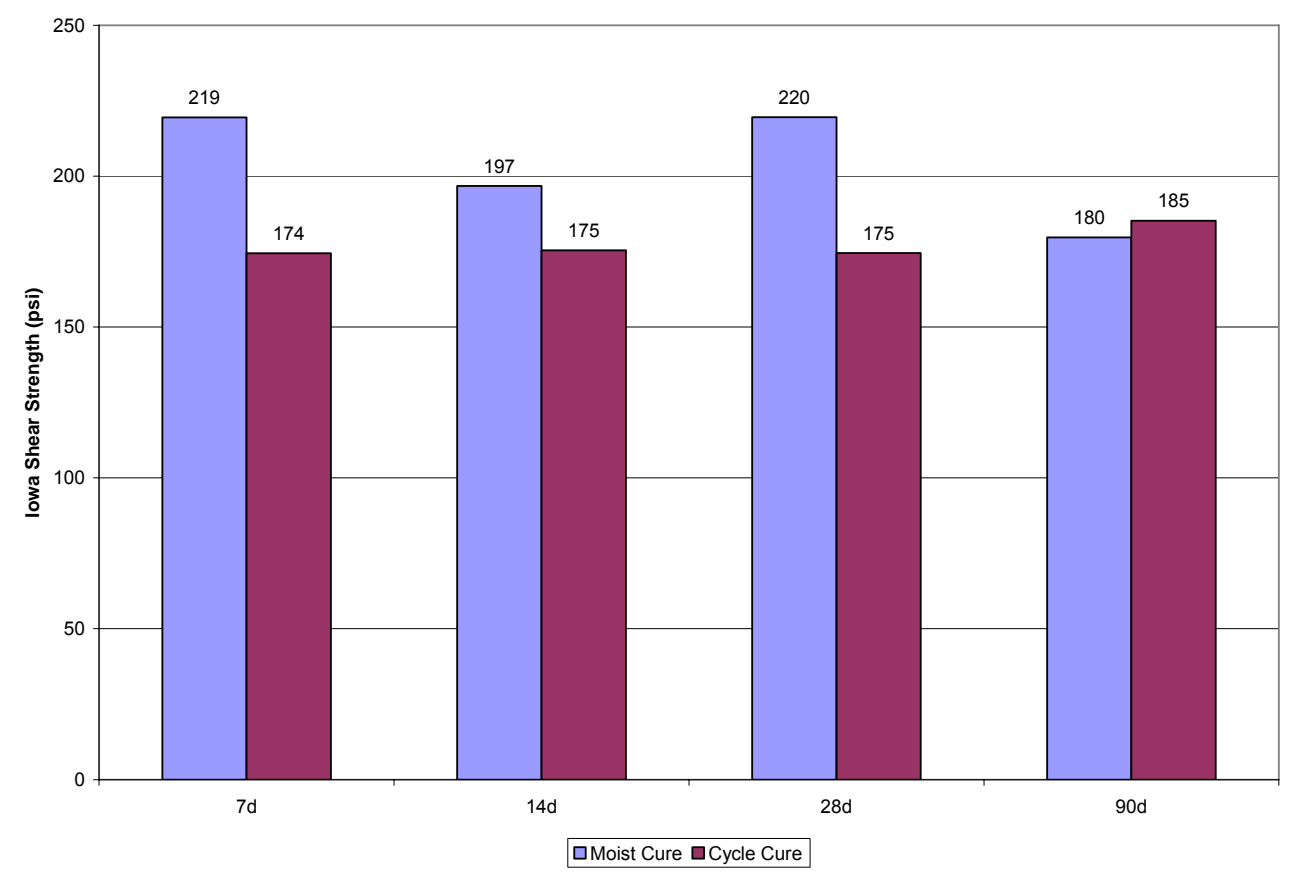

Figure 5.15 lowa Shear Test Results for Laboratory Specimens

\subsection{Flexural Bond Test Results}

The laboratory study was conducted in order to evaluate the effect of temperature changes on the bond between the UTW and HMA under controlled conditions. A flexural bond test was conducted on the UTW beams whose production and curing was described in Section 4.6.2. A control set was cured in a moist room. Another set was cycled through freeze-thaw cycles. The specimens remained in their respective environments for $7,14,28$, or 90 days. After curing, the specimens were removed and subjected to third-point, flexural fatigue loading ranging from $100 \mathrm{lbs}$ to $885 \mathrm{lbs}(0.44 \mathrm{kN}$ to $3.93 \mathrm{kN})$. This loading was applied at a rate of $7 \mathrm{~Hz}$ for a total of 100,000 load repetitions. After the fatigue loading was complete, the UTW beam specimens were loaded in thirdpoint flexure to failure. Results of these tests are presented in Figure 5.16. 


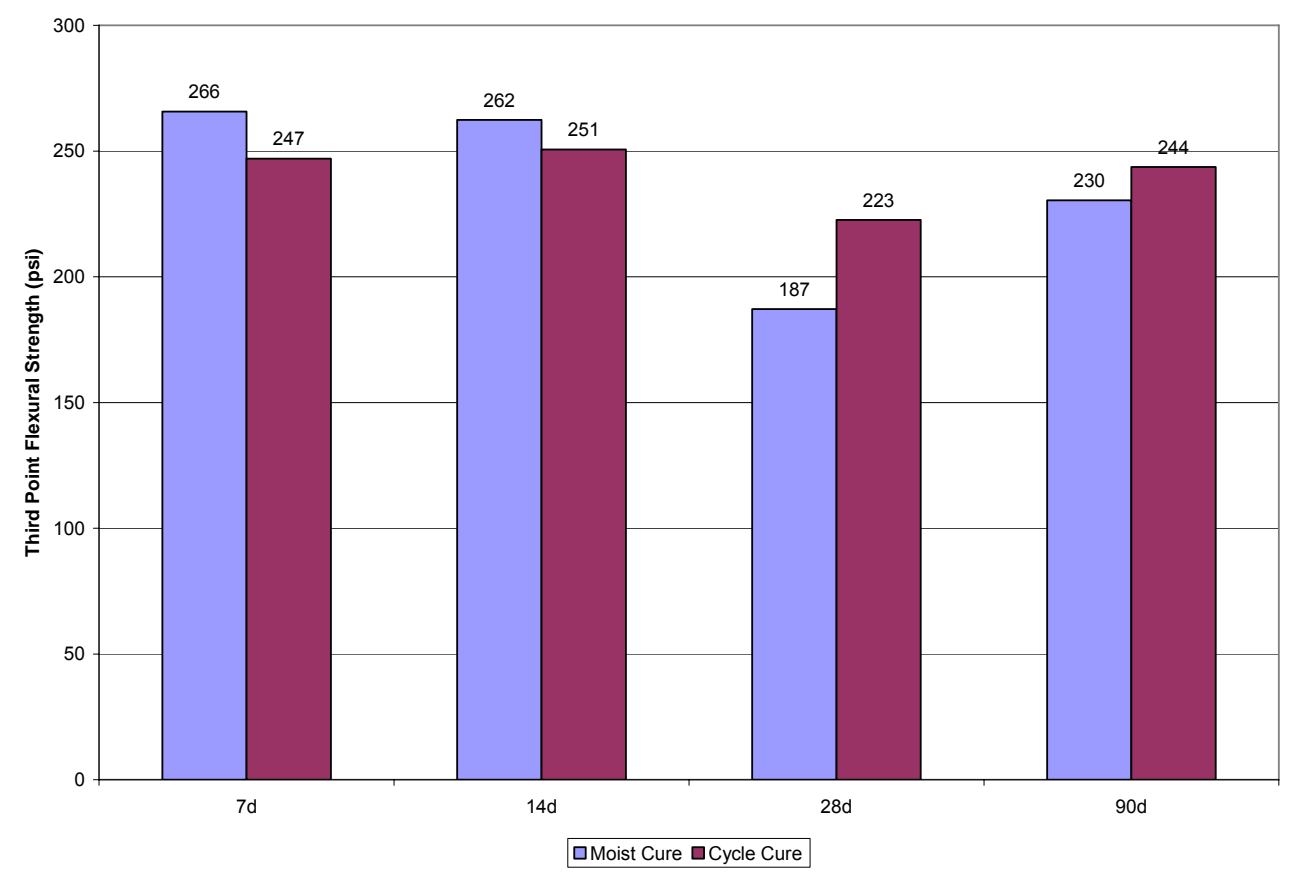

Figure 5.16 Flexural Bond Test Results for UTW Beam Specimens

\subsection{Pavement Deflection Analysis}

To assess the stiffness of the pavement sections constructed in Test Areas 2-4 Pavement deflection measurements were conducted using an FWD. These data are presented in Figure 5.17 for Test Areas 2 through 4. For Test Areas 2 and 3 , FWD data were collected prior to milling of the HMA (Pre-Mill) and after the completion of the curing period of the UTW concrete (Pre-Load). Additionally, FWD testing was conducted after completion of the loading in each lane (PostLoad). 


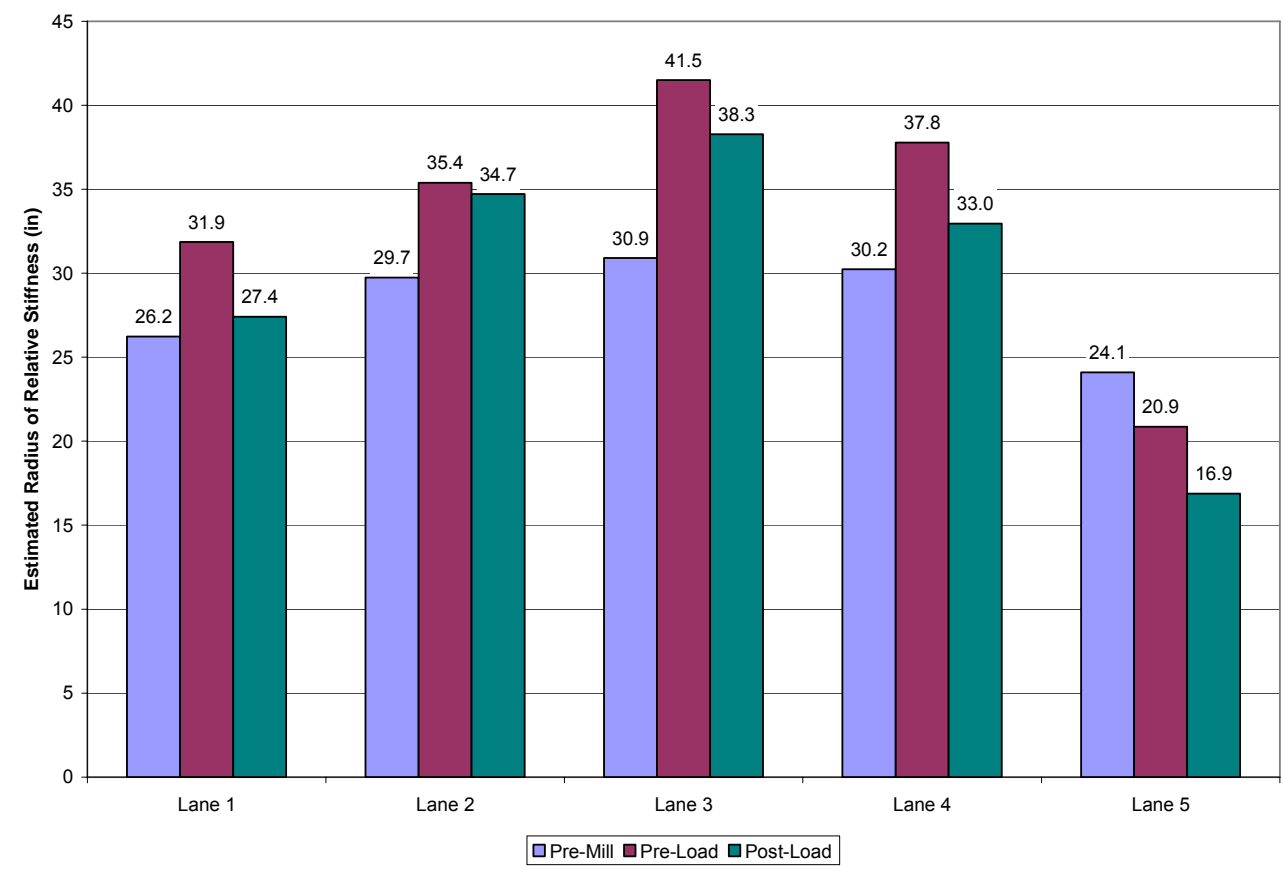

(a)

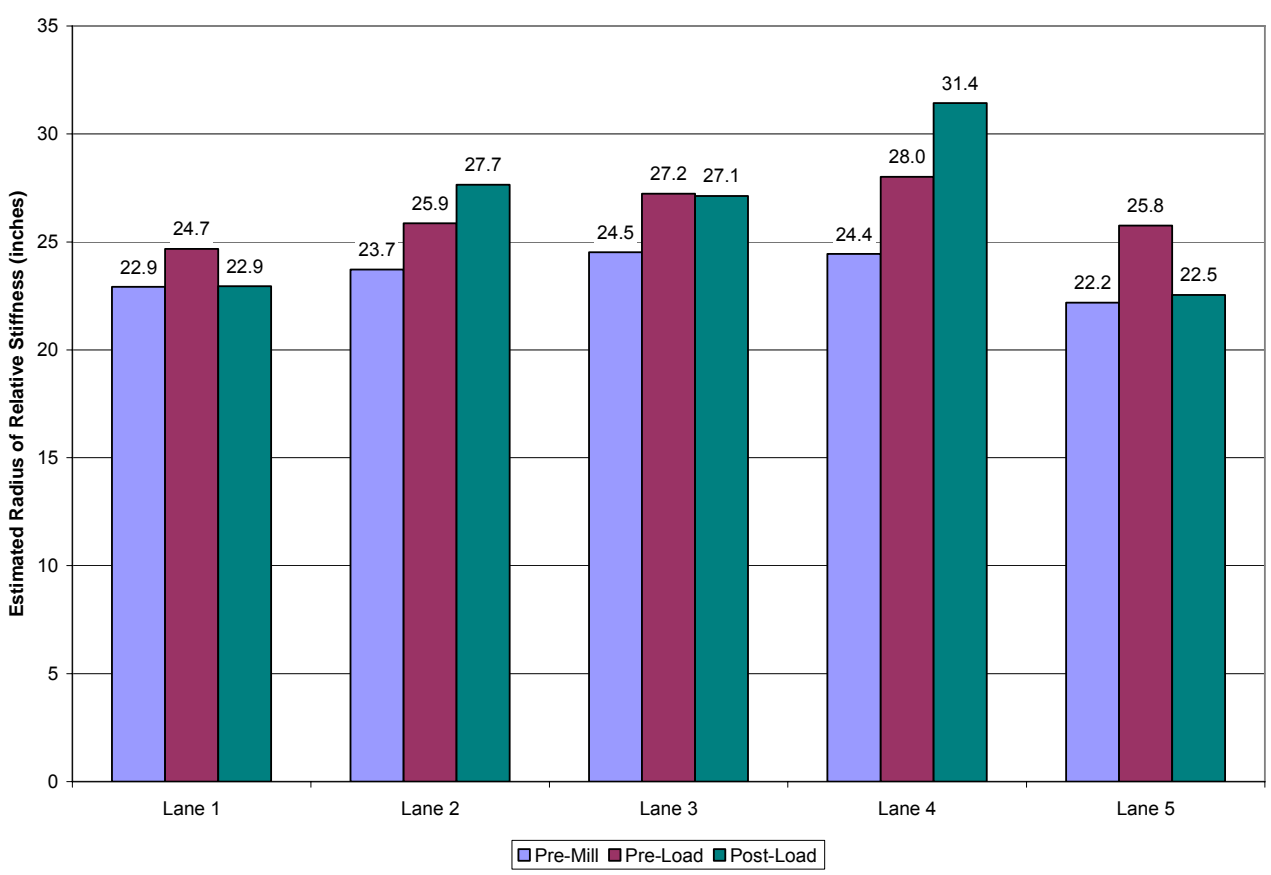

(b)

Figure 5.17 Estimated Radii of Relative Stiffness (a) TA2 (b) TA3 (c) TA4 (continued) 


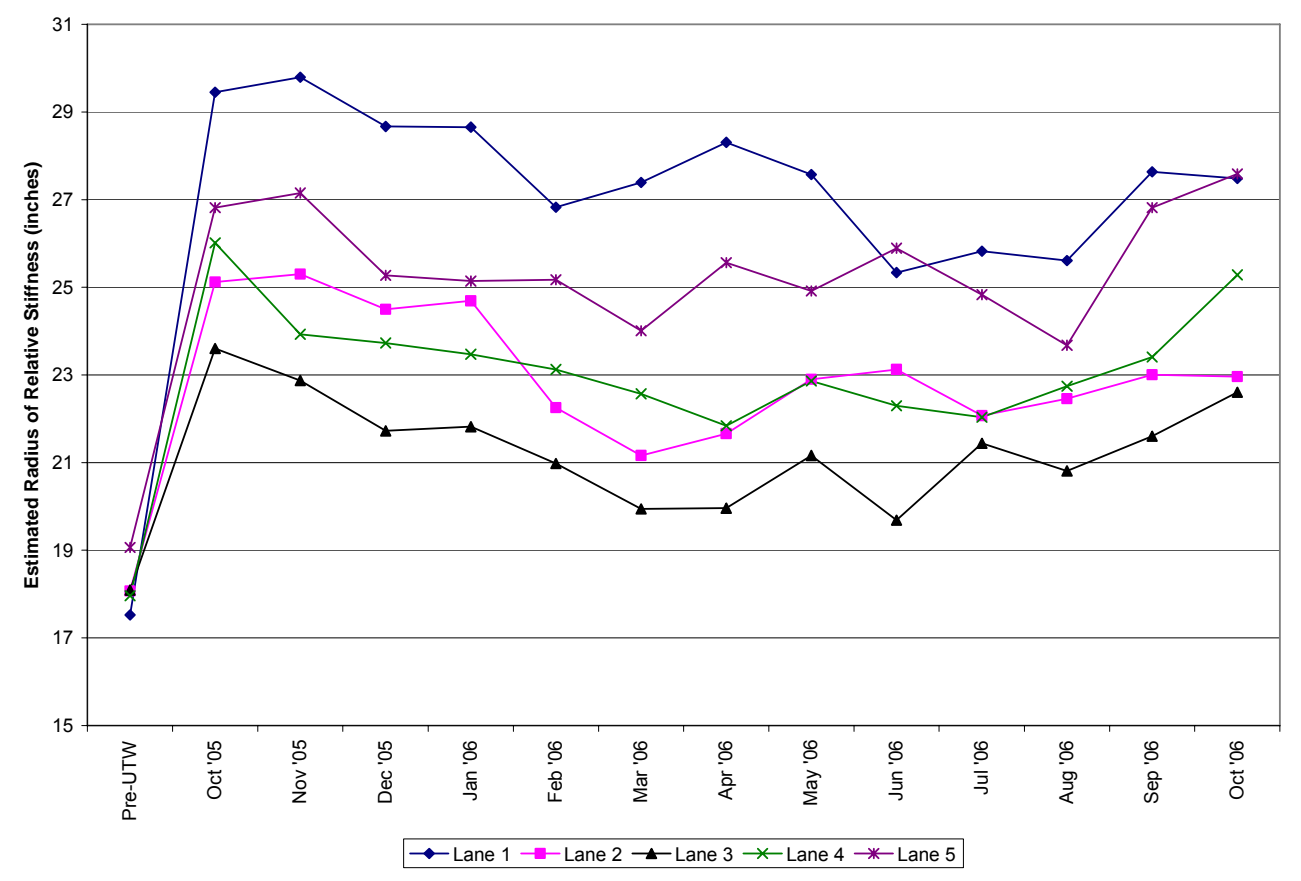

(c)

Figure 5.17 Estimated Radii of Relative Stiffness (a) TA2 (b) TA3 (c) TA4

For TA4, FWD testing was conducted on a monthly basis in each lane (denoted by month). The data from each test period were averaged for each lane and the estimated radius of relative stiffness for a composite pavement was calculated according to AASHTO Guide Supplement [1998].

\subsection{Ultrasonic Pulse Velocity and Impact Echo Testing}

The laboratory study was conducted in order to evaluate the effect of temperature changes on the bond between the UTW and HMA under controlled conditions. Two types of specimens were prepared: flexural bond beams and lowa shear test cylinders. Both types were composed of PCC placed over HMA. A control set was cured in a moist room. Another set was cycled through freezethaw cycles. The specimens remained in their respective environments for 7,14 , 
28 , or 90 days. Production and of these specimens is described in Sections 4.7.1 and 4.8.1 for the flexural bond and lowa shear test specimens, respectively.

Periodic readings using the ultrasonic pulse velocity technique were taken during the cure periods. A description of the methodology is presented in Section 4.9. A summary of these readings is presented in Figure 5.18.

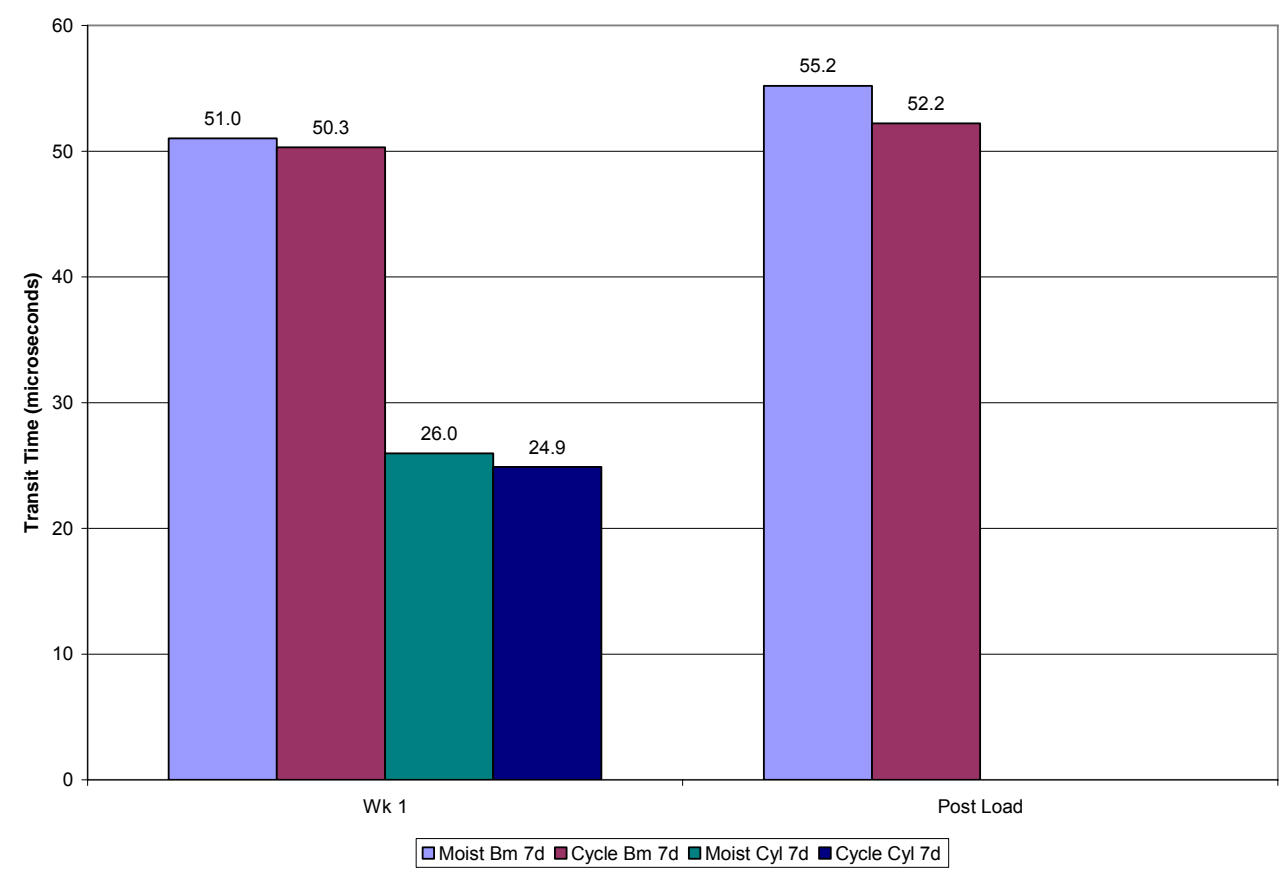

(a)

Figure 5.18 Ultrasonic Pulse Velocity Data for Laboratory Specimens (a) 7d Specimens (b) 14d Specimens (c) 28d Specimens (d) 90d Specimens (continued) 


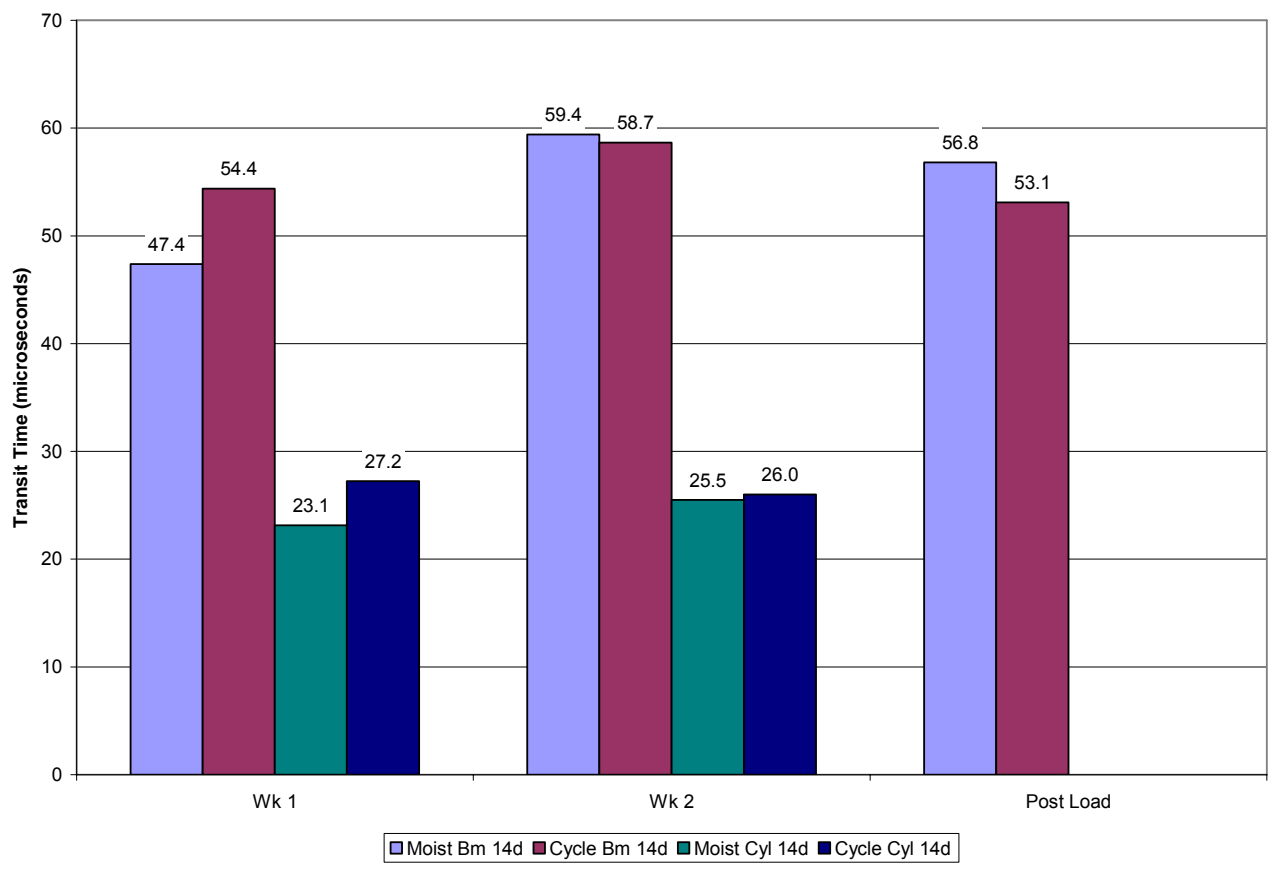

(b)

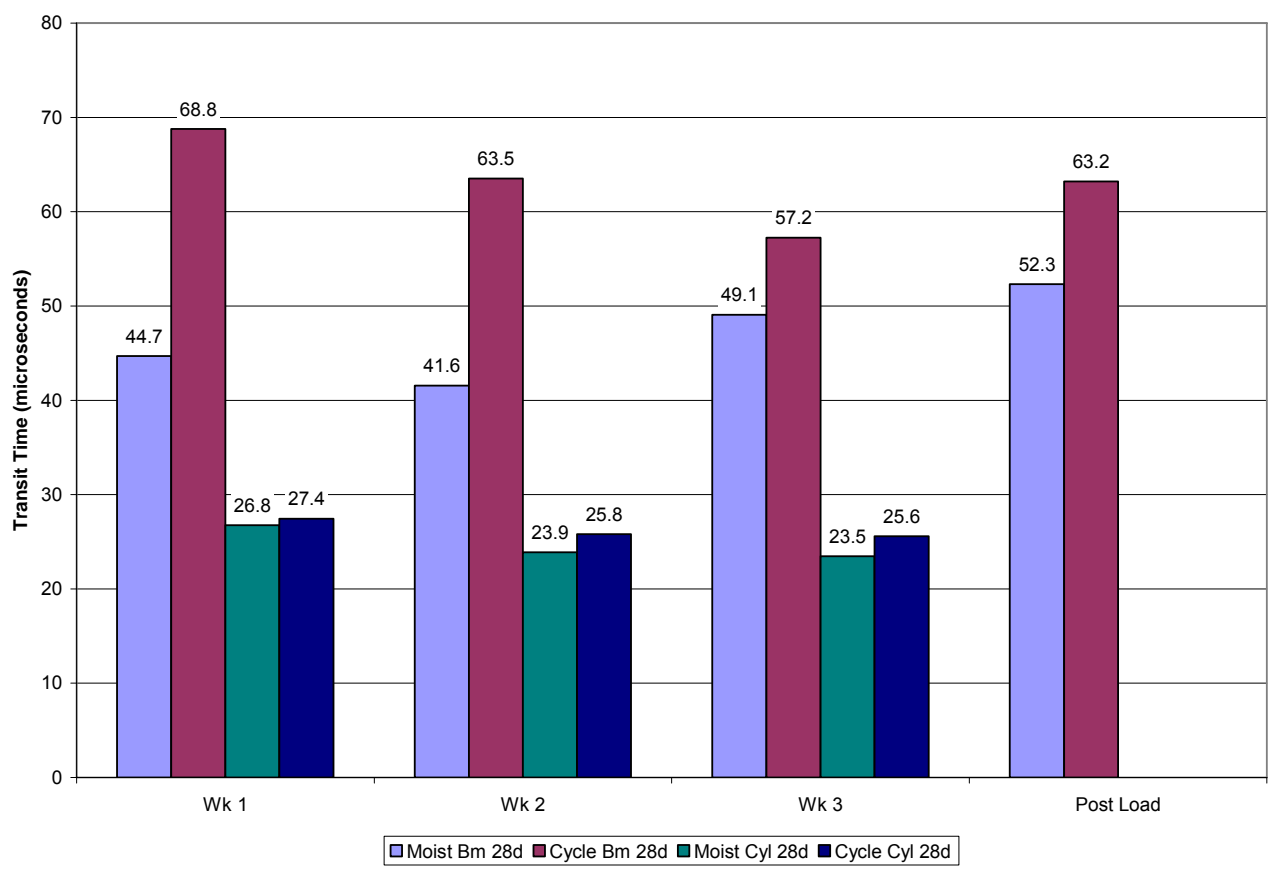

(c)

Figure 5.18 Ultrasonic Pulse Velocity Data for Laboratory Specimens (a) 7d Specimens (b) 14d Specimens (c) 28d Specimens (d) 90d Specimens (continued) 


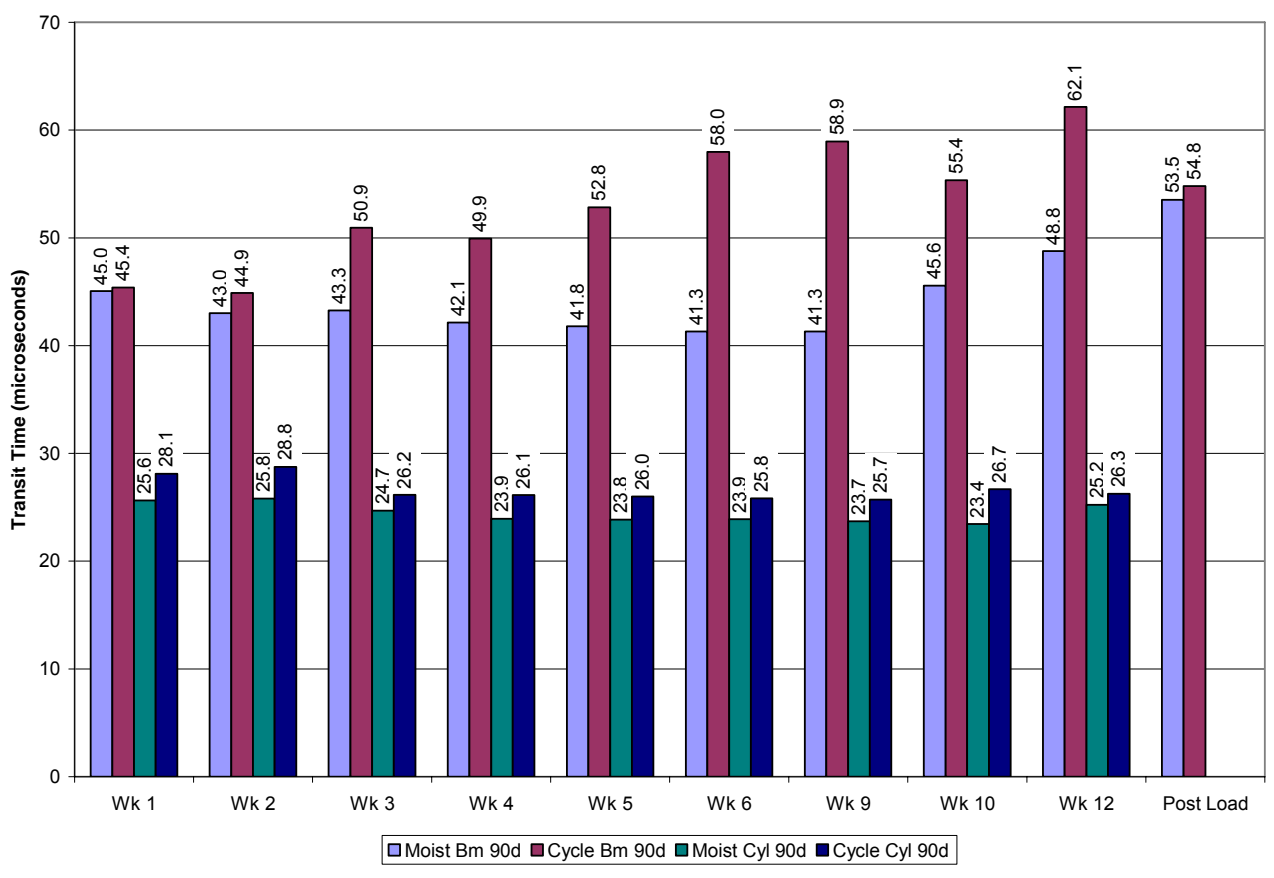

(d)

Figure 5.18 Ultrasonic Pulse Velocity Data for Laboratory Specimens (a) 7d Specimens (b) 14d Specimens (c) 28d Specimens (d) 90d Specimens 


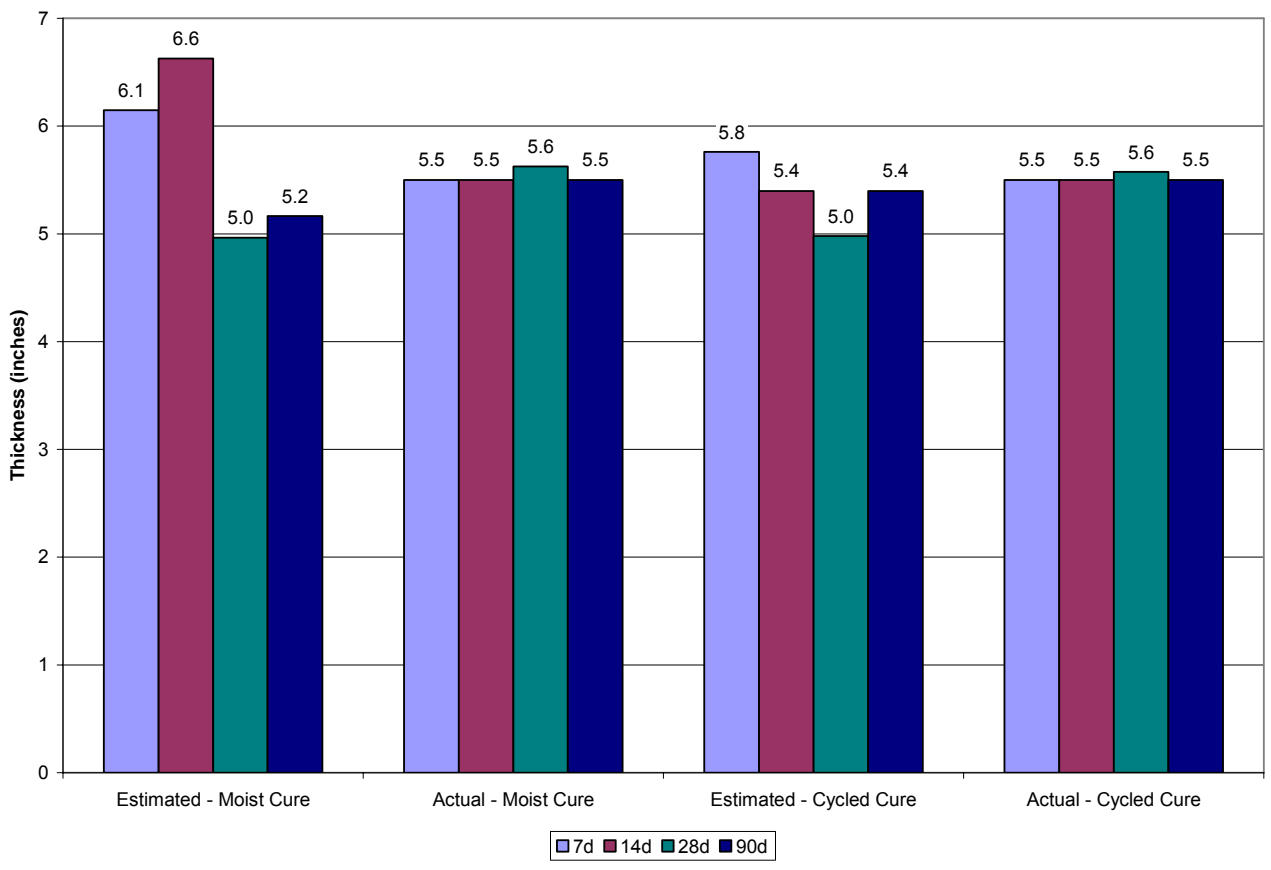

(a)

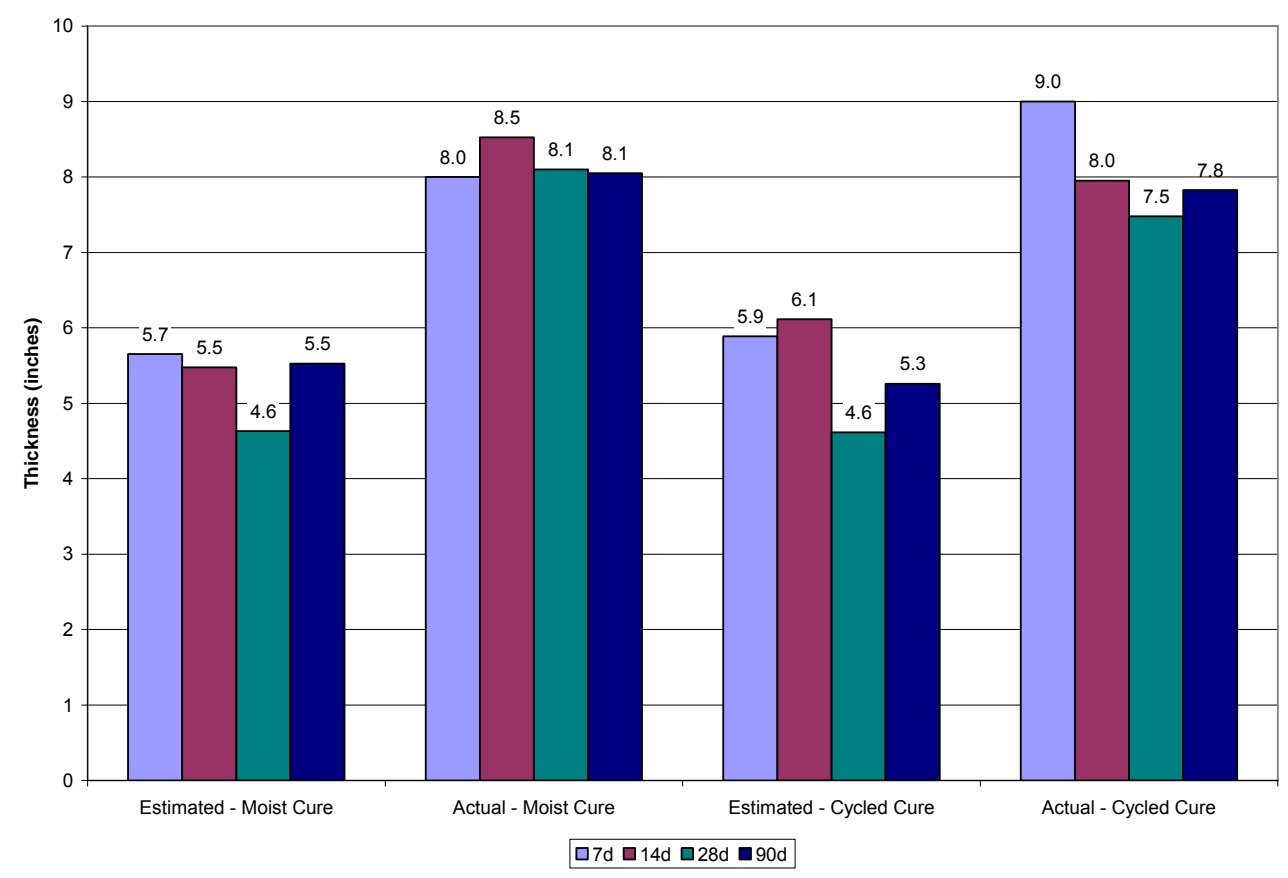

(b)

Figure 5.19 Impact Echo Estimated and Actual Specimen Thicknesses for Laboratory Specimens (a) Beams (b) Cylinders 
At the end of the curing, Impact Echo testing (described in Section 4.10) was performed for both the lowa shear cylinder specimens and the flexural bond beam specimens. The device used for the impact echo test was designed to determine concrete thickness and thus estimated the thickness of the specimen. Figure 5.19 contains the impact echo data (Estimated) as well as the actual measured thickness (Actual) of the specimens for each curing period. 


\section{CHAPTER 6. ANALYSIS AND DISCUSSION OF UTW RESPONSES}

In this chapter, analyses and comparisons of the data from the four test areas and Laboratory Study are discussed. As presented in Chapter 3, there were six main responses recorded among the four test areas and Laboratory Study: curing strains, drying shrinkage strains, strain distribution and maximum loadinduced strains, type and severity of distresses, bond strength, and radius of relative stiffness. The six main sections of this chapter correspond to these parameters. The influences of up to five parameters on these responses were evaluated. These parameters were: structural properties of the pavement section, concrete mixture (composition or mechanical properties), interfacial bond conditions, mechanical load applications, and temperature gradient (environmental loading). The subsections in this chapter correspond to the influence of these parameters on the subject response.

\subsection{Curing Strains}

This section discusses the influence of concrete mixture composition and interfacial bond conditions on the curing strains (either early-age shrinkage or expansion). Test areas TA2 and TA3 are used for this discussion. TA1 and TA4 are not included in the discussion since the same mix design and interfacial bond conditions were utilized for all test lanes in these two test areas. The strains included in this discussion were recorded from gages UEB, UET, UCBmax, and UCTmax (strain gage installation was discussed in Section 4.3.4). The strain data were recorded every hour during the cure period for the concrete placed in the test areas. These data were presented in Section 5.2.1. Figures B.2 through B. 6 include the curing strain data from TA2, Lanes 1 to 5 . The curing 
strain data from TA3, Lanes 1 through 5 are included in Figures B.7 through B.11. In regards to the strain readings, if early-age shrinkage occurred, the strains would be compressive (in this study negative) and expansive strains would be tensile (in this study positive).

\subsubsection{Influence of Concrete Mixture Composition on Curing Strains}

\section{Background}

Prior to setting, concrete in thin slabs (less than 12 inches $(300 \mathrm{~mm})$ ) is susceptible to plastic shrinkage cracking, Aïtcin et al. [1997]. Plastic shrinkage is caused by water loss from concrete while it is in a plastic state. However, it was also noted by Aïtcin et al. that proper curing of the slabs will prevent plastic shrinkage. In fact, sufficient water supply during curing will actually result in expansion of concrete. While not measurable using standard strain gage technology, the presence of plastic shrinkage cracking would be indicative of this phenomenon.

Aïtcin et al. [1997] also noted that concrete made with high cement content can exhibit large shrinkage strains as a result of a low bleed rate, a high heat of hydration, and rapid hydration. The total cementitious content (cement + fly ash) in all the mix designs used was very high $\left(754 \mathrm{lb} / \mathrm{cyd}\left(440 \mathrm{~kg} / \mathrm{m}^{3}\right)\right)$. Additionally, MD-2 and MD-4 contained Type III cement in order to produce rapid strength gain. As such, all mixes were susceptible to plastic shrinkage not only because of their use in thin slabs, but also due to their compositions.

Taylor et al. [2006], noted that fibers are typically added to UTW concrete mixtures to, among other things, increase plastic shrinkage cracking resistance. Concrete made using mix designs MD-3 and MD-4 contained fibers. As such, if plastic shrinkage were to occur it was expected that the lanes with these two mixes would perform better in terms of plastic shrinkage cracking. 
This section first discusses the general trends that were observed in the curing data, next the influence of the mix design (mainly the use of a high early strength mix (containing Type III cement) or fibers) on the curing strains is discussed.

\section{General Trends in the Curing Strain Data}

As can be seen in Figures B.2 though B.6, The UTW curing strain data at both the top (UET and UCTmax) and bottom of the layers (UEB and UCBmax) for all lanes in TA2 followed the same general trend of a sharp increase in strain that tapered off to a certain level (at around 10 hours) for the remainder of the curing period. Some decreases in the strain values occurred around 20 hours due to uncovering the concrete for saw-cutting. The strains were positive (tensile) in all cases, which indicated an expansion of the concrete during the cure period.

Most UTW curing strain data collected from the test lanes in TA3 (from gages UET, UCTmax, UEB and UCBmax in Figures B.7 through B.11) exhibited trends that were very similar to those from TA2. However, it was noted in TA3 Lanes 2 and 4 that there was an initial decrease in the UTW curing strains to a level of approximately - 75 microstrain at the corner location. This decrease in the strain was likely due to early-age shrinkage. However no shrinkage cracking was noted in Lane 2. It is likely that other lanes (in TA2 as well as TA3) also had some initial shrinkage prior to the start of curing. However, the data acquisition was likely not begun early enough to record this phenomenon. Further, there was no shrinkage cracking noted in the other test lanes, either. This indicates that even though there may have been some initial shrinkage, the curing was applied at an early enough time to prevent any damage due to shrinkage.

Additionally, there were no decreases in the curing strains due to removal of the curing for saw-cutting (as was noted for the lanes in TA2) since early entry saws were used in all test lanes in TA3. Also there is a noticeable difference in the UTW curing strain readings between the two test areas. The UTW curing strain 
readings for TA3 are significantly less than in TA2. This was due to a change in the saw-cutting time. As noted previously, the UTW lanes in TA2 were cut at approximately 20 hours after concrete placement using a standard concrete saw. The lanes in TA3, however, were cut using an early entry saw at approximately 3 hours after placement. This result indicates that the use of early entry sawing with UTW pavements can significantly reduce the strain development in the pavement.

\section{Influence of Mix Designs}

In both TA2 and TA3 only Lanes 1 through 3 varied the mix design used in the construction of the test lanes (Sections 4.2.2 and 4.2.3). Thus, only these lanes are discussed in this section. In TA2, Lane 1 was constructed using MD-1 (base mix) while Lanes 2 and 3 were built using MD-2 (high early strength), and MD-3 (fiber mix), respectively. For the test lanes in TA3, Lane 1 again was constructed using MD-1 (base mix), while Lanes 2 and 3 was built using MD-4 (high early strength and fiber mix) and MD-2 (high early strength), respectively. These mix designs were presented in Section 4.3.5.

As noted previously, the curing strains all followed the same general trend of an initial increase which quickly leveled off. The values at which the curing strains leveled off were obtained from Lanes 1 to 3 in TA2 and TA3 and are presented in Table 6.1. 
Table 6.1 Terminal Curing Strains for UTW Concrete Mix Designs

\begin{tabular}{|c|c|c|c|}
\hline Mix Design & Gage & $\begin{array}{c}\text { Strain TA2 } \\
\text { (microstrain) }\end{array}$ & $\begin{array}{c}\text { Strain TA3 } \\
\text { (microstrain) }\end{array}$ \\
\hline \multicolumn{4}{|c|}{ Lane 1} \\
\hline \multirow[t]{4}{*}{ MD-1 } & UET & 350 & 400 \\
\hline & UEB & 500 & 350 \\
\hline & UCT & 600 & 500 \\
\hline & UCB & 500 & 400 \\
\hline \multicolumn{4}{|c|}{ Lane 2} \\
\hline \multirow[t]{4}{*}{ MD-2 (TA2) or MD-4 (TA3) } & UET & 300 & 100 \\
\hline & UEB & 225 & -25 \\
\hline & UCT & 650 & 125 \\
\hline & UCB & 450 & 125 \\
\hline \multicolumn{4}{|c|}{ Lane 3} \\
\hline \multirow[t]{4}{*}{ MD-3 (TA2) or MD-2 (TA3) } & UET & 200 & 50 \\
\hline & UEB & 200 & 75 \\
\hline & UCT & 250 & 150 \\
\hline & UCB & 250 & 250 \\
\hline
\end{tabular}

Note: Strain values are approximated for comparison purposes.

The data in Table 6.1 indicate that for TA2, the curing strains (from gages HEB, HET, HCBmax, and HETmax) recorded for Lane 1 (constructed with MD-1) were generally the greatest, followed by Lane 2 (constructed with MD-2) and then Lane 3 (constructed with MD-3). MD-2 contained Type III cement which was likely to cause more shrinkage. This was reflected in the reduced expansion (lower strain readings) relative to that exhibited by the concrete made using MD1. However, since adequate curing was provided, the shrinkage of the MD-2 concrete never caused any damage. The lower strain results observed for MD-3 (which contained fibers) indicate that the fibers may have caused restraint to the expansive curing stresses. As noted above, fibers are often added to UTW 
concrete to reduce shrinkage strains. However it may be that the reverse mechanism occurred also for expansive stresses.

For TA3, the lanes constructed with MD-1 again exhibited the highest curing strains (from gages UEB, UET, UCBmax, and UETmax), followed by the lanes constructed with MD-2 and MD-4 concrete. The explanation for the reduced curing strains in the concrete made from MD-2 is the same as for TA2. Additionally, the restraint offered by the fibers again was observed for the MD-4 concrete. However, it is worth noting that the combined effect of the Type III cement and the fibers. The combination of these two components produced the lowest curing strain values observed during curing. This was most likely caused by a greater degree of shrinkage resulting from the Type III cement and the restrained expansion that resulted from the use of fibers. However, it is likely that if excessive shrinkage were to result from the addition of Type III cement, the fibers would also act to restrain the shrinkage.

\section{Summary}

General observations of the curing strain data indicated that expansive strains were observed in all test lanes. These were the result of the moisture supplied to the concrete during curing. Some initial early-age shrinkage was noted in a few test lanes, however no shrinkage cracking was noted. These results indicated that even though early-age shrinkage may have initially occurred, the curing was applied in an adequate time frame to prevent cracking. There was a difference noted in the curing strains that developed in the lanes that were saw-cut using standard saw-cutting practices versus early entry sawing.

The resulting trend for mix designs indicated that the mixes containing Type III cement did exhibit higher shrinkage, but this was mitigated by proper curing. Additionally the mixes that contained fibers may also reduce the expansive strains during curing. 


\subsubsection{Influence of Interfacial Bond Conditions on Curing Strains}

\section{Background}

Volume changes in concrete pavement slabs (such as those that occur during curing) will be restrained by underlying layers (Huang [1993]). This restraint causes a build up of tensile stresses in the pavement. If the restraint is sufficient enough cracking can occur in the pavement. Whether cracking occurs or not is dependent upon (amongst other factors such as the concrete tensile strength) the degree of restraint provided by the underlying layer. In the case of UTW overlays, this restraint is provided by the bond between the UTW and underlying HMA. Thus, interfacial bond conditions (fully bonded, partially bonded or unbonded) may have an influence on the degree of curing strain restraint.

\section{General Trends in the Curing Data}

As previously discussed, the curing method employed in both TA2 and TA3 supplied a sufficient amount of moisture to produce expansive strains in the concrete. The data from Table 6.1 also indicate that generally, the curing strains at the top of the UTW layer (UET and UCTmax) were higher than at the bottom (UEB and UCBmax). This followed what was expected as more water would be taken in at the surface thus producing larger expansive strains. Additionally, the bottom of the UTW was restrained by the underlying HMA. In all cases the corner curing strains were higher than those at the edge. This may be the result of the strain differential (exhibited by the difference in the top and bottom curing strains) produced a warping effect in the slabs which lead to the development of larger strains at the corners. These observations were present regardless of which test area in which the curing strains were measured.

\section{Influence of Various Interfacial Bond Conditions}

The previous result was for test lanes that were initially prepared to be fully bonded. However, in both TA2 and TA3 only Lanes 1, 4 and 5 varied the interfacial bond conditions used in the construction of the test lanes (Sections 
4.2.2 and 4.2.3). Thus, only these lanes are discussed in this section. In TA2, Lane 1 was intended to be constructed using fully bonded conditions. However, during construction, no vibration was performed and as a result the bond in this test lane was not well developed (illustrated by the excessive debonding in Figure 5.10). As such, in further discussions TA2 Lane 1 the bond condition will be considered partially bonded. The interfacial bond conditions in Lanes 4 and 5 in TA2 were partially bonded and unbonded, respectively.

As noted above, restraint of the slab movement at the bottom of the layer produced a strain gradient across the UTW. It was expected that the lanes with the fully bonded conditions (TA3 Lanes 1 and 4) would provide the greatest degrees of restraint and thus develop the largest gradients. The partially bonded lanes (TA2 Lanes 1 and 4 ) were expected to provide less restraint and therefore develop smaller gradients than the fully bonded lanes. The unbonded lanes (Lanes 5 in TA2 and TA3) were expected to provide little to no restraint to the UTW movement, and thus little or no gradients were expected to develop.

The data in Figures B.2, B.5, B.6, B.7, B.10, and B.11 follows the same general trend, as noted in the previous section, of a sharp increase in curing strain that tapers off to a certain level for the remainder of the curing period. The values at the end of the curing period are presented in Table 6.2. Given that the slabs were relatively the same thickness $(2.5$ inches $(63 \mathrm{~mm}))$ the gradient is represented by the difference between the top (UET or UCTmax) and bottom strains (UEB or UEBmax) in Table 6.2. 
Table 6.2 Terminal Curing Strains for UTW Concrete and HMA under Various Bond Conditions

\begin{tabular}{|c|c|c|c|c|c|}
\hline Lane & Gage & $\begin{array}{c}\text { Curing } \\
\text { Strain TA2 } \\
\text { (microstrain) }\end{array}$ & $\begin{array}{c}\text { TA2 } \\
\text { Strain } \\
\text { Difference } \\
\text { (Top - } \\
\text { Bottom) } \\
\text { (microstrain) }\end{array}$ & $\begin{array}{c}\text { Curing } \\
\text { Strain TA3 } \\
\text { (microstrain) }\end{array}$ & $\begin{array}{c}\text { TA3 } \\
\text { Strain } \\
\text { Difference } \\
\text { (Top - } \\
\text { Bottom) } \\
\text { (microstrain) }\end{array}$ \\
\hline \multirow{4}{*}{$\begin{array}{c}1 \text { (Partially } \\
\text { Bonded } \\
\text { (TA2) or } \\
\text { Full } \\
\text { Bonded } \\
(\text { TA3)) }\end{array}$} & UET & 350 & \multirow[t]{2}{*}{-150} & 400 & \multirow[t]{2}{*}{50} \\
\hline & UEB & 500 & & 350 & \\
\hline & UCTmax & 600 & \multirow[t]{2}{*}{100} & 500 & \multirow[t]{2}{*}{100} \\
\hline & UCBmax & 500 & & 400 & \\
\hline \multirow{3}{*}{\begin{tabular}{|c|}
4 (Partially \\
Bonded \\
(TA2) or \\
Fully
\end{tabular}} & UET & 190 & \multirow[t]{2}{*}{50} & 50 & \multirow[t]{2}{*}{40} \\
\hline & UEB & 140 & & 10 & \\
\hline & UCTmax & 600 & \multirow[t]{2}{*}{75} & 100 & \multirow[t]{2}{*}{50} \\
\hline $\begin{array}{c}\text { Fully } \\
\text { Bonded } \\
\text { (TA3)) }\end{array}$ & UCBmax & 525 & & 50 & \\
\hline \multirow{4}{*}{$\begin{array}{c}5 \\
\text { (Unbonded) }\end{array}$} & UET & 100 & \multirow[t]{2}{*}{-100} & 50 & \multirow[t]{2}{*}{0} \\
\hline & UEB & 200 & & 50 & \\
\hline & UCTmax & 150 & \multirow[t]{2}{*}{-150} & 175 & \multirow[t]{2}{*}{25} \\
\hline & UCBmax & 300 & & 150 & \\
\hline
\end{tabular}

Note: Strain values are approximated for comparison purposes.

The strain differences listed in Table 6.2 indicate that for the fully bonded slabs (TA3 Lanes 1 and 4) the expected restraint did develop. The restraint indicated by the strain differences was greatest at the corner locations which follows the previously mentioned result that the strains were higher at the corner location. 
The partially bonded lanes (TA2 Lanes 1 and 4) had mixed results. Lane 4 (which was originally prepared to be partially bonded) performed better than expected with strain differences indicating restraint comparable to that of the fully bonded lanes. The results from Lane 1 however, indicated that restraint varied at different locations under the slab. The strain difference was large at the corner location, while at the edge location the strain difference was similar to those in the unbonded lanes. This indicates that the corner was likely bonded (initially) and the edge was unbonded. The strain differences in the unbonded lane in TA2 (Lane 5) indicate that the strains at the bottom of the UTW layer were actually greater than the strains at the top. This indicates that there was no restraint provided in this lane. For the unbonded lane in TA3 (Lane 5) the strain difference was either very low indicating very low restraint or equal to 0 indicating no restraint. Therefore, little or no restraint was provided by the unbonded lanes.

\section{Summary}

The underlying HMA did provide restraint to the expansive UTW curing strains. The degree of restraint was different for the unbonded lanes, but there was little difference between the degrees of restraint provided by the partially bonded (intentionally) and fully bonded lanes.

\subsection{Drying Shrinkage Strains}

This section discusses the influence of UTW concrete material properties and interfacial bond conditions on the drying shrinkage strains. Test areas TA2 and TA3 are used for this discussion. TA1 and TA4 are not included in the discussion since the same mix design and interfacial bond conditions were utilized for all test lanes in these two test areas.

Vibrating wire strain gages (Section 4.3.4) were placed at the surface of the UTW to measure the drying shrinkage strains during the APT testing. These data were presented in Section 5.2.3 and Figures B.56 through B.66 in Appendix B. Gages 
discussed are designated as Bonded Mid, Bonded Edge, Unbonded Mid, and Unbonded Edge.

Data from the gages embedded in the UTW for both TA2 and TA3 were collected during APT testing. These data were filtered to isolate the unloaded strains as described in Section 5.2.2. Gages used in these comparisons were the UEB, UET, UCBmax, and UCTmax gages. These data are presented in Figures B.14, B.16, B.18, B.20, B.22, B.24, B.26, B.28, B.30, and B.32. While it is likely that there are other factors contributing to these strains (such as permanent loadinduced strains), it was assumed that these strains were the result of drying shrinkage. The trend for these data was to become more negative (compressive) over the test period. For comparison purposes when magnitude of these strains is discussed, larger strains refer to more negative values: e.g. a strain of -500 microstrain is referred to as being greater than a strain of -400 microstrain.

\subsubsection{Influence of Concrete Mixture Composition on Drying Shrinkage Strains} Hypothesis

After curing is terminated, drying shrinkage begins (Aïtcin et al. [1997]). This is the result of the evaporation of water from the concrete at the exposed surfaces which is driven by the differential between the relative humidity in the air and in the concrete. Drying shrinkage cracking results when the tensile stress in the concrete exceeds the local tensile strength. Drying shrinkage in thin slabs can be very significant.

In general, the cement type is not expected to affect the drying shrinkage of the concrete (Neville [1997]). Thus, it was not anticipated that there would be any difference between the drying shrinkage strains used in the lanes constructed with MD-1 or MD-2. The advantage of including fibers in the concrete is not necessarily to reduce shrinkage (although indeed there is some restraint 
provided by their inclusion) but rather the fibers serve to delay the initial cracking and to significantly reduce crack widths when cracking finally occurs (Shah, Weiss, and Yang [1998]). Thus, the mixes containing fibers (MD-3 and MD4) are not expected to perform differently than the other mixes in regards to drying shrinkage.

\section{Discussion of Results}

As in the discussion of the effect of UTW concrete mixture composition on curing strains, only Lanes 1 through 3 from both TA2 and TA3 are discussed in this section. In TA2, Lane 1 was constructed using MD-1 (base mix) while Lanes 2 and 3 were built using MD-2 (high early strength mix), and MD-3 (fiber mix), respectively. For the test lanes in TA3, Lane 1 again was constructed using MD1 (base mix), while Lanes 2 and 3 was built using MD-4 (high early strength and fiber) and MD-2 (high early strength), respectively. Both vibrating wire gages (surface gages) as well as gages embedded in the concrete were used in this comparison. The drying shrinkage strains measured by the surface gages placed in the test lanes (bonded edge and bonded mid) are discussed, however, the data from the companion slabs are not evaluated presently as bond influences are discussed in the next section.

\section{Surface Gages}

Comparisons using the surface gage drying shrinkage data from TA2 were difficult given as there were several gaps in the data due to equipment malfunctions (Figures B.57, B.58, and B.59). Thus, only the TA3 data are discussed further (Figures B.62, B.63, and B.64). A general review of the surface gage drying shrinkage strains (both edge and mid locations) for TA3 indicate that the strains in Lanes 1 to 3 follow the same trend: after the cure period was terminated, the drying shrinkage strains at the surface of the concrete reduced gradually during the evaluation period. For the bonded slabs (APT test lanes) at the edge location (bonded edge gages), the drying shrinkage strains at 
the end of the APT evaluation were $-400,-325$, and -400 microstrain for the lanes constructed with concrete mix design MD-1, MD-2, and MD-3, respectively. These results indicate that there was not much difference between the drying shrinkage strains at the edge location for the different mix designs.

At the mid-slab location for the bonded slabs (bonded mid gages), the drying shrinkage strains at the end of the APT evaluation were $-500,-300,-325$ microstrain for the lanes constructed with concrete mix design MD-1, MD-4, and MD-2, respectively. At this location the concrete made with MD-1 did exhibit higher strains than the concrete made from the other two mixes, which were approximately equal. While the environmental conditions (temperature and relative humidity) in the APT were relatively constant during the testing of particular test lanes, it was noticed that the relative humidity during the testing of TA3 Lane 1 was somewhat lower than in the other test lanes. The relative humidity during the testing of Lane 1 (constructed with MD-1) ranged from $35 \%$ to $45 \%$, while that of the other two lanes (constructed with MD-4 and MD-2) ranged from $60 \%$ to $70 \%$. Thus, the greater drying shrinkage in TA3 Lane 1 was likely due to differences in the relative humidity in the APT facility rather than the result of the concrete mix. Thus, the dryer environment likely led to higher drying shrinkage of the concrete in Lane 1 (MD-1).

\section{Embedded Gages}

For the drying shrinkage strains measured by the gages embedded in the UTW layer (UEB, UET, UCBmax, and UCTmax in Figures B.14, B.16, B.18, B.24, B.26, and B.28), the trend, in general, was similar to the trend from the surface mounted gages discussed previously: after the cure period was terminated, the drying shrinkage strains at the surface of the concrete reduced gradually during the evaluation period. Drying shrinkage strain data from these gages taken at the end of the APT evaluation are presented in Table 6.3. These gages were placed at 0.5 inches $(13 \mathrm{~mm})$ from the top and bottom of the UTW layer and 
differences in the magnitude of the drying shrinkage strains were noted at different depths. The drying shrinkage strains at the top of the slab (UET and UCTmax) at the end of the APT evaluation were, in general, comparable to those measured at the surface. The strains measured from the gages at the top (UET and UCTmax) were greater than the strains measured at the bottom (UEB and UCBmax). This result may have been due to the restraint from the underlying HMA which induce a strain gradient across the UTW slab. (Restraint as a result of the bond is discussed further in the next section.) The strain gradient may also be the result of moisture gradient in the UTW layer. Since the UTW slab is placed on the HMA, the water must migrate to the surface in order for drying to occur. Thus, concrete closer to the surface dries (and shrinks) more than the concrete deeper in the slab and warping of the slab occurs.

The data in Table 6.3 indicate that overall the drying shrinkage strains from TA2 Lanes 1, 2, and 3 (MD-1, MD-2, and MD-3) were similar. The drying shrinkage strains from TA3 Lane 1 constructed with MD-1 did appear to be moderately higher than the lanes in TA3 constructed from the different mix designs. This difference was greatest for the strain measured by the gages at the top of the UTW slab (UET and UCTmax). This result was also noted with the drying shrinkage data measured with the surface gages. It was previously noted that this was likely due to humidity differences at the time of testing. 
Table 6.3 Drying Shrinkage Strains for UTW Concrete Mix Designs

\begin{tabular}{|c|c|c|c|}
\hline Mix Design & Gage & Strain TA2 & Strain TA3 \\
\hline \multicolumn{4}{|c|}{ Lane 1} \\
\hline \multirow[t]{4}{*}{ MD-1 } & UET & -375 & -350 \\
\hline & UEB & -200 & -225 \\
\hline & UCT & -400 & -390 \\
\hline & UCB & 0 & -120 \\
\hline \multicolumn{4}{|c|}{ Lane 2} \\
\hline \multirow[t]{4}{*}{ MD-2 (TA2) or MD-4 (TA3) } & UET & -500 & -300 \\
\hline & UEB & -50 & -200 \\
\hline & UCT & -400 & -300 \\
\hline & UCB & -300 & -190 \\
\hline \multicolumn{4}{|c|}{ Lane 3} \\
\hline \multirow[t]{4}{*}{ MD-3 (TA2) or MD-2 (TA3) } & UET & -325 & -300 \\
\hline & UEB & -250 & -175 \\
\hline & UCT & -400 & -225 \\
\hline & UCB & -250 & NA \\
\hline
\end{tabular}

\section{Summary}

The drying shrinkage strains were measured at the surface of the UTW during testing in the APT. These results indicated that the surface strains were, in general, the same at both the edge and mid-panel locations regardless of the mix design used in the concrete. The only exception was in at the mid-panel location for TA3 Lane 1 (base mix), however this discrepancy was likely due to the humidity differences in the test area during testing.

Also, the unloaded strains from the gages installed in the UTW test lanes were measured. These results also reflected similar results as the surface mounted 
gages in regards to the mix designs. The drying shrinkage strains at the top of the slab (UET and UCTmax) at the end of the APT evaluation were, in general, comparable to those measured at the surface. The strains measured from the gages at the top (UET and UCTmax) were greater than the strains measured at the bottom (UEB and UCBmax). This may have been due to the restraint provided by the bond with the underlying HMA or may also have been indicative of moisture warping in the slab.

\subsubsection{Influence of Interfacial Bond Conditions on Drying Shrinkage Strains}

\section{Background}

Petersson and Silfwerbrand [1993] modeled the shrinkage of UTW over HMA. It was noted that if the volume decrease that results from the concrete shrinkage is restrained, stresses will develop in the concrete. Two different static conditions were analyzed. The first was a beam freely supported on both ends and the second was a beam fixed at both ends. The modeling assumed a full bond between the two layers. The Comité Euro-International du Beton (CEB) models for shrinkage and creep were employed. The results indicated that in no case did the maximum tensile stress exceed more than half of the tensile stress of the concrete. The greatest stress occurs for the situation where the movement is restrained, the overlay is thin and the modulus of the HMA is low.

As noted in Section 6.1.2, the UTW bond condition did affect the degree of expansive strain restraint during the cure period. Test lanes that were unbonded provided little to no restraint while the partially and fully bonded lanes provided roughly equal amounts of restraint. It was expected that the interfacial bond conditions would again provide similar restraint to the drying shrinkage strains that were measured in during the APT testing.

To evaluate the influence of the bond condition on the drying shrinkage strains, two different comparisons were made. The first comparison utilized data from 
the surface gages (bonded edge, unbonded edge, bonded mid, and unbonded mid) to compare the bonded and unbonded conditions. The second comparison used data collected from the gages embedded in the UTW layer (UEB, UET, UCBmax, and UCTmax).

In both TA2 and TA3 only Lanes 1,4 and 5 varied the interfacial bond conditions used in the construction of the test lanes (Sections 4.2.2 and 4.2.3). Thus, only these lanes are discussed in this section. As mentioned previously, Lane 1 in TA2 was intended to be constructed using fully bonded conditions. However, during construction, no vibration was performed and as a result the bond in this test lane was not well developed (illustrated by the excessive debonding in Figure 5.10).

\section{Surface Gages}

As noted in Section 6.2.1, comparisons using the surface gage drying shrinkage data from TA2 were difficult given as there were several gaps in the data due to equipment malfunctions (Figures B.57, B.60, and B.61). Thus, only the TA3 data are discussed further (Figures B.62, B.65, and B.66). The strains measured at the end of the APT evaluation for each lane were obtained from these figures and are presented in Table 6.4.

The data from TA3 Lane 4 (fully bonded) were all very similar and did not reflect any differences as a result of the bond condition at either location (edge or mid). For TA3 Lane 1 (fully bonded) the drying shrinkage strains in the test lane (bonded mid and edge) were greater than the companion slabs (unbonded mid and edge) at both locations, respectively. This may have been the result of the bond restraining the shrinkage at the bottom of the slab causing the top of to experience larger strains. In TA3 Lane 5, (unbonded) the mid gage in the test lane reported greater drying shrinkage strains than the mid gage in the companion slab. However, the surface gage in the test lane at the edge location 
reported lesser shrinkage strains than the surface gage in the companion slab at the edge location. Since the results should have been similar for both the test lane and the companion slab (both were unbonded), the underlying HMA may have provided a small degree of restraint against shrinkage in the test lane given the rough surfaces between the two layers even though no bond was present.

Table 6.4 Drying Shrinkage Strains from Surface Gages

\begin{tabular}{|c|c|c|c|}
\hline \multirow{2}{*}{ Gage } & \multicolumn{3}{|c|}{ Drying Shrinkage Strain (microstrain) } \\
\hline $\begin{array}{c}\text { Lane 1 } \\
\text { (Fully Bonded) }\end{array}$ & $\begin{array}{c}\text { Lane 4 } \\
\text { (Fully Bonded) }\end{array}$ & $\begin{array}{c}\text { Lane 5 } \\
\text { (Unbonded) }\end{array}$ \\
\hline $\begin{array}{c}\text { Unbonded Mid } \\
\text { (Companion Slab) }\end{array}$ & -325 & -425 & -410 \\
\hline $\begin{array}{c}\text { Unbonded Edge } \\
\text { (Companion Slab) }\end{array}$ & -350 & -425 & -460 \\
\hline $\begin{array}{c}\text { Bonded Mid } \\
\text { (Lane) }\end{array}$ & -500 & -425 & -500 \\
\hline $\begin{array}{c}\text { Bonded Edge } \\
\text { (Lane) }\end{array}$ & -450 & -425 & -400 \\
\hline
\end{tabular}

Note: Strains are approximated for comparison purposes.

\section{Embedded Gages}

Data from gages at the top (UET, UCTmax) and bottom (UEB, UCBmax) (Figures B.14, B.20, B.22, B.24, B.30, and B.32) of the UTW slab at both the edge and corner locations were used for this comparison. Data were obtained from TA2 Lane 1 (partially bonded (as discussed previously)), Lane 4 (partially bonded), and Lane 5 (unbonded) TA3 Lane 1 (fully bonded). Data were also obtained from TA3 Lane 1 (fully bonded) and Lane 5 (unbonded). The trend of these strains in general was to decrease gradually throughout the APT test 
period. Data from these gages taken at the end of the APT evaluation are presented in Table 6.5 .

As noted in Section 6.1.2, restraint of the slab movement at the bottom of the layer produced a strain gradient across the UTW. The gradient is represented by the strain difference between the top and bottom of the UTW slab in Table 6.5 since the thickness of the slabs was relatively constant throughout. This gradient would be expected to be negative if induced by drying shrinkage strains since the strains at the top would be more compressive than those below.

The previous comparison in Section 6.1.2 indicated that the UTW in TA2 Lane 1 behaved as a fully bonded slab at the corner location while it behaved as if it were unbonded at the edge. The results of the comparison in Section 6.1.2 also indicated that there was no noticeable difference between the partially bonded Lane 4 in TA2 and the fully bonded lanes (TA3 Lanes 1 and 4). 
Table 6.5 Drying Shrinkage Strains for Different Bond Conditions

\begin{tabular}{|c|c|c|c|c|c|}
\hline Lane & Gage & $\begin{array}{c}\text { Curing } \\
\text { Strain TA2 } \\
\text { (microstrain) }\end{array}$ & $\begin{array}{c}\text { TA2 } \\
\text { Strain } \\
\text { Difference } \\
\text { (Top - } \\
\text { Bottom) } \\
\text { (microstrain) }\end{array}$ & $\begin{array}{c}\text { Curing } \\
\text { Strain TA3 } \\
\text { (microstrain) }\end{array}$ & $\begin{array}{c}\text { TA3 } \\
\text { Strain } \\
\text { Difference } \\
\text { (Top - } \\
\text { Bottom) } \\
\text { (microstrain) }\end{array}$ \\
\hline \multirow{4}{*}{\begin{tabular}{|c|}
1 (Partially \\
Bonded \\
(TA2) or \\
Full \\
Bonded \\
$(\mathrm{TA} 3))$
\end{tabular}} & UET & -375 & \multirow[t]{2}{*}{-175} & -350 & \multirow[t]{2}{*}{-125} \\
\hline & UEB & -200 & & -225 & \\
\hline & UCTmax & -400 & \multirow[t]{2}{*}{-400} & -390 & \multirow[t]{2}{*}{-270} \\
\hline & UCBmax & 0 & & -120 & \\
\hline \multirow{3}{*}{$\begin{array}{c}4 \text { (Partially } \\
\text { Bonded } \\
\text { (TA2) or } \\
\text { Fully }\end{array}$} & UET & -400 & \multirow[t]{2}{*}{25} & -375 & \multirow[t]{2}{*}{-125} \\
\hline & UEB & -425 & & -225 & \\
\hline & UCTmax & 200 & \multirow[t]{2}{*}{600} & -340 & \multirow[t]{2}{*}{-365} \\
\hline $\begin{array}{c}\text { Fully } \\
\text { Bonded } \\
\text { (TA3)) }\end{array}$ & UCBmax & -400 & & 25 & \\
\hline \multirow{4}{*}{$\begin{array}{c}5 \\
\text { (Unbonded) }\end{array}$} & UET & 200 & \multirow[t]{2}{*}{500} & $\mathrm{NA}$ & \multirow[t]{2}{*}{$\mathrm{NA}$} \\
\hline & UEB & -300 & & 100 & \\
\hline & UCTmax & 800 & \multirow[t]{2}{*}{850} & -150 & \multirow[t]{2}{*}{-325} \\
\hline & UCBmax & -50 & & 175 & \\
\hline
\end{tabular}

Note: Strain values are approximated for comparison purposes. 
The data in Table 6.5 indicate that the drying shrinkage strains at the top of the UTW layer were greater than at the bottom, for TA2 Lanes 1 (partially bonded) and TA3 Lanes 1 and 4 (fully bonded) as was expected for partially bonded and fully bonded conditions. There was no discernable difference between the two conditions in these lanes. However, the partially bonded lane in TA2 (Lane 4) had similar results to the unbonded lane (Lane 5) in TA2. Further, the unbonded lane in TA3 (Lane 5) exhibited a strain gradient closer to the fully bonded lanes (TA3 Lanes 1 and 4). These results indicate that the bonded lanes do provide restraint to the shrinkage. However, since these lanes were also under cyclic loading in the APT it may be that when debonding (full or partial) occurs the strain development is dominated more by the loading than by the drying shrinkage.

\section{Summary}

This section discussed the drying shrinkage strain data recorded in the UTW test lanes for bonded, partially bonded and unbonded conditions. The results indicated that the bonded and did provide restraint. However, the long-term strain development in the lanes with the partially bonded or unbonded conditions was dominated by load-induced strains.

\subsection{Strain Distribution and Maximum Load-Induced Strains}

This section discusses the influence of structural properties of the pavement sections, concrete mechanical properties, interfacial bond conditions, mechanical load applications, and temperature gradient on the strain distribution and the maximum load-induced strains. All test areas are used for this discussion. Instrumentation of the pavement sections and accelerated pavement loading were described in Sections 4.3.4 and 4.4, respectively. The strains included in this discussion were from gages PEB, PET, HEB, HET, UEB, UET, PCB, PCT, HCB, HCT, UCBmax, and UCTmax. These strain data were recorded every 500 to 2500 load applications of the APT carriage and were summarized in Section 
5.2.2. Figures B.13, B.15, B.17, B.19, B.21, B.23, B. 25 , B. 27 , B. 29 , B. 31 , and B.33 contain plots of cumulative strain versus the number of load applications for the loaded condition (APT carriage located directly over the gage). Figures B.34 through B.55 contain the dynamic strain responses of the different gages as a function of the location of the APT load carriage. The results of the environmentally induced temperature gradient evaluation were presented in Section 5.3. Figure 5.9 contains the temperature data collected as part of this evaluation. Note: In the following discussions, the compressive strains in the pavement are considered negative while tensile strains are considered positive.

\subsubsection{Influence of Structural Properties of the Pavement Sections on Strain Distributions and Maximum Load-Induced Strains}

\section{Theoretical Strain Distribution}

The PCA UTW design methodology described by Wu et al. [1998] was developed for UTW placed over a HMA pavement. As such, the design equations in that method do not take into account the situation where UTW would be placed over an existing composite pavement. Rajan et al. [2001] indicated that low strain values measured in the pavement with a stiff concrete layer underlying the HMA and tested in the APT were the reason for the observed lack of distresses in the UTW.

In a multi-layered pavement section, the cross-sectional distribution of the strains will vary depending on the thicknesses and moduli of the different pavement layers. The test lanes in all test areas each consisted of a stiff, $2.5 \mathrm{inch}(63 \mathrm{~mm})$ UTW layer that was constructed over a relatively stiff HMA layer the thickness of which varied by test area. TA1 contained a very stiff and relatively thick (12 inch $(300 \mathrm{~mm})$ ) reinforced concrete layer below the HMA layer. TA2 likewise had a concrete layer below the HMA layer, however, this layer was thinner (only 6 inches $(150 \mathrm{~mm})$ ) and not reinforced. The pavement section for TA3 did not contain a concrete layer below the HMA layer. 
Accordingly, it was hypothesized that the presence of a concrete layer below the HMA pavement layer will significantly effect the strain distribution across the pavement section. To confirm this hypothesis, the layer elastic analysis program WinJULEA was used to calculate the stresses across the pavement depth for Lane 1 in each of the test areas. The strains calculated using this program will heretofore be referred to as "JULEA" strains. Where available, measured values of the layer properties and thicknesses were used as inputs into the program otherwise, the parameters were estimated using standard reported material property values and design thicknesses. (Note: Linear elastic analysis techniques are valid under liner elastic conditions. For purposes of this, and subsequent comparisons, the HMA is treated as a linear elastic material. Given the relatively constant temperature conditions in the APT and similar load conditions, the linear elastic assumption should be reasonable. However under real world conditions, this assumption would not be valid. One area in which the visco-elastic properties of the HMA are expected to influence is the bond between the UTW and HMA. This effect is not evaluated as part of this study, but would be an item that would warrant further research).

A load equal to $9,000 \mathrm{lbs}(40 \mathrm{kN})$ was used as an input for TA1 and a load equal to $15,000 \mathrm{lbs}(67 \mathrm{kN})$ was used as an input for TA2 and TA3 to correspond to the load applied by the APT load carriage. The calculations for TA1 were conducted also using an applied load of $15,000 \mathrm{lbs}(67 \mathrm{kN})$ to illustrate the effect of the increased load on this lane. However, since there is no difference in the shape of the distribution, these strains are not discussed further. A full bond was assumed between all layers. The strains were calculated just above and below the interfaces between the pavement layers and these strains were plotted across the depth of the section. These data are presented in Figure 6.1 where JULEA1, JULEA2, JULEA3 are respectively strains in TA1, TA2, and TA3. 
As can be seen from the results of the WinJULEA analysis, the strain distribution for pavement sections with a PCC layer below the HMA layer was significantly different than the strain distribution of the pavement with just the HMA layer below the UTW layer. In the PCA design method, the critical locations for design are at the bottom of the UTW layer and the bottom of the HMA layer. The theoretical distribution indicates that the maximum tensile strain in the UTW layer is greatest at the bottom of the UTW layer for all test areas (JULEA1, JULEA2 and JULEA3). Additionally, the maximum tensile strain is at the bottom of the HMA layer in TA3 (JULEA3). These results match the critical locations utilized in the PCA design methodology. However, in TA1 (JULEA1) and TA2 (JULEA2), the maximum tensile strain in the HMA is at the top of the layer. Due to the bond between the two layers, this strain is equal to the strain at the bottom of the UTW. This result does not match the critical location for the HMA in the PCA methodology.

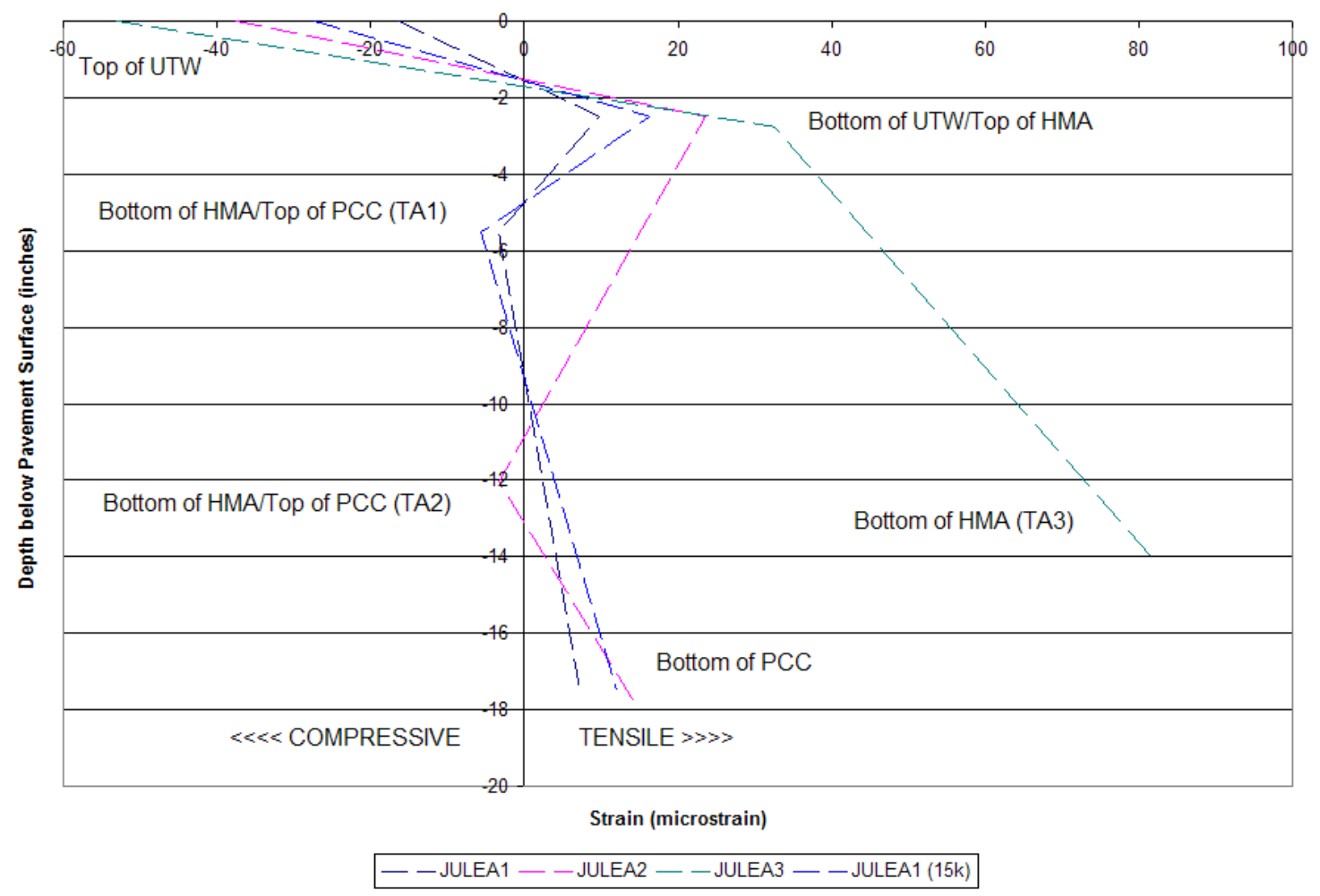


Figure 6.1 Comparisons of Theoretical Strain Distributions

\section{Comparison of Measured and Theoretical Strain Distributions}

To verify if the results of the theoretical analysis, the strain data from TA1, TA2, and TA3 (presented in Section 5.2.2) were obtained. To make a direct comparison to the theoretical analysis, only the data from Lane 1, edge location in each of the test areas was utilized. (The edge location was chosen so that the corner loading effects would be minimized. Layer elastic analysis techniques do not account for discontinuities such as joints.) TA1 was instrumented with only one strain gage embedded at a depth of 0.5 inches $(13 \mathrm{~mm})$ from the top of the UTW layer and one affixed to the top of the HMA layer. Thus, the data for this test area will only provide a limited comparison. However, the test lanes in test areas TA2 and TA3 had multiple strain gages placed throughout the pavement depth in order to evaluate the strains across the pavement depth.

The measured strains were filtered to identify the maximum strains under the applied load for the gages places across the pavement sections. For each test area, data from the Lane 1, edge location collected during the "initial" load application (0 to 20,000 load applications) were used for comparison with the theoretical strains calculated for the same location and load conditions. The "initial" loading was chosen as so that the strains used in the comparison would not reflect any fatigue effects from multiple loadings since the layer elastic analysis did not take fatigue effects into account. The strains were obtained from gages PEB, PET, HEB, HET, UEB, and UET. These data were plotted the proper depths for each section and are presented in Figure 6.2. 


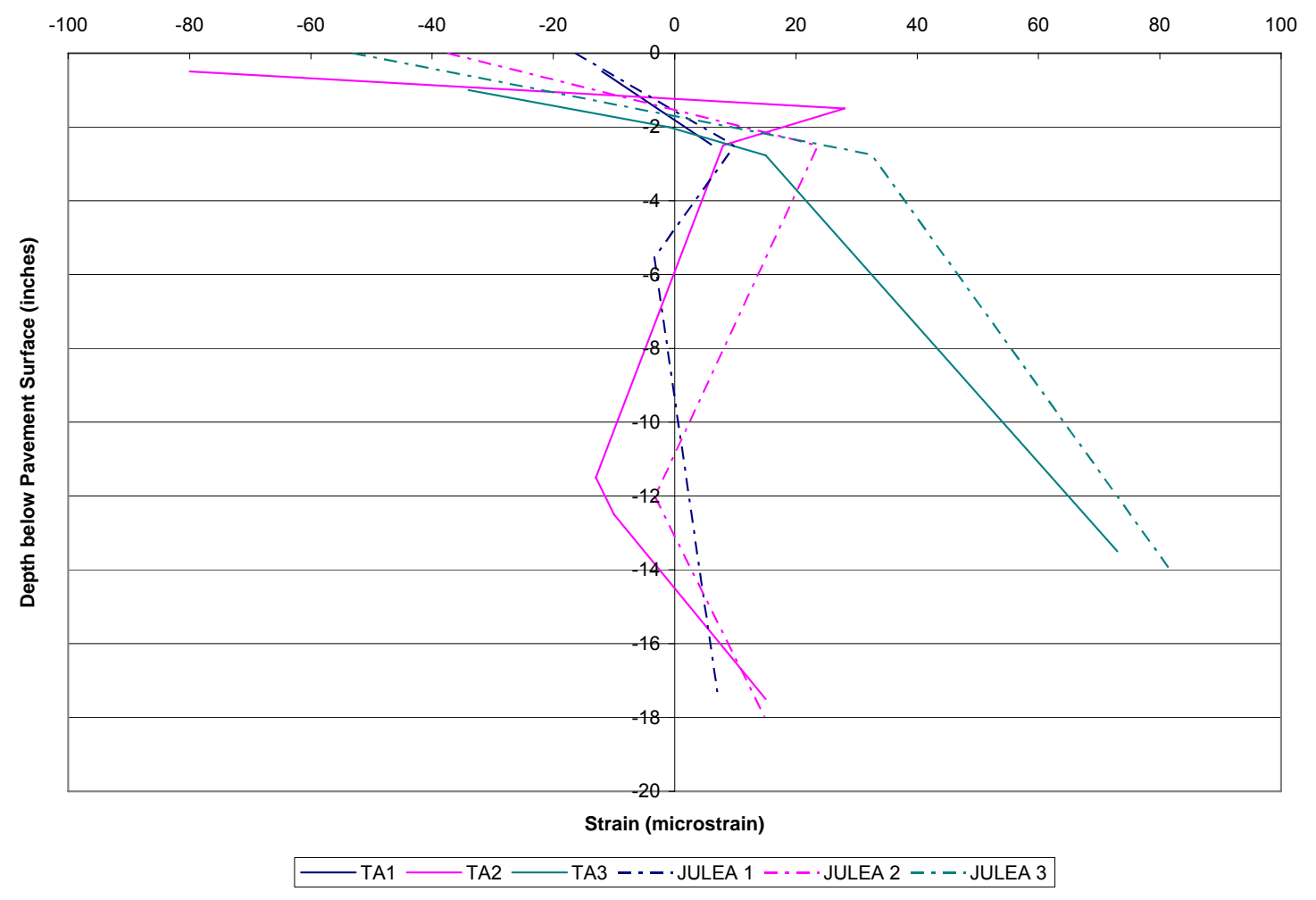

Figure 6.2 Comparisons of Theoretical and Measured Strain Distributions

As can be seen from Figure 6.2, the measured strains from the APT test areas match fairly well with the theoretical strains for the same test areas. The measured distribution matches the theoretical strains in that the maximum tensile strain in the UTW layer is greatest at the bottom of the UTW layer for all test areas (TA1, TA2 and TA3). Additionally, the maximum measured tensile strain is at the bottom of the HMA layer in TA3. This result was also indicated by the theoretical analysis. These results also match the critical locations utilized in the PCA design methodology. However, also as noted in the theoretical distribution, in TA2 (JULEA2) the measured maximum tensile strain in the HMA is at the top of the layer. However, this measured strain is not equal to the strain at the bottom of the UTW. This is likely due to the debonding that occurred in this lane. The influence of the bond condition on the strain distribution is discussed further in Section 6.3.3. Regardless of this observation, both the theoretical and 
measured strain distributions provide different critical locations than the PCA design method for the HMA layer when the HMA also has an underlying PCC layer.

For TA1, the measured strains did match the JULEA strains very well in the UTW layer. The measured strain distribution from TA2, which contains the underlying PCC layer, does differ from that of TA3 which did not have the PCC layer. The measured tensile strain is greatest at the bottom of the UTW layer for TA2. As there was no other data collected from the pavement layers in TA1 this observation cannot be confirmed for this test area. The maximum tensile strain in the section does occur at the bottom of the HMA layer for TA3. Due to the bond between the two layers, the strain at the bottom of the UTW does equal the strain at the top of the HMA layer in TA3. However, this is not the case for TA2. This indicates that the layers did not have a full bond between them in this lane.

Table 6.6 Comparisons of Theoretical and Measured Maximum Strains (continued)

\begin{tabular}{|c|c|c|}
\hline Location & $\begin{array}{c}\text { Theoretical Strains } \\
\text { (microstrain) }\end{array}$ & $\begin{array}{c}\text { Measured Strains } \\
\text { (microstrain) }\end{array}$ \\
\hline \multicolumn{3}{|c|}{ TA1 } \\
\hline Top UTW & -16 & -16 \\
\hline Bottom UTW & 9.5 & NA \\
\hline Top HMA & 9.5 & 6 \\
\hline Bottom HMA & -3.2 & NA \\
\hline Top PCC & -3.2 & NA \\
\hline Bottom PCC & 7.2 & NA \\
\hline
\end{tabular}


Table 6.6 Comparisons of Theoretical and Measured Maximum Strains

\begin{tabular}{|c|c|c|}
\hline Location & $\begin{array}{c}\text { Theoretical Strains } \\
\text { (microstrain) }\end{array}$ & $\begin{array}{c}\text { Measured Strains } \\
\text { (microstrain) }\end{array}$ \\
\hline \multicolumn{3}{|c|}{ TA2 } \\
\hline Top UTW & -38 & -100 \\
\hline Bottom UTW & 23 & 100 \\
\hline Top HMA & 23 & 8 \\
\hline Bottom HMA & -3.2 & -15 \\
\hline Top PCC & -3.2 & -15 \\
\hline Bottom PCC & 15 & 16 \\
\hline Top UTW & TA3 & -60 \\
\hline Bottom UTW & -53 & 15 \\
\hline Top HMA & 32 & 15 \\
\hline Bottom HMA & 32 & 75 \\
\hline
\end{tabular}

The maximum strains in each layer are summarized in Table 6.6. In order to make a direct comparison to the theoretical strains, the measured strains presented in this table were extrapolated linearly to the top and bottoms of the layers. In regards to the magnitude of the strains, the theoretical and measured values matched fairly well for test areas TA1 (limited comparison) and TA3. The measured strains from TA2 however, again reflect the debonded condition noted previously and therefore these strains do not match the theoretical strains as well.

The underlying reinforced concrete layer in TA1 provided it with the stiffest pavement section. TA2 also had a less stiff PCC layer under the HMA making it stiffer than TA3 with an HMA layer under the UTW. Overall, both the theoretical and measured strains indicate that TA1 had the lowest strains throughout the 
section, followed by TA2 and TA3. These results indicate that the structural properties do also have an influence on the maximum strains in each of the pavement layers.

\section{Summary}

The structural properties of the pavement sections did have a significant influence on the strain distribution and maximum strains. The results also indicated that for UTW constructed over composite sections, the critical location for the HMA layer is at the top of the HMA not at the bottom as in the PCA design methodology.

\subsubsection{Influence of Concrete Mixture Mechanical Properties on Strain}

Distributions and Maximum Load-Induced Strains

\section{Theoretical Strain Distribution}

As mentioned in Section 6.3.1, the cross-sectional distribution of the strains will vary depending on the thicknesses and moduli of the different pavement layers. Throughout TA2 and TA3 the thickness of the UTW was 2.5 inches (63 mm). This being constant allows the direct comparison of the strain responses for the different lanes. As can be seen from Figure 5.3, the 7 day moduli of elasticity for the UTW layers for MD- 1 through MD-3 in TA2 ranged from $4.01 \times 10^{6}$ to $5.34 \times 10^{6}$ psi (27.6 to $36.8 \mathrm{GPa}$ ). MD-1, MD-2, and MD-4 in TA3 had 7 day moduli ranging from $5.34 \times 10^{6}$ to $5.96 \times 10^{6} \mathrm{psi}(36.8$ to $41.1 \mathrm{GPa})$. These data represent an overall range of $4.01 \times 10^{6}$ to $5.96 \times 10^{6}$ psi which is a fairly broad range and would include a majority of moduli values encountered for UTW concrete.

A similar analysis to that which was conducted in Section 6.3.1 using the WinJULEA program was conducted to provide a basis for comparison. All input parameters were the same except the strains were calculated across the pavement depth for Lanes 1 to 3 in each of the TA2 and TA3 using moduli values from MD-1 to MD-4. Modulus values determined at 7 days were used to 
compare the theoretical strains with measured strains recorded at approximately the same age. These data are presented in Figure 6.3.

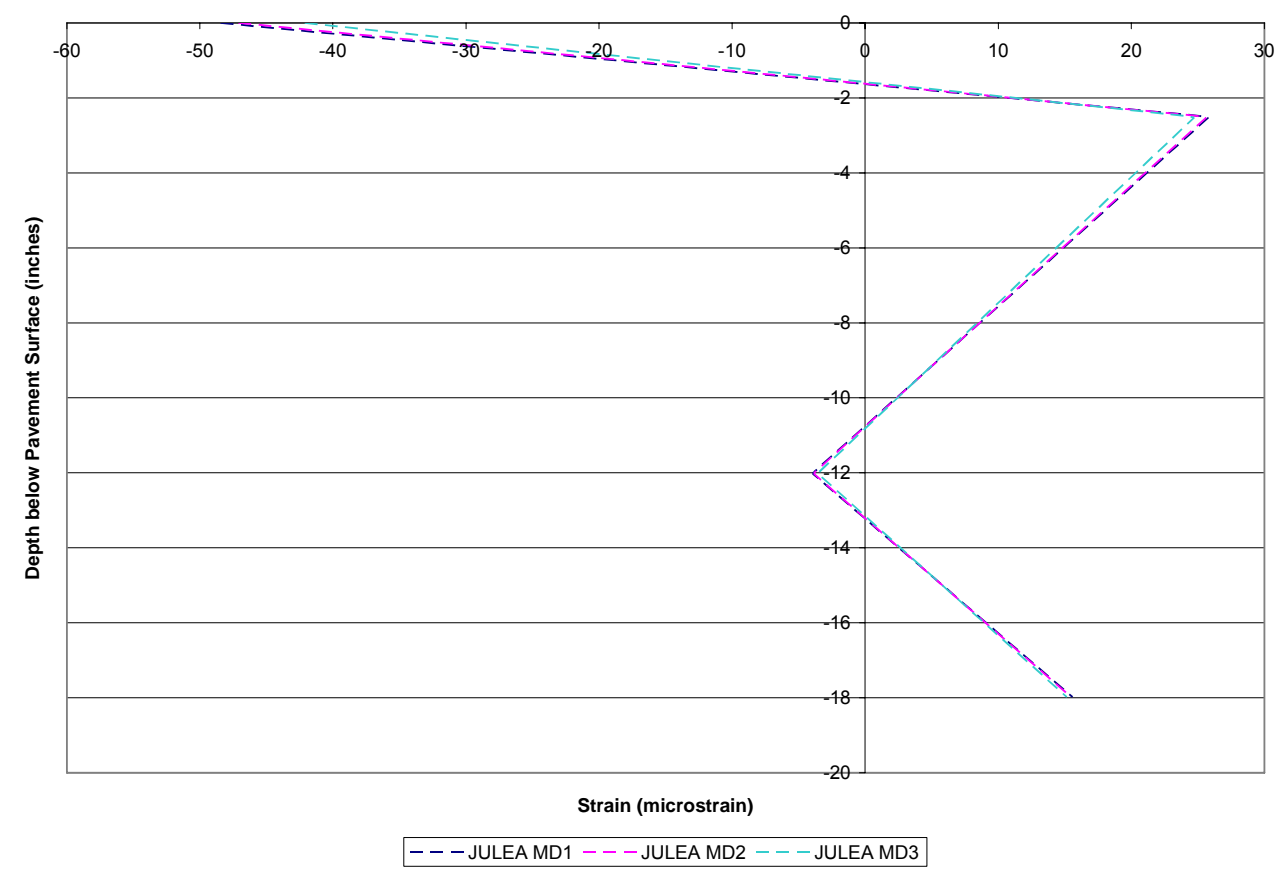

(a)

Figure 6.3 Comparisons of Theoretical Strains for Different Mix Designs (a) TA2 (b) TA3 (continued) 


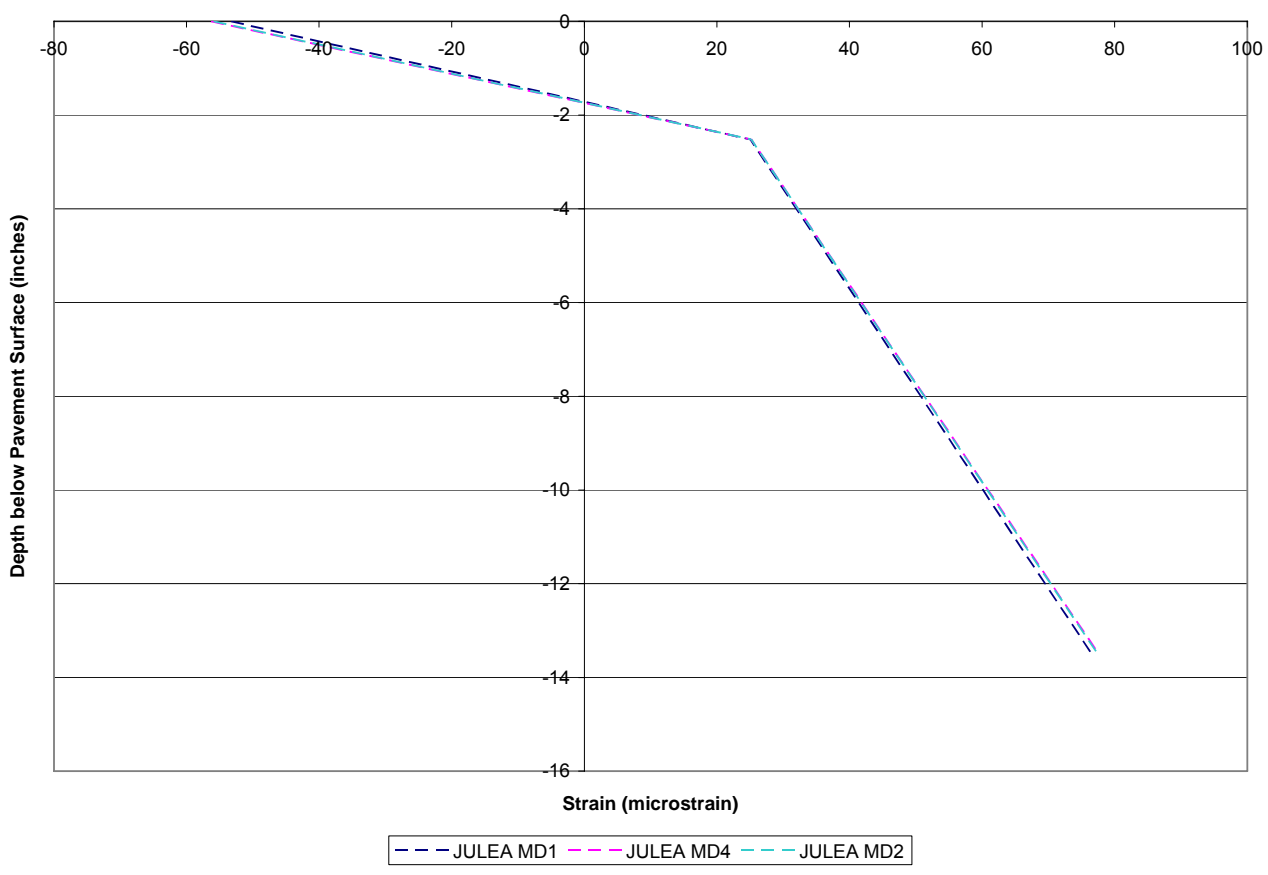

(b)

Figure 6.3 Comparisons of Theoretical Strains for Different Mix Designs (a) TA2 (b) TA3

As can be seen in Figure 6.3, the theoretical strain distribution and maximum strain magnitudes are very similar for the all mix designs in TA2 and TA3.

\section{Comparison of Theoretical and Measured Strains}

A similar method to that described in Section 6.3.1 was used to obtain measured strain data for comparison to the theoretical strains. The filtering process was applied to data from Lanes 1, 2, and 3 in TA2 (using MD-1, MD-2, and MD-3, respectively) and TA3 (using MD-1, MD-4, and MD-2, respectively). Again, data collected during the "initial" load application (0 to 5,000 load applications) were used for this comparison. Gages used to provide strains for comparison to the theoretical strains were PEB, PET, HEB, HET, UEB, and UET, for TA2 and HEB, HET, UEB, and UET for TA3. These data are presented in Figure 6.4. 


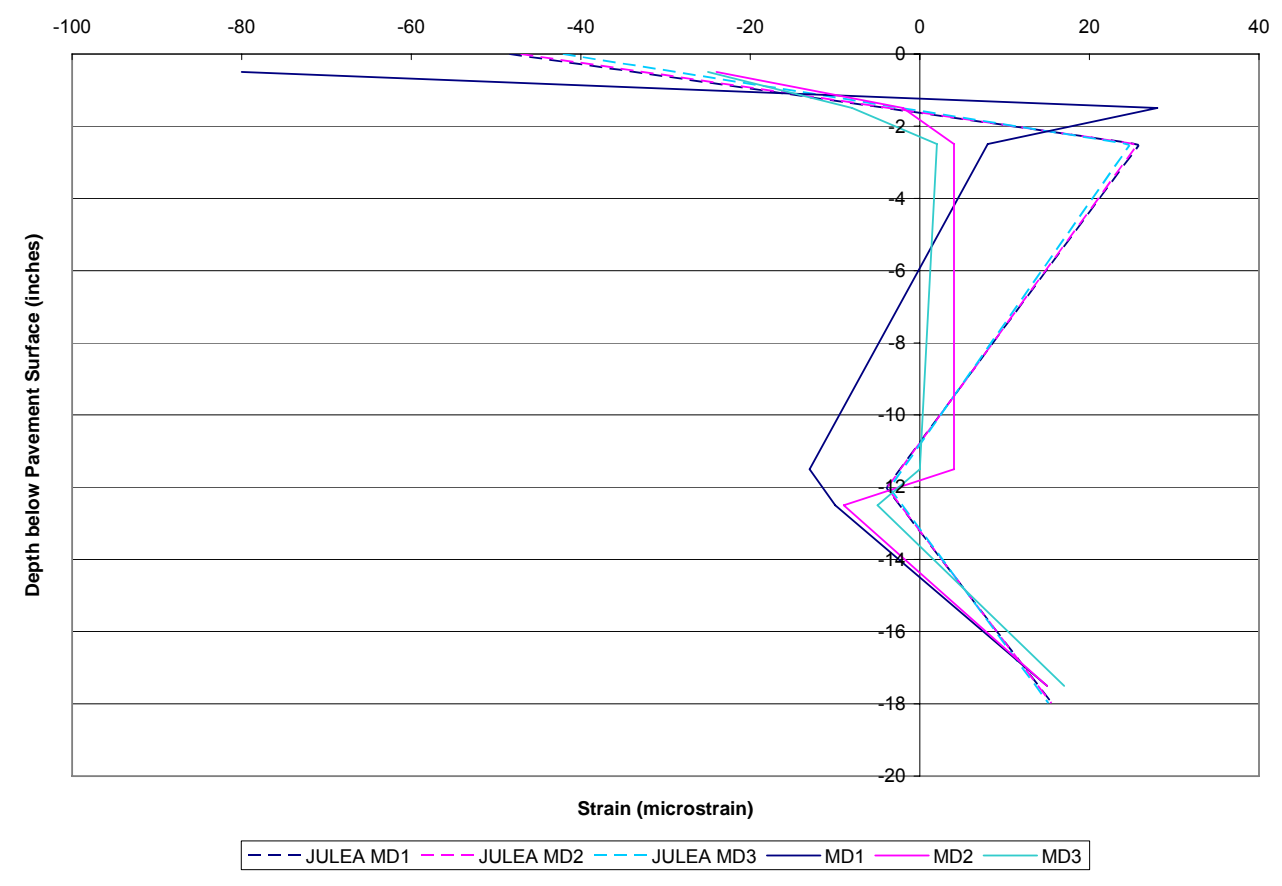

(a)

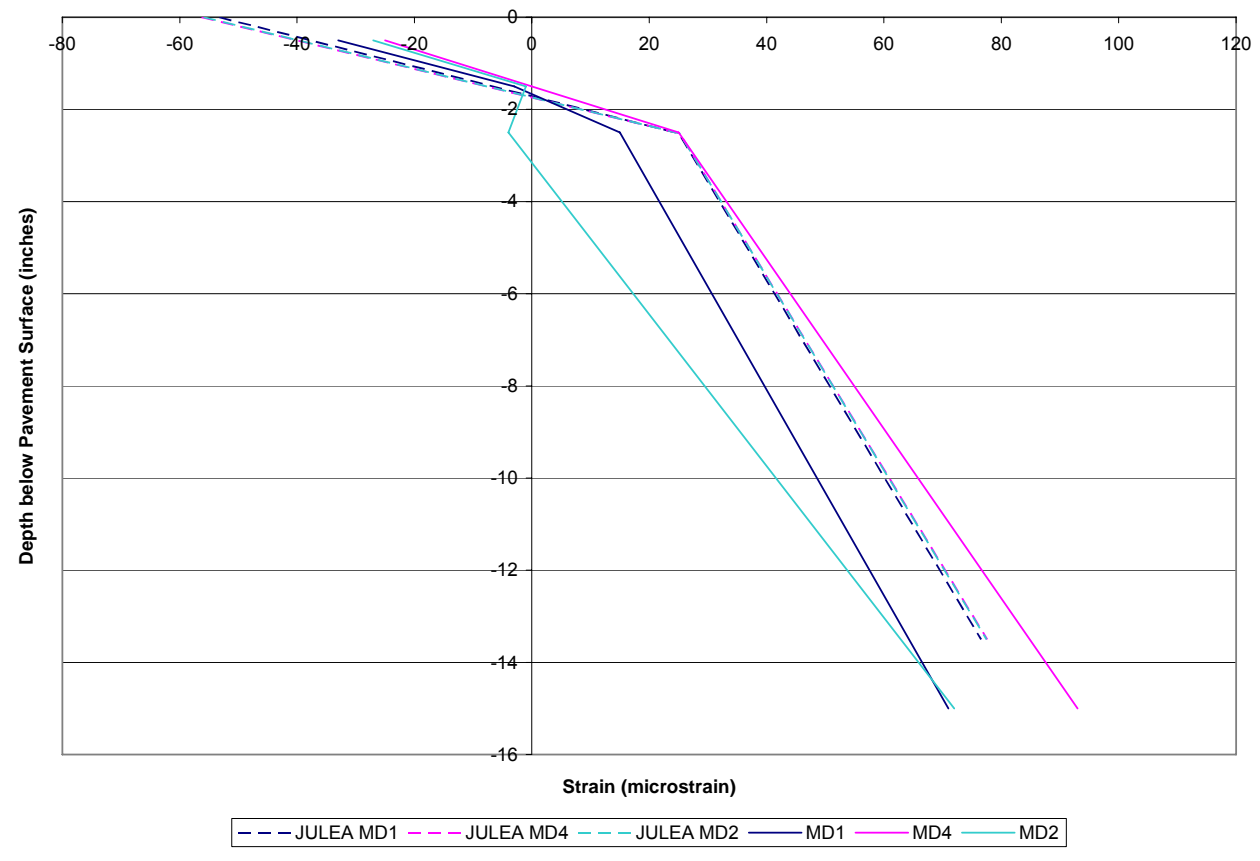

(b)

Figure 6.4 Comparisons of Theoretical and Measured Strains for Lanes Constructed with MD-1 through MD-4 (a) TA2 (b) TA3 
The measured strain data matches the general shape of the distribution of the JULEA data for the mix designs in TA2. The magnitude of the measured strain values in the UTW concrete layer are generally close to the theoretical values for lanes using MD2 and MD3, but the lane constructed with MD1 had measured strains over a greater range than the theoretical (-80 to 28 microstrain measured versus -48 to 15 microstrain theoretical). The measured strains differ somewhat from the theoretical values in the HMA layer. This however is more likely influenced by the bond between the UTW and HMA rather than the UTW concrete properties since the measured strains at the bottom of the HMA are fairly close to the theoretical strains. The measured strains in the PCC layer match well with the theoretical values.

A comparison for TA3 indicates a similar result. The shapes of the distributions are similar for both measured and theoretical values for Lanes 1, 2, and 3 constructed with mix designs MD-1, MD-4, and MD-2, respectively. However, while the magnitude of the measured strains in the UTW layers constructed with all UTW mix designs were very close to the theoretical strains from the JULEA analysis, the measured strains from the HMA layer are somewhat lower than the theoretical strains.

The comparisons conducted in Section 6.3.1 indicated that the mechanical pavement section did have a significant influence on the strain distribution and maximum strains. However, this result indicates that changes within the range of expected values of the concrete modulus do not contribute to these variations.

\section{Summary}

The previous comparison indicated that strain distribution and maximum load induced strains were not affected by changes in the UTW moduli. The strain distributions and magnitudes in the UTW layers generally reflected this result regardless of mix design. The measured strain distributions in the HMA layer 
varied from the theoretical strain distributions, but this was most likely due to a weakened bond between the UTW and HMA layers.

\subsubsection{Influence of Interfacial Bond Conditions on Strain Distributions and} Maximum Load-Induced Strains

\section{Theoretical Strain Distribution}

Mack et al. [1998] indicated that the excellent performance of UTW was dependent on the bond between the UTW and HMA layers. The bond allows the two layers to act monolithically and causes the neutral axis to shift down in the pavement, thereby reducing the stress in the concrete below the tensile strength of the concrete.

As indicated in Sections 6.3.1 and 6.3.2, the magnitude of strains in the UTW and HMA layers may also depend on the degree of bond between the layers. To evaluate this theory, a similar analysis to that which was conducted in Section 6.3.1 using the WinJULEA program was conducted to provide a basis for comparison. All parameters that were used in the analysis were the same as in Section 6.3.1 except as follows. The strains used in the comparison were from Lanes 1 (fully bonded for purposes of this comparison), 4 (partially bonded), and 5 (debonded) in TA2 and Lanes 1 (bonded) and 5 (debonded) in TA3. (Lane 4 for TA3 was not included as it was originally intended to be partially bonded but was inadvertently constructed as fully bonded.) The Win JULEA program had the ability to vary the slippage between the two layers. Thus, for the bond between the UTW and HMA no slippage (a full bond) was input for Lane 1, a moderate degree of slippage (partial bond) was input for Lane 4 in TA2, and full slippage (no bond) was input for Lanes 5 in both TA2 and TA3. The theoretical strain distributions that resulted from these analyses are presented in Figure 6.5. 


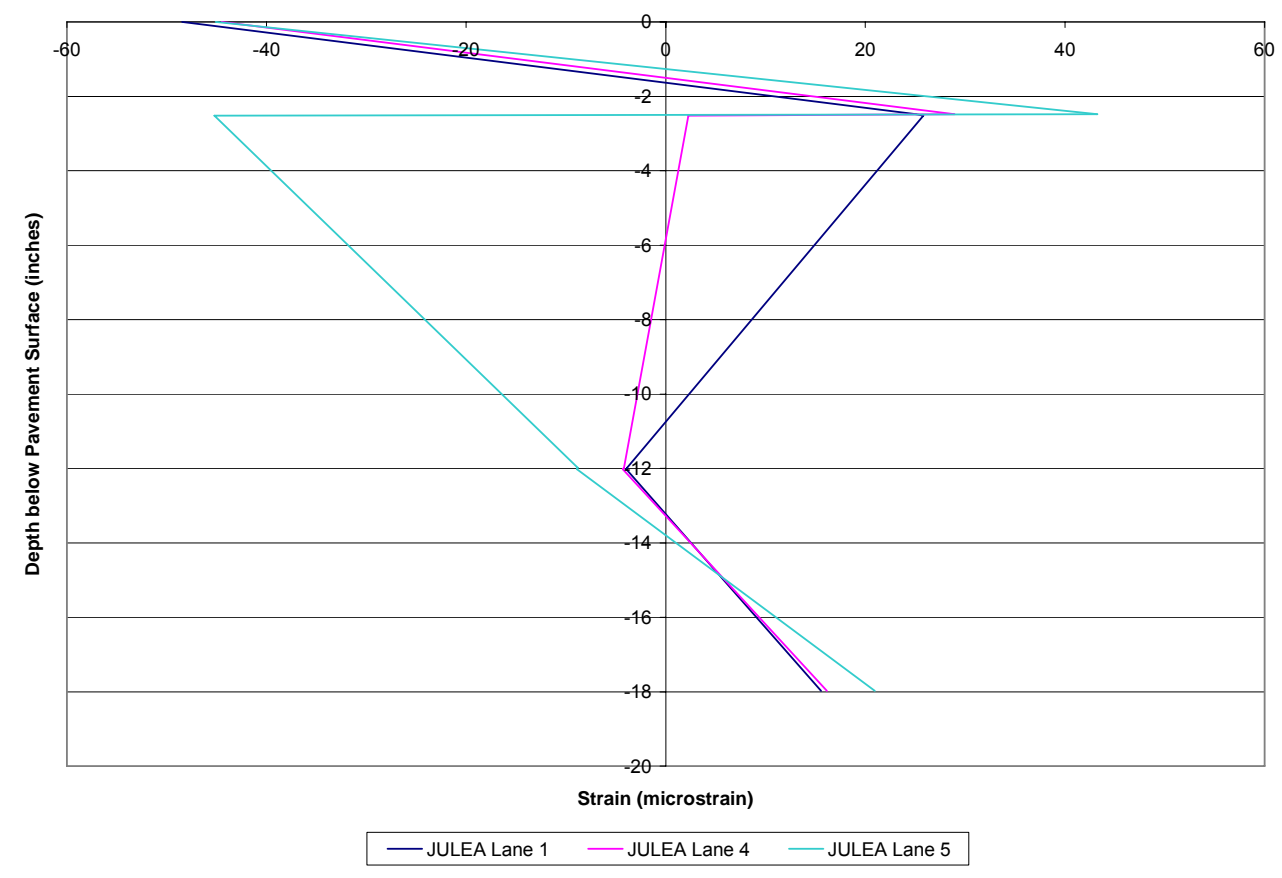

(a)

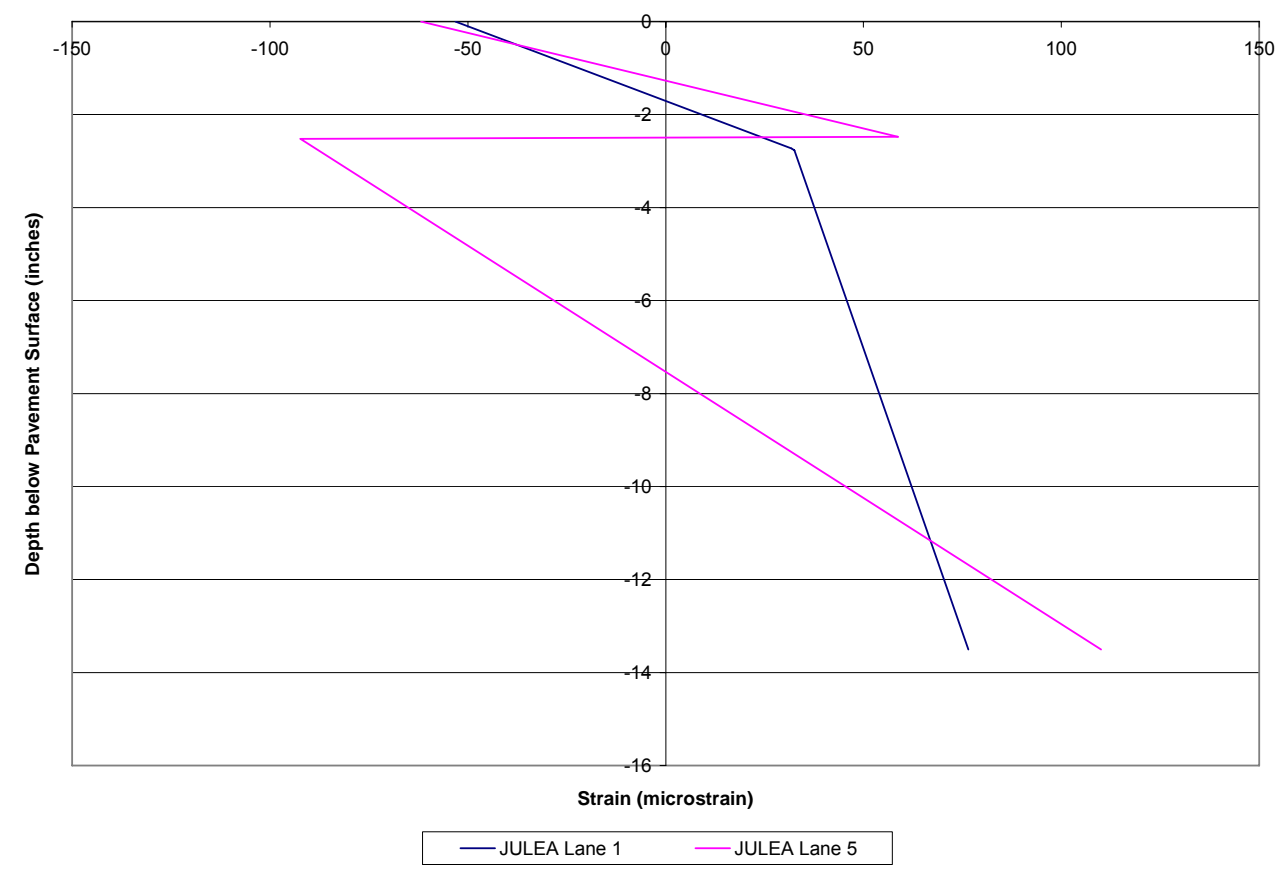

(b)

Figure 6.5 Comparisons of Calculated Strains for Different Bond Conditions (a) TA2 (b) TA3 
As can be seen in Figure 6.5, the strain distribution and maximum strain magnitudes vary significantly when the interfacial bond conditions are modified for both TA2 and TA3. Also, the neutral axis in the UTW layer shifts higher in the layer when the bond is decreased. This shift results in a corresponding increase in the maximum strain at the bottom of the UTW layer.

\section{Comparison of Theoretical and Measured Strains}

The strain data from test areas Lanes 1, 4, and 5 in TA2 and Lanes 1 and 5 in TA3 were filtered as described in Section 6.3.1. Gage readings taken during the "initial" load application (0 to 5000 load applications) were again used. Gages used to provide strains for comparison with the theoretical strains were PEB, PET, HEB, HET, UEB, and UET, for TA2 and HEB, HET, UEB, and UET for TA3. These data are presented in Figure 6.6.

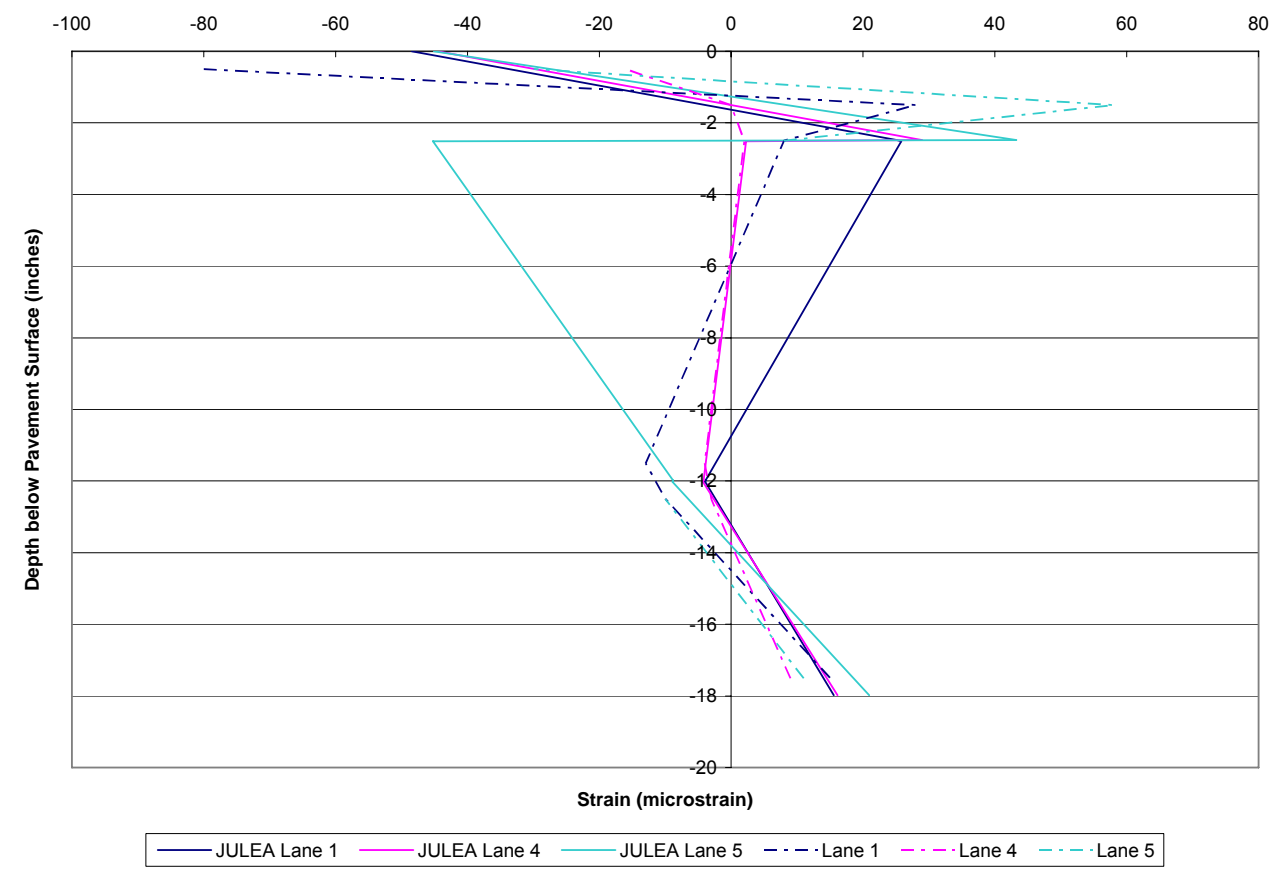

(a)

Figure 6.6 Comparisons of Calculated and Measured Strains for Different Bond Conditions (a) TA2 (b) TA3 (continued) 


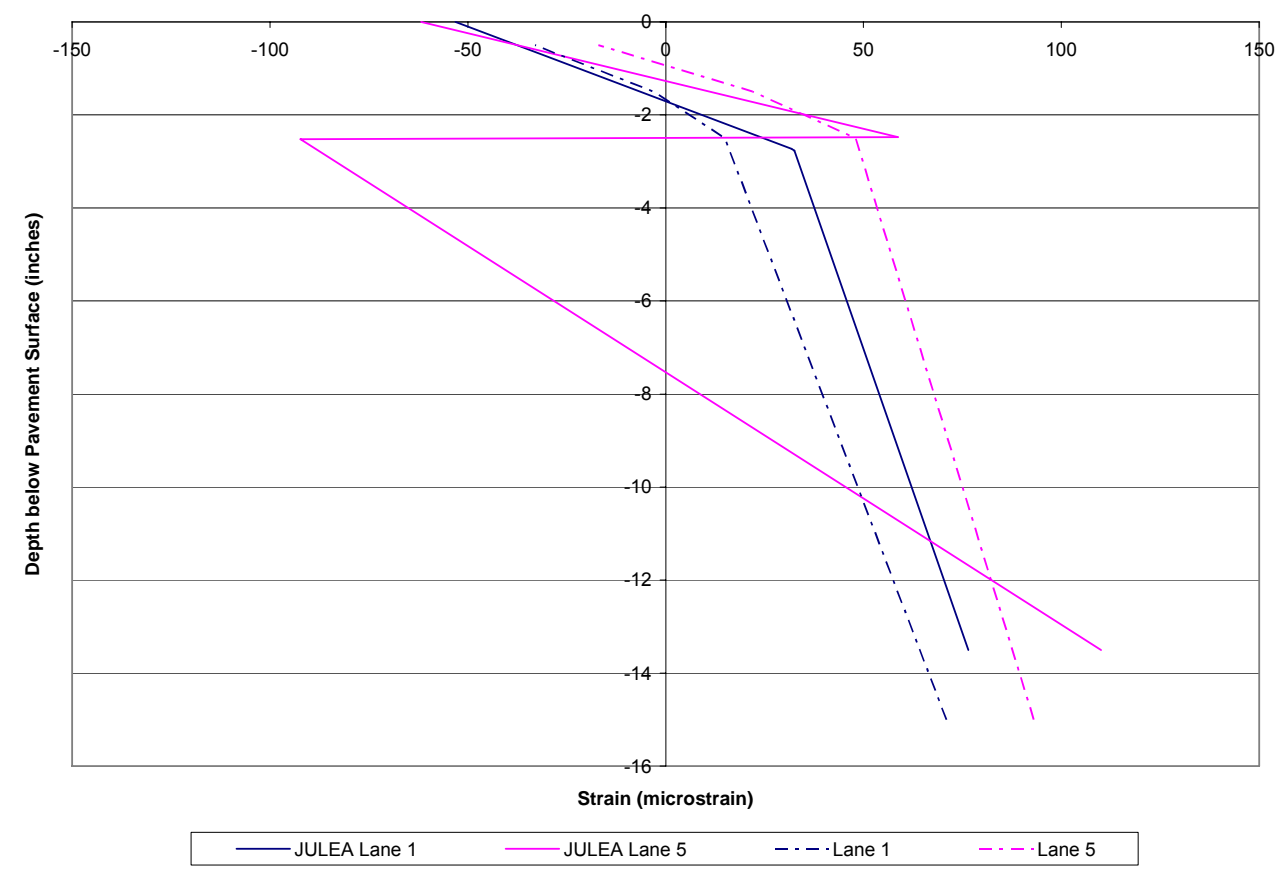

(b)

Figure 6.6 Comparisons of Calculated and Measured Strains for Different Bond Conditions (a) TA2 (b) TA3

The strain distribution for the TA2 Lane 1 generally followed the shape of the theoretical distribution but did not match the corresponding strain magnitudes. This discrepancy is particularly evident when the strains are extrapolated to the extremes of the UTW layer (see Table 6.6). The partially bonded lane in TA2 (Lane 4) did, in general, match the theoretical distribution and magnitudes fairly well. The one exception was a discrepancy between the measured and theoretical strain at the top of the HMA layer. It was thought that this discrepancy was the result of the input parameter used for the modeling of the bond, however, in subsequent runs of the program using different factors the theoretical result presented was the closest match to the measured values. 
The unbonded lane in TA2 (Lane 5) did not follow the theoretical distribution or match the magnitude of the expected strains in the UTW or HMA layers (though they do match well in the PCC layer). The magnitude of the measured UTW strains was significantly higher than the theoretical strains. Also the measured HMA strain at the top of the layer was actually tensile (positive) while the theoretical strain was negative. This may have been the result of the value of the input used for the bond modeling in the WinJULEA program. As noted previously, the input used for the unbonded condition assumed full slippage between the two layers. This assumption appears to have overestimated the bond condition for an unbonded lane. The measured values indicate that there was at least a moderate level of friction between the two layers.

For test area TA3, the measured strain distribution for Lane 1 (bonded) matched the shape of the theoretical strain distribution and magnitudes fairly well. For Lane 5 (unbonded) however, the strains did not match the expected distribution or magnitudes. This discrepancy was likely the result of the same reasons noted above for Lane 5 in TA2.

In regards to the shifting of the neutral axis in the UTW layer, taking into account the discrepancies discussed above, the neutral axes in all test lanes shifted in a similar way as the neutral axes from the theoretical analyses. For those lanes that were bonded well (e.g. TA3 Lane 1) the measured distributions had neutral axes lower in the UTW layer than those that were unbonded (e.g. TA3 Lane 5). Accordingly, the measured strains at the bottom of the UTW layer were less for the fully bonded lanes (e.g. TA3 Lane 1) than in the unbonded lanes (e.g. TA3 Lane 5).

\section{Summary}

The interfacial bond conditions did affect the strain distribution and maximum load-induced strains. The measured strains in the bonded lanes matched the 
theoretical values well. There was some discrepancy between the measured and theoretical unbonded strain distributions. Further analysis into this discrepancy indicated that even in an unbonded condition there is moderate level of friction between the UTW and HMA layers.

6.3.4. Influence of Mechanical Load Applications on Strain Distributions and Maximum Load-Induced Strains

\section{Background}

The influences of mechanical loading on the strain distribution were discussed in the literature (see Chapter 2). Three different influences were identified for further discussion. The first influence is the influence of repeated load applications on the progressive increase in the load-induced strains. Previous research by Rajan et al. [2001] indicated that the load-induced strains in a UTW pavement increase under repeated loading. That is the load-induced strain measured at an initial load application on a new UTW pavement would be less than the load-induced strain measured after, for example, 100,000 of the same load applications. The second influence is in the influence of the rolling wheel on the strain response of the UTW layer. Rajan et al. [2001] also noted that there was a strain reversal in the pavement as the wheel passed over and that this reversal produced a wave-like effect in the pavement as the wheel traveled across the surface. This reversal was confirmed by the FHWA in the report by Rasmussen et al. [2002]. The third influence noted was the location of the maximum strain in the UTW panel. The literature is in agreement that the most common distress in UTW pavements is corner cracking. This suggests that the strains at the corner location are higher than in other locations in the UTW. The strain results were presented in Section 5.2. These results are discussed in the following section.

All gages installed in the test lanes at different depths across the pavement sections are were presented however this discussion will primarily focus on the 
strains in the HMA and UTW layers. These strain data were separated by the location of loads (joint, edge, mid, or corner). Data from the joint (TA1), midpanel (TA1), edge (TA1-TA3), and corner (TA1-TA3) locations are used to discuss the influence of repeated load applications on the maximum loads in the HMA and UTW layers. Data from the edge (TA2-TA3) and corner locations (TA2-TA3) are utilized to discuss the influence of repeated load applications on the strain distributions (the number of load applications is included with each gage identifier, for example HET 560000 is data from the HMA layer, edge location, top layer at load application 560,000). Data from the mid-panel location (TA1) are used for the discussion of the influence of the rolling wheel on the UTW strain response. Data from the edge and corner locations (TA1-TA3) are used for discussion of the location of the maximum-load induced strain in the UTW layer. All figures referenced are located in Appendix B.

For comparison purposes failure strain values (strains that will cause cracking) for both UTW concrete and HMA materials were calculated using typical failure stresses and elastic moduli for these materials. The 28 day material property values (Section 5.1) of the UTW concrete ranged from $5.75 \times 10^{6}$ to $7.42 \times 10^{6} \mathrm{psi}$ for the elastic moduli and from 675 to 1265 psi for the flexural strength. Using the linear elastic equation $(\sigma=E \varepsilon)$ the theoretical failure strains for the UTW concrete ranges from 120 to 170 microstrain. Similarly using a book value of 65 psi for the Indirect Tensile strength of the HMA and the layer modulus of the HMA (550,000 psi back-calculated from the pavement deflection analysis) the theoretical failure strain in the HMA was 120 microstrain. While using the linear elastic relationship for the HMA would not normally be valid for a visco-elastic material, given that the testing in the APT was conducted at relatively stable temperatures, the resulting strain is expected to be reliable. 


\section{Influences of Repeated Load Applications}

Figure B.34, illustrates the effect of the repeated load applications on the measured strains at the joint location (TA1 - Gages UJT and HJT). As can be seen in this figure, the measured strains increase by more than double (13 to 40 microstrain) in the UTW layer. Also, the measured strains in the HMA layer increase significantly (-7 to -58 microstrain) over the load period $(20,000$ to 560,000 load applications). However, the magnitude of the strains was still fairly low and thus they were not at a level that would cause any distresses in either the UTW or HMA. This was supported by the fact that no distresses were observed at the joints (see Section 5.4).

The effect of repeated load applications on the measured UTW and HMA strains at the edge location (TA1 - Lane 1 gages HET and UET) is illustrated in Figure B.36. The maximum measured tensile strain in the HMA increased only slightly (8 to 14 microstrain) with the number of load applications, while the tensile strain in the UTW increases quite significantly (2 to 45 microstrain). However, both the HMA and UTW strain values were still well below the strain level necessary to cause cracking. The measured strains in the unloaded lane (TA1 Lane 2 Gages HET and UET) are also represented in this figure. The value of the measured strain in the HMA layer under Lane 2 is the same as in Lane 1 after 560,000 load applications. The value of the measured strain in the UTW layer in Lane 2 increased with the number of load applications indicating that the load transfer was transferred across the joint between the two lanes. The magnitude of the measured strain in Lane 2 was approximately 65 percent of the load in Lane 1 at the edge location.

The influence of repeated load applications on the measured UTW and HMA strains at the corner location (TA1 - Lane 1 gages HCT and UCT) is illustrated in Figure B.37. The maximum strain in the HMA was very low (-2 microstrain) and did not increase with the number of load applications. Likewise the strain in the 
UTW was also very low (5 microstrain) and also did not increase with the number of load applications. The unloaded lane in TA2 also produced similar results in that the measured strain values were very low in both the UTW and HMA layers and these values did not increase with the number of load applications.

The effects of repeated load applications on the measured strain responses are illustrated in Figures B.38 to B.47 for Lanes 1 through 5 in TA2 and Figures B.48 to B.57 for Lanes 1 through 5 in TA3. In TA2 at the edge location, the UTW strains (UEB, UET) were either relatively constant or increased moderately with the number of load applications. The largest UTW strain (UET) increase (increasing from 10 to 25 microstrain) that resulted from repeated loading was observed in Lane 4, the partially bonded lane. The HMA strains (HEB, HET) generally followed a similar trend as the UTW strains within a given lane. The largest increase in the HMA strains (HET) (increasing from 8 to 20 microstrain) was also in Lane 4.

For the corner location in TA2 (Lanes 1 through 5) the strains in the UTW (UCBmax) were either consistent or showed moderate increases with an increasing number of load applications (typically having values ranging from 10 to 15 microstrain measured throughout the evaluations) for all lanes. The largest increase with the number of load applications was in Lane 1 (increasing from 55 to 140 microstrain) which, as discussed in previous sections, debonded due to lack of vibration of the concrete during construction. This upper value converts to a stress of $610 \mathrm{psi}(4.21 \mathrm{MPa})$. The 14 day flexural strength of the concrete in Lane 1 was 635 psi (4.38 MPa). Obviously, the concrete could not withstand many load applications at this level before cracking. This result illustrates why this lane exhibited so much cracking (see Figure B.67). For the HMA strains at the corner location (HCB or HCT), the strains were near zero or were in compression in all lanes. This result indicates that the risk of failure in the HMA layer due to cracking was minimal. 
In TA3, the measured UTW strains (UEB) were relatively constant with increases in the number of load applications (approximately 10 microstrain) at the edge location regardless of lane. The HMA strains at the bottom of the layer (HEB) in general increased with the number of load applications in all the lanes. The largest increase in HMA strains (HEB - increasing from 105 to 130 microstrain) was in Lane 5, the unbonded lane. This value was within the range that could cause cracking at the bottom of the HMA layer.

In TA3 at the corner location, the UTW strains were either consistent or showed moderate increases with the number of load applications. The largest increase (from 5 to 40 microstrain) occurred in Lane 3 . This increase is still was still fairly low and would not be expected to cause any damage to the concrete. For the HMA layer, all strains showed an increase with the number of load applications in all the lanes. The largest increase (112 to 160 microstrain) was in Lane 5, the unbonded lane. Again, this result indicates that when the UTW is unbonded, there is also a risk of cracking at the bottom of the HMA.

Test Areas TA2 and TA3 were instrumented with gages at different depths within the pavement layers to evaluate the strain distribution across the section. In order to evaluate the effect of repeated load applications on the strain distribution the data in Figures B.38 to B.57 were filtered to isolate the strains when the APT wheel was directly over the gages (PEB, PET, HEB, HET, UEB, UET, PCB, PCT, HCB, HCT, UCBmax, and UCTmax gages were utilized). These strain data were plotted at the depths corresponding to their depths within the pavement to produce strain distribution plots. This was performed for strain distributions at initial load application (0 to 20,000 load applications) a load application approximately at the middle of the testing (150,000 to 300,000 load applications) and near the end of the APT testing (275,000 to 560,000 load applications). An example of these plots from TA2, Lane 3 is shown in Figure 6.8. For the all the 
lanes in TA2 and TA3, the remaining strain distribution plots are presented in Appendix C, Figures C.1 through C.10. Discussion of these plots follows.

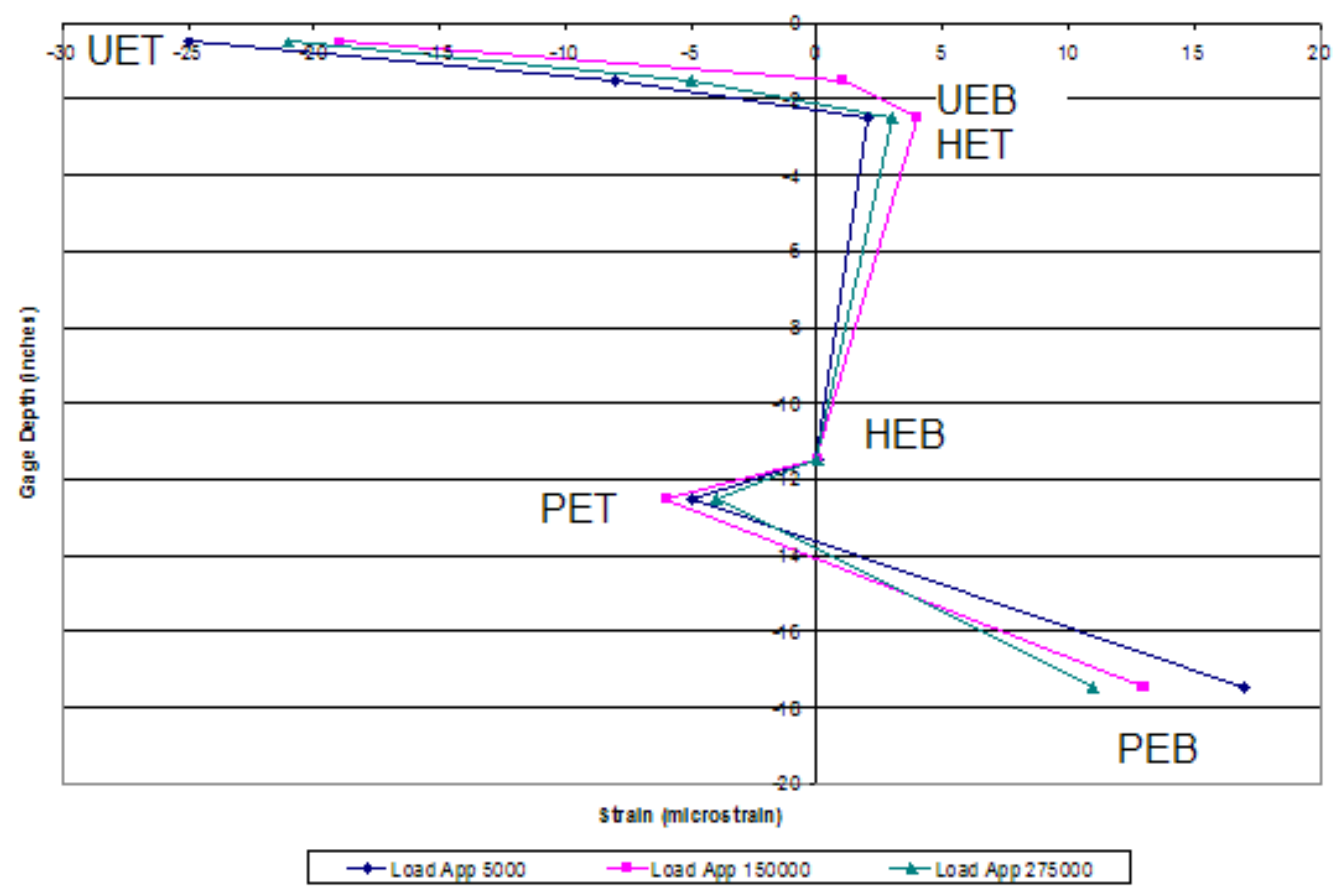

(a)

Figure 6.7 Strain Distribution for TA2 - Lane 3 (a) Edge (b) Corner (continued) 


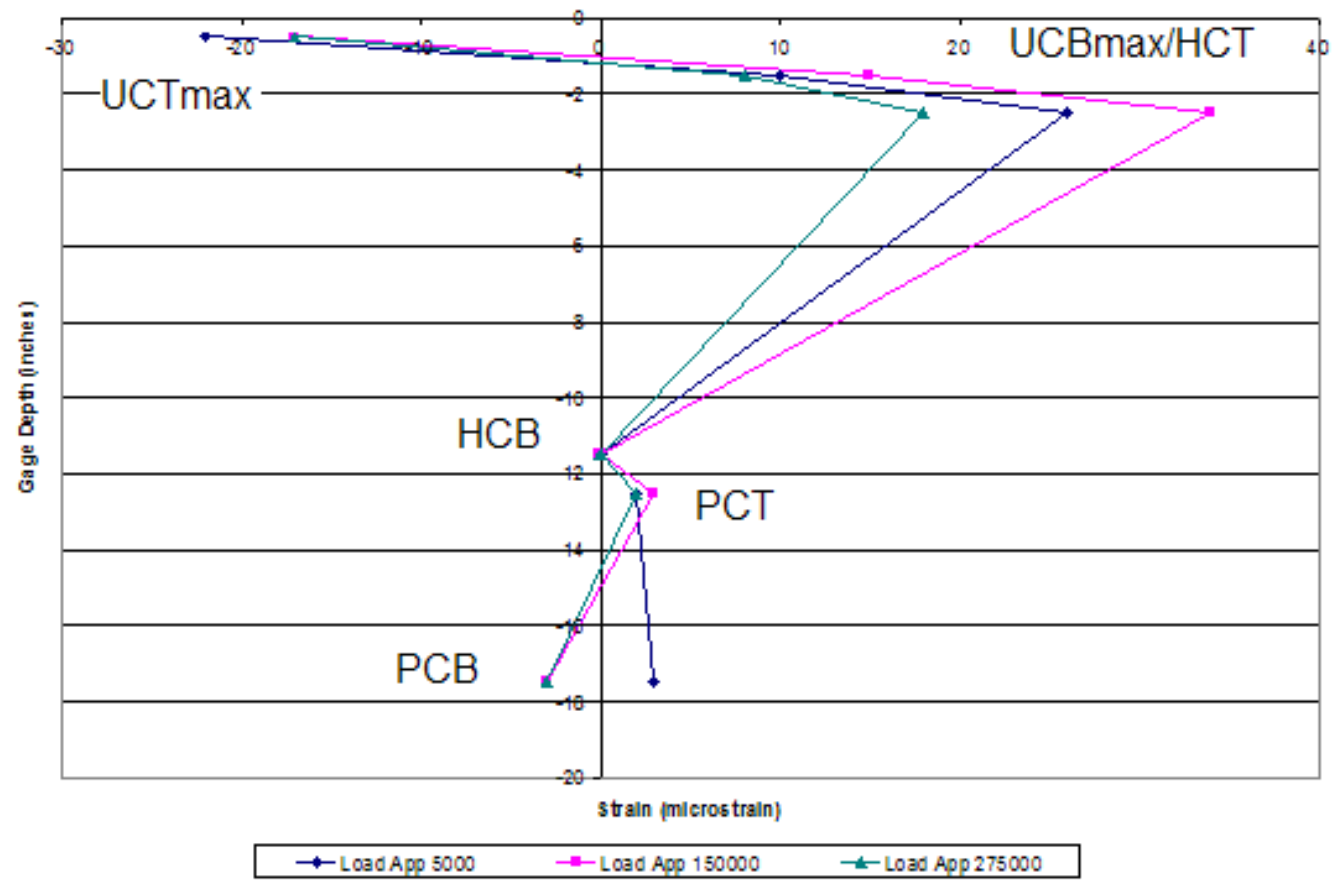

(b)

Figure 6.7 Strain Distribution for TA2 - Lane 3 (a) Edge (b) Corner

In general the strains fell within a narrow band and the strain distribution did not change much with the number of load applications. There were some exceptions, however. As discussed in Section 6.3.3., debonding in the strain distribution is reflected in a decrease in the strain at the top of the HMA layer. This phenomenon was noted in TA2 Lane 1 (unbonded as a result of the construction error) edge and corner locations, Lane 4 (partially bonded) edge location, and Lane 5 (unbonded) edge and corner locations. Also the debonding was noted in TA3, Lane 2 (fully bonded) corner location, Lane 3 (fully bonded) edge and corner locations, Lane 4 (fully bonded) corner location, and Lane 5 (unbonded) edge and corner locations. Thus, the only changes that were noted in the strain distribution were as a result of debonding or the bond conditions (partially bonded or unbonded). The effect of the repeated load applications on 
this debonding was mixed in that the strains at the top of the HMA did not necessarily decrease with increasing load applications.

\section{Location of the Critical Load in the UTW Layer}

Comparing the results of the edge and corner data from TA1, the location of the maximum strain in the UTW layer actually was at the edge location, not at the corner location as was expected. While the measured strains (UET) generally were low for the first 300,000 load applications there was an apparent change in the after this point. It is possible that there may have been some debonding at the edge location which resulted in the UTW strain increase. However, as no sounding was done on this test lane this theory could not be confirmed. A comparison of the edge and corner locations for was made to evaluate the critical load location for the UTW layer.

A similar comparison of the measured strain data for all the test lanes in test areas TA2 and TA3 indicates that the corner location did indeed have the higher strains than the edge location in the UTW layer. Given that this was noted over all test lanes in both test areas it is likely that the result from the TA1 was an anomaly.

Figure B.35 illustrates the influence of the rolling wheel on the UTW strain response at the mid panel location (TA1 - Gages UMTa, UMTb, and UMTC). As can be seen in the figure, there is a strain reversal as the wheel passes over the gage. The gages placed in series also indicate that this reversal moves in front of the wheel as it travels along the pavement confirming the "wave-like" effect that was noted in the literature. The influence of repeated load applications on the measured strain response at the mid-panel location can also be seen in this figure. The magnitude of the tensile and compressive strains in the UTW layer remained very low under repeated loading only increasing to levels of 5 and -10 microstrain, respectively. This result indicates that the strains in the mid-panel 
are low when the load is applied at the edge. This result is also supported by the lack of distress in at the mid-panel location (see Section 5.4).

\section{Summary}

The influence of multiple load applications on the strain distribution and maximum load induced strains was as follows. For those sections that had a good bond, the number of load applications had little effect on the maximum strains or the strain distributions. For those sections that were partially bonded or debonded, both the maximum strains and the strain distribution were affected by an increase in the number of load applications. Even in the debonded sections (with the exception of TA2 Lane 1), the measured strains were all well below that which would be expected to cause cracking in the UTW. However, in some cases the HMA in the debonded sections did experience strains large enough to cause cracking. The results also indicated that the "wave-effect" in front of the rolling wheel does exist. This result indicates that the UTW response to the applied wheel load is primarily flexural. Further, a comparison of the measured strains at the edge and corner locations indicated that the critical load location in the UTW layer was at the corner.

\subsubsection{Influence of Temperature Gradient on Strain Distribution and Maximum Load-Induced Strains}

\section{Background}

The PCA UTW design method (Wu et al. [1998]) includes calculations for HMA strain and UTW stress that result from the temperature gradient in the UTW. Vandenbossche [2001] evaluated the strains in thee UTW test sections at MnROAD and indicated that temperature gradients can be significant in UTW pavements. However, that the short joint spacing and bond reduced these effects. 
This section will evaluate the influence of temperature gradients resulting from changes in the environmental temperatures over a 1 year evaluation period. The temperature data was collected from test area TA4 which had different UTW and HMA layer thicknesses (see Section 4.2.4). Thermocouples were placed at middepth of the UTW layers and at the surface of the HMA layers to record the temperatures in these layers throughout the evaluation period. Details of the instrumentation of this test area were discussed in Section 4.3.4. The temperatures recorded during the evaluation period were presented in Section 5.3.

\section{Theoretical Curling Strains}

Westergaard developed a theoretical relationship that related the curling strain to the temperature gradient in a concrete slab (Huang [1993]). Thus, to estimate the theoretical curling strains in the UTW that would result from the temperature changes in the environment, the temperature gradient in the pavement was determined by calculating the difference between the recorded UTW and HMA temperatures (presented in Figure 5.9). Temperatures were recorded for Lane 1 (4 inch $(100 \mathrm{~mm})$ thickness), Lane 2 (3 inch $(75 \mathrm{~mm}$ ) thickness), and Lane 3 (2 inch $(50 \mathrm{~mm})$ thickness). The data were sorted for a high temperature condition $($ Time $=16: 00)$ and a low temperature condition $($ Time $=4: 00)$.

Using Westergaard's equation for curling (Equation 6.1), the theoretical curling strain was calculated. The other input values were the coefficient of thermal expansion, $\alpha_{T}\left(5 \times 10^{-6} /{ }^{\circ} \mathrm{F}\left(9 \times 10^{-6} /{ }^{\circ} \mathrm{C}\right)\right)$ and the Poisson's ratio of the concrete, $\mu$ (0.22). These data were plotted as a function of time and are presented in Figure 6.9 .

$$
\varepsilon=\frac{\alpha_{T} \Delta t}{2(1-v)}
$$




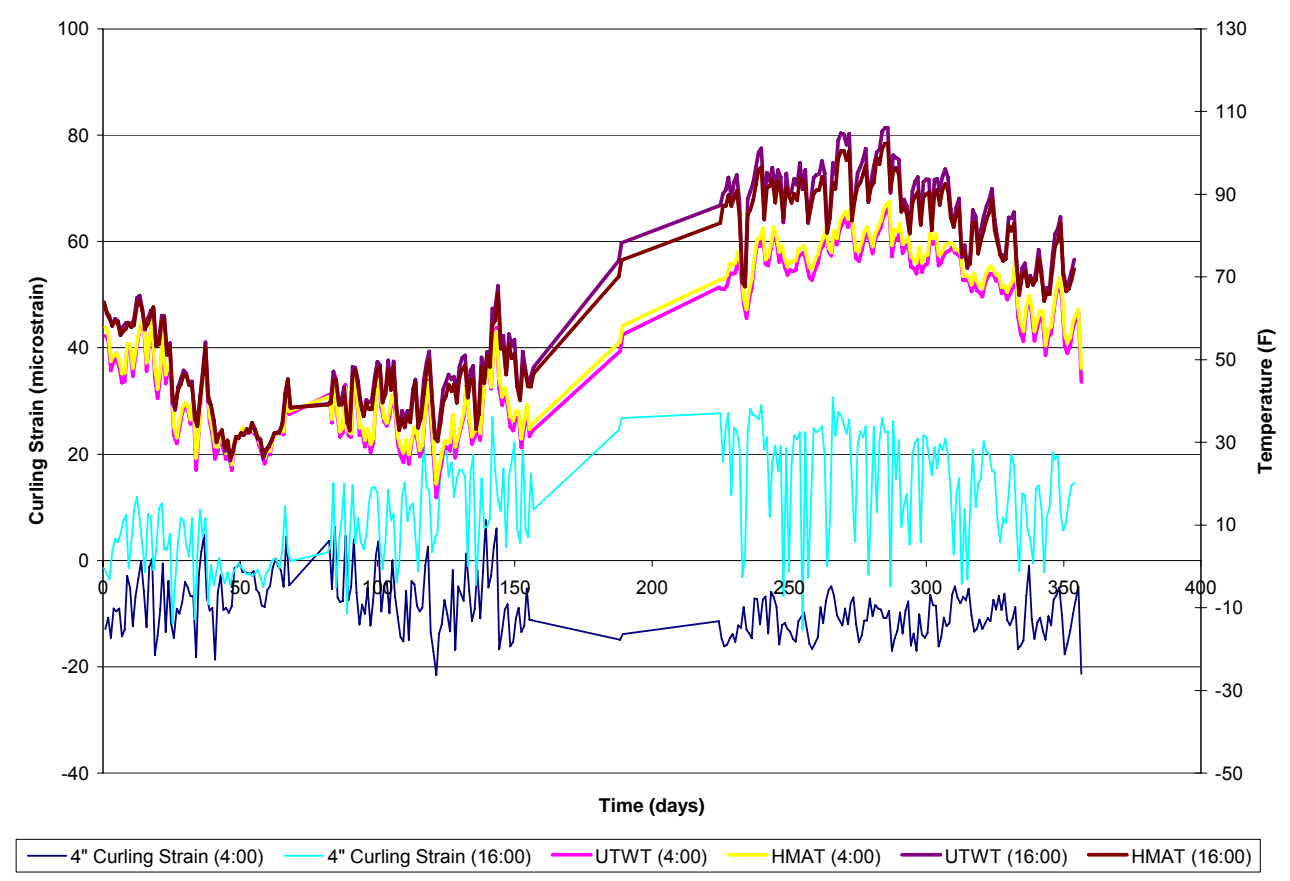

(a)

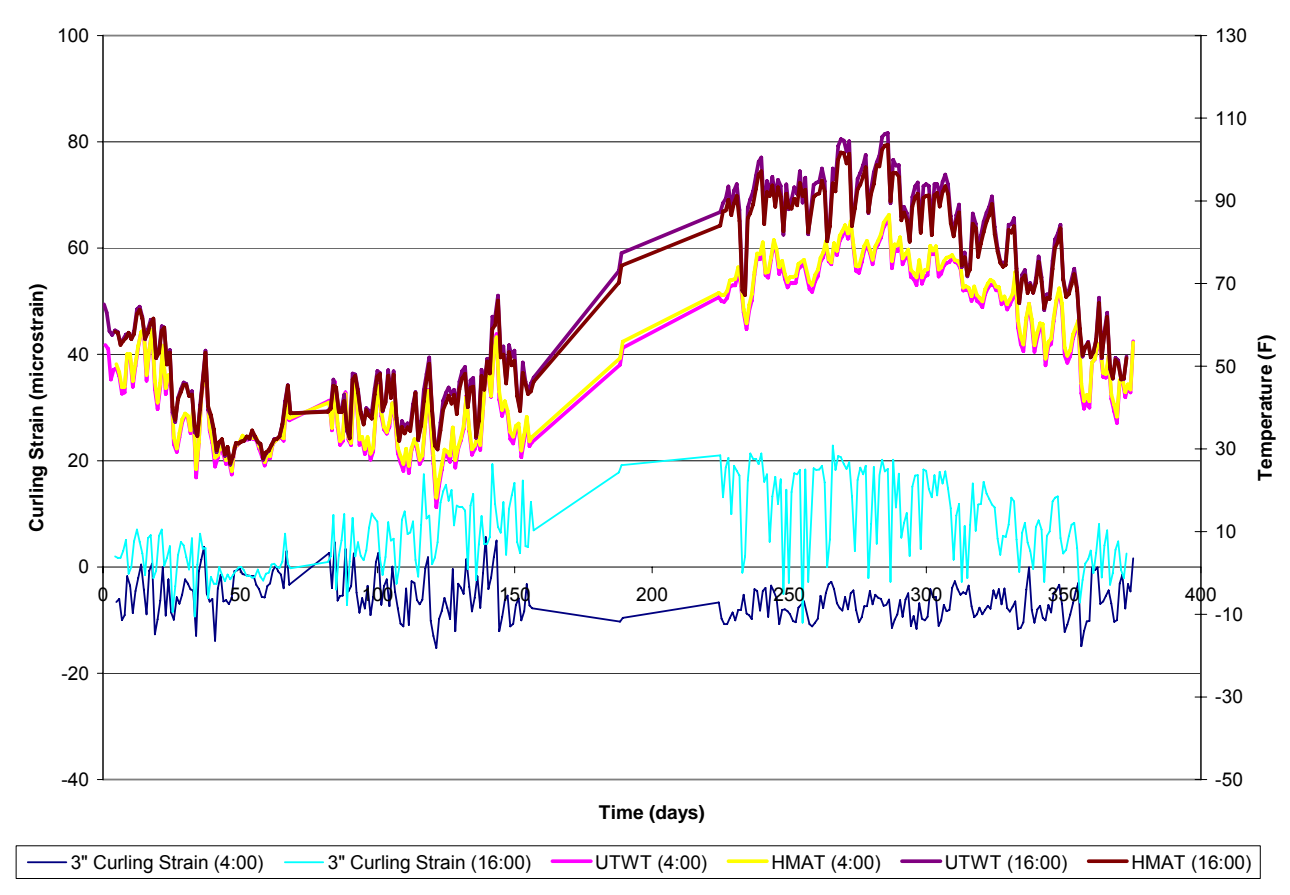

(b)

Figure 6.8 Theoretical Curling Strains in UTW resulting from Measured Temperature Gradients (a) Lane 1 (b) Lane 2 (c) Lane 3 (continued) 


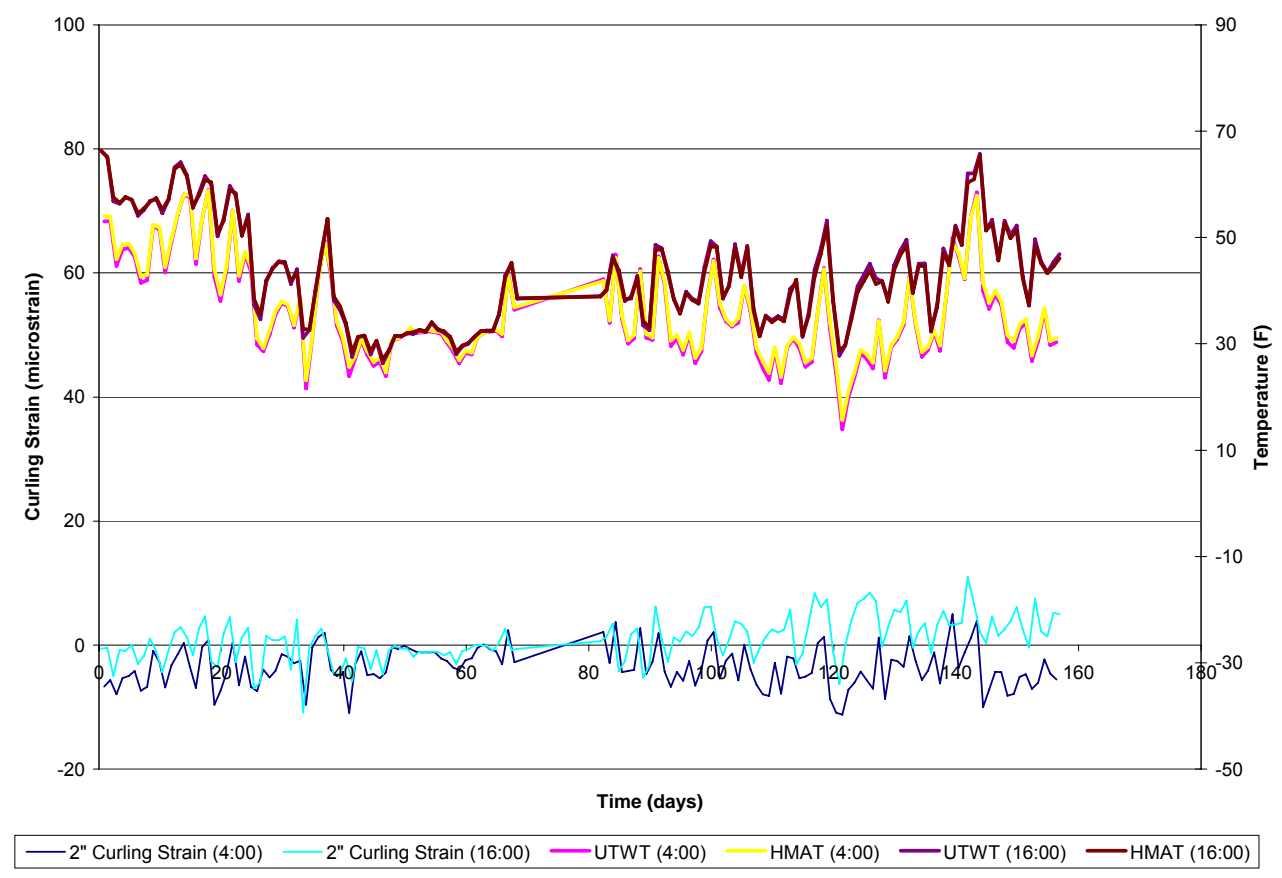

(c)

Figure 6.8 Theoretical Curling Strains in UTW resulting from Measured Temperature Gradients (a) Lane 1 (b) Lane 2 (c) Lane 3

As can be seen in the figure, for all lanes the temperatures during the high temperature condition are higher in the UTW than in the HMA as would be expected during the day. Also, the reverse happens during the low temperature condition with the higher temperature carrying over in the HMA during the night. The temperature difference (top - bottom) does vary by lane with the largest difference occurring in the 4 inch $(100 \mathrm{~mm})$ UTW, followed by the 3 inch $(75 \mathrm{~mm})$ and 2 inch $(50 \mathrm{~mm})$ sections. The temperature difference also was greatest during the day.

These observations are also reflected in the calculated curling strains as well. The curling strains are greatest in Lane $1(4$ inch $(100 \mathrm{~mm}))$ followed by Lane 2 (3 inch $(75 \mathrm{~mm}))$ and Lane $3(2$ inch $(50 \mathrm{~mm}))$. Additionally, the strains were 
greatest during the day and at a minimum at night. The magnitude of the strains is very low for Lane 3 ranging only from -11 to 13 microstrain. For Lane 2 the strain range was greater varying from -15 to 23 microstrain, while for Lane 1, the same range was -21 to 31 microstrain. Using the linear elastic relationship ( $\sigma=$ $E \varepsilon$ ), this maximum tensile strain (31 microstrain) corresponds to a maximum curling stress in the UTW layer equal to $158 \mathrm{psi}(1.09 \mathrm{MPa})$ which is low relative to the flexural (tensile) strength of the concrete used in TA4 (970 psi (6.69 MPa) at 28 days).

A comparison was conducted using the same gradients with the PCA UTW design equations for UTW temperature-induced strains (Equation 2.6). The PCA equation actually calculates the stress that results from the temperature gradient, thus, to compare the PCA values with those calculated by the Westergaard equation, these values were converted to strains using the linear elastic conversion $(\sigma=E \varepsilon)$. The results were comparable to the Westergaard strains. The ranges using the using the PCA equation were -9 to 17 microstrain for Lane 3, - -14 to 26 microstrain for Lane 2 and -22 to 33 microstrain for Lane 1 . These results indicate that for a wide range of temperature conditions either the PCA or Westergaard approaches produce similar results. This is true even though the PCA equation takes into account the finite dimensions of the slab, while the Westergaard equation is based on a quasi-infinite slab. These results indicate that under normal service conditions, the effect of the UTW slab size on curling is negligible.

\section{Summary}

In summary, the temperature gradient was greater in thicker UTW pavement sections as would be expected. As a result the theoretical curling strains were greater in the thicker sections as well. Further, the curling strains were greater during the warm day than during cool night conditions. However, these strains were not large enough to cause any distress in the UTW. Additionally, a 
comparison of the Westergaard curing solution to the PCA equation indicated that there was little difference in the results calculated using the two approaches.

\subsection{Type and Severity of Distresses}

This section discusses the influence of structural properties of the pavement sections, UTW concrete mechanical properties, interfacial bond conditions, repeated mechanical load applications, and temperature gradient on the type and severity of distresses. All test areas are used for this discussion. Distress evaluations were conducted intermittently during the APT test evaluations (TA1 through TA3) as well as at the end of the one year evaluation of TA4. The distress evaluation methodology was described in Section 4.5. The results of the distress surveys for these test areas were presented in Section 5.4. Figures B.67 through B.77 contain maps of the distresses observed in the test lanes.

6.4.1. Influence of Structural Properties of the Pavement Sections on Type and Severity of Distresses

\section{Background}

In the NCHRP report on the state of the practice of UTW, Rasmussen and Rozycki [2005] described the common distresses observed in UTW pavements and proposed mechanisms for their development. It was noted that one major factor influencing distress development was the quality of the underlying layers. Sections constructed with HMA mixes that had a higher quality, mixes that were more rut resistant, performed better. It is thus, hypothesized that the stiffness of all layers underlying the UTW will affect the distress development.

As noted previously, Test Areas 1 through 3 were constructed with different pavement layers. The construction of these test areas was discussed in Sections 4.2.1 through 4.2.3. As shown in Section 6.3, the strains measured in 
pavement were less for test lanes with underlying PCC layers (TA1 and TA2) than in test lanes without PCC layers (TA3). The lower strains in pavement sections with the underlying PCC layers are expected to lead to less distress in the test lanes for TA1 and TA2, than in TA3.

\section{Discussion of Results}

As noted previously, TA1 (containing a very stiff underlying concrete layer) had the stiffest pavement section. No formal distress survey was conducted for TA1 as was performed in the other test areas. However, no cracking was noted in the UTW at the end of the APT loading. This result indicates that the strains remained low enough to prevent cracking (as indicated in Section 6.3), even after over 550,000 load applications with a load of 9,000 lbs.

The results of the distress surveys for TA2 and TA3 were presented in Section 5.4. As noted previously, TA2 (also contained an underlying PCC layer) was stiffer than TA3 (constructed over an HMA section). A comparison of the distresses observed for all test lanes in these two test areas is presented in Figure 6.10. These two diagrams illustrate the distresses observed after load testing of the lane was completed. The total number of load applications applied to each lane at the end of testing is included in the figure. 


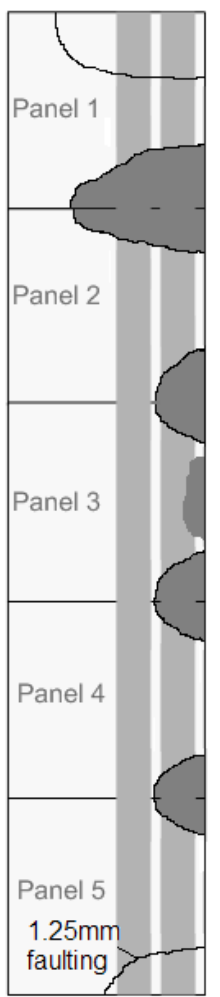

Lane 1

300,000 Load Applications

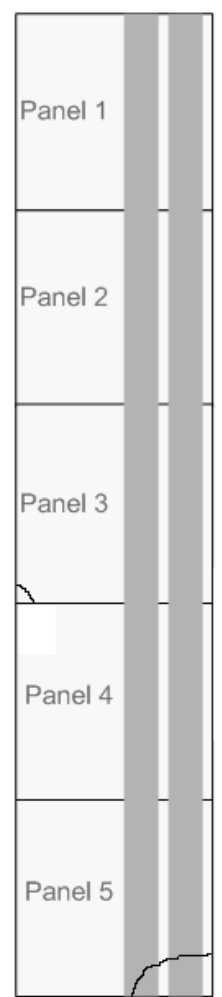

Lane 2 315,000 Load Applications

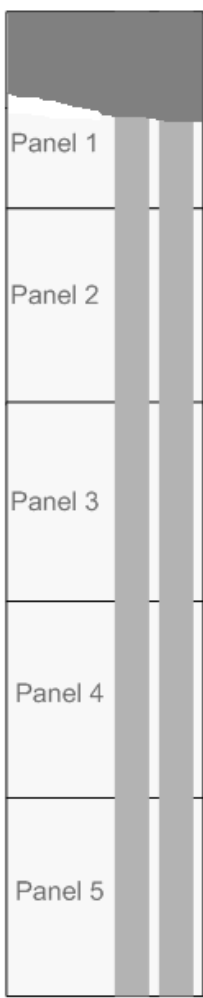

Lane 3 260,000 Load Applications

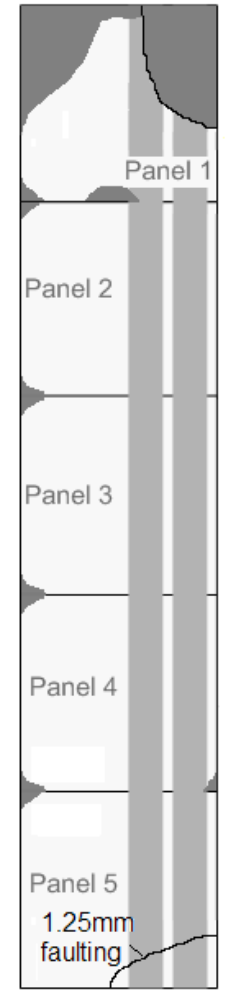

Lane 4 330,000 Load Applications

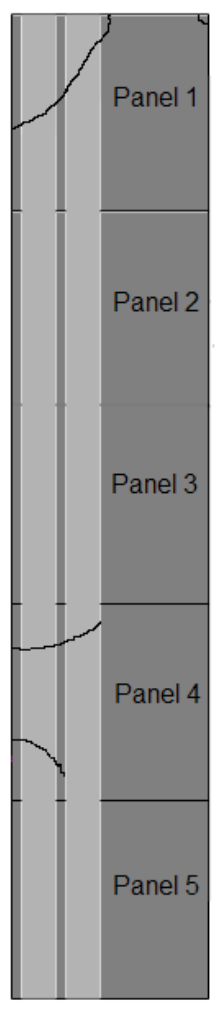

Lane 5 180,000 Load Applications

(a)

Figure 6.9 Final Distress Comparisons for Test Areas 2 and 3 (a) TA2 (b) TA3 (continued) 


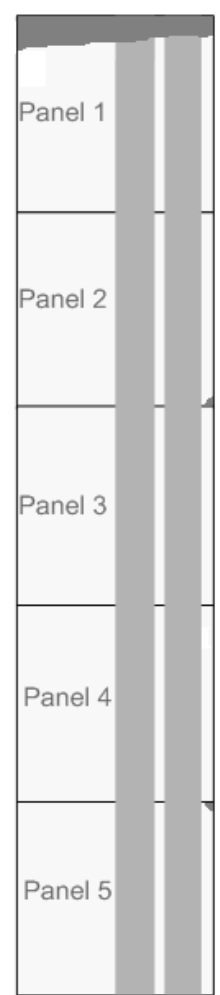

Lane 1

300,000 Load Applications

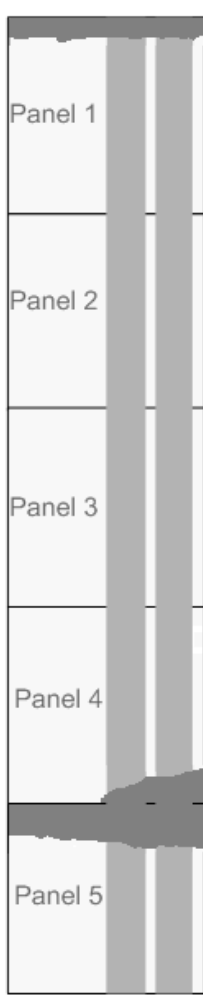

Lane 2 300,000 Load Applications

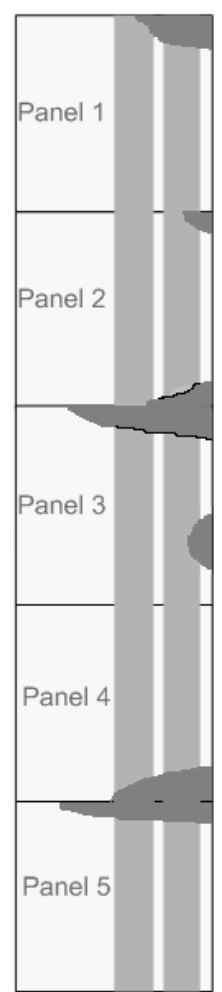

Lane 3

300,000 Load Applications

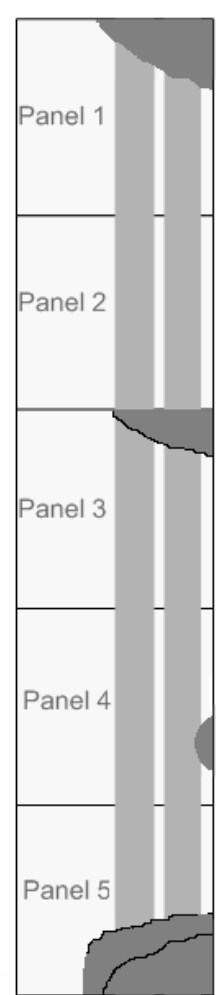

Lane 4

300,000 Load Applications

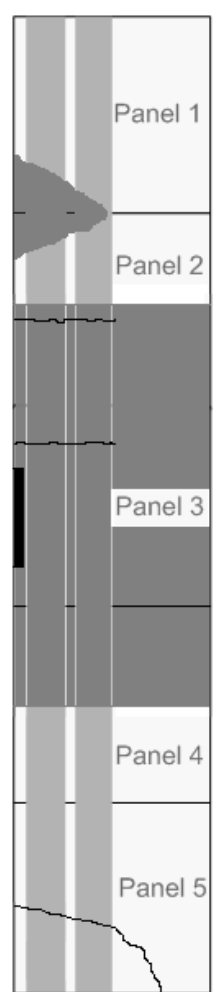

Lane 5 300,000 Load Applications

(b)

Figure 6.9 Final Distress Comparisons for Test Areas 2 and 3 (a) TA2 (b) TA3

As can be seen in Figure 6.10, the observed distresses in Lane 1 initially do not match what was expected for the section with an underlying PCC layer.

Comparing this lane to the Lane 1 in TA3, there is much less distress observed in TA3 than in TA2. However, for TA2, Lane 1, as was noted previously, this lane debonded as a result of no vibration of the UTW concrete during construction. Therefore, the distresses observed for Lane 1 in TA2 were the result of debonding, not the structural properties of the pavement section. 
For the other lanes, neglecting the edge effects of the APT test pit (milling was non-uniform in these areas and may have caused uneven bonding and/or stress concentrations to develop in the UTW layer) the results fairly well match what was expected. There is little debonding and very little cracking from the middle of Panel 1 through the middle of Panel 5 for Lanes 2 through 4 in TA2.

Additionally, the debonding in Lane 4 is most likely due to partially bonded condition in this lane (bond preparation was eliminated intentionally to evaluate its effects on the performance of the UTW). In TA3, there is some debonding and cracking from the middle of Panel 1 through the middle of Panel 5 for Lanes 2 through 4 . In this test area Lanes 2 through 4 lanes were all fully bonded and thus, the results cannot be attributed to the initial bonding condition. In regards to the distresses observed, these results should be taken in context of the variable mechanical properties of the test lanes. The influence of the concrete mechanical properties is discussed in the next section.

\section{Summary}

The structural properties of the pavement section did have an effect on the observed distresses at the end of the APT loading period. The test areas reflected this affect, as was expected, with the stiffer sections having the less distress than the more flexible sections. However, these results may also be influenced by the mechanical properties of the UTW concrete.

6.4.2. Influence of UTW Concrete Material Properties on Type and Severity of Distresses

\section{Background}

The PCA fatigue equations (Equations 2.10 through 2.12) are employed in the PCA UTW design methodology, Wu et al. [1998] to calculate the number of allowable load applications at a given stress level. These equations are based on the stress to strength ratio, which is the ratio of the applied stress in the concrete to the strength of the concrete. As this ratio increases, the number of 
load applications that can be applied at this level before failure decreases. Conversely, if the concrete strength is high, the number of load applications it can withstand before cracking is also high.

To evaluate the effect of the concrete mechanical properties on the distresses a comparison of the test lanes constructed with different mix designs (in TA2 and TA3) is conducted. Concrete mixed using mix designs MD-1 through MD-3 were used to construct Lanes 1 through 3, respectively in TA2. Concrete mixed using MD-1, MD-4, and MD-2 were used to construct Lanes 1 through 3, respectively, in TA3.

The flexural strengths are used as a basis for this comparison as this is the value of the concrete strength that is commonly used in the PCA fatigue equations. The flexural strengths of MD-1 through MD-4 used in TA2 and TA3 were presented in Figure 5.2. The 28 day flexural strengths of the mixes in TA2 were 635,705 , and 945 psi $(4.38,4.17$, and 6.52 MPa) for MD-1, MD-2, and MD-3, respectively. For TA3, the 28 day flexural strengths for MD-1, MD-4, and MD-2 were 1060, 990, and 1060 psi $(7.31,6.83$ and $7.31 \mathrm{MPa})$, respectively. Accordingly, in TA2, the lanes in order of decreasing distress were expected to be Lane 1 (MD-1), Lane 2 (MD-2), and Lane 3 (MD-3). Similarly in TA3, it was expected that Lane 2 (MD-4) would have greater distress than either Lane 1 (MD-1) or Lane 3 (MD-2) which had equivalent strengths.

\section{Discussion of Results}

Figure 6.10 illustrated the final distresses in TA2 and TA3. In TA2, The extent of distresses generally followed the expected trend. Lane 1 (MD-1) had the highest degree of distress. The extent of distress observed in both Lanes 2 (MD-2) and 3 (MD-3) overall was relatively little. The debonding of Panel 1 in Lane 3 and the crack in Panel 5 of Lane 2 are most likely due to the edge conditions in the APT. Disregarding the distresses caused by the edge conditions, there was little 
difference between the performance of MD-2 (high early strength mix) and MD-3 (fiber mix) in regards to distresses.

It should be noted that Lane 3, in which MD-3 was used, debonded only at the outer edge of Panel 1. No cracking was noted in Lane 3 even though debonding had occurred. Thus, the higher flexural strength of MD-3 (which contained fibers) appears to have prevented cracking in the presence of debonding.

In TA3, Lanes 1 and 3 constructed with MD-1 and MD-2, respectively, were expected to have similar degree of distresses given that they had equal flexural strengths. However, the lane constructed with MD-2 (high early strength mix) did have more distresses (both debonding and cracking) than the lane constructed with MD-1 (base mix). The lane (Lane 2) constructed using with MD-4 (high early strength and fiber mix), which had a lower flexural strength than in Lanes 1 and 3, did have some distress (debonding only), but not as much as in the lane constructed with MD-2 (Lane 3). Additionally, as noted with the lane constructed with the fiber mix in TA2 (Lane 3) the fibers in the mix may have prevented cracking in the debonded areas of the lane constructed with MD-4 (Lane 2). Overall, however, the flexural strengths among the lanes were fairly close (within 7 percent). As such, this difference may not be significant enough to influence the distress development. This mixed result indicates that there are likely other factors, that have a greater influence on the distresses than UTW concrete properties.

\section{Summary}

In TA2, the results indicated that the mix with fibers may delay cracking even in the presence of debonding. The fiber mix (MD-3) had the highest flexural strength and performed the best in regards to cracking. Ignoring APT edge effects, both the fiber reinforced concrete and the high early strength concrete performed well in regards to the final distresses. 
Definite trends were difficult to identify for TA3. The lack of cracking in the lane constructed with MD-4 again indicated that the use of fibers may have delayed cracking of the pavement in the debonded areas. The mixed results in TA3 may have been due to the fact that flexural strengths were all fairly close to one another and the difference may not have been significant enough to discern a difference amongst them based on the material properties alone.

6.4.3. Influence of Interfacial Bond Conditions on Type and Severity of Distresses Background

Armaghani and Tu [1997] in their study of the Florida UTW sections noted that when debonding of the UTW layer occurs, cracking of the UTW layer soon follows. This finding was also confirmed by Burnham [2005] in his review of the UTW sections installed at MnROAD.

As discussed in Section 6.3, when debonding of the UTW layer occurred during the APT evaluations, the strains in the UTW layer increase. It would thus be expected that the sections with lower bond strengths (partially bonded or debonded) would exhibit greater distress than full bonded sections. Lanes 1, 4, and 5 in test areas TA2 and TA3 were constructed to influence of variable bond conditions. In TA2, Lane 1 behaved as a unbonded or partially bonded section (see Section 6.3), Lane 4 was partially bonded and Lane 5 was unbonded. In TA3, Lanes 1 and 4 were fully bonded while Lane 5 included panels that were unbonded and partially bonded. These test areas are used in the subsequent discussion to evaluate the influence of bond conditions on the type and severity of distresses.

\section{Discussion of Results}

Figure 6.10 illustrated the final distresses in TA2 and TA3. In test area TA2, while there was a fair amount of overall distress (debonding and cracking) for Lane 4 (partially bonded) it was less than both Lane 1 and Lane 5 . The 
distresses in Lane 4 were mainly debonding at the corners. Lane 1 (partially or unbonded) actually performed worse than Lane 5 (unbonded) which was deliberately debonded. However, this may have been due to the fact that there significantly fewer load applications in Lane 5 . Had the same number of load applications been applied to Lane 5 more distresses likely would have been noted.

For TA3, the distress summary presented in Figure 6.10 indicated that Lane 1 (fully bonded) had very little distress. The debonding noted was likely the result of edge affects of the APT test pit. Lane 4 (fully bonded), neglecting the distresses likely caused by the APT edge effects (in Panels 1 and 5), did have some debonding and one of the debonded areas did crack at the corner. In Lane 5 , the degree of distress was greater than in Lane 1 and Lane 4. The UTW in Lane 5 cracked in the unbonded section. Additionally there was debonding noted in the partially bonded areas under Panels 1 and 2 in Lane 5. These results indicate that, as expected the interfacial bond conditions do influence the type and severity of distresses in the UTW layer.

\section{Summary}

The amount of distress generally followed the expectations based on the interfacial bond condition. Those lanes having a lower degree of bonding (partially bonded or unbonded conditions) typically exhibited higher amounts of distress. Conversely, the lanes with the highest degree of bonding (fully bonded) typically showed the lowest degree of distress.

\subsubsection{Influence of Mechanical Load Applications on Type and Severity of} Distresses

\section{Background}

The number of load applications that a pavement receives will obviously affect the number and severity of the distresses in that pavement. However, the 
mechanism by which the distresses in the UTW occur are less understood. Rasmussen et al. [2002] in their review of the FHWA ALF results proposed that corner cracking was due to the local densification of the HMA at the corner location. The name for this phenomenon was "virtual void". However, addressing the development of cracking in the UTW at MnROAD, Burnham [2005] indicated that debonding occurred before cracking in the UTW pavement.

To gain insight into the development of these distresses, evaluations of the pavement condition in TA2 and TA3 were performed intermittently at different load applications during the APT evaluations. The results of these surveys were presented in Appendix B, Figures B.67 to B76.

\section{Discussion of Results}

TA2, Lane 1 exhibited the most distress (cracking and debonding) as indicated in Figure B.67. Unfortunately, no sounding to assess the bond condition was performed until after loading was completed. However, the progression of the cracking at the corner is fairly regular such that by the end of the testing all corners in the wheelpath had cracked. The bond evaluation conducted after testing was terminated indicates that all the cracked areas were also debonded. The increasing number of load applications had a large affect on the distress development in this test lane.

Figures B.68 and B.69 indicate that there were little distresses observed for Lanes 2 and 3 in TA2. While the figures indicate that these observations were made at lower numbers of load applications, these figures are also representative of the distresses observed at the end of the APT evaluations. Thus, the increasing number of load applications had little affect on the distresses in these lanes. 
Figure B.70 presents the distresses for TA2, Lane 4. This figure indicates a debonded area in Panel 1 in the wheel path. This debonded area was noted at 40,000 load application and is most likely due to the edge effects of the APT test pit. That said, further analysis of this progression indicates that at 135,000 load applications, the debonded area cracks. This result indicates that debonding does occur prior to cracking in the UTW.

Figure B.71 illustrates the distress progression for TA2 Lane 5. As can be seen in this figure, cracking of the UTW at the corner was noted at 180,000 load applications. This indicates that even though the area was unbonded, the UTW was still able to withstand a significant number of load applications prior to cracking.

The results of the distress mapping for TA3 Lane 1 are presented in Figure B.72. Other than a debonded area (likely the result of the edge of the APT test pit) there was no distress observed in this lane even after 275,000 load applications.

The results from TA3, Lane 2, shown in Figure B.73 indicate that even though there was debonding, no cracking developed even after 300,000 load applications. As mentioned previously, the concrete in this lane used fibers and had a very high flexural strength (990 psi (6.83 MPa)). This indicates that even if debonding occurs, the mix properties can prevent crack development.

Figure B.74 illustrates the distresses observed in TA3, Lane 3. This figure also illustrates the same phenomenon as was observed in TA2 Lane 4. Debonding was observed at 135,000 load applications (in Panels 2 and 3) and subsequent cracking of the debonded area was noted at 210,000 load applications. The observation combined with the observation in TA2 indicates that debonding occurs prior to corner cracking supports the findings that were observed at MnROAD (Burnham [2005]). 
The distress progression for TA3 Lane 4 is presented in Figure B.75. Neglecting the edge effects of the APT test pit, the results indicate that little distress (debonding or cracking) was observed during the first 60,000 load applications. A debonded and cracked area was noted at the corner of Panel 3 after 300,000 load applications.

Figure B.76 presents the distresses observed in TA3 Lane 5. Cracking of the unbonded sections under Panels 2 and 3 was noted at 195,000 load applications. Additionally, debonding of the corners in Panels 1 and 2 was noted at the same number of load applications. These areas however did not crack even after 300,000 load applications. This was likely due to a high UTW concrete flexural strength in this test lane (1120 psi at 28 days).

For all test lanes overall, neglecting the APT edge effects, no debonding was observed until $60,000,15,000 \mathrm{lb}$ load applications (this converts to approximately 460,000 Equivalent Single Axles Loads (ESALs)). This was observed in TA3, Lane 2. Similarly, no load-induced cracking was observed until 110,000, 15,000 Ib load applications (approximately 840,000 ESALs). This was observed in TA2, Lane 1.

\section{Summary}

The results indicate that debonding does occur prior to cracking. This finding supports the results observed at MnROAD. Additionally, the progression of distress development is such that no debonding was observed before 60,000, 15,000 load applications. No cracking was observed until 110,000, 15,000 lb load applications. 
6.4.5. Influence of Environmental Loading on Type and Severity of Distresses

\section{Background}

Vandenbossche [2001] indicated that magnitude of temperature gradients in UTW pavements can be significant. To evaluate the influence of such gradients on the UTW pavement, the temperatures in the UTW layer and HMA layer were recorded over a year long evaluation period. These data were presented in Section 5.3 and their effect on the maximum load induced strains was discussed in Section 6.3.5. The results of this analysis concluded that theoretical curling strains based on these gradients were not expected to be significant enough to cause distresses in the pavement. As such it was expected that the distresses in TA4 (which had no mechanical loading) would not be influenced by the environmentally induced curling strains.

\section{Discussion of Results}

A distress survey was conducted on TA4 as described in Section 4.5. The results of the distress survey were presented in Section 5.4 and Figure B.77. This evaluation was conducted one year after the UTW was placed. As can be seen in Figure B.77, there was debonding of the UTW panels at the corners in Lanes 1, 2, and 3. However, as was expected, there was no cracking observed in the UTW.

In regards to debonding it is worthy to note that the debonding of the UTW was limited to the free edges of the UTW lanes. To create the different UTW depths in TA4, dimensional lumber was placed between Lanes 1, 2 and 3 during construction. As such there was a physical separation between Lanes 1, 2, and 3. The areas along this separation were the locations of the debonding. As such the debonding noted in Figure B.77 was likely the construction related. 


\section{Summary}

As was expected, the environmentally-induced temperature gradients did not have an influence on the type and severity of the distresses. Debonding of TA4 was observed in a distress evaluation conducted after one year; however, no cracking was noted. Debonding was likely construction related.

\subsection{Bond Strength}

This section discusses the influence of the structural properties of the pavement sections, concrete mixture mechanical properties, mechanical load applications, and temperature gradient (environmental loading) on the bond strength. All test areas and the Laboratory Study results are used for this discussion. The flexural bond and lowa shear tests were described in Sections 4.7 and 4.8, respectively. Nondestructive ultrasonic pulse velocity and impact echo tests were described in Sections 4.9 and 4.10 , respectively. The bond strength test results were presented in Sections 5.5 (lowa Shear) and 5.6 (Flexural Bond Test). Figures 5.11 through 5.15 contain the results of the lowa shear tests. Figure 5.16 contains the results of the of the flexural bond test. Additionally the results of the non-destructive bond evaluations are discussed in this section. These results were presented in Section 5.8. Figures 5.18 and 5.19 contain the results of the ultrasonic pulse velocity and impact echo evaluations, respectively.

\subsubsection{Influence of Structural Properties of the Pavement Sections on Bond} Strength

\section{Background}

Pavement sections are expected to have an indirect effect on the bond between the UTW and HMA layers. Repeated loading of the UTW pavement is expected to fatigue the bond thereby causing a decrease in the bond strength with the degree of debonding expected to vary based on the magnitude of the loadinduced strain at the interface. In Figure 6.2, the strain at the interface between 
the UTW and HMA layers is nearly 40 percent greater in TA3 versus the same reading in TA2 and over 200 percent greater than the same reading in TA1 (using the data for the $15,000 \mathrm{lb}$ loading). Thus, it is expected that the bond shear strength for cores taken from the test areas after APT loading was completed will be greater for TA2 than for TA3.

\section{Discussion of Results}

Cores were taken from the pavement sections after the APT loading of TA2 and TA3 was completed. These cores were testing using the lowa Shear Test to evaluate the bond strength. Results of these tests are presented in Section 5.5. Figure 5.11 summarizes the results for TA2 and indicates that the average bond shear strength was $118 \mathrm{psi}(0.814 \mathrm{MPa})$ for Lanes 1 through 4 . Similarly, the results presented in Figure 5.13 indicate average bond shear strength of $296 \mathrm{psi}$ (2.04 MPa) for TA3, Lanes 1 through 4. This result is opposite of the result that was expected. This discrepancy thus indicates that even though there is a significant difference in the strains at the interface between the UTW and HMA layers these strains still may not be great enough to fatigue the bond. Thus, other factors must influence the in-situ bond strength.

\section{Summary}

In regards to the bond tests, the shear strength of the cores taken from the indicated that other factors than the structural properties of the pavement may influence the shear strength. However, the test area that had lower bond strengths also had a greater degree of distress than the test area with higher bond strengths.

\subsubsection{Influence of UTW Concrete Material Properties on Bond Strength}

\section{Background}

The degree of debonding was expected to vary based on the magnitude of the load-induced strain at the interface. That is, a UTW overly made from concrete 
with a lower modulus would have higher strains at the bottom of the UTW layer and thus, given that there would be more strain on the bond, the bond would fatigue more and therefore have a lower bond strength. However, in Figure 6.3, the strains at the interface between the UTW and HMA layers are very close regardless of the mix design used in both test areas. This result indicates the moduli, while different, were not different enough to have a significant impact on the strains at the bottom of the UTW. Thus, it was expected that the bond shear strength will not vary much among cores taken from Lanes 1 through 3 within the test area.

\section{Discussion of Results}

Cores were taken from the pavement sections after the APT loading of TA2 and TA3 was completed. These cores were testing using the lowa Shear Test to evaluate the bond strength. Results of these tests were presented in Section 5.5. Figure 5.10 summarizes the results for TA2 and indicates that the average bond shear strength was 103,104 , and $141 \mathrm{psi}(0.710,0.717$, and $0.972 \mathrm{MPa})$ for the lanes constructed with MD-1, MD-2, and MD-3, respectively. The results presented in Figure 5.13 for TA3 indicate average bond shear strengths of 318, 272 , and $341 \mathrm{psi}(2.19,1.88$, and $2.35 \mathrm{MPa})$ for the lanes constructed with MD-1, MD-4, and MD-2, respectively.

There were some differences in the shear strengths among the cores taken from the lanes prepared with the different mixes. In TA2, the bond strength for cores taken from the lanes constructed with MD-3 (fiber mix) concrete was approximately 40 percent higher than the bond strength of the cores taken from the lanes constructed with MD-1 (base mix) and MD-2 (high early strength) which had bond strengths that were essentially equal. In TA3, the highest bond strength was from cores taken from the lane constructed with MD-2 (high early strength) followed by cores taken from the lane constructed with MD-1 (the base mix) and then the cores taken from the lane constructed with MD-4 (high early 
strength and fibers). However, given the variability of the lowa shear readings the differences noted are likely not significant.

However, there was an interesting trend noted that was observed with these data. The shear strengths exhibited a similar trend to the flexural strength trend for the different mixes. Figure 6.10 is a combined plot of lowa shear strengths and flexural strengths for the different mix designs. As can be seen in this figure, the increasing trend of the bond shear strengths from the cored specimens is matched by a similar trend in the flexural strengths.

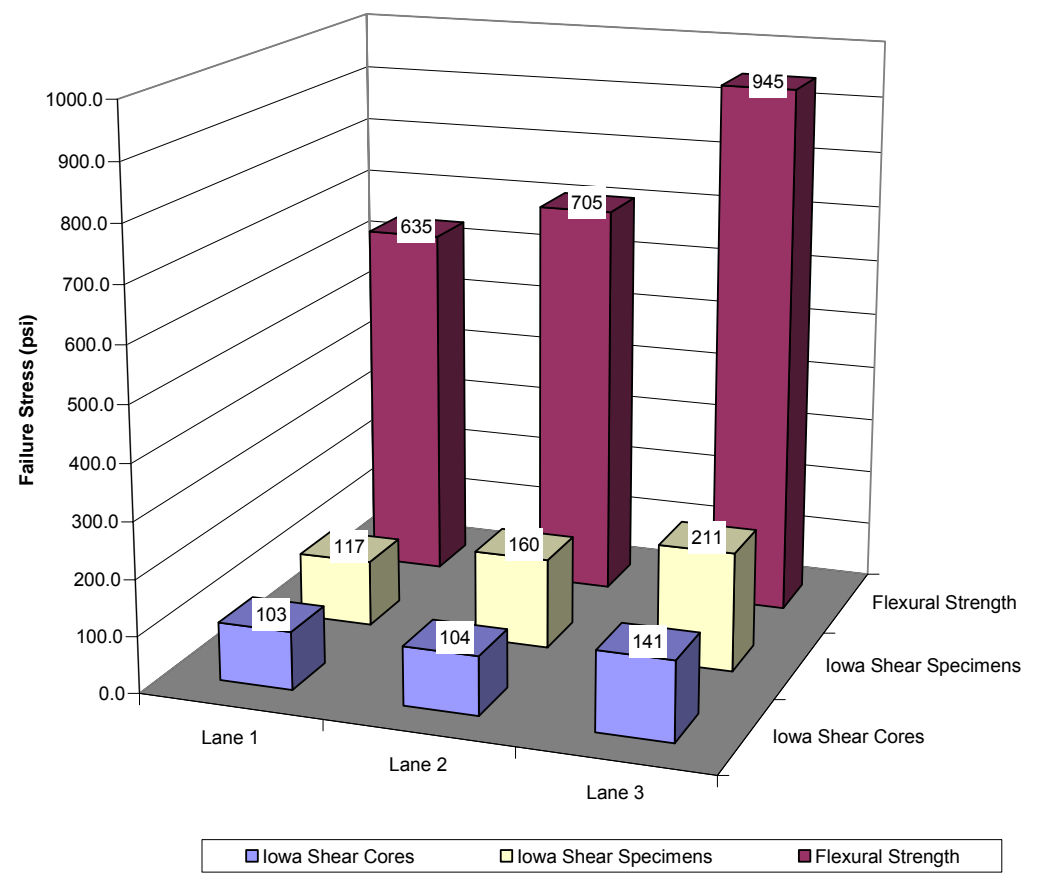

(a)

Figure 6.10 Comparisons of Flexural and lowa Shear Strengths (a) TA2 (b) TA3 (continued) 


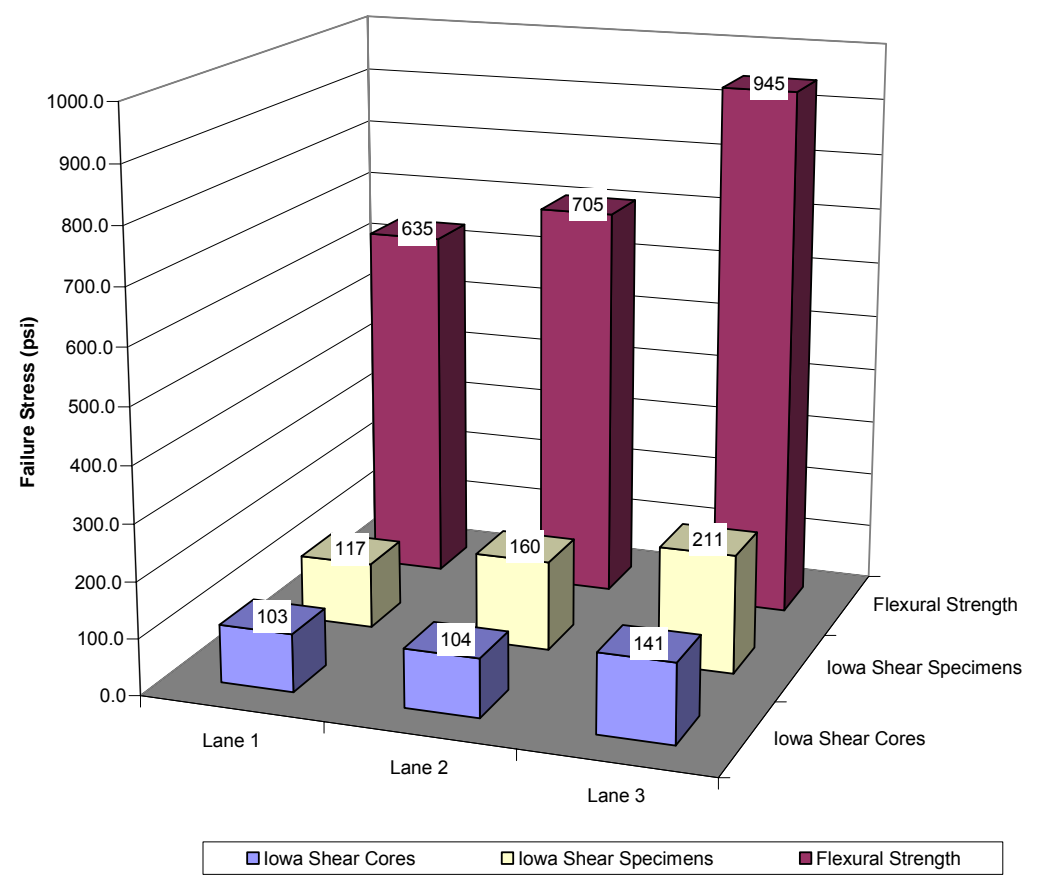

(b) TA3

Figure 6.10 Comparisons of Flexural and lowa Shear Strengths (a) TA2 (b) TA3

Specimens were also prepared using cores from the milled HMA taken prior to placement of the UTW concrete. The preparation and testing of the specimens was discussed in Section 4.8. Results of the tests were presented in Section 5.5. The average of the 7 day and 14 day shear strength values presented in Figure 5.10 were 117,160 , and $211 \mathrm{psi}(0.806,1.10$, and $1.45 \mathrm{MPa})$, respectively for the lanes prepared in TA2 using MD-1, MD-2, and MD-3. Similarly, for TA3, the average of the 28 day and 90 day shear strength values presented in Figure 5.12 were 199,178 , and $177 \mathrm{psi}(1.37,1.23$, and $1.22 \mathrm{MPa})$, respectively for the lanes prepared using MD-1, MD-4, and MD-2. These data were also included in Figure 6.10. A review these data along with the flexural strengths indicated that the same trend exists. Thus, it was hypothesized that there may be a correlation between the flexural strength of the concrete and the shear strength of the bond between the UTW and HMA layers. 
To confirm this, the data from the two test areas were combined by either cored specimens and prepared specimens. A plot of flexural strength (at 90 days since this was the test data closest to the age of the shear specimens when tested) versus bond shear strength was prepared to evaluate the correlation. This plot is presented in Figure 6.11.

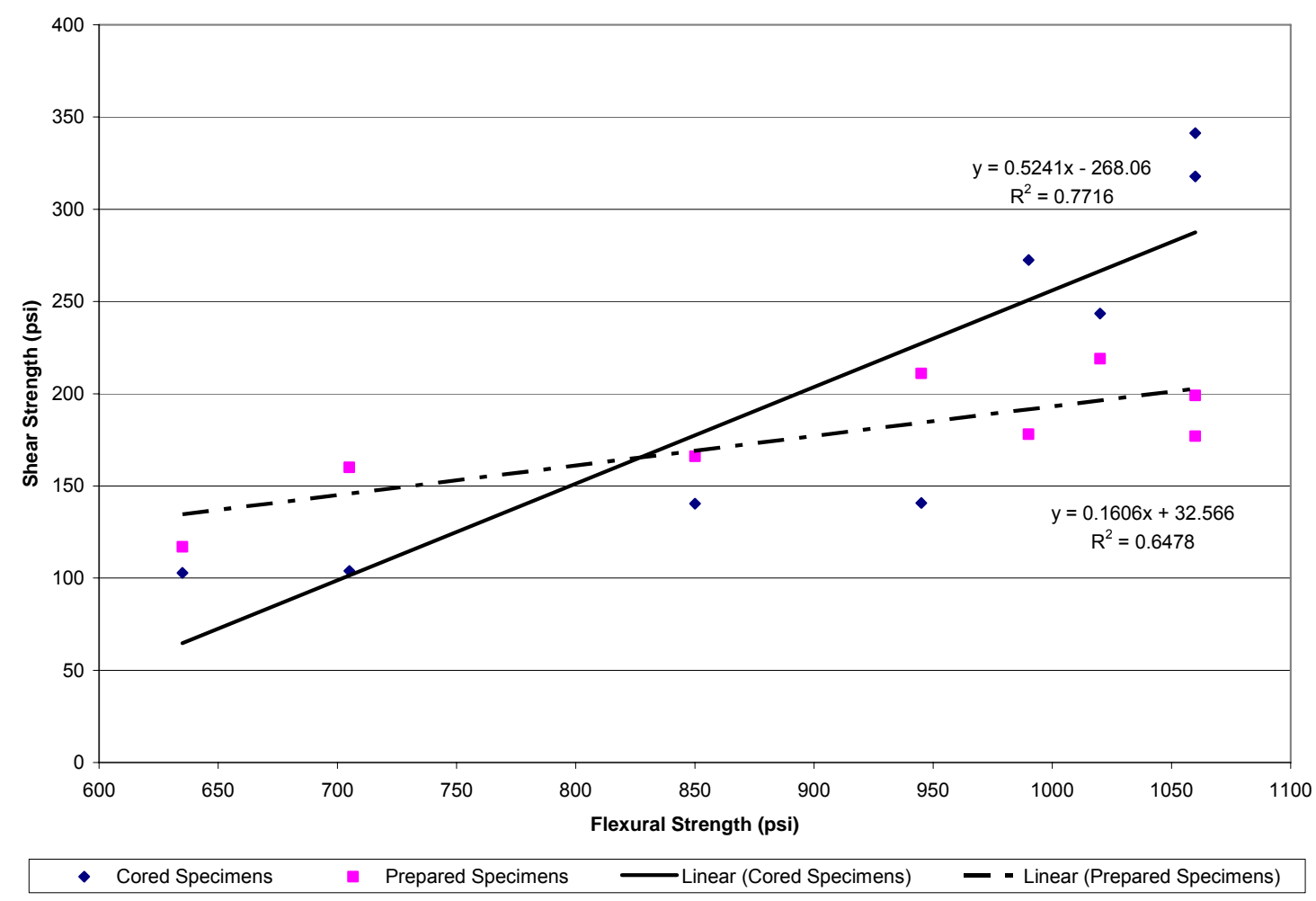

Figure 6.11 Flexural Strength versus Bond Shear Strength

The trends in Figure 6.11 indicated that for the cored specimens, there existed a fairly good correlation between the concrete flexural strength and the bond shear strength. The coefficient of determination of this relationship was 0.77 . The trend for the prepared specimens while not as well correlated was still a fair relationship. The coefficient of determination of this relationship was 0.65 . While the data in these comparisons is somewhat limited, the results indicate that the flexural strength of the concrete is a possible factor that influences the bond 
shear strength. This relationship should be investigated further. The other material properties (compressive strength and modulus of elasticity) were compared as well, but these were not as well correlated and thus, are not presented.

\section{Summary}

The specimens prepared using different concrete mixes exhibited a difference in the bond shear strength from mix to mix. This was seen whether the shear specimens were cored from the APT or prepared. It was determined that there is a fairly good correlation between the flexural strength of the concrete and the bond shear strength. Thus, the flexural strength may be a factor that can be used to influence the bond strength. Additional research is needed to verify this influence.

\subsubsection{Influence of Environmental Loading on Bond Strength}

\section{Background}

There was no literature found that addresses the effect of repeated freeze-thaw temperature changes on the bond. As indicated in Section 6.3.5, environmental temperature changes can have an effect on the strains that develop in the UTW. Additionally given that there is a difference in the coefficient of thermal expansion between the two materials (asphalt and concrete), the two materials will expand and contract at different rates. The bond between the two layers will initially prevent this. However, repeated temperature changes may cause the bond to weaken over time. It is thus hypothesized that repeated strain changes can cause fatigue to the bond between the UTW and HMA.

\section{Discussion of Results}

The Laboratory Study was conducted to evaluate the effect of repeated temperature changes on the bond. The testing performed as part of the Laboratory Study was described in Chapter 4. Mechanical property (Section 
4.6), flexural bond (Section 4.7), and lowa shear testing (Section 4.8) was conducted. The results of these tests were presented in Sections 5.1, 5.6, and 5.5 , respectively. The specimens were cured in two different environments, either a standard moist curing chamber or in an environmental chamber that cycled through a freezing and thawing temperature regimen. To assess the bond during the conditioning, two different non-destructive evaluations were conducted using either pulse velocity (Section 4.9) or Impact Echo (Section 4.10) on both the flexural bond and lowa shear specimens. Results of these non-destructive tests were presented in Section 5.8.

This discussion first focuses on the flexural bond specimens. The results of the pulse velocity testing in general indicate that there was no difference between the specimens that were moist cured or temperature cycled for 7 or 14 days. There was an increase in the transit time for the moist cured specimens versus the temperature cycled specimens cured for 28 days. This difference was present as soon as the first week of testing and indicates that the cycle-cured specimens may have had some level of damage that was most likely debonding. This increase was relatively consistent for the remaining observation period. The 90 day specimens also exhibited an increased transit time for the moist cured versus the temperature cycled specimens. Thus, the pulse velocity results indicated that temperature cycling may have had an effect on the bond strength.

In regards to the lowa shear specimens, the trends were similar to those observed for the flexural bond specimens. However, the increase in transit time was not as large for the cycle cured specimens.

Impact echo results did not provide any indication that the bond had changed. This may be due to inconsistencies in this test that were observed during testing. 
The lowa shear results indicate that in all but the 90 day specimens, there was a difference between the moist cured and cycled specimens. The cycled specimens had shear strengths on average approximately 20 percent less than the moist cured specimens. This result was not observed in the flexural test however. The flexural strength results were mixed with the 7 day and 14 day specimens performing as expected, while the 28 day and 90 day specimens actually had increases in the strengths for the cycled specimens. These results combined with the pulse velocity and impact echo results indicate that overall there was little difference between the two treatments. This may be due to the limited number of temperature cycles to which the specimens were exposed. Also, the temperature range used, while set using actual data, may have not been great enough to cause any damage to the bond. This conclusion is corroborated by the observed distresses that were discussed in Section 6.4.5.

\section{Summary}

The results indicate that there was little observable difference between the specimens that were moist cured and the specimens that were exposed to repeated temperature cycling. While limited, these results may indicate that for up to 90 freeze-thaw cycles at realistic temperatures, the cycling does not have any effect on the bond.

\subsection{Radius of Relative Stiffness}

This section discusses the influence of the structural properties of the pavement sections, concrete mixture mechanical properties, interfacial bond conditions, mechanical load applications, and temperature gradient (environmental loading) on the radius of relative stiffness. Test areas TA2, TA3, and TA4 are used for this discussion. The pavement deflection analysis was described in Section 4.11. The results of the pavement deflection analysis were presented in Section 5.7. Figure 5.17 contains the results of the radii of relative stiffness values that resulted from the pavement deflection analyses. 
6.6.1. Influence of Structural Properties of the Pavement Sections on Radius of Relative Stiffness

\section{Theoretical Analysis}

The radius of relative stiffness is a value that compares the stiffness of a pavement section to the stiffness of the subgrade (Huang [1993]). In this project it is used as a surrogate to quantify the stiffness of various pavement layers into one value that can be used for comparison purposes. The value has the unit of length with higher numbers indicating a stiffer pavement section. Thus, a multilayered pavement that has layers with high moduli would be expected to have a higher radius of relative stiffness than a pavement section that has layers with lower moduli. The estimated radius of relative stiffness is determined from pavement deflection analysis (described in Section 4.11).

Given the stiff underlying PCC layers in TA1 and TA2 it is expected that the test lanes in these two areas will have a greater radius of relative stiffness than TA3 which only contained underlying HMA layers. The WinJULEA program was used to determine the expected deflections necessary to calculate an estimated radius of relative stiffness. This was performed for test areas TA1 through TA3 utilizing the input values as described in Section 6.3.1. The calculated deflections were input into the AASHTO equations and the values for each test area were determined. The theoretical estimated radii of relative stiffness were 46.5, 37.3, and 27.2 inches $(1181,947,691 \mathrm{~mm})$ for TA1, TA2, and TA3, respectively. These data support the hypothesis that the sections with the stiffer pavement layers will have a greater radius of relative stiffness.

\section{Comparison of Measured and Theoretical Radii of Relative Stiffness}

No pavement deflection analyses were conducted on TA1, thus this section will be excluded from the following discussion. FWD testing was performed on TA2 and TA3. These data were presented in Figure 5.14. The results for Lane 1 for 
each test area (from which the data for the WinJULEA analysis was taken) are presented with the WinJULEA results in Figure 6.12.

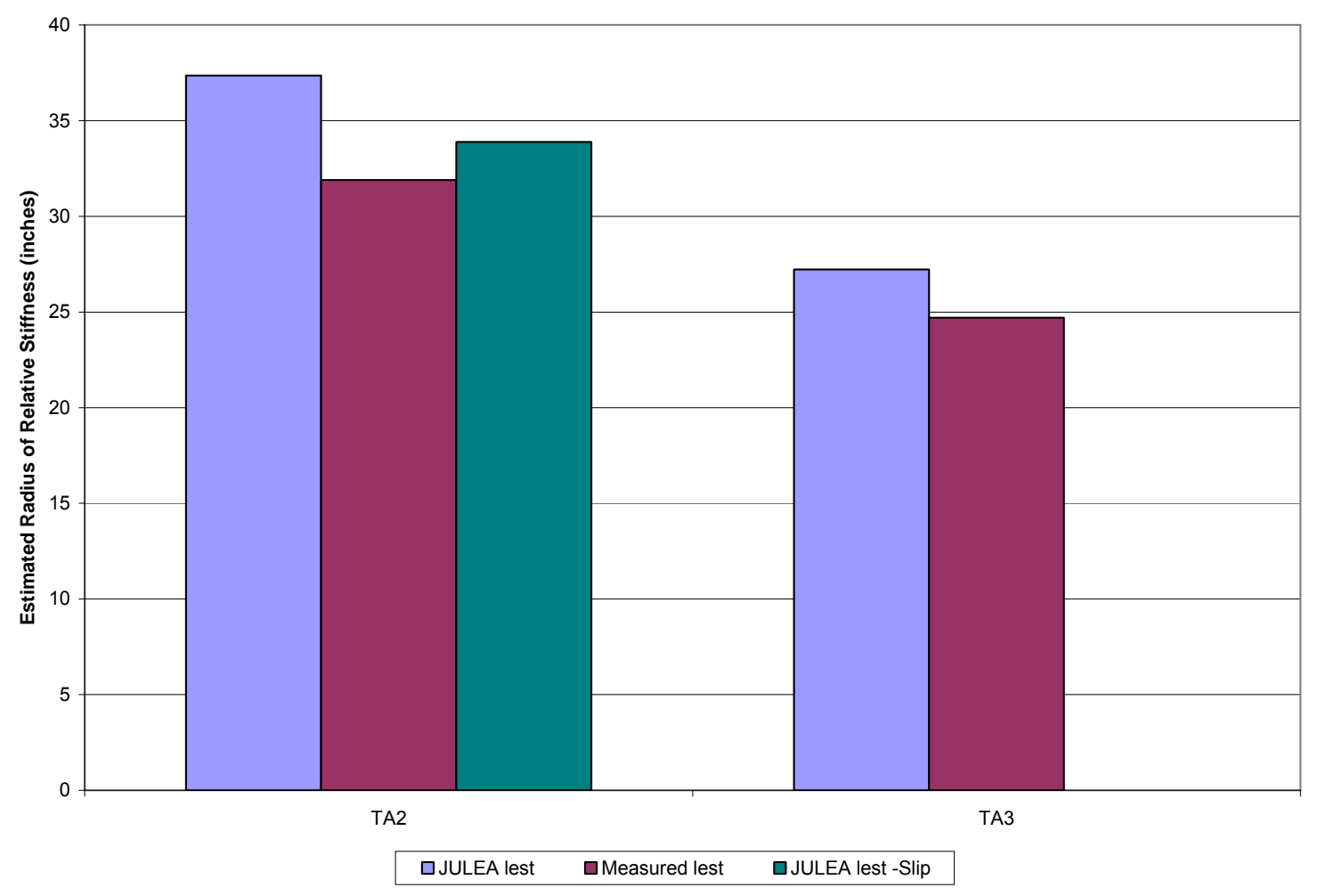

Figure 6.12 Comparisons of Theoretical and Measured Radii of Relative Stiffness $\left(l_{\text {est }}\right)$

The results support the expected outcome that the estimated radius of relative stiffness accounts for the stiffness of the layers in the pavement sections. Although they are fairly close, the measured values are less than the values calculated using layer elastic analysis. The theoretical values for TA2 were 17 percent higher than the measured values. While the measured value from TA3 was 10 percent less than the theoretical value. The greater difference for TA2 may be the result of a lower bond strength between the UTW and HMA layers. The JULEA analysis was performed again for TA2 with a small amount of slip between the UTW and HMA layers included. As shown in Figure 6.12, the 
JULEA value of the estimated radius of relative stiffness reduced to a level only 6 percent greater than the measured value.

\section{Summary}

The pavement section did have an influence on the estimated radius of relative stiffness. The measured value for the radius of relative stiffness matched fairly well to the theoretical values calculated by JULEA, particularly when a moderate amount of slippage was introduced in the analysis. This result indicated that the radius of relative stiffness was a good indicator of the pavement stiffness overall. Also, the theoretical value also appeared to reflect debonding at the UTW-HMA interface.

\subsubsection{Influence of UTW Concrete Material Properties on Radius of Relative} Stiffness

Theoretical Analysis

As noted in the previous section, the radius of relative stiffness is a value that compares the stiffness of a pavement section to the stiffness of the subgrade with higher numbers indicating a stiffer pavement section. To compare the influence of the UTW material properties (in this case, modulus of elasticity) the WinJULEA program was used to determine the expected deflections necessary to calculate an estimated radius of relative stiffness for the lanes constructed using MD1 through MD3. This analysis was performed for TA2 and TA3 utilizing the program inputs as described in Section 6.3.1. The calculated deflections were input into the AASHTO equations and the values of radius of relative stiffness was calculated (see Section 4.11) for each lane constructed with the different mix designs were determined.

The theoretical radii of relative stiffness were in a narrow range from 37.3 to 37.4 inches (947 to $950 \mathrm{~mm}$ ) for MD1 to MD3 in TA2. For TA3, the theoretical estimated radii of relative stiffness were also in a narrow range from 27.1 to 27.2 inches (688 to $691 \mathrm{~mm}$ ) for MD1 to MD3. These data indicate that the modulus 
of the UTW concrete for a 2.5 inch ( $63 \mathrm{~mm}$ ) overlay is not expected to have a large influence on the radius of relative stiffness.

Comparison of Measured and Theoretical Radii of Relative Stiffness Pavement deflection analysis was conducted on TA2 and TA3. The radii of relative stiffness were calculated for these the lanes constructed using MD-1 (Lane 1), MD-2 (Lane 2), and MD-3 (Lane 3) in TA2 and MD-1 (Lane 1), MD-4 (Lane 2), and MD-2 (Lane 3) in TA3. These data were presented in Figure 5.14. The results for the lanes using MD1 to MD3 for each test area are presented with the WinJULEA analysis results in Figure 6.14.

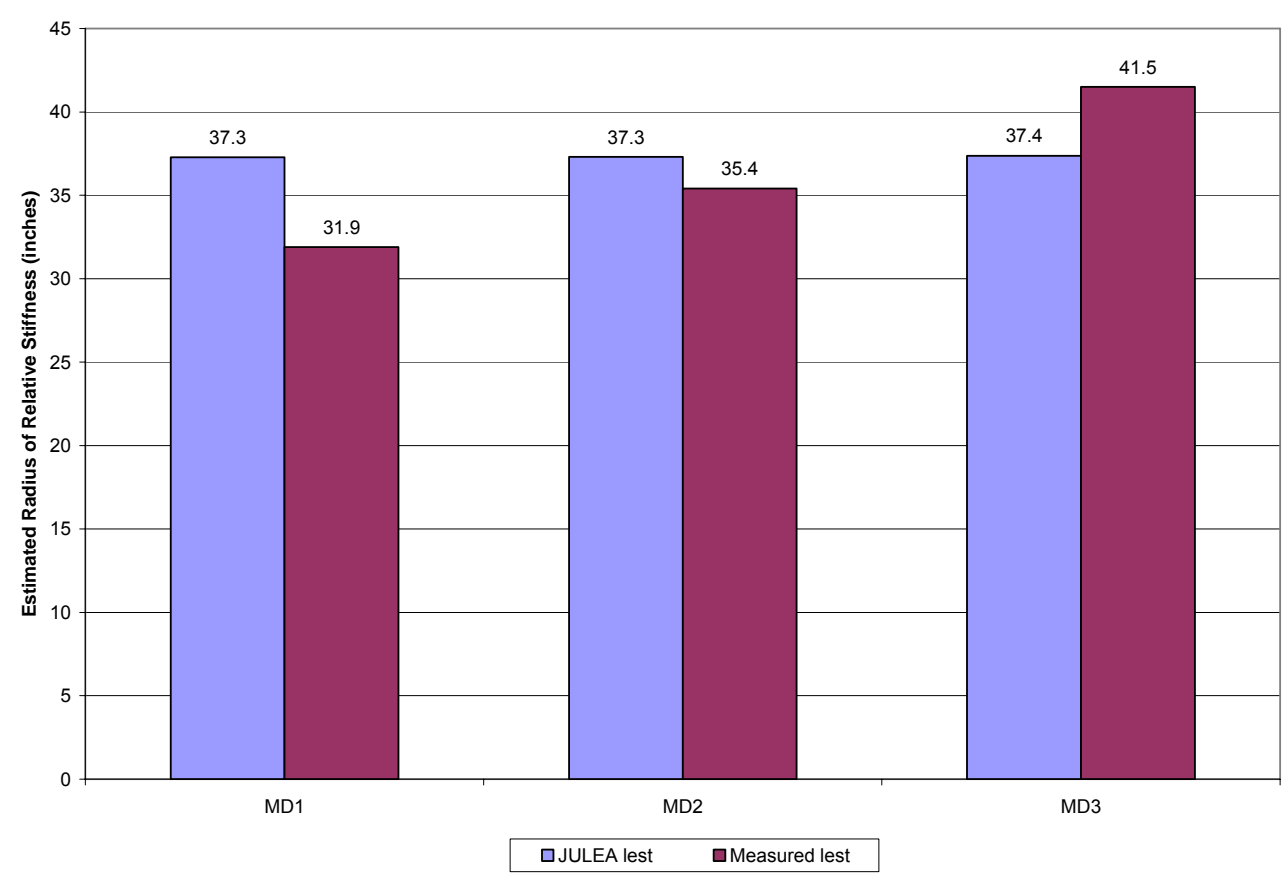

(a)

Figure 6.13 Comparison of Theoretical and Measured Estimated Radii of Relative Stiffness for Different Mix Designs (a) TA2 (b) TA3 (continued) 


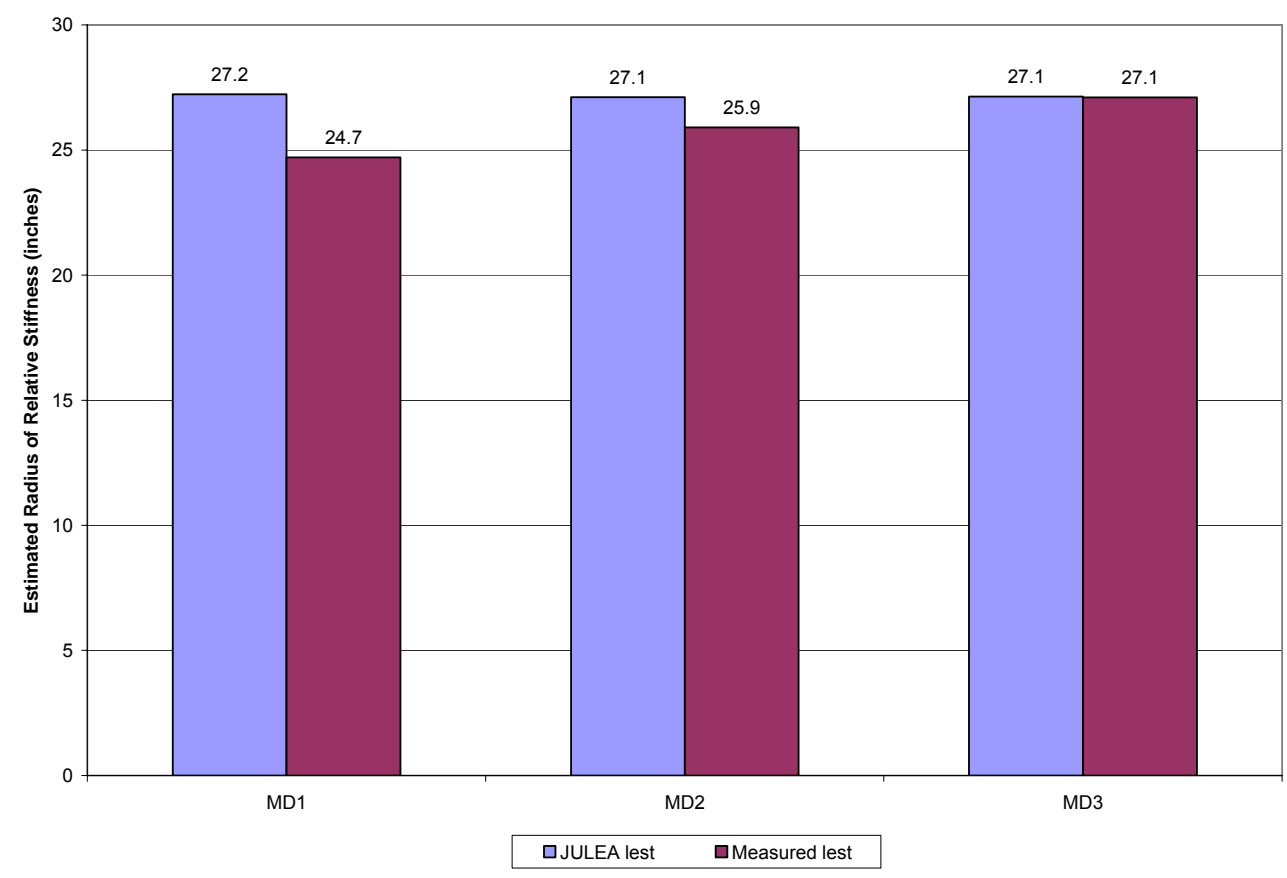

(b)

Figure 6.13 Comparison of Theoretical and Measured Estimated Radii of Relative Stiffness for Different Mix Designs (a) TA2 (b) TA3

These measured results indicate that, in general, the radii of relative stiffness for the lanes using MD-1 through MD-4 exhibited some variability amongst the different mix designs. There was more variability for the values in TA2. However as indicated in Section 6.6.1 the lower value of the measured radius was most likely due to a weaker bond in this lane. Neglecting, this observation then, the difference between MD-2 and MD-3 was 17 percent. For TA3, there was a narrower range of values. Amongst all the mix designs there was no more than 10 percent difference.

As indicated previously, the radius of relative stiffness is a ratio of the stiffness of the pavement layers to stiffness of the subgrade. These differences between the different test lanes may have been the result of different values (also obtained 
from deflection analysis) for the moduli of subgrade reaction in these lanes (274, 158, and 135 pci for Lanes 1, 2, and 3 in TA2, respectively and 238, 201, and 176 pci for Lanes 1, 2 and 3 in TA3, respectively). A lower subgrade stiffness would effectively increase the radius of relative stiffness.

\section{Summary}

The theoretical results indicate that while there is significant variation amongst the elastic moduli for the mix designs, for this particular UTW section these values did not have a large effect on the estimated radius of relative stiffness. There was however, some variability in the measured radius of relative stiffness values amongst the lanes constructed with MD-1, MD-2, MD-3, and MD-4. This result indicates that there are other factors that have a greater influence on the radius than the UTW material properties, one possible influence being the modulus of subgrade reaction.

6.6.3. Influence of Interfacial Bond Conditions on Radius of Relative Stiffness Theoretical Analysis

The estimated radius of relative stiffness determined by pavement deflection analysis is dependent upon the pavement deflections. The relationship between the two is an inverse relationship in that higher deflections (from a more flexible pavement) result in a lower radius of relative stiffness. Layered pavement sections that act as a composite (those which have a good bond between the layers) have lower deflections and thus, have a higher radius of relative stiffness. This effect can be illustrated by using layer elastic analysis.

Using the WinJULEA program, the deflections for TA2 Lane 1 were calculated, using the methodology described in Section 6.3.1, first with a full bond, and then again without a bond. These deflections were input in the AASHTO equations to calculate the estimated radius of relative stiffness. The value calculated for the 
fully bonded condition was 37.3 inches $(947 \mathrm{~mm})$ versus the unbonded condition which was 32.5 inches $(825 \mathrm{~mm})$.

Li et al. [2004] reported that the degree of bonding of a UTW pavement could be determined using pavement deflection analysis. The methodology employed was very similar to the comparison that was just conducted in that the limits of the fully bonded and unbonded condition were used to frame the extremes expected for a given parameter. However, in Li's method the parameter utilized was the pavement deflection (as opposed to the radius of relative stiffness). Once the deflections were determined, a factor representing the degree of bonding was calculated. It may be possible to employ a similar methodology using the estimated radius of relative stiffness as the parameter.

\section{Results and Discussion}

The estimated radii of relative stiffness were calculated for TA2 Lanes 1 (effectively partially bonded), 4 (partially bonded), and 5 (unbonded) for fully bonded and unbonded conditions. The same values were also calculated for Lanes 1 (fully bonded) and 5 (FWD deflections would reflect partially bonded and unbonded conditions (see Section 4.2,3)) in TA3. The measured radii values for these lanes were presented in Figure 5.14. The theoretical and measured data were combined and are presented in Figure 6.14. 


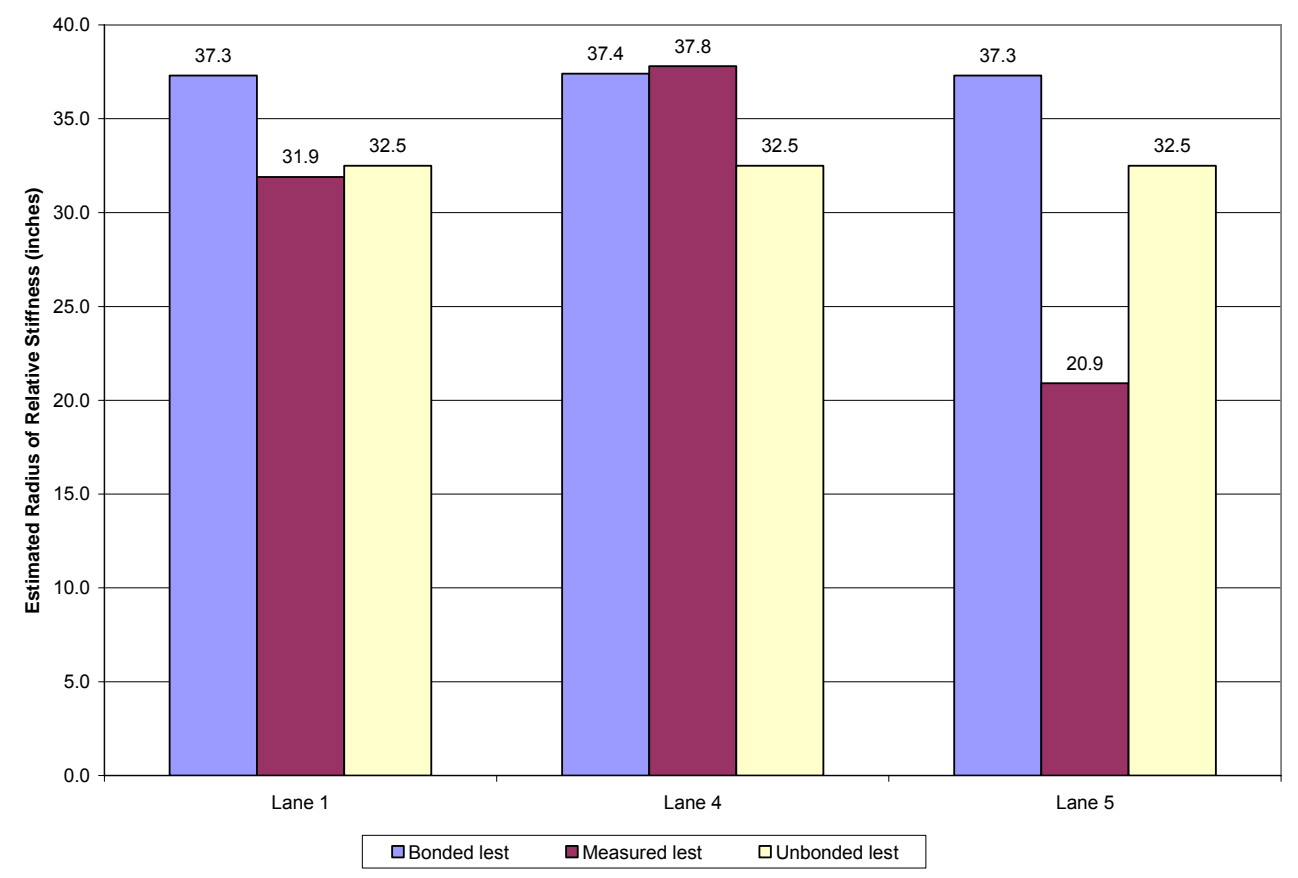

(a)

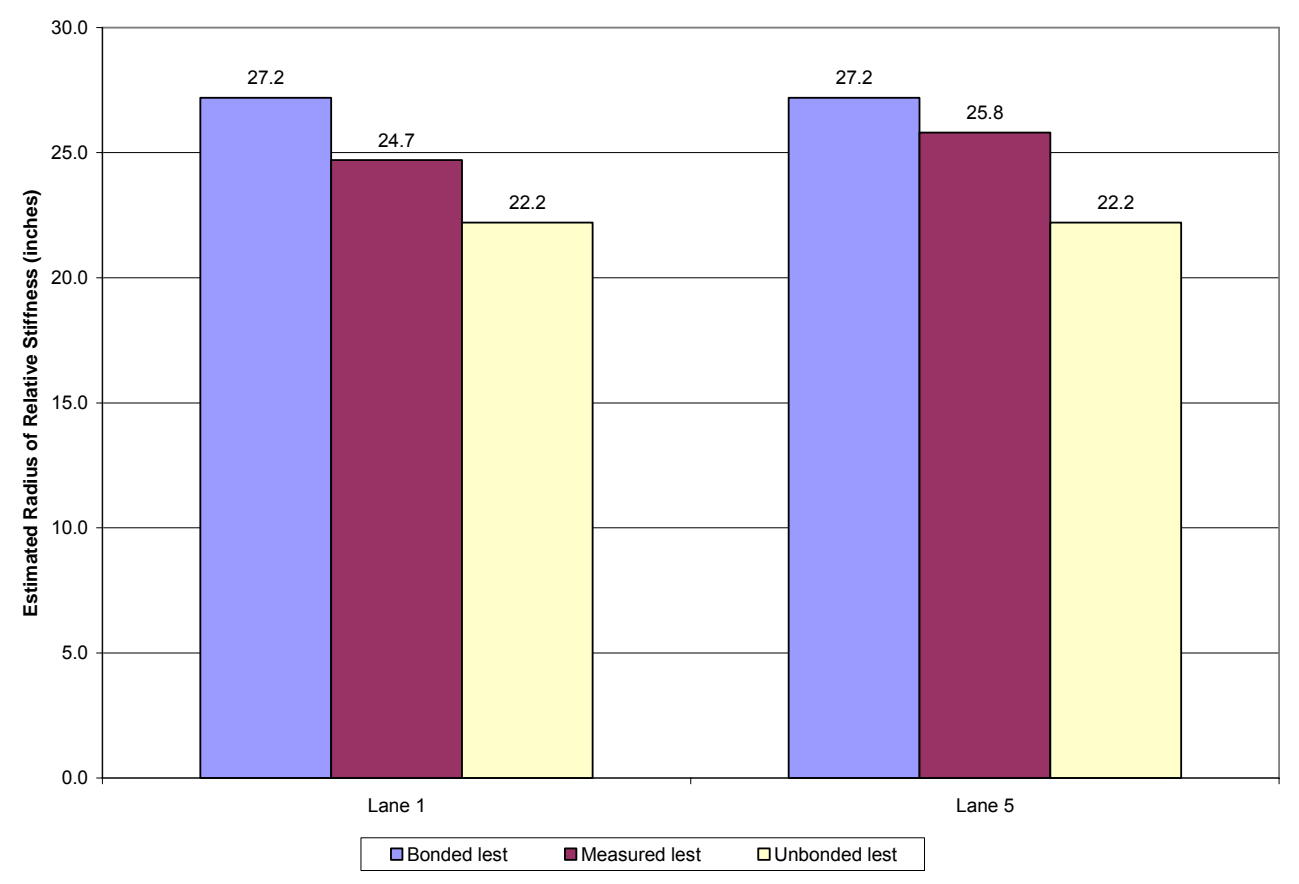

(b)

Figure 6.14 Comparisons of Measured Radii of Relative Stiffness with Theoretical Bonded and Unbonded Radii (a) TA2 (b) TA3 
As shown in this figure for TA2, the data indicate that the radius was lower than the fully bonded condition for Lane 1. Again, this would be reflective of the weak bond conditions actually observed in this test lane. For TA2 Lane 4, the measured results indicate a fairly high value for the radius. This does not follow what would be expected for a partially bonded lane and may indicate that this method is not sensitive to partially bonded conditions. However, the radius for TA2 Lane 1 is less than the radius for TA2 Lane 4. The actual shear strength values (Section 5.5) from the cored specimens also reflected this trend. The results for TA2 Lane 5 show a very low value of the radius for the unbonded lane. While this would be expected, the value is still significantly less than the lowest theoretical value. This may be the result of the dynamic loading of the pavement in the FWD test. The dynamic loading imparted by the FWD may cause greater deflections than those expected with a theoretical static load. The results further indicate that using these data to characterize the degree of bonding would not be possible since the actual values of the radii are outside the theoretical range for all lanes.

For Lane 1 in TA3, the value of the radius for the fully bonded condition falls within the expected range of values. However, the value was expected to be closer to the theoretical value for the fully bonded condition. The value of the radius in TA3 Lane 5 was also between the two expected values. Because Lane 5 reflected partially bonded and unbonded conditions, it was expected that the value of the radius would be less than the value of the radius for the fully bonded condition in Lane 1. However, the bond shear strengths for cores taken from these lanes were also very close. Thus, the result that the measured radii were close on TA3 Lanes 1 and 5 was corroborated by the actual bond strengths. In regards to the degree of debonding, given the position of these results within the expected range, approximately half way, it does not appear that this methodology would provide a good estimate of the degree of bonding, which in this case would be 50 percent. 


\section{Summary}

The interfacial bond conditions did have an influence on the estimated radius of relative stiffness. The results indicate that the radius can be used as a method to determine whether or not the UTW was bonded. However, using the radius to determine the degree of bonding did not provide very good results. The relative values of the radius matched the trend exhibited by the bond strengths for cores taken from the same lanes.

\subsubsection{Influence of Mechanical Load Applications on Radius of Relative Stiffness}

\section{Background}

The effect of the bond on the radius was discussed in Section 6.6.3. It was concluded that the radius could be determined if the UTW layer was bonded or debonded, however it was not able to be used to assess the degree of bonding. Further, the effect of mechanical loading on the bond was discussed in Section 6.5.4. These results indicated that loading did not have much effect on the bond if there was a good bond initially. However, if there was a weaker bond, the increasing the number of load applications further weakened the bond. Given these two findings, it would be expected that repeated mechanical load applications would decrease the bond strength between the UTW and HMA in sections that were partially bonded which would in turn result in a decrease in the radius of relative stiffness for the pavement section.

Additionally, as in any pavement under repeated loads, fatigue would be expected to increase the load induced deflections. An increase in deflections would result in a decrease in the radius of relative stiffness. Thus, it would be expected that the radius would decrease with the number of load applications.

\section{Results and Discussion}

The results of the pavement deflection analysis were presented in Section 5.7. Testing was conducted both prior to loading by the APT and after loading was 
completed. The measured values of the radius for TA2 and TA3 were presented in Figure 5.17. Table 6.7 summarizes these results.

Table 6.7 Summary of Load-Induced Changes in Radius of Relative Stiffness, lest

\begin{tabular}{|c|c|c|c|}
\hline Test Lane & $\begin{array}{c}\text { Pre-Load } l_{\text {est }} \\
\text { (inches) }\end{array}$ & $\begin{array}{c}\text { Post-Load } l_{\text {est }} \\
\text { (inches) }\end{array}$ & Percent Change \\
\hline TA2 - L1 & 31.9 & 27.4 & -14 \\
\hline TA2 - L2 & 35.4 & 34.7 & -1.9 \\
\hline TA2 - L3 & 41.5 & 38.3 & -7.8 \\
\hline TA2 - L4 & 37.8 & 33.0 & -13 \\
\hline TA2 - L5 & 20.9 & 16.9 & -19 \\
\hline TA3 - L1 & 24.7 & 23.0 & -7.0 \\
\hline TA3 - L2 & 25.9 & 27.6 & +7.0 \\
\hline TA3 - L3 & 27.2 & 27.2 & -0.4 \\
\hline TA3 - L4 & 28.0 & 31.4 & +12 \\
\hline TA2 - L5 & 25.8 & 22.5 & -12 \\
\hline
\end{tabular}

These data indicate that in all but two cases, the loading by the APT did cause a decrease in the radius of relative stiffness. The distresses observed in the test lanes were presented in Figure 6.4. A comparison of the radii data and the distress observations show that the decreases in the TA2 radii do correspond to the amount of debonding observed in the lanes. This result, however, does not hold true for the radii from TA3. Two of the radii actually increased as a result of loading. It may be that given that the HMA was placed new and that the HMA layer has a greater thickness than the HMA layer in TA2 that some densification of the HMA was taking place during the APT loading. This would cause the pavement to be stiffer with increasing load applications thereby causing an increase in the radius. This effect may have prevented the trend observed in TA2 from occurring in TA3. 


\section{Summary}

The results indicate that in general increasing the number of load applications does result in a decrease in the estimated radius of relative stiffness. The decrease in the radius appeared to be related to the amount of debonding observed in TA2. However, this trend was not observed in TA3. This may have been due to densification of the HMA pavement under the repeated loads.

\subsubsection{Influence of Environmental Loading on Radius of Relative Stiffness}

\section{Background}

The Section 6.5.5 indicated that repeated freeze thaw temperature cycling did not have any observable effect on the bond between the UTW and HMA. Additionally, it was shown in Section 6.6.3, that debonding of the UTW did influence the estimated radius of relative stiffness values. As such, if there was any debonding resulting from the environmental loading, it would be reflected in data from the monthly pavement deflection analysis.

\section{Discussion of Results}

Pavement deflection analysis was performed on TA4 as indicated in Section 4.11. The results of these tests were presented in Section 5.7. As can be seen in Figure 5.17 (c), the estimated radii of relative stiffness values followed the same trend for all lanes. Initially, there was in increase due to the placement of the UTW. However, after the initial increase, the values tapered off slightly. By the end of the one year evaluation the values were increasing slightly again. If the bond had been degrading due to temperature cycling (or other environmental effects) there would have been a steady decrease in the radii. However, since the values increase consistently at the end of the evaluation (for all lanes), this result indicates that the debonding was not the result of temperature induced bond degradation. The changes observed were most likely the result of temperature induced changes in the modulus of the HMA layer. 


\section{Summary}

The radii of relative stiffness were calculated for all test lanes in TA4 for a period of one year. The results indicated that for all lanes, the same general trend was followed. This trend did not reflect any decrease in the radius of relative stiffness and thus, no debonding. Thus, the temperature cycles (and/or other environmental effects) did not cause any significant damage to the bond. However, the observed trend was most likely the result of temperature influences on the modulus of the HMA layer. 


\section{CHAPTER 7. PROPOSED CHANGES TO UTW DESIGN METHODOLOGY}

The PCA UTW design method (Wu et al. [1998]) was developed for the overlay of an HMA pavement. This chapter compares the PCA method results to the data collected in the APT for both existing HMA and composite pavement sections. The method is calibrated using the measured data. Reliability concepts are introduced into the PCA method to provide a more efficient design methodology. Additionally, a modified design approach based on pavement deflection analysis is proposed for the design of UTW overlays. This chapter contains a discussion of the proposed methodology and presents comparisons with data collected from the APT and data collected from other sites in Missouri and Minnesota.

The PCA UTW design method (Wu et al. [1998]) was developed for the overlay of an HMA pavement. It did not take into account other existing pavement layers, such as existing composite sections. However, in some circumstances it may be necessary to design a UTW layer over existing composite pavements. The need for a UTW design methodology that takes the effects of existing composite pavements into account was noted by Cable et al. [2001].

Rasmussen and Rozycki [2004] conducted a review of the PCA UTW design method. It was noted that one of the drawbacks of this method was that it did not utilize reliability concepts. Thus, a method of incorporating reliability into the UTW design method is needed. 
Rasmussen and Rozycki [2004] also noted that another limitation of the PCA method resulted from the manner in which the finite element modeling used to develop the method took into account the bond condition. Initially the model produced stresses that were significantly less than those observed in the field. It was determined that this discrepancy was the result of the model's assumption of a full bond between the UTW and HMA layers. As a result, the model incorporated a correction factor (1.36 or a 36 percent increase in stress) to account for a partially bonded condition. However this factor was based on only one test and therefore may not be applicable to all situations. An evaluation of this correction factor is needed.

The critical strain location identified for the HMA in the PCA method was the bottom of the HMA layer under edge loading. However, the analysis conducted in Section 6.3.1 indicated that the critical strain locations in the HMA layers identified by the measured strains did not match the critical strain location. For the case where the UTW is constructed over a composite section this location was actually at the top of the HMA layer. This discrepancy warrants further analysis.

\subsection{Evaluation of PCA UTW Design Method}

This section compares the PCA method results to the measured data collected in the APT. The strain data collected from Lanes 1 through 4 in test areas TA2 and TA3 (Sections 4.2.2. and 4.2.3) are used for comparison to the PCA calculated strains. Lanes 5 in both test areas were not included because they were deliberately unbonded and comparisons were not possible using these data. Gages used in these comparisons are HEB, HCB, HCT, and UCBmax (instrumentation of the test lanes was discussed in Section 4.3.4). 


\subsubsection{Comparison of Calculated PCA and Measured UTW Strains} UTW stresses were calculated using the PCA design equations along with material and thickness data taken from TA2 and TA3. To compare the calculated UTW stresses to the recorded strains, the calculated UTW stresses were converted to strains using a linear elastic assumption $(\sigma=E \varepsilon)$. The strain data recorded from Lanes 1 through 4 in the APT were obtained. The critical strain location identified for the UTW in the PCA method was at the bottom of the layer at the corner location. Thus, the UTW corner strains used in the comparison were from gages placed at the bottom of the UTW layer at the corner location (gage UCBmax). The measured load-induced strains were calculated from the data by subtracting the unloaded strain reading (APT carriage location $=0)$ from the maximum value recorded for the pass (when the APT carriage is over the gage at either the edge or corner locations). To illustrate the spread of the strain data, 30 of the initial strain readings were obtained from each lane and location. These data were paired for each lane and plotted versus each other. Figure 7.1 presents the comparisons of PCA calculated strains versus the APT measured strains for the UTW layer (values for TA2 Lane 1 were eliminated from charts as the debonded data skewed the plots). 


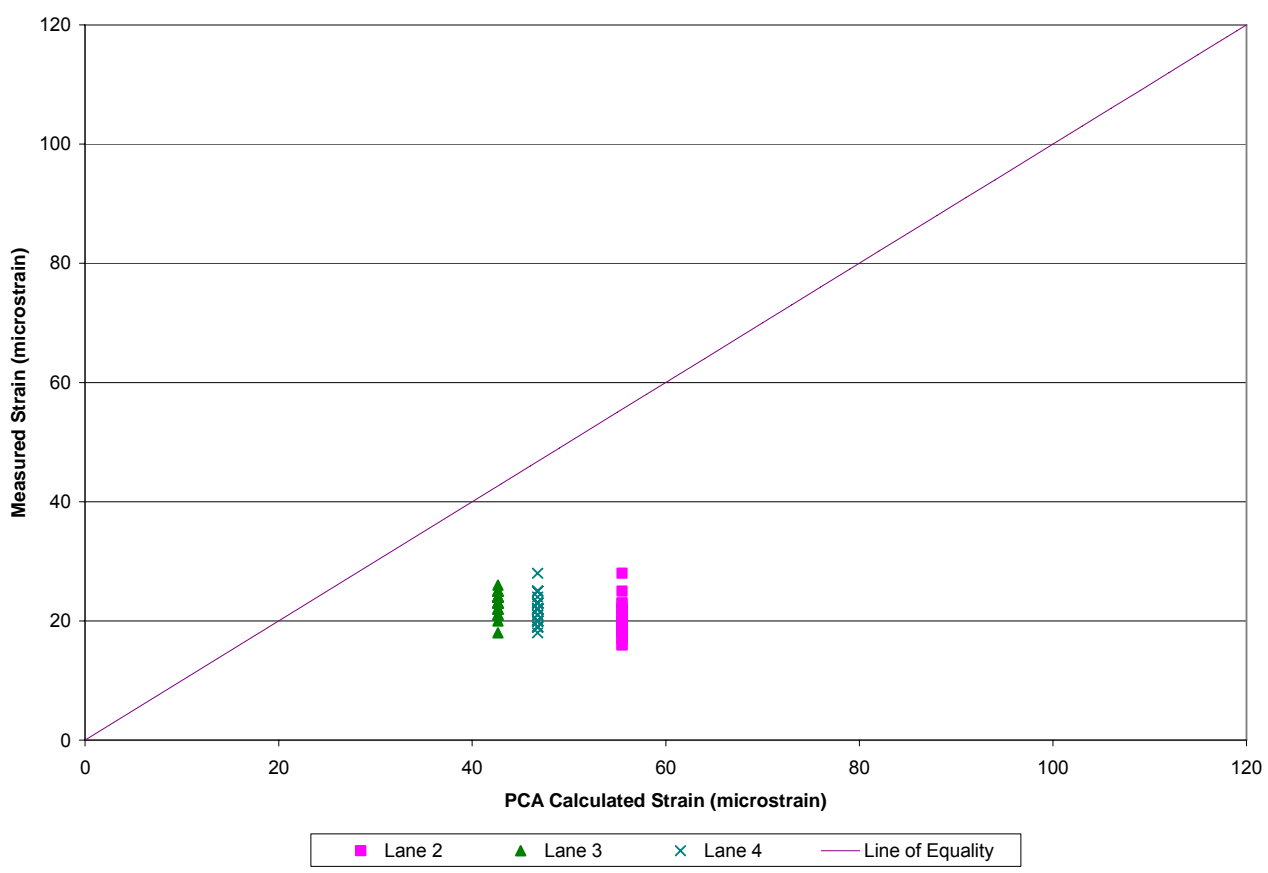

(a)

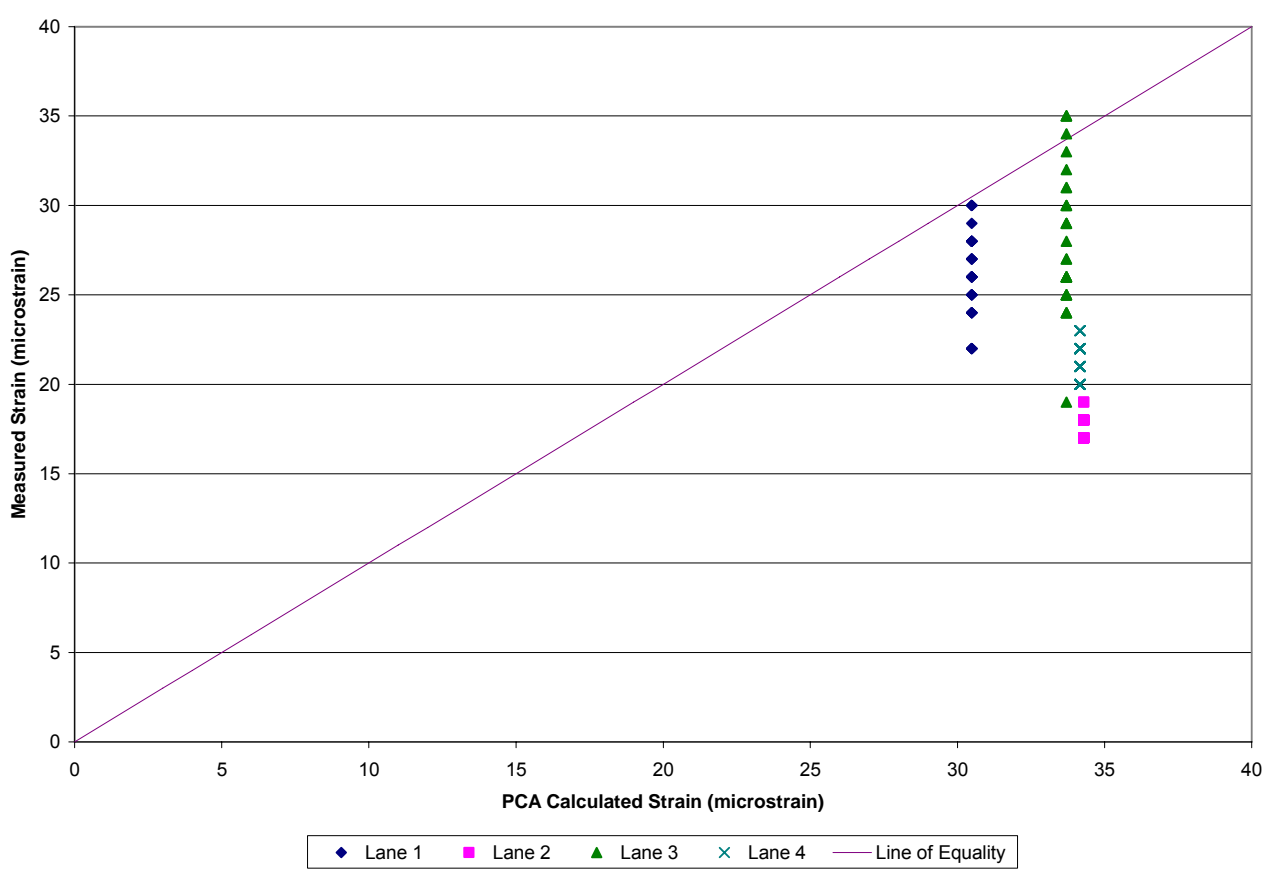

(b)

Figure 7.1 Comparison of PCA Calculated and APT Measured UTW Strains (Bottom of UTW Layer - Corner Location) (a) TA2 (b) TA3 
As can be seen from Figure 7.1, the strain values calculated by the PCA equations in general overestimate the UTW strains measured in the APT for both TA2 and TA3. The degree of overestimation can be determined with a ratio of calculated to measured UTW strains. These data were calculated for each lane and are presented in Table 7.1. For TA2 the ratio of PCA to measured values ranged from 0.95 to 2.8. The low value was in Lane 1 which was debonded. The same ratio ranged from 1.2 to 1.9 for the data in TA3. These ratios confirm that there is an overestimation of the UTW strains calculated by the PCA equations.

Table 7.1 Comparison of PCA Calculated and Measured UTW Strains at the Bottom of the UTW Layer - Corner Location (continued)

\begin{tabular}{|c|c|c|c|c|}
\hline & \multicolumn{4}{|c|}{ TA2 } \\
\hline & Lane 1 & Lane 2 & Lane 3 & Lane 4 \\
\hline PCA Strain $(x)$ & 60.26 & 55.47 & 42.66 & 46.76 \\
\hline $\begin{array}{c}\text { Average } \\
\text { Measured } \\
\text { Strains }(\mu) \\
(n=30)\end{array}$ & 62.77 & 19.74 & 23.13 & 21.93 \\
\hline $\begin{array}{c}\text { Standard } \\
\text { Deviation +/- } \\
(s)\end{array}$ & 21.13 & 2.63 & 1.71 & 2.18 \\
\hline $\begin{array}{c}\text { Z = }(x-\mu) / \mathrm{s} \\
\text { Reliability }\end{array}$ & -0.12 & 13.6 & 11.4 & 11.4 \\
\hline $\begin{array}{c}\text { Ratio } \\
(\text { PCA/Measured })\end{array}$ & 0.97 & $>99.9 \%$ & $>99.9 \%$ & $>99.9 \%$ \\
\hline
\end{tabular}


Table 7.1 Comparison of PCA Calculated and Measured UTW Strains at the Bottom of the UTW Layer - Corner Location

\begin{tabular}{|c|c|c|c|c|}
\hline & \multicolumn{4}{|c|}{ TA3 } \\
\hline & Lane 1 & Lane 2 & Lane 3 & Lane 4 \\
\hline PCA Strain $(x)$ & 30.49 & 34.29 & 33.70 & 34.16 \\
\hline $\begin{array}{c}\text { Average } \\
\text { Measured } \\
\begin{array}{c}\text { Strains }(\mu) \\
(\mathrm{n}=30)\end{array}\end{array}$ & 26.03 & 17.71 & 28.13 & 21.42 \\
\hline $\begin{array}{c}\text { Standard } \\
\text { Deviation +/- } \\
(\mathrm{s})\end{array}$ & 2.34 & 0.59 & 3.86 & 0.92 \\
\hline $\begin{array}{c}\text { Z = }(x-\mu) / \mathrm{s} \\
\text { Reliability }\end{array}$ & 1.90 & 28.2 & 1.44 & 13.8 \\
\hline $\begin{array}{c}\text { Ratio } \\
(\text { PCA/Measured })\end{array}$ & 1.17 & 1.94 & 1.20 & $>99.9 \%$ \\
\hline
\end{tabular}

\subsubsection{Calibration of Calculated UTW Strains}

Table 7.1 contains additional comparisons of the data for the UTW strains. The standard deviations of the measured values were determined. Additionally, Zvalues were calculated to compare the calculated values to the measured values. Using a one-tailed distribution, the probability that the PCA value was greater than the measured value was determined using statistical tables. These probabilities represent the reliability provided by the PCA equation. For example, for the PCA calculated strain in TA2 Lane 2, there is a 99.9 percent probability that the calculated strain is greater than the measured strain.

The Z-values ranged from -0.12 (unbonded Lane 1) to 13.6 in TA2 and 1.44 to 28.2 for TA3. These results indicate that in most cases the reliability was much 
higher than necessary (greater than 99.9 percent) for a rehabilitation technique. While the reliability can be much lower, though still acceptable (e.g. 85 percent), these lower values however were most likely the result of a higher standard deviation of the strain readings.

The average ratio of PCA calculated to measured strains for the test lanes in both test areas was 1.74 . As noted previously a factor to account for the partially bonded condition between the two layers (1.36) was applied to the PCA equations. As such, the factor of 1.36 that was applied to account for the partially bonded condition appears to be unnecessary.

The general form of a 100(1- $\alpha)$ percent confidence interval for the mean of a normal population when the standard deviation, $s$, is known is as shown in Equation 7.1 (Devore, [2000]).

$$
x \pm Z_{\alpha / 2} \cdot \frac{s}{\sqrt{n}}
$$

In order to introduce reliability into the design methodology, this equation was utilized. However, changes were made in order to adopt it for use. The PCA equations already overestimate the average measured strain value. Thus to calibrate the PCA calculated UTW strains to a 50 percent reliability (such that they would equal the measured values) the calculated values were divided by the average ratio of PCA calculated to measured strains. This calibration value heretofore is referenced as the $\mathrm{K}$ factor. It is always desirable to have calculated design strains that are greater than the strains that are expected to be encountered in the actual pavement. Thus, only the positive side of the confidence interval was used. The general form of this modification is presented in Equation 7.2. 


$$
\varepsilon_{\text {mod }}=\frac{1}{K} \varepsilon_{P C A}+Z_{\alpha / 2} \sqrt{\frac{s_{p}^{2}}{n}}
$$

$\varepsilon_{\text {mod }}=$ modified strain at given reliability

$\varepsilon_{P C A}=$ PCA strain

$K=$ calibration factor (average ratio of PCA to measured strains)

$s_{p}{ }^{2}=$ pooled variance

$Z_{\alpha / 2}=Z$-value at given reliability

The PCA strains that were presented in Table 7.1 were modified using this equation. The $\mathrm{K}$ factor (average ratio of PCA calculated to measured strains) was determined to be equal to 1.74 . The pooled standard deviation from the test lanes in both test areas was used for the pooled variance, $s_{p}{ }^{2}(60.33$ microstrain ${ }^{2}$ ). The modified strains were calculated at 80 percent reliability, thus the Z-value used was 0.85 . These modified data are presented in Figure 7.2 shows the result of this correction with all data combined. 


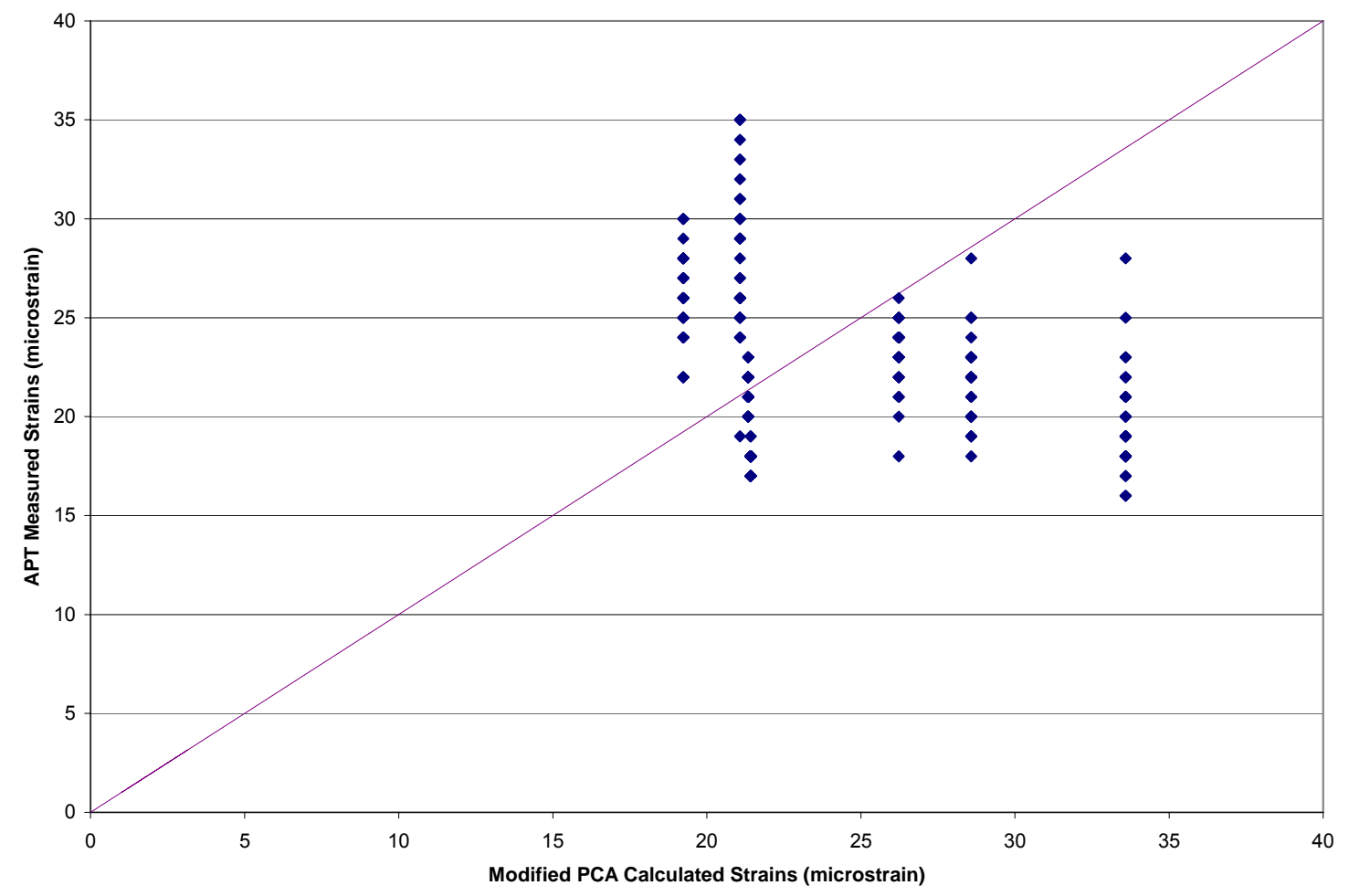

Figure 7.2 Comparisons of Modified PCA UTW Strains at an $80 \%$ Reliability with Measured Strains at the Bottom of the UTW Layer Corner Location

The results shown in this figure show that these modifications were reasonable and that the modified strains provided a good estimate of the measured values while providing an appropriate degree of reliability.

\subsubsection{Comparison of PCA Calculated and Measured HMA Strains} HMA strains were calculated using the PCA design equations along with material and layer thickness data taken from TA2 and TA3. The strain data recorded from Lanes 1 through 4 in the APT were obtained. The critical strain location identified for the HMA in the PCA method was at the bottom of the layer at the edge location. Thus, for initial comparisons, the HMA strains used were from gages placed at the bottom of the HMA layer at the edge location (gage HEB). As 
described previously with the UTW strains, the measured load-induced strains were calculated from the data by subtracting the unloaded strain reading (APT carriage location (axle centerline $)=0$ inches $(0 \mathrm{~mm})$, which is located at the edge of the test pit) from the maximum value recorded for the pass (when the APT carriage is over the gage at either the edge or corner locations). Again, 30 of the initial strain readings were obtained from each lane and location. These data were paired for each lane and plotted versus each other. Figure 7.3 presents the comparisons of PCA calculated strains versus the APT measured strains for the HMA layer.

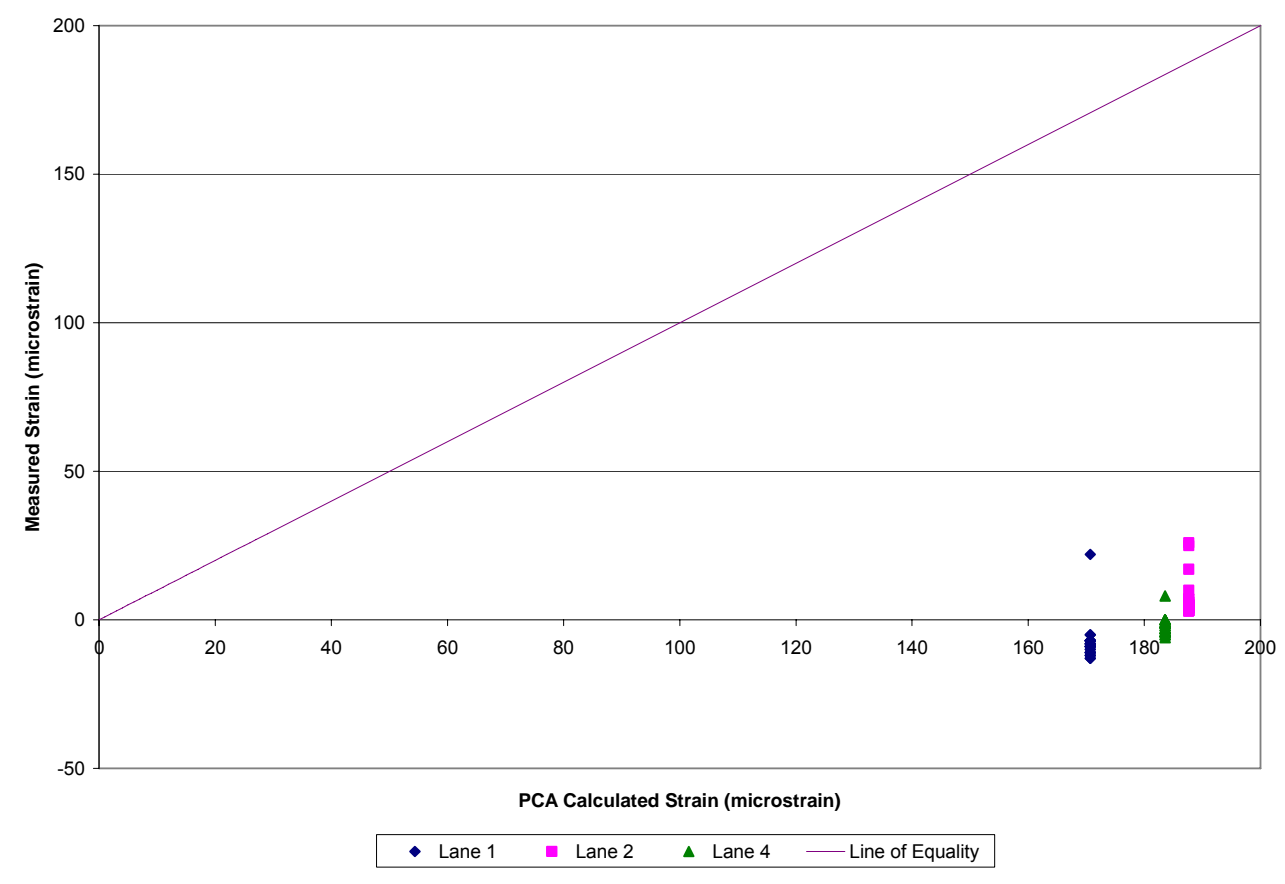

(a)

Figure 7.3 Comparison of PCA Calculated and APT Measured HMA Strains at the Bottom of the HMA - Edge Location (a) TA2 (b) TA3 (continued) 


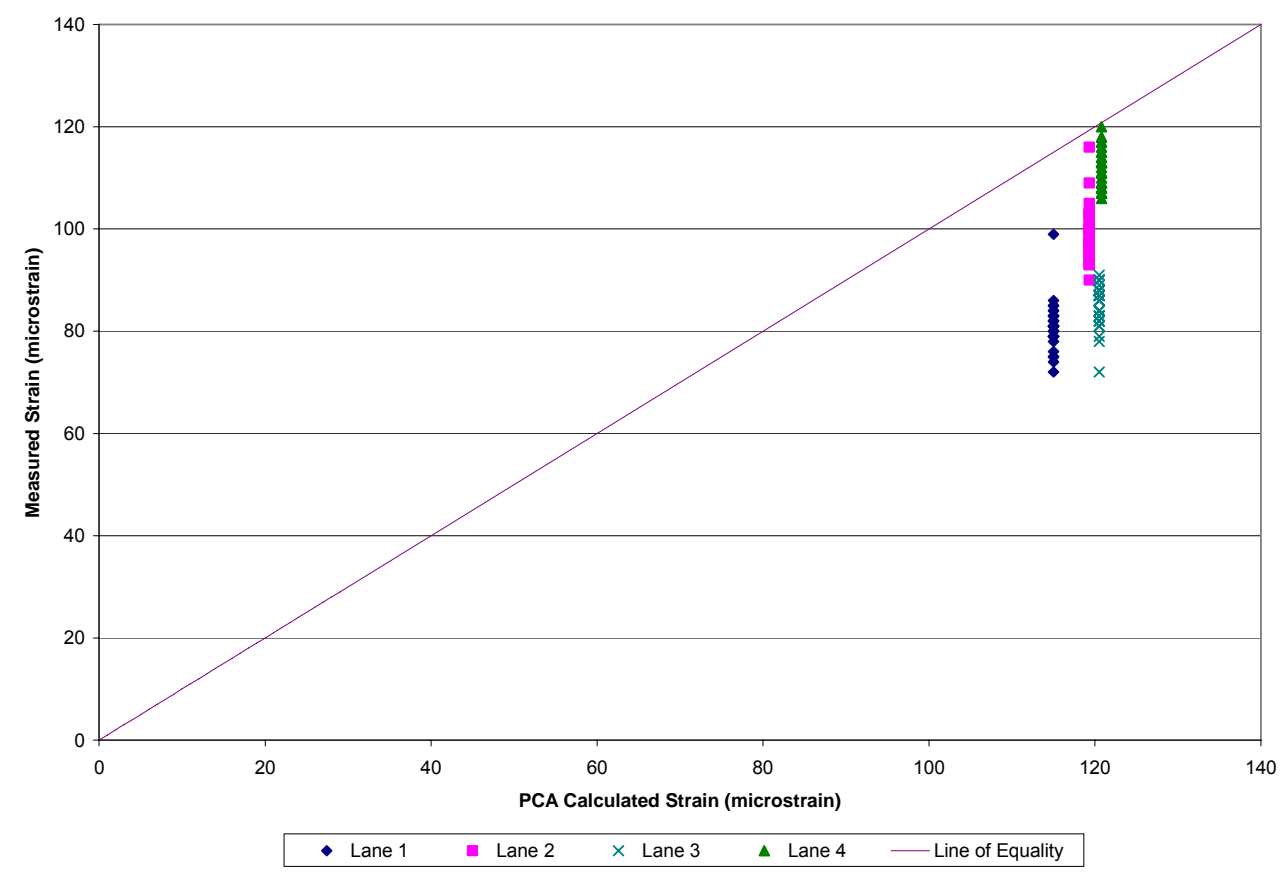

(b)

Figure 7.3 Comparison of PCA Calculated and APT Measured HMA Strains at the Bottom of the HMA - Edge Location (a) TA2 (b) TA3

As can be seen in Figure 7.3, the PCA calculated HMA strains for TA2 were not very accurate for calculating the strain in TA2 (test area with underlying composite section). The degree of discrepancy can be determined with a ratio of calculated to measured HMA strains. These values were calculated for each lane and are presented in Table 7.2. For TA2 the ratio of PCA to measured values ranged from -94 to 29 . The same ratio ranged from 1.08 to 1.41 for the data in TA3 indicating that for design of UTW over HMA pavements (conditions for which the method was developed) the method was fairly good. 
Table 7.2 Comparison of PCA Calculated and Measured HMA Strains

\begin{tabular}{|c|c|c|c|c|}
\hline & \multicolumn{4}{|c|}{ TA2 } \\
\hline & Lane 1 & Lane 2 & Lane 3 & Lane 4 \\
\hline PCA Strain & 171 & 187.6 & NA & 183.5 \\
\hline $\begin{array}{c}\text { Average } \\
\text { Measured } \\
\text { Strains }(n=30)\end{array}$ & -8.03 & 6.38 & NA & -1.93 \\
\hline $\begin{array}{c}\text { Ratio } \\
\text { (PCA/Measured) }\end{array}$ & -21.3 & 29.4 & NA & -94.8 \\
\hline $\begin{array}{c}\text { PCA Strain }(x) \\
\text { Average } \\
\text { Measured } \\
\text { Strains }(\mu) \\
(n=30)\end{array}$ & 115.0 & 119.3 & 120.5 & 120.8 \\
\hline $\begin{array}{c}\text { Ratio } \\
(\text { PCA/Measured) }\end{array}$ & 1.40 & 98.94 & 85.29 & 111.9 \\
\hline
\end{tabular}

It was noted previously that the analysis of the measured strain data in Section 6.3.1 indicated that the critical strain location for the HMA strains in TA2 was not as assumed in the PCA design. It was noted that the larger strains occurred at the top of the HMA at the corner location. Given the large discrepancy noted between the calculated and measured strains this theory seems likely. It was also noted in Section 6.3.1 that for the data from TA3, the critical strain location may also be at the corner.

Thus, to verify the critical strain location in the HMA layer for both the test areas the load-induced strain data (filtered as described earlier) from the edge and corner locations were obtained (gages HEB, HCT for TA2 and HEB, HCT for TA3). These data are presented in Figure 7.4. 
As indicated in this figure, for TA2, the critical strain location in the HMA layer to the top of the layer. Also, the critical strain location was at the corner instead of the edge. As noted previously, Lane 1 at the corner location was unbonded, but initial values indicated that the strains at the corner were higher than at the edge. Lane 4 was also partially bonded, which explains why the measured values were less than in the other lanes (see discussions in Section 6.3.3).

For TA3, Figure 7.4 indicates that the corner location is also more critical than the edge location for the HMA layer. In all lanes, the strains measured at the corner location at the bottom of the HMA were higher than at the edge location. Thus, the measured data indicate that for the TA3 sections the critical strain location of the HMA layer is at the corner not at the edge. The PCA method calculates the HMA strain at the edge location. 


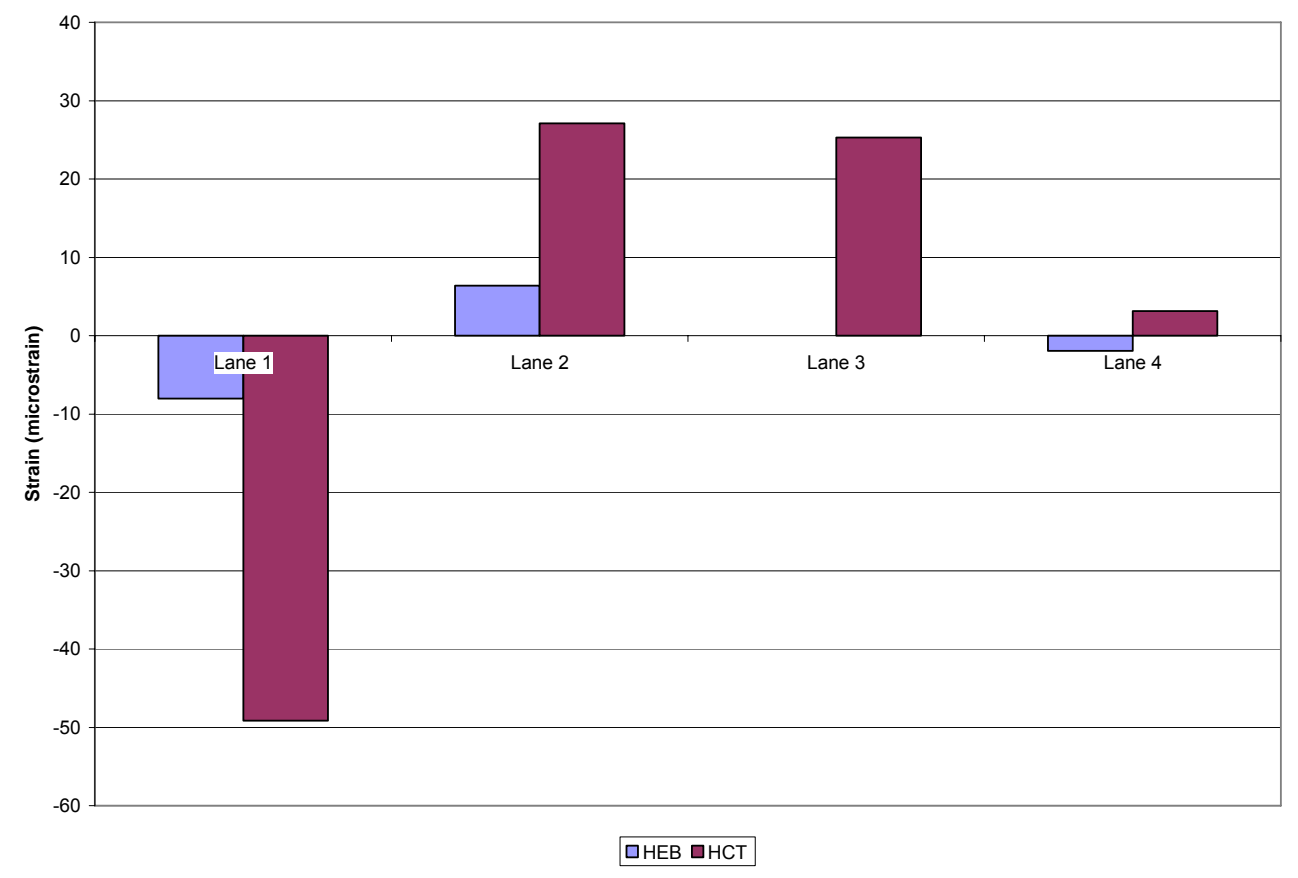

(a)

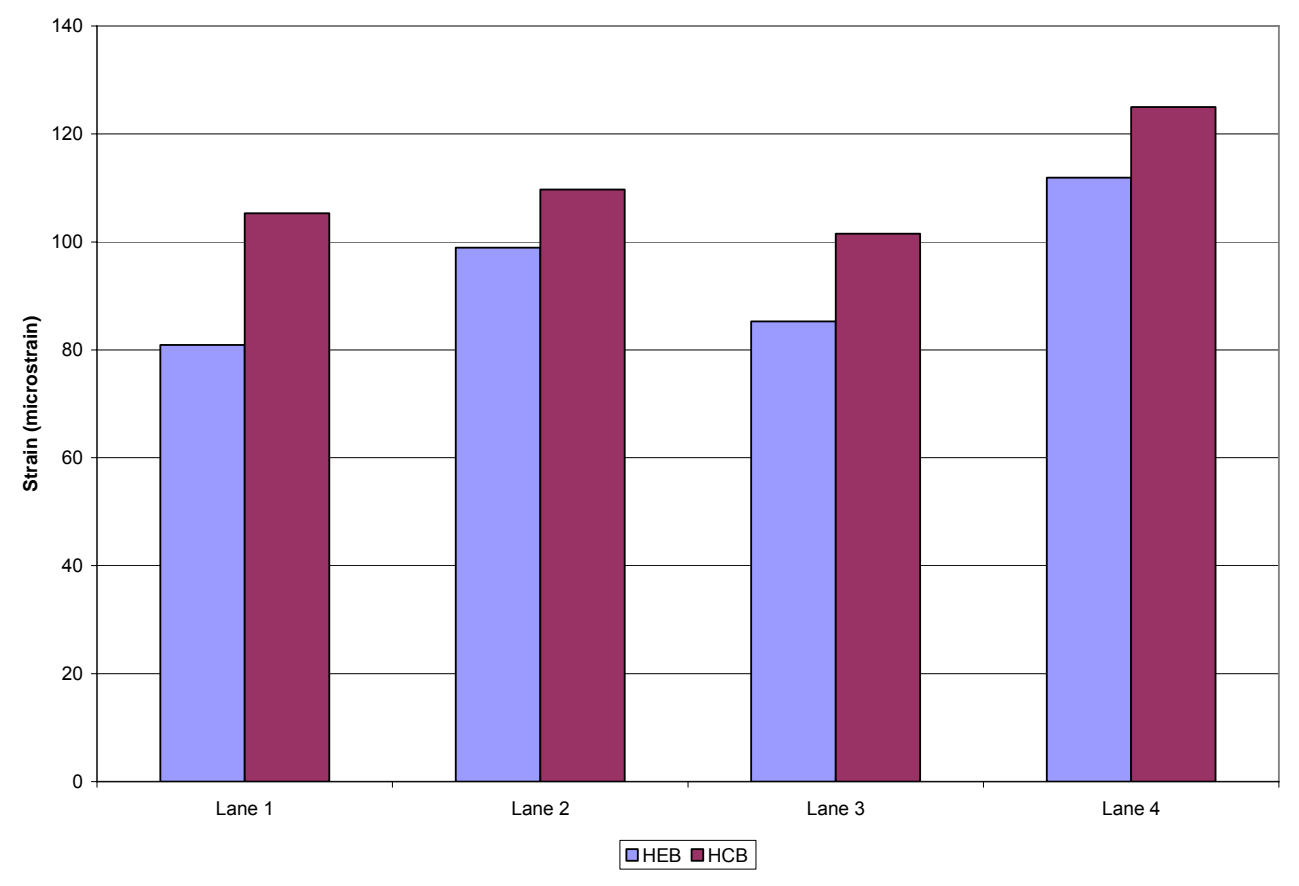

(b)

Figure 7.4 Comparisons of Strains at the Edge and Corner Locations in HMA Layer (a) TA2 (b) TA3 
These results have the following implications. First, when designing UTW pavements over an existing composite section, the design HMA strain should be located at the top of the HMA layer, corner location. This strain should be equal to the UTW strain at the bottom of the UTW layer, corner location. That these strains are equivalent is supported by the theoretical data presented in Figure 6.1. This is also a conservative estimate since even if debonding occurs, the tensile strain at the top of the HMA would actually reduce. Debonding would cause the HMA and underlying PCC layer to act as in independent system, with the HMA layer mostly in compression due to flexure under loading (see Figure C.1 for an example of this phenomenon). One scenario in which the HMA would experience tensile strains at the bottom again would be if the bond between the HMA and underlying PCC layer were to also fail. However, at this point, it is likely that the UTW layer would already have failed. Thus, the HMA strain at the top of the layer can be assumed to be equal to the UTW strain at the bottom, both at the corner location. 


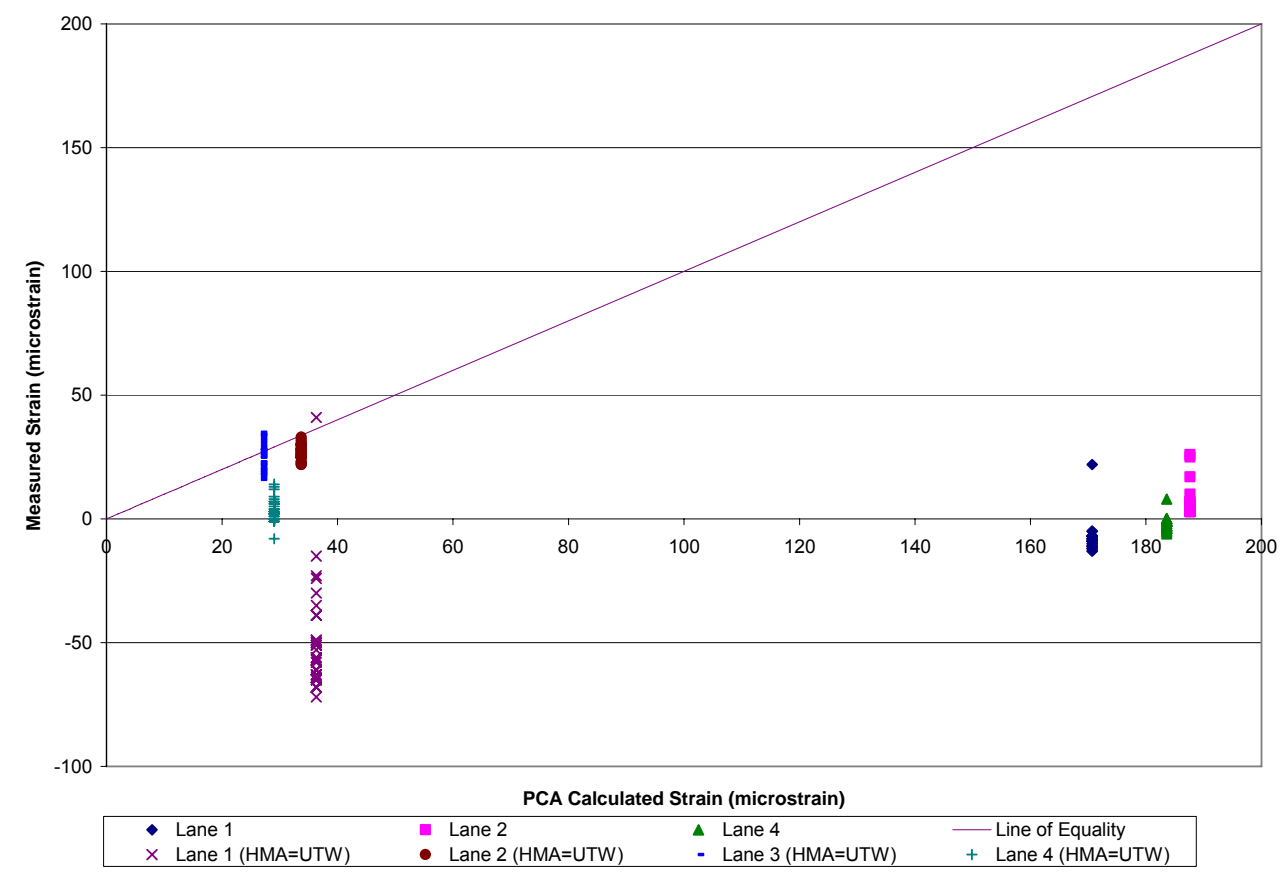

Figure 7.5 Comparison of PCA Calculated HMA Strains and HMA Strains Equal to UTW Strains

Figure 7.5 illustrates the effect of making this assumption. Assuming that the HMA strains are equal to the UTW strains does shift the HMA strains closer to those measured in the APT. The ratios of the calculated to measured strains for these data were calculated and are presented in Table 7.3. In TA2, Lane 1 was debonded (as discussed previously) thus, the ratio of calculated to measured strains reflects this condition. For Lanes 2 and 3, the assumption approximated the strains fairly well having calculated to measured strain ratios of 2.05 and 1.68 , respectively. Lane 4 was partially debonded and this is reflected in the HMA strains measured at the top of the layer. The ratio of calculated to measured strains in Lane 4 was 13.7. This is likely the result of the partially bonded condition in this lane. Overall, this assumption provided a better estimate than the existing equations for the design of UTW pavements over existing composite pavements. 
Table 7.3 Comparison of PCA Calculated and Measured HMA Strains Assuming New Critical Strain Location

\begin{tabular}{|c|c|c|c|c|}
\hline & \multicolumn{4}{|c|}{ TA2 } \\
\hline & Lane 1 & Lane 2 & Lane 3 & Lane 4 \\
\hline PCA Strain & 60.3 & 55.5 & 42.7 & 46.7 \\
\hline $\begin{array}{c}\text { Average } \\
\text { Measured } \\
\text { Strains (n=30) }\end{array}$ & -49.1 & 27.1 & 25.3 & 3.42 \\
\hline $\begin{array}{c}\text { Standard } \\
\text { Deviation }\end{array}$ & 22.2 & 2.83 & 5.48 & 4.61 \\
\hline Z $=(x-\mu) / \sigma$ & 4.93 & 10.0 & 3.17 & 9.39 \\
\hline Reliability & NA & $>99.9 \%$ & $>99.9 \%$ & $>99.9 \%$ \\
\hline $\begin{array}{c}\text { Ratio } \\
(\text { PCA/Measured) }\end{array}$ & -1.23 & 2.05 & 1.68 & 13.7 \\
\hline
\end{tabular}

\subsubsection{Calibration of Calculated HMA Strains}

To calibrate the HMA strains (for use with existing composite pavements) calculated using the assumption outlined in the previous section, the method outlined in Section 7.1.2 was employed. Data from Table 7.3 were used to calculate the $\mathrm{K}$ factor and pooled variance. The resulting $\mathrm{K}$ factor was 1.86 and the pooled variance was 138.0 microstrain $^{2}$. A reliability level of 80 percent was used. These data were input into Equation 7.2 and the modified strains were calculated. These modified strains are presented in Figure 7.6. As indicated in this figure, again, neglecting the debonded lane (Lane 1) the adjustment appears reasonable and provides a good level of reliability. 


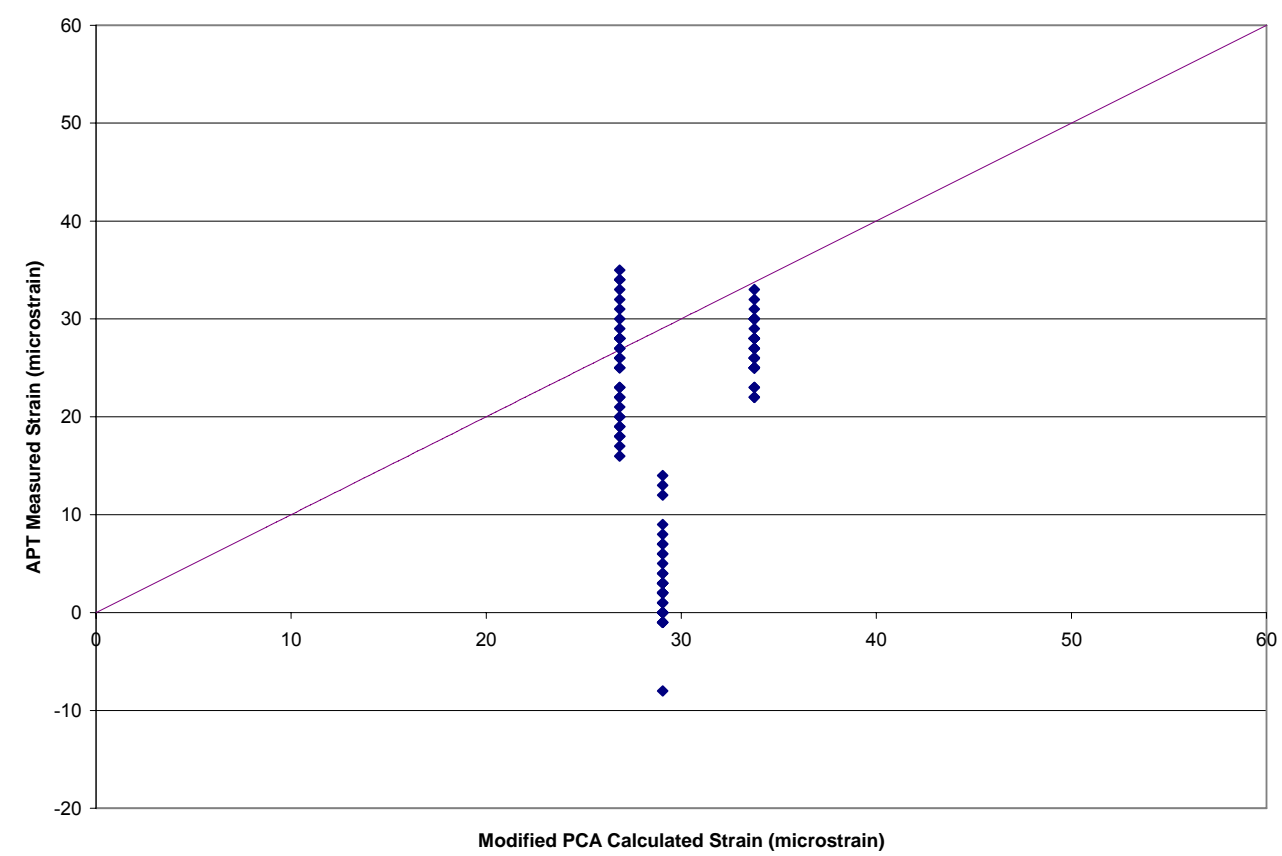

Figure 7.6 Modified HMA Strains for Composite Section (TA2) at 80\% Reliability

The analysis of the critical strain locations also indicated that, as was shown in Figure 7.4, the critical strain location in the HMA layer for all lanes in TA3 was at the bottom of the layer, corner location not at the edge location as assumed in the PCA design methodology. Thus for design purposes, the strains in the HMA for a UTW pavement constructed over an HMA pavement section should be calculated at the corner location. The PCA design values and the measured HMA strain at the corner location are shown in Figure 7.7. A comparison of these values is shown in Table 7.4. 


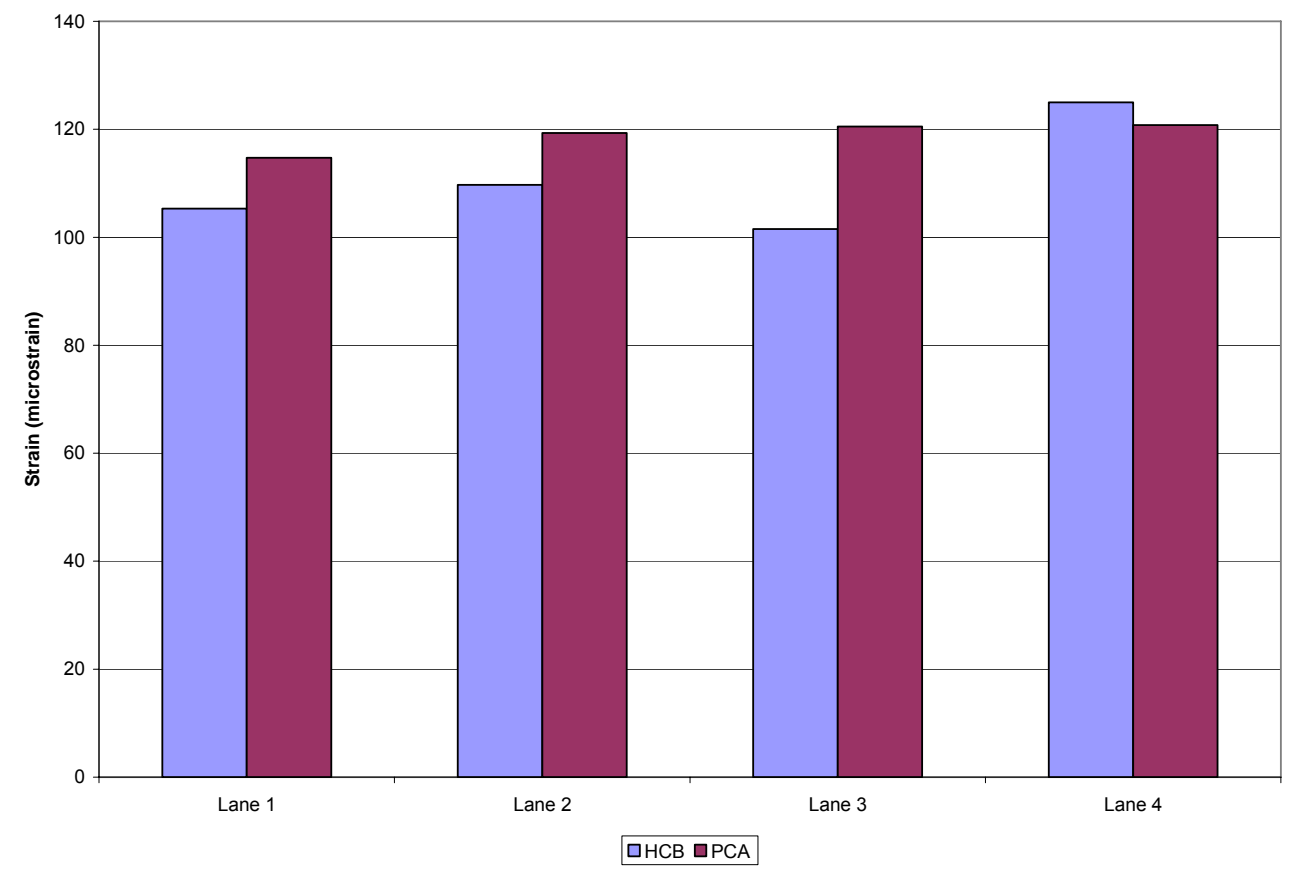

Figure 7.7 Comparison of PCA HMA Strains and Measured HMA Corner Strains in TA3 
Table 7.4 Comparison of PCA Calculated and Measured HMA Strains at Corner Location

\begin{tabular}{|c|c|c|c|c|}
\hline & \multicolumn{4}{|c|}{ TA3 } \\
\hline & Lane 1 & Lane 2 & Lane 3 & Lane 4 \\
\hline PCA Strain & 115.0 & 119.3 & 120.5 & 120.8 \\
\hline $\begin{array}{c}\text { Average } \\
\text { Measured } \\
\text { Strains (n=30) }\end{array}$ & 105.6 & 109.7 & 101.5 & 125.5 \\
\hline $\begin{array}{c}\text { Standard } \\
\text { Deviation }\end{array}$ & 10.35 & 3.44 & 2.84 & 2.67 \\
\hline Z $=(x-\mu) / \sigma$ & 0.91 & 2.79 & 6.71 & -1.79 \\
\hline Reliability & $63.7 \%$ & $99.5 \%$ & $>99.9 \%$ & NA \\
\hline $\begin{array}{c}\text { Ratio } \\
(\text { PCA/Measured) }\end{array}$ & 1.09 & 1.09 & 1.19 & 0.96 \\
\hline
\end{tabular}

To calibrate the PCA calculated HMA strains (used with existing HMA pavements) the method outlined in Section 7.1.2 was again followed. Data from Table 7.4 were used to calculate the $\mathrm{K}$ factor and pooled variance. The resulting $\mathrm{K}$ factor was 1.081 and the pooled variance was 33.54 microstrain $^{2}$. A reliability level of 80 percent was used. These data were input into Equation 7.2 and the modified strains were calculated. These modified strains are presented in Figure 7.8. The results indicate that the modified strains provide a reasonable approximation of the measured strains and at a good level of reliability. 


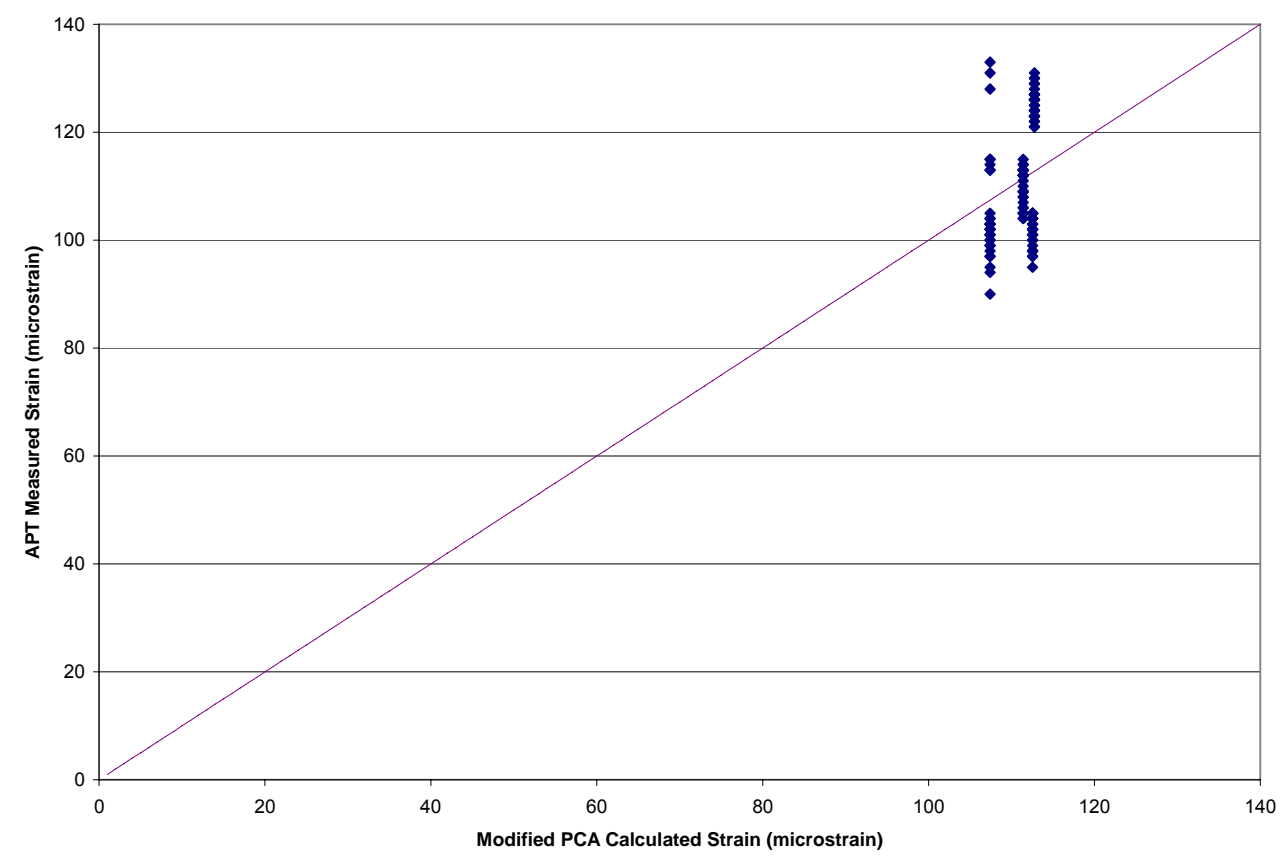

Figure 7.8 Modified HMA Strains for HMA Pavement Section (TA3) at 80\% Reliability

The previous sections outlined the calibration of the PCA equations with the measured data and the incorporation of reliability into the design method. However, the PCA method still requires several inputs (for the in situ pavement) that may not be readily available to designers. As such a new design approach based on pavement deflection analysis is proposed.

\subsection{Falling Weight Deflectometer Approach}

As presented in the previous section, the PCA design method was modified to produce results that were more in line with the measures strain data that was collected in the APT and to introduce reliability concepts. However, the proposed methodology still required several inputs related to the existing pavement section that would be difficult for designers to obtain, namely the modulus of elasticity of the HMA and the modulus of subgrade reaction. As indicated in Section 2.4, the 
modulus of the HMA is an input into the radius of relative stiffness equation which in turn is used to calculate the UTW stresses and HMA strains. However, the radius of relative stiffness values can also be determined directly using pavement deflection analysis techniques which would provide more accurate information regarding the in situ pavement and subgrade conditions.

For mechanistic design applications, the estimated radius of relative stiffness, $l_{e s t}$, can be determined by in-situ falling weight deflectometer (FWD) testing. As can be seen in Equations 2.1 through 2.4 the stress and strain are a function of $l_{e}$. Thus, it is proposed that FWD data be used to calculate the $l_{\text {est }}$ value for UTW section and use this value in the PCA equations for UTW stress and HMA strain.

To illustrate this concept, data from the FWD testing conducted on the UTW lanes before milling the HMA and prior to testing in the APT facility was obtained. FWD testing was described in Section 4.11 and the results are presented in Section 5.7. The $l_{e}$ values for each lane were calculated and these data were input directly into the PCA equations for HMA strain and UTW stress (Equations 2.1 and 2.3, respectively). Values for UTW modulus of elasticity and thickness were obtained by direct measurements and subgrade modulus was calculated from the pavement deflection analysis. To compare the results from the PCA equations for the UTW layer to the measured data from the APT, the calculated UTW stresses were converted to strains using a linear elastic assumption ( $\sigma=$ $E \varepsilon)$. Strains under loading in the APT were obtained as described in the section 7.1.1. Measured data were obtained from gages $\mathrm{HCB}, \mathrm{HCT}$, and UCBmax. The following section describes a comparison for the calculated and measured UTW strains. 


\section{UTW Strains}

The UTW FWD calculated strains and measured strains from the APT obtained as described above. These data were plotted against each other were combined for each lane and plotted in Figure 7.9 for the UTW strains.

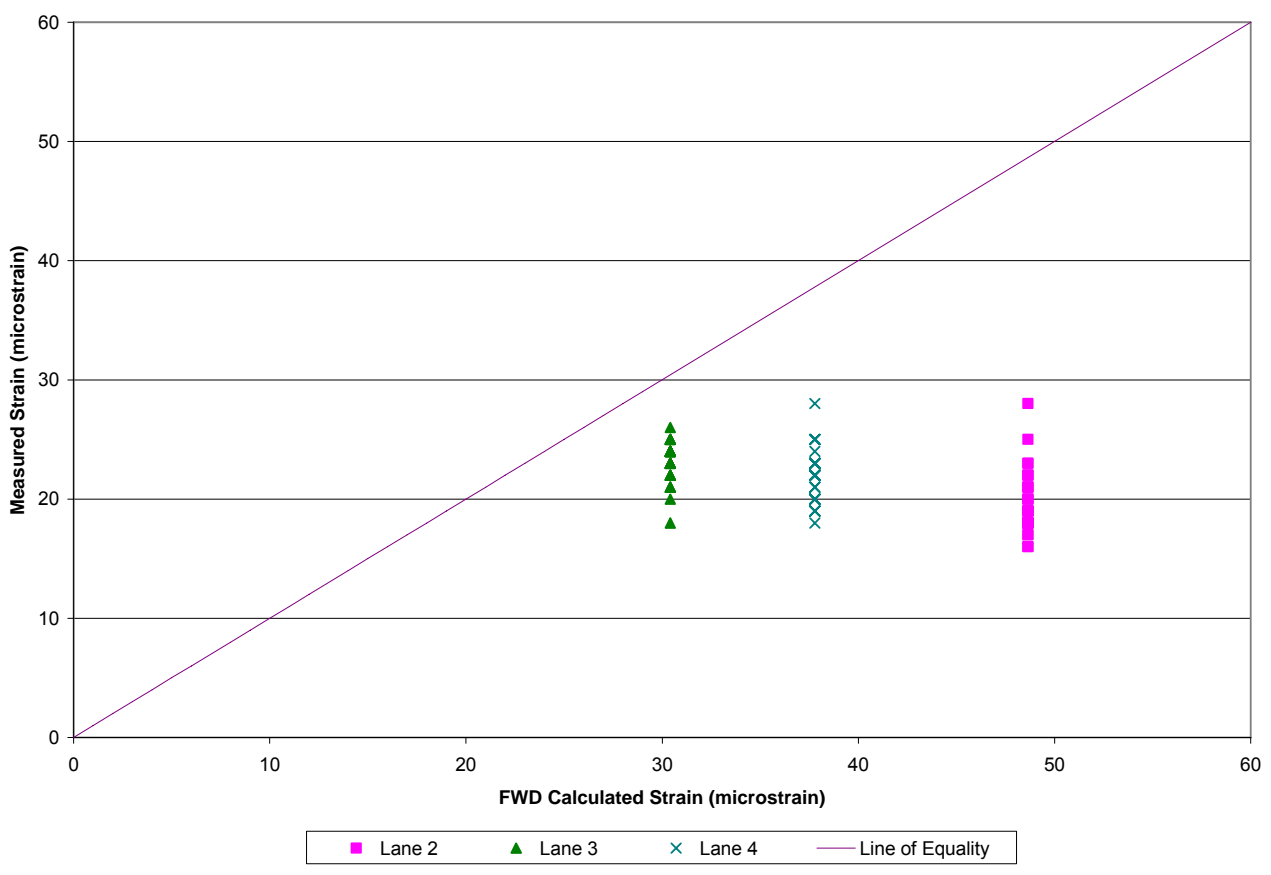

(a)

Figure 7.9 Comparison of Falling Weight Deflectometer Calculated and Measured UTW Strains (a) TA2 (b) TA3 (continued) 


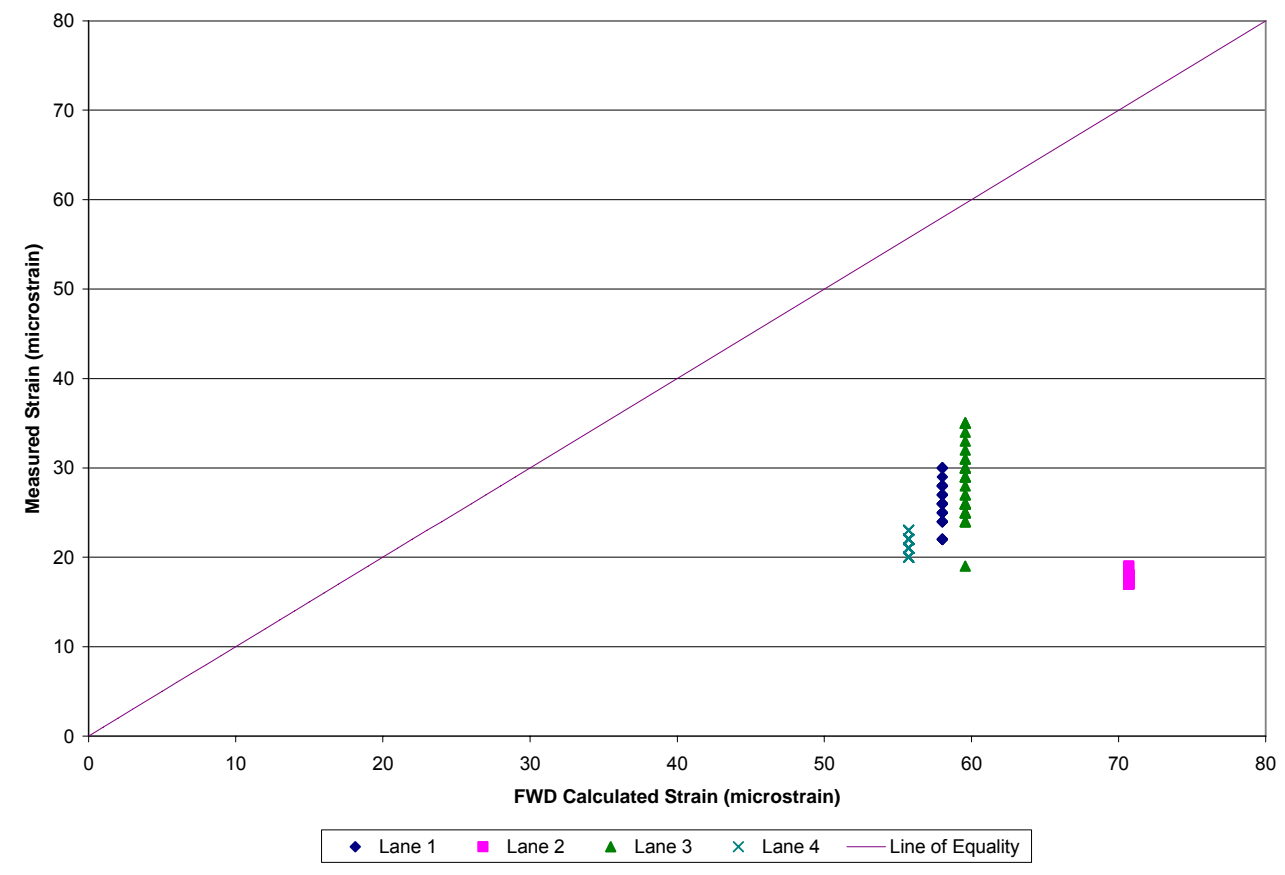

(b)

Figure 7.9 Comparison of Falling Weight Deflectometer Calculated and Measured UTW Strains (a) TA2 (b) TA3

As can be seen from Figure 7.9 the UTW strain values determined from the FWD were reasonably comparable to those measured in the APT. The ratio of calculated strains to measured strains ranged from 0.97 to 2.64 for TA2 and from 1.17 to 1.94 for TA3. These data and additional comparisons are included in Table 7.5.

In terms of reliability, the FWD approach provided over 99.9 percent reliability in the estimate of the UTW strains in all cases. This indicates that the method overestimates the measured values. The calibration method outlined in Section 7.1.2 was applied to these data to correct the overestimation and incorporate reliability into the estimate. Equation 7.2 was used for this modification. The data in Table 7.5 were used to calculate the input parameters for this equation. 
The $\mathrm{K}$ factor was 2.17 , the pooled variance was 60.33 microstrain $^{2}$, and a reliability of 80 percent was applied. The adjusted strains are presented in Figure 7.10. The adjustment appears reasonable and provides a good level of reliability.

Table 7.5 Comparison of FWD Calculated and Measured UTW Strains (continued)

\begin{tabular}{|c|c|c|c|c|}
\hline & \multicolumn{4}{|c|}{ TA2 } \\
\hline & Lane 1 & Lane 2 & Lane 3 & Lane 4 \\
\hline FWD Strain $(x)$ & 49.03 & 48.64 & 30.42 & 37.78 \\
\hline $\begin{array}{c}\text { Average } \\
\text { Measured } \\
\text { Strains }(\mu) \\
(\mathrm{n}=30)\end{array}$ & 62.77 & 19.74 & 23.13 & 21.93 \\
\hline $\begin{array}{c}\text { Standard } \\
\text { Deviation +/- } \\
(\mathrm{s})\end{array}$ & 21.13 & 2.63 & 1.71 & 2.18 \\
\hline $\begin{array}{c}\text { Z = }(x-\mu) / \mathrm{s} \\
\text { Reliability }\end{array}$ & -0.65 & 10.98 & 4.27 & 7.27 \\
\hline $\begin{array}{c}\text { Ratio } \\
(\text { FWD/Measured) }\end{array}$ & 0.79 & $>99.9 \%$ & $>99.9 \%$ & $>99.9 \%$ \\
\hline
\end{tabular}


Table 7.5 Comparison of FWD Calculated and Measured UTW Strains

\begin{tabular}{|c|c|c|c|c|}
\hline & \multicolumn{4}{|c|}{ TA3 } \\
\hline & Lane 1 & Lane 2 & Lane 3 & Lane 4 \\
\hline PCA Strain $(x)$ & 58.02 & 70.69 & 59.59 & 55.72 \\
\hline $\begin{array}{c}\text { Average } \\
\text { Measured } \\
\begin{array}{c}\text { Strains }(\mu) \\
(\mathrm{n}=30)\end{array}\end{array}$ & 26.03 & 17.71 & 28.13 & 21.42 \\
\hline $\begin{array}{c}\text { Standard } \\
\text { Deviation +/- } \\
(\mathrm{s})\end{array}$ & 2.34 & 0.59 & 3.86 & 0.92 \\
\hline $\begin{array}{c}\text { Z = }(x-\mu) / \mathrm{s} \\
\text { Reliability }\end{array}$ & 13.64 & 90.04 & 8.15 & 37.17 \\
\hline $\begin{array}{c}\text { Ratio } \\
(\text { FWD/Measured })\end{array}$ & 2.23 & $>99.9 \%$ & $>99.9 \%$ & $>99.9 \%$ \\
\hline
\end{tabular}

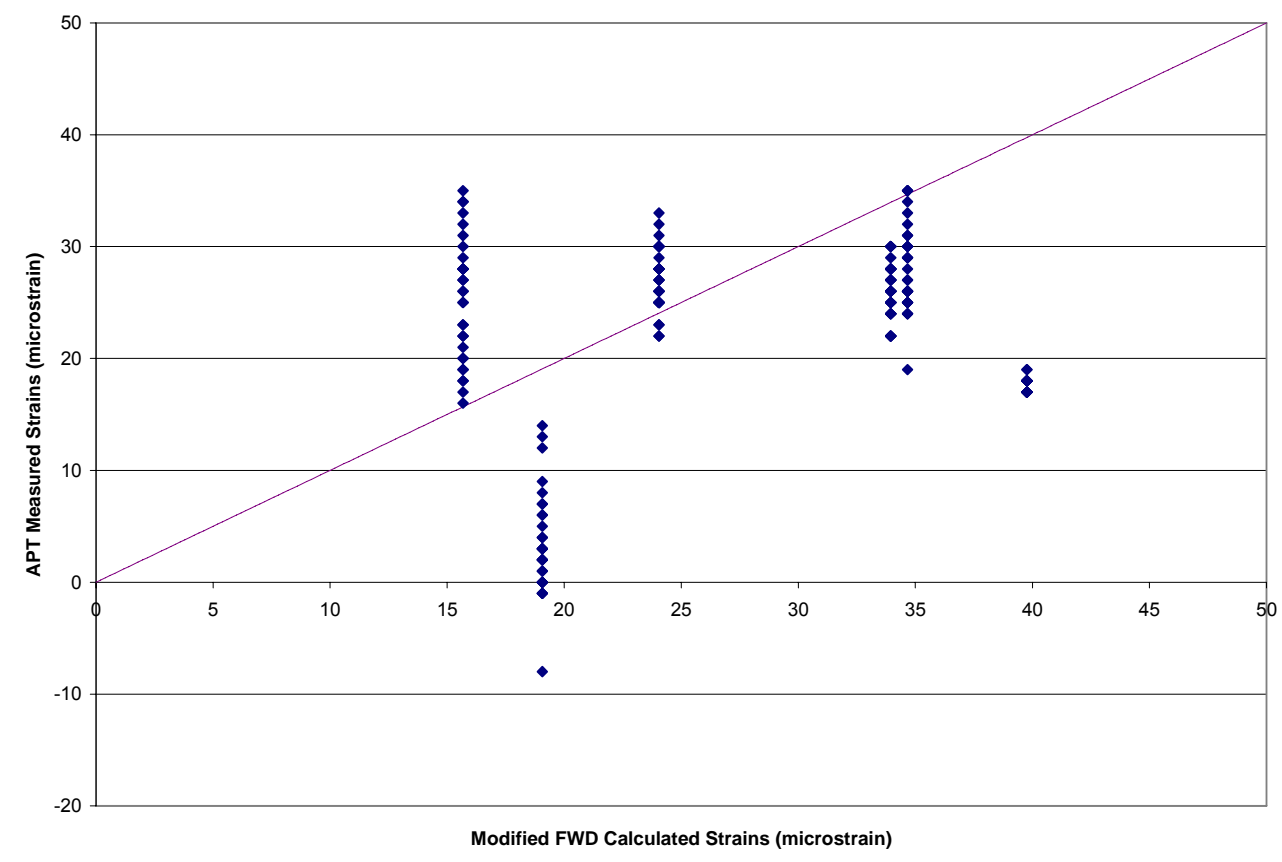

Figure 7.10 Modified UTW Strains based on FWD Approach at $80 \%$ Reliability 


\section{HMA Strains}

The FWD calculated and measured HMA strain data were collected and plotted against each other for each lane. This plot is presented in Figure 7.11. As can be seen from this Figure, the HMA strain values determined from the FWD in TA2 are reasonably comparable to those measured in the APT. However, the calculated values for TA3 provide large overestimations of the measured data. Comparisons of these data are presented in Table 7.6.

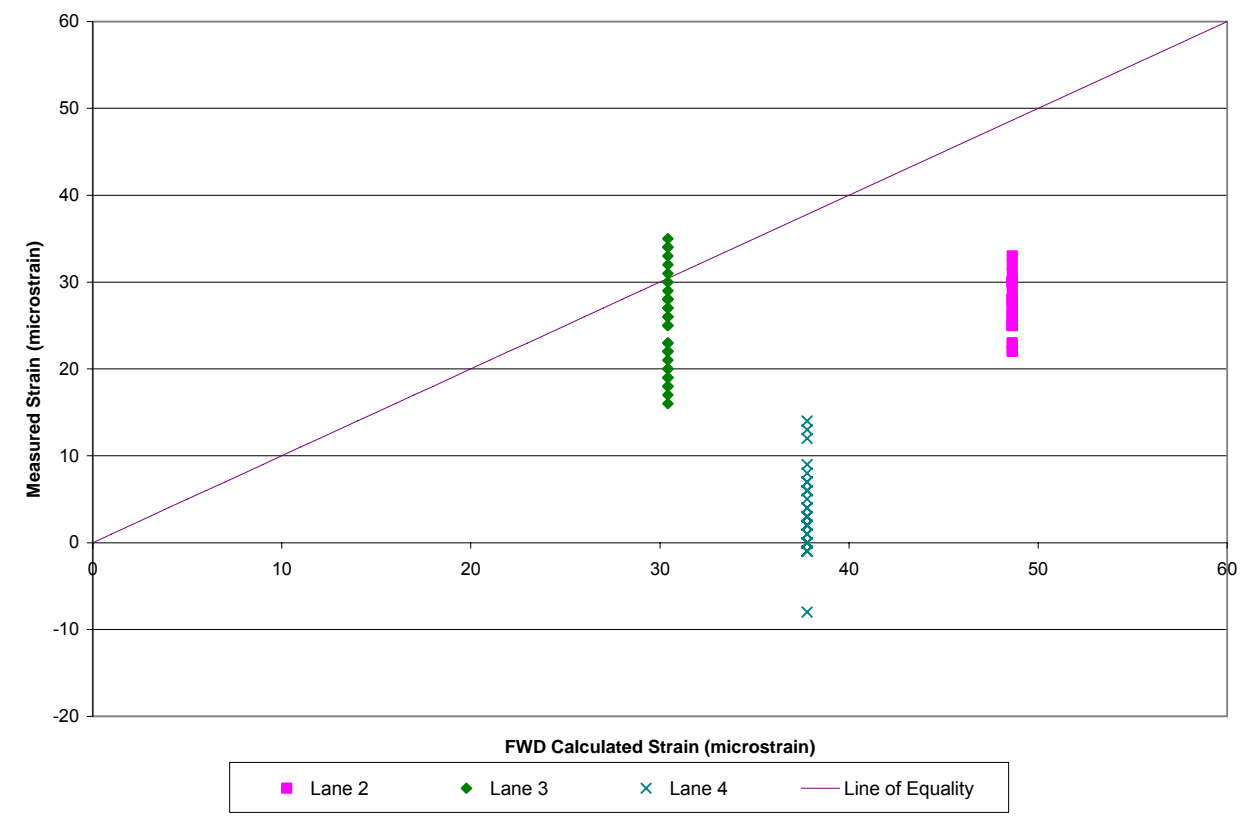

(a)

Figure 7.11 Comparison of Falling Weight Deflectometer Calculated and Measured HMA Strains (a) TA2 (b) TA3 (continued) 


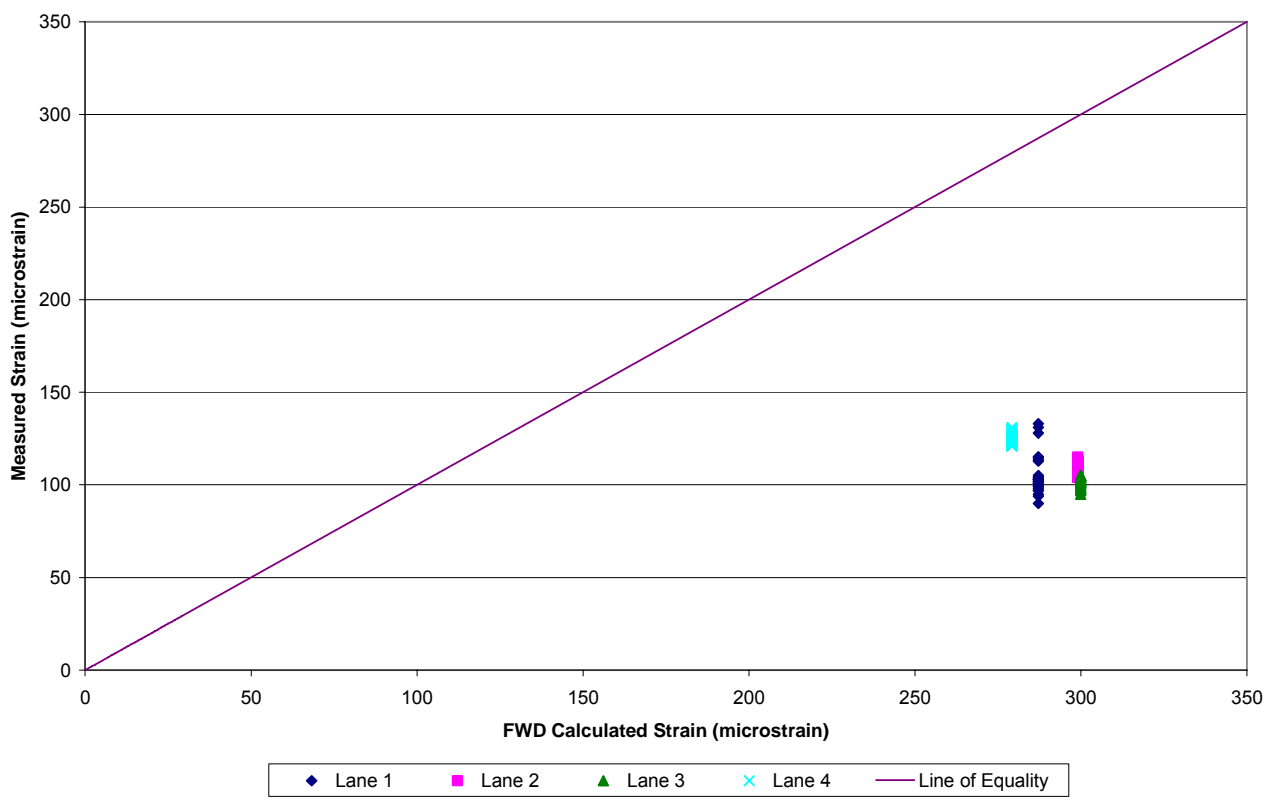

(b)

Figure 7.11 Comparison of Falling Weight Deflectometer Calculated and Measured HMA Strains (a) TA2 (b) TA3 
Table 7.6 Comparison of FWD Calculated and Measured HMA Strains

\begin{tabular}{|c|c|c|c|c|}
\hline & \multicolumn{4}{|c|}{ TA2 } \\
\hline & Lane 1 & Lane 2 & Lane 3 & Lane 4 \\
\hline FWD Strain $(x)$ & 49.03 & 48.64 & 30.42 & 37.78 \\
\hline $\begin{array}{c}\text { Average } \\
\text { Measured } \\
\text { Strains }(\mu) \\
\quad(n=30)\end{array}$ & -49.13 & 27.10 & 25.29 & 3.419 \\
\hline $\begin{array}{c}\text { Standard } \\
\text { Deviation +/- } \\
\text { (s) }\end{array}$ & 22.18 & 2.83 & 5.48 & 4.61 \\
\hline$Z=(x-\mu) / s$ & 4.43 & 7.61 & 0.93 & 7.44 \\
\hline Reliability & $>99.9 \%$ & $>99.9 \%$ & 65.2 & $>99.9 \%$ \\
\hline \begin{tabular}{|c|} 
Ratio \\
(FWD/Measured)
\end{tabular} & -1.00 & 1.79 & 1.20 & 11.0 \\
\hline & \multicolumn{4}{|c|}{ TA3 } \\
\hline PCA Strain $(x)$ & 287 & 299 & 300 & 279 \\
\hline $\begin{array}{c}\text { Average } \\
\text { Measured } \\
\text { Strains }(\mu) \\
\quad(n=30)\end{array}$ & 105.32 & 109.71 & 101.48 & 125.55 \\
\hline $\begin{array}{c}\text { Standard } \\
\text { Deviation +/- } \\
\text { (s) }\end{array}$ & 10.38 & 3.44 & 2.84 & 2.67 \\
\hline $\mathrm{Z}=(x-\mu) / \mathrm{s}$ & 17.52 & 55.07 & 69.90 & 57.57 \\
\hline Reliability & $>99.9 \%$ & $>99.9 \%$ & $>99.9 \%$ & $>99.9 \%$ \\
\hline $\begin{array}{c}\text { Ratio } \\
\text { (FWD/Measured) }\end{array}$ & 2.73 & 2.73 & 2.96 & 2.22 \\
\hline
\end{tabular}


The ratio of calculated to measured strains ranged from -1.00 (unbonded lane) to 11.0 for TA2 and from 2.22 to 2.96 for TA3. These results indicate that for most cases, these uncalibrated strain values provide significant overestimations. A comparison of the reliability also showed that the FWD approach provides over 99.9 percent reliability in the estimate of the HMA strains in all but one case.

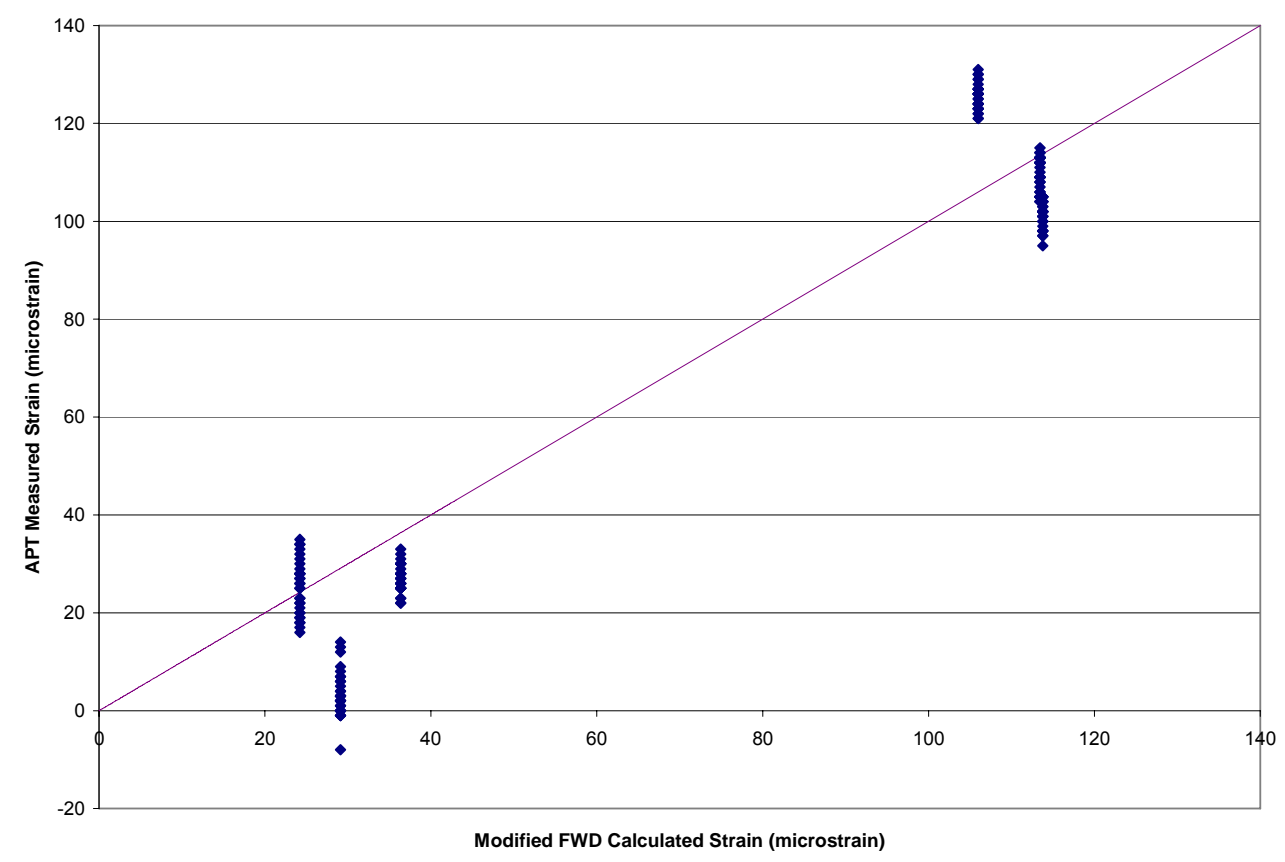

Figure 7.12 Modified HMA Strains based on FWD Approach at $80 \%$ Reliability

The calibration as described in Section 7.1.2 was applied to these data to correct the overestimation and incorporate reliability into the estimate. Equation 7.1 was used for this modification. The data from Table 7.6 were used to provide inputs for this equation. For the calibration of the TA2 data, the $\mathrm{K}$ factor applied was 1.499 and the pooled variance was 138.0 microstrain $^{2}$. The applied $\mathrm{K}$ factor was 2.658 and the pooled variance was 33.54 microstrain $^{2}$ for the calibration of the data in TA3. A reliability of 80 percent was used in the analysis for both test areas. The calibrated strains are presented in Figure 7.12. As can be seen in this figure, the adjustment appears to be acceptable as a majority of the FWD 
estimated strains (neglecting the debonded lane) trend with and to the right of the line of equality indicating that the approach provides a good estimate at an adequate level of reliability.

\subsection{UTW Design Methodology Using the Falling Weight Deflectometer Approach} In order to implement a UTW design methodology using the FWD approach, a way to estimate the UTW design radius of relative stiffness must be developed. In practice only in situ FWD testing of the distressed HMA pavement will be conducted. The $l_{e}$ of the in-situ pavement can be calculated from the FWD data however, the $l_{e}$ used in the PCA design equations is based on the final UTW pavement section. Thus, the in-situ $l_{e}$ needs to be adjusted to account for the milling of the HMA pavement and the increase in structural capacity provided by the UTW layer.

In order to adjust the in-situ $l_{e}$ value, a multivariable regression analysis was conducted using data from TA4. TA4 was constructed with five different UTW lanes varying in UTW depth, HMA depth, and milling depth. This provided a range of values for the analysis. These variables are summarized in Table 7.7. TA4 and its construction were described in Sections 4.2.4, and 4.3, respectively. The lanes were evaluated using the FWD. Pavement deflection analysis was described in Section 4.11 and the results were presented in Section 5.7. Data from prior to milling the HMA, after placement of the UTW, and monthly thereafter were collected. Additionally, the FWD data collected from the APT for TA2 and TA3 were combined with the TA4 data. These data were also collected prior to milling the HMA and after placement of the UTW (prior to loading).

The general form of the radius of relative stiffness expression is presented in Equation 7.3. Discussion of the variables used in the regression follows. The data collected prior to milling the HMA were used to calculate an in-situ estimated radius of relative stiffness, $l_{\text {esti. }}$ A design radius, $l_{\text {estd }}$, was calculated 
from the FWD data collected after the placement of the UTW. To account for the placement of the UTW the modulus of elasticity, $E_{u t w}$, and the thickness, $t_{u t w}$, of the respective UTW layers was added to the data set. Finally the milling depth, $t_{\text {mill, }}$ was also included with the data. A total of 397 cases were included in the data set. An unweighted least squares linear regression of $l_{\text {estd }}$ was conducted using a proprietary statistical analysis program. The results of the regression analysis are presented in Table 7.7.

$$
y=b_{o}+b_{1} x_{1}+b_{2} x_{2}+\ldots+b_{k} x_{k}
$$

Table 7.7 Results of Regression Analysis

\begin{tabular}{|c|c|c|c|c|}
\hline $\begin{array}{c}\text { Predictor } \\
\text { Variables }\end{array}$ & Coefficient & Std. Error & $\mathrm{T}$ & $\mathrm{P}$ \\
\hline Constant & 1.28530 & 0.66 & 1.93487 & 0.5069 \\
\hline$l_{\text {esti }}$ & 1.59578 & 0.03084 & 51.75 & 0.0000 \\
\hline$E_{\text {utw }}$ & $-2.177 \mathrm{E}-06$ & $2.710 \mathrm{E}-07$ & -8.03 & 0.0000 \\
\hline$t_{\text {mill }}$ & -1.24118 & 0.28509 & -4.35 & 0.0000 \\
\hline$t_{\text {utw }}$ & 3.63527 & 0.29672 & 12.25 & 0.0000 \\
\hline
\end{tabular}

The resulting equation for the design estimated radius of relative stiffness, $l_{\text {estd, }}$, is as follows.

$$
l_{\text {estd }}=1.285+1.596 l_{\text {esti }}-2.177 \times 10^{-6} E_{u t w}-1.241 t_{\text {mill }}+3.635 t_{u t w}
$$

The adjusted coefficient of determination, $R_{a d j}{ }^{2}$, for this relationship is 0.881 . This indicates that the variables in the equation provide a good relationship for the $l_{\text {estd }}$ value. 
To validate this relationship, FWD data was obtained from UTW pavements constructed in Missouri and Minnesota. The project in Missouri (Amos [2001]) was a 3 inch $(75 \mathrm{~mm})$ UTW pavement placed after milling 3 inches $(75 \mathrm{~mm})$ of HMA. The modulus of the UTW was $4.39 \times 10^{6} \mathrm{psi}(30.3 \mathrm{GPa})$. The $l_{\text {esti }}$ values were calculated from the FWD data collected prior to milling the HMA. These data were input into Equation 7.4 and the $l_{\text {estd }}$ was calculated. This value was compared to the actual $l_{\text {est }}$ value calculated after UTW placement. A total of 60 cases were included. A two sample T-test was conducted to compare the calculated and measured values. The null hypothesis was that the difference between the means of the two data sets was equal to $0, H_{0}: \mu-x=0$. The results indicate a T-statistic for unequal variances equal to -0.03 which indicates that there is a 97.27 percent probability that the null hypothesis is correct.

The Minnesota data was collected from FWD testing conducted on the MnROAD UTW test cells. Data from the I-94 site were obtained from prior to the placement of the UTW. These data were collected in August prior to construction in October. Data from the first two months available after construction following were also utilized. These data were obtained in February and March.

The test cells had two different UTW thicknesses ( 3 inches or 4 inches $(75 \mathrm{~mm}$ or $100 \mathrm{~mm}$ )) which were also equal to the milling depth. The modulus of the UTW layer varied depending on the type of fibers used (either $4.4 \times 10^{6} \mathrm{psi}$ or $4.8 \times 10^{6}$ psi (30.3 GPa or 33.1 GPa)) (Vandenbossche and Retner [1998]). Following the same methodology as used in with the Missouri data, the $l_{\text {esti }}$ values were calculated from the FWD data collected prior to milling the HMA. These data were used as an input into Equation 7.4 and the $l_{\text {estd }}$ was calculated. This value was compared to the actual $l_{\text {est }}$ value calculated after UTW placement.

A two sample T-test was conducted to compare the calculated and measured values. The null hypothesis was that the difference between the means of the 
two data sets was equal to $0, H o: \mu-x=0$. The difference between the means (39.520 and 38.362 for the measured and calculated values, respectively) was 1.204. The results indicate a T-statistic for unequal variances equal to 6.10 which indicates a rejection of the null hypothesis. However, the overall difference between the two means is relatively small and only represents a 3 percent difference between the two values. Thus, despite the inability to provide statistical basis, the relative difference between the two values indicates that the relationship in Equation 7.3 is adequate in estimating the effect of the milling and UTW for design purposes.

\subsection{Overview of Proposed FWD UTW Design Methodology}

This section presents an overview of the steps involved in the proposed FWD UTW design methodology. In order for the modification outlined in Section 7.1 to be applied to the PCA UTW stress equations, Equation 7.1 needs to be adapted for use with stresses. The form of the equation applicable for stresses is presented in Equation 7.5.

$$
\sigma_{\text {mod }}=\left(\frac{1}{K} \varepsilon_{P C A}+s Z_{\alpha / 2}\right) E_{u t w}
$$

$\sigma_{\text {mod }}=$ modified stress at given reliability

$\varepsilon_{P C A}=$ PCA strain

$K=$ Calibration Factor

$s=$ standard deviation

$Z_{\alpha / 2}=(x-\mu) / s$

$E=$ modulus of elasticity of the UTW layer

The values of the standard deviation and $\mathrm{K}$ factor were calculated in previous sections. The recommended values of the standard deviation and $K$ factor to use for the different strain calculations are summarized in Table 7.8. 
Table 7.8 Recommended Calibration Factors

\begin{tabular}{|c|c|c|c|}
\hline Strain Location & UTW & HMA & $\begin{array}{c}\text { HMA } \\
\text { (Composite) }\end{array}$ \\
\hline $\begin{array}{c}\text { Pooled Variance, } \\
\mathrm{n}=30 \\
\left(s_{p}{ }^{2}\right)\end{array}$ & 60.33 & 33.53 & 138.0 \\
\hline$K$ & & & \\
\hline
\end{tabular}

Building on the results of the analysis conducted in the previous sections, a new design methodology was developed. The steps involved in the proposed methodology were modified from those previously outlined by Riley [2005]. The equations needed for the design are summarized in Table 7.9.

1. Conduct FWD testing on the site and determine the in-situ estimated radius of relative stiffness, $l_{\text {esti, }}$ the elastic modulus of the HMA, $E_{h m a}$, and the in-situ modulus of subgrade reaction, $k$.

2. Using Equation 7.4 calculate the design estimated radius of relative stiffness, $l_{\text {estd. }}$.

3. Input this value into the PCA equations (2.1 to 2.4 ) to calculate the PCA stresses and strains. Convert the UTW stresses to strains using the modulus of the UTW layer, $E_{u t w}$.

4. Using Equations 7.2 and 7.5 calculate the modified HMA strains and UTW stresses.

5. Use a linear relationship to determine the concrete stress and asphalt strain for all other weights in the axle load distribution category.

6. Compute the temperature-induced concrete stresses and asphalt strains (Equations 2.5 and 2.6).

7. Sum the load-induced and temperature-induced stresses and strains to get total concrete stress and total asphalt strain.

8. Conduct the fatigue analyses (Equations 2.10 through 2.14). 
9. If either asphalt or concrete fatigue is greater than 100 , alter the design inputs and rerun the analysis.

Table 7.9 Summary of Design Equations (continued)

\begin{tabular}{|c|c|}
\hline Equation & \\
\hline 7.4 & $l_{\text {estd }}=1.285+1.596 l_{\text {esti }}-2.177 \times 10^{-6} E_{u t w}-1.241 t_{\text {mill }}+3.635 t_{u t w}$ \\
\hline 2.1 & $\log _{10}\left(\varepsilon_{\text {HMA,18k,SAL }}\right)=5.267-0.927 \log _{10} k+0.299 \log _{10}\left(\frac{L_{a d j}}{l_{e}}\right)-0.037 l_{e}$ \\
\hline 2.2 & $\log _{10}\left(\varepsilon_{\text {HMA,36k,TAL }}\right)=6.070-0.891 \log _{10} k+0.786 \log _{10}\left(\frac{L_{a d j}}{l_{e}}\right)-0.028 l_{e}$ \\
\hline 2.3 & $\log _{10}\left(\sigma_{U T W, 18 k, S A L}\right)=5.025-0.465 \log _{10} k+0.686 \log _{10}\left(\frac{L_{a d j}}{l_{e}}\right)-1.291 \log _{10} l_{e}$ \\
\hline 2.4 & $\begin{array}{l}\log _{10}\left(\sigma_{U T W, 36 k, T A L}\right)=4.898-0.599 \log _{10} k+1.395 \log _{10}\left(\frac{L_{a d j}}{l_{e}}\right)-0.963 \log _{10} l_{e} \\
-0.088\left(\frac{L_{a d j}}{l_{e}}\right)\end{array}$ \\
\hline 7.2 & $\varepsilon_{\bmod }=\frac{1}{K} \varepsilon_{P C A}+s Z_{\alpha / 2}$ \\
\hline 7.5 & $\sigma_{\bmod }=\left(\frac{1}{K} \varepsilon_{P C A}+s Z_{\alpha / 2}\right) E_{u t w}$ \\
\hline 2.5 & $\Delta \varepsilon_{H M A, \Delta T}=-28.698+2.131 \alpha_{P C C} \Delta T+17.692\left(\frac{L_{a d j}}{l_{e}}\right)$ \\
\hline 2.6 & $\Delta \sigma_{U T W, \Delta T}=28.037-3.496 \alpha_{P C C} \Delta T+18.382\left(\frac{L_{a d j}}{l_{e}}\right)$ \\
\hline
\end{tabular}


Table 7.9 Summary of Design Equations

\begin{tabular}{|c|c|}
\hline 2.10 & For $S R>0.55 \quad \log _{10}(N)=\frac{(0.97187-S R)}{0.0828}$ \\
\hline 2.11 & For $0.45 \leq S R \leq 0.55 \quad N=\left(\frac{4.2577}{(S R-0.43248)}\right)^{3.268}$ \\
\hline 2.12 & For $S R<0.45 \quad N=\infty$ \\
\hline 2.13 & $N_{\text {HMA }}=0.0795 \cdot\left(\frac{1}{\varepsilon_{\text {HMA }}}\right)^{3.29} \cdot\left(\frac{1}{E_{\text {HMA }}}\right)^{0.854}$ \\
\hline 2.14 & $F D=\sum_{i}^{m} \sum_{j}^{n} \frac{n_{i, j}}{N_{i, j}}$ \\
\hline
\end{tabular}

\subsection{Example Using Proposed FWD Design Methodology}

This section contains a design example using the proposed FWD design method. The design parameters are as follows. The pavement is on a section of road that is to be designed for total truck traffic of 2,000,000 over a ten year period using a Class A distribution (Wu et al. [1998]). The existing pavement is a composite pavement of which the properties of the layers are unknown. The design modulus of elasticity and modulus of rupture for the UTW are 5,000,000 psi (34.4 $\mathrm{GPa}$ ) and $650 \mathrm{psi}(4.48 \mathrm{GPa})$, respectively. The UTW overlay is to be designed for a temperature gradient of $-2.8{ }^{\circ} \mathrm{F} /$ inch $\left(-0.062{ }^{\circ} \mathrm{C} / \mathrm{mm}\right)$ and the coefficient of thermal expansion of the concrete is $5.5 \times 10^{-6} /{ }^{\circ} \mathrm{F}\left(9.9 \times 10^{-6} /{ }^{\circ} \mathrm{C}\right)$. To maintain clearances, the thickness of the UTW should be equal to the depth of the milling. The Poisson's ratios for the UTW concrete and HMA are 0.2 and 0.35 , respectively. In order to keep the saw-cutting to a minimum and to keep the longitudinal joints out of the wheel paths, a joint spacing of 72 inches $(1800 \mathrm{~mm})$ is to be used. The initial design thickness of the UTW is 2 inch (50 mm). The design should be for an 80 percent reliability level. The design follows the steps outlined in Section 7.4. 
1. Conduct FWD testing on the site and determine the in-situ estimated radius of relative stiffness, $l_{\text {esti, }}$ the elastic modulus of the HMA, $E_{H M A}$, and the in-situ modulus of subgrade reaction, $k$.

FWD testing was conducted at the proposed site. The $l_{\text {esti }}$ is determined to be 24.52 inches $\left(613 \mathrm{~mm}\right.$ ), the $E_{H M A}$ is determined to be 550,000 psi (3.8 $\mathrm{GPa})$ and the $k$ is determined to be $135 \mathrm{pci}(37 \mathrm{~Pa} / \mathrm{m})$.

2. Using Equation 7.3 calculate the design estimated radius of relative stiffness, $l_{\text {estd. }}$

The design estimated radius of relative stiffness, $l_{\text {estd, }}$ is determined to be equal to 34.32 inches $(872 \mathrm{~mm})$.

3. Input this value into the PCA equations (2.1 to 2.4) to calculate the PCA stresses and strains. Convert the UTW stresses to strains using the modulus of the UTW layer, $E_{u t w .}$

The results of the calculations are as follows.

$$
\begin{aligned}
& \varepsilon_{\mathrm{HMA}, 18 \mathrm{k}, \mathrm{SAL}}=33.07 \text { microstrain } \\
& \varepsilon_{\mathrm{HMA}, 18 \mathrm{k}, \mathrm{TAL}}=33.07 \text { microstrain } \\
& \varepsilon_{\mathrm{UTW}, 18 \mathrm{k}, \mathrm{SAL}}=51.76 \text { microstrain } \\
& \varepsilon_{\mathrm{UTW}, 18 \mathrm{k}, \mathrm{TAL}}=51.76 \text { microstrain }
\end{aligned}
$$

4. Using Equations 7.2 and 7.5 calculate the modified HMA strains and UTW stresses. 
The results of the calculations using the proposed values in Table 7.8 and $Z_{\alpha / 2}=0.85$ (corresponding to 80 percent reliability) are as follows.

$$
\begin{gathered}
\varepsilon_{\mathrm{HMA}, 18 \mathrm{k}, \mathrm{SAL}}=25.97 \text { microstrain } \\
\varepsilon_{\mathrm{HMA}, 18 \mathrm{k}, \mathrm{TAL}}=38.44 \text { microstrain } \\
\sigma_{U T W, 18 \mathrm{k}, \mathrm{SAL}}=84.50 \mathrm{psi}(583.6 \mathrm{kPa}) \\
\sigma_{U T W, 18 \mathrm{k}, \mathrm{TAL}}=137.6 \mathrm{psi}(949.1 \mathrm{kPa})
\end{gathered}
$$

5. Use a linear relationship to determine the concrete stress and asphalt strain for all other weights in the axle load distribution category.

The UTW stress and HMA strain values for different single and double axle loads were determined. An example of the results for the single axle loads is presented in Table 7.10.

Table 7.10 UTW Stresses and HMA Strains for Single Axle Loads

\begin{tabular}{|c|c|c|}
\hline Axle Load (1000 lbs) & $\sigma_{\text {UTW }}(\mathrm{psi})$ & $\varepsilon_{\text {HMA }}$ \\
\hline 20 & 94 & 29 \\
\hline 18 & 85 & 26 \\
\hline 16 & 75 & 23 \\
\hline 14 & 66 & 20 \\
\hline 12 & 56 & 17 \\
\hline 10 & 47 & 14 \\
\hline 9 & 42 & 13 \\
\hline 8 & 38 & 12 \\
\hline 6 & 28 & 9 \\
\hline 4 & 19 & 6 \\
\hline 2 & 9 & 3 \\
\hline
\end{tabular}

Note: $1 \mathrm{lb}=2.21 \mathrm{~kg}, 1 \mathrm{psi}=6.89 \mathrm{kPa}$ 
6. Compute the temperature-induced concrete stresses and asphalt strains (Equations 2.5 and 2.6).

The results of the calculations are as follows.

$$
\begin{gathered}
\varepsilon_{\mathrm{HMA}, \Delta \mathrm{T}}=-63.40 \text { microstrain } \\
\sigma_{U T \mathrm{UW}, \Delta \mathrm{T}}=103.6 \mathrm{psi}(714.3 \mathrm{kPa})
\end{gathered}
$$

7. Sum the load-induced and temperature-induced stresses and strains to get total concrete stress and total asphalt strain.

The total UTW stress and HMA strain values for different single and double axle loads were determined. An example of the results for the single axle loads is presented in Table 7.11.

Table 7.11 Total UTW Stresses and HMA Strains for Single Axle Loads

\begin{tabular}{|c|c|c|}
\hline Axle Load (1000 lbs) & $\sigma_{\text {UTW }}(\mathrm{psi})$ & $\varepsilon_{\text {HMA }}$ \\
\hline 20 & 197 & -35 \\
\hline 18 & 188 & -37 \\
\hline 16 & 179 & -40 \\
\hline 14 & 169 & -43 \\
\hline 12 & 160 & -46 \\
\hline 10 & 151 & -49 \\
\hline 9 & 146 & -50 \\
\hline 8 & 141 & -52 \\
\hline 6 & 132 & -55 \\
\hline 4 & 122 & -58 \\
\hline 2 & 113 & -61 \\
\hline
\end{tabular}

Note: $1 \mathrm{lb}=2.21 \mathrm{~kg}, 1 \mathrm{psi}=6.89 \mathrm{kPa}$ 
8. Conduct the fatigue analyses (Equations 2.10 through 2.14).

The fatigue analysis was conducted for the UTW stresses and the HMA strains for both single and tandem axle loads. An example of the results for the UTW single axle load stresses are presented in Table 7.12.

Table 7.12 Fatigue Analysis of UTW Stresses for Single Axle Loads

\begin{tabular}{|c|c|c|c|c|}
\hline $\begin{array}{c}\text { Axle Load } \\
(1000 \mathrm{lbs})\end{array}$ & $\begin{array}{c}\text { Expected } \\
\text { Repetitions } \\
(\mathrm{A})\end{array}$ & $\begin{array}{c}\text { Stress Ratio } \\
\mathrm{SR}= \\
\text { outw/Modulus } \\
\text { of Rupture }\end{array}$ & $\begin{array}{c}\text { Allowable } \\
\text { Repetitions } \\
\text { (Equations } \\
2.10 \text { through } \\
2.13)(\mathrm{B})\end{array}$ & $\begin{array}{c}\text { Fatigue } \\
\text { Percent } \\
\left(\mathrm{A} / \mathrm{B}^{*} \text { 100 }\right)\end{array}$ \\
\hline 20 & 0 & 0.304 & unlimited & 0.0 \\
\hline 18 & 23140 & 0.289 & unlimited & 0.0 \\
\hline 16 & 41740 & 0.275 & unlimited & 0.0 \\
\hline 14 & 78140 & 0.260 & unlimited & 0.0 \\
\hline 12 & 206800 & 0.246 & unlimited & 0.0 \\
\hline 10 & 515200 & 0.232 & unlimited & 0.0 \\
\hline 9 & 566260 & 0.217 & unlimited & 0.0 \\
\hline 8 & 739940 & 0.203 & unlimited & 0.0 \\
\hline 6 & 1692300 & 0.188 & unlimited & 0.0 \\
\hline 4 & 0 & 0.174 & unlimited & 0.0 \\
\hline 2 & 0 & 0.304 & unlimited & 0.0 \\
\hline & & & & 0.0 \\
\hline
\end{tabular}

9. If either asphalt or concrete fatigue is greater than 100, alter the design inputs and rerun the analysis.

The check at the bottom of Table 7.12 indicates that the sum of the fatigue percents is equal to zero for the single axle UTW stresses. A similar check 
for the tandem axle UTW stresses (not shown) resulted in a total fatigue of 28 percent. Since the HMA strains were negative, no fatigue was expected in this layer. Therefore, the design thickness of 2 inches $(50 \mathrm{~mm})$ and design joint spacing of 72 inches $(1800 \mathrm{~mm}$ ) was determined to be adequate. 


\section{CHAPTER 8. SUMMARY AND CONCLUSIONS}

This chapter contains a summary of the conclusions that were made in Chapters 6 and 7. Chapter 6 contained analysis and discussion of the results of the UTW responses. Chapter 7 included the development and discussion of proposed changes to the UTW design methodology.

\subsection{Factors Influencing Curing Strains}

General observations of the curing data indicated presence of expansive strains in all test lanes. These strains were the result of moisture supplied to concrete during curing. Some initial early-age shrinkage was noted in a few test lanes. However, no shrinkage cracking was observed. These results indicated that curing was applied in an adequate time frame to prevent cracking. There was a difference noted in the curing strains that developed in the lanes that were sawcut using standard saw-cutting practices versus early entry sawing. Namely, the former were less than the latter.

With respect to the trends observed for mixes of different composition, those containing Type III cement did exhibit higher shrinkage. Additionally mixes with fibers also developed lower expansive strains during curing.

The underlying HMA did provide restraint to the expansive UTW curing strains. The degree of restraint was different for the unbonded lanes, but there was little difference partially bonded (intentionally) and fully bonded lanes. 


\subsection{Factors Influencing Drying Shrinkage Strains}

The drying shrinkage strains were measured at the surface of the UTW during testing in the APT. In addition, strains from the gages installed in the unloaded UTW test lanes were also collected. The results indicated that, in general, the concrete mixture composition did not influence the drying shrinkage strains. Although the degree of bonding (full, partial, or none) influenced the strains somewhat, the long-term strain development was dominated by the applied load.

\subsection{Factors Influencing Strain Distribution and Maximum Load-Induced Strains}

The structural properties of the pavement sections did have a significant influence on the strain distribution and on the values of maximum strains. The results also indicated that for UTW constructed over composite sections, the critical location for the HMA layer is at the top of the HMA, not at the bottom as in the PCA design methodology.

The strain distribution and maximum strains indicated that these parameters did not appear to be affected by the concrete mixture composition and changes in the UTW moduli. The measured strain distributions in the HMA layer varied from the theoretical strain distributions, but this was most likely due to a weakened bond between the UTW and HMA layers.

The interfacial bond conditions did affect the strain distribution and maximum load-induced strains. The measured strains in the bonded lanes matched the theoretical values well. There was some discrepancy between the measured and theoretical unbonded strain distributions. Further analysis into this discrepancy indicated that even in an unbonded condition there was a moderate level of friction between the UTW and HMA layers.

As expected, multiple load applications did influence the strain distribution and maximum load induced strains. For sections with a good bond, the number of 
load applications had little effect on the maximum strains or the strain distributions. For those sections that were partially bonded or debonded, both the maximum strains and the strain distribution were affected by an increase in the number of load applications. Even in the debonded sections (with the exception of TA2 Lane 1), the measured strains were all well below that which would be expected to cause cracking in the UTW. However, in some cases the HMA in the debonded sections did experience strains large enough to cause cracking in the bottom of the HMA layer itself. The results also confirmed the existence of the "wave-effect" in front of the rolling wheel. This result indicates that the UTW response to the applied wheel load is primarily flexural. Further, a comparison of the measured strains at the edge and corner locations indicated that the critical load location in the UTW layer was at the corner.

The temperature gradient was greater in thicker UTW pavement sections as would be expected. As a result the theoretical curling strains were greater in the thicker sections as well. Further, the curling strains were greater during the warm day than during cool night conditions. However, these strains were not large enough to cause any distress in the UTW. Additionally, a comparison of the Westergaard curling solution to the PCA model indicated that there was little difference in the results calculated using the two approaches.

\subsection{Factors Influencing Type and Severity of Distresses}

The structural properties of the pavement section did have an effect on the observed distresses at the end of the APT loading period. In general, the stiffer sections developed less distress than the more flexible sections. However, one should keep in mind that these results, are to some extent also influenced by the mechanical properties of the UTW concrete.

The evaluation of the influence of mixture composition indicated that the mix with fibers may delay cracking even in the presence of debonding. The fiber mix 
(MD-3) had the highest flexural strength and performed the best in regards to cracking. Ignoring APT edge effects, both the fiber reinforced concrete and the high early strength concrete performed well in regards to controlling the amount of final distresses.

With respect to the interfacial bond conditions, the observed amount of distress generally followed the expected trends. Lanes with a lower degree of bonding (partially bonded or unbonded conditions) typically exhibited higher amounts of distress. Conversely, fully bonded lanes typically showed the lowest degree of distress.

The results also indicate that debonding does occur prior to cracking. This finding supports the results previously observed at MnROAD. Additionally, the progression of distress development is such that no debonding was observed before 60,000 load applications at 15,000 lbs $(67 \mathrm{kN})$ were applied. No cracking was observed until about 110,000 load applications at 15,000 lbs (67 kN) were applied.

As expected the environmentally-induced temperature gradients (due to their low magnitude) did not have an influence on the type and severity of the distresses. Although debonding of TA4 was observed in a distress evaluation conducted after one year, no cracking was noted. The observed debonding was likely construction related.

\subsection{Factors Influencing Bond Strength}

In regards to the bond test results, the shear strength of the cores taken from TA2 and TA3 indicated that structural properties of the pavement section did not have a significant influence the shear strength. 
The specimens prepared using different concrete mixes exhibited a difference in the bond shear strength from mix to mix. This was observed regardless of whether the shear specimens were cored from the APT or prepared in the laboratory. Further, bond strength was found to correlate well with the flexural strength of concrete.

The results of the Laboratory Study indicated that there was little observable difference in the bond strength between the specimens that were moist cured and the specimens that were exposed to repeated temperature cycling. While limited, these results seem to suggest moderate (up to 90 cycles) freeze-thaw exposure does not have any significant effect on the bond strength.

\subsection{Factors Influencing Radius of Relative Stiffness}

The radius of relative stiffness was observed to be influenced by the type of pavement section. The measured radius of relative stiffness matched fairly well to the theoretical values calculated by JULEA for different pavement sections, particularly when a moderate amount of slippage was introduced in the analysis. This parameter was also sensitive to the bond strength at the UTW-HMA interface.

The theoretical results indicate that while there was significant variation in the values of the elastic modulus of the concrete (reflecting differences in the mixture compositions) for the UTW sections tested in this study the changes in the elastic modulus did not have any effect on the estimated radius of relative stiffness. There was however, some variability in the measured radius of relative stiffness values amongst the lanes constructed with MD-1, MD-2, MD-3, and MD-4. These results indicate that there are other factors that have a greater influence on the radius than the UTW material properties. 
The interfacial bond conditions did have an influence on the estimated radius of relative stiffness. The results indicate that the radius can be used as a method to determine whether or not the UTW was bonded. However, using the radius to determine the degree of bonding did not provide very good results. The relative values of the radius matched the trend exhibited by the bond strengths for cores taken from the same lanes.

The results indicate that, in general, increasing the number of load applications does result in a decrease in the estimated radius of relative stiffness. The percent decrease appeared to be related to the amount of debonding observed in TA2. However, this trend was not observed in TA3. This may have been due to densification of the HMA pavement under the repeated loads in TA3.

The radii of relative stiffness were calculated for all test lanes in TA4 for a period of one year. The observed trend indicated that the temperature cycles (or other environmental effects) did not cause any significant damage to the bond during the one year evaluation period.

\subsection{Proposed Changes to UTW Design Methodology}

The results of the PCA method were compared to the data collected in the APT. The strain values calculated by the PCA equations in general overestimated the UTW strains measured in the APT for both TA2 and TA3. These results indicated that in most cases the reliability of the PCA method was much higher than necessary (greater than 99.9 percent).

The PCA calculated HMA strains for TA2 (UTW over a composite section) were not very accurate. Thus, for cases of existing composite sections, the PCA equations for the HMA strain were not useable. However, for TA3 (the test area constructed over the existing HMA section) the comparison shows that the PCA calculated strains were close to the measured strains. 
The measured data confirmed the critical strain location for the UTW layer (bottom of the layer, corner location). However, the underlying PCC layer forced the critical strain location in the HMA layer to the top of the layer in sections constructed over composite pavements. Also, the critical strain location shifted from the edge location to the corner location. This shift to the corner location also occurred in the test area constructed over the HMA pavement. Thus, the measured data indicated that the critical strain location for the HMA layer is at the corner not at the edge as assumed in the PCA method.

As a result, when designing UTW pavements over an existing composite section, the design HMA strain should be assumed to be located at the top of the HMA layer, corner location. This strain should be further assumed to be equal to the UTW strain at the bottom of the UTW layer, corner location.

The PCA method was modified (by utilizing the above assumptions and by introducing reliability concepts) and used to re-calculate strains in various lanes during this research study. The overall conclusion from this exercise was that the modified method is more appropriate for the design of UTW layers over existing composite pavements since the calculated strains provided a good estimate of the measured values at an appropriate degree of reliability.

Further modification of the proposed UTW design methodology incorporates FWD test results from the underlying pavement to be overlaid by the UTW layer. This modification involves testing of the in situ pavement and calculating its initial radius of relative stiffness. A design radius of relative stiffness is calculated next using statistically derived equations based on data collected from the test areas. (This approach was validated with data obtained from UTW sites in Missouri and Minnesota.) The FWD-based strains are then calibrated with the APT data and reliability is incorporated into the design strain value. The proposed approach 
was shown to be acceptable in that it provided a good estimate of the measured strains at an adequate level of reliability.

Based on the results of this study, the modified UTW design methodology should consist of the following steps. The equations noted were summarized in Table 7.9 .

1. Conduct FWD testing on the site and determine the in-situ estimated radius of relative stiffness, $l_{\text {esti, }}$ and the in-situ modulus of subgrade reaction, $k$.

2. Using Equation 7.3 calculate the design estimated radius of relative stiffness, $l_{\text {estd. }}$.

3. Input this value into the PCA equations (2.1 to 2.4 ) to calculate the PCA stresses and strains. Convert the UTW stresses to strains using the modulus of the UTW layer, $E_{u t w}$.

4. Using Equations 7.1 and 7.4, calculate the modified strains and stresses.

5. Use a linear relationship to determine the concrete stress and asphalt strain for all other weights in the axle load distribution category.

6. Compute the temperature-induced concrete stresses and asphalt strains.

7. Sum the load-induced and temperature-induced stresses and strains to get total concrete stress and total asphalt strain.

8. Conduct the fatigue analyses.

9. If either asphalt or concrete fatigue is greater than 100 , alter the design inputs and rerun the analysis. 


\section{CHAPTER 9. IMPLEMENTATION RECOMMENDATIONS AND COST EFFECTIVENESS}

The results discussed in Chapter 6 indicate that when proper bonding is achieved, UTW pavements can perform well. Additionally, no debonding was noted before $60,000-15,000 \mathrm{lb}(67 \mathrm{kN})$ load applications and no cracking was observed until after $110,000-15,000 \mathrm{lb}(67 \mathrm{kN})$ load applications. These findings confirm the results observed in other states that UTW is a viable technique for the rehabilitation of distressed HMA pavements. As such, it is recommended that INDOT proceed with implementation of the UTW technique. Implementation can proceed statewide. The following sections outline the recommendations for implementation of the UTW rehabilitation technique in Indiana. These recommendations are based on the results of this research, existing INDOT practices, and ACPA (2007) recommendations.

\subsection{Recommendations for Design Implementation}

Site Selection

The UTW is appropriate for rehabilitation of distressed HMA pavements and composite pavements. The following is a list of criteria that should be considered when selecting a site to use UTW.

- Candidates for UTW overlays include HMA or composite (HMA over PCCP) roads, streets, and intersections that are good-to-fair structurally but exhibit surface distresses (rutting, shoving, slippage, and thermal cracking). UTW can be used in conjunction with widening. UTW overlays can also be used to 
increase the structural capacity, improve friction, mitigate reflective cracking, and improve rideability of the existing pavement. Section 52-6.02 in the INDOT Design Manual can be modified to include UTW as an option for these cases.

- FWD testing should be conducted to evaluate the existing structural capacity of the pavement. A minimum structure number of 2.5 should be obtained. The capacity of the subgrade should also be checked so that it provides uniform support throughout. Problem areas should be identified and mitigated with full-depth patching. The INDOT Design Manual Chapter 527.03 covers requirements for rehabilitation projects and discusses the FWD and coring options.

\section{UTW Thickness Design Method}

It is recommended that designs initially be performed using the existing PCA method with in-situ material property data (back-calculated layer moduli and thicknesses) supplied by FWD testing. Such information can be provided by the INDOT Office of Research and Development. Training on the design method can be provided to INDOT pavement designers via a formal training course. After training, this design method could be used statewide. A research implementation project can be initiated to evaluate the new PCA-UTW design method spreadsheet (ACPA 2007) and the proposed FWD method for UTW design (in Chapter 7) prior to usage throughout the state.

A design program or spreadsheet based on the existing PCA design method and/or proposed FWD method should be developed to aid the designers. This could be developed as part of the research implementation project.

\section{UTW Concrete Mixture Design}

The success in the UTW performance seen in this project was due in part to the quality concrete mixture used. Therefore, it is recommended that the concrete mixture design have the following characteristics. 
- Maximum water-cementitious materials ratio of 0.42 . Fly ash can be used at the typical replacement rate (1.25:1) in these mixtures.

- Flexural strength at 7 days should be greater than 650 psi.

- Maximum aggregate size of 0.75 in $(19 \mathrm{~mm})$ can be used, but should not exceed $1 / 3$ of the design thickness. Efforts should be made to match the thermal properties of the aggregates in the UTW with the thermal properties of the aggregates in the underlying HMA. Thus, the aggregate type in the existing HMA should be noted on the plans.

- Slump between 2 to 3 inches (50 to $75 \mathrm{~mm}$ ). Slump should be sufficient enough to provide good workability and consolidation. Proper consolidation is needed to establish a good bond between the UTW and HMA layers. Depending on the mix components, water reducers or high-range water reducers may be needed to attain proper workability.

- Type III cement or accelerators may be used to increase the early strength development.

- Fibers may be added to the UTW mixture. Synthetic fibers such as polypropylene are commonly used in UTW applications. Fibers should be added at the manufacturers recommended rate. Fibers should be uniformly dispersed throughout the concrete mixture. (NOTE: There are conflicting reports in regards to the benefits of fibers. However, in some studies, including this study, fibers have been shown to be a benefit. Benefits noted include a decrease plastic shrinkage cracking, a delay load-induced cracking, and an improvement in post-cracking performance. A good reference on the use of fibers is Design and Control of Concrete Mixtures, $14^{\text {th }}$ Ed. [2002] produced by the PCA.)

\section{Joint Design}

Joint spacing should be included as part of the plans. If there are joints in the underlying pavement, efforts should be made to match those in the UTW to the existing joints. Typically, the joints should be kept out of the wheel path of the 
vehicles. Joints are not dowelled or tied. Details for joint layout around drainage structures should also be included in the plans. Or, a standard drawing for jointing around structures may be developed. A 2:1 joint spacing (feet) to thickness (inches) ratio is a good rule of thumb for determining the joint spacing. (NOTE: Joint spacing of 2 feet by 2 feet $(600 \mathrm{~mm}$ by $600 \mathrm{~mm}$ ) has been used in the past with thinner sections (ratio of 1:1 (joint spacing in feet: thickness in inches)). However, in this research project, relatively thin sections ( 2 to 2.5 inches $(63 \mathrm{~mm})$ ) were used with a joint spacing of 4 feet by 4 feet $(1200 \mathrm{~mm}$ by $1200 \mathrm{~mm})$. No problems were attributed to this combination during either the mechanical or environmental loading.)

\section{Repairs and Milling Thickness}

If there are any significant distresses in the HMA (fatigue cracking, potholes, etc.) these should be mitigated with full-depth patching (see INDOT Standard Specifications section 304.04). Surface distresses such as thermal cracking, rutting, shoving, and/or slippage will be removed during the milling. There may be faulting at cracks or joints in existing composite pavements. Deteriorated cracks or joints should be repaired and load transition be reestablished prior to milling.

The depth of milling is dependent upon the following factors.

- Existing grade considerations.

- Thickness of the existing HMA.

- Type and severity of distresses.

Typically to match existing grade, the depth of the HMA milling will match the design thickness of the UTW. However, the other criteria should not be ignored. The remaining thickness of the HMA should be between 3 to 4 inches (75 to $100 \mathrm{~mm}$ ). It is recommended that half of the existing HMA lift into which you are milling should be left after milling. Otherwise, the HMA lifts may separate and bonding with the UTW may be compromised. It is not necessary to mill the entire rutting depth. The INDOT Design Manual covers Milling of Asphalt Pavements in Section 52-7.05. This section will need to be modified to include UTW applications. 


\section{Transition}

Transition details should be included in the design. Typically, a 12 foot $(3600 \mathrm{~mm})$ transition is adequate. The existing HMA should be milled at a taper over the first 6 feet $(1800 \mathrm{~mm})$ of the transition to an additional depth of the depth plus 3 inches (75 $\mathrm{mm})$. The remaining 6 feet $(1800 \mathrm{~mm})$ of the transition should maintain this depth. A saw-cut should be made at the end of the transition. Transition milling is also covered in Section 52-7.05. A standard drawing for transitions may be developed for UTW applications.

\subsection{Recommendations for Construction Implementation}

\section{Milling and Surface Cleaning}

The existing INDOT specification on milling (Section 306 - INDOT 2008) should be adequate for the construction of UTW. However, the specification is somewhat limited on requirements for cleaning after milling, stating that "The roadway shall be cleaned prior to opening to traffic". Thus, given that a clean surface is optimal for the development of the bond between the UTW and HMA layers, the following recommendations are made in regards to the surface cleaning after the milling procedure.

Final surface cleaning should be performed just prior to the placement of the UTW concrete. It is recommended that the milled surface first be swept. After sweeping, the surface should be blown with compressed air. Power-washing with water is allowable, but, care should be made to ensure that no standing water is left on the milled surface.

\section{Placement of UTW Concrete}

The concrete can be placed using standard concrete paving techniques. Either fixed-form or slip-form paving can be utilized. The surface of the milled HMA should be kept below $120^{\circ} \mathrm{F}\left(49^{\circ} \mathrm{C}\right)$. Keeping the temperatures low will reduce the potential 
for early-age shrinkage cracking. Water may be used to cool the surface but, no standing water should remain on the surface.

Efforts should be made to ensure that the concrete is adequately consolidated throughout. Particular attention should be paid to outside edges of the UTW layer. Lack of proper vibration of the concrete will lead to debonding and premature failure of the UTW layer.

\section{Finishing and Texturing}

Finishing of UTW should be done in accordance with Section 504.03. Texturing of the UTW can be done either by tining in accordance with Section 504.03 or the tining can be eliminated with texture provided by the burlap or turf drag.

\section{Curing}

Curing should be conducted in accordance with Section 504.04. However, in some instances it may be desirable to accelerate opening to traffic. In such cases, the curing time may be reduced. However, it is recommended that trial batches be conducted to ensure that the adequate strength gain (550 psi flexural strength minimum required for opening to traffic) and durability can be attained under the accelerated curing regime.

\section{Sawing of Joints}

Joint sawing should be performed as soon as the concrete has hardened sufficiently to permit sawing without raveling, usually 2 to 12 hours after placement. Maturity methods as described in Joint Transportation Research Program Report FHWA/IN/JTRP-2007/5 are also recommended to determine the optimum time for saw-cutting. In this study both traditional sawing techniques as well as early-entry saw-cutting techniques were performed. Both techniques performed adequately and provided that the proper precautions are taken, both techniques can be employed with UTW. The saw-cut depth for traditional saw-cutting techniques should be $1 / 3$ the UTW depth for longitudinal joints and 1/4 the UTW depth for transverse joints. Early-entry saw-cuts can be performed at lesser depths. 


\section{Pay Items}

The UTW overlay can be paid at a given thickness ( $\mathrm{mm}$ or inches) on a per area basis ( $\mathrm{m}^{2}$ or SYD). Additionally, it may be necessary to include a pay item for volume of concrete ( $\mathrm{m}^{3}$ or CYD) for possible material overruns. This would address the situation where localized distressed areas were deeper than planned more overlay material is required. (This item is similar to the item used for bridge deck overlays.)

\section{Acceptance}

Prior to accepting the UTW pavement, bond checks should be conducted. Sounding of the pavement should be conducted to determine if there were any locations that were not adequately bonded during construction. Sounding can be conducted using a chain drag over the general area with a hammer used to isolate problem areas. This research indicated that if the bond was initially in tact, the UTW overlay could withstand several tens of thousands of load applications prior to any load induced debonding. Any panels that are not fully bonded should be removed and replaced. Removal of individual panels can be conducted using a jack-hammer. The concrete used for replacement should be the same mix design as used in the original construction.

\subsection{Cost Effectiveness}

In order to determine the cost-effectiveness of UTW overlays versus typical Mill and Overlay Asphalt, Life Cycle Cost Analysis (LCCA) was conducted using the RealCost 2.0 Spreadsheet Application. A simplified intersection of two, four-lane roads was developed. This intersection contained a paved area of approximately 2389 SYD. The comparison was between a 4 inch HMA overlay and a 2 inch UTW overlay. Unit costs used in the analysis were based on 2006 construction data obtained from INDOT. UTW 
costs were prorated based on a per inch of pavement thickness basis. Analysis was conducted using the parameters included in INDOT Design Manual, Chapter 52. The analysis period was over a 40 year period and a discount rate of 4 percent was used. The Equivalent Uniform Annual Cost (EUAC) was determined. The design life of the UTW overlay was varied to determine the break even point with the typical design life for an HMA overlay at 8 years (standard design life) 6 years and 4 years to represent scenarios in which the HMA was not meeting the design life. Detailed inputs used in the analysis are included in Appendix E. Figure 9.1 illustrates the results of the analysis.

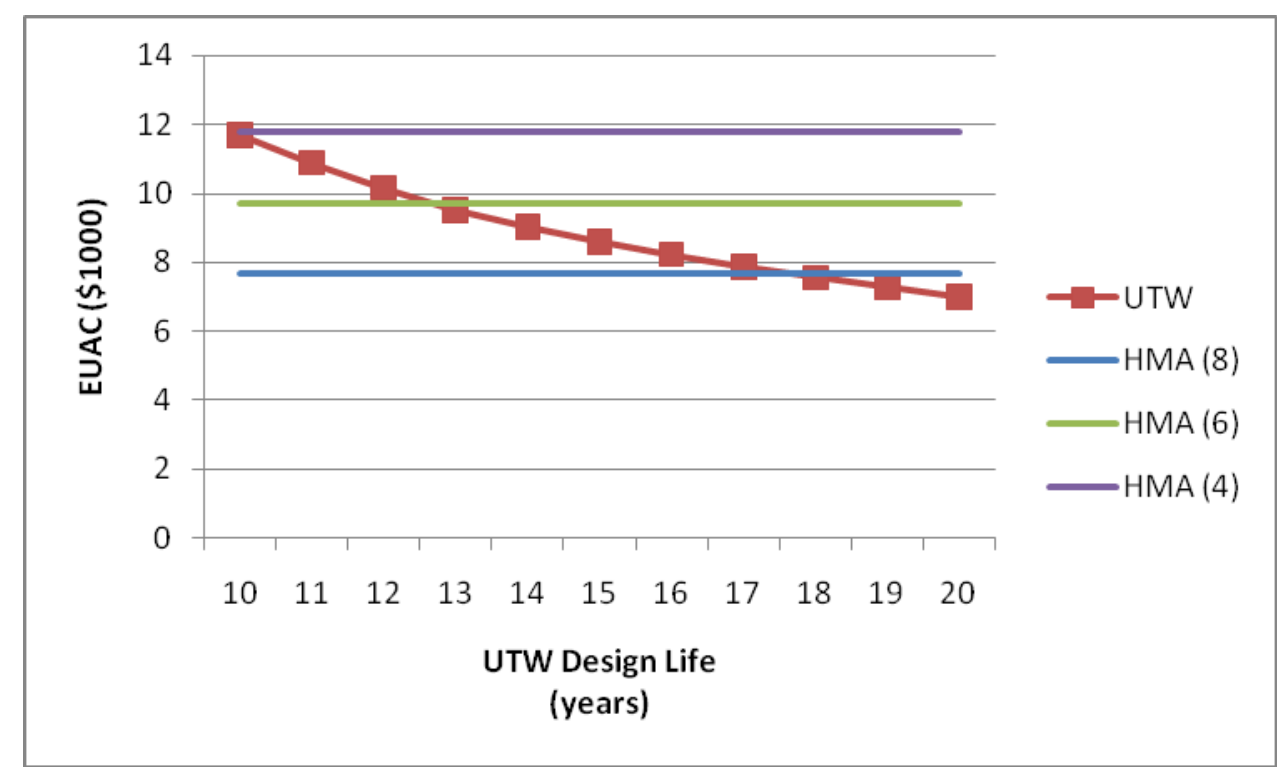

Figure 9.1 Cost Comparison

As can be seen from this figure, the UTW overlay becomes cost-effective against the HMA overlay (standard design life) at between 17 and 18 years. If the HMA fails to meet the design life the UTW becomes cost effective at design lives much sooner. The UTW break-even design life for HMA lasting 6 years was between 12 and 13 years and for an HMA pavement lasting 4 years the break-even point was 10 years. The design life for concrete pavement over existing pavement is 25 years (INDOT Design Manual). This design life would not necessarily be applicable for UTW overlays, though given the results of this study, a 15-20 year service life could be attainable. Thus, given the longer expected life of the UTW overlay, the UTW can be an economical alternative to HMA overlays. 
BIBLIOGRAPHY 


\section{BIBLIOGRAPHY}

AASHTO, Guide for Design of Pavement Structures, American Association of State Highway and Transportation Officials, Washington DC, 1993.

AASHTO, Supplemental to the AASHTO Guide for Design of Pavement Structures, Part II, - Rigid Pavement Design \& Rigid Pavement Joint Design, American Association of State Highway and Transportation Officials, Washington, D.C., 1998.

Aïtcin, P.-C., Neville, A.M., and Acker, P., "Integrated View of Shrinkage Deformation," Concrete International, Volume 19, No. 9, September 1997.

Amos, D. "Evaluation of Ultra-Thin Whitetopping," Research Investigation RI99012, Missouri Department of Transportation, Research and Technology Division, Jefferson City, MO, October 2001.

Armaghani, J.M. and Tu, D., "Performance of Ultra-Thin Whitetopping in Florida," Conference Proceedings, Sixth International Conference on Concrete Pavements, Indianapolis, IN, November 1997.

Armaghani, J.M. and Tu, D., "Rehabilitation of Ellaville Weigh Station with Ultrathin Whitetopping," Transportation Research Record - 1654, Transportation Research Board, Washington, DC, 1999.

Burnham, T.R., "Forensic Investigation Report for MnROAD Ultrathin Whitetopping Test Cells 93, 94 and 95," Final Report, 2005-45, Minnesota Department of Transportation, St. Paul, Minnesota, September 2005.

Cable, J. K. and Hart, J.M., "Evaluation of Bonding between Ultra-Thin Portland Cement Concrete and Asphaltic Concrete," Transportation Conference Proceedings, Transportation Research Board, Washington, DC, 1998.

Cable, J.K., Hart, J.M., and Ciha, T.J., "Thin Bonded Overlay Evaluation," Final Report, lowa DOT Project HR-559, lowa State University of Science and Technology Department of Civil and Construction Engineering, Ames, IA, June 2001. 
Cable, J.K., Fanous, F.S., Ceylan, H., Wood, D., Fentress, D., Tabbert, T., Oh, S.Y., and Gopalakrishnan, K., "Design and Construction Procedures for Concrete Overlay and Widening of Existing Pavements," Final Report, lowa Highway Research Board Project TR-511, lowa State University, Ames, IA, September 2005.

Churilla, C.J., "Ultra-Thin Whitetopping," Public Roads, Vol. 62, No.2 SeptemberOctober, 1998

Cole, L.W., "Pavement Condition Surveys of Ultrathin Whitetopping Projects," Conference Proceedings, Sixth International Conference on Concrete Pavements, Indianapolis, IN, November 1997.

Devore, J.L., Probability and Statistics, Duxbury Thompson Learning, Pacific Grove, CA, pp. 775, 2000.

Huang,Y.H., Pavement Analysis and Design, Prentice Hall, Englewood Cliffs, NJ, pp. 805, 1993.

Harrington, D., DeGraaf, D., Riley, R., Rassmussen, R.O., Grove, J., and Mack, J., Guide to Concrete Overlay Solutions, National Concrete Pavement Technology Center, ACPA Publication TB021P, January 2007.

INDOT, Indiana Department of Transportation Project Management System, SPMS, Average of Total Rehabilitation Costs for Fiscal Years 1994-2003, August 2005.

Li, Shuo, Li, Yongqi, Way, G., and Noureldin, S., "Mechanistic-Empirical Characterization of Bonding between Ultra-Thin Whitetopping and Asphalt Pavement," Journal of Testing and Evaluation, Volume 32, No. 4, July 2004.

Mack, J.W., Hawbaker, L.D., and Cole, L.W., "Ultrathin Whitetopping - State of the Practice for Thin Concrete Overlays of Asphalt, Transportation Research Record - 1610 Transportation Research Board, Washington, DC, 1998.

Neville, A.M., Properties of Concrete, Fourth Edition, John Wiley and Sons, New York, NY, pp. 844, 1997.

Petersson, O. and Swilfwerbrand, J., "Thin Concrete Overlays on Old Asphalt Roads," Conference Proceedings, Fifth International Conference on Concrete Pavements, Purdue University, West Lafayette, IN, April 1993. 
Rajan, S., Olek, J., Robertson, T.L., Galal, K., Nantung, T., and Weiss, W.J., "Analysis of Performance of the Ultra-Thin Whitetopping Subjected to Slow Moving Loads in an Accelerated Pavement Testing Facility," Conference Proceedings, Seventh International Conference on Concrete Pavements, Orlando, FL, September, 2001.

Rasmussen, R.O., McCullough, B.F., Ruiz, J.M., and Mack, J., Sherwood, J., "Identification of Pavement Failure Mechanisms at FHWA Accelerated Loading Facility Ultrathin Whitetopping Project," Transportation Research Record - 1816, Transportation Research Board, Washington, DC, 2002.

Rasmussen, R.O., and Roczycki, D.K., "Thin and Ultra-Thin Whitetopping," National Cooperative Highway Research Program Synthesis 338, Transportation Research Board, Washington, DC, 2004.

Riley, R.C., Mallella, J., and Gotlif, J., "Whitetopping - Atypical is Typical," Conference Proceedings, International Conference on Best Practices for Ultrathin and Thin Whitetoppings, Denver, CO, April 2005.

Risser, R.J., LaHue, S.P., Voigt, G.F., and Mack, J.W., Ultra-Thin Concrete Overlays on Existing Asphalt Pavement, Conference Proceedings, Fifth International Conference on Concrete Pavements, Purdue University, West Lafayette, IN, April 1993.

Sprinkel, M.M. and Ozylidirim, C., "Evaluation of Hydraulic Cement Concrete Overlays Placed on Three Pavements in Virginia," Proceedings, Seventh International Conference on Concrete Pavements, Orlando, FL, September 2001.

Stiady, J.L., Hand, A.J.T., Noureldin, A.S., Galal, K., Hua, J., and White, T.D., "Validation of SHRP Asphalt Mixture Specifications Using Accelerated Testing," Final Report, National Pooled Fund Study No. 176, Indiana Department of Transportation, February 2003.

Tarr, S.M., Sheehan, M.J., and Okamoto, P.A., "Guidelines for the Thickness Design of Bonded Whitetopping Pavement in the State of Colorado," Report No. CDOT-DTD-R-98-10, Colorado Department of Transportation, Research Branch, Denver CO, December 1998.

Tawfiq, K. "Field Assessment and Analytical Modeling of Ultra-Thin Whitetopping," Final Report, FAMU-FSU College of Engineering, May 2001. 
Taylor, P.C., Kosmatka, S.H., Voigt, G.F., "Integrated Materials and Construction Practices for Concrete Pavement: A State-of-the-Practice Manual," Report Number, FHWA HIF-07-004, National Concrete Pavement Technology Center, Ames, IA, December 2006.

Vandenbossche, J.M. and Retner, D., "The Construction of US-169 and I-94 Experimental Thin and Ultra-thin Whitetopping Sections in Minnesota," State Project No. 7106-60, Construction Report, Minnesota Department of Transportation, St. Paul, Minnesota, April 1998.

Vandenbossche, J.M., "The Measured Response of Ultra-Thin and Thin Whitetopping to Environmental Loads," Conference Proceedings, Seventh International Conference on Concrete Pavements, Orlando FL, September 2001.

Vandenbossche, J.M., "The Construction and Performance of Ultra-thin Whitetopping Intersections on US-169," Final Report, State Project No. 7106-60, Minnesota Department of Transportation Office of Research Administration, May 2002.

Wu, C.L., Tarr, S.M., Refai, T.M., Nagi, M.A., Sheehan, M.J., "Development of Ultra-Thin Whitetopping Design Procedure," PCA Research and Development Serial No. 2124, Construction Technology Laboratories, Inc., Skokie, IL, 1998.

Wu, C.L., Tayabji, S., Sheehan, M., and Sherwood, J., "Performance and Repair of UTW Pavements," Conference Proceedings, Seventh International Conference on Concrete Pavements, Orlando, FL, September 2001. 
APPENDICES 


\section{Appendix A. Instrumentation Plan}

\section{Overview}

This document presents the instrumentation used to evaluate four Ultra-Thin Whitetopping (UTW) test areas. Three of the four test areas were constructed in the INDOT-Purdue Accelerated Pavement Testing (APT) facility. Test Area 4 was constructed in a parking lot outside the APT. The test areas were constructed to evaluate the UTW performance under mechanically loaded, unloaded, and environme:ntally loaded conditions. Parameters evaluated were Hot Mix Asphalt (HMA) strains, Portland Cement Concrete (PCC) strains, and pavement temperatures. Dynamic strains were recorded as the APT load passed over the pavement. Static strains records were needed to assess the shrinkage affects on the pavement.

UTW is a layered pavement configuration. In order to evaluate the strains throughout the depth of the pavement, strain gages were placed in the underlying PCC (if present), HMA, and UTW layers. Four different types of strain gages were used in this experiment.

\section{Gage Types and Data Acquisition}

The first gage type, Texas Measurements ${ }^{\mathrm{TM}}$ embedment-type gage (PML-60-2L), was embedded in the UTW and PCC layers at a level of 0.5 -inches $(12 \mathrm{~mm})$ below the surface and at 0.5 -inches $(12 \mathrm{~mm})$ from the bottom of the layer. The second gage type, Texas Measurements ${ }^{\mathrm{TM}}$ surface-mount-type gage (WFLM-6011-2LT), was glued to the surface of the milled HMA. The third type of gage was a CTL (ASG-152) HMA embedment gage that was placed at the bottom of the HMA layer. The fourth gage type (used in Test Areas 1, 2, and 3), Roctest ${ }^{\mathrm{TM}}$ surface mounted vibrating-wire-type gages (SM5-A), were attached to the surface of the UTW concrete and companion slabs. Locations of the gages for the test areas were as indicated in Figure A.1. 
For Test Areas 1-3, the surface-mounted and embedment strain gages were connected to a Vishay ${ }^{\text {TM }}$ System 6100 data acquisition system. This system had the ability to take individual strain readings at a very high sampling rate (up to 10,000 samples per second per channel). The high frequency of data sampling enabled the recording of the dynamic strains as the wheel passed over the pavement. Dynamic strain data were collected after every 2500 load applications. In all cases the scan rate was 100 samples per second per channel and the filtering was set at $10 \mathrm{~Hz}$. At an APT carriage speed of $5 \mathrm{mph}(8 \mathrm{kph})$ this corresponded to a reading being taken every 0.9 " $(23 \mathrm{~mm})$.

A previous study by Rajan et al. [2001] compared the strain readings obtained by this system and using the Texas Measurements ${ }^{\mathrm{TM}}$ gages to the strains expected using finite element analysis. The study concluded that the measured strain readings and the finite element calculated strains were of similar magnitudes for both the asphalt and the concrete.

The vibrating wire strain gages used in Test Areas 1-3 were connected to a Campbell Scientific ${ }^{\circledR}$ CR-10X datalogger that recorded the long-term development of the PCC surface strains. Readings were taken every hour during the test period (started at the initiation of the APT loading). These dataloggers were designed for long-term, unattended usage with minimal maintenance. This feature allowed the datalogger to be programmed and set in the APT throughout testing with minimal intervention. The vibrating wire gages were chosen due to their compatibility with the CR-10X and because they were relatively inexpensive. Gages were calibrated by the manufacturers. 


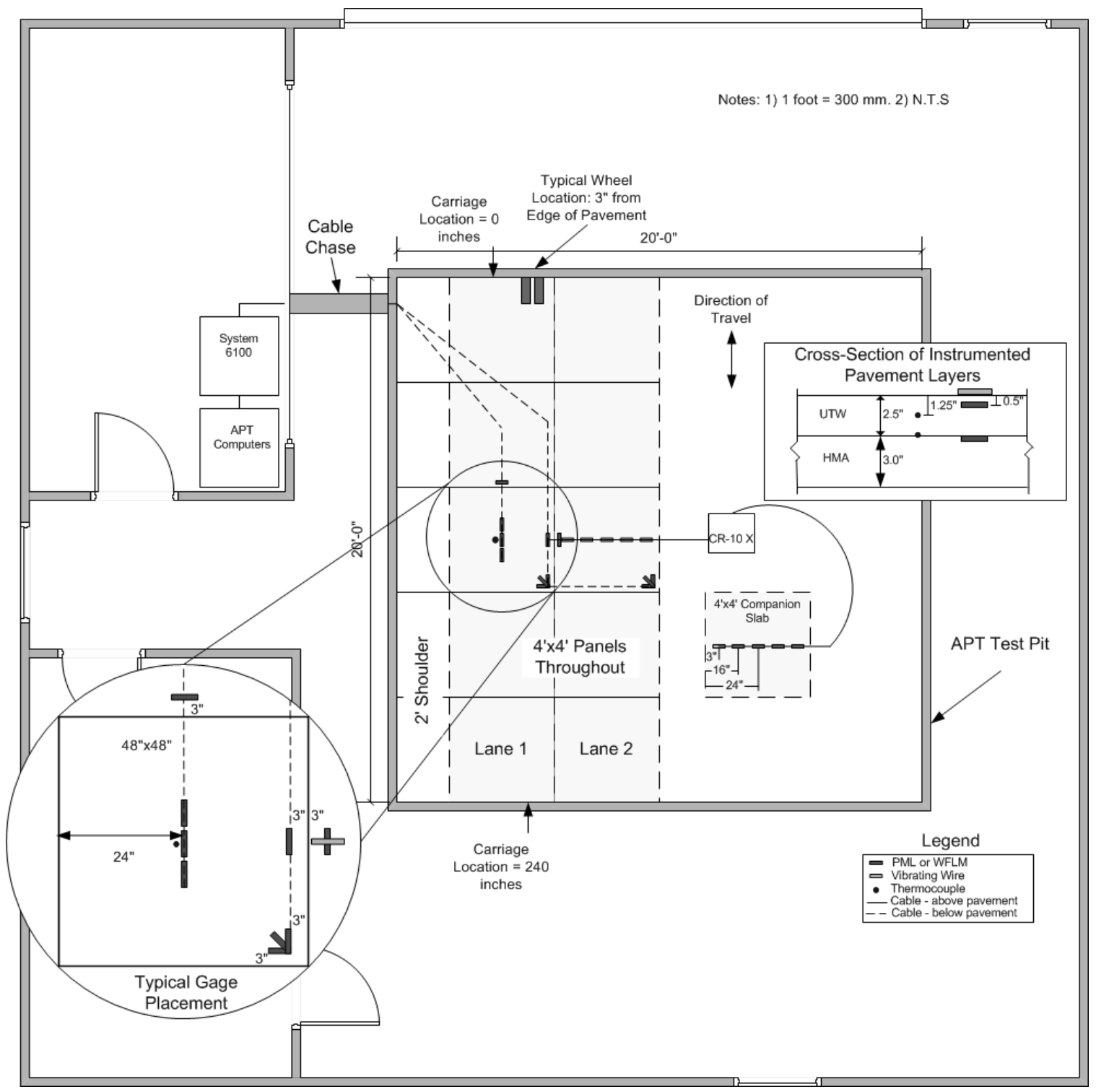

(a)

Figure A.1 Overview of Instrumented Test Areas (a) Test Area 1 (b) Test Area 2 (c) Test Area 3 (d) Test Area 4 (continued) 


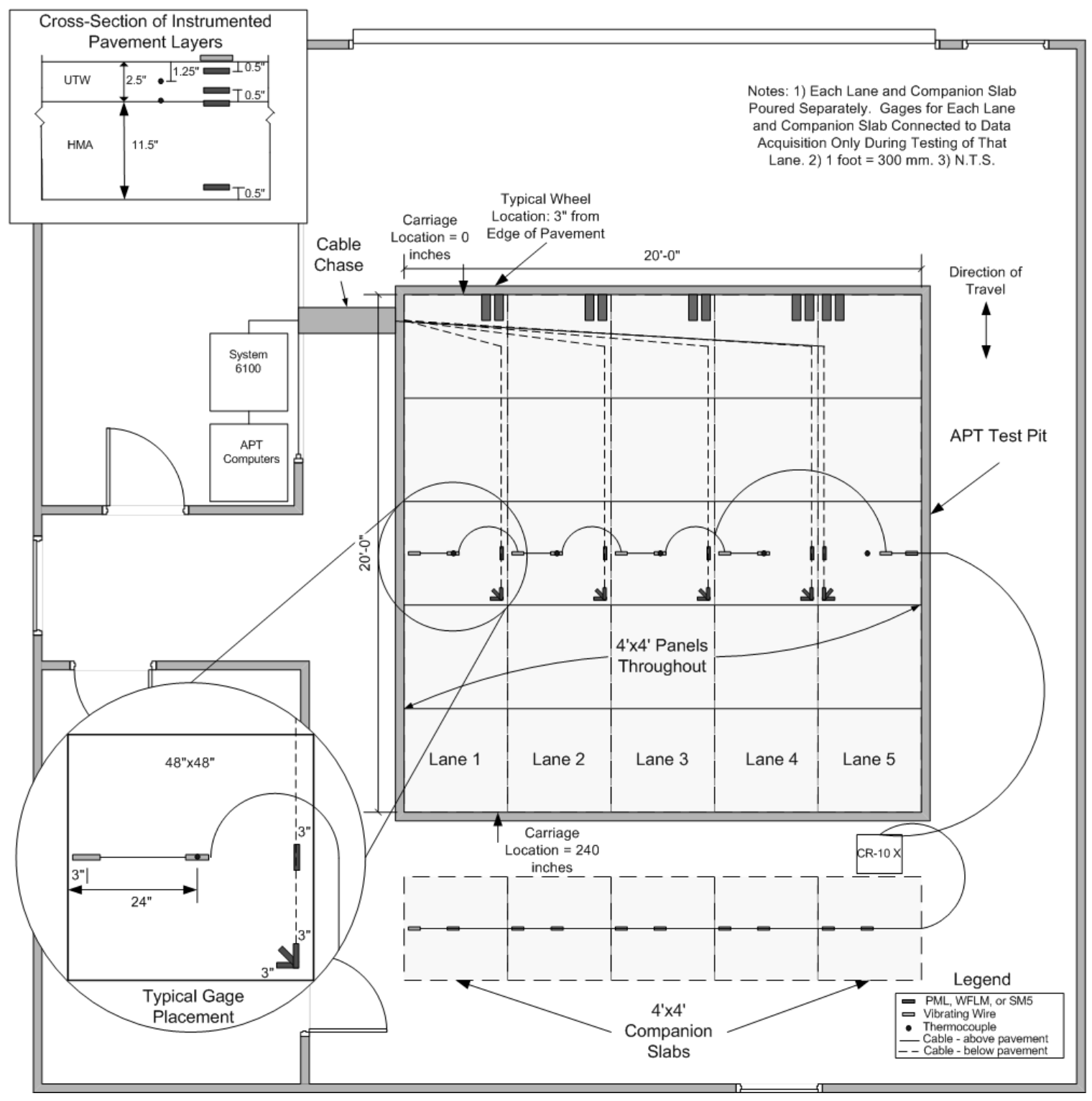

(b)

Figure A.1 Overview of Instrumented Test Areas (a) Test Area 1 (b) Test Area 2 (c) Test Area 3 (d) Test Area 4 (continued) 


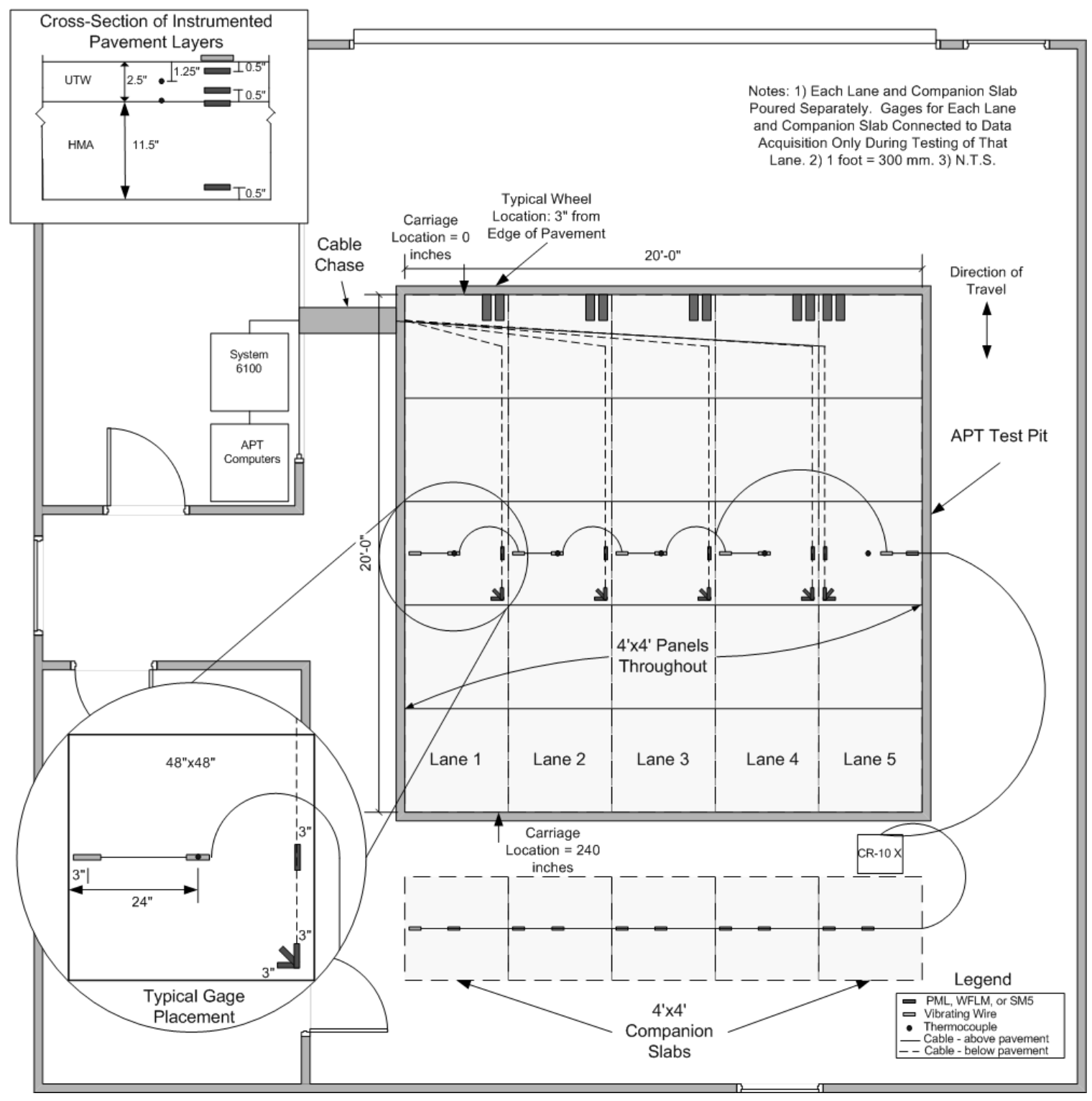

(c)

Figure A.1 Overview of Instrumented Test Areas (a) Test Area 1 (b) Test Area 2 (c) Test Area 3 (d) Test Area 4 (continued) 


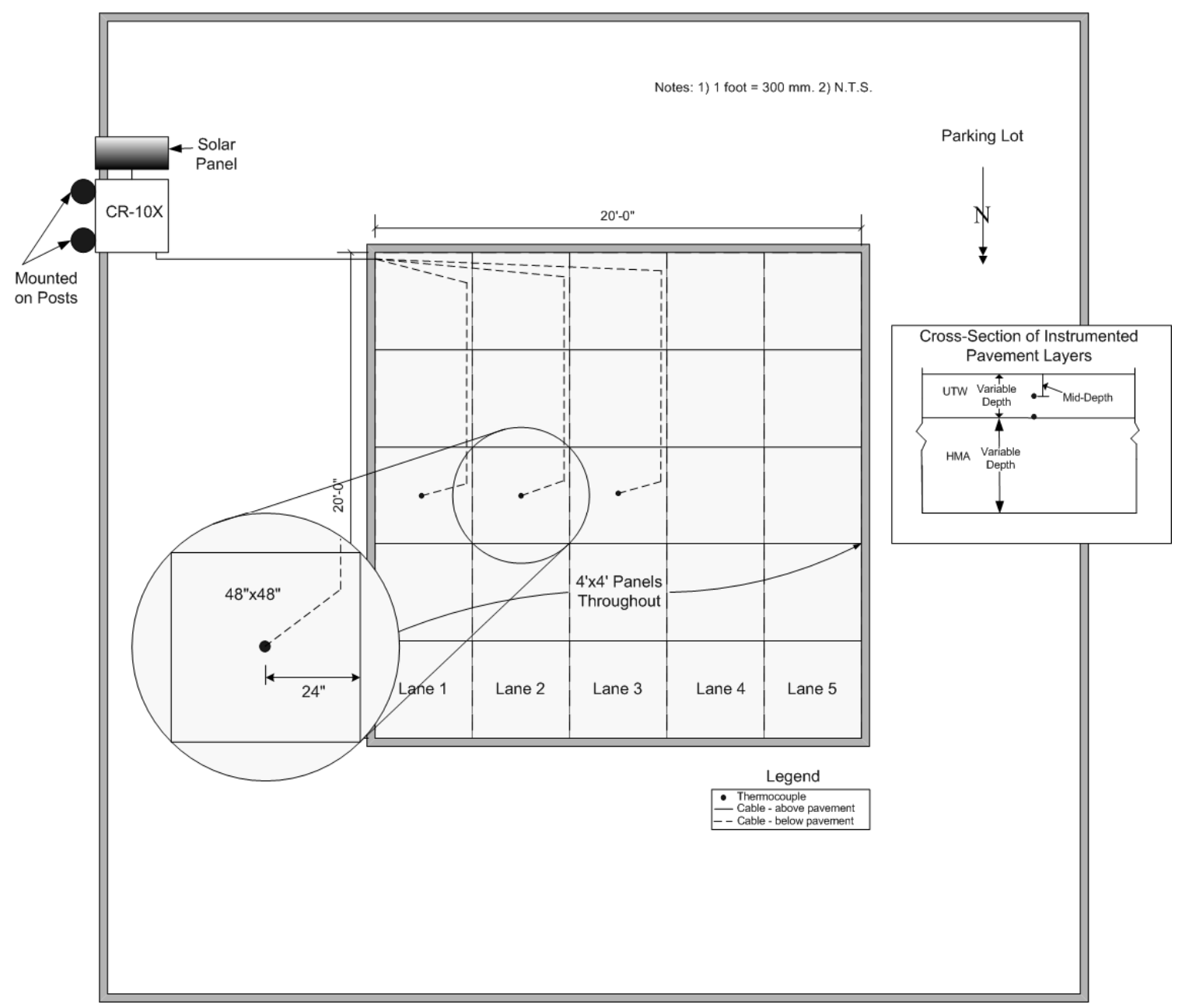

(d)

Figure A.1 Overview of Instrumented Test Areas (a) Test Area 1 (b) Test Area 2 (c) Test Area 3 (d) Test Area 4

For Test Areas 1-3, thermocouples placed in the pavement at different depths were connected to the System 6100 unit to measure the pavement temperature in the different layers. Omega ${ }^{\mathrm{TM}}$ Heavy-Duty Washer Thermocouples (Model WTT-HD72 OSTW-M), Type-T, were used. These readings were taken every 2500 load applications. For Test Area 4, Type-T thermocouples were also placed in the pavement and connected to the CR-10 X datalogger. These thermocouples were used to determine the temperature changes in the 
pavement. Readings were taken every ten minutes for a 1 year period. Table A.1 summarizes the gage usage in each of the test areas.

Table A.1 Summary of Gage Usage

\begin{tabular}{|c|c|c|c|}
\hline $\begin{array}{l}\text { Test } \\
\text { Area }\end{array}$ & Gage Type & Location & $\begin{array}{c}\text { Data } \\
\text { Acquisition }\end{array}$ \\
\hline \multirow[t]{4}{*}{1} & PML-60-2L & $\begin{array}{l}0.5 "(12.7 \mathrm{~mm}) \text { from top and bottom of both } \\
\text { the UTW and PCC layers at corner and edge } \\
\text { locations }\end{array}$ & $\begin{array}{c}\text { System } \\
6100\end{array}$ \\
\hline & $\begin{array}{l}\text { WFLM-60-11- } \\
\text { 2LT }\end{array}$ & $\begin{array}{l}\text { Top of Milled HMA at corner and edge } \\
\text { locations }\end{array}$ & $\begin{array}{c}\text { System } \\
6100\end{array}$ \\
\hline & SM5-A & Surface of UTW and companion slabs & CR10X \\
\hline & $\begin{array}{l}\text { WTT-HD72 } \\
\text { OSTW-M }\end{array}$ & Top of HMA and middle of UTW & $\begin{array}{c}\text { System } \\
6100\end{array}$ \\
\hline \multirow[t]{5}{*}{$2 \& 3$} & PML-60-2L & $\begin{array}{l}0.5 "(12.7 \mathrm{~mm}) \text { from top and bottom of both } \\
\text { the UTW and PCC layers at corner and edge } \\
\text { locations }\end{array}$ & $\begin{array}{c}\text { System } \\
6100\end{array}$ \\
\hline & $\begin{array}{l}\text { WFLM-60-11- } \\
\qquad 2 \mathrm{LT}\end{array}$ & $\begin{array}{l}\text { Top of Milled HMA at corner and edge } \\
\text { locations }\end{array}$ & $\begin{array}{c}\text { System } \\
6100\end{array}$ \\
\hline & ASG-152 & Bottom of HMA at corner and edge locations & $\begin{array}{c}\text { System } \\
6100\end{array}$ \\
\hline & SM5-A & Surface of UTW and companion slabs & CR10X \\
\hline & $\begin{array}{l}\text { WTT-HD72 } \\
\text { OSTW-M }\end{array}$ & $\begin{array}{l}\text { Middle of PCC (TS-2), top of HMA and middle } \\
\text { of UTW }\end{array}$ & $\begin{array}{c}\text { System } \\
6100\end{array}$ \\
\hline \multirow[t]{3}{*}{4} & PML-60-2L & $\begin{array}{l}0.5 "(12.7 \mathrm{~mm}) \text { from top of the UTW at edge } \\
\text { location }\end{array}$ & CR10X \\
\hline & $\begin{array}{l}\text { WFLM-60-11- } \\
\text { 2LT }\end{array}$ & Top of Milled HMA at edge locations & CR10X \\
\hline & $\begin{array}{l}\text { Type T } \\
\text { Thermo- } \\
\text { couples }\end{array}$ & Top of Milled HMA and Middle of UTW Layer & CR10X \\
\hline
\end{tabular}




\section{Expected Data Values}

The strains in the concrete were expected from three different mechanisms: dynamic loads, shrinkage, and temperature. Dynamic loads were expected to be small based on preliminary design calculations. Strains on the order of 25-35 microstrain were expected. Shrinkage strains were expected to vary from 2001200 microstrain depending on concrete composition and curing conditions. Temperatures in the APT were held relatively constant so the strain resulting from temperature changes in the APT were expected to be minimal. However, the temperatures of Test Area 4 were expected to vary seasonally. Air temperatures between $-5^{\circ} \mathrm{F}$ and $+100{ }^{\circ} \mathrm{F}\left(-21^{\circ} \mathrm{C}\right.$ and $\left.37.8^{\circ} \mathrm{C}\right)$ were expected. Using a coefficient of thermal expansion of $5 \times 10^{-6}$ per ${ }^{\circ} \mathrm{F}\left(9 \times 10^{-6}\right.$ per $\left.{ }^{\circ} \mathrm{C}\right)$, this temperature range would result in strains changes of 525 microstrain.

For asphalt, the strains were expected from two different mechanisms: dynamic loads and temperature. Dynamic loads were expected to be small based on preliminary design calculations. Strains on the order of 90-115 microstrain were expected. As noted previously, temperatures in the APT were held relatively constant so the strain resulting from temperature changes in the APT would be minimal. Again, however, the temperatures of Test Area 4 were expected to vary seasonally. Air temperatures between $-5^{\circ} \mathrm{F}$ and $+100^{\circ} \mathrm{F}\left(-21^{\circ} \mathrm{C}\right.$ and $\left.37.8^{\circ} \mathrm{C}\right)$ were expected. Using a coefficient of thermal expansion of $1 \times 10^{-5}$ per ${ }^{\circ} \mathrm{F}$ $\left(1.8 \times 10^{-5}\right.$ per $\left.{ }^{\circ} \mathrm{C}\right)$, this temperature range would result in strains changes of 1050 microstrain. Table A.2 summarizes the measurements, expected ranges, and corresponding gage information.

Efforts were made initially to ensure that all gages were working properly prior to final installation. Gages were connected to their respective data acquisition systems and readings were taken to ensure proper function. This was done since once encased in the concrete most of the gages would not be able to be accessed for repair. All gages were monitored periodically during the test period 
to ensure that the values obtained by the sensors were not out of range. If gage readings were found to be erratic, efforts were made to correct the readings by re-zeroing the channels. If the gage was accessible (as in the case of the vibrating wire gages) the gage was also inspected to ensure that there was no visible damage. However, if the gage was inaccessible and the re-zeroing did not work the gage was considered to be non-functioning.

Table A.2 Summary of Expected Data and Sensor Ranges

\begin{tabular}{|c|c|c|c|}
\hline Data Sensed & Expected Range & Sensor & $\begin{array}{c}\text { Sensor } \\
\text { Range/Limit }\end{array}$ \\
\hline $\begin{array}{c}\text { Concrete Mechanical } \\
\text { Strain }\end{array}$ & 25-35 microstrain & $\begin{array}{l}\text { PML-60-2L } \\
\quad \text { or } \\
\text { PMR-60-2L } \\
\text { Strain Gage }\end{array}$ & 20,000 microstrain \\
\hline $\begin{array}{c}\text { Concrete Thermal } \\
\text { Strain }\end{array}$ & 525 microstrain & $\begin{array}{l}\text { PML-60-2L } \\
\text { or } \\
\text { PMR-60-2L } \\
\text { Strain Gage }\end{array}$ & 20,000 microstrain \\
\hline $\begin{array}{c}\text { Concrete Shrinkage } \\
\text { Strain }\end{array}$ & $\begin{array}{c}200-1200 \\
\text { microstrain }\end{array}$ & $\begin{array}{c}\text { SM-5-A } \\
\text { Strain Gage }\end{array}$ & 3,000 microstrain \\
\hline $\begin{array}{c}\text { Asphalt Mechanical } \\
\text { Strain }\end{array}$ & 90-115 microstrain & $\begin{array}{c}\text { WFLM-60-11-2LT } \\
\text { or } \\
\text { ASG-152 } \\
\text { Strain Gage }\end{array}$ & $\begin{array}{c}\text { 30,000 microstrain } \\
\text { (WFLM) } \\
+/-1500 \\
\text { microstrain (ASG) }\end{array}$ \\
\hline $\begin{array}{c}\text { Asphalt Thermal } \\
\text { Strain }\end{array}$ & 1050 microstrain & $\begin{array}{c}\text { WFLM-60-11-2LT } \\
\text { or } \\
\text { ASG-152 } \\
\text { Strain Gage }\end{array}$ & $\begin{array}{l}\text { 30,000 microstrain } \\
\text { (WFLM) } \\
+/-1500 \\
\text { microstrain (ASG) }\end{array}$ \\
\hline Temperature & $\begin{array}{c}-5 \text { to } 100^{\circ} \mathrm{F} \\
\left(-21 \text { to } 37.8^{\circ} \mathrm{C}\right)\end{array}$ & $\begin{array}{c}\text { WTT-HD-72 } \\
\text { OSTMW-M } \\
\text { Type T } \\
\text { Thermocouple }\end{array}$ & $\begin{array}{l}-250^{\circ} \mathrm{C} \text { to } 350^{\circ} \mathrm{C} \\
\left(-418^{\circ} \mathrm{F} \text { to } 662{ }^{\circ} \mathrm{F}\right)\end{array}$ \\
\hline
\end{tabular}




\section{Data Acquisition System for Dynamic Strain Readings}

The system used for the instrumentation data acquisition during APT testing was the Vishay ${ }^{\mathrm{TM}}$ Measurements Group System 6100. This system, previously installed in the APT under a different project, was chosen due to its capabilities in regards to scan rate and filtering. In order to take dynamic strain readings in the pavement while the tire was passing over a strain gage a high sampling rate was needed. The System 6100 has the ability to scan at a very high sampling rate (up to 10,000 samples per second per channel). This capability permitted a high resolution data set of the strain reading changes to be obtained. Additionally, the electro-mechanical systems that operated the APT generated a significant amount of electrical noise (square, 480V AC, 3 phase, step waveform from the $30 \mathrm{hp}(22 \mathrm{~kW})$ motor). This noise interfered with the strain gage readings and thus needed to be filtered. The System 6100 had the ability to digitally filter the noise for each individual channel. Several filtering options were available.

Figure A.2 shows the System 6100.

Two Model 6100 Scanners were used in conjunction with the System 6100. Each scanner unit accepted up to 20 input cards. One card was needed for each channel required. Cards varied by the type of instrumentation connected to them. The project in the APT required the measurement of strains in the pavement, pavement temperatures, and pavement deflections. The cards chosen for this experiment were Model 6010 Strain Gage Cards (18 each), Model 6020 Thermocouple Cards (3 each), and Model 6030 High Level Voltage Cards ( 8 each). These cards all contained signal conditioners and 16 bit analogdigital converters.

The Model 6010 Strain Gage Card was programmable and the excitation voltage could be set at $0,0.5,1,2,5$, and $10 \mathrm{~V}$ with an excitation current up to $50 \mathrm{~mA}$. 
Internal bridge completion resistors were provided for $120 \mathrm{ohm}, 350 \mathrm{ohm}$, and $1000 \mathrm{ohm}$ full bridge readings which were jumper selectable. The range of strain readings capable using these cards was $+/-16,300$ microstrain with a resolution of 0.5 microstrain. Strain gages were connected using a removable 9-pin D-sub connector.

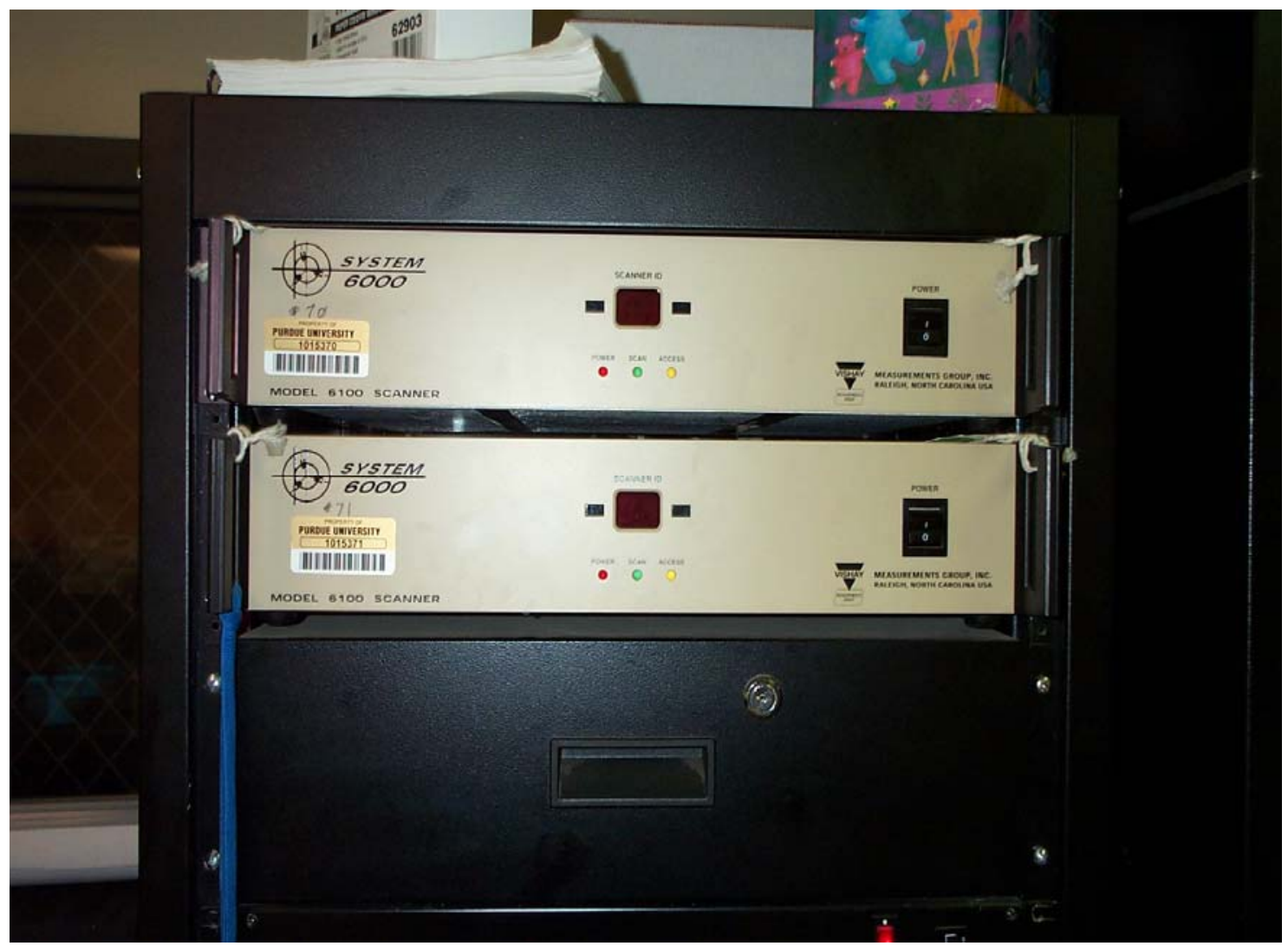

Figure A.2 System 6100

The Model 6020 Thermocouple Card provided compensation for J, K, T, N, E, R, $\mathrm{S}$, and $\mathrm{B}$ type thermocouples. The cold-junction reference was programmable. Thermocouples were connected using a removable three-terminal screw connector. Resolution and range depended upon the type of thermocouple selected.

The Model 6030 High Level Transducer Card had a programmable excitation voltage selectable for $0,0.5,1,2,5,10,15,20,24$, and $30 \mathrm{~V}$. An excitation 
current up to $50 \mathrm{~mA}$ was also available. Connections to the card were made using a 9-pin D-sub type connector. Measurements ranges available were $+/-1$, $+/-2,+/-5$, or $+/-10 \mathrm{~V}$ with a resolution of $30.5,61,152.5$, or 305 microvolts, respectively.

To reconcile the data with the number of passes applied by the APT an approximation of the cumulative number of passes was determined by the computer. A Model 6090 Digital I/O Card was selected for this connection. This card had two relay outputs per card, two optically isolated digital inputs per card which were variable from $5 \mathrm{~V}$ to $28 \mathrm{~V}$. Connections were made with a removable six-terminal screw connector. A variable voltage reading was correlated to the number of passes. The digital output was set high and readings were taken until the output was set low.

\section{StrainSmart Software}

StrainSmart was the software that was used to program the System 6100 and its components. The software allowed the set-up and configuration of different sensors such as uniaxial strain gages, strain gage rosettes, transducers, thermocouples, and high level sensors. Specific gage factors, thermal effects, gage calibration, and bridge completion information were programmable for each sensor type. Material information was programmable in order for the program to calculate stresses from the measured strains. Once sensors were input they were assignable to specific channels and input cards on a scanner. As noted previously, the excitation and filtering options were configurable for each independent channel. Once assigned, the software had the capability to resolve the rosette components into principal strains.

When the sensors were configured and assigned, a scan session can be programmed. The scan session was the part of the program that connects the assignments to the data measurements taken over a period of time. The first 
step was to set-up the scan rate. Scans up to 10,000 scans per second per channel were programmable. The program also automatically selected the appropriate digital filter for each channel. Data recording options were also be selectable. Options include time-based, manual, and limits-based recording. The recording interval was settable at a multiple of the scanning interval. Once these options were selected, measurements were able to be taken.

\section{Zeroing and Calibration}

To zero and calibrate the gages, the zeroing function included in the program was used. The zeroing operation eliminated any imbalance in the measurement signal. If the offset was too large the gages were flagged and re-zeroed. If zeroing could not be accomplished and it was verified that the gage was connected properly, the gage was considered unusable. Once the gages were properly zeroed, the calibration was able to be done. A shunt calibration was done by the System 6100 and the calibration of the gages was automatically updated. When these operations were complete, the system was able to be armed and the scan session begun.

\section{Data Reduction and Analysis}

Once the data was collected, the StrainSmart software was able to be used to reduce it. The appropriate scan session was chosen and the raw data was converted into data of different types. The data type chosen depended on the sensor. The size of the file produced depended on the number of gages, the duration of the scan session, and the data reduction options chosen. Output files were either ASCII Text or HTML formats. The StrainSmart software had the ability to view the data or to import the data file into another program, such as Microsoft Excel, for analysis.

\section{System 6100 Experimental Setup}

Materials/Equipment List 
Vishay ${ }^{\mathrm{TM}}$ Measurements Group Model 6100 Scanners (2)

Input Cards, Model 6010 - Strain Gage, Model 6020 - Thermocouple, Model 6030 - High Level Voltage, and Model 6090 Digital I/O

Strain Smart Software

Desk Top Computer with Windows XP Pro Operating System

Table A.3 presents the configuration of the System 6100 and its components for the UTW project. The channels varied by Test Area. Each channel is noted with its corresponding configuration. Temperature compensation was not utilized as the temperature in the APT was relatively constant $\left(75-85^{\circ} \mathrm{F}\left(24-29^{\circ} \mathrm{C}\right)\right)$.

In all cases the scan rate was 100 samples per second per channel and the filtering was a sharp roll of low pass filter at $10 \mathrm{~Hz}$. This was applied to address the significant noise issues in the APT (discussed previously). At an APT carriage speed of $5 \mathrm{mph}(8 \mathrm{kph}$ ) this corresponded to a reading being taken every 0.9 " $(23 \mathrm{~mm})$. It was desired that the data be taken at a given number of APT passes. This information was determined by the computer that controls the APT. The APT computer was connected to the System 6100 and the computer was programmed to output a signal to the System 6100 at a given number of APT load applications or passes of the APT wheel. Loading was done in both directions with the APT wheel thus the pass counts were independent of direction. Limits based recording was selected and the System 6100 was programmed to record data based on limits set for the digital I/O card. A recording interval of 0.01 seconds was set. 
Table A.3 System 6100 Channel Configurations (continued)

\begin{tabular}{|c|c|c|c|c|c|}
\hline Sensor Type & Gage Type & $\begin{array}{c}\text { Channel } \\
\text { Number }\end{array}$ & Scanner & $\begin{array}{c}\text { Sample Rate } \\
\text { (samples/sec/ } \\
\text { channel) }\end{array}$ & Excitation \\
\hline \multicolumn{5}{|c|}{ TA1 } \\
Strain Gage & $\begin{array}{c}\text { PML-60-2L } \\
120 \Omega\end{array}$ & $1-6$ & 1 & 100 & $5 \mathrm{~V}$ \\
\hline $\begin{array}{c}\text { Rectangular } \\
\text { Rosette }\end{array}$ & $\begin{array}{c}\text { PMR-60-2L } \\
120 \Omega\end{array}$ & $7-12$ & 1 & 100 & $5 \mathrm{~V}$ \\
\hline $\begin{array}{c}\text { Uniaxial } \\
\text { Strain Gage }\end{array}$ & $\begin{array}{c}\text { WFLM-60-11- } \\
2 \mathrm{LTT} \\
120 \Omega\end{array}$ & $13-18$ & 1 & 100 & $5 \mathrm{~V}$ \\
\hline $\begin{array}{c}\text { High Level } \\
\text { Voltage }\end{array}$ & $\begin{array}{c}\text { APT Carriage } \\
\text { Position }\end{array}$ & 21 & 2 & 100 & Off \\
\hline $\begin{array}{c}\text { Thermo- } \\
\text { couple }\end{array}$ & $\begin{array}{c}\text { WTT-HD-72 } \\
\text { OSTMW-M } \\
\text { Type T }\end{array}$ & $25-27$ & 2 & 100 & N/A \\
\hline $\begin{array}{c}\text { High Level } \\
\text { Voltage }\end{array}$ & $\begin{array}{c}\text { APT Pass } \\
\text { Count }\end{array}$ & 28 & 2 & 100 & Off \\
\hline
\end{tabular}


Table A.3 System 6100 Channel Configurations (continued)

\begin{tabular}{|c|c|c|c|c|c|}
\hline Sensor Type & Gage Type & $\begin{array}{c}\text { Channel } \\
\text { Number }\end{array}$ & Scanner & $\begin{array}{c}\text { Sample Rate } \\
\text { (samples/sec/ } \\
\text { channel) }\end{array}$ & Excitation \\
\hline \multicolumn{5}{|c|}{ TA2 } \\
Strain Gage & $\begin{array}{c}\text { PML-60-2L } \\
120 \Omega\end{array}$ & $1-4,9,10$ & 1 & 100 & $5 \mathrm{~V}$ \\
\hline $\begin{array}{c}\text { Strain Gage } \\
\text { Transducer }\end{array}$ & $\begin{array}{c}\text { ASG-152 } \\
350 \Omega\end{array}$ & 5,7 & 1 & 100 & $5 \mathrm{~V}$ \\
\hline $\begin{array}{c}\text { Uniaxial } \\
\text { Strain Gage }\end{array}$ & $\begin{array}{c}\text { WFLM-60-11- } \\
2 \text { LT } \\
120 \Omega\end{array}$ & 6,8 & 1 & 100 & $5 \mathrm{~V}$ \\
\hline $\begin{array}{c}\text { Rectangular } \\
\text { Rosette }\end{array}$ & $\begin{array}{c}\text { PMR-60-2L } \\
120 \Omega\end{array}$ & $11-16$ & 1 & 100 & $5 \mathrm{~V}$ \\
\hline $\begin{array}{c}\text { High Level } \\
\text { Voltage }\end{array}$ & $\begin{array}{c}\text { APT Carriage } \\
\text { Position }\end{array}$ & 21 & 2 & 100 & Off \\
\hline $\begin{array}{c}\text { Thermo- } \\
\text { couple }\end{array}$ & $\begin{array}{c}\text { WTT-HD-72 } \\
\text { OSTMW-M } \\
\text { Type T }\end{array}$ & $25-27$ & 2 & 100 & N/A \\
\hline $\begin{array}{c}\text { High Level } \\
\text { Voltage }\end{array}$ & $\begin{array}{c}\text { APT Pass } \\
\text { Count }\end{array}$ & 28 & 2 & 100 & Off \\
\hline
\end{tabular}


Table A.3 System 6100 Channel Configurations

\begin{tabular}{|c|c|c|c|c|c|}
\hline Sensor Type & Gage Type & $\begin{array}{l}\text { Channel } \\
\text { Number }\end{array}$ & Scanner & $\begin{array}{c}\text { Sample Rate } \\
\text { (samples/sec/ } \\
\text { channel) }\end{array}$ & Excitation \\
\hline \multicolumn{6}{|c|}{ TA3 } \\
\hline $\begin{array}{c}\text { Uniaxial } \\
\text { Strain Gage }\end{array}$ & $\begin{array}{c}\text { PML-60-2L } \\
120 \Omega\end{array}$ & 1,2 & 1 & 100 & $5 \mathrm{~V}$ \\
\hline $\begin{array}{l}\text { Strain Gage } \\
\text { Transducer }\end{array}$ & $\begin{array}{c}\text { ASG-152 } \\
350 \Omega\end{array}$ & 5,7 & 1 & 100 & $5 \mathrm{~V}$ \\
\hline $\begin{array}{c}\text { Uniaxial } \\
\text { Strain Gage }\end{array}$ & $\begin{array}{c}\text { WFLM-60-11- } \\
2 \text { LT } \\
120 \Omega\end{array}$ & 6,8 & 1 & 100 & $5 \mathrm{~V}$ \\
\hline $\begin{array}{l}\text { Rectangular } \\
\text { Rosette }\end{array}$ & $\begin{array}{l}\text { PMR-60-2L } \\
120 \Omega\end{array}$ & $11-16$ & 1 & 100 & $5 \mathrm{~V}$ \\
\hline $\begin{array}{l}\text { High Level } \\
\text { Voltage }\end{array}$ & $\begin{array}{c}\text { APT Carriage } \\
\text { Position }\end{array}$ & 21 & 2 & 100 & Off \\
\hline $\begin{array}{l}\text { Thermo- } \\
\text { couple }\end{array}$ & $\begin{array}{c}\text { WTT-HD-72 } \\
\text { OSTMW-M } \\
\text { Type T }\end{array}$ & $25-27$ & 2 & 100 & $\mathrm{~N} / \mathrm{A}$ \\
\hline $\begin{array}{l}\text { High Level } \\
\text { Voltage }\end{array}$ & $\begin{array}{c}\text { APT Pass } \\
\text { Count }\end{array}$ & 28 & 2 & 100 & Off \\
\hline
\end{tabular}

Additionally, the position of the APT carriage as it passed over the pavement was needed. This information was also obtained from a laser range sensor that is connected to the APT computer and fed into the System 6100 via a high level input card (Model 6030) as an analog voltage.

Zeroing of the gages was performed after all the gages were in place and prior to the placement of the UTW concrete. A program that sent a signal to the system to take readings every hour was programmed in the APT computer. The system was armed and data acquisition was begun immediately after the UTW concrete 
placement was completed. This was done to allow the strains in the concrete to be monitored during the curing period. After the curing was complete, the data was downloaded and the system was armed again to allow for data acquisition during the load testing with the APT.

Data Acquisition System for Static Strain Readings

The system was constructed of components available from Campbell Scientific ${ }^{\circledR}$. It consisted of a datalogger, 2 multiplexers, a vibrating wire interface, and battery. The unit had the capability of reading 16 separate vibrating wire or surfacemounted or embedment strain gages and 32 separate thermocouples at user chosen time intervals. The system was programmed using a computer and equipment-specific software called PC-208w.

\section{Materials/Equipment List}

Campbell Scientific ${ }^{\circledR}$ CR10X datalogger with wiring panel and thermistor reference

Campbell Scientific ${ }^{\circledR}$ AM16/32 multiplexer

Campbell Scientific ${ }^{\circledR}$ SC32A optically isolated RS232 interface

Campbell Scientific ${ }^{\circledR}$ AVW4 vibrating wire interface (AVW1 would also work) Campbell Scientific ${ }^{\circledR}$ PC208W software

Laptop computer with Serial I/O or USB/Serial I/O adapter

12 volt gel cell battery

Multi-Conductor wires - 8 conductor (e.g. Belden-M Datatwist 5E 1583A CM 4PR24) and 4 conductor (e.g. Omega TX4-1000 Multi-Conductor Wire)

Suitable electrical enclosure (e.g. Hoffman A-181610CHQRFG with mounting panel A-18P16)

Small straight screwdriver

Configuration for Vibrating Wire Gages 
The system components were connected using light gage wire and the screw terminals on the components. Figures A.3 and A.4 illustrate the datalogger and multiplexer components. Table A.4 shows the connections between the datalogger and the multiplexer, the connections between the datalogger and the vibrating wire interface (8-conductor), and the connections between the vibrating wire interface and the multiplexer ( 4 conductor +2 additional conductors for power). The multiplexer was set for the $4 \times 16$ mode. The $12 \mathrm{~V}$ battery was connected to the datalogger using the "Power In" connector.

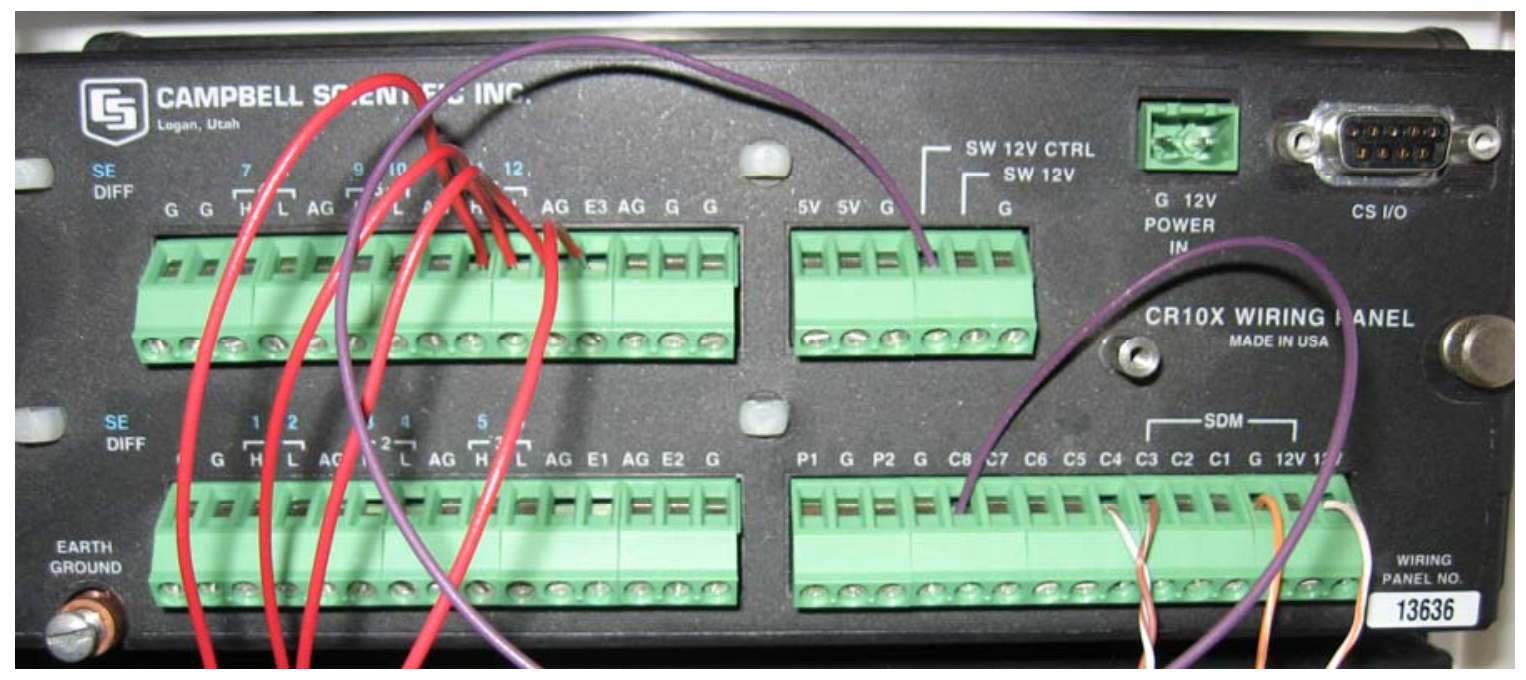

Figure A.3 Campbell Scientific CR10X Datalogger 


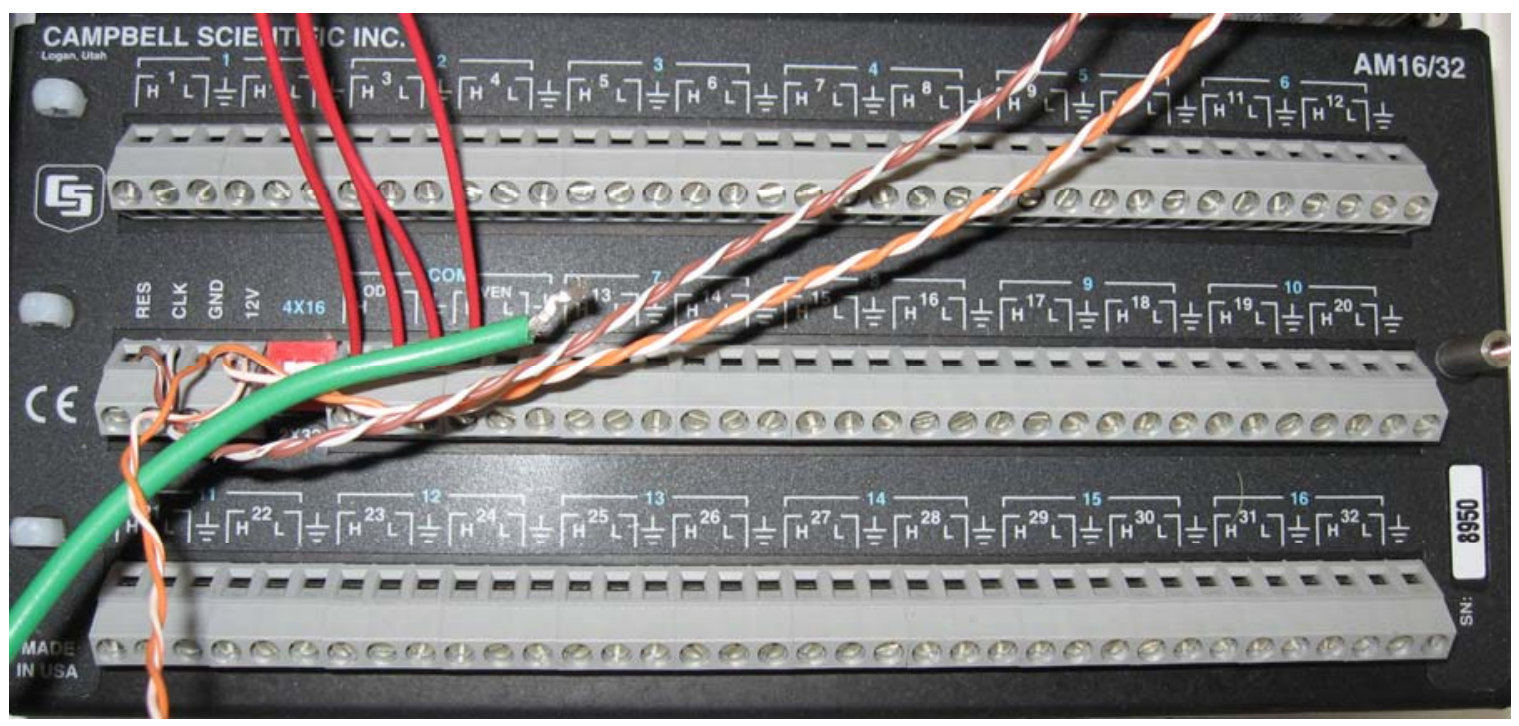

Figure A.4 Campbell Scientific AM16/32 Multiplexer

Table A.4 Configuration for Vibrating Wire Gages

\begin{tabular}{|c|c|c|}
\hline Datalogger CR10X & Multiplexer AM16/32 & VW Interface AVW4 \\
\hline $2 \mathrm{H}$ & & T1 \\
\hline $2 \mathrm{~L}$ & & F1 \\
\hline AG & & AG \\
\hline E1 & & EX \\
\hline $12 \mathrm{~V}$ & $12 \mathrm{~V}$ & \\
\hline $\mathrm{C} 3$ & RES & \\
\hline $\mathrm{C} 4$ & CLK & \\
\hline \multirow[t]{8}{*}{ G } & G & \\
\hline & $12 \mathrm{~V}$ & $V x$ \\
\hline & G & G \\
\hline & ODD H & T1+ \\
\hline & ODD L & T1- \\
\hline & EVEN H & $\mathrm{C} 1+$ \\
\hline & EVEN L & C1- \\
\hline & $G$ & G \\
\hline
\end{tabular}




\section{Datalogger Programming for Vibrating Wire Gages}

The system was programmed using the PC-208w software. The software allowed the user to write programs for the datalogger, send the program to the datalogger, and download the data collected by the datalogger. The computer communicated with the datalogger via a RS232 interface and Serial I/O port.

The program was set-up to allow for 32 channels (i.e. 16 vibrating wire readings and 16 corresponding thermistor readings) or twice the number of gages that you are using. Additional input labels were programmed for reference temperature (reference thermistor) and battery voltage.

Vibrating wire readings were based on frequency. Formulas were added to the program to perform calculations with these readings and ultimately provide readings in microstrain. In all cases the readings were taken every 20 minutes and the average value was stored in memory every hour. Zeroing of the gages was not part of the program. Zeroing was done in the spreadsheet by subtracting the initial reading out of all readings. Table A.5 contains a summary of the CR-10X configuration for vibrating wire gages.

Table A.5 CR-10X Channel Configurations (Vibrating Wire)

\begin{tabular}{|c|c|c|c|c|c|}
\hline $\begin{array}{c}\text { Sensor } \\
\text { Type }\end{array}$ & Gage Type & $\begin{array}{c}\text { Channel } \\
\text { Number }\end{array}$ & Multiplexer & $\begin{array}{c}\text { Sample } \\
\text { Rate } \\
\text { (seconds) }\end{array}$ & Excitation \\
\hline $\begin{array}{c}\text { Vibrating } \\
\text { Wire Strain } \\
\text { Gage }\end{array}$ & SM-5-A & $1-10$ & AM16/32 & 1800 & $2.5 \mathrm{~V}$ \\
\hline
\end{tabular}

\section{Configuration for Thermocouples}

The system components were connected using light gage wire and the screw terminals on the components. Table A.6 shows the connections between the 
datalogger and the multiplexer (refer to Figures A.3 and A.4). One multiplexer was set-up for 32 thermocouples (set in $2 \times 32$ mode). The $12 \mathrm{~V}$ battery was connected to the datalogger using the "Power In" connector. A $10 \mathrm{~W}$ solar panel was connected to the battery to provide trickle charging.

Table A.6 Configuration for Thermocouples

\begin{tabular}{|c|c|}
\hline Datalogger CR10X & $\begin{array}{c}\text { Multiplexer AM16/32 } \\
\text { Thermocouples }\end{array}$ \\
\hline $1 \mathrm{H}$ & ODD H \\
\hline $1 \mathrm{~L}$ & ODD L \\
\hline $\mathrm{C} 1$ & RES \\
\hline $\mathrm{C} 2$ & CLK \\
\hline $12 \mathrm{~V}$ & $12 \mathrm{~V}$ \\
\hline $\mathrm{G}$ & $\mathrm{G}$ \\
\hline
\end{tabular}

\section{Datalogger Programming for Thermocouples}

The system was programmed using the PC-208w software. The software allowed the user to write programs for the datalogger, send the program to the datalogger, and download the data collected by the datalogger. The computer communicated with the datalogger via an RS232 interface. 
The program was set-up to allow for six thermocouple channels. Additional input labels were programmed for datalogger reference temperature and battery voltage.

In all cases the readings were taken every 10 minutes and the average value was stored in memory. The downloaded data was inserted into a spreadsheet for analysis. Table A.7 contains the configuration of the CR-10X channels for use with the surface mounted and embedment gages.

Table A.7 CR-10X Channel Configurations for Thermocouples

\begin{tabular}{|l|c|c|c|c|c|}
\hline Sensor Type & Gage Type & $\begin{array}{c}\text { Channel } \\
\text { Number }\end{array}$ & Multiplexer & $\begin{array}{c}\text { Sample } \\
\text { Rate } \\
\text { (seconds) }\end{array}$ & Excitation \\
\hline Thermocouple & $\begin{array}{c}\text { WTT-HD- } \\
72 \\
\text { OSTMW-M } \\
\text { Type T }\end{array}$ & $1-4$ & AM16/32 & 600 & $2.5 \mathrm{~V}$ \\
& & & & \\
\hline
\end{tabular}

Data Downloading and Analysis

The PC-208 software was used to download the data files. The CR10X had the capability to store $2 \mathrm{MB}$ of data. Data file size depends on the number of data channels stored and the frequency of data sampling. The downloaded data was stored in a text file and transferred to a spreadsheet for analysis.

\section{Gage Layout and Surface Preparation}




\section{Materials/Equipment List}

Air hose

String

Permanent marker

Measuring tape

Chalk Line

Small hand-held grinder

Prior to beginning the installation of the surface-mounted and embedded strain gages the surface preparation of the existing layer was completed. In the case of the aggregate layer, the aggregate was placed to its proper depth and compacted. The asphalt layer was ground to an adequate depth with respect to the UTW thickness and, if necessary, the forms for the UTW concrete were placed. The surface of the asphalt was relatively free from the dust left from grinding and formwork placement. An air hose was used for removing the dust.

The locations of the gages were chosen based on the PCA-UTW design guide failure mechanisms. Thus, gages were placed at the edge and corner locations. For the UTW concrete a strain gage rosette was placed to determine the maximum strains in the corner location. No gage redundancy was used since the gages needed to be placed in specific locations within the pavement. See Figure A.1.

The gages were placed within specific panels of the UTW pavement thus, string lines that represented the boundaries of the UTW panels were placed. String lines were attached to the top of the formwork or edge of the APT test pit to provide a good reference for the top of the UTW from which depths of the gages could be determined. Chalk lines were also used to provide the panel outlines. 
The location of the gages was determined using the measuring tape and marked on the surface. The location of the center of the gage was found and marked. Then, using the length of the gage, the ends of the gage were also located and marked. If there was an embedded gage at this location, the width of the support assembly was used to locate and mark the holes for the support legs. Figure A.5 illustrates the marked locations.

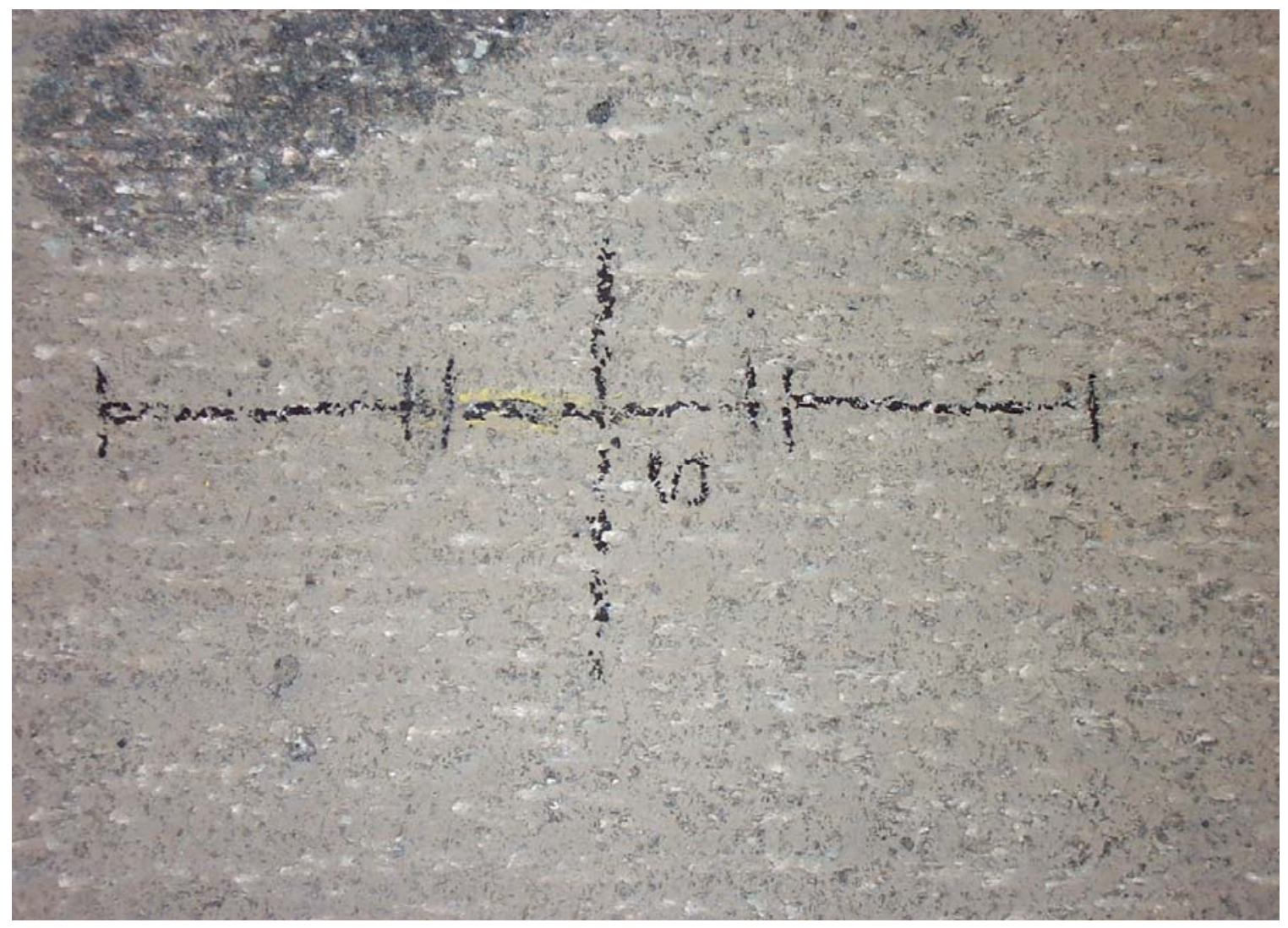

Figure A.5 Marking of Gage Locations

For gages to be mounted to the surface of the asphalt, the surface of the asphalt was ground smooth using a small hand-held grinder. The area to be ground was based on the size of the gage. An area with a perimeter of approximately 0.25 to 0.5 inches ( 6 to $12 \mathrm{~mm}$ ) wider than the dimensions of the gage was ground. The surface of the asphalt was again cleared of dust and the location of the gage was again marked on the asphalt surface. 


\section{Extension Wiring of Standard Embedded and Surface Mounted Gages}

Materials/Equipment List

Gage cable - TX4-1000 Multi-Conductor Wire (Omega Engineering) (1000'

spools were purchased since smaller spools resulted in too much waste.)

Wire cutter/stripper

Shrink tube (3 sizes)

Heat gun

Soldering Iron

Solder

U-pins

Screw terminal input connectors - 6000-a69 (Measurements Group)

Measuring tape

Hammer

Silicone sealant

Small straight screwdriver

\section{Placement of Gage Cable}

A length of the gage cable was laid out from the gage furthest from the data acquisition unit to the data acquisition unit. This length was measured and an equivalent length of cable was cut for each gage. Once the cables were cut to length all the cables were placed in the proper position. A sufficient length for splicing at the gage end and for the input connectors at the other end was left and the cables were pulled tight along the surface of the asphalt. The cables were grouped together in small bundles of two to three cables where possible. See Figure A.1.

\section{Gage Connection}

The gage leads were cut to length. The ends of the gage leads and the gage end of the cable and wires were stripped. The cable contained four colored wires 
and a shield wire. The embedded gages had two lead wires and the surface mount gages had three lead wires. Table A.8 shows the wiring scheme for the different gages. The green wire that was not connected and the shield wire were cut back to the point of stripping on the cable.

Two pieces of the shrink tube, one large and one medium, were placed over the cable end. Small pieces of shrink tube were placed over each of the gage leads. The appropriate wires were twisted and soldered together. The small shrink tubes were placed over the twisted wires and shrunk with the heat gun. The twisted portion was placed against the cable and the medium shrink tube was placed over this section. This tube was shrunk. The previous steps were repeated with the large shrink tube.

Table A.8 Gage and Cable Connections

\begin{tabular}{|c|c|}
\hline Cable Wire & PML-60-2L Lead Wire \\
\hline Red & Red \\
\hline Black & Red (Same as White) \\
\hline Green & Red (Same as Black) \\
\hline White & Not Connected \\
\hline Shield Wire & WFLM-60-2LT Lead Wire \\
\hline Cable Wire & Red \\
\hline Red & Black \\
\hline Black & Yellow \\
\hline Green & Not Connected \\
\hline White & \\
\hline Shield Wire &
\end{tabular}

The remaining end of the gage cable and wires were stripped. For strain gages (PML-60-2L, ASG-152, and WFML-60-11-2LT) used with the System 6100 the 
cable wires were connected to the screw terminal input connectors using the screwdriver. The connection scheme is presented in Table A.9. Again, the green wire that was not connected was cut back.

Table A.9 Standard Gage Screw Terminal Connections for System 6100

\begin{tabular}{|c|c|}
\hline Cable Wire & Connector Pin Number \\
\hline Red & 5 \\
\hline Black & 4 \\
\hline Green & Not Connected \\
\hline White & 3 \\
\hline Shield Wire & 9 \\
\hline
\end{tabular}

Once the cables were in position pilot holes $(1 / 8$ inch $(3 \mathrm{~mm})$ diameter and 1 inch $(25 \mathrm{~mm})$ deep) were drilled in the asphalt to anchor the cables in place. The holes were on either side of the cables/bundles and spaced to allow the insertion of a U-pin. These pins were used to hold the cables in place during construction. Once the holes were drilled the U-pins were inserted and tapped into place. Care was taken not to damage the wires in this process.

Concrete Embedment Strain Gages - PML(R)-60-2L

This section describes the steps necessary for the placement of embedded gages. These gages were used to determine the strains in the concrete. The PM series gages were designed specifically for use in concrete under loading. The gage was sealed between thin resin plates which had been impregnated with sand to provide good bonding between the gage and the concrete. The gages had a gage length of $60 \mathrm{~mm}$ (2.4 inches), a gage factor of approximately 
2.0, and have a resistance of $120 \mathrm{ohms}$. The operational temperature of the gages was -20 to $60^{\circ} \mathrm{C}\left(-4\right.$ to $\left.140{ }^{\circ} \mathrm{F}\right)$. There were two-wire paralleled leads wires approximately 2 meters (6.5 feet) long that were cut down to 3 " to 4 " (75 to $100 \mathrm{~mm}$ ) in order that a greater length of protective extension cable could be used.

\section{Installation}

Materials/Equipment List

Metal straps with pre-drilled holes (like that used for duct work)

Threaded steel rod $(0.25 "(6 \mathrm{~mm}))$

Thin gage wire

Nuts - fit to threaded rod

Quick-set (2 part) epoxy

Gages - PML-60-2L or PMR-60-2L (Texas Measurements ${ }^{\mathrm{TM}}$ - PMR gages no longer available)

Metal shears

Grinding wheel

Drill $\mathrm{w} / \mathrm{mason} r y$ bit (slightly larger than $0.25 "(6 \mathrm{~mm})$ )

Measuring tape

Hammer

Torpedo level

Wire cutter/stripper

\section{Support Assembly}

The support assembly held the concrete embedment gages (PML-60-2L or PMR60-2L) in position while the UTW was constructed. Thus, the support needed to be assembled and placed to withstand the placement and consolidation of concrete around all sides of the gages. The assembly consisted of two identical 
two leg supports (threaded rod) which were connected by the gage itself. The following instructions assume only one gage per assembly. However, in Test Areas 2 and 3, two gages were placed at different depths at the same location.

The metal straps were cut to length using metal shears. The holes in the straps were placed such that the larger holes in the strap were spaced to allow symmetric placement of the threaded rods through the holes. The strap was cut to allow for the width of the strain gage to fit between the rods with nuts attached. Two lengths of strap were needed per assembly.

The threaded rod was cut to length using the grinding wheel. The length of the cut rod was based on the thickness of the concrete. For example, the depth of the UTW was nominally 2.5 inch $(63 \mathrm{~mm})$ and a gage was to be placed at 0.5 inch $(13 \mathrm{~mm})$ below the UTW surface. An adequate length of rod needed to be left at the top of the rod for placement of nuts, approximately 0.25 inch $(6 \mathrm{~mm})$. Also, an adequate length needed to be left at the bottom of the rod for placement into the asphalt, approximately 1.0 inch $(25 \mathrm{~mm})$. Thus, a sufficient length of rod for this configuration was 2.5 inch -0.5 inch +0.25 inch +1.0 inch=3.25 inch (63 $\mathrm{mm}-13 \mathrm{~mm}+6 \mathrm{~mm}+25 \mathrm{~mm}=81 \mathrm{~mm})$.

A rod was placed through one of the large holes in the strap. One nut each was placed on the top and bottom of the strap to hold the strap in place. The procedure was repeated for a second rod. This assembly represented one half of the total support assembly. Four nuts were needed for each half-assembly. These nuts not only held the assembly together but allowed the height of the gage to be adjusted and the gage to be leveled once it was in position. The above procedure was repeated for the remaining half-assemblies.

Once all the half-assemblies were complete, a gage was placed between two of the half-assemblies. Using the thin wire, the gage was wired to the assembly. 
Care was made to allow motion of the gage in the longitudinal direction. Prior to attaching the gages to the supports, the lead wires on the gages were cut to a length of approximately 3 " to 4 " (75 to $100 \mathrm{~mm})$.

\section{Gage Placement}

Locations of the gages and supports should have previously been marked. If there is to be a gage mounted to the surface of the asphalt, grinding of the asphalt surface should be completed prior to placement of the embedded gages. Drill holes into the asphalt to a depth of approximately 1.0" $(25 \mathrm{~mm})$. Insert the support legs into the holes in the asphalt to ensure a proper fit. Adjust the depths of the holes as necessary. It may be necessary to blow air into the holes to remove dust. Also, a hammer might be needed to tap the rods into the holes. Once you are sure of the position of the all the supports mix the two part epoxy. Remove the support legs, apply a small amount of epoxy to each leg, and reinsert the legs into the holes. Repeat for each gage assembly.

Once the epoxy has set, adjust the height of the gages by measuring the depth from the string line. Also, level the gages using a torpedo level. As previously mentioned, depth and level adjustments can be made by raising or lowering the nuts holding the gage in place. Figure A. 6 shows an installed embedment gage. 


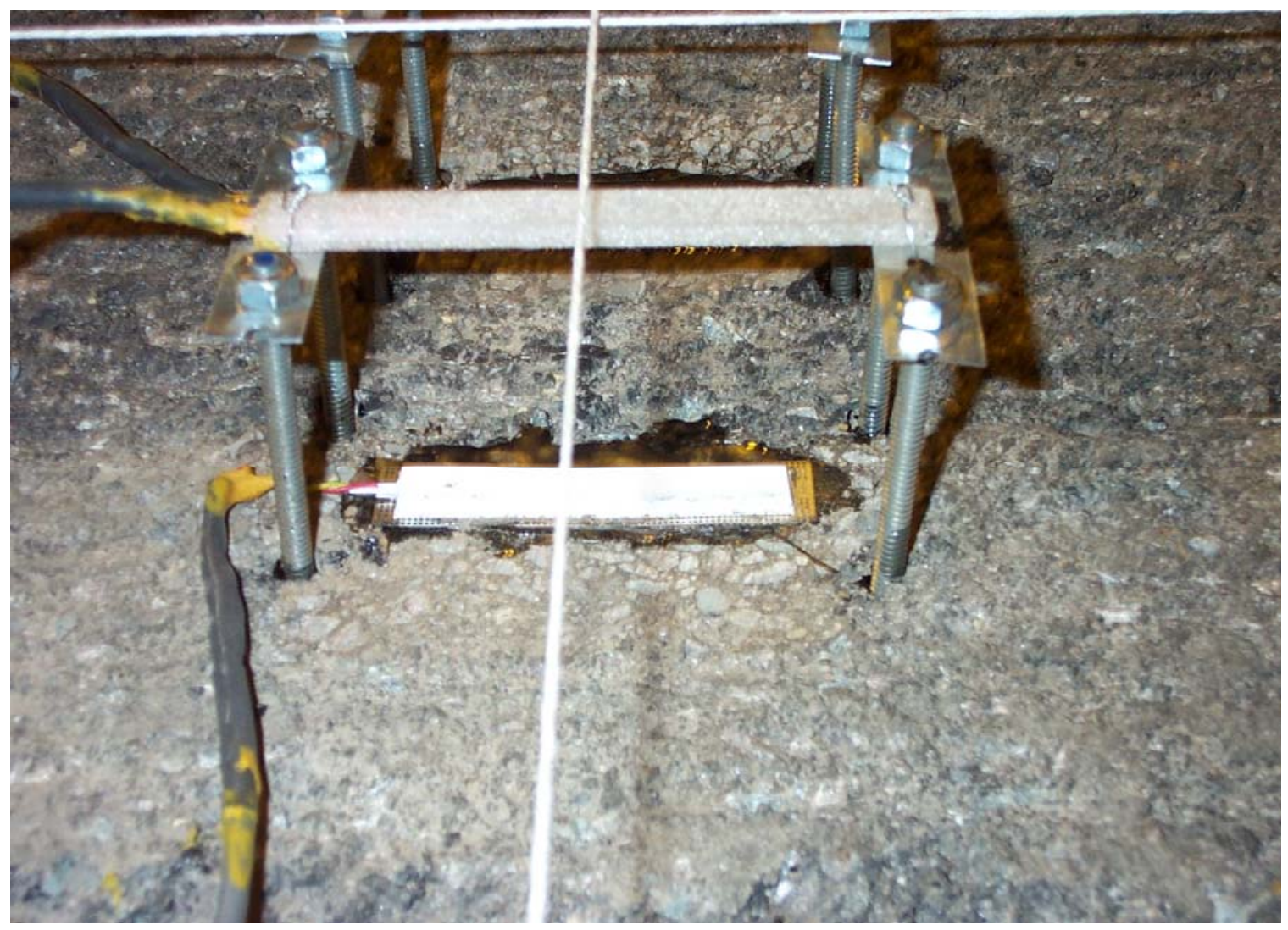

Figure A.6 Installed Support Assembly with Gage

Surface-Mounted Asphalt Strain Gages - WFLM-60-11-2LT

This section describes the steps necessary for the placement of the surface mounted asphalt gages. These gages were used to determine the strains at the top of the asphalt layer. The WF series gages were designed to provide a moisture proof coating and for use as a concrete surface mounted gage. In the selection of these gages, the general term of concrete was extended to include asphalt concrete as well. The gage had a metal backing that was glued to the asphalt to provide good bonding between the gage and the asphalt. The gages had a gage length of $60 \mathrm{~mm}$, a gage factor of approximately 2.0, and have a resistance of $120 \mathrm{ohms}$. The operational temperature of the gages was $-20^{\circ} \mathrm{C}$ to $80^{\circ} \mathrm{C}\left(-4^{\circ} \mathrm{F}\right.$ to $\left.176{ }^{\circ} \mathrm{F}\right)$. There were three-wire paralleled leads wires approximately 2 meters ( 6.5 feet) long that were cut down in order that a greater length of protective extension cable could be used. 


\section{Installation}

Materials/Equipment List

Gages - WFLM-60-11-2LT (Texas Measurements ${ }^{\mathrm{TM}}$ )

Adhesive - PS (Texas Measurements ${ }^{\mathrm{TM}}$ )

Adhesive applicator

Small ballast

\section{Gage Placement}

Grinding of the asphalt surface and the marking of the gage locations was completed prior to gage placement (see Section 4). Gage lead wires were cut to a length of 3" to 4" (75 to $100 \mathrm{~mm}$ ). The adhesive was mixed according to manufacturer's instructions. Using the applicator a uniform layer of adhesive was spread on the asphalt surface. The gage was set in its proper location in the adhesive. The thickness of the adhesive layer was sufficient enough to completely bond the gage to the asphalt. A small ballast was placed on top of the gage to keep the gage in place while the adhesive set. Refer to Figure A.7 which also shows the installed surface mounted gage.

\section{Asphalt Embedment Strain Gages - ASG-152}

This section describes the steps necessary for the placement of the asphalt embedment gages. These gages were used to determine the strains in the asphalt layer. The ASG-152 gages were designed to withstand the high temperatures and compaction loads encountered in the asphalt during placement. The gages were connected to a metal "l" support which provided protection to the gage as well as ensured that the gage stayed in place during construction. The gages had a gage factor of approximately 2.0 and have a resistance of 350 ohms. The gages are a full bridge configuration and no completion of the bridge was required. The operational temperature of the gages was $-34{ }^{\circ} \mathrm{C}$ to $204^{\circ} \mathrm{C}\left(-25^{\circ} \mathrm{F}\right.$ to $\left.396{ }^{\circ} \mathrm{F}\right)$. The strain range of the gages was $+/-$ 1500 microstrain. There were four-wire shielded lead wires approximately 30 
feet (9 meters) long. These wires were in an abrasion-resistant, Teflon polymer coating that protected the wires. Thus, these leads were not cut as done with the other gages.

\section{Installation}

Materials/Equipment List

Gages - ASG-152 (Construction Technologies Laboratories)

Liquid Asphalt Binder

Sand

\section{Gage Placement}

The location of the gages was identified as noted previously. A small amount of liquid asphalt was placed on the surface of the underlying pavement layer at the location of the supports. The gages were placed into the liquid asphalt. Once properly oriented, additional liquid asphalt was poured over the gages to hold them in place. Sand was sprinkled over the tacky asphalt to ensure that the gages would bond with the HMA layer. Figure A.7 shows the installed ASG-152 gage. 


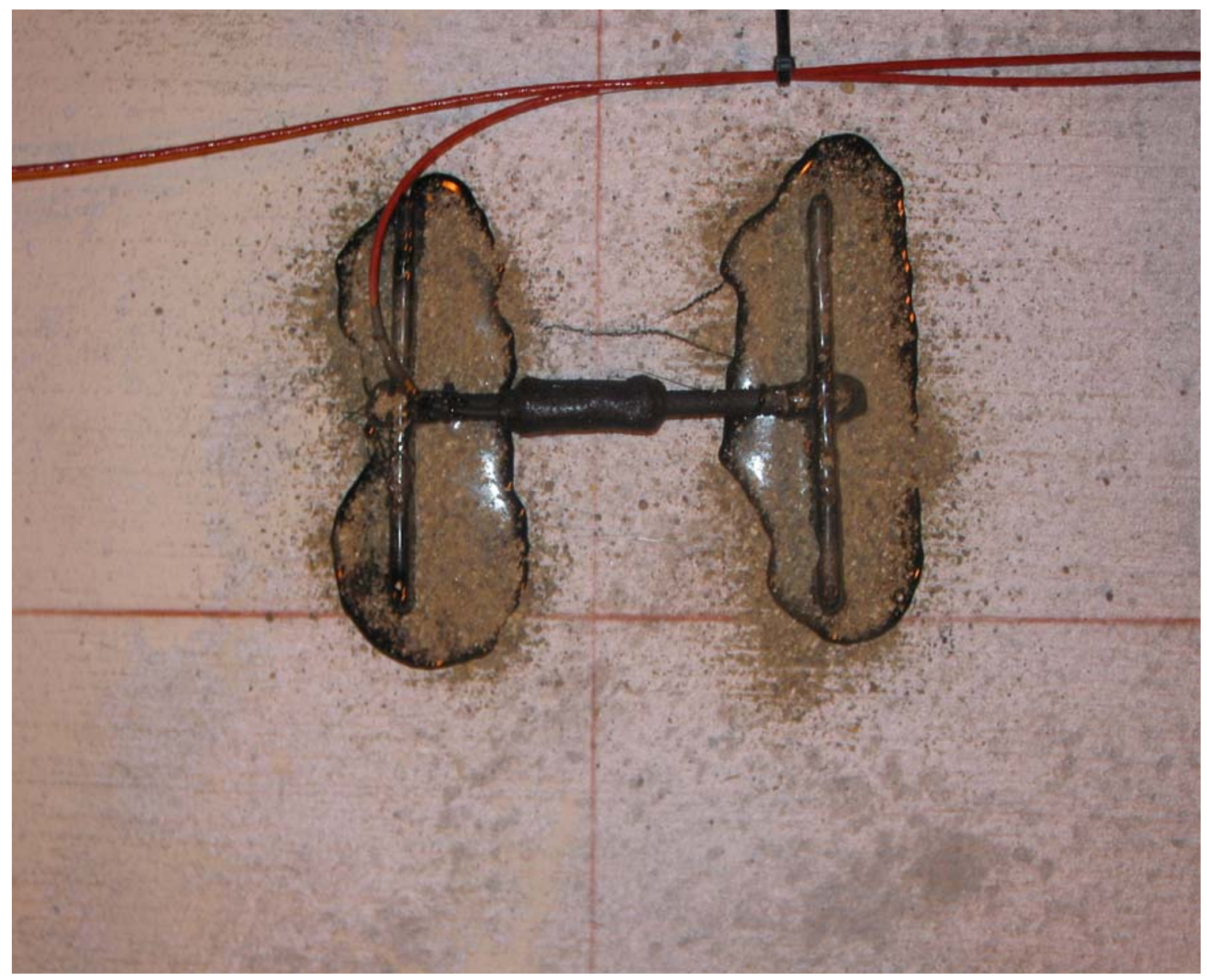

Figure A.7 Installed ASG-152 Gage

\section{Thermocouples - WTT-HD-72-OSTW-M}

Thermocouples were placed in the pavement layers for Test Areas 1-4 to record the temperature of the pavement at different depths. The thermocouples used were Type-T thermocouples with a heavy-duty armor cable. The armored cable was selected to protect the cable during subsequent construction. The sensor had a stainless steel, washer mounting surface which allowed the thermocouple to be mounted onto a threaded rod. The thermocouples also had a standard male connector. The Type $\mathrm{T}$ thermocouples had a temperature range of $-250^{\circ} \mathrm{C}$ to $350{ }^{\circ} \mathrm{C}\left(-418{ }^{\circ} \mathrm{F}\right.$ to $\left.662{ }^{\circ} \mathrm{F}\right)$ and read to within $1{ }^{\circ} \mathrm{C}\left(0.6{ }^{\circ} \mathrm{F}\right)$. 


\section{Installation}

\section{Materials/Equipment List}

Thermocouples - Omega Engineering WTT-HD-72-OSTW-M

Threaded steel rod $(0.25 "(6 \mathrm{~mm}))$

Nuts - fit to threaded rod

Quick-set epoxy

\section{Thermocouple Placement}

A hole was drilled into the underlying layer. The depth of the hole was approximately 2 inches $(50 \mathrm{~mm})$. A threaded rod was cut to a suitable length and placed into the hole (sizing of the rod was discussed previously. Quick-set epoxy was placed in the hole to hold the rod in place. When the epoxy was set the washer end of the thermocouples was placed over the rod and held in place with one or two washers as needed. The location of the thermocouple was also adjusted to the proper height using the washers. The connector was connected to a standard, Type-T thermocouple extension cable. This in turn was attached to the removable three-terminal screw connector on the Model 6020 input card for the System 6100 for use in the APT. Alternately, the thermocouple extension cable was connected to the multiplexer on the CR-10X.

\section{Vibrating Wire Strain Gages - SM-5-A}

The vibrating wire gages were used to evaluate the shrinkage strains in the concrete. The Roctest ${ }^{\mathrm{TM}}$ Model SM-5-A gages were designed for use with concrete. The gage had two end pieces which are connected by a length of steel wire. When fixed to the surface of the concrete the changes in strain in the concrete caused resulting changes in the tension of the steel wire. An electromagnetic sensor was located at the center of the tube. This sensor monitored the changes in the resonant frequency of the wire which is then related to the strain change in the concrete. The gages had a high resolution of 0.1 microstrain with a range of 3000 microstrain. The operating temperature of 
the gages was $-50{ }^{\circ} \mathrm{C}$ to $60^{\circ} \mathrm{C}\left(-58^{\circ} \mathrm{F}\right.$ to $\left.140{ }^{\circ} \mathrm{F}\right)$. The gage length was $149 \mathrm{~mm}$ (6 inches). Each gage also contained a thermistor to record temperatures. The gage had a 40 foot (12 meter) long cable which was connected directly to the multiplexer in the CR-10X datalogger box.

\section{Installation}

\section{Materials/Equipment List}

Vibrating wire strain gage (Roctest ${ }^{\mathrm{TM}}$ SM-5-A) with 40 foot (12 meter) cable Surface mounting blocks for Roctest ${ }^{\mathrm{TM}}$ SM-5-A gages

Two-part quick-set epoxy

Permanent marker

Measuring tape

Hex-head wrenches

\section{Gage Placement}

The vibrating wire gages were mounted to the surface of the concrete in the UTW pavement. No other preparation of the surface was necessary but to ensure that the surface was oil-free and clear of dust.

Using the measuring tape and permanent marker the center of the strain gages were located and marked. Using the length of the gages and support dimensions the ends of the gage and the location of the gage supports were located and marked. The gage supports were also check to verify that they were also free of oil and dust. The epoxy was mixed per the manufacturer's recommendations. The epoxy was applied to the concrete surface at the gage support locations. The gage supports were placed into the epoxy at the appropriate location. Care was used to ensure that the gage supports were not displaced from their proper location. This procedure was repeated for all the gages. Once the epoxy was set, the gages were placed into the gage supports. Finally, the gages were 
tightened in place using the hex-head wrenches. Figure A.8 shows the installed vibrating wire strain gages.

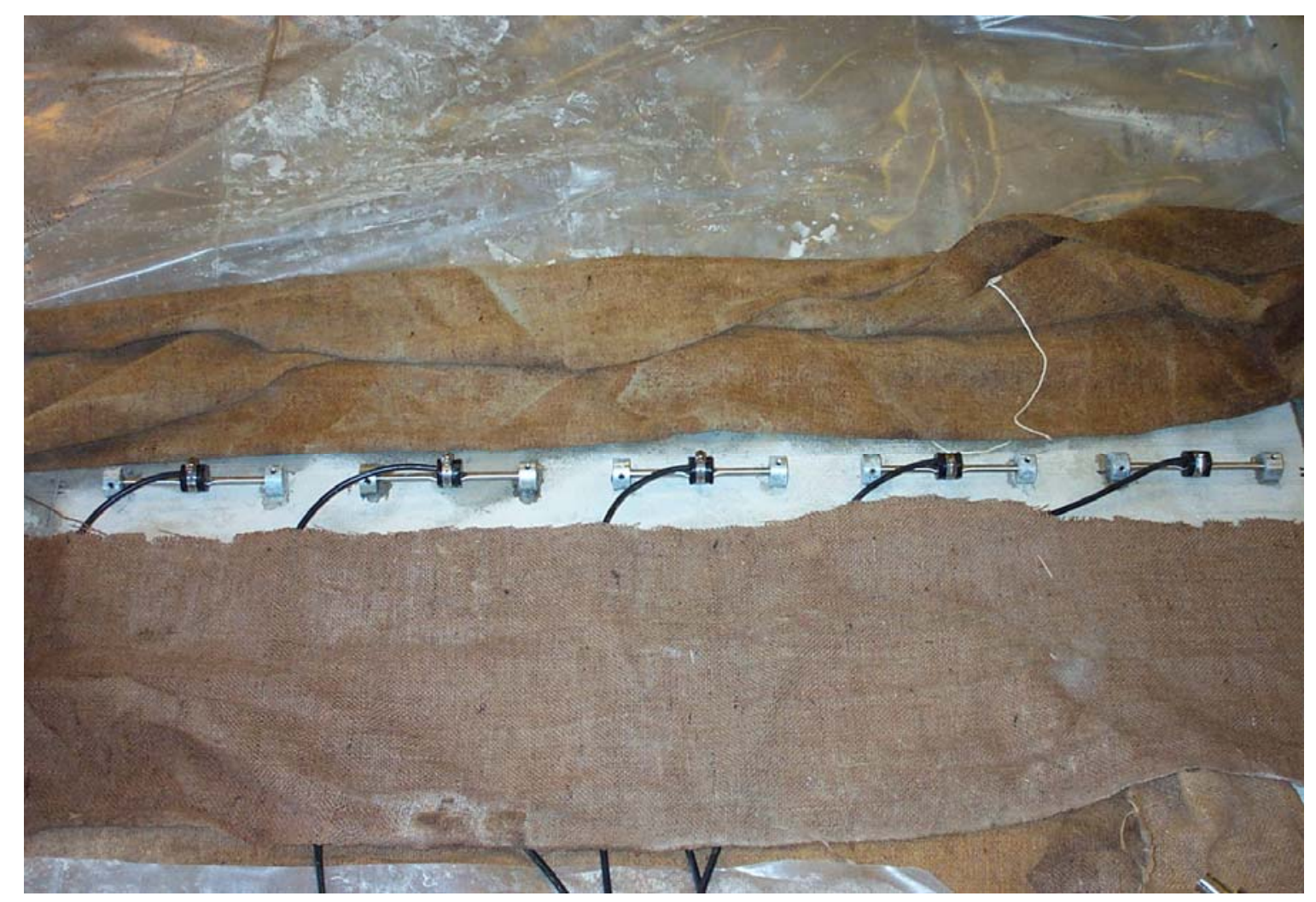

Figure A.8 Installed Vibrating Wire Strain Gages

Once the gages were in place the gage wires were connected to the datalogger system. The gages were connected to the channels available in the multiplexer. The vibrating wire cable consisted of four conductors and a shield wire. An example wiring scheme for the gage is shown in Table A.10. The scheme is similar for all even and odd numbered inputs.

Table A.10 Vibrating Wire Gage Connections to Multiplexer

\begin{tabular}{|c|c|}
\hline Multiplexer & Gage Wire \\
\hline
\end{tabular}




\begin{tabular}{|c|c|}
\hline $1 \mathrm{H}$ & Green \\
\hline $1 \mathrm{~L}$ & White \\
\hline $2 \mathrm{H}$ & Red \\
\hline $2 \mathrm{~L}$ & Black \\
\hline $\mathrm{G}$ & Shield \\
\hline
\end{tabular}


Appendix B. Results

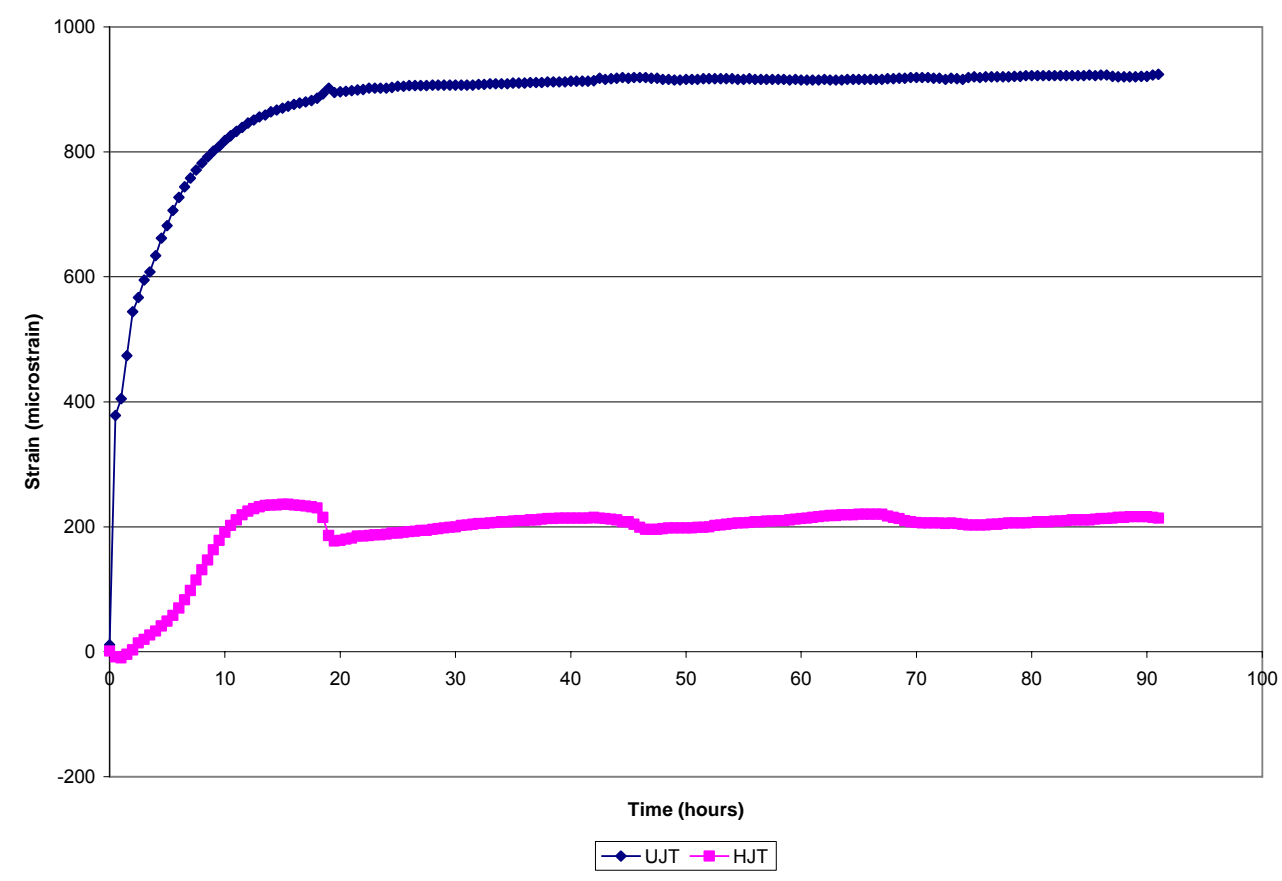

(a)

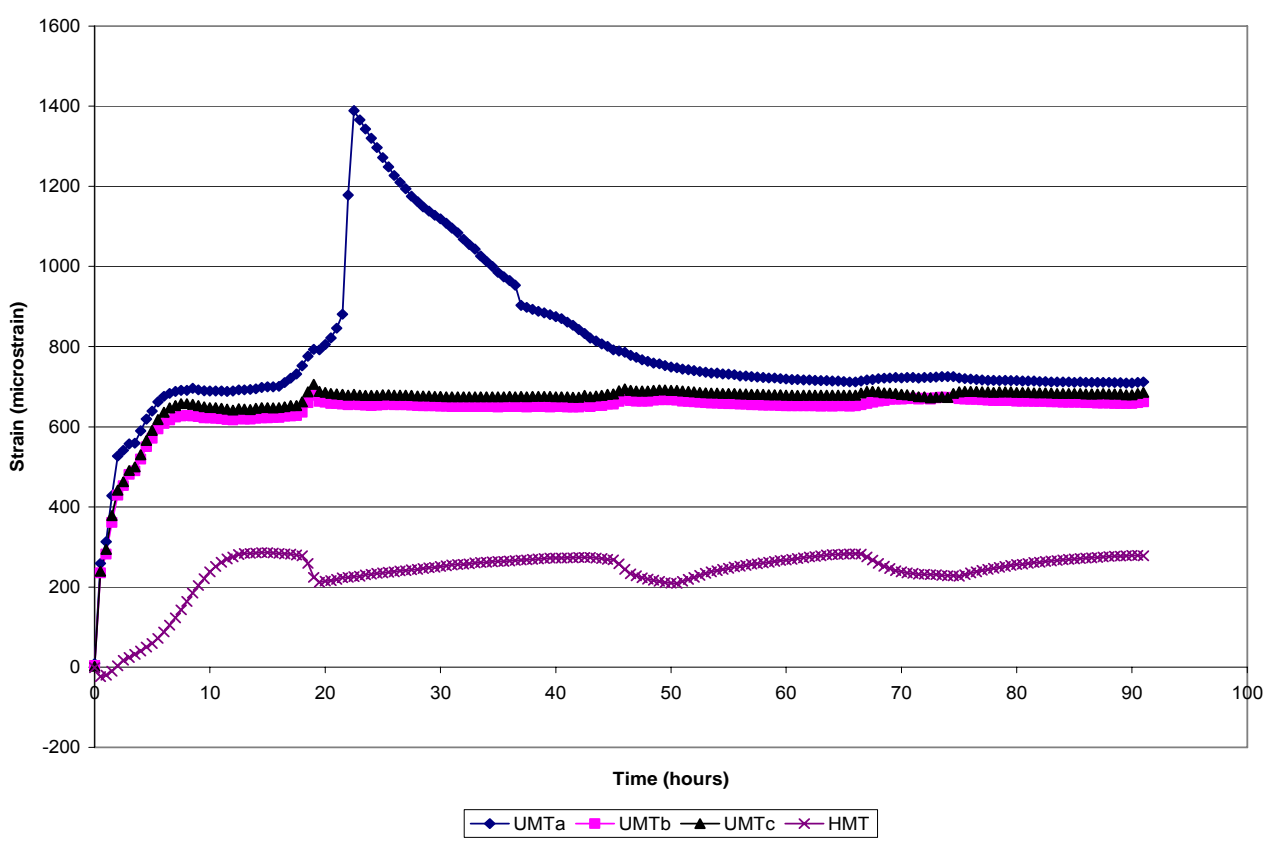

(b)

Figure B.1 Curing Strains - Test Area 1 (a) Joint (b) Mid-Panel (c) Edge (d) Corner (continued) 


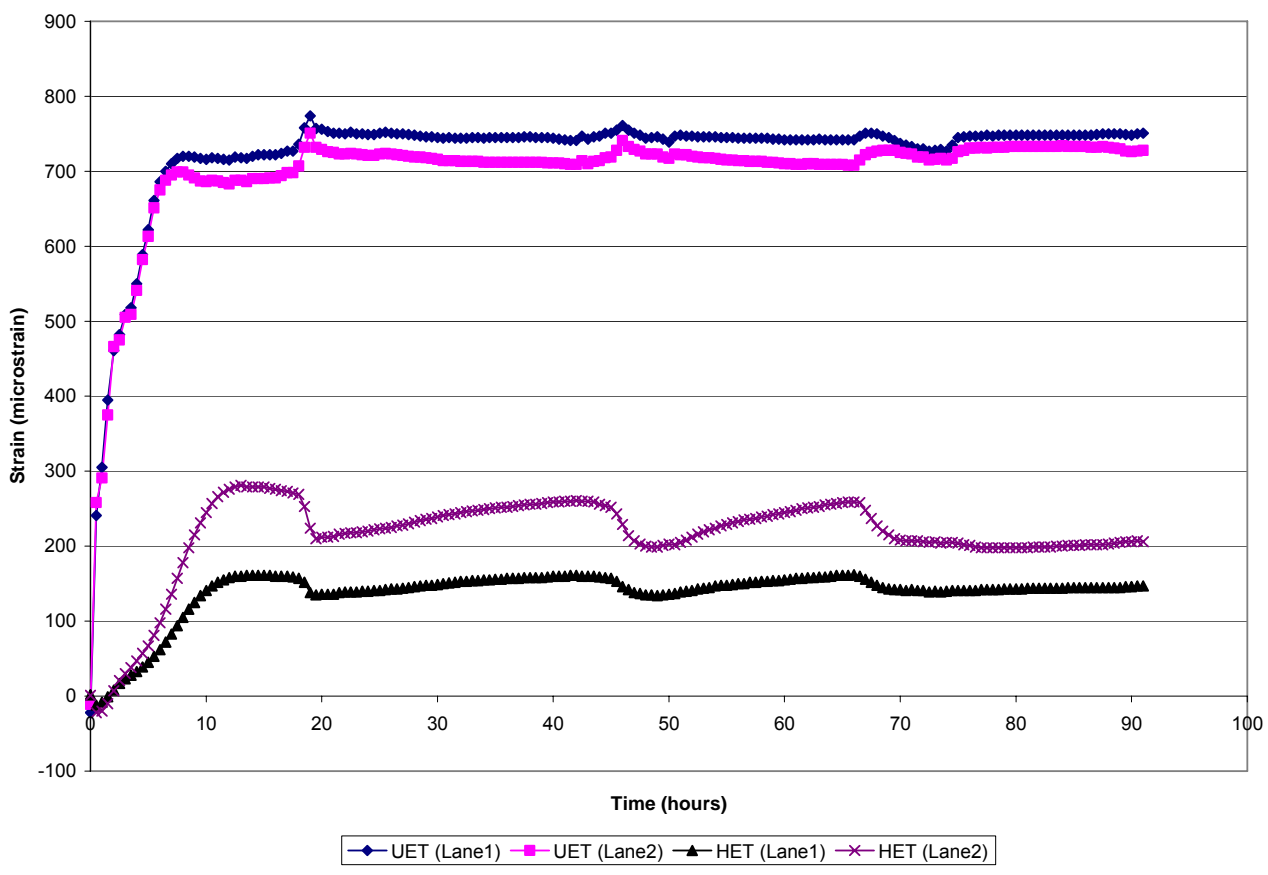

(c)

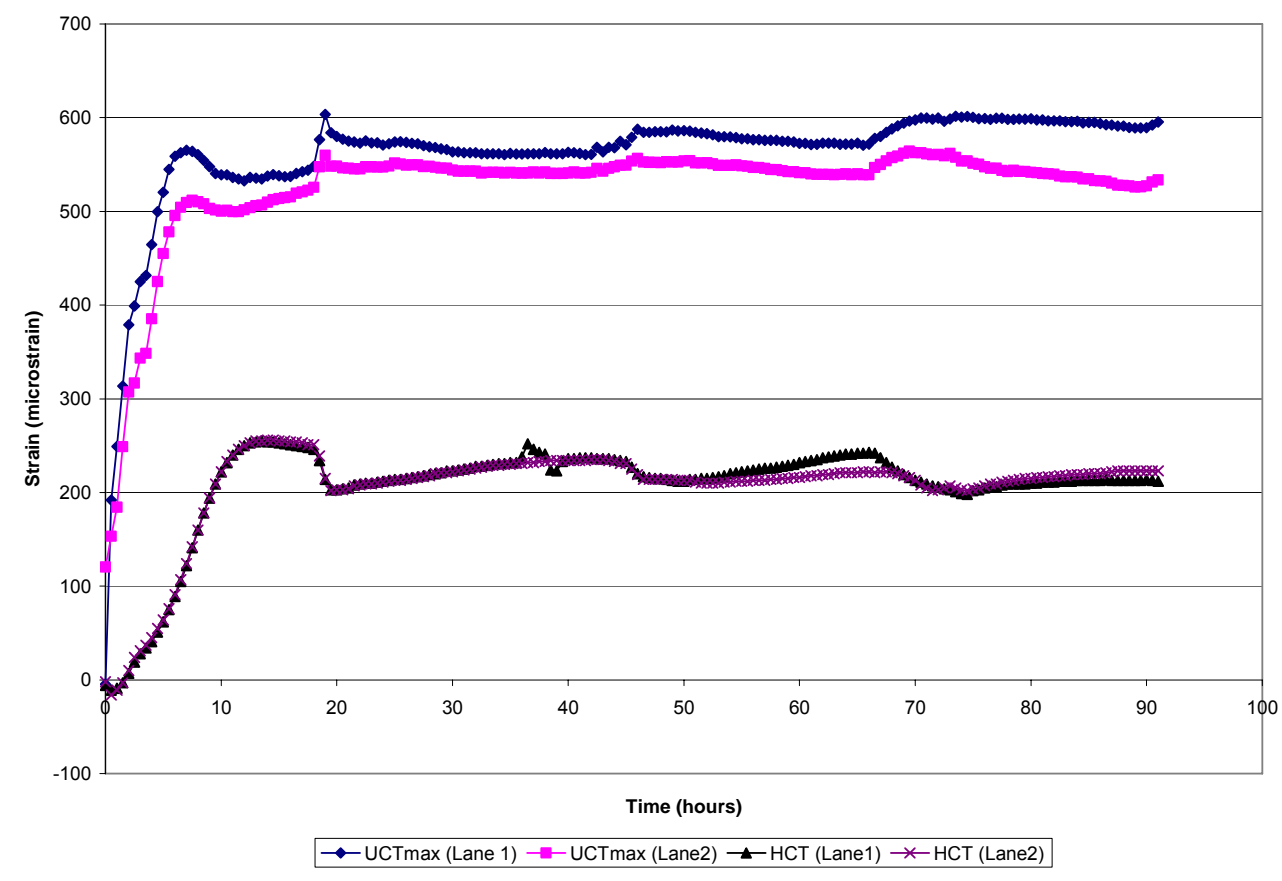

(d)

Figure B.1 Curing Strains - Test Area 1 (a) Joint (b) Mid-Panel (c) Edge (d) Corner 


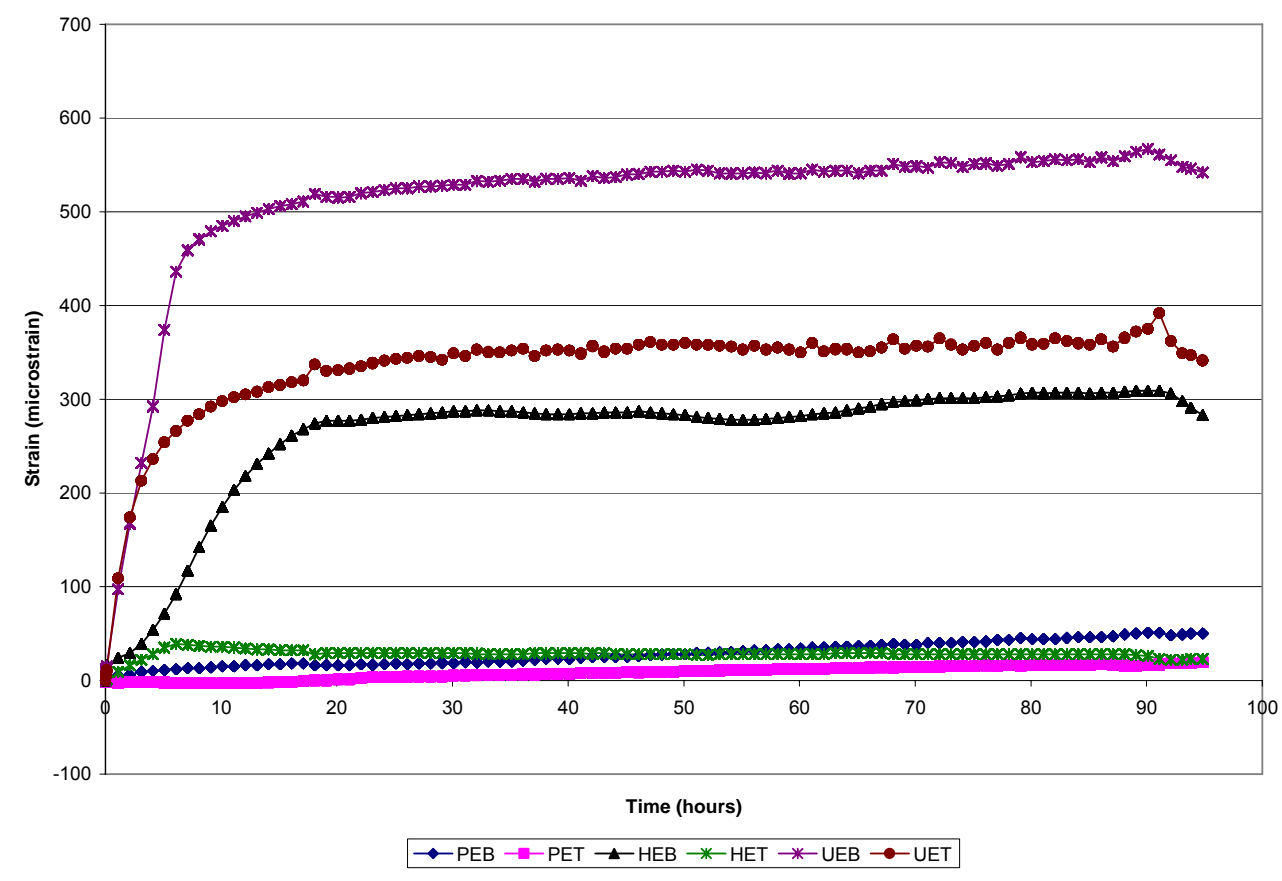

(a)

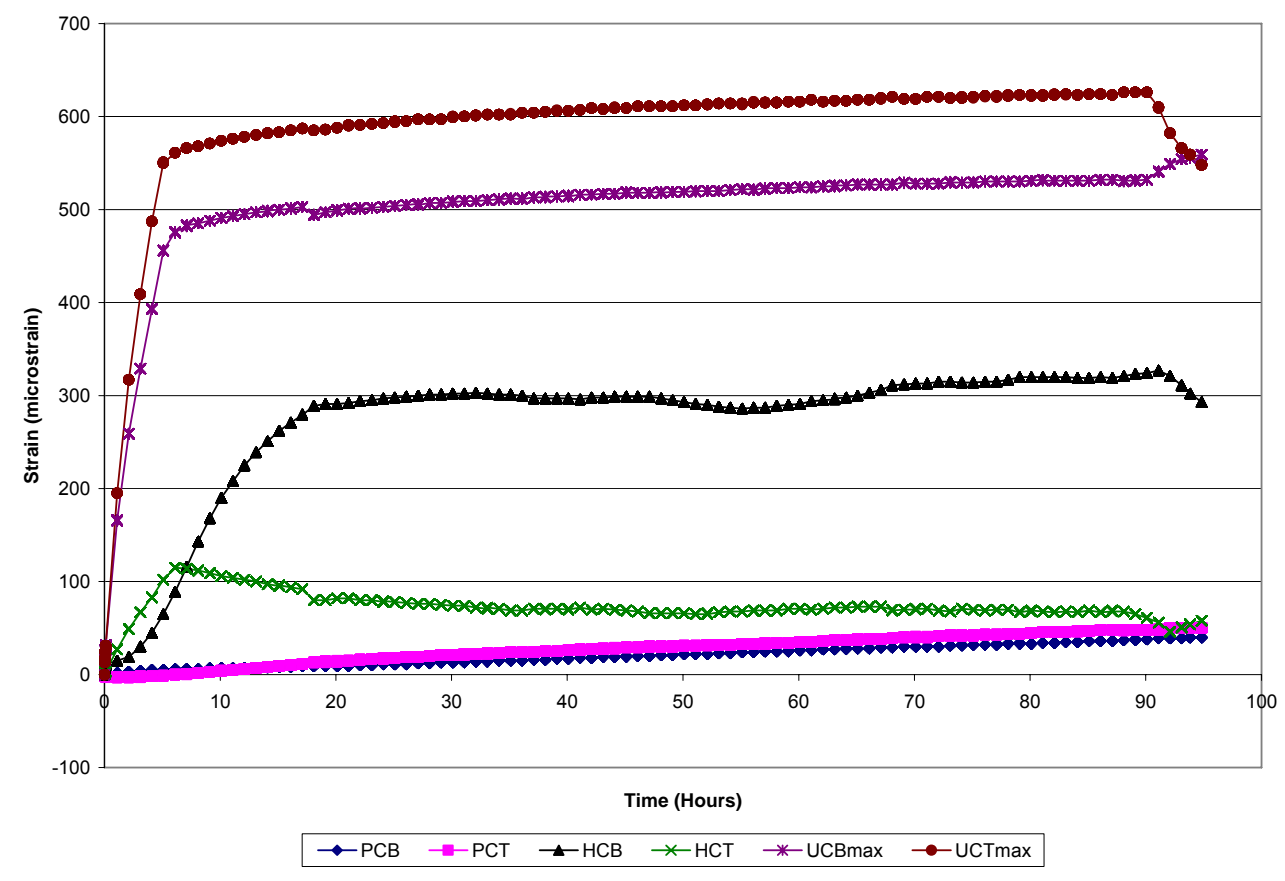

(b)

Figure B.2 Curing Strains - Test Area 2 - Lane 1 (a) Edge (b) Corner 


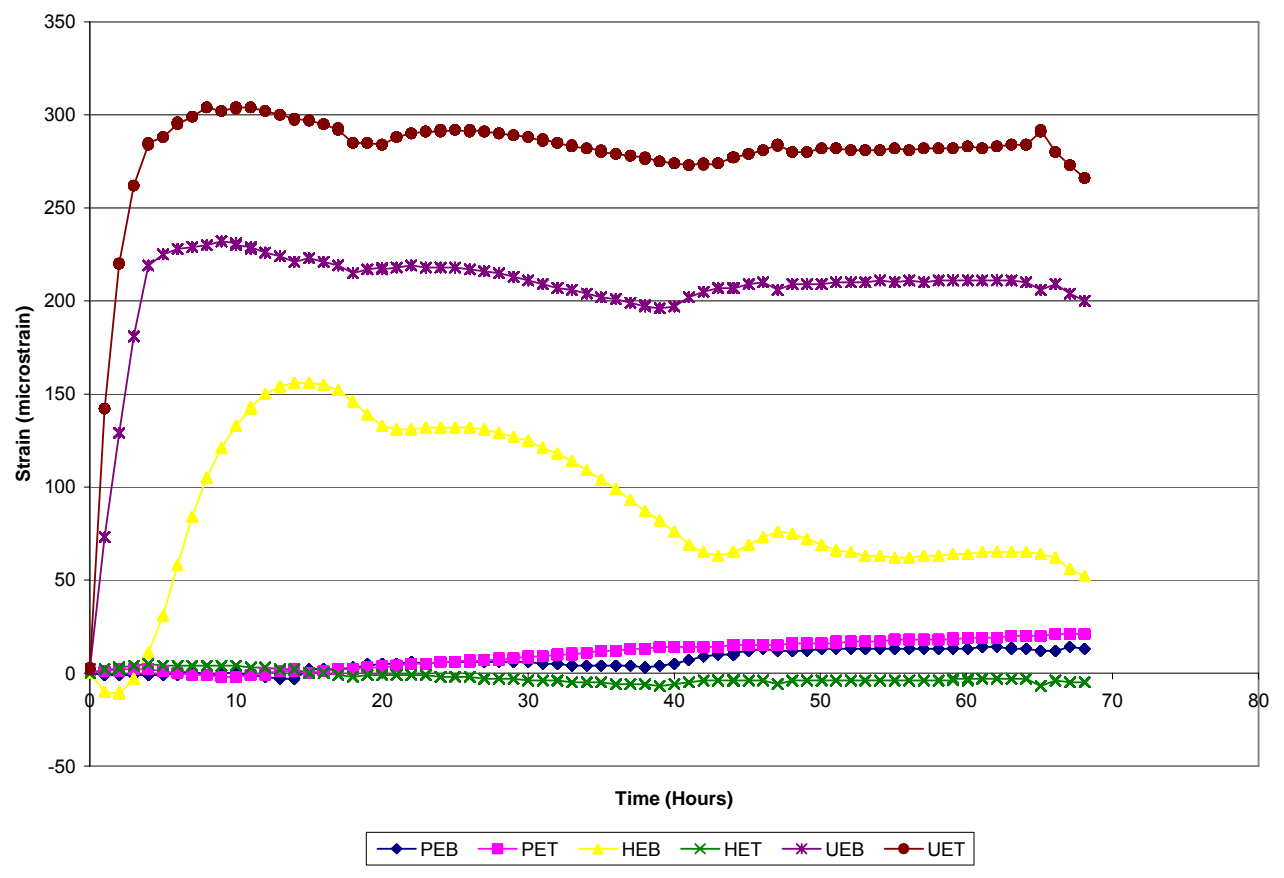

(a)

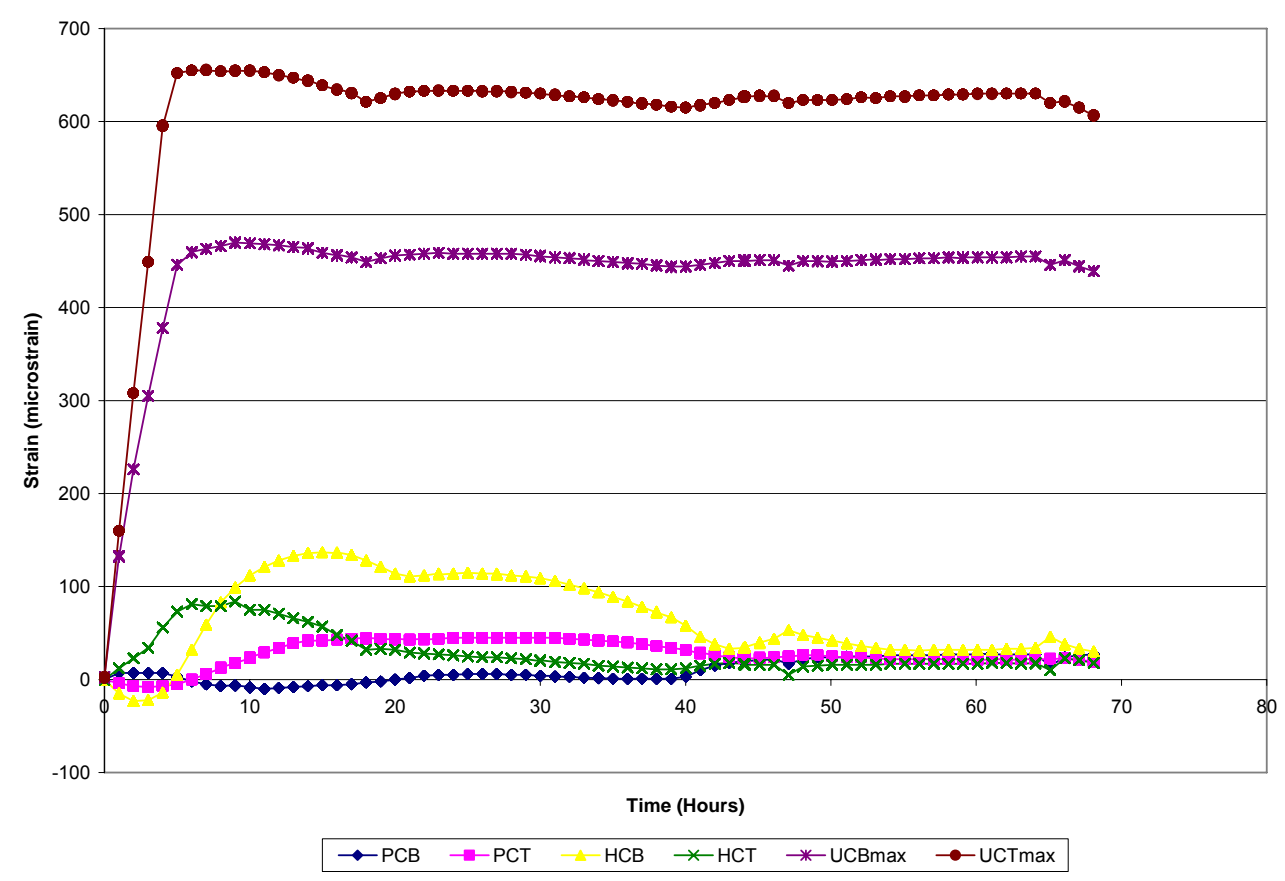

(b)

Figure B. 3 Curing Strains - Test Area 2 - Lane 2 (a) Edge (b) Corner 


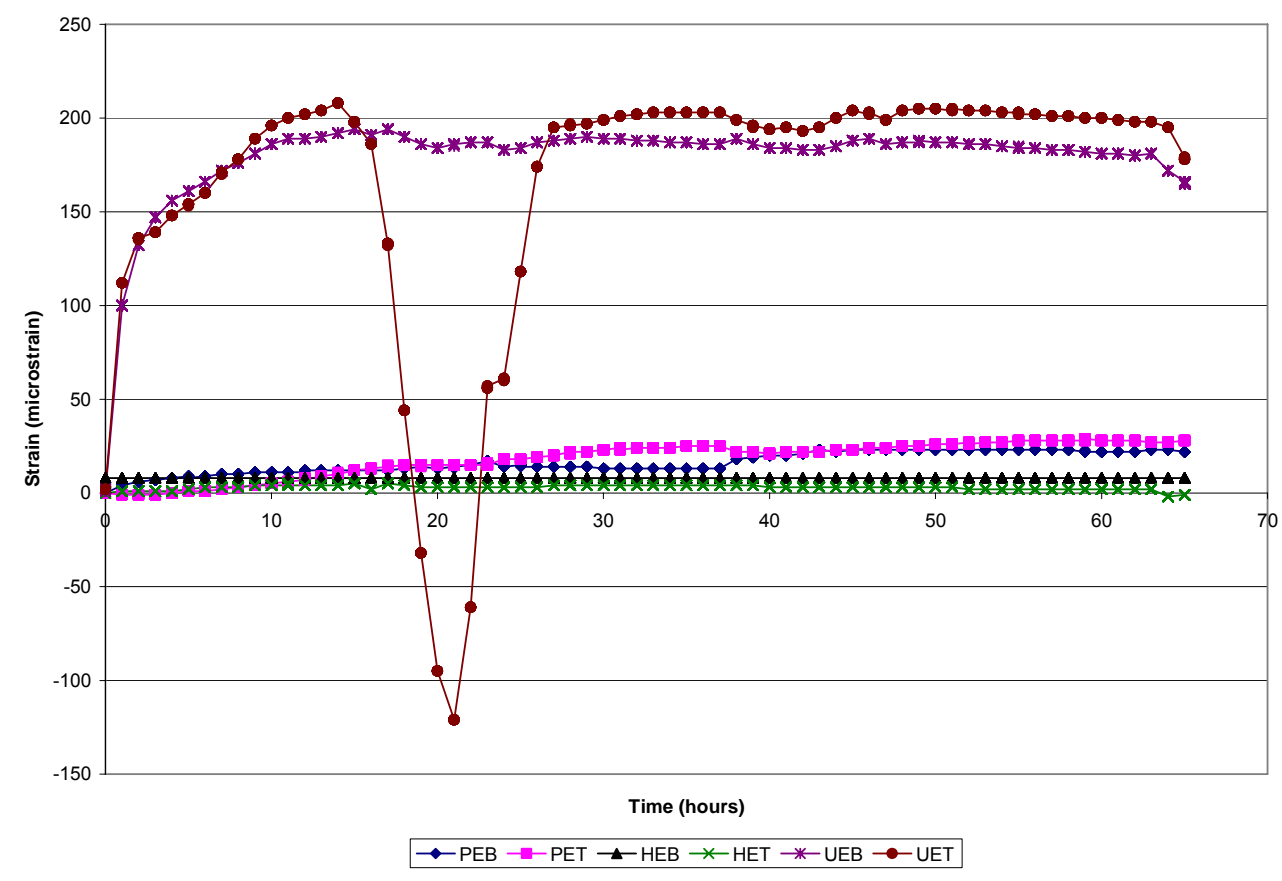

(a)

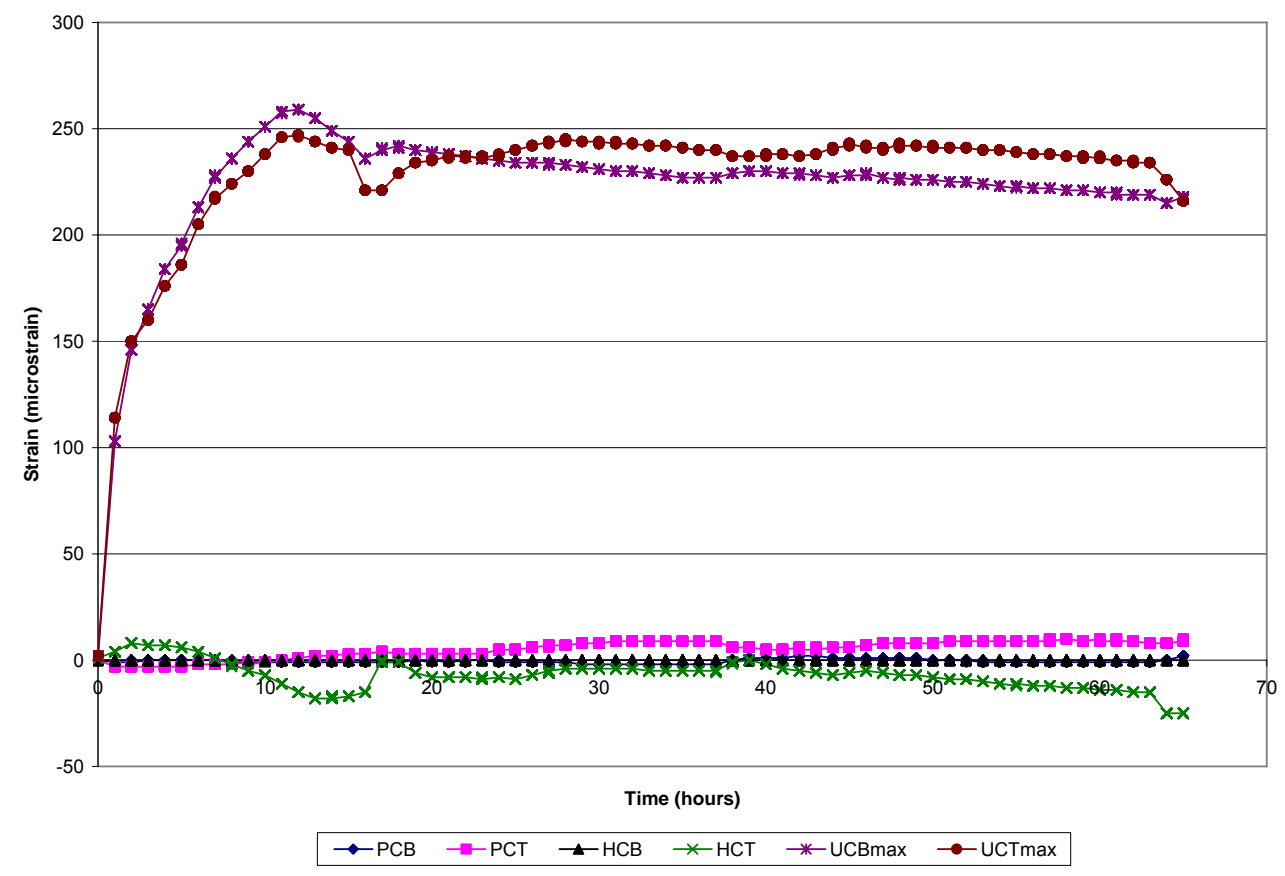

(b)

Figure B.4 Curing Strains - Test Area 2 - Lane 3 (a) Edge (b) Corner 


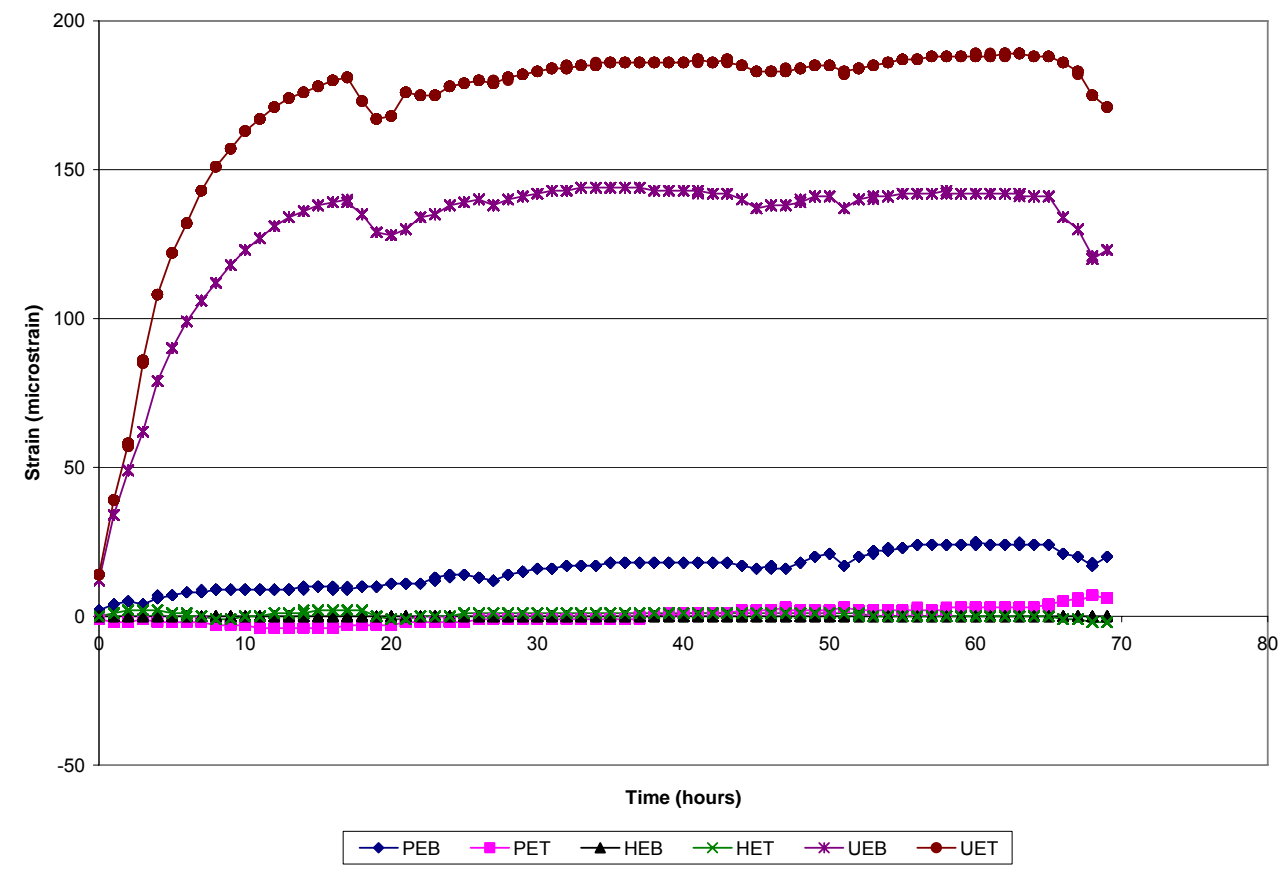

(a)

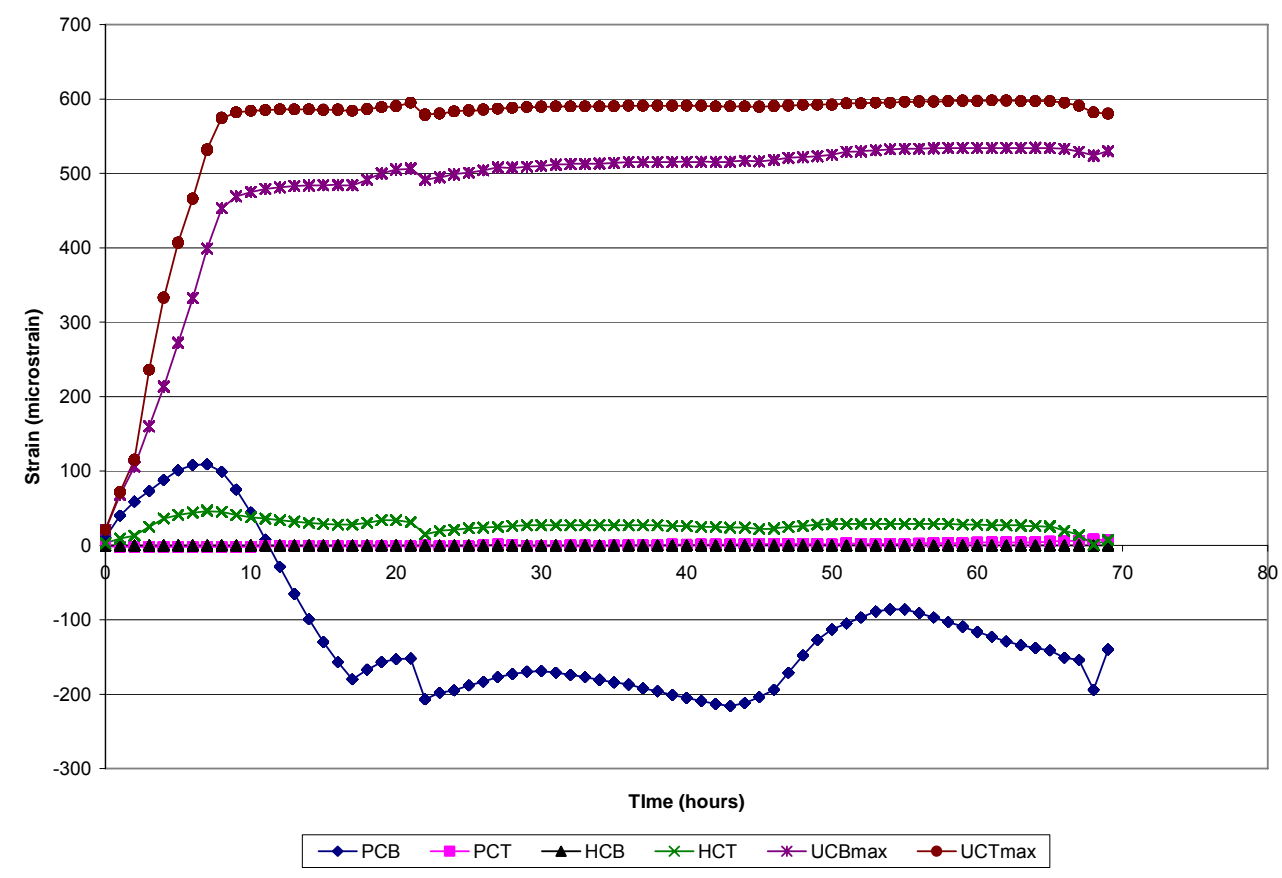

(b)

Figure B.5 Curing Strains - Test Area 2 - Lane 4 (a) Edge (b) Corner 


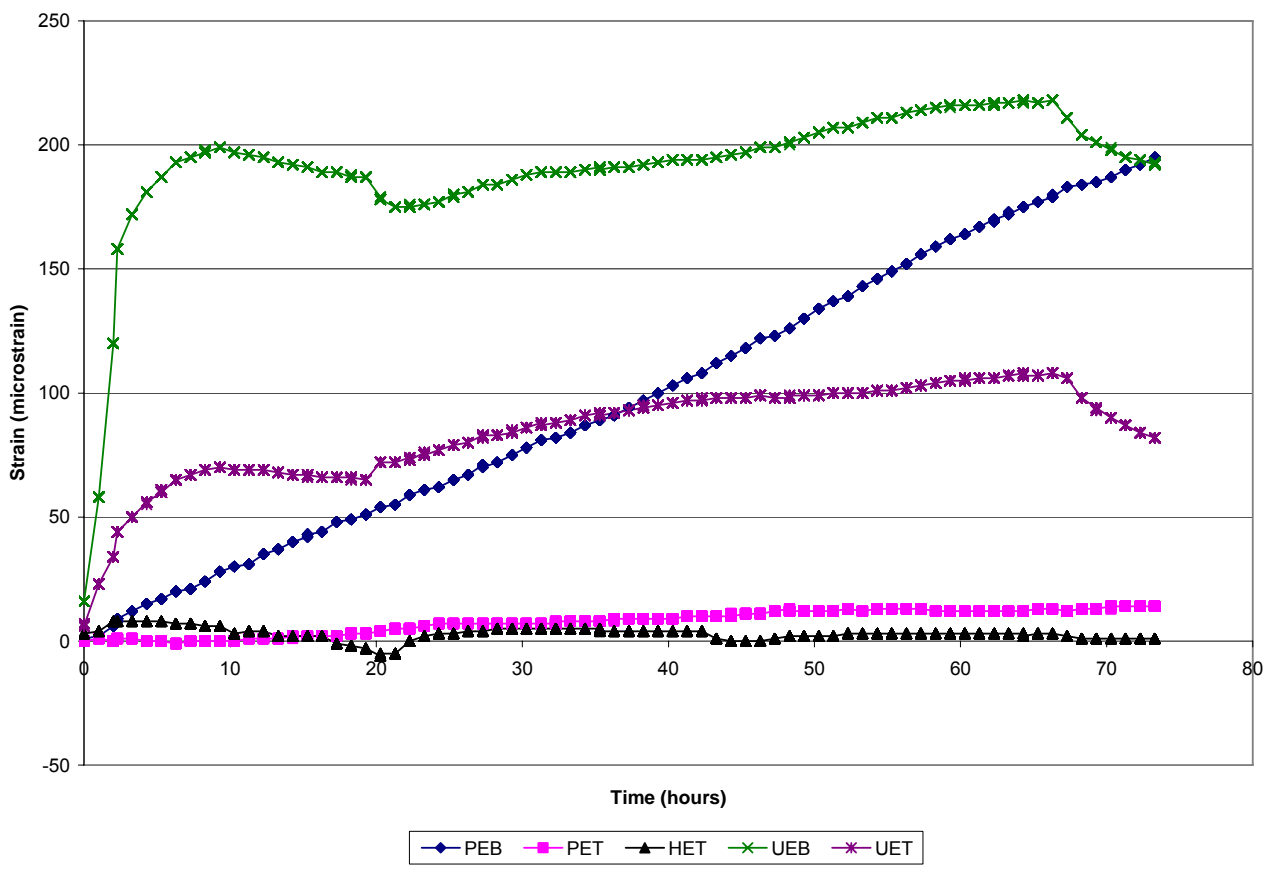

(a)

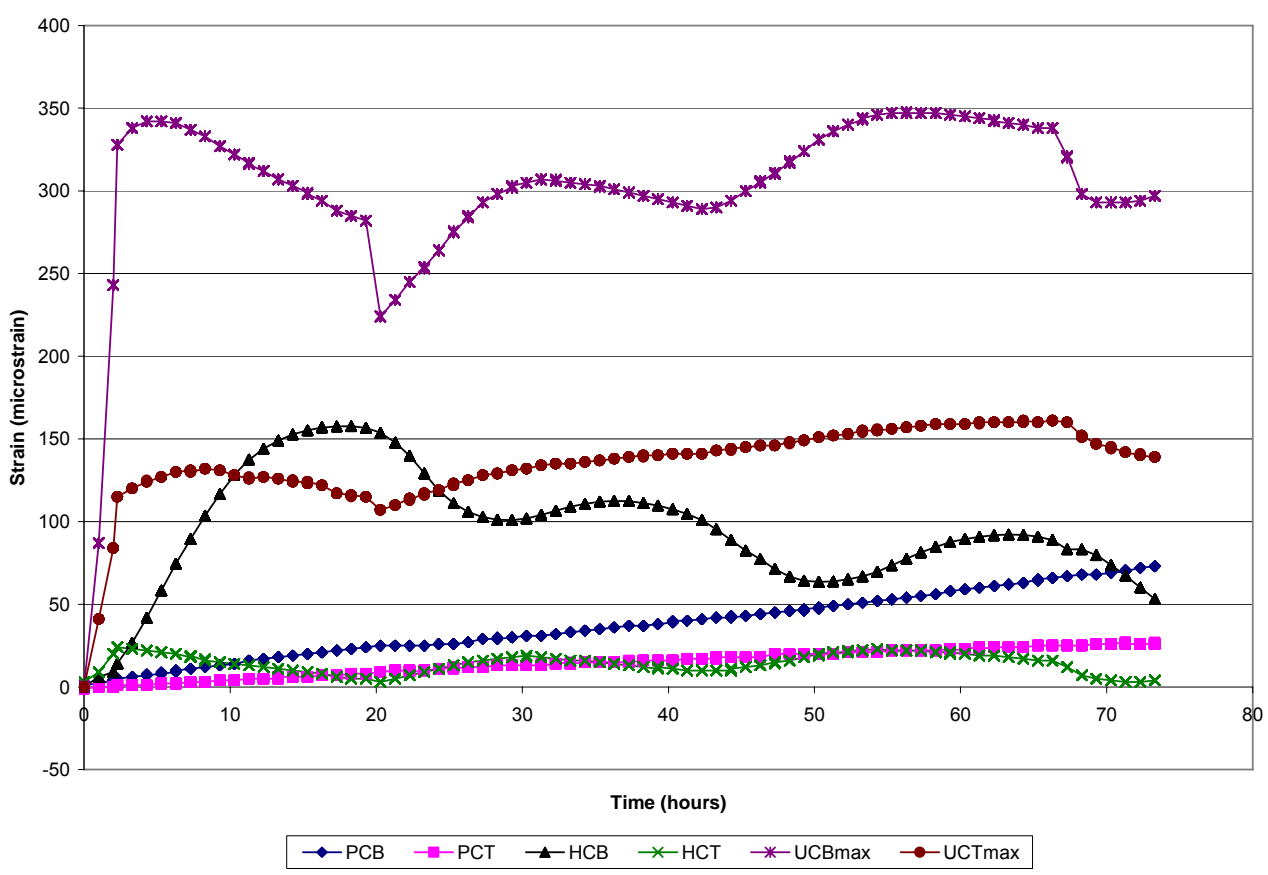

(b)

Figure B.6 Curing Strains - Test Area 2 - Lane 5 (a) Edge (b) Corner 


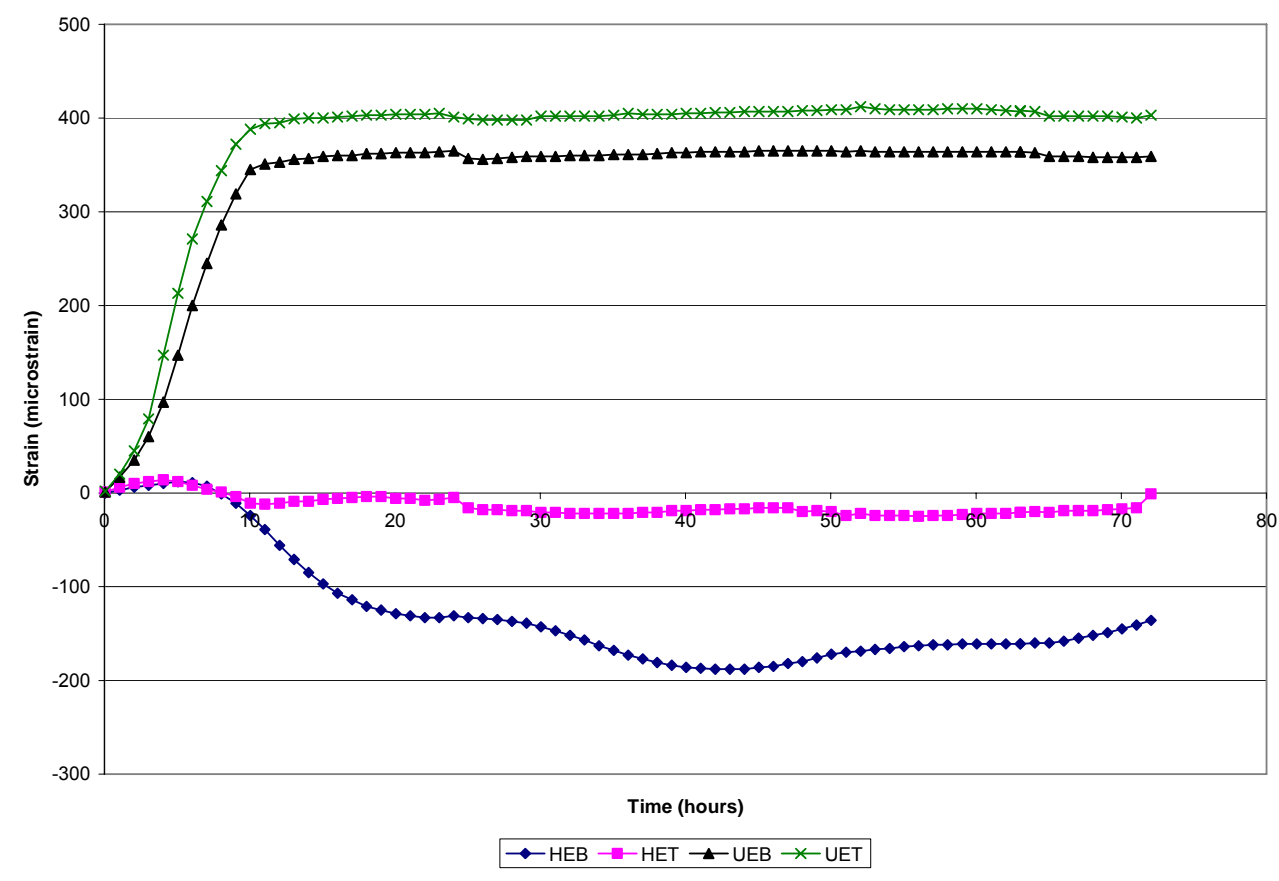

(a)

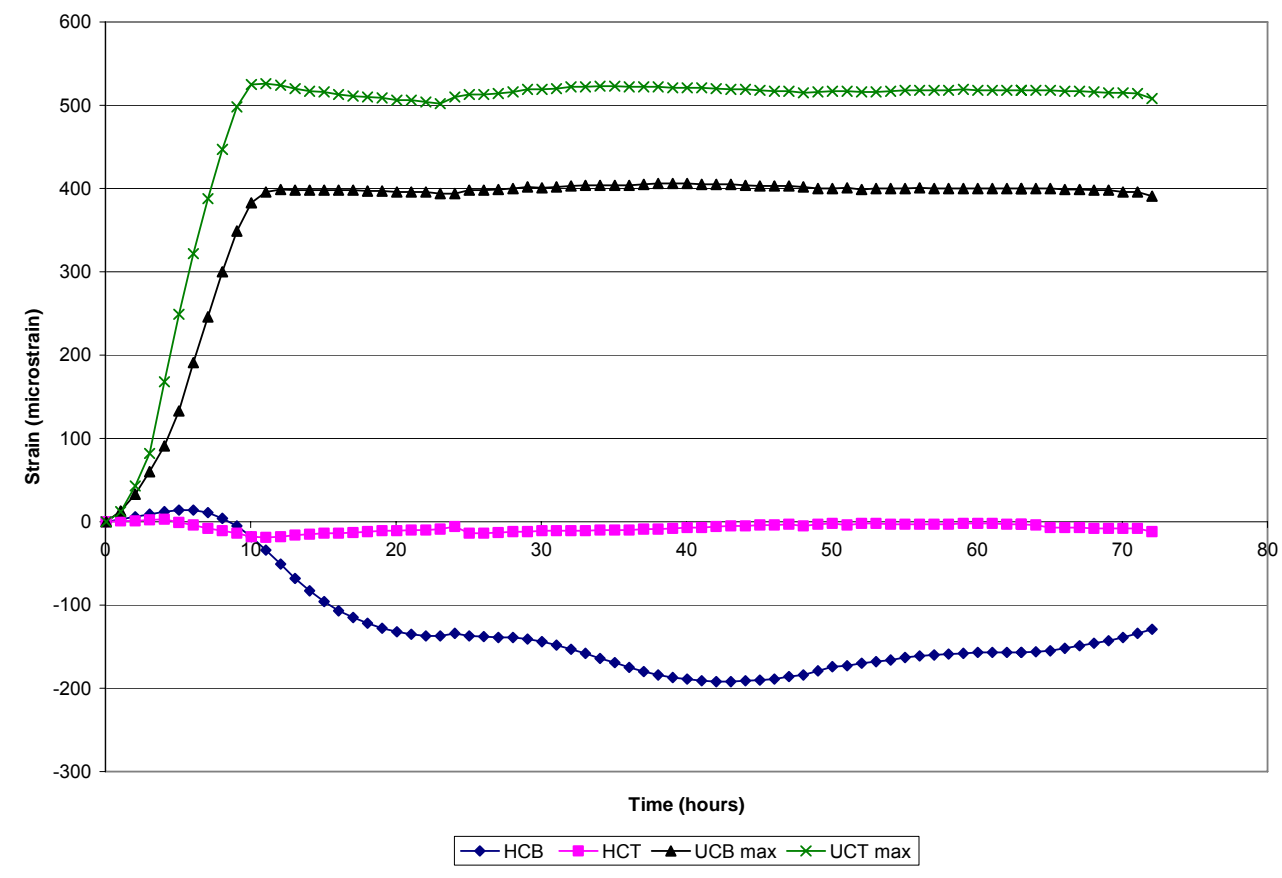

(b)

Figure B.7 Curing Strains - Test Area 3 - Lane 1 (a) Edge (b) Corner 


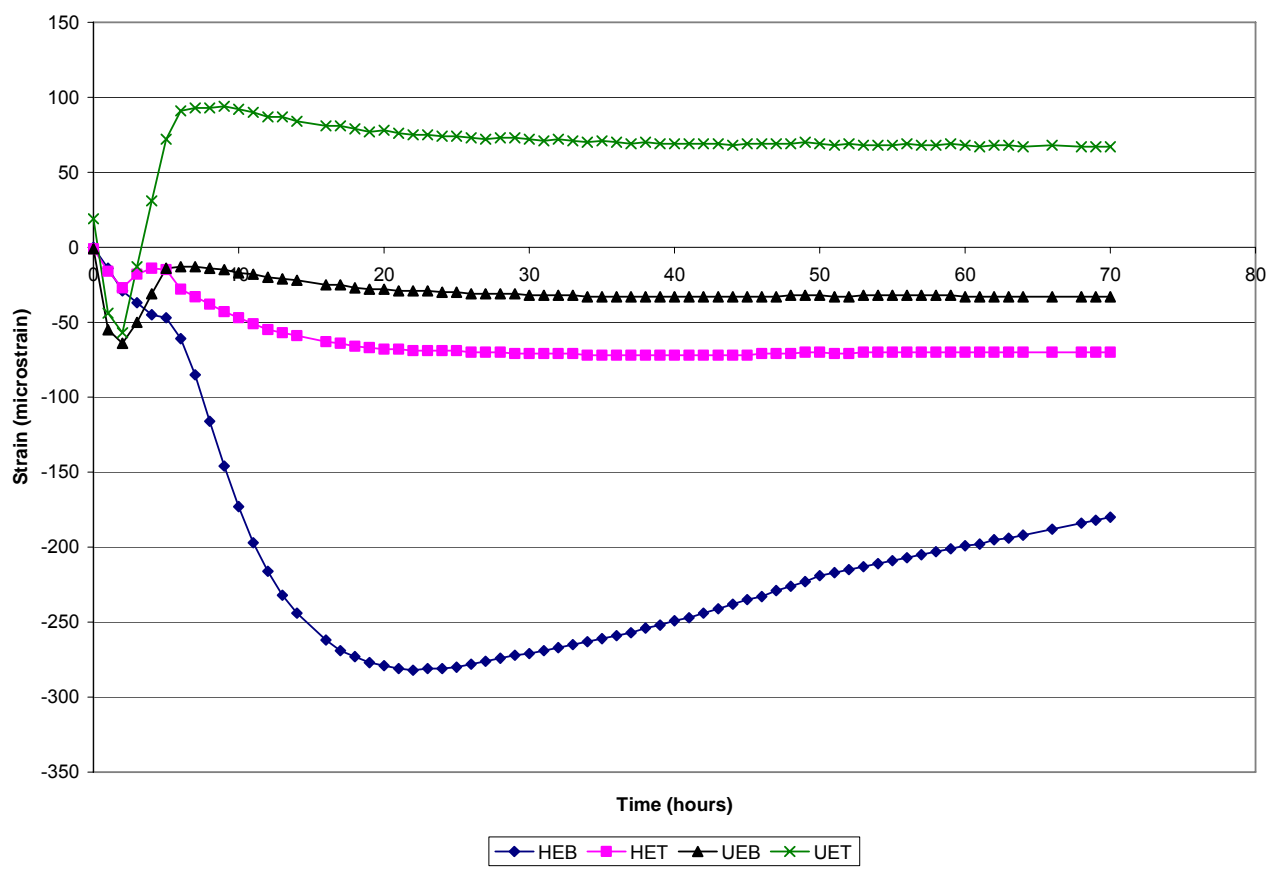

(a)

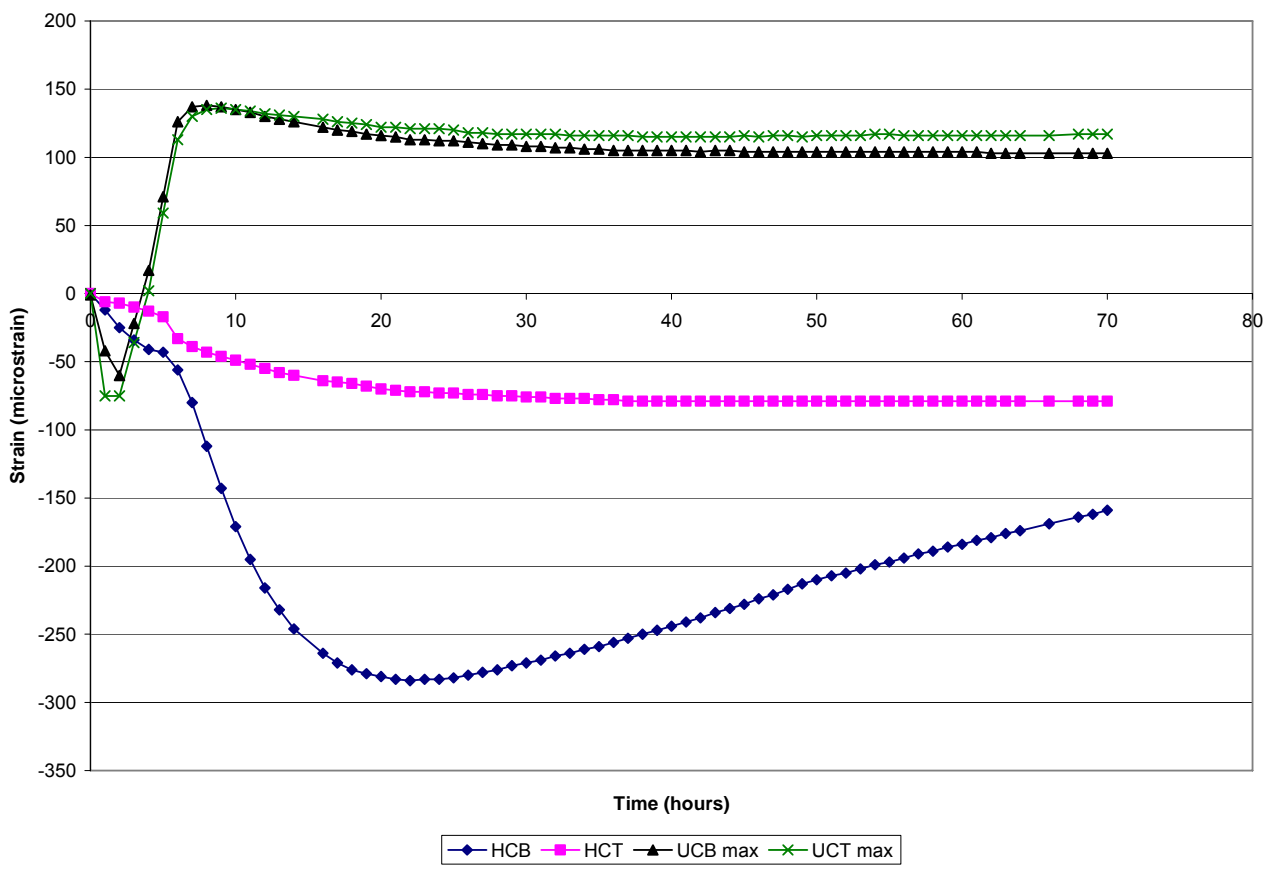

(b)

Figure B.8 Curing Strains - Test Area 3 - Lane 2 (a) Edge (b) Corner 


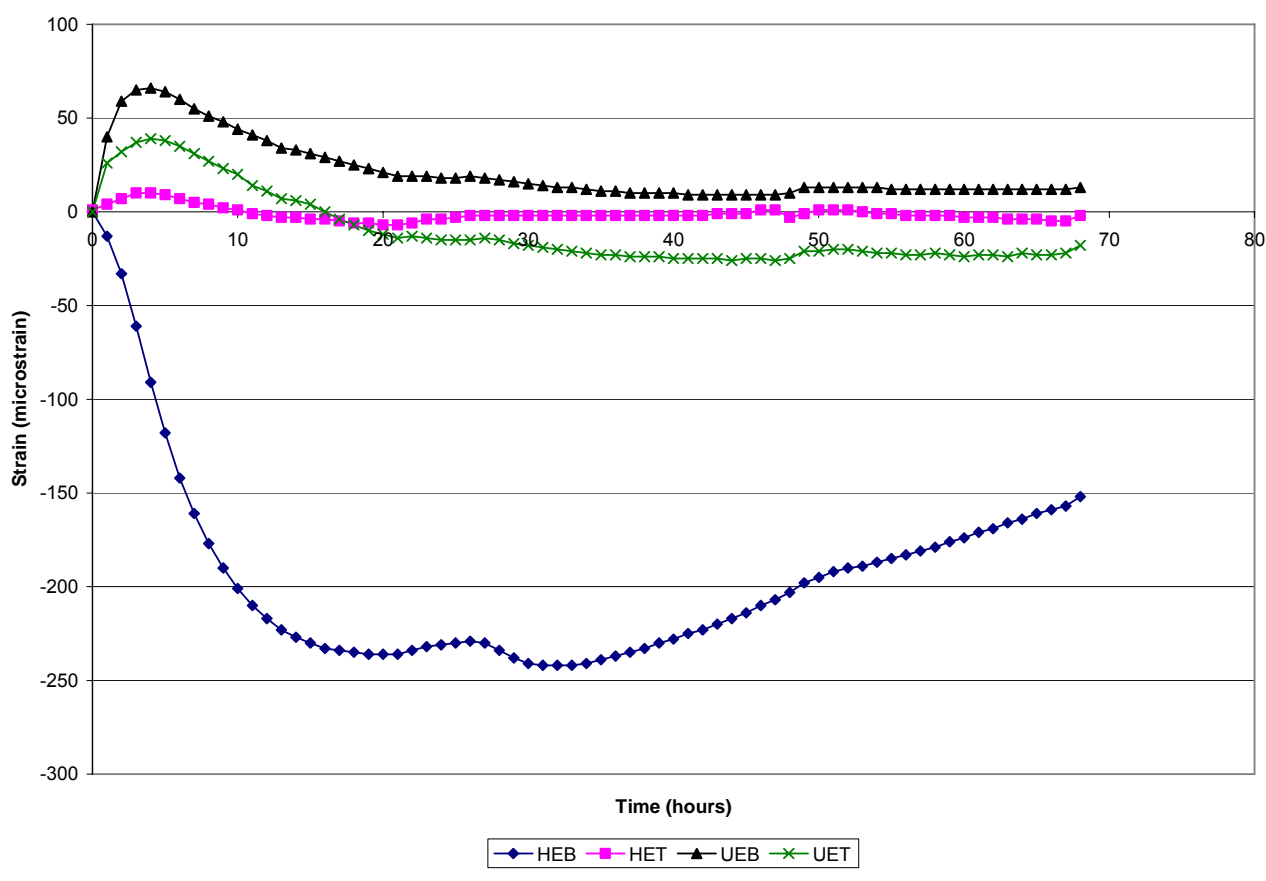

(a)

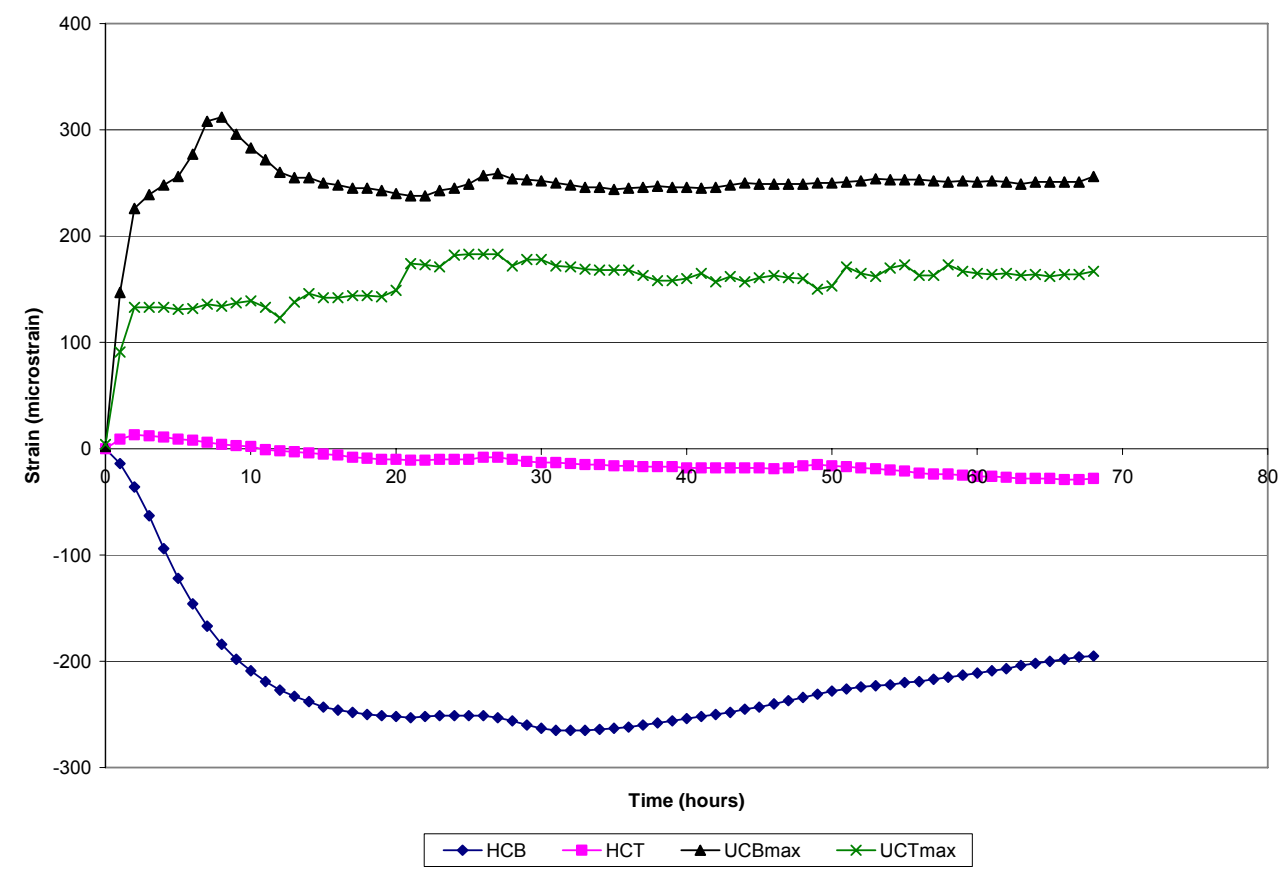

(b)

Figure B.9 Curing Strains - Test Area 3 - Lane 3 (a) Edge (b) Corner 


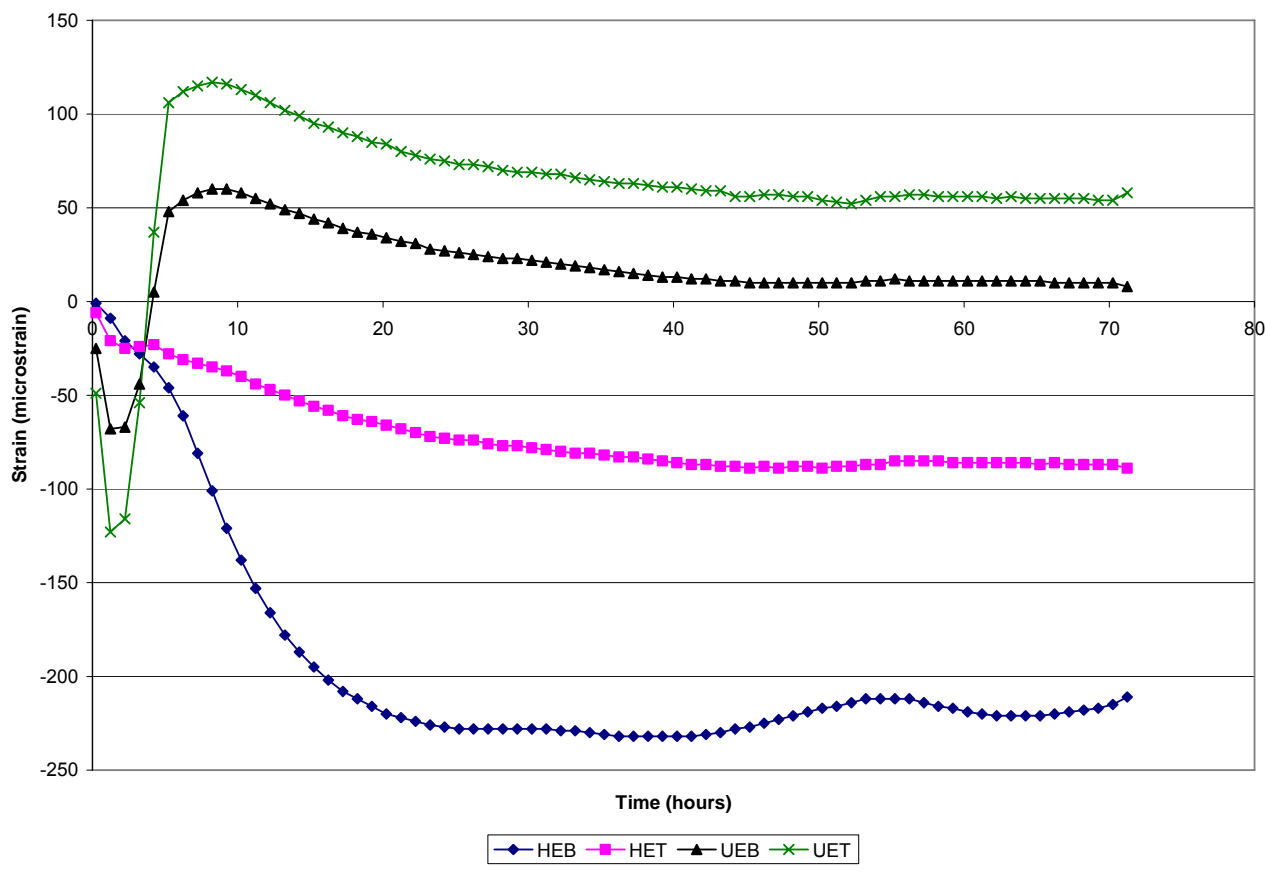

(a)

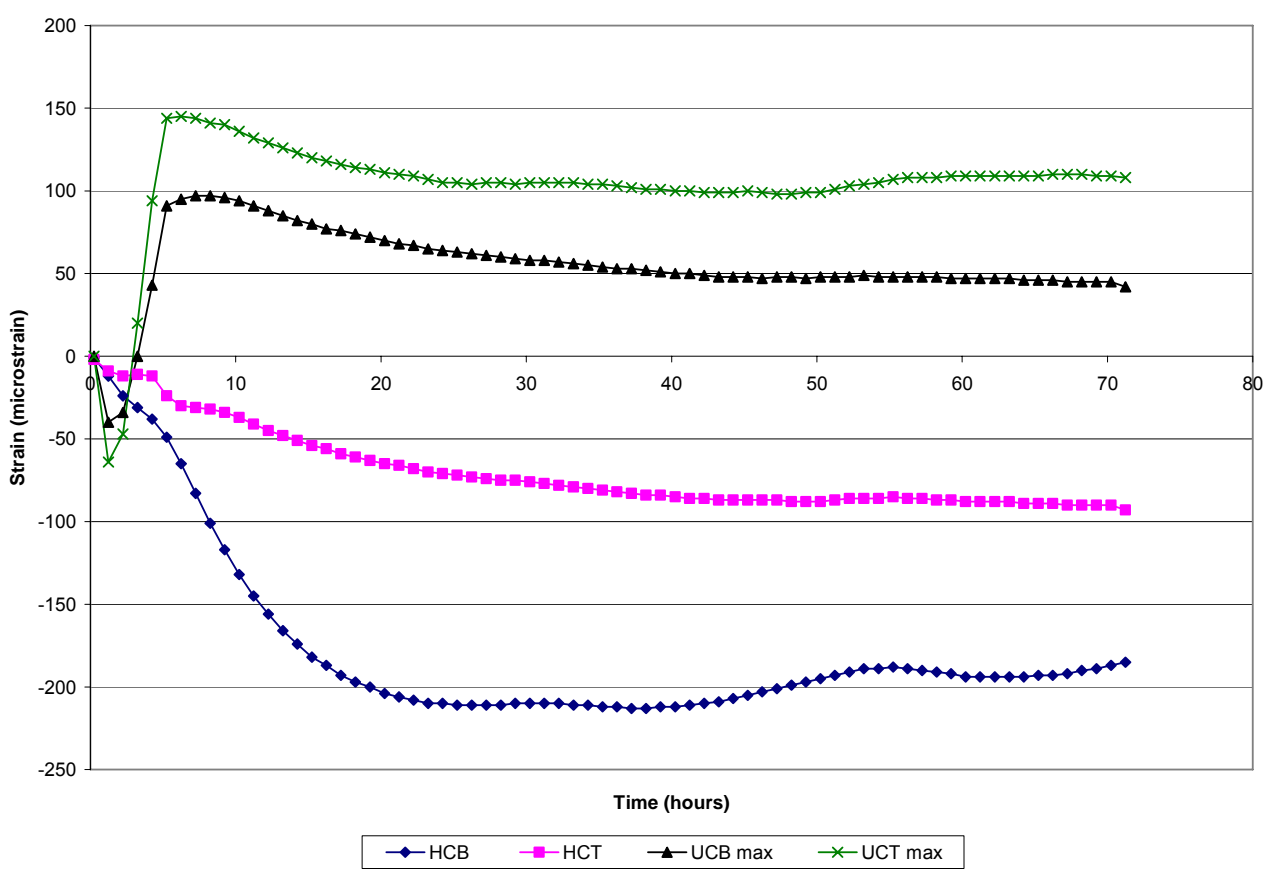

(b)

Figure B.10 Curing Strains - Test Area 3 - Lane 4 (a) Edge (b) Corner 


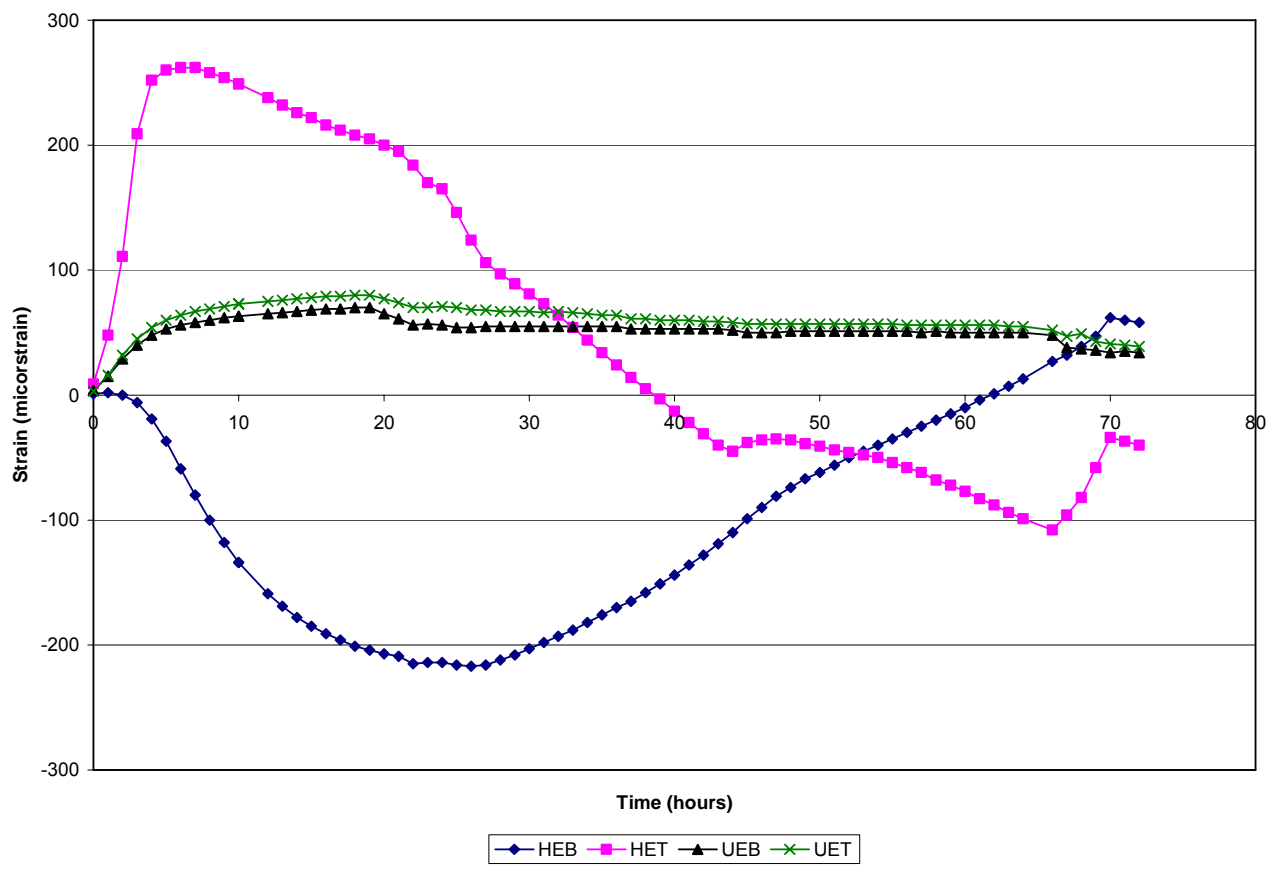

(a)

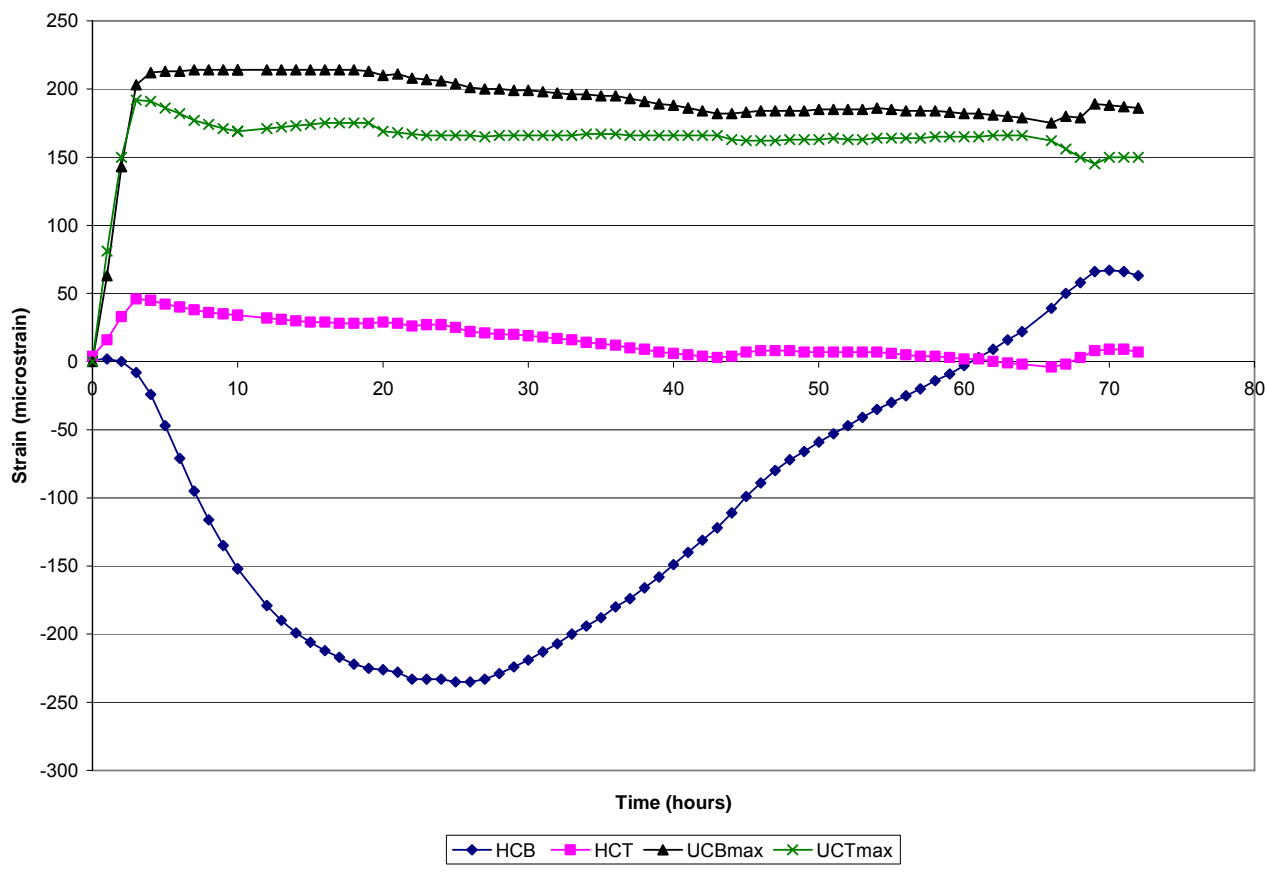

(b)

Figure B.11 Curing Strains - Test Area 3 - Lane 5 (a) Edge (b) Corner 


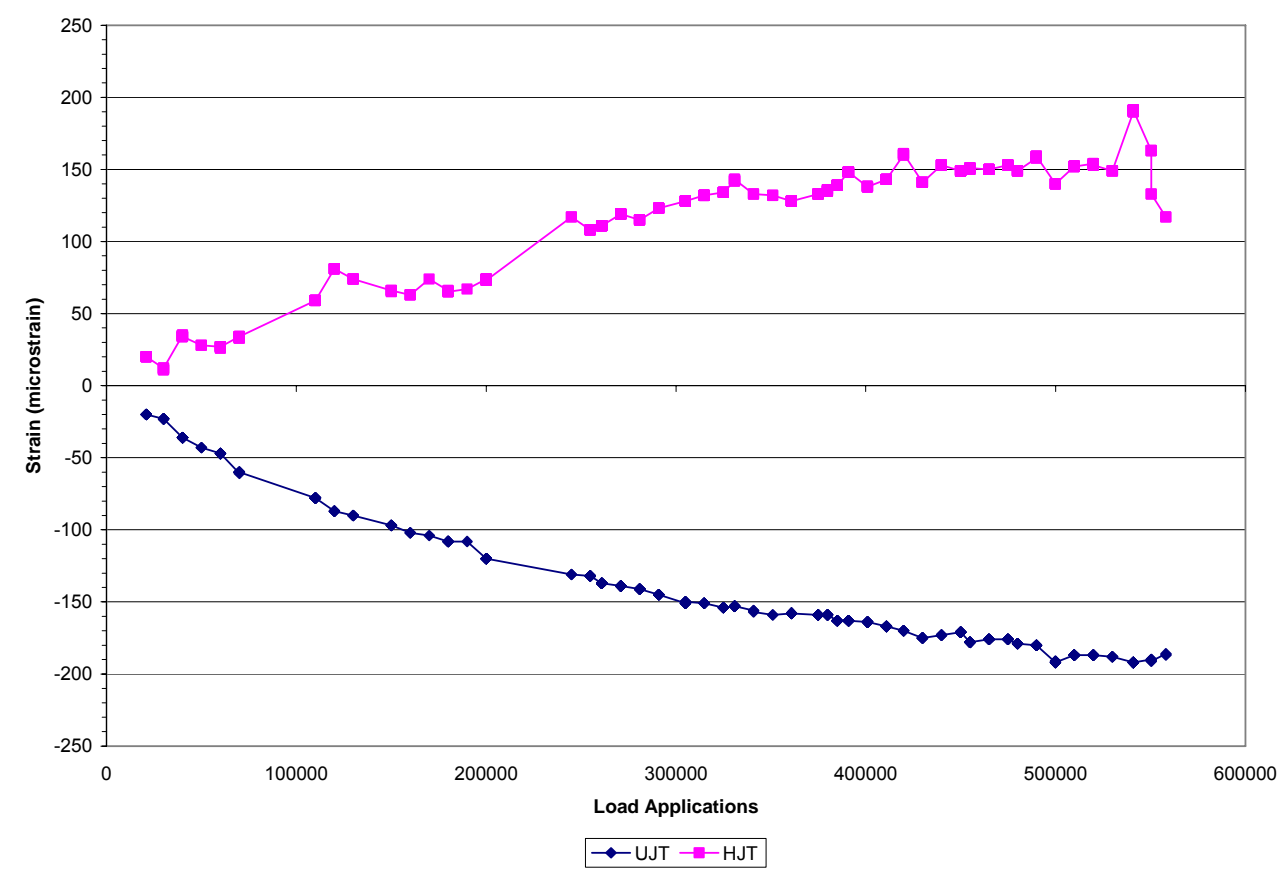

(a)

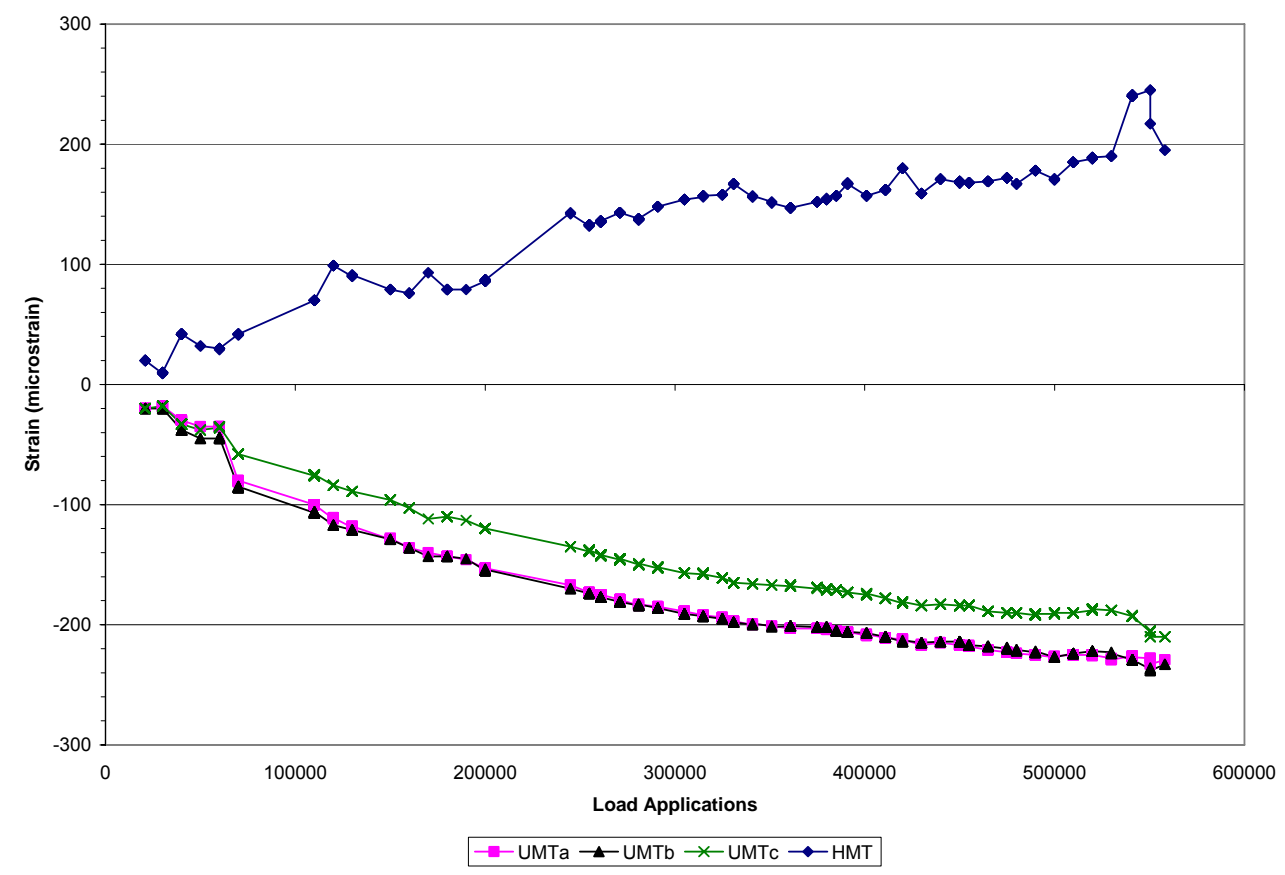

(b)

Figure B.12 Strain versus Load Applications - Test Area 1 - Unloaded (a) Joint (b) Mid-Panel (c) Edge (d) Corner (continued) 


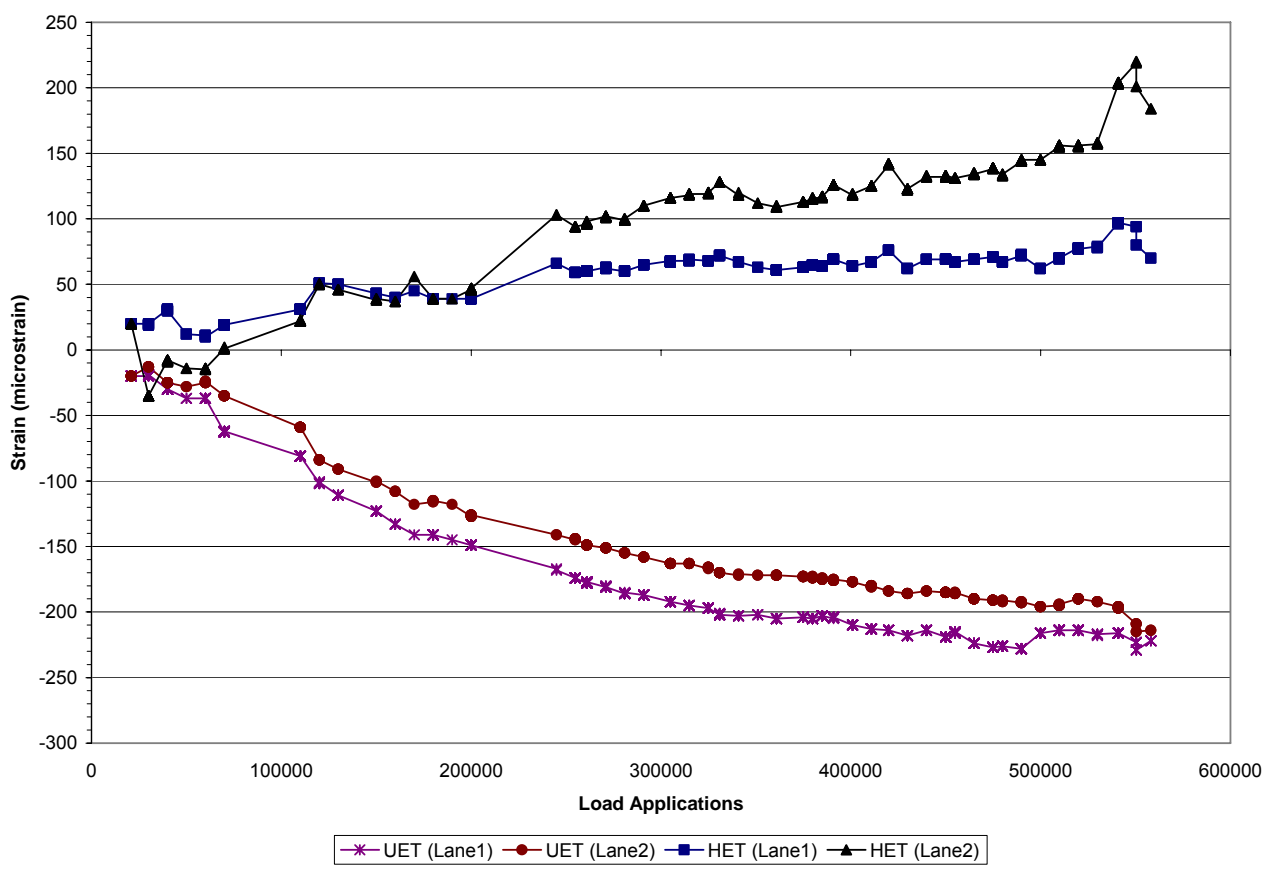

(c)

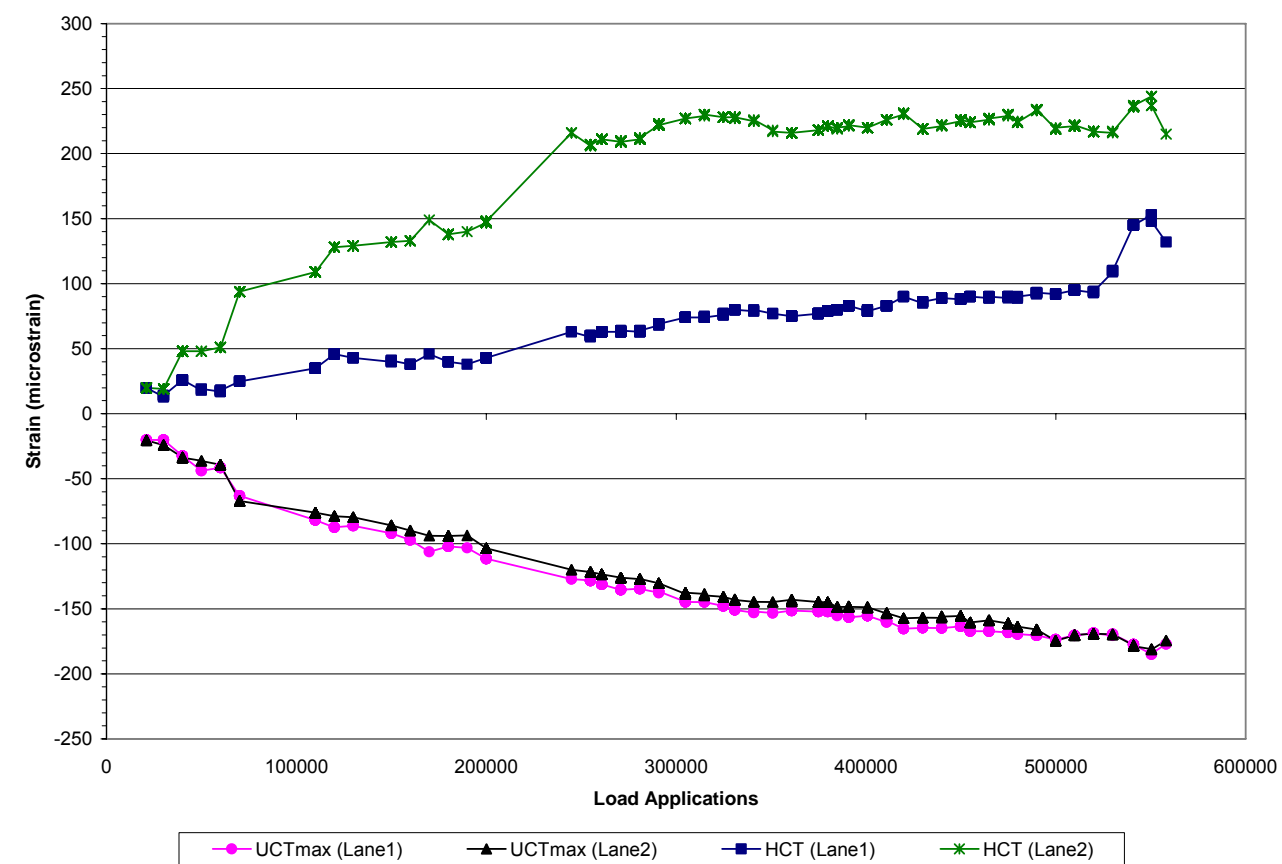

(d)

Figure B.12 Strain versus Load Applications - Test Area 1 - Unloaded (a) Joint (b) Mid-Panel (c) Edge (d) Corner 


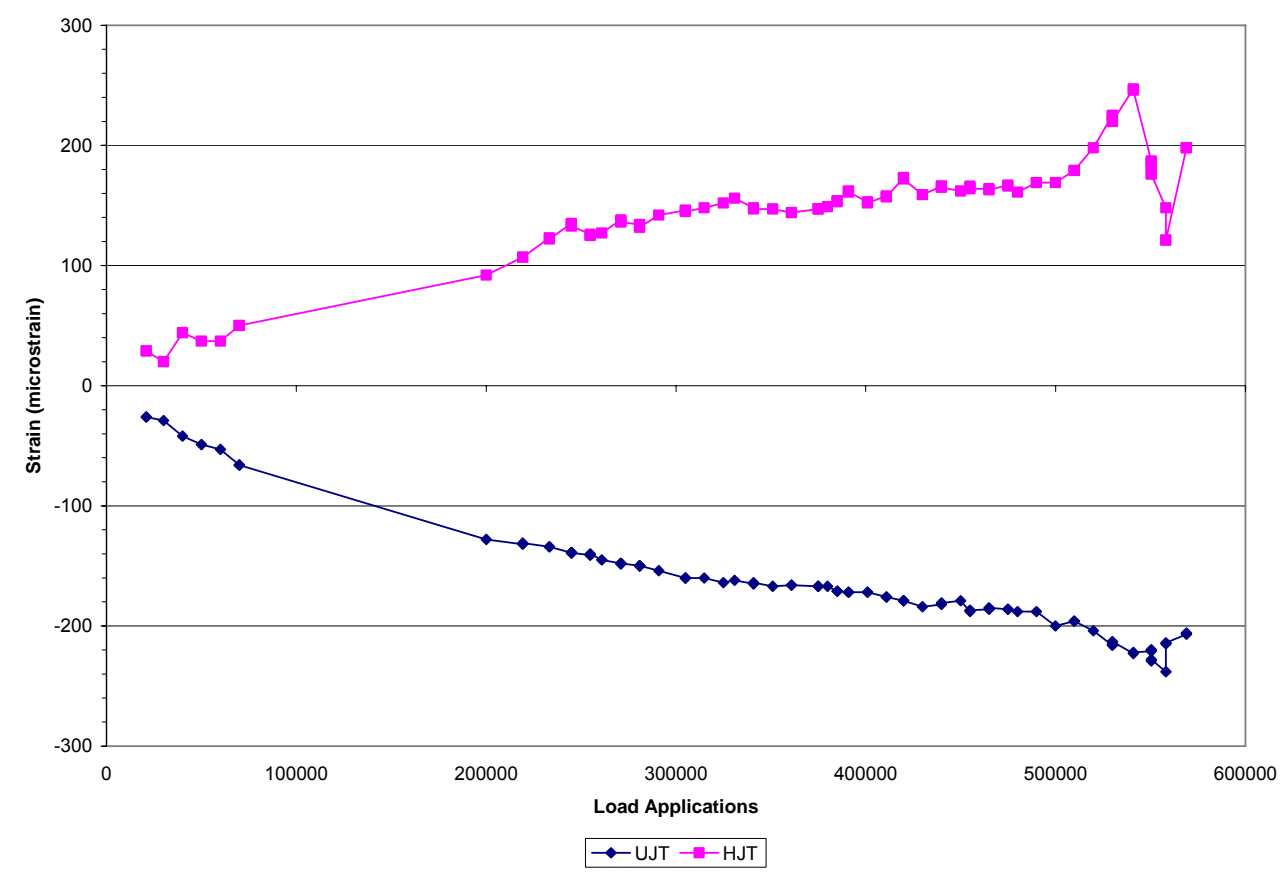

(a)

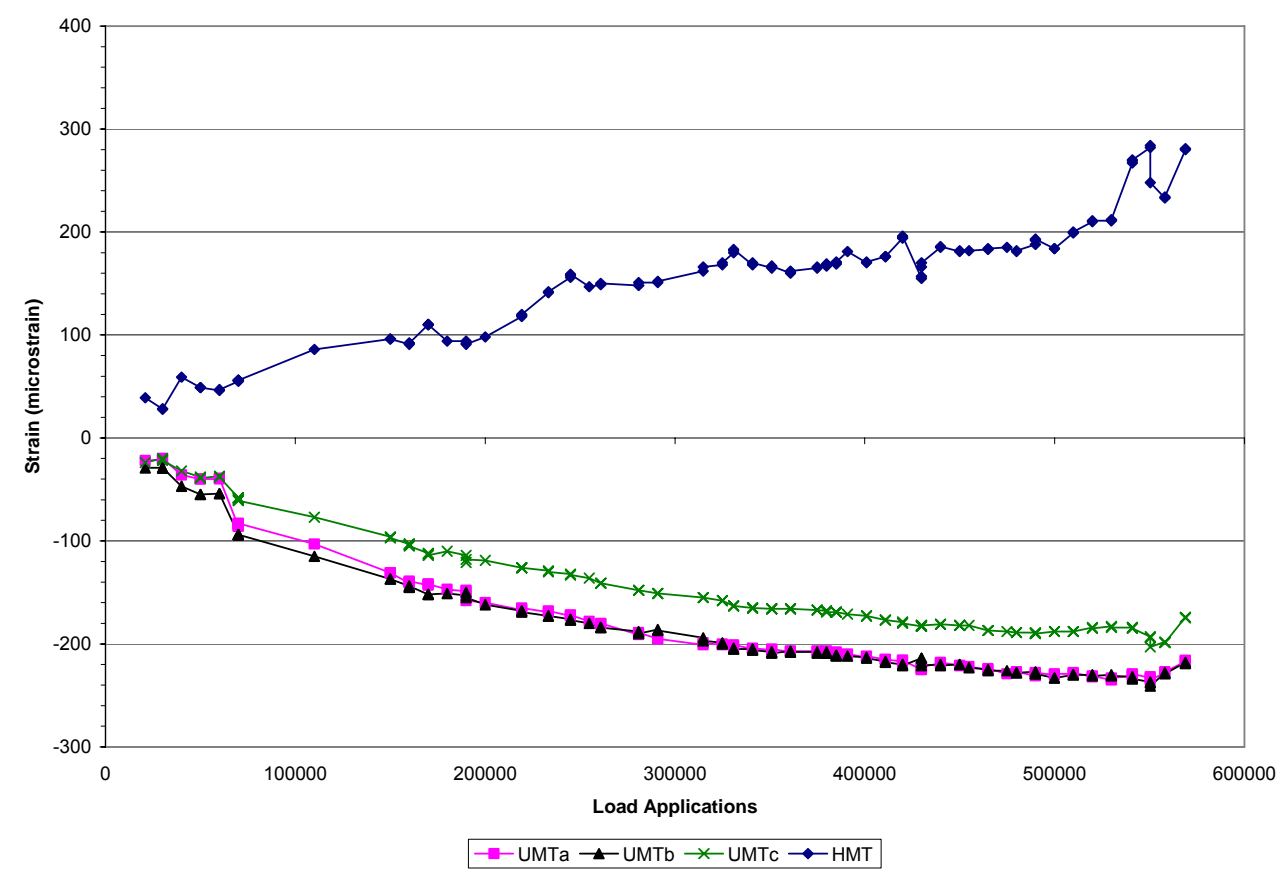

(b)

Figure B.13 Strain versus Load Applications - Test Area 1 - Loaded (a) Joint (b) Mid-Panel (c) Edge (d) Corner (continued) 


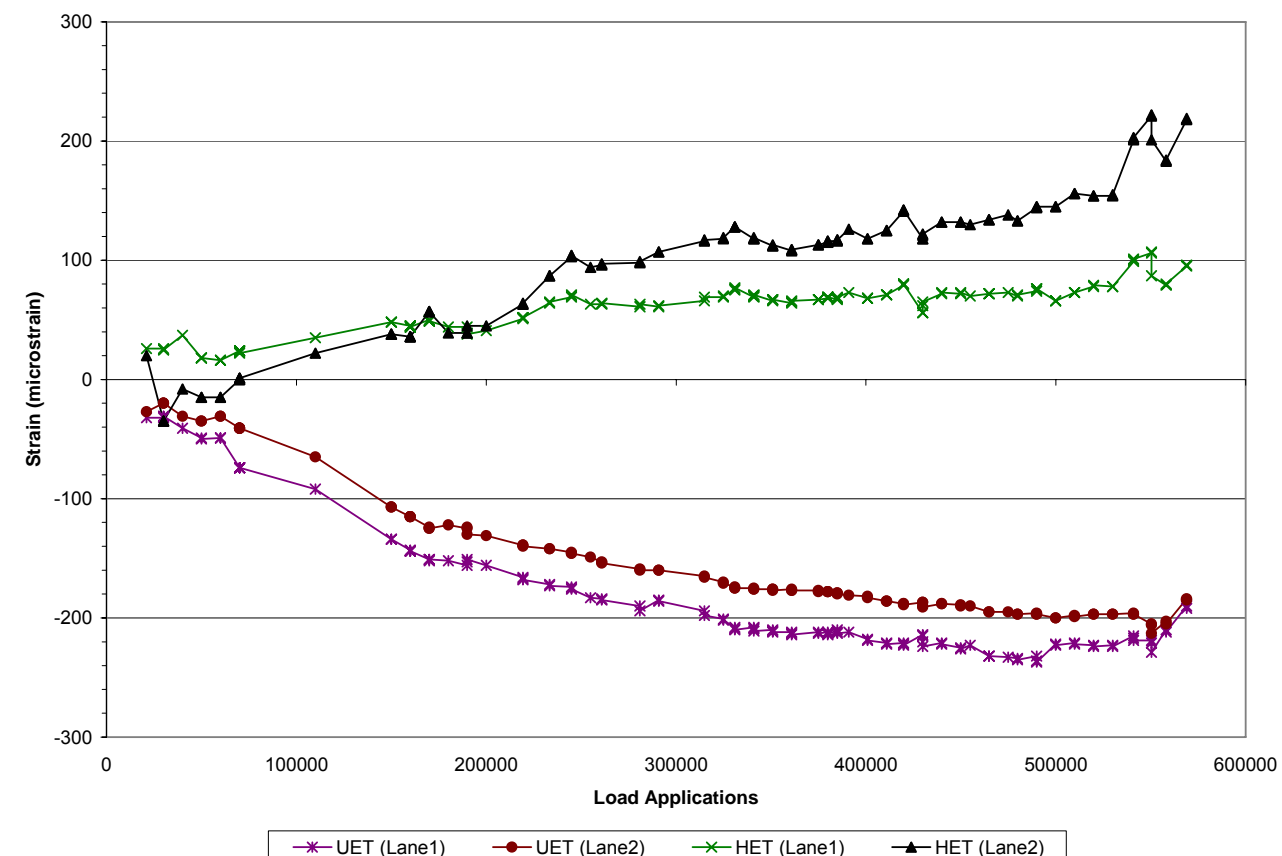

(c)

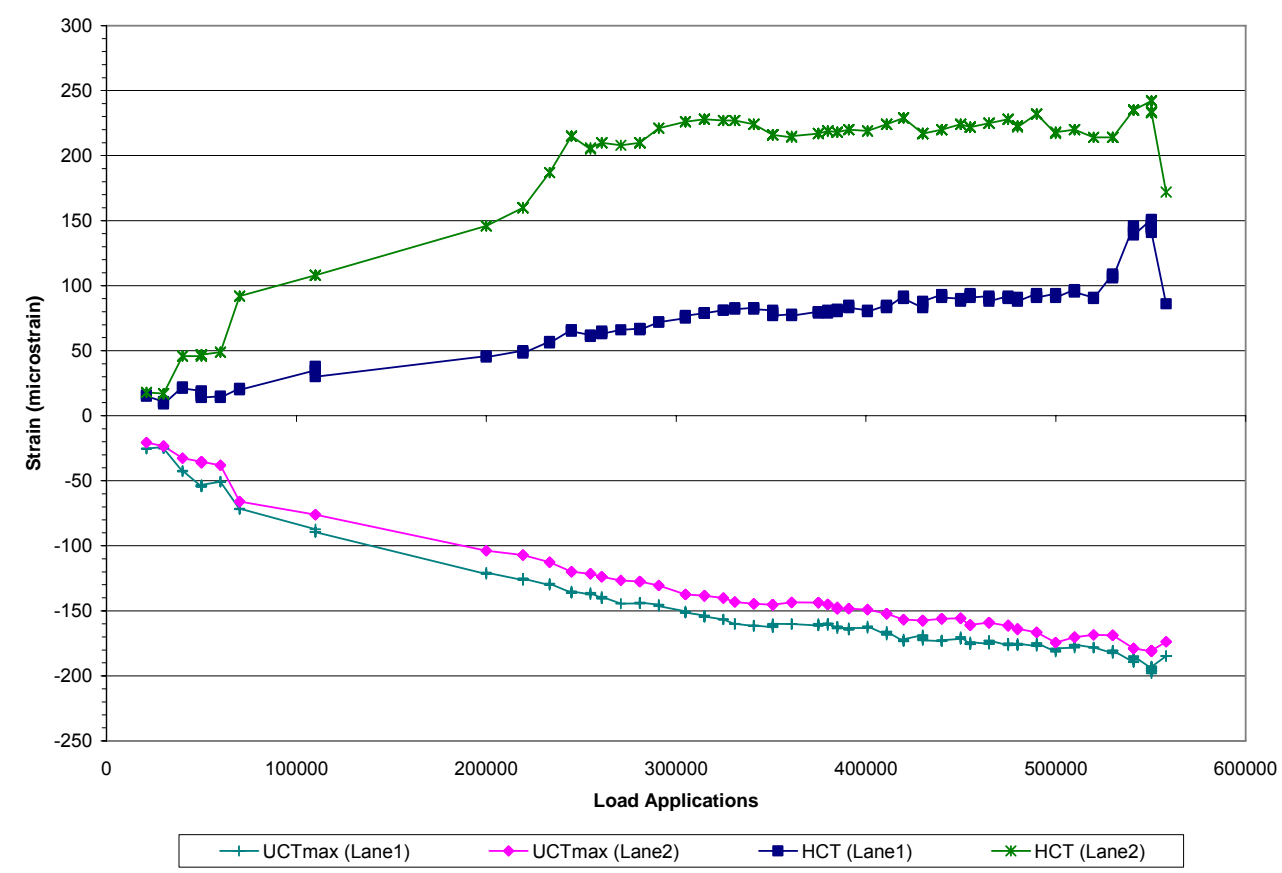

(d)

Figure B.13 Strain versus Load Applications - Test Area 1 - Loaded (a) Joint (b) Mid-Panel (c) Edge (d) Corner 


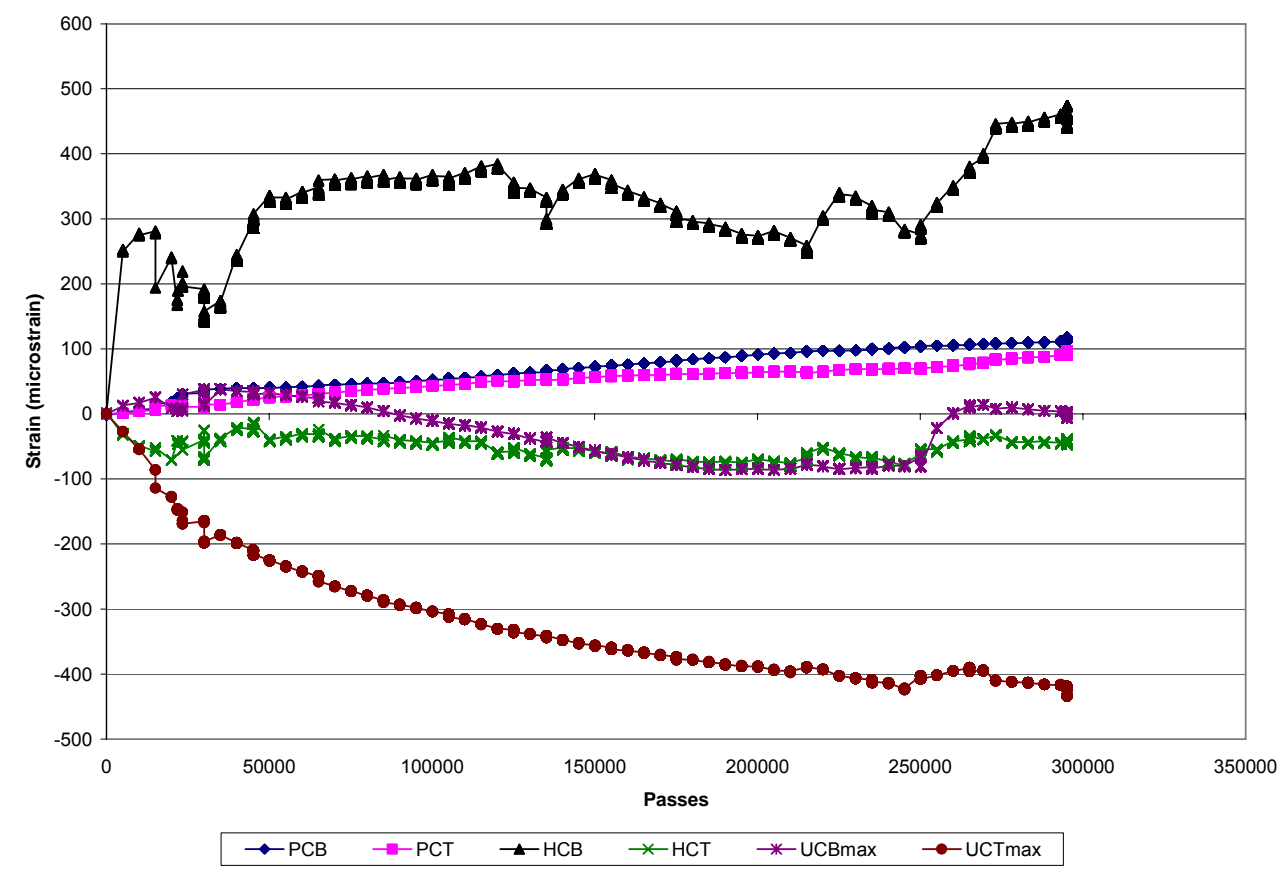

(a)

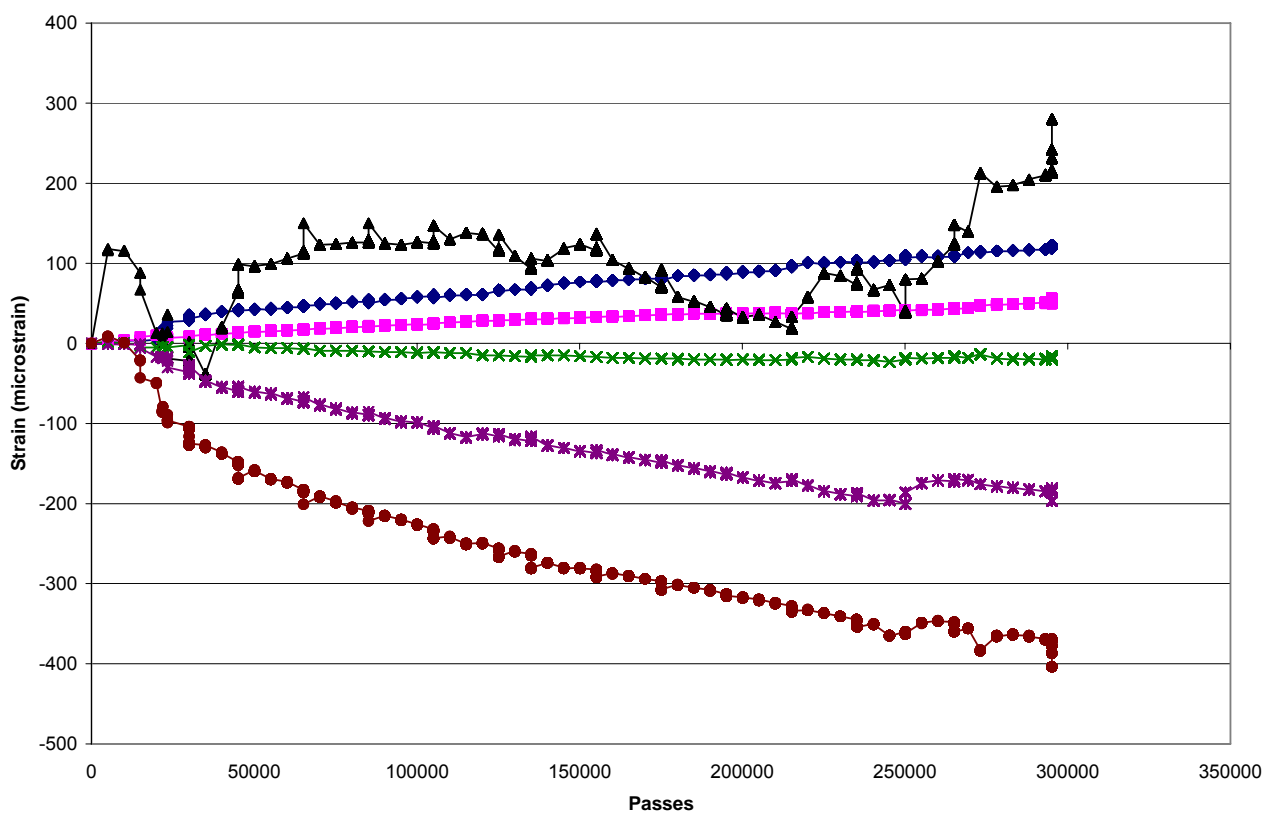

$\rightarrow-\mathrm{PEB} \rightarrow-\mathrm{PET} \rightarrow \mathrm{HEB} \rightarrow \mathrm{HET} \rightarrow$ UEB $\rightarrow-\mathrm{UET}$

(b)

Figure B.14 Strain versus Load Applications - Test Area 2 - Lane 1 Unloaded (a)

Edge (b) Corner 


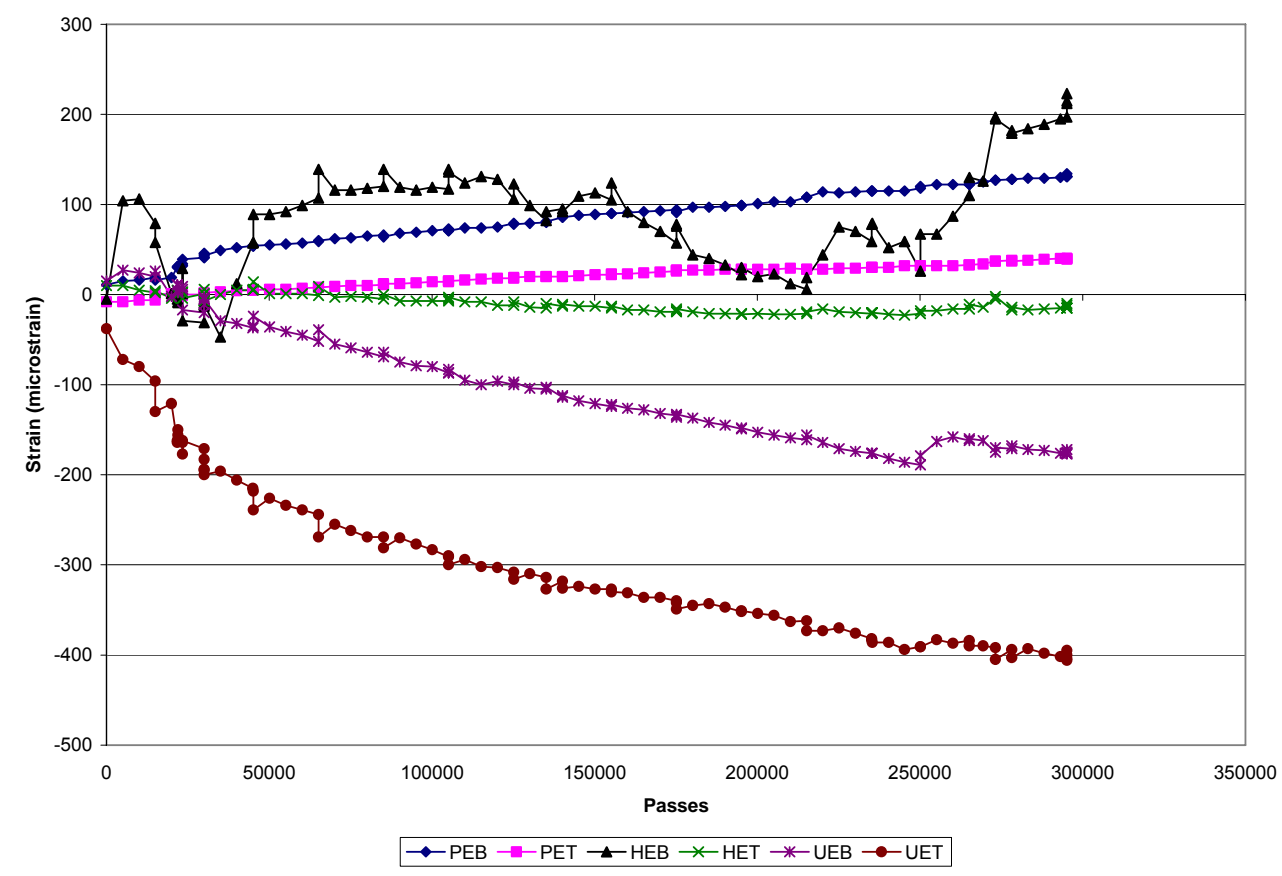

(a)

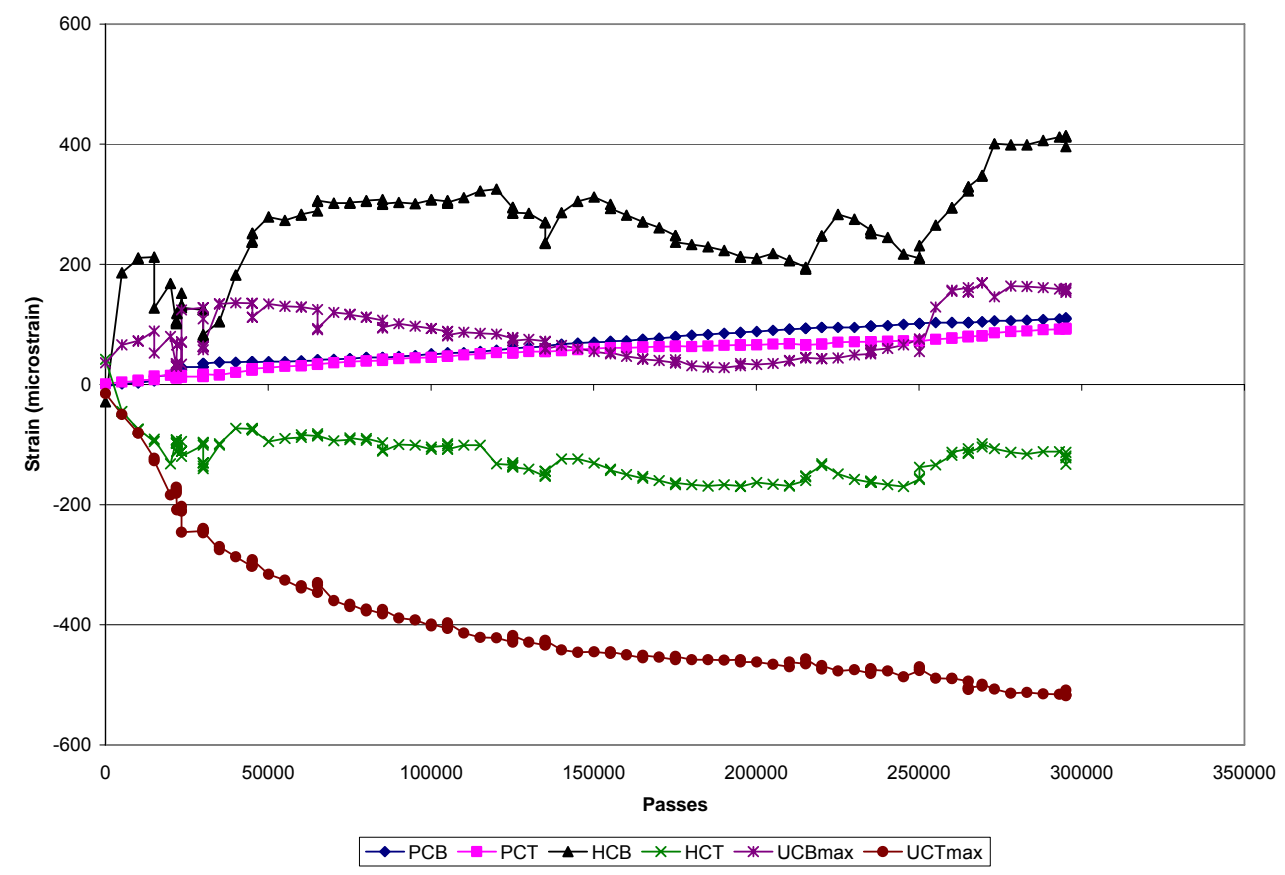

(b)

Figure B.15 Strain versus Load Applications - Test Area 2 - Lane 1 Loaded (a) Edge (b) Corner 


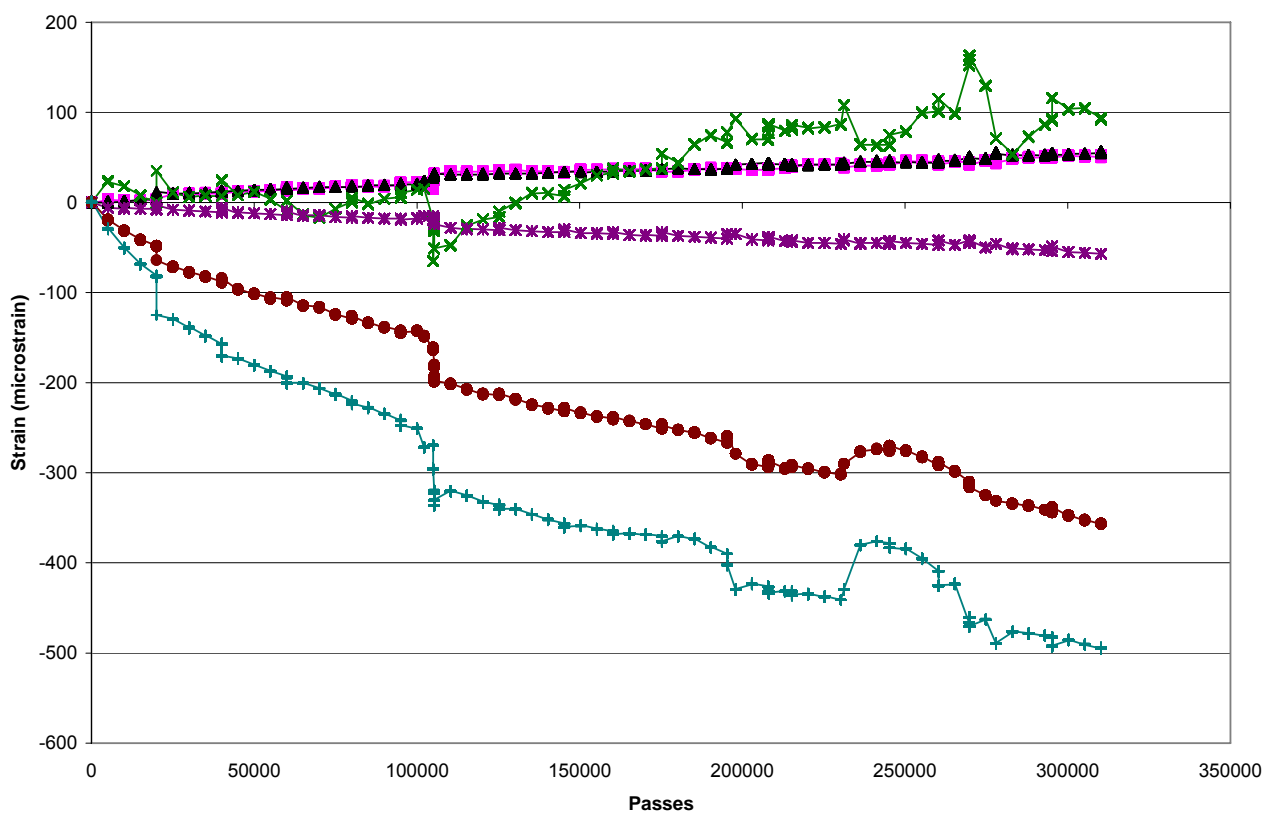

$\rightarrow-\mathrm{PEB} \rightarrow \mathrm{PET} \rightarrow \mathrm{HEB} \rightarrow \mathrm{HET} \rightarrow \mathrm{UEB} \leftarrow \mathrm{UET}$

(a)

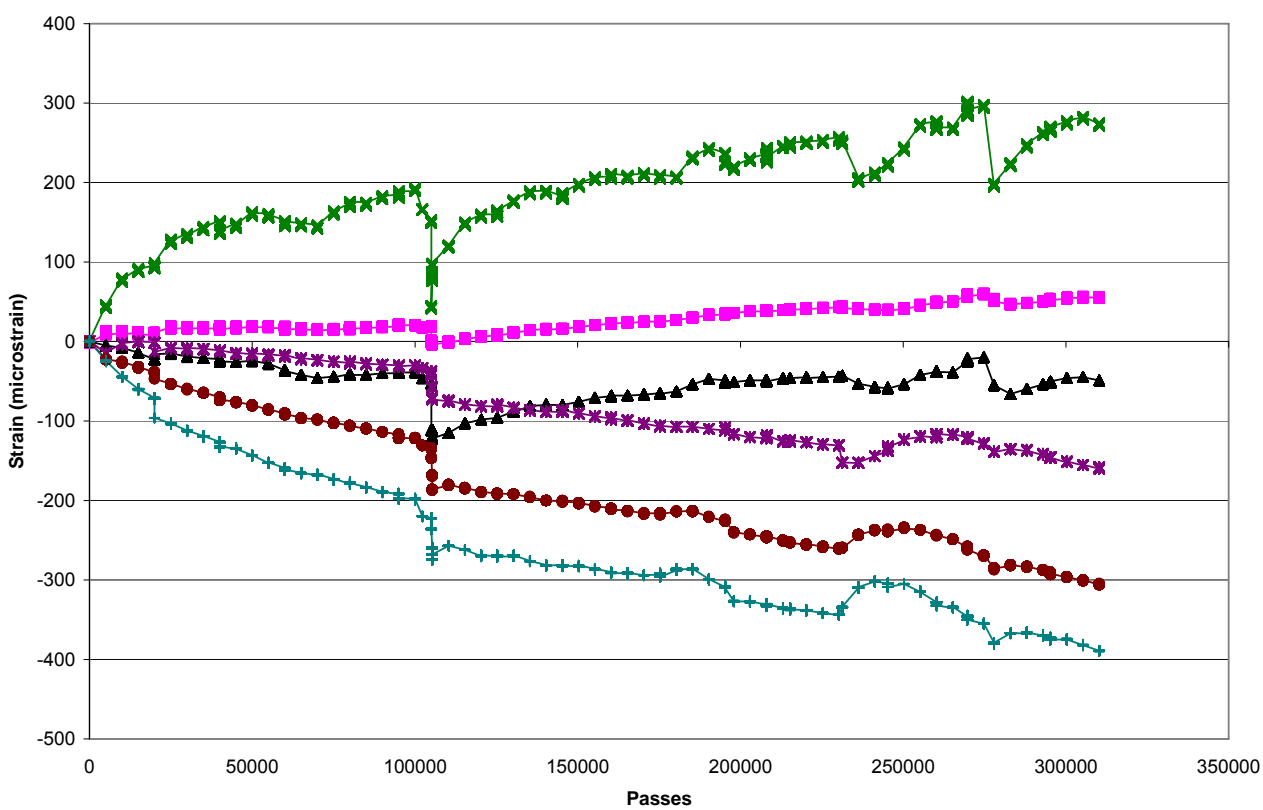

$\rightarrow-\mathrm{PCB} \rightarrow$ -

(b)

Figure B.16 (Viva il Papa) Strain versus Load Applications - Test Area 2 - Lane 2 Unloaded (a) Edge (b) Corner 


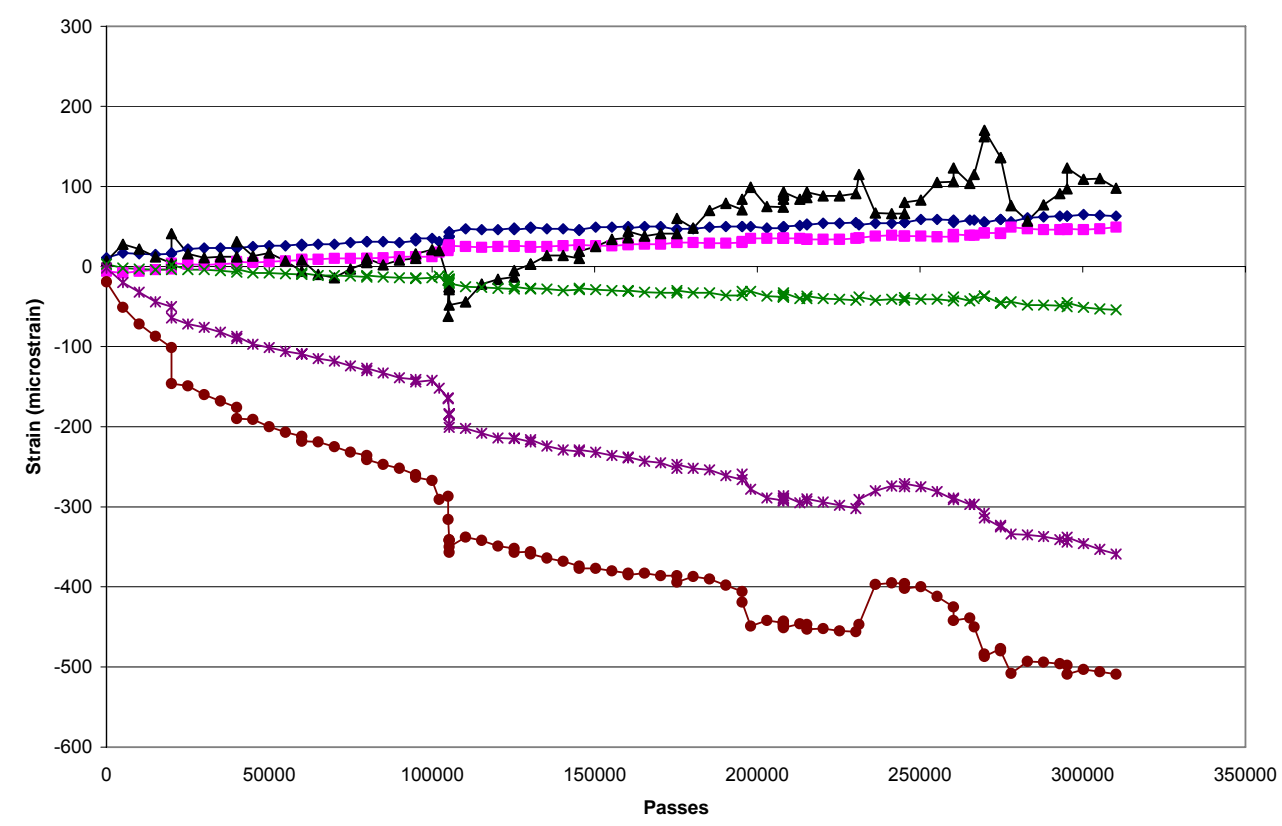

$\rightarrow-\mathrm{PEB} \rightarrow-\mathrm{PET} \rightarrow \mathrm{HEB} \rightarrow \mathrm{HET} \rightarrow \mathrm{UEB} \rightarrow-\mathrm{UET}$

(a)

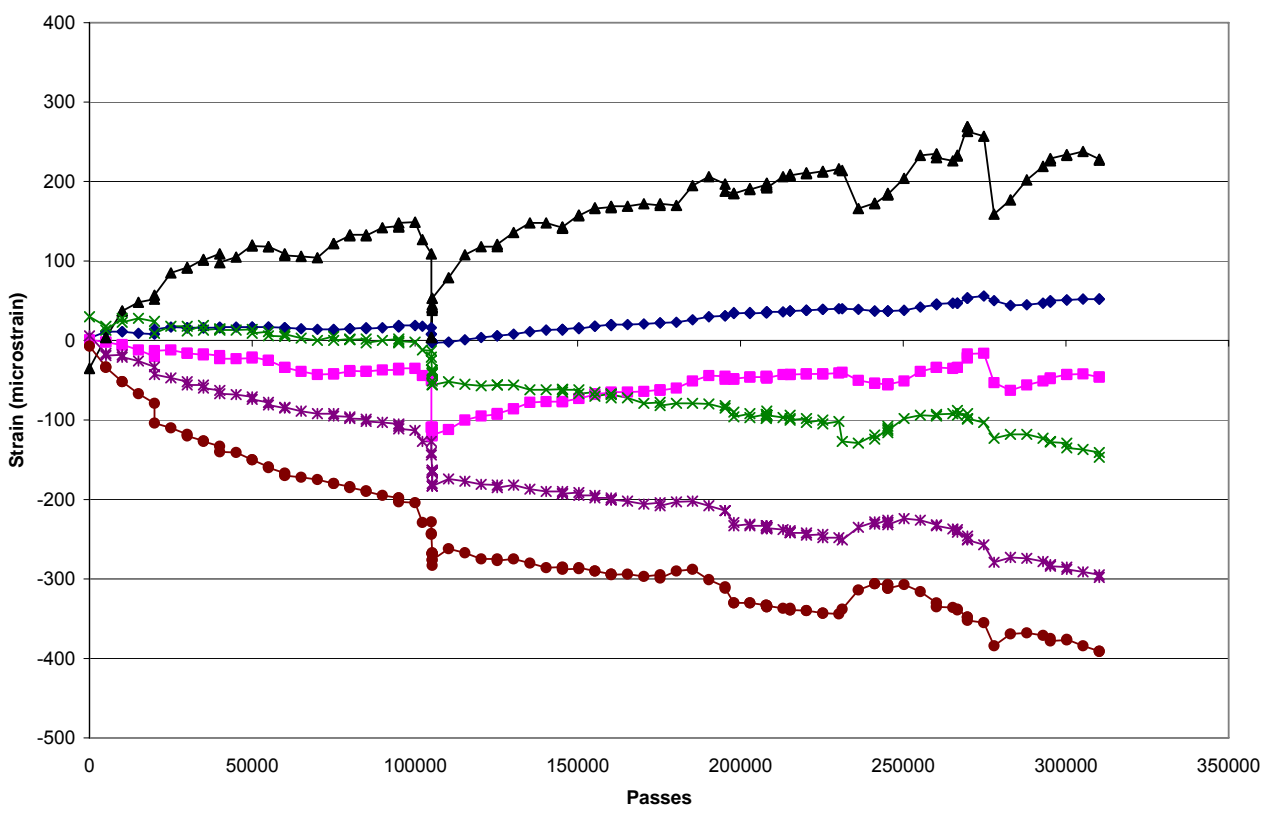

$\rightarrow \bullet$ PCB $\rightarrow$ -

(b)

Figure B.17 Strain versus Load Applications - Test Area 2 - Lane 2 Loaded (a) Edge (b) Corner 


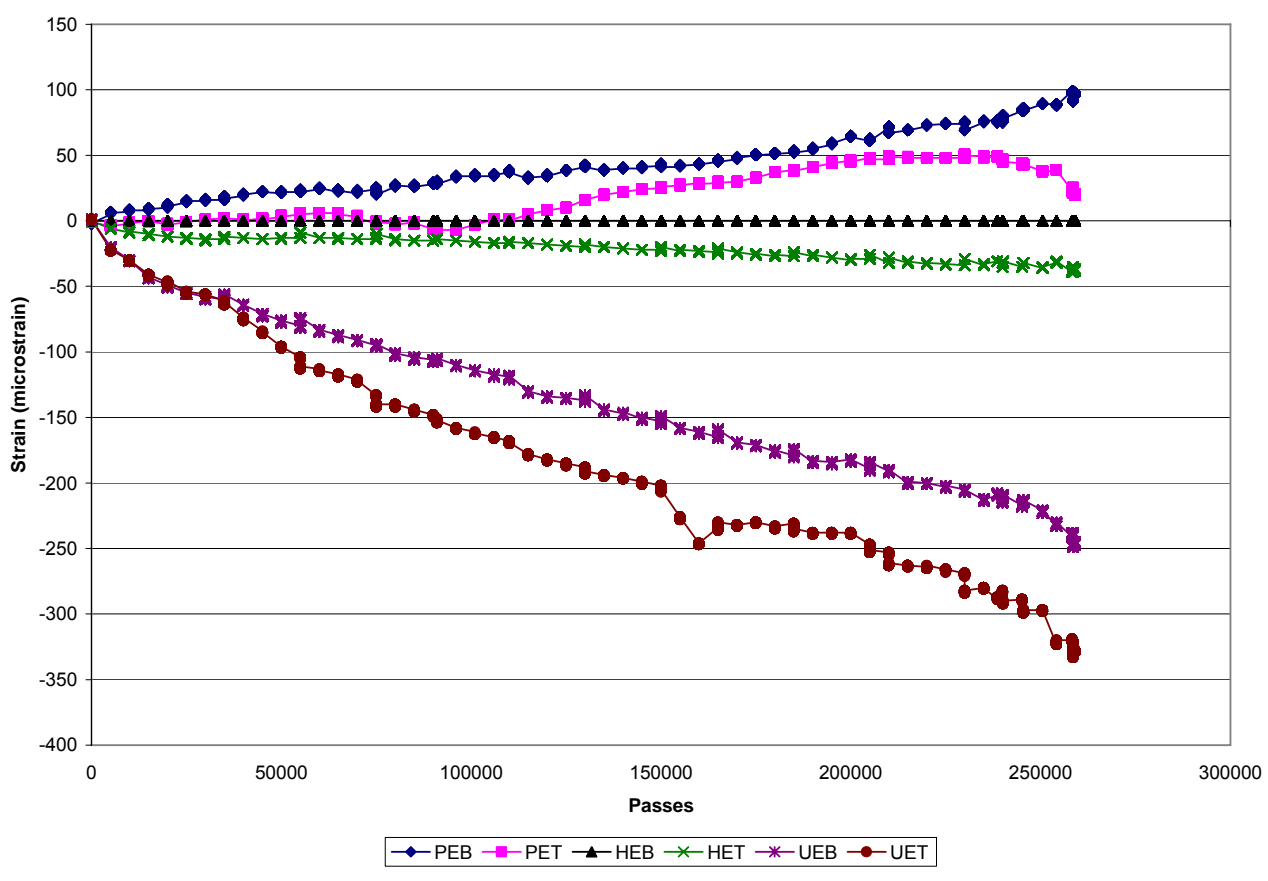

(a)

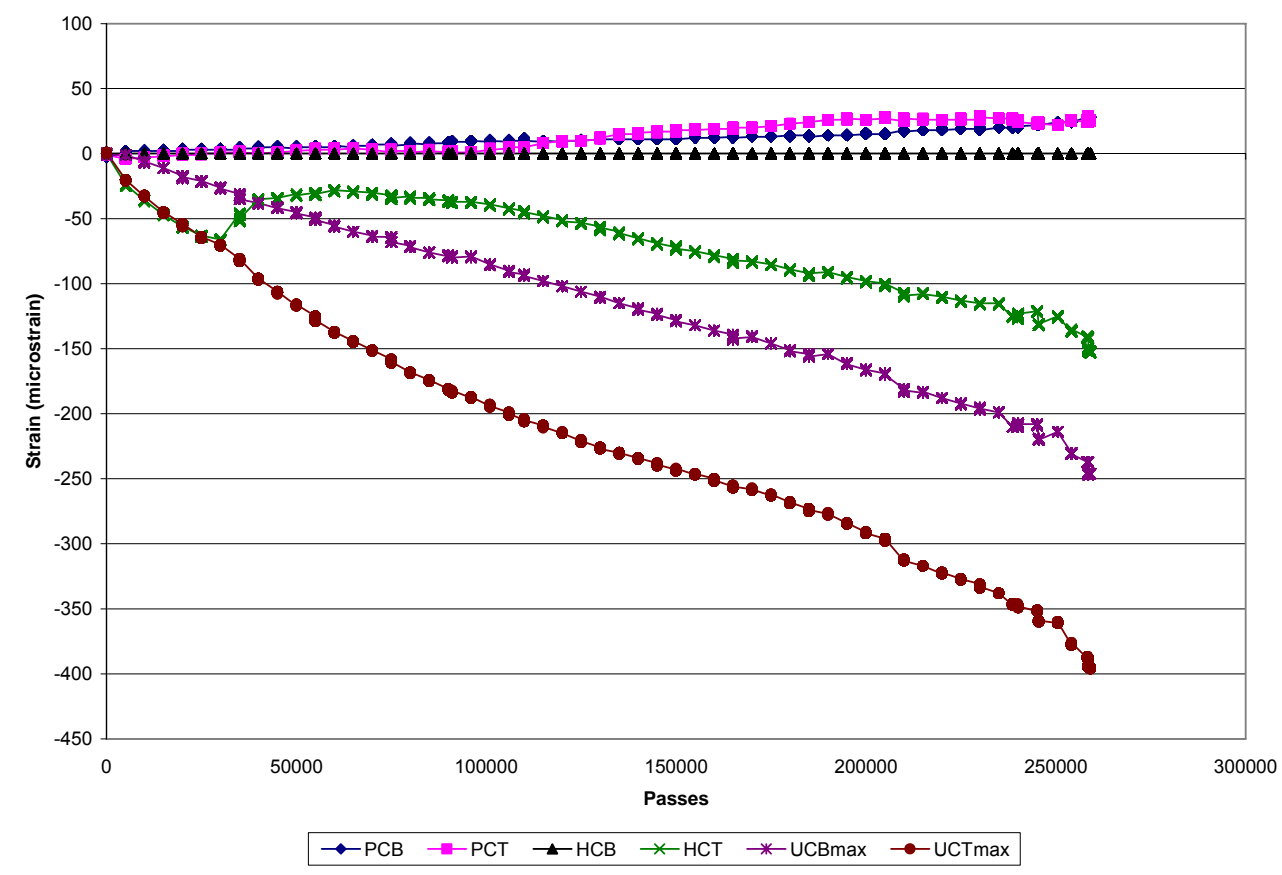

(b)

Figure B.18 Strain versus Load Applications - Test Area 2 - Lane 3 Unloaded (a) Edge (b) Corner 


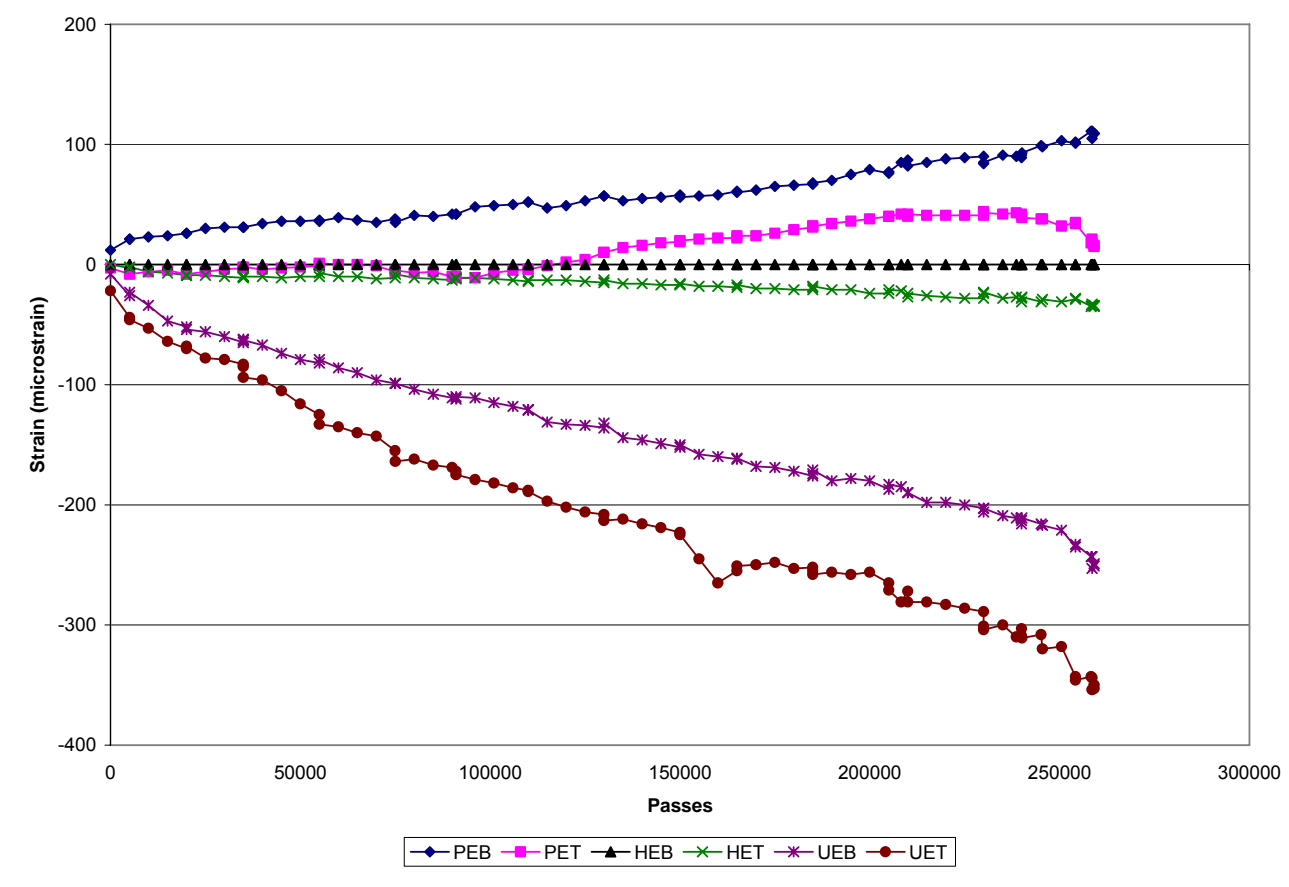

(a)

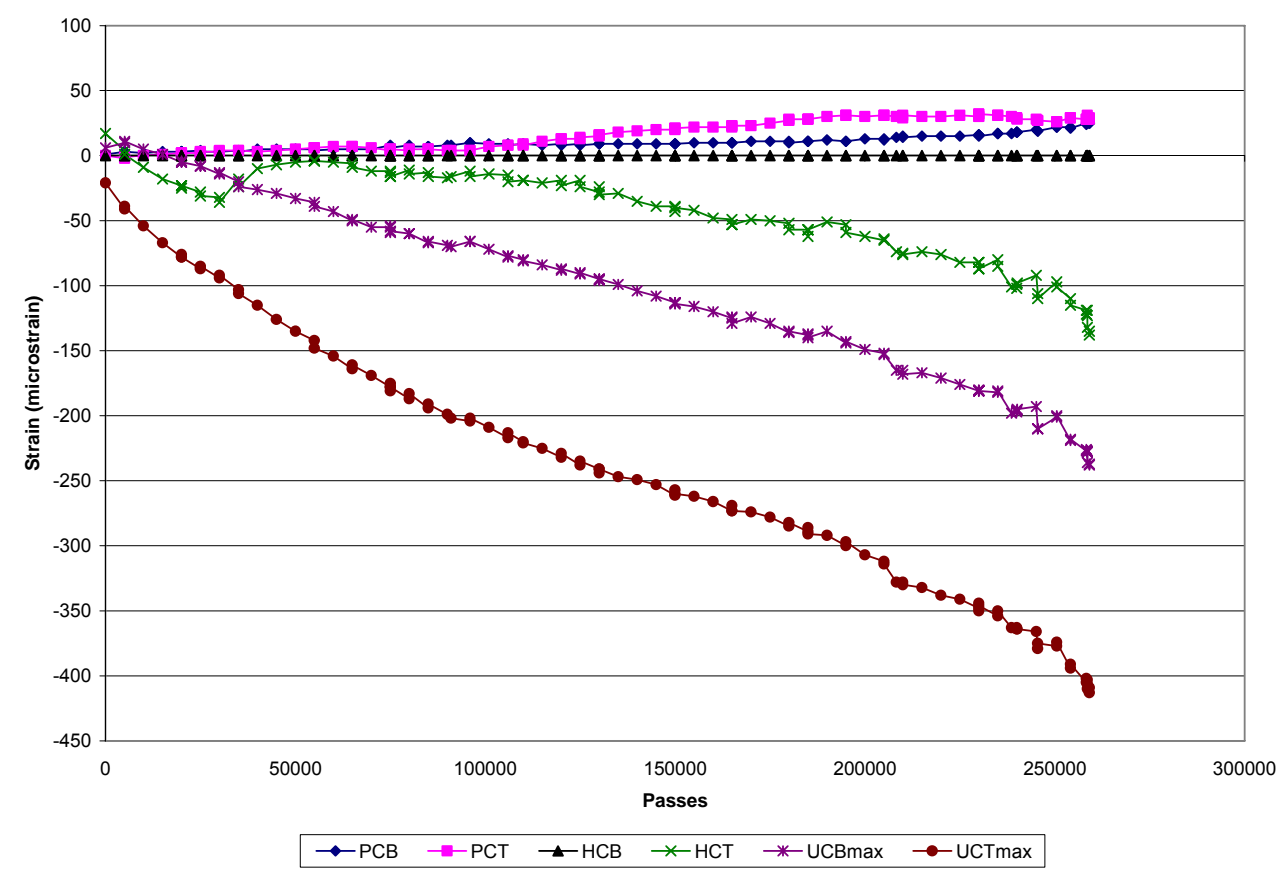

(b)

Figure B.19 Strain versus Load Applications - Test Area 2 - Lane 3 Loaded (a) Edge (b) Corner 


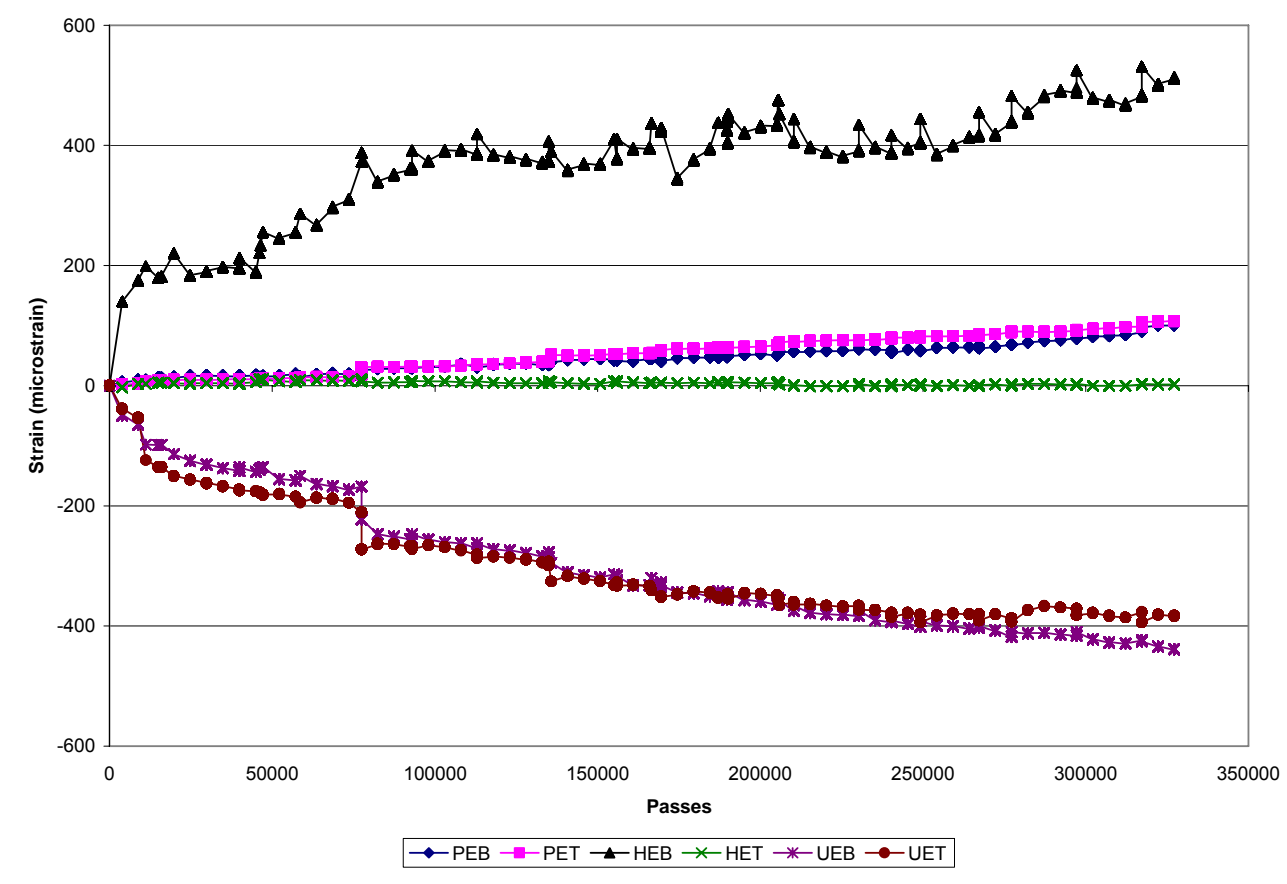

(a)

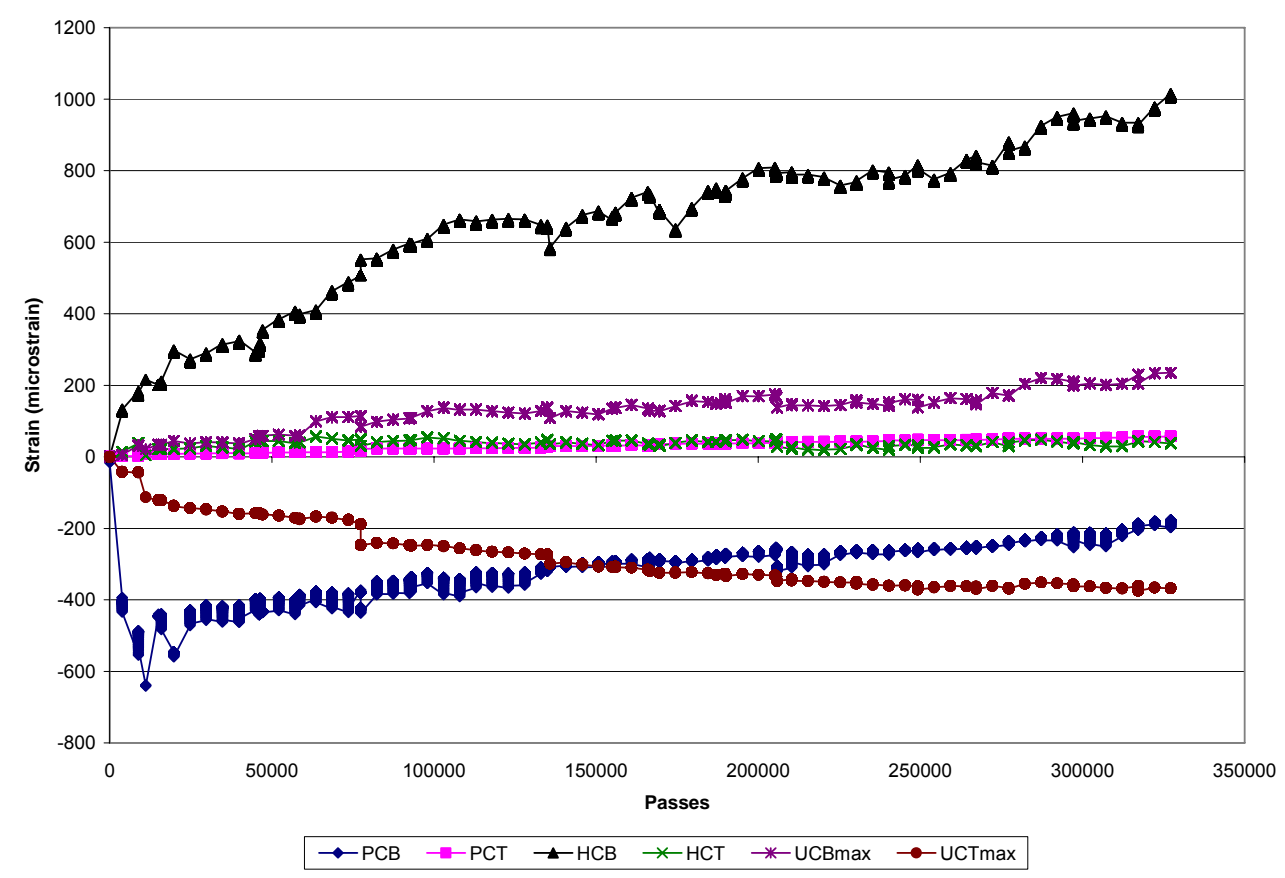

(b)

Figure B.20 Strain versus Load Applications - Test Area 2 - Lane 4 Unloaded (a) Edge (b) Corner 


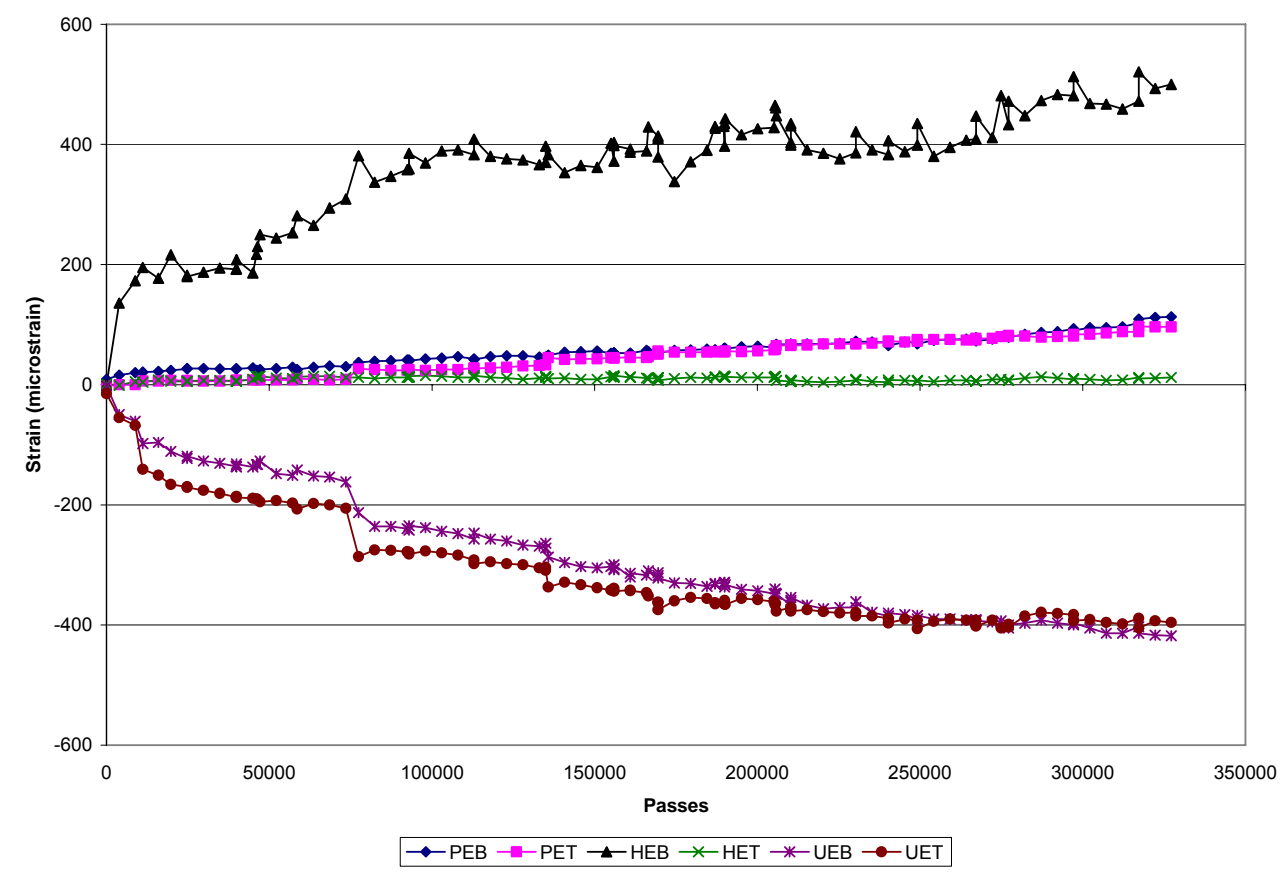

(a)

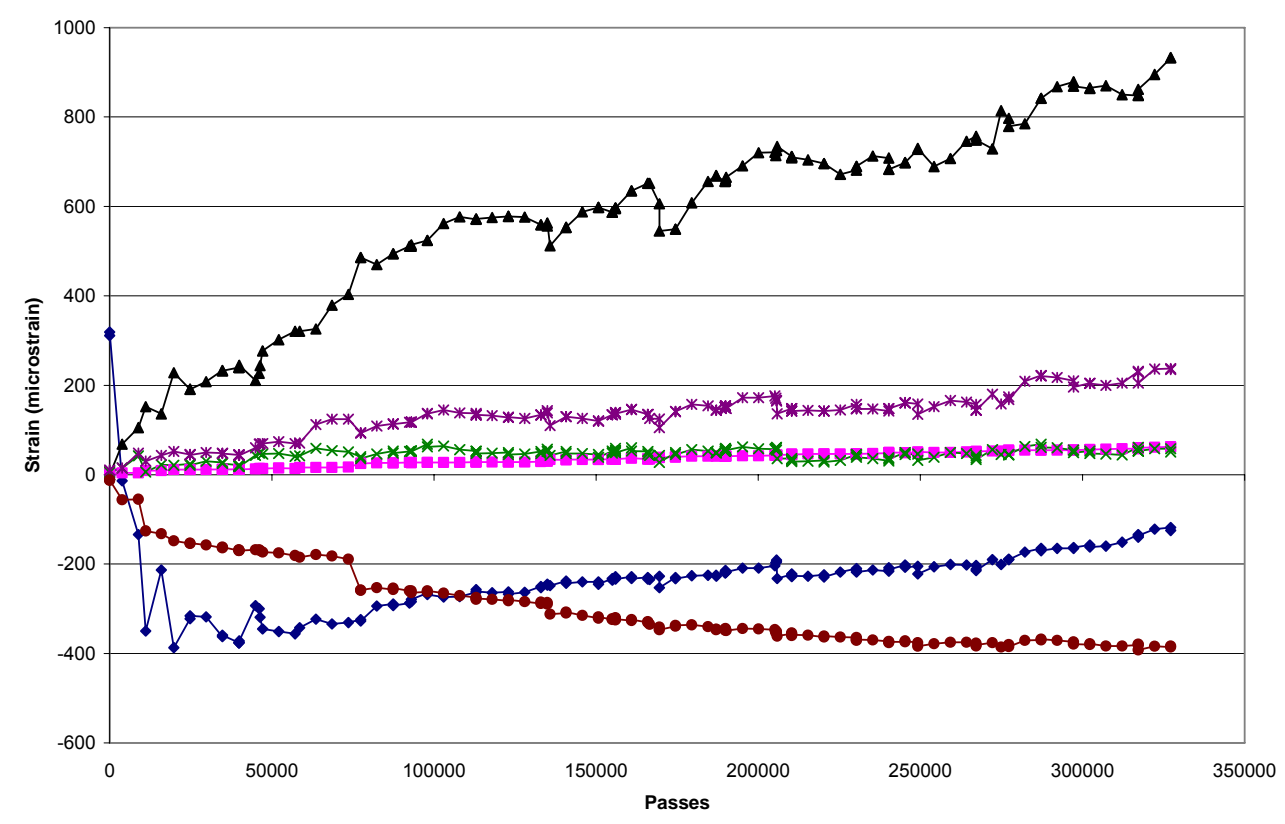

$\rightarrow$ -

(b)

Figure B.21 Strain versus Load Applications - Test Area 2 - Lane 4 Loaded (a) Edge (b) Corner 


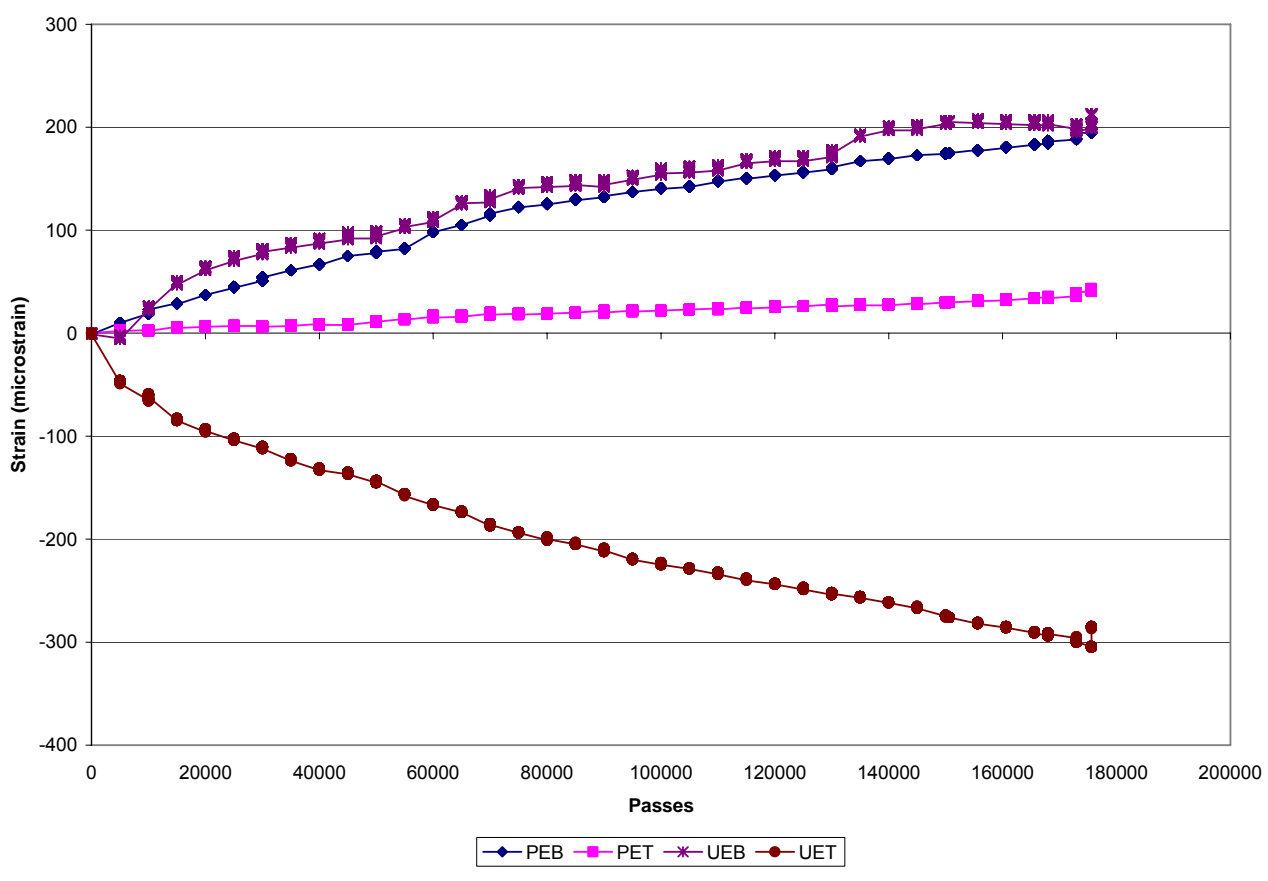

(a)

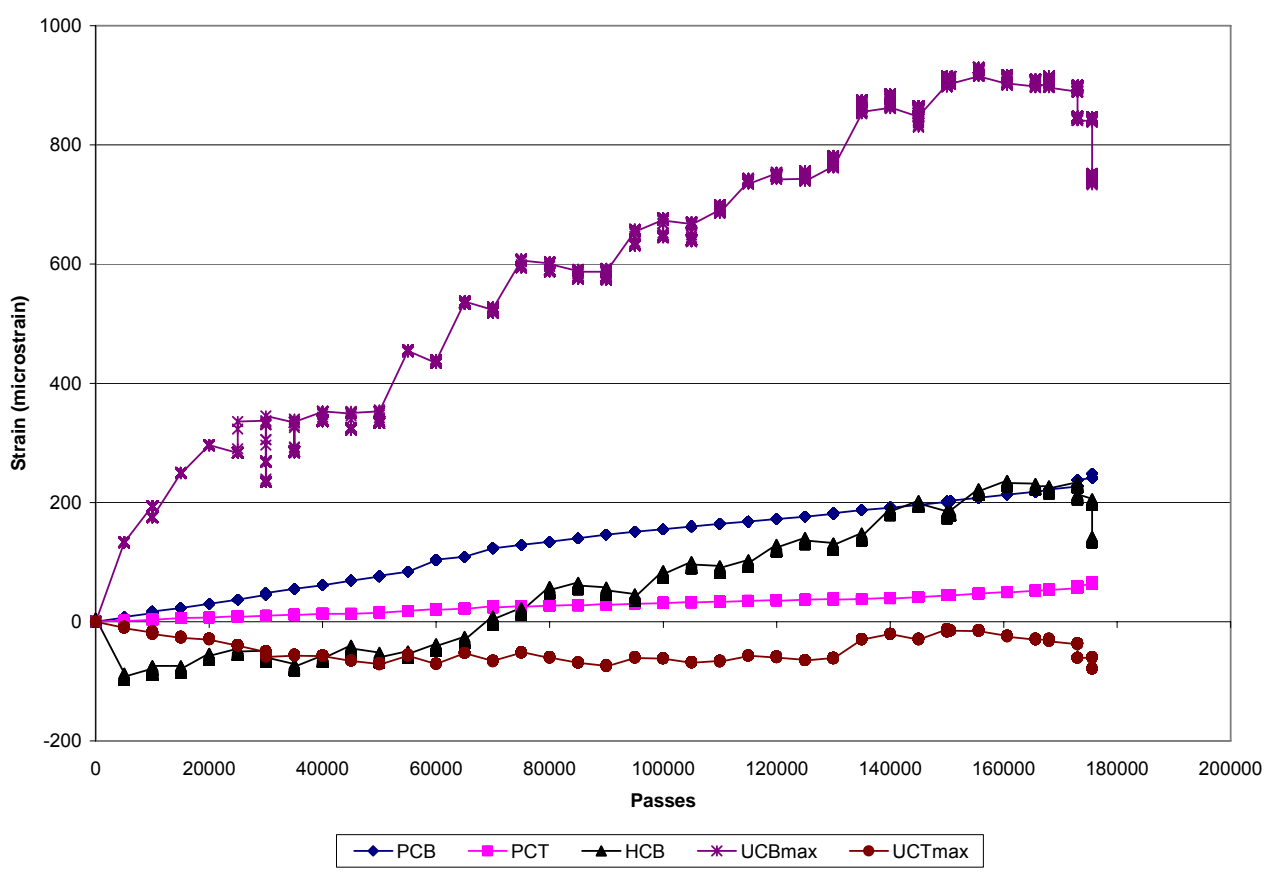

(b)

Figure B.22 Strain versus Load Applications - Test Area 2 - Lane 5 Unloaded (a) Edge (b) Corner 


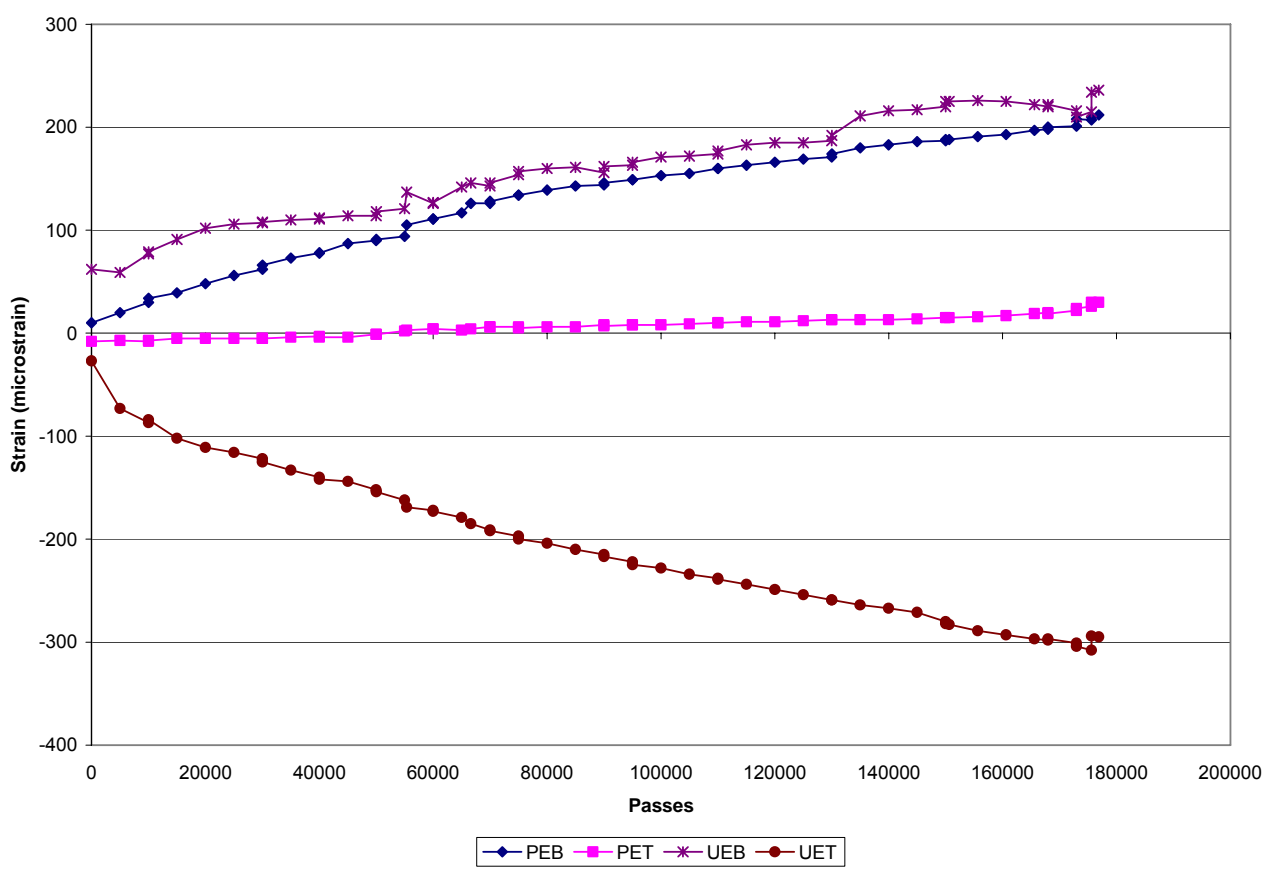

(a)

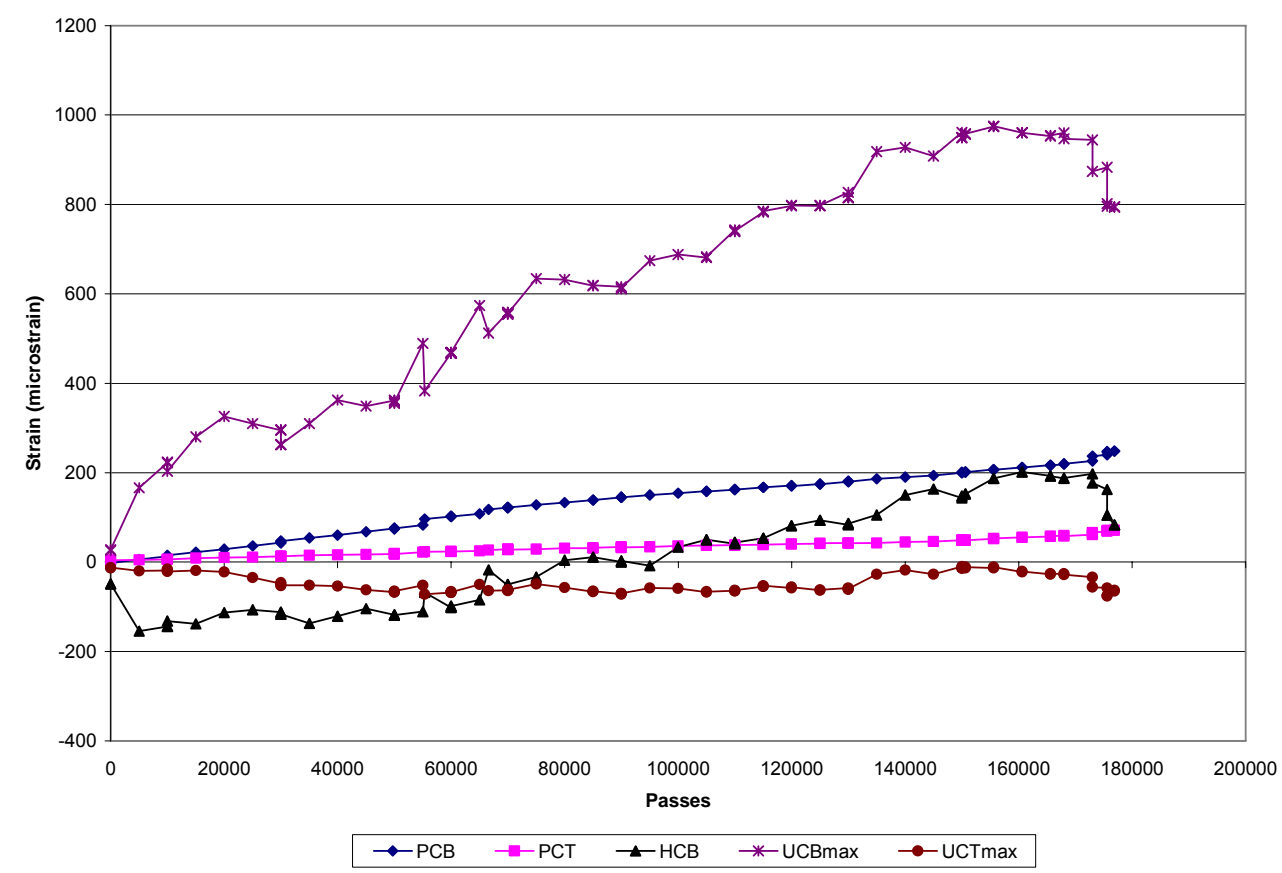

(b)

Figure B.23 Strain versus Load Applications - Test Area 2 - Lane 5 Loaded (a) Edge (b) Corner 


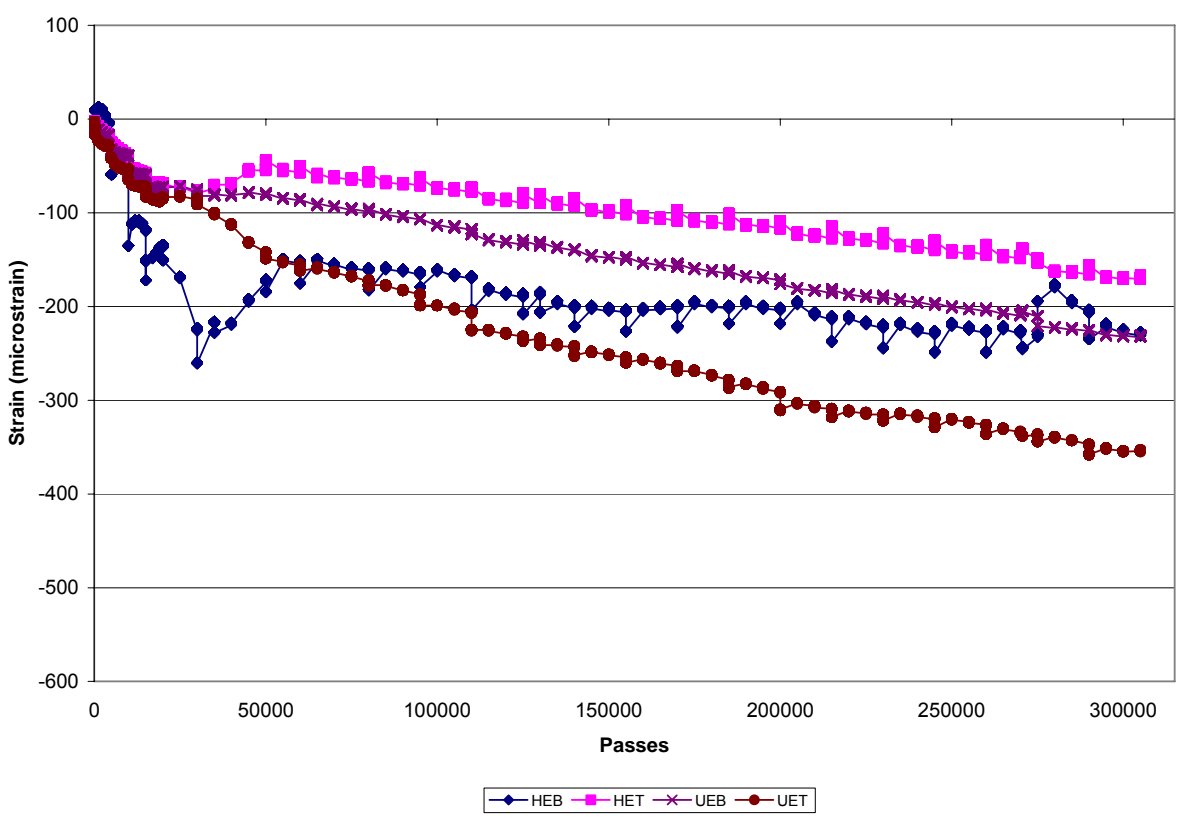

(a)

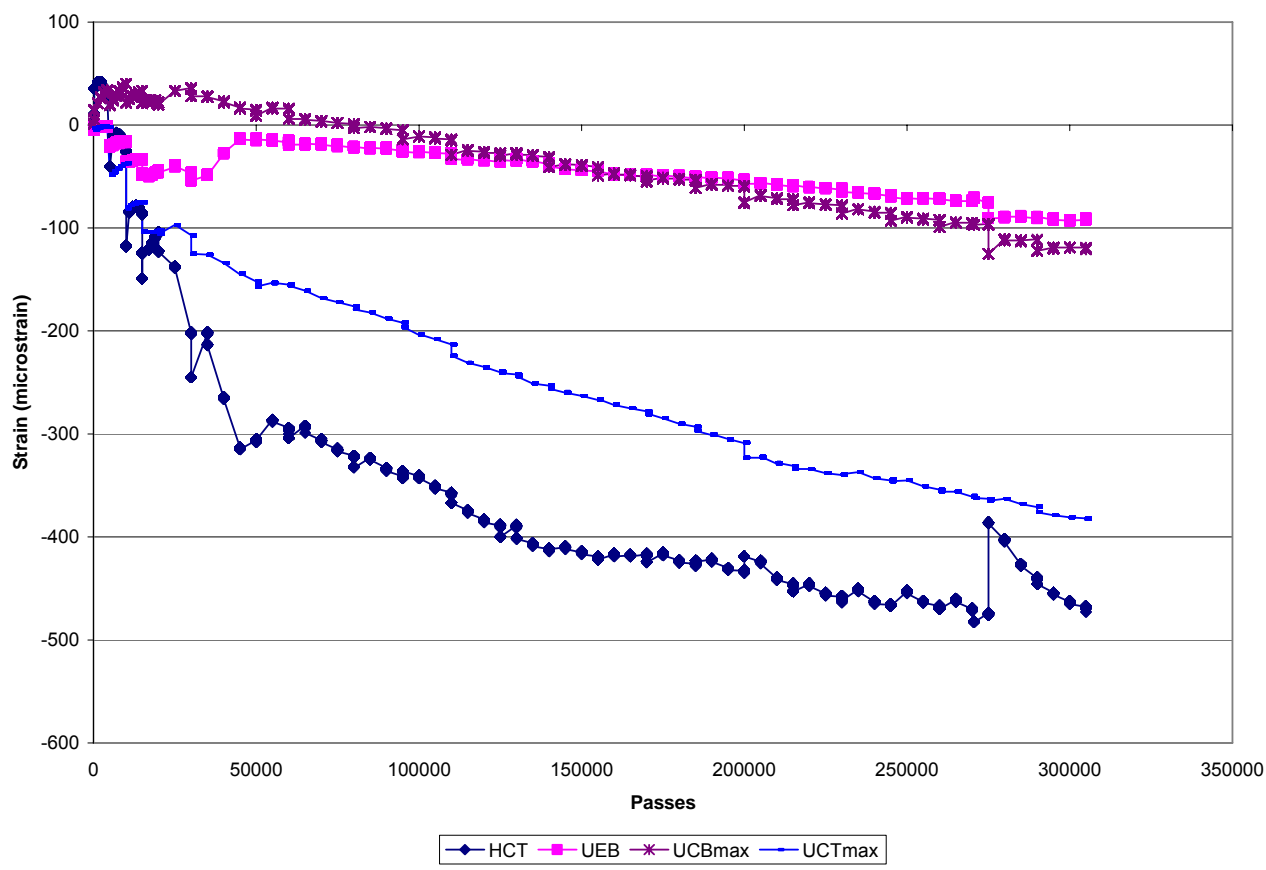

(b)

Figure B.24 Strain versus Load Applications - Test Area 3 - Lane 1 Unloaded (a) Edge (b) Corner 


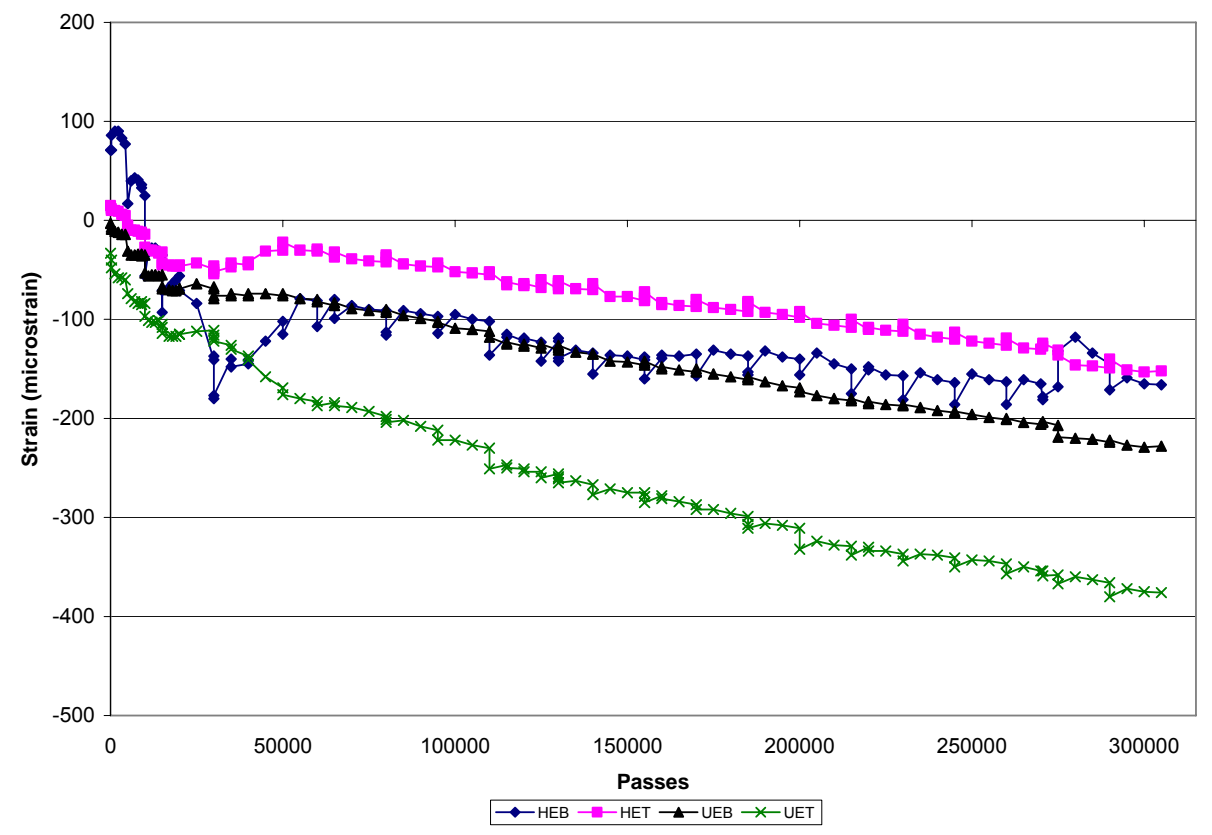

(a)

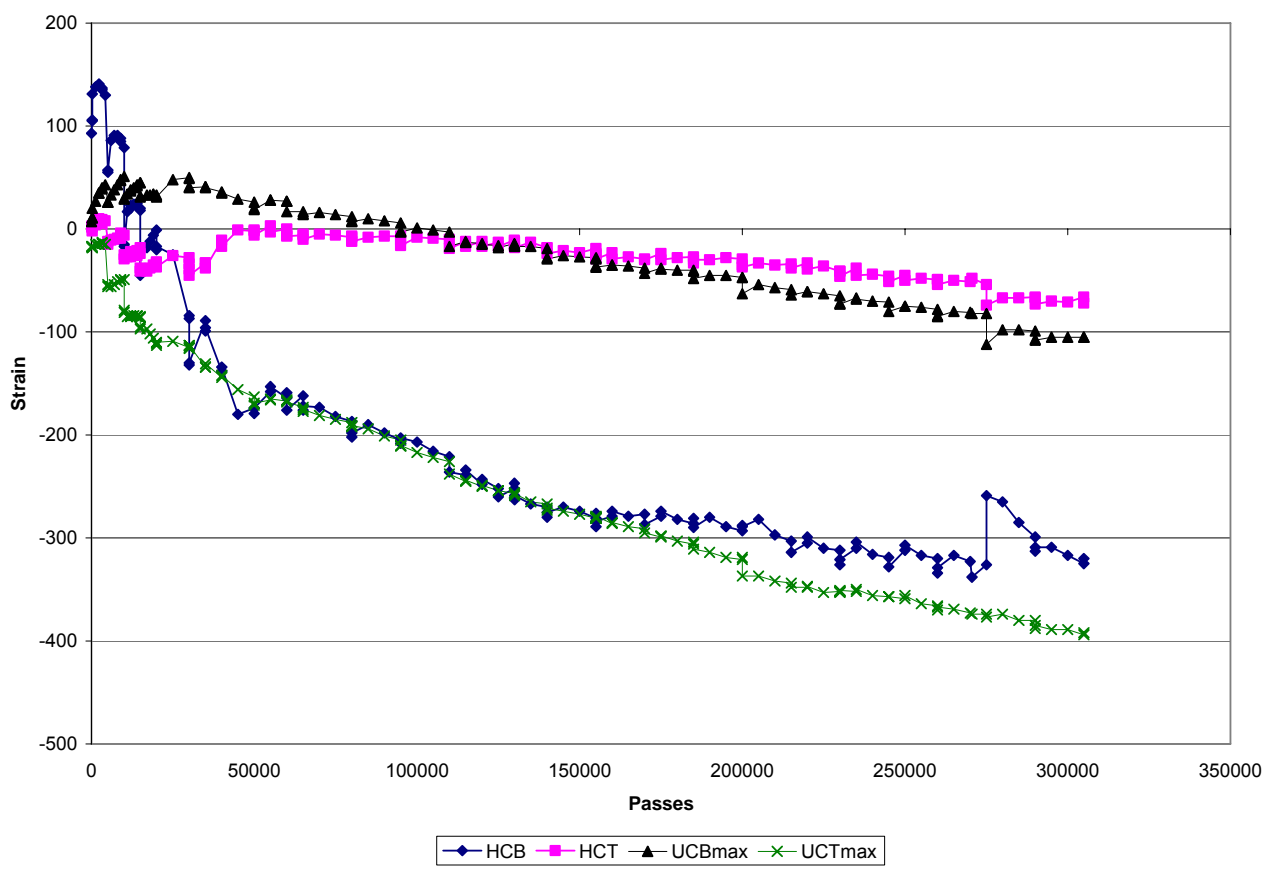

(b)

Figure B.25 Strain versus Load Applications - Test Area 3 - Lane 1 Loaded (a) Edge (b) Corner 


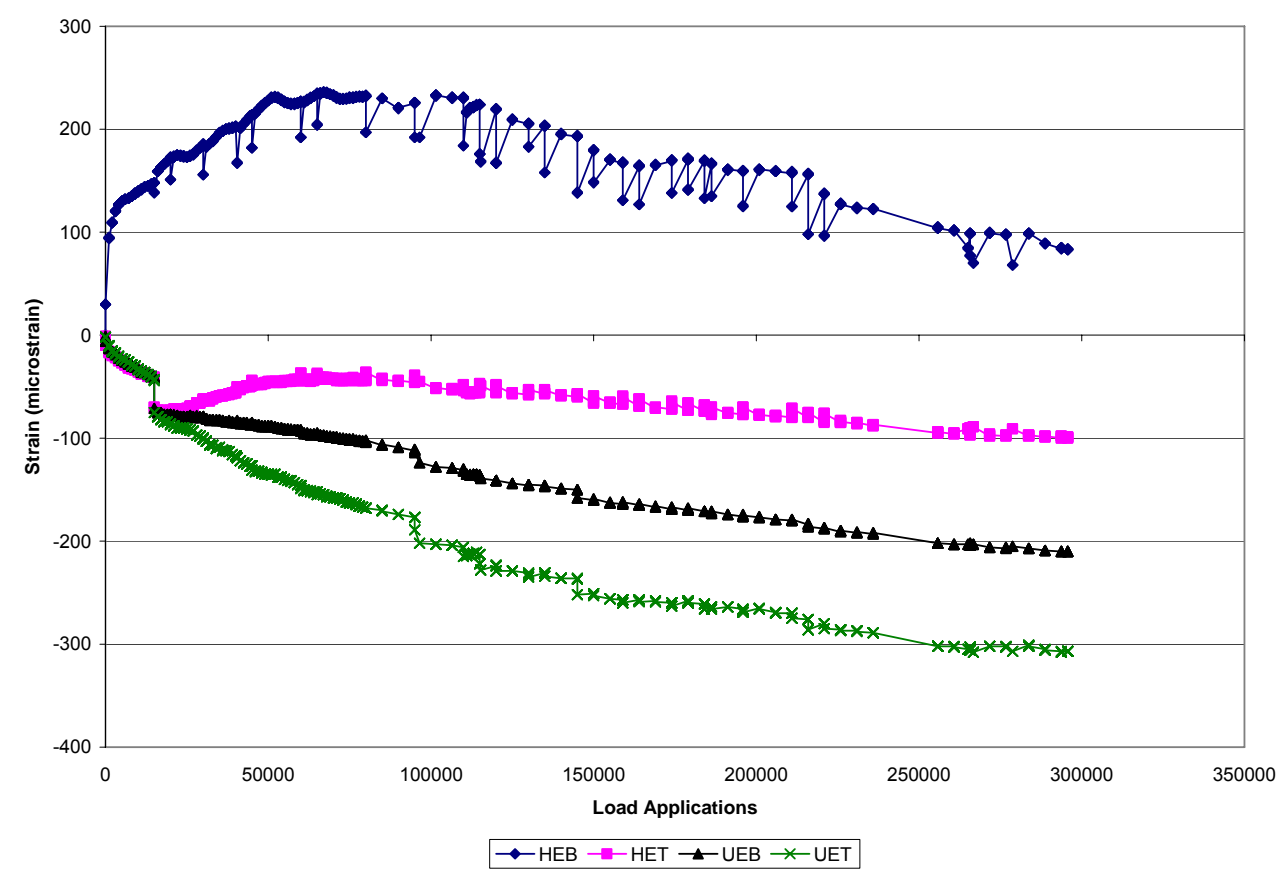

(a)

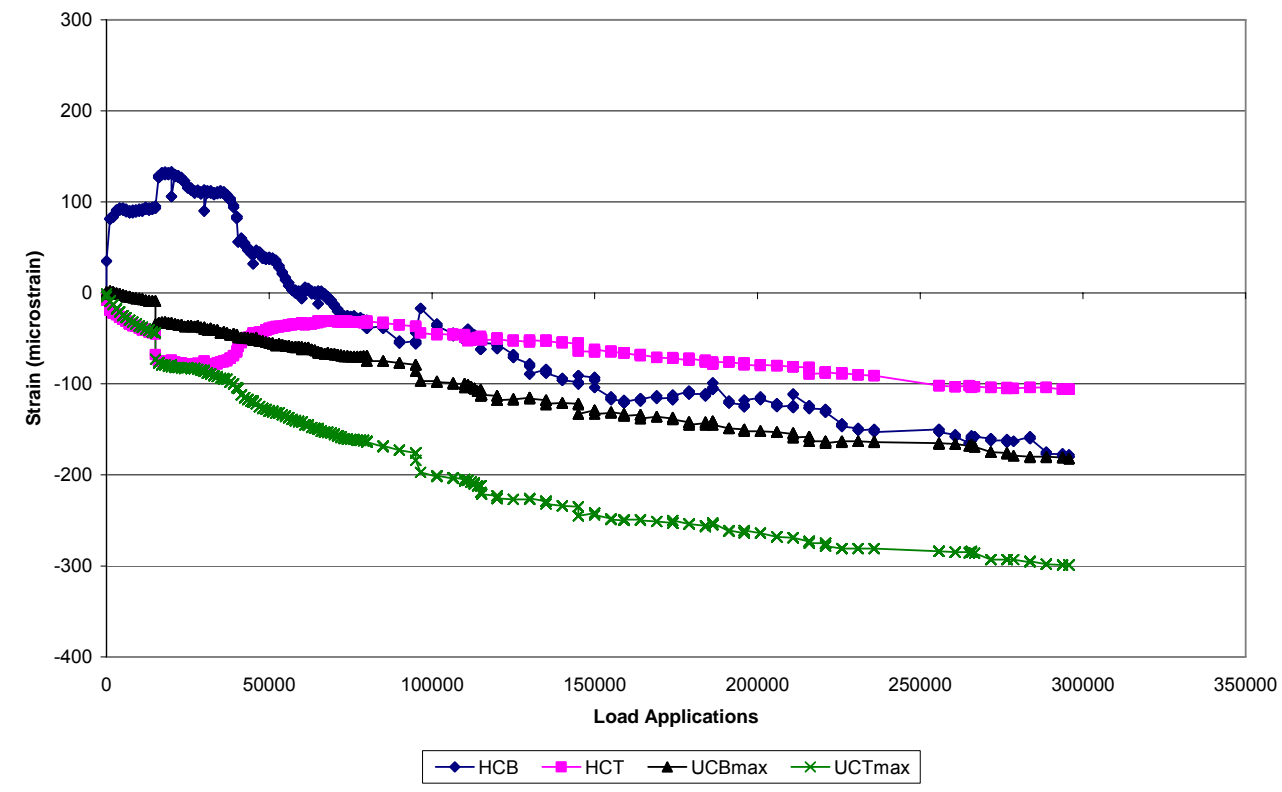

(b)

Figure B.26 Strain versus Load Applications - Test Area 3 - Lane 2 Unloaded (a) Edge (b) Corner 


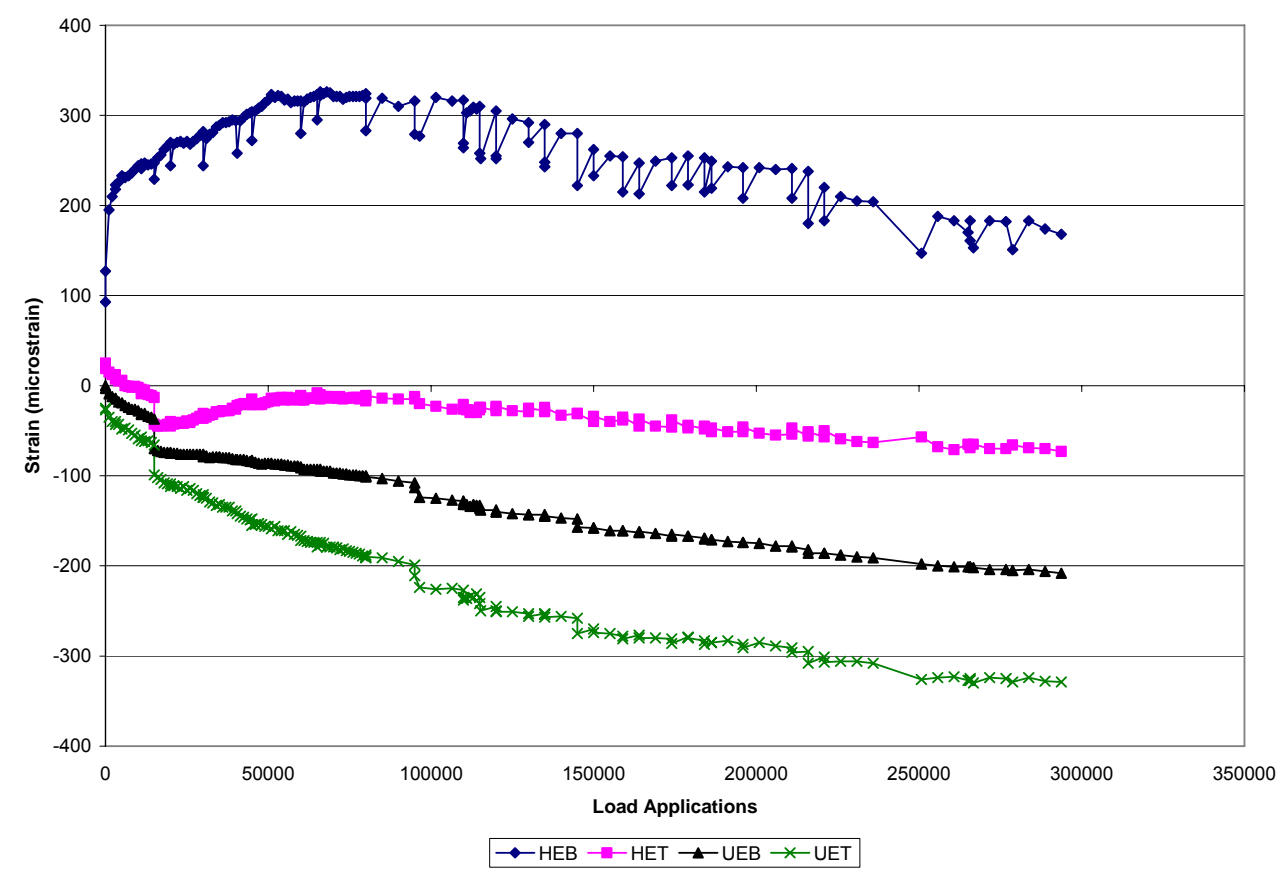

(a)

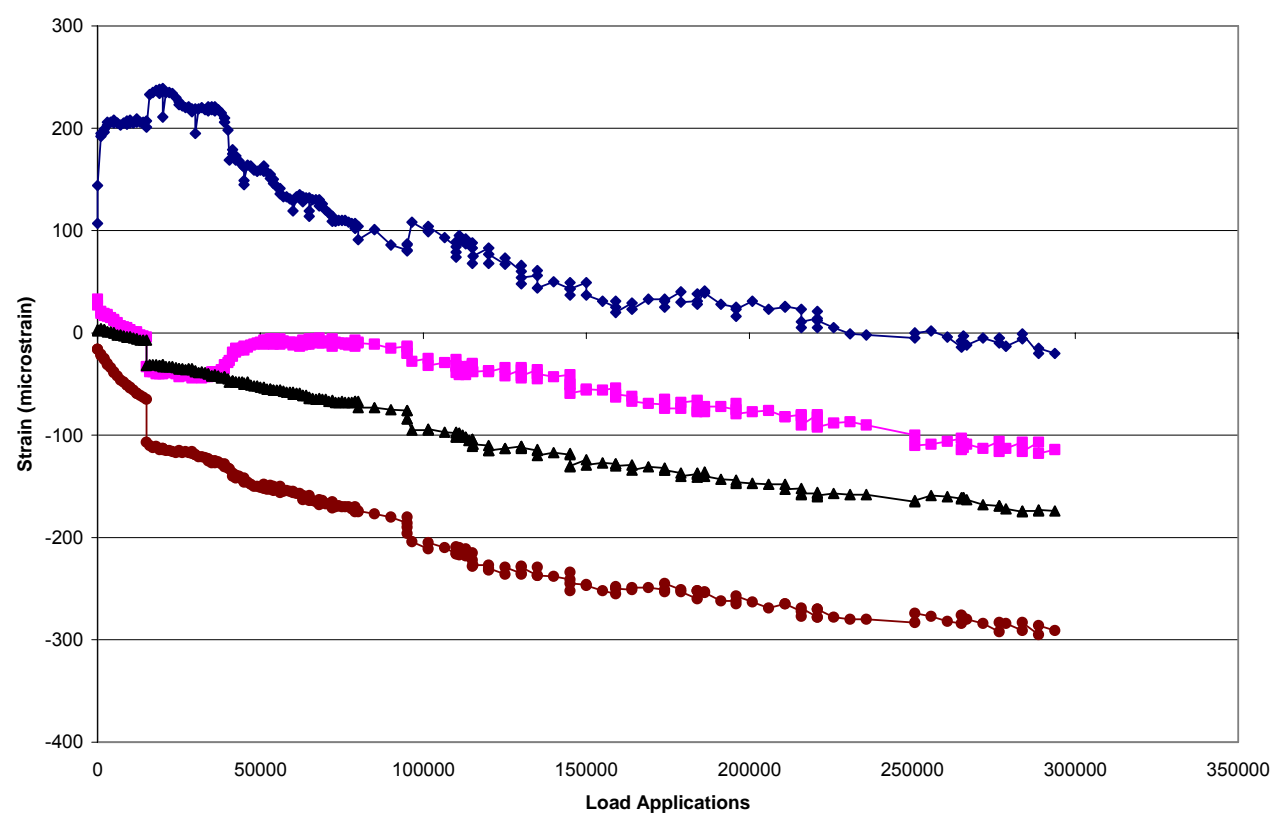

$\rightarrow-\mathrm{HCT} \rightarrow-\mathrm{HCT} \rightarrow$ - UCBmax $\rightarrow-$ UCTmax

(b)

Figure B.27 Strain versus Load Applications - Test Area 3 - Lane 2 Loaded (a) Edge (b) Corner 


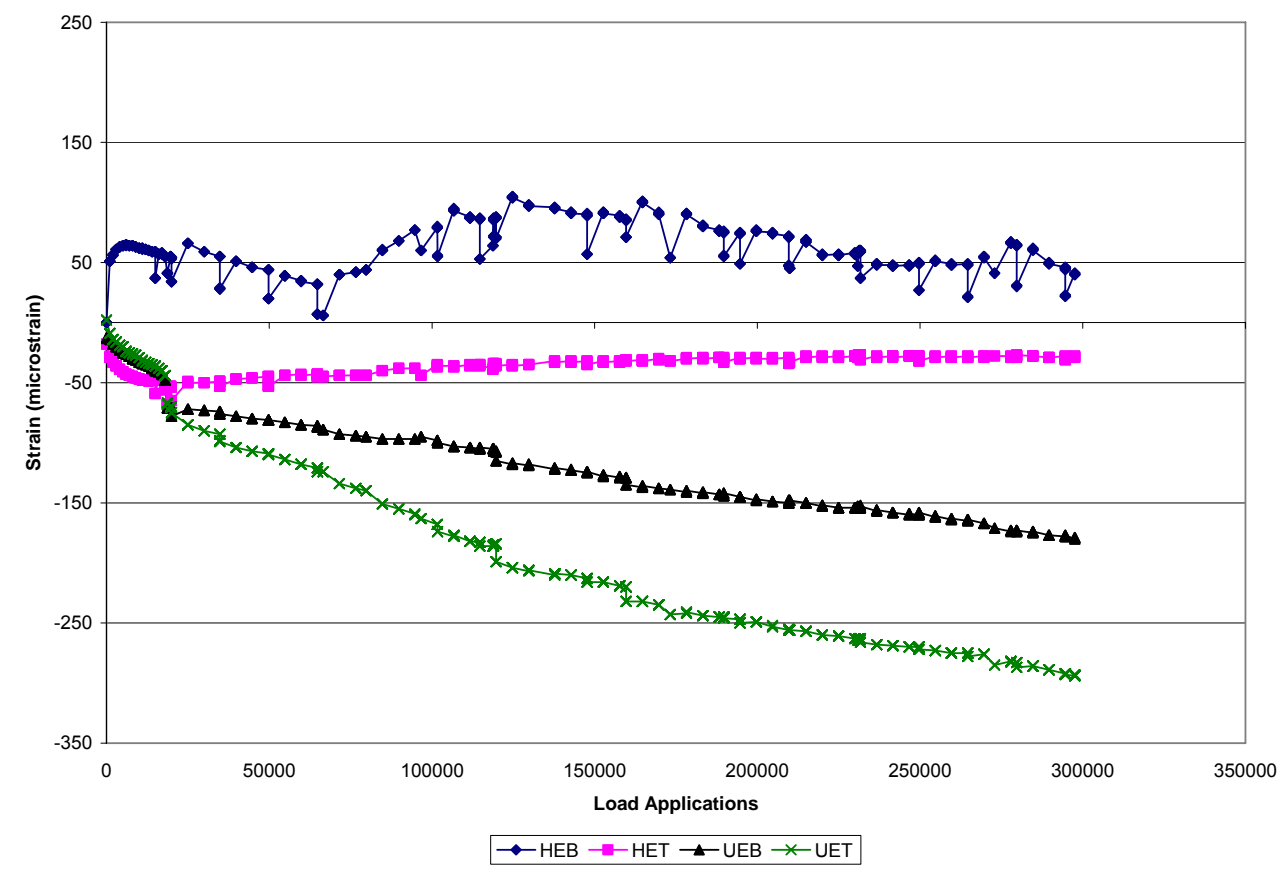

(a)

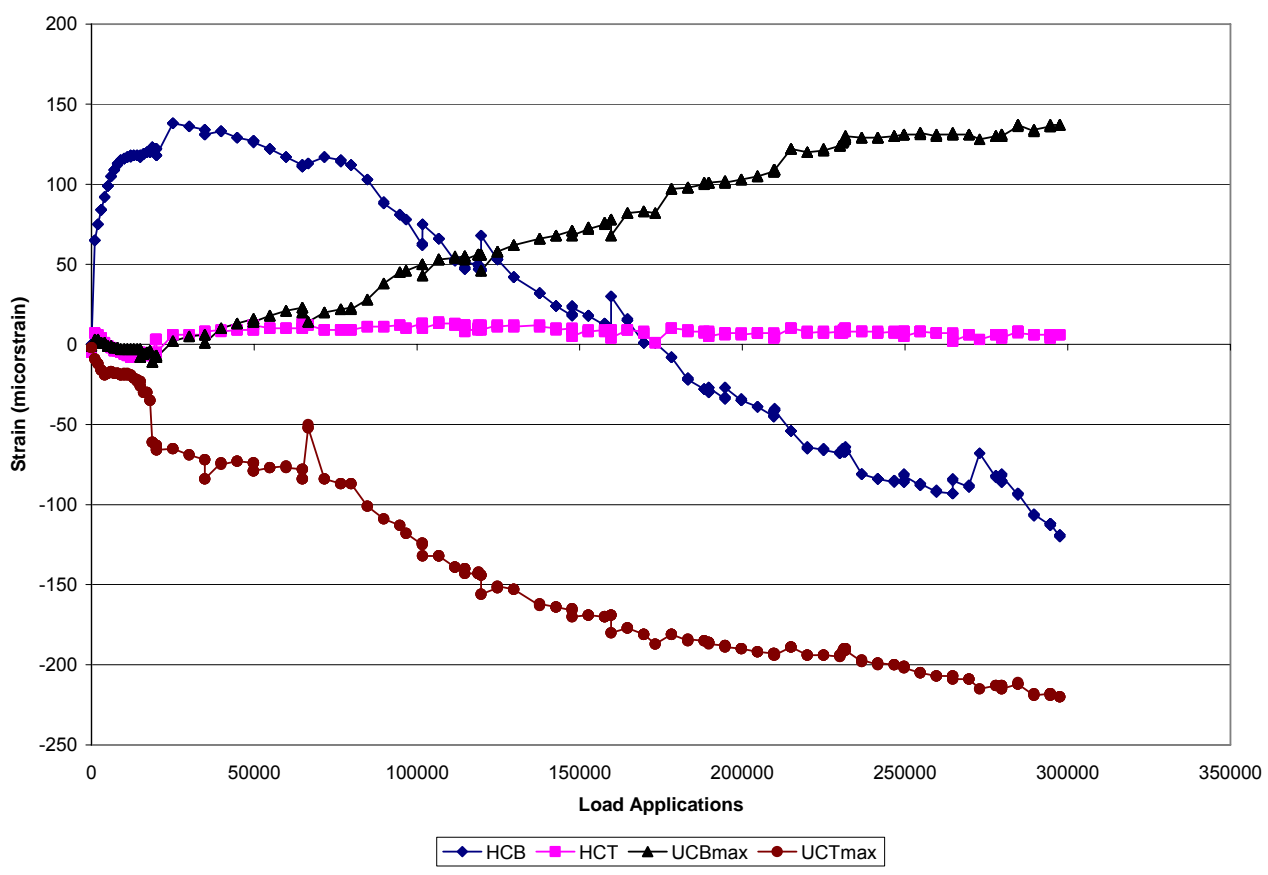

(b)

Figure B.28 Strain versus Load Applications - Test Area 3 - Lane 3 Unloaded (a) Edge (b) Corner 


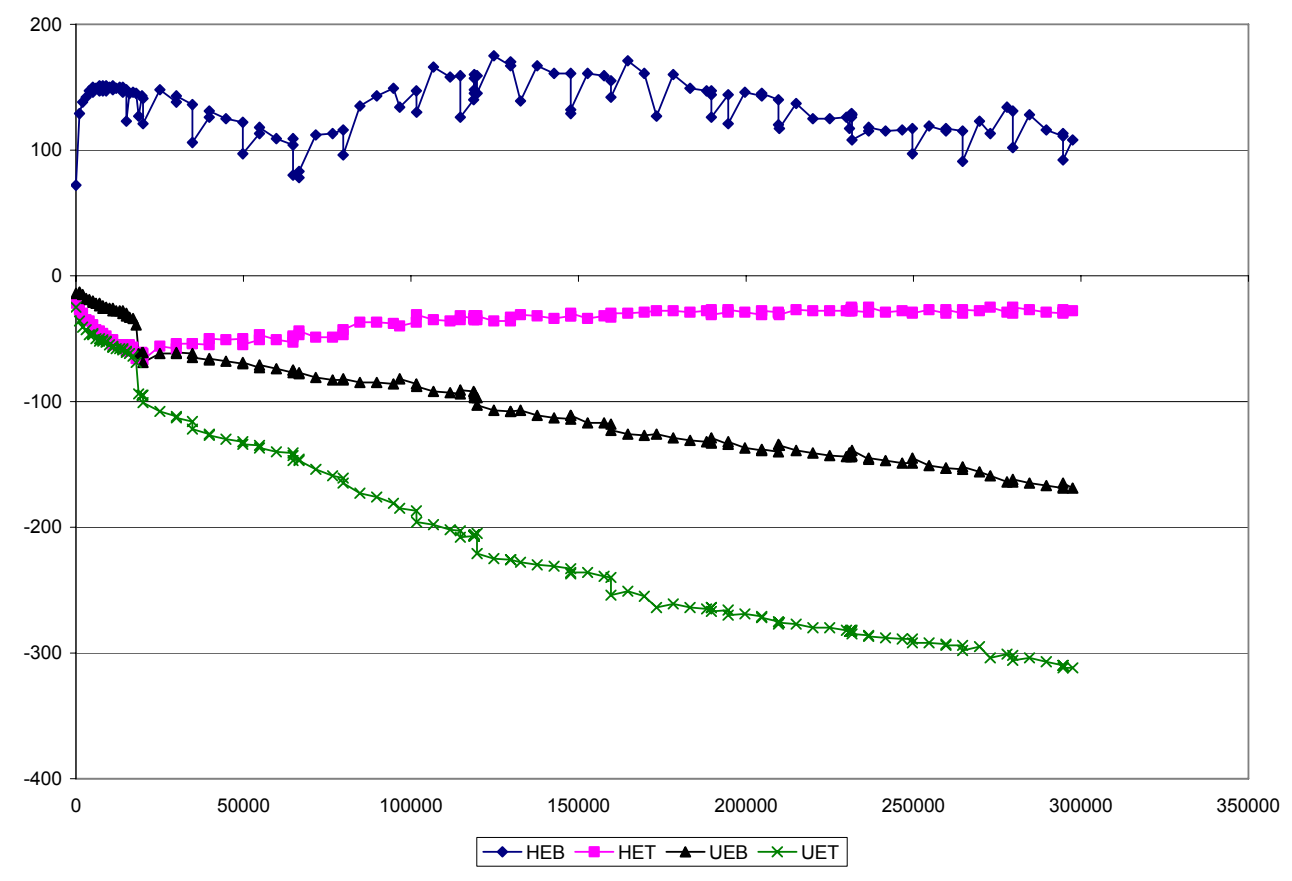

(a)

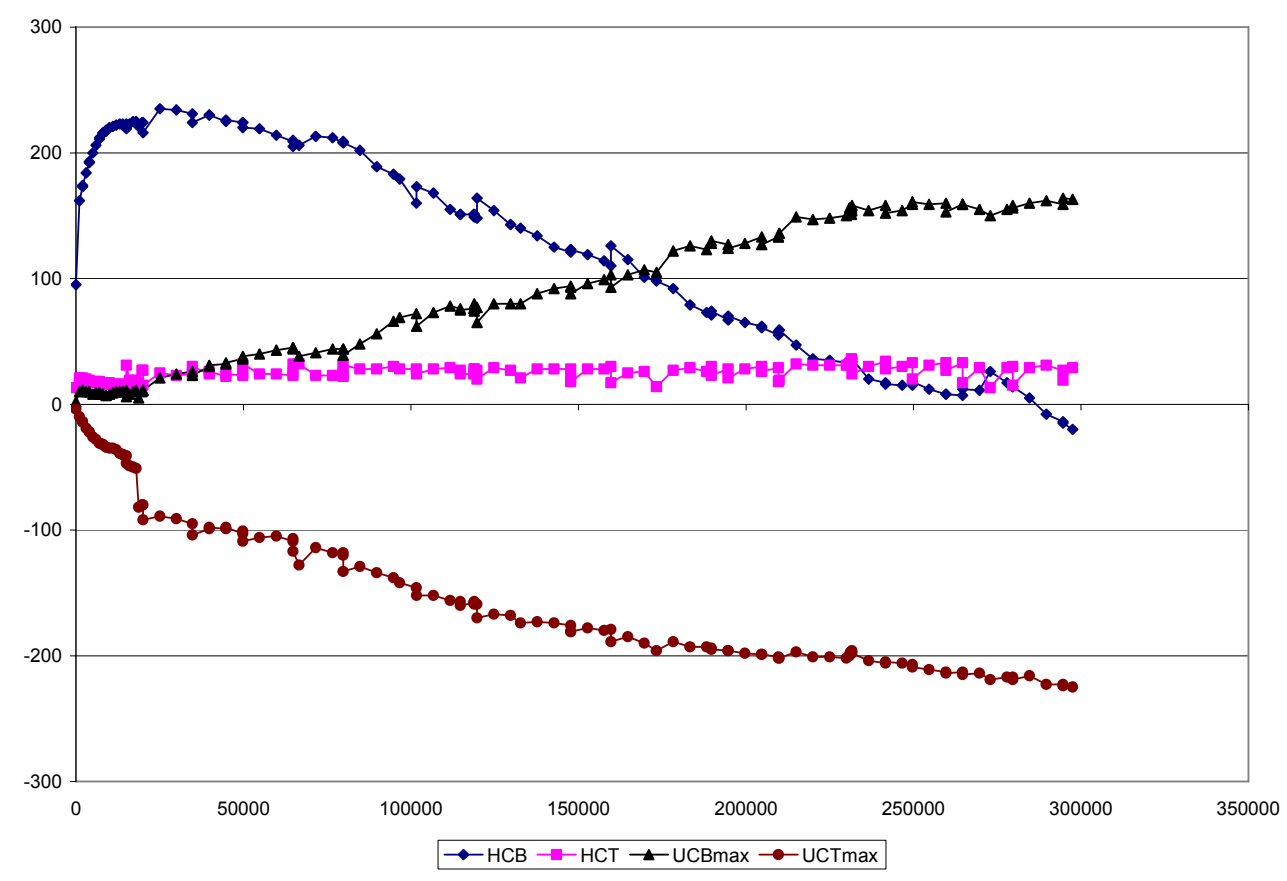

(b)

Figure B.29 Strain versus Load Applications - Test Area 3 - Lane 3 Loaded (a) Edge (b) Corner 


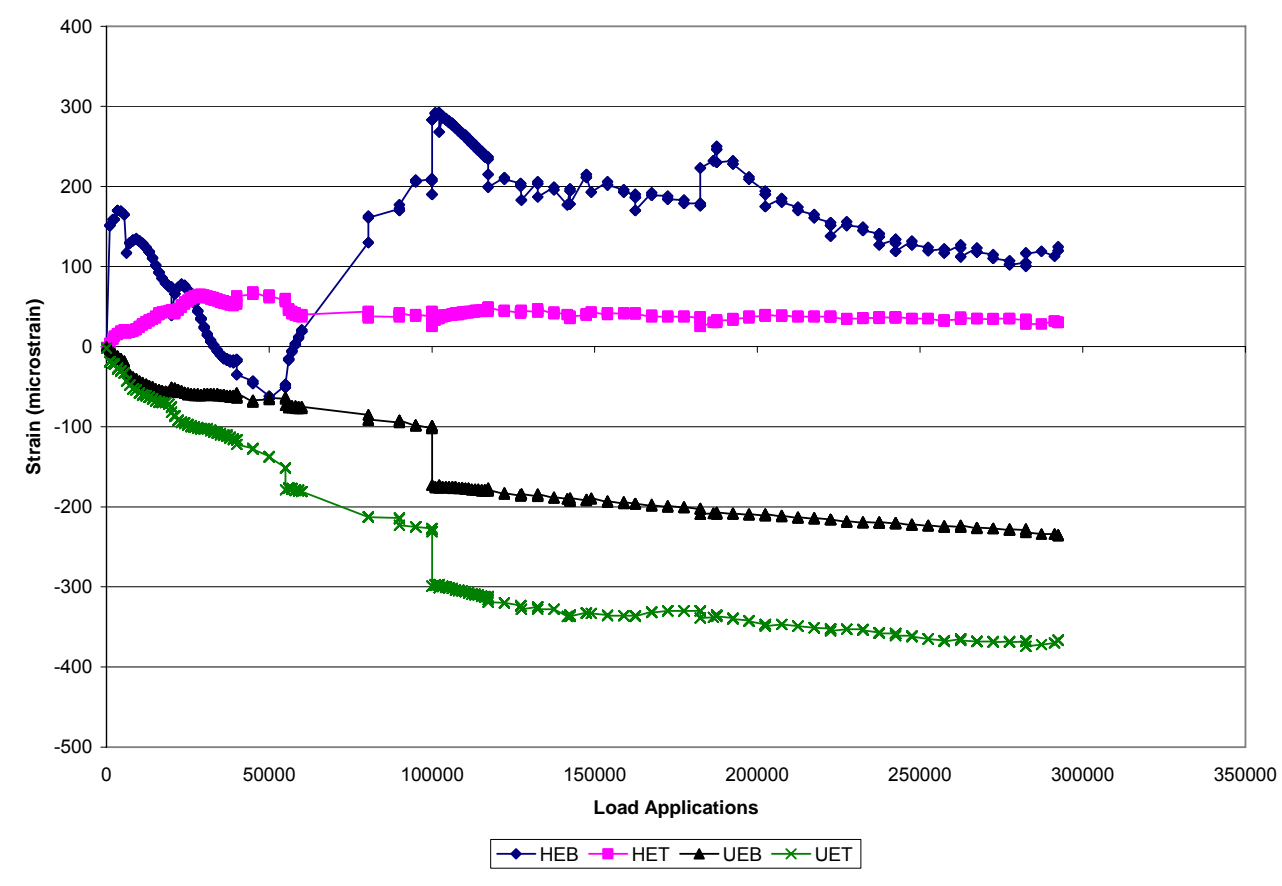

(a)

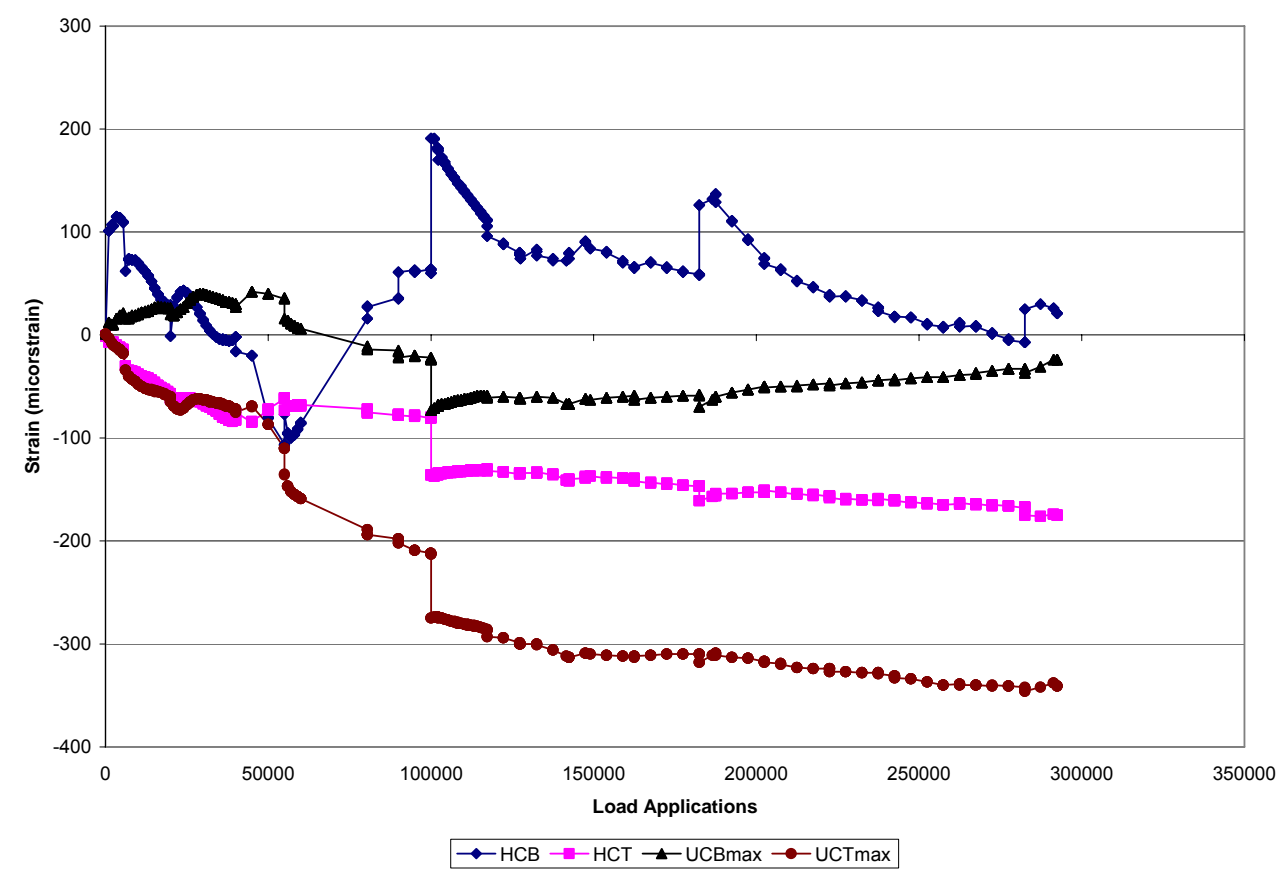

(b)

Figure B.30 Strain versus Load Applications - Test Area 3 - Lane 4 Unloaded (a) Edge (b) Corner 


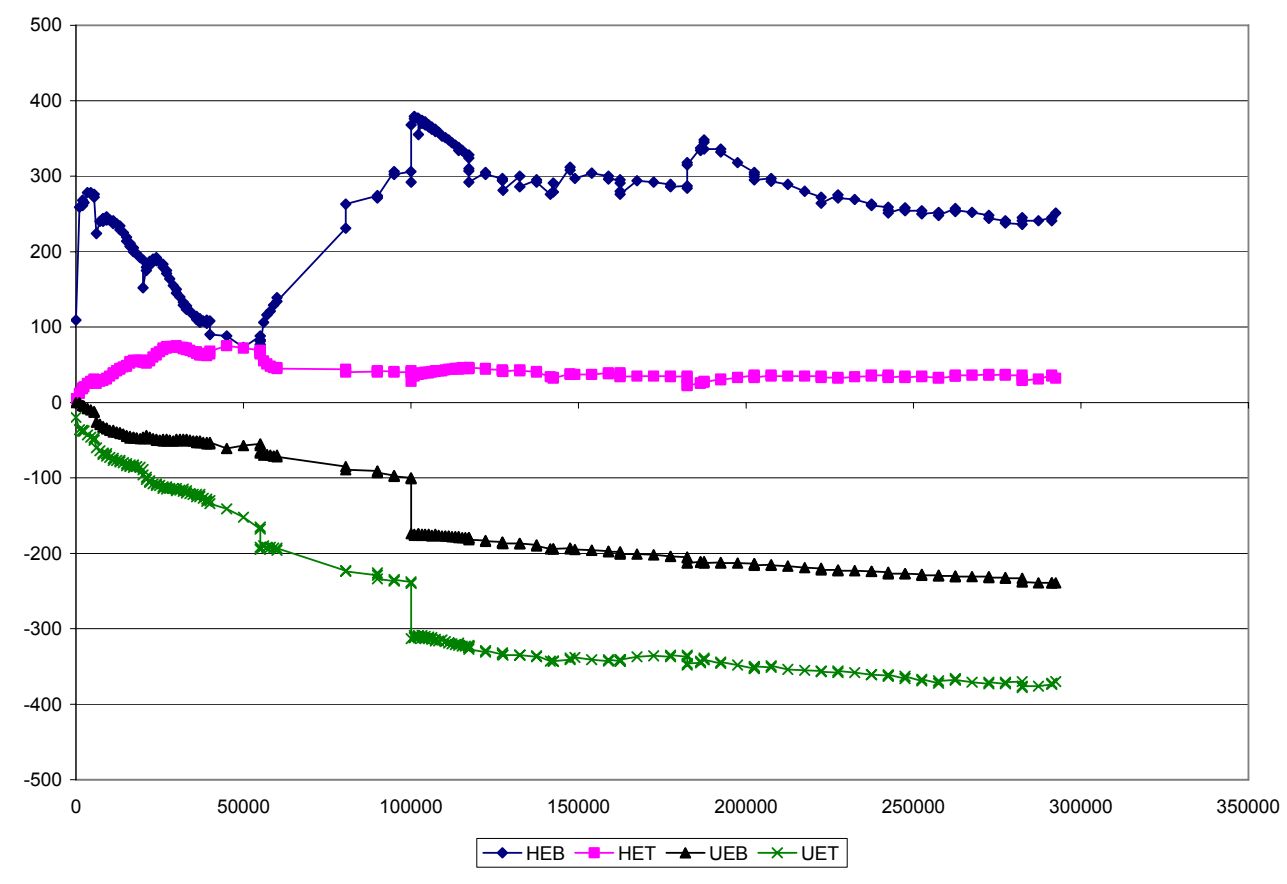

(a)

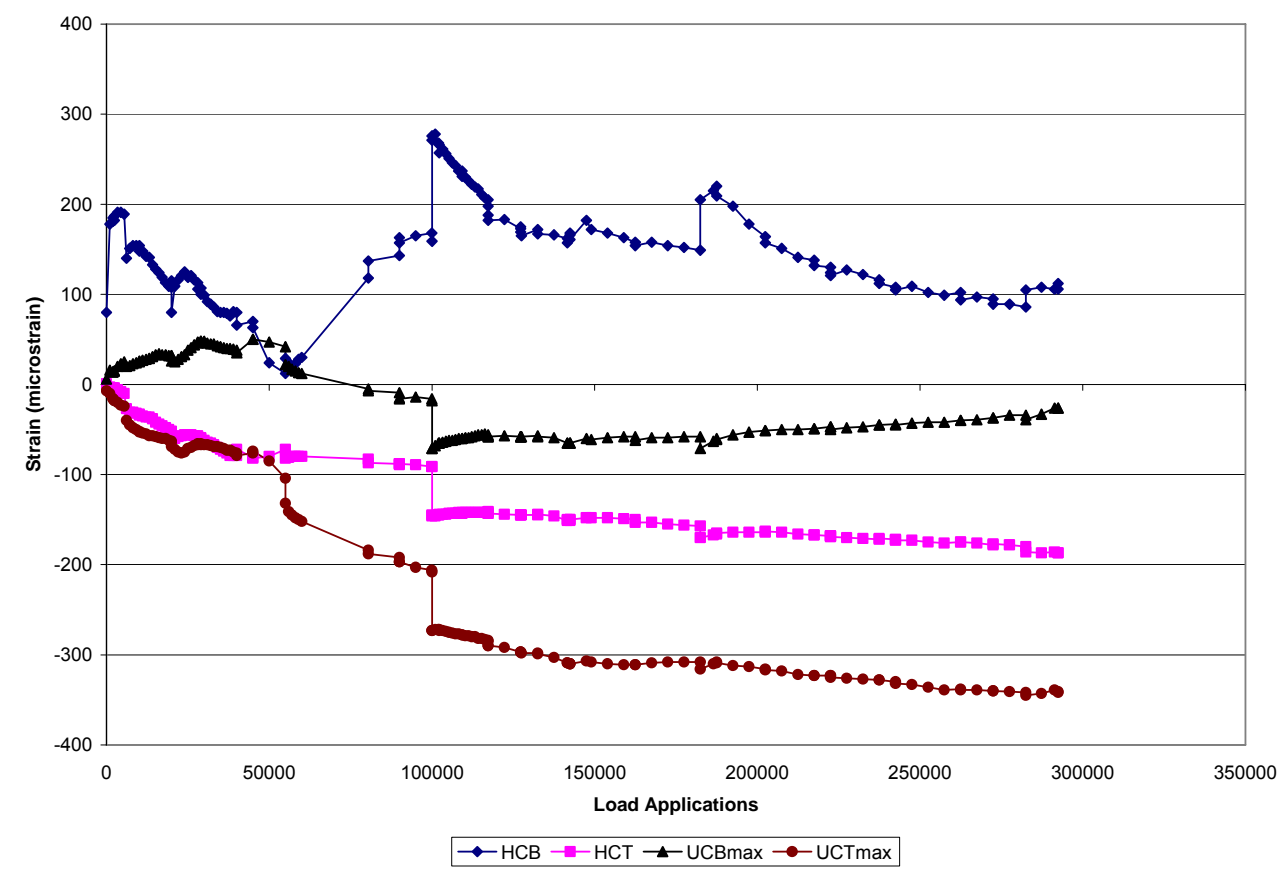

(b)

Figure B.31 Strain versus Load Applications - Test Area 3 - Lane 4 Loaded (a) Edge (b) Corner 


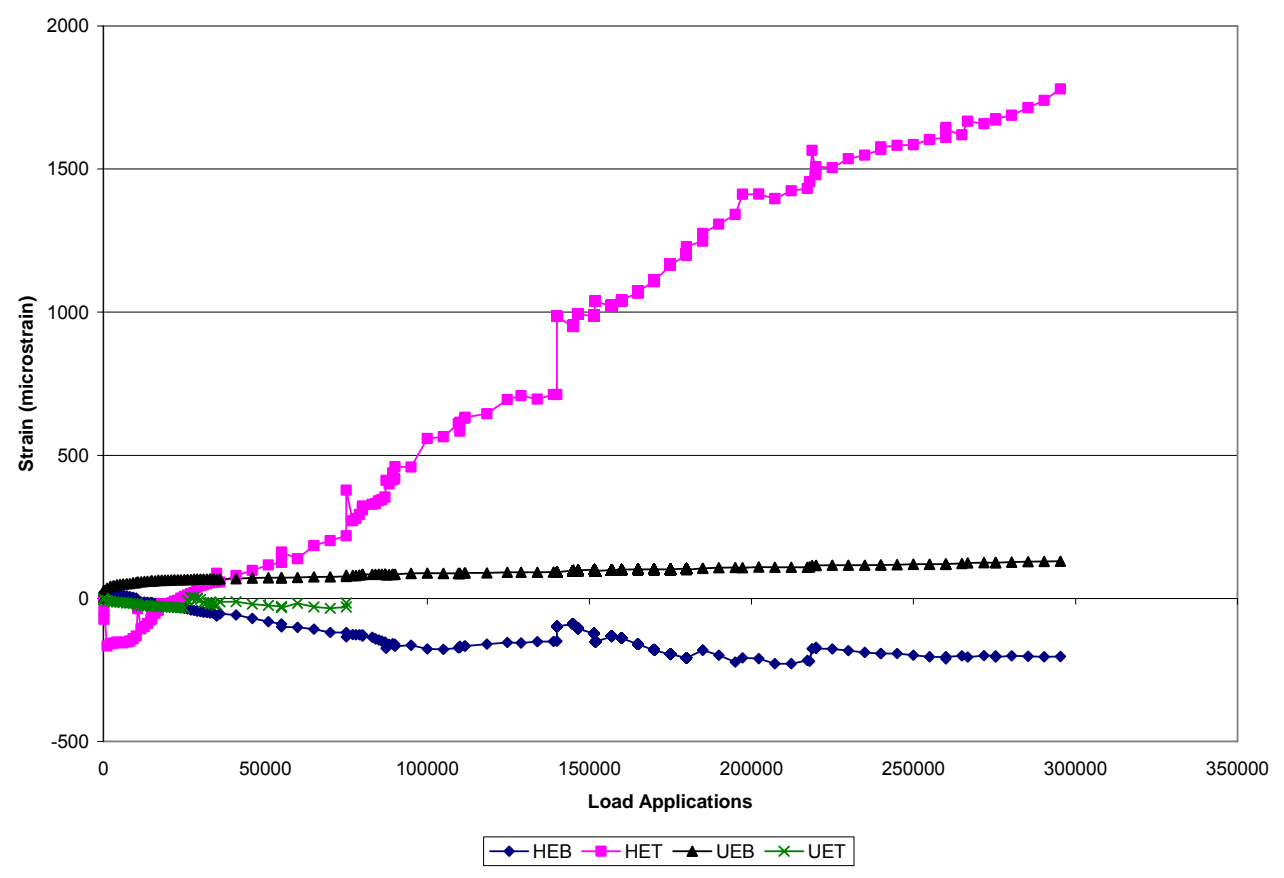

(a)

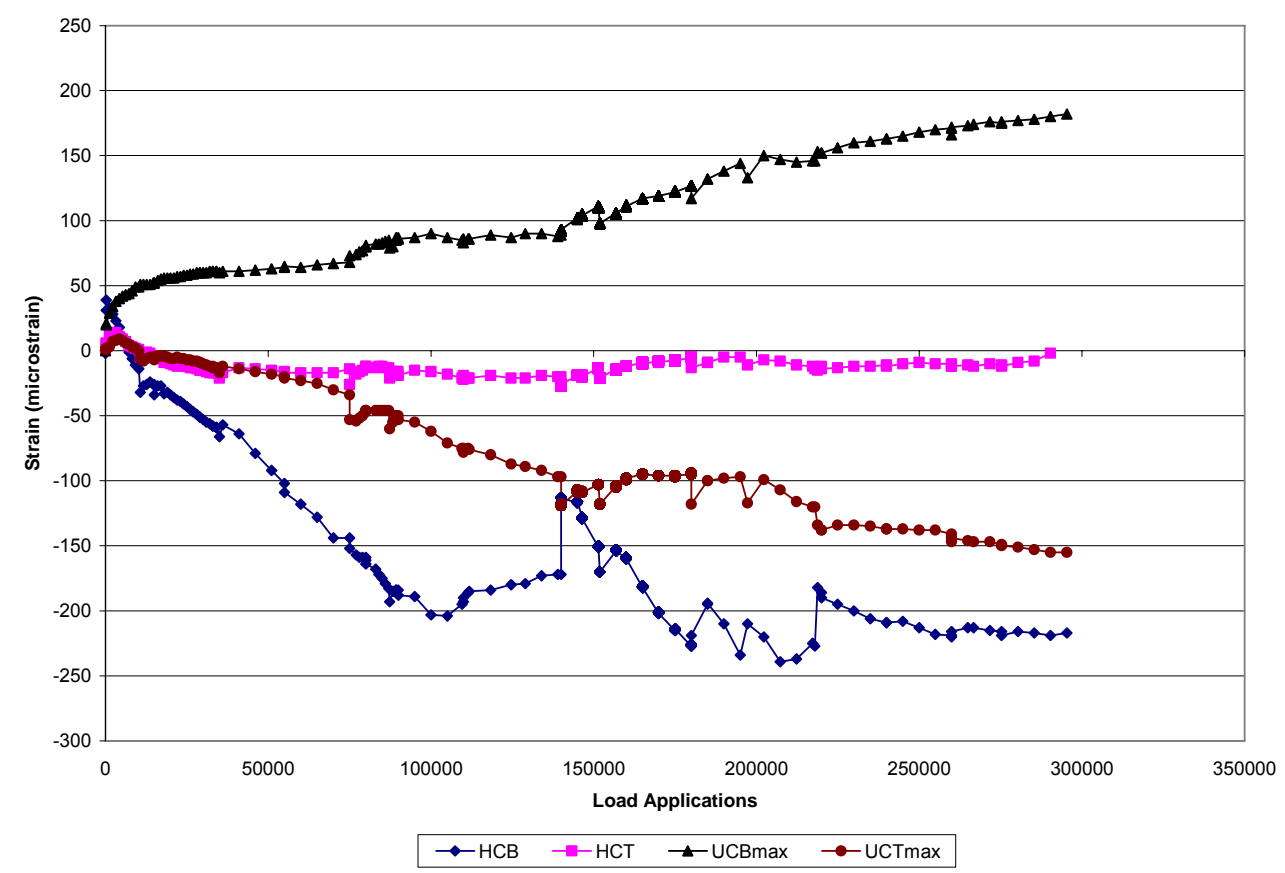

(b)

Figure B.32 Strain versus Load Applications - Test Area 3 - Lane 5 Unloaded (a) Edge (b) Corner 


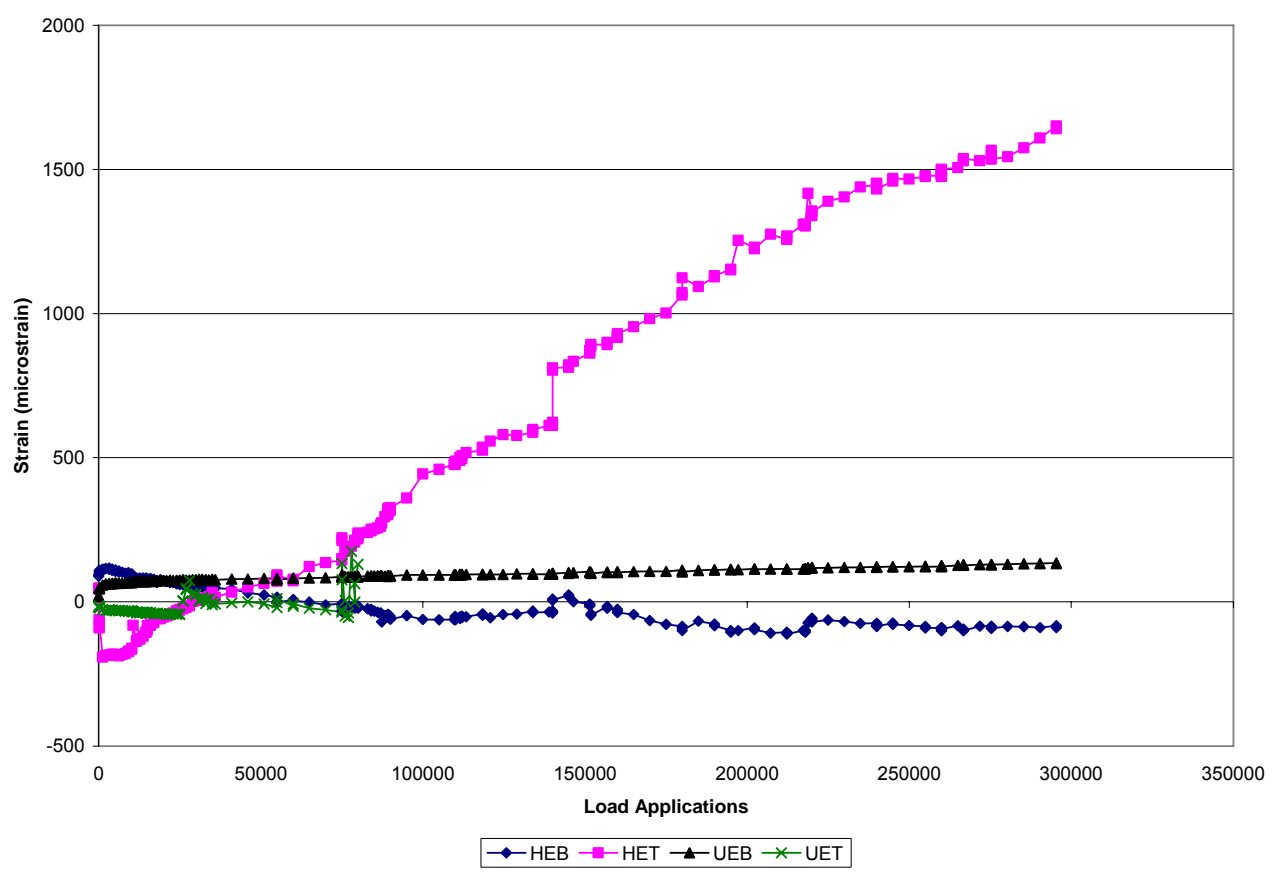

(a)

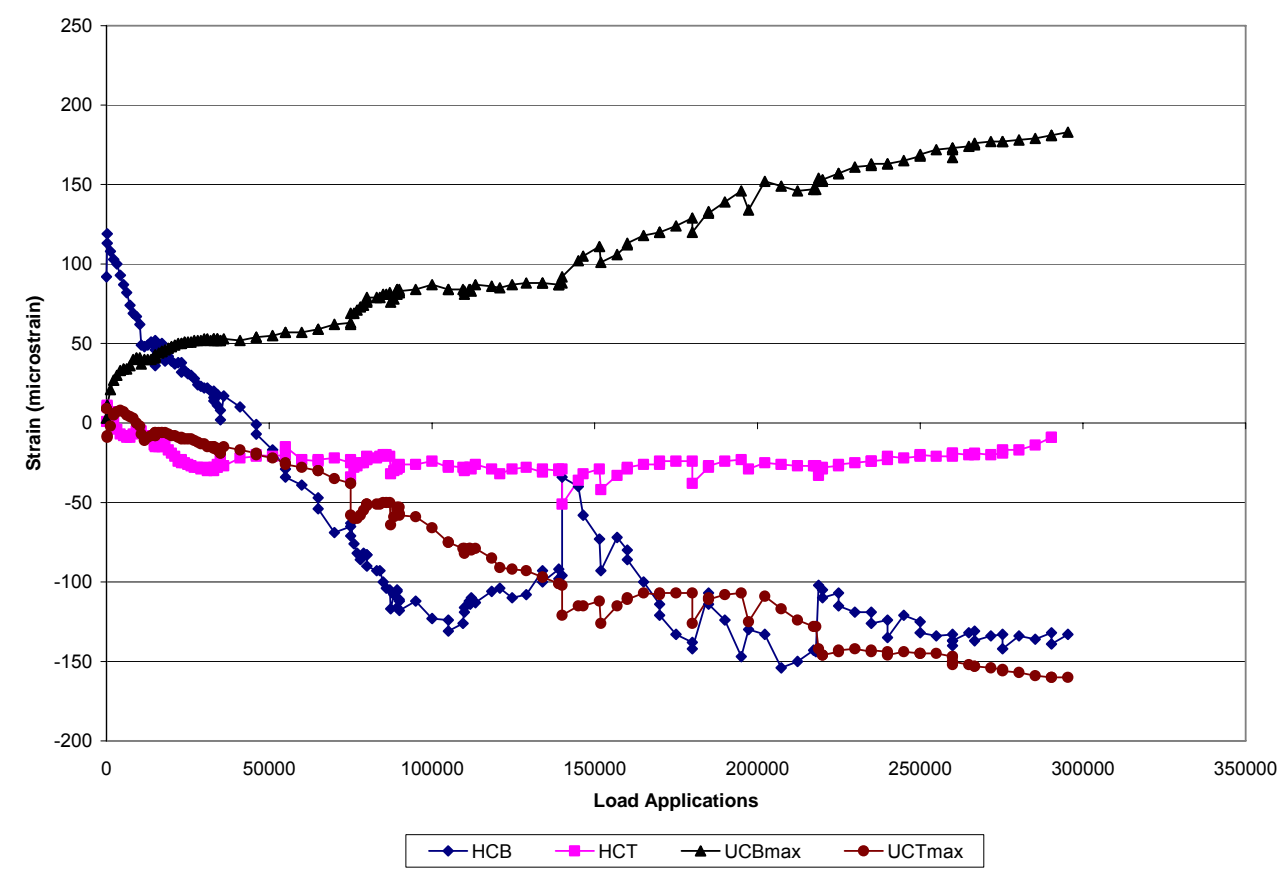

(b)

Figure B.33 Strain versus Load Applications - Test Area 3 - Lane 5 Loaded (a) Edge (b) Corner 


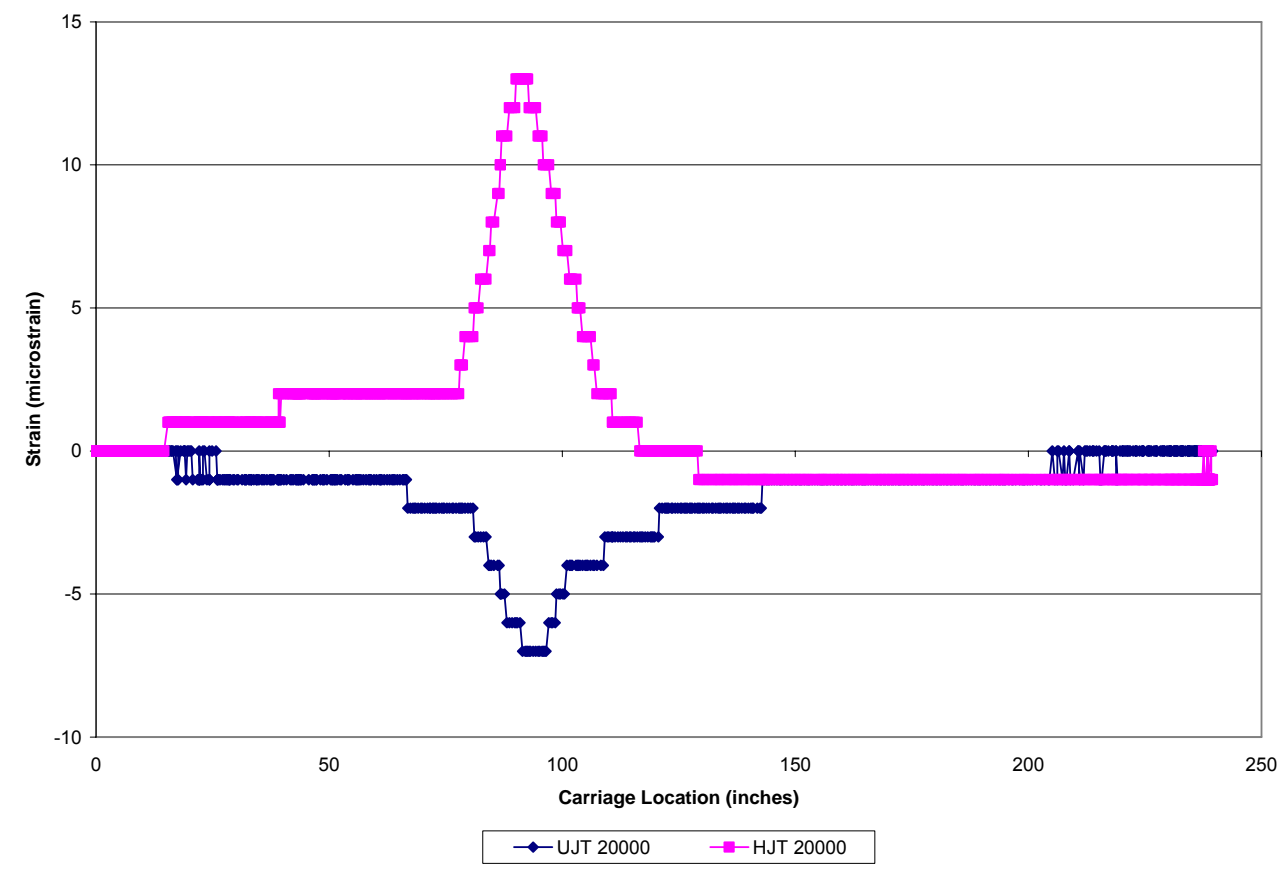

(a)

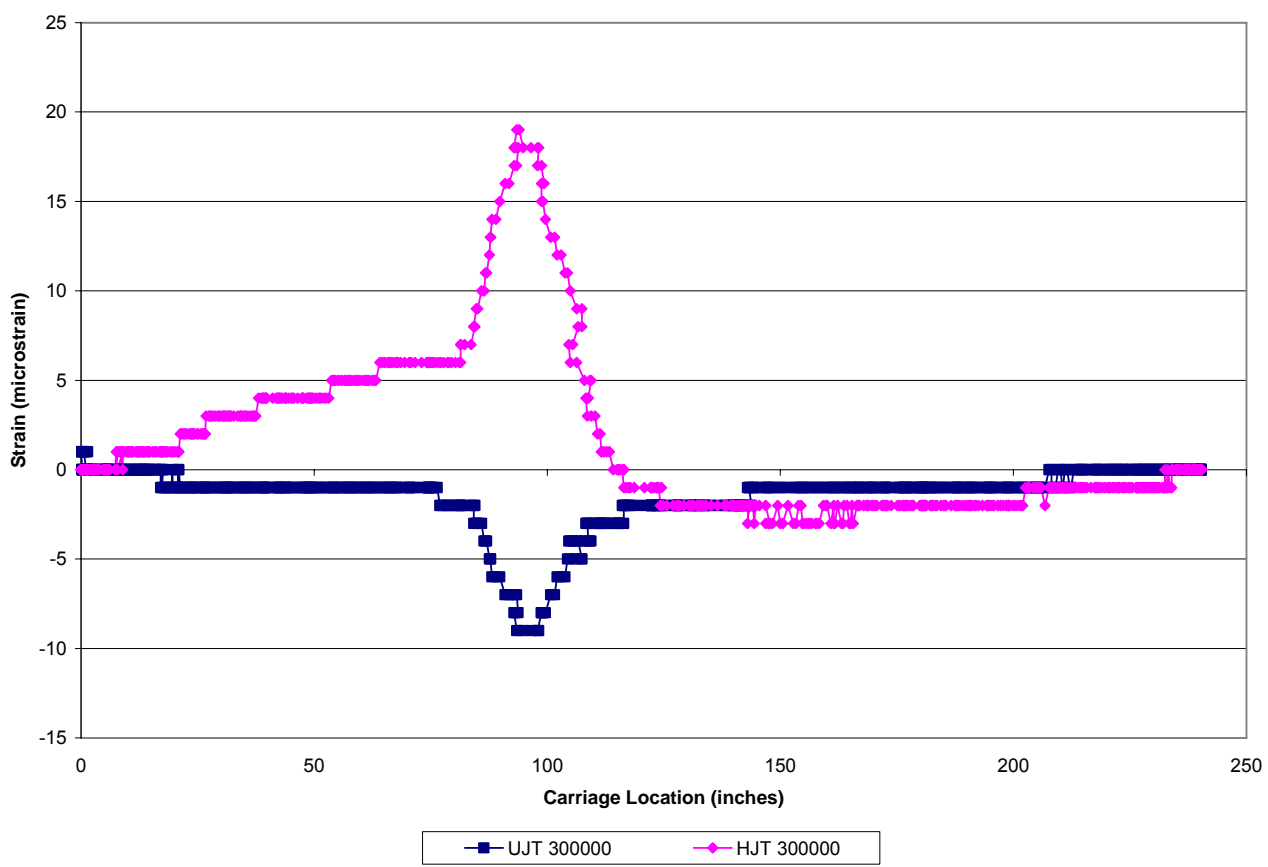

(b)

Figure B.34 Strain versus APT Carriage Location - Test Area 1 - Joint Location (a) 20,000 Load Applications (b) 300,000 Load Applications (c) 560,000 Load Applications (continued) 


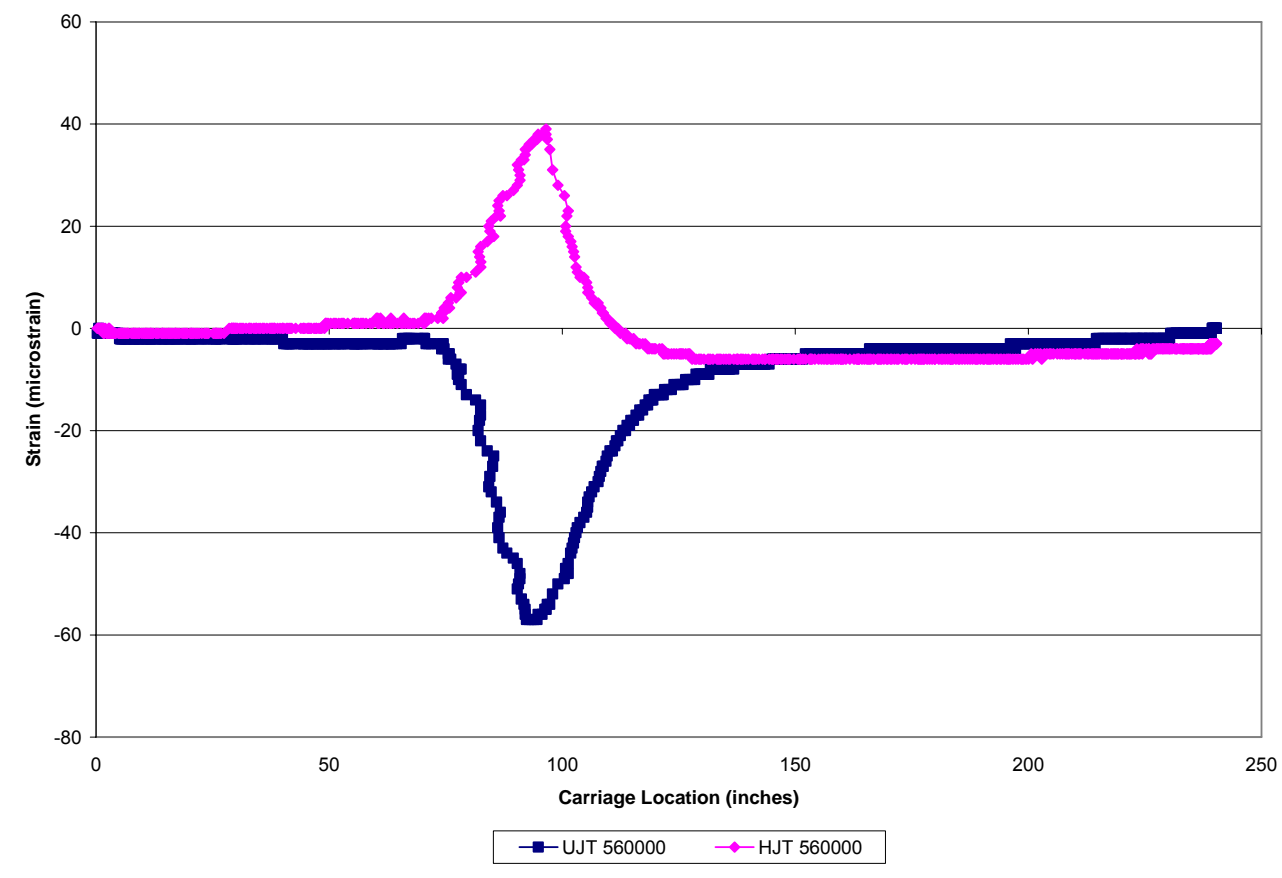

(c)

Figure B.34 Strain versus APT Carriage Location - Test Area 1 - Joint Location (a) 20,000 Load Applications (b) 300,000 Load Applications (c) 560,000 Load Applications 


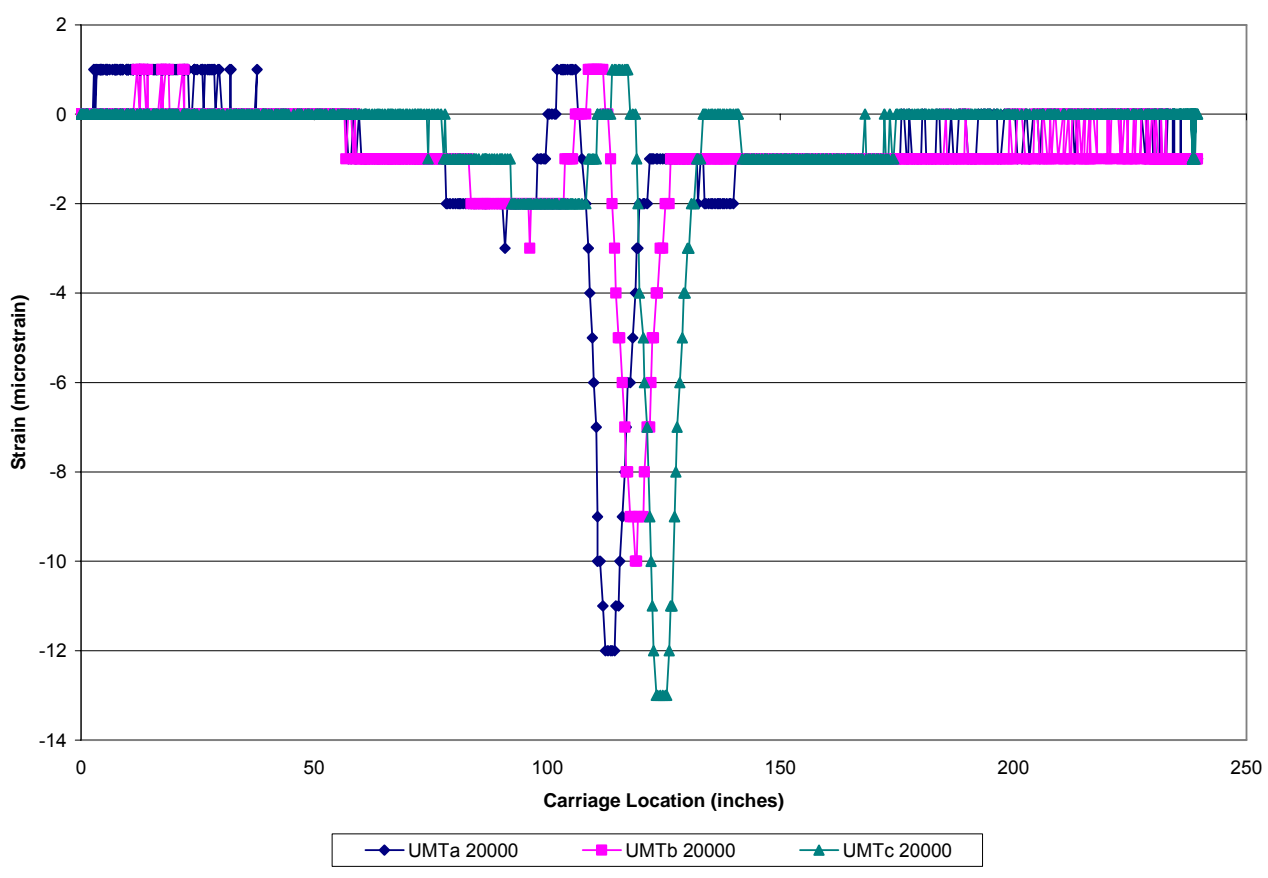

(a)

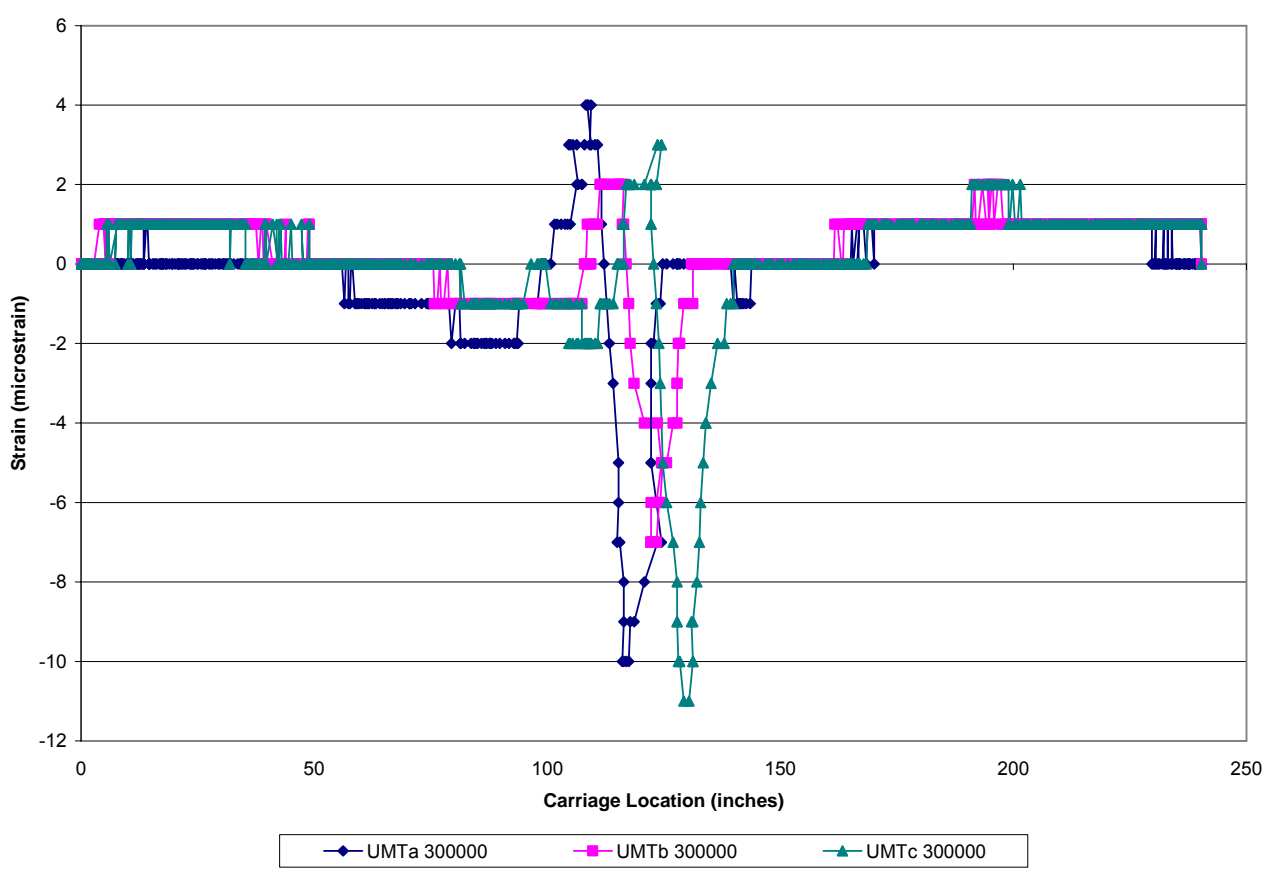

(b)

Figure B.35 Strain versus APT Carriage Location - Test Area 1 - Mid-Panel Location (a) 20,000 Load Applications (b) 300,000 Load Applications (c) 560,000 Load Applications (continued) 


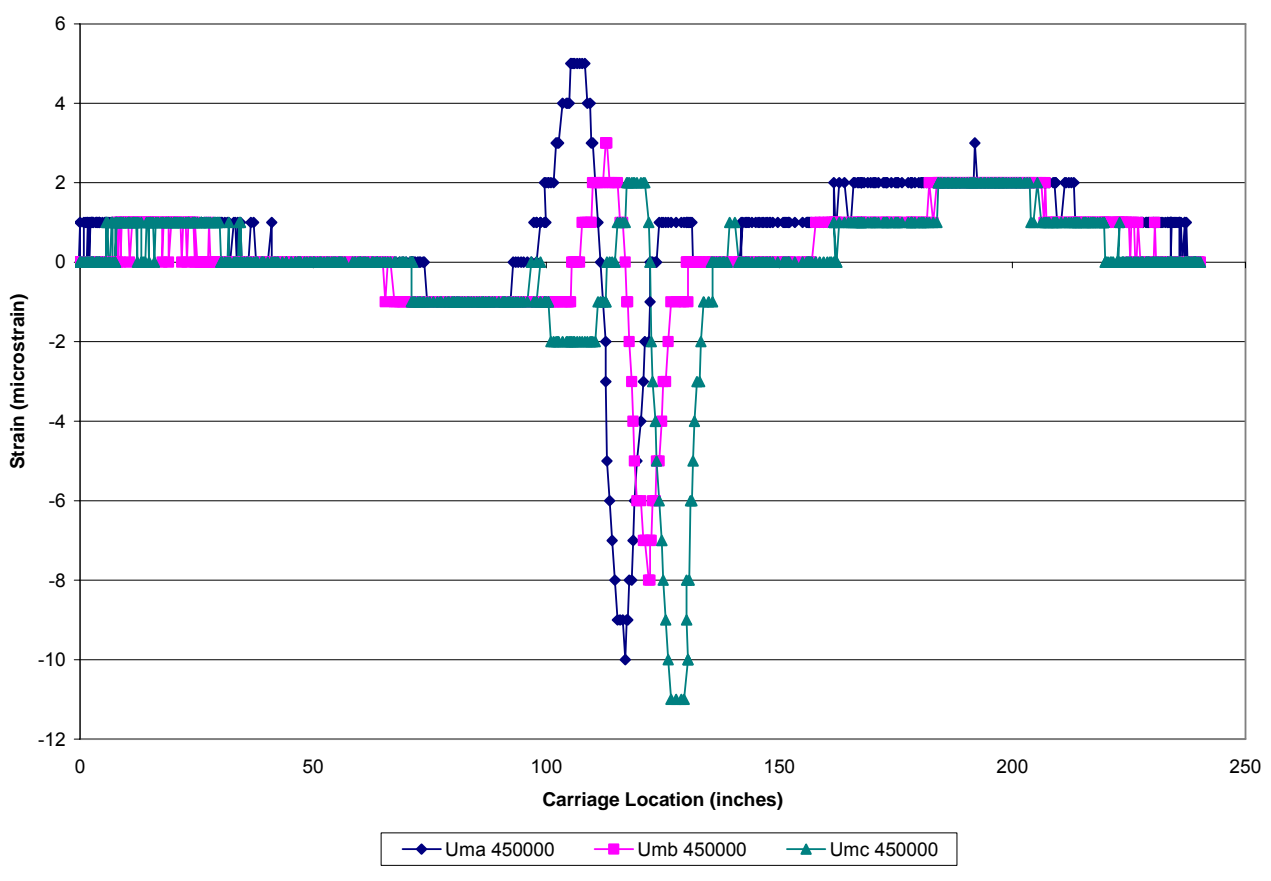

(c)

Figure B.35 Strain versus APT Carriage Location - Test Area 1 - Mid-Panel Location (a) 20,000 Load Applications (b) 300,000 Load Applications (c) 450,000 Load Applications 


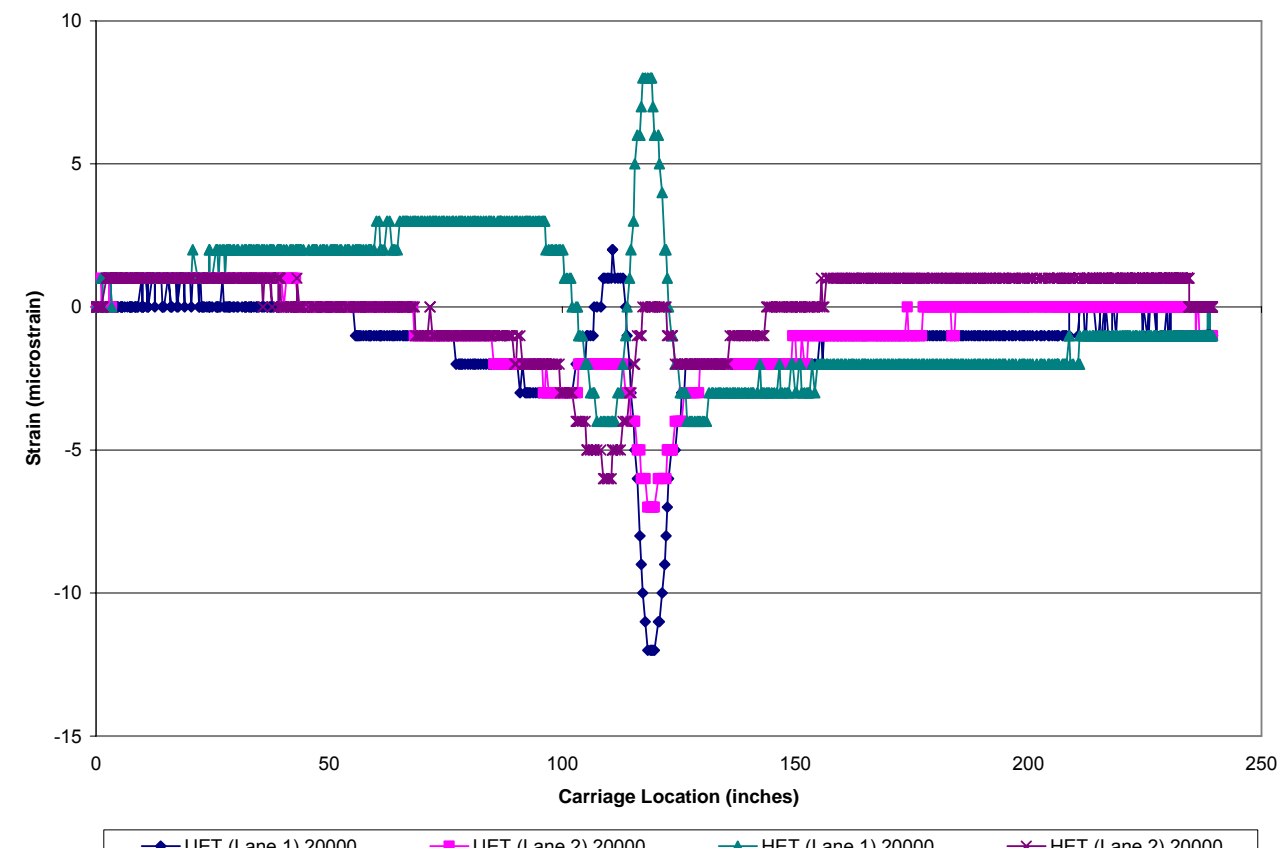

(a)

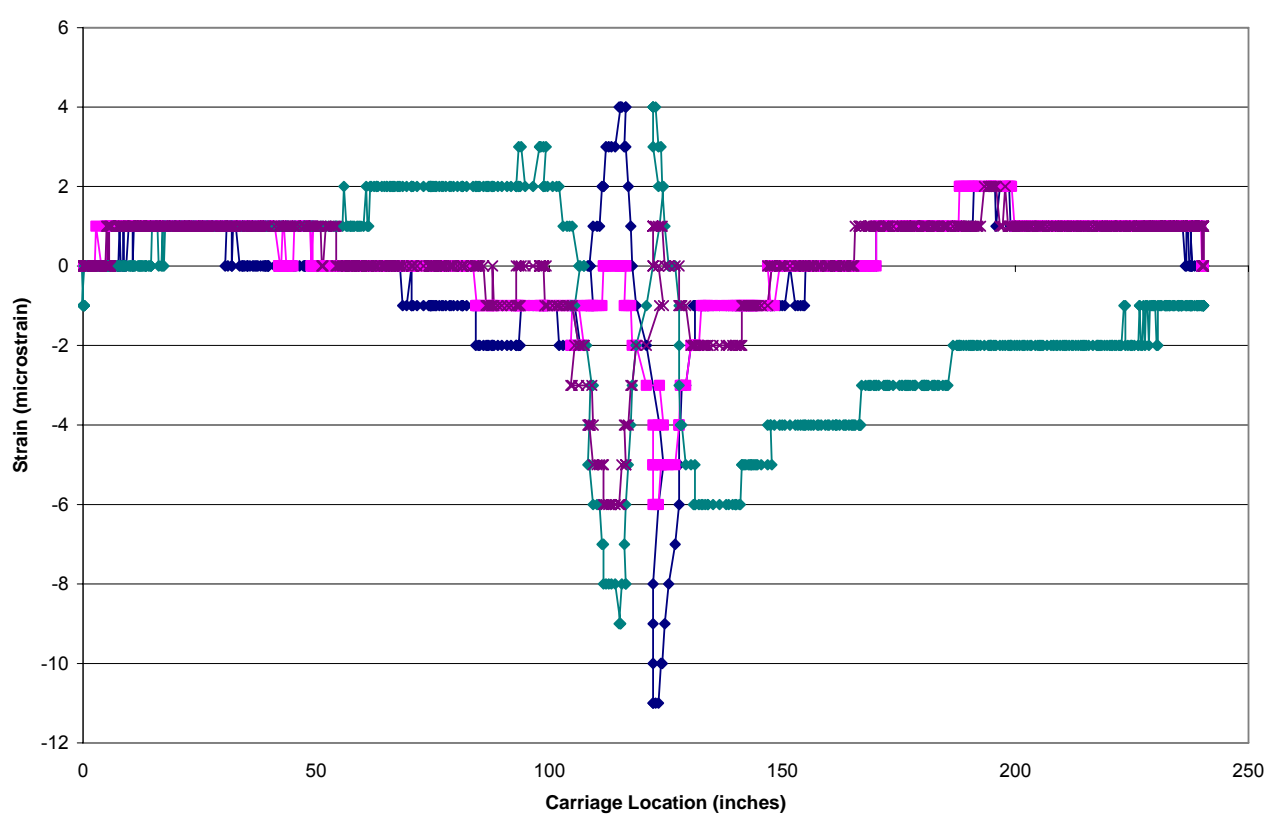

$\rightarrow-$ UET (Lane 1) $300000 \quad \rightarrow-$ UET (Lane 2) $300000 \quad \rightarrow-$ HET (Lane 1) $300000 \quad *$ HET (Lane 2) 300000

(b)

Figure B.36 Strain versus APT Carriage Location - Test Area 1 - Edge Location

(a) 20,000 Load Applications (b) 300,000 Load Applications (c) 560,000 Load Applications (continued) 


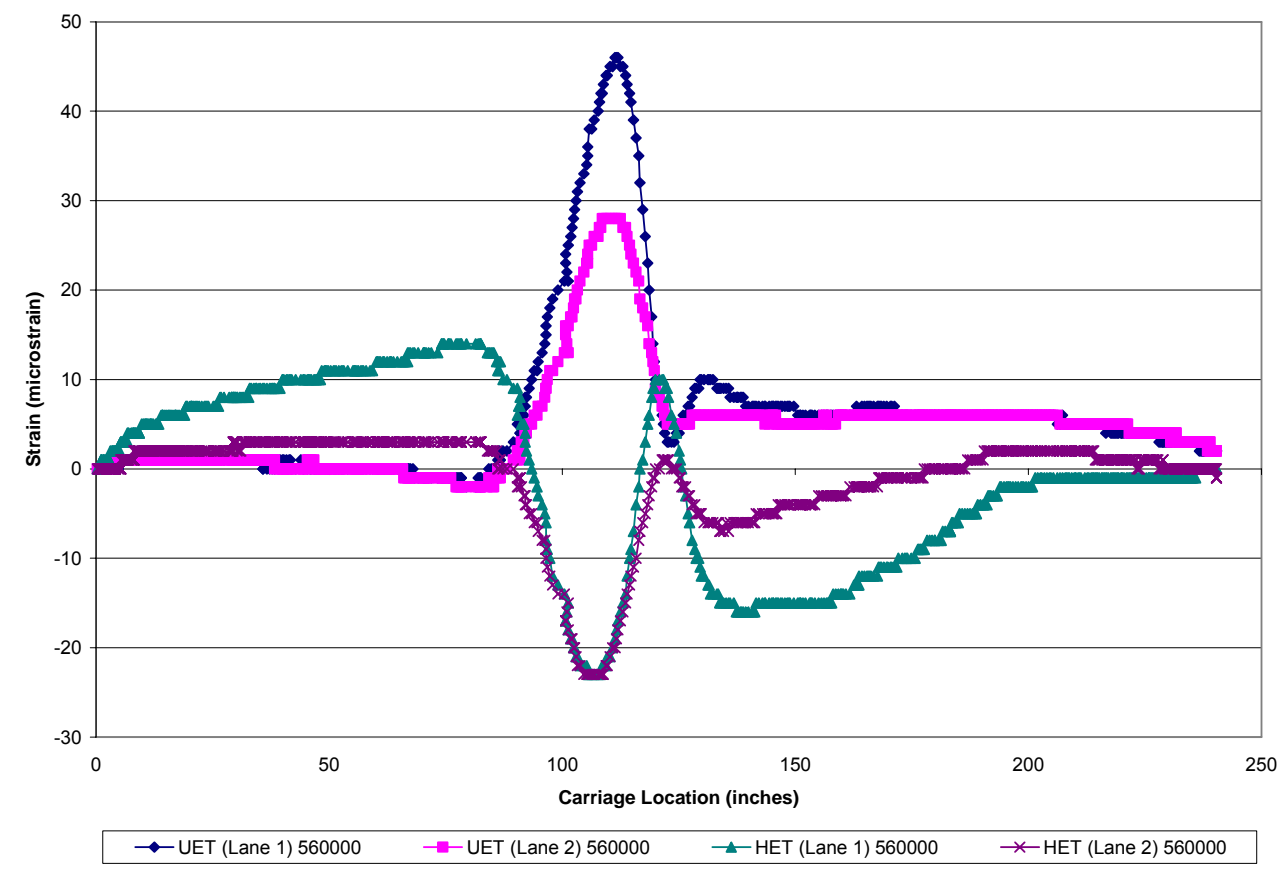

(c)

Figure B.36 Strain versus APT Carriage Location - Test Area 1 - Edge Location (a) 20,000 Load Applications (b) 300,000 Load Applications (c) 560,000 Load Applications 


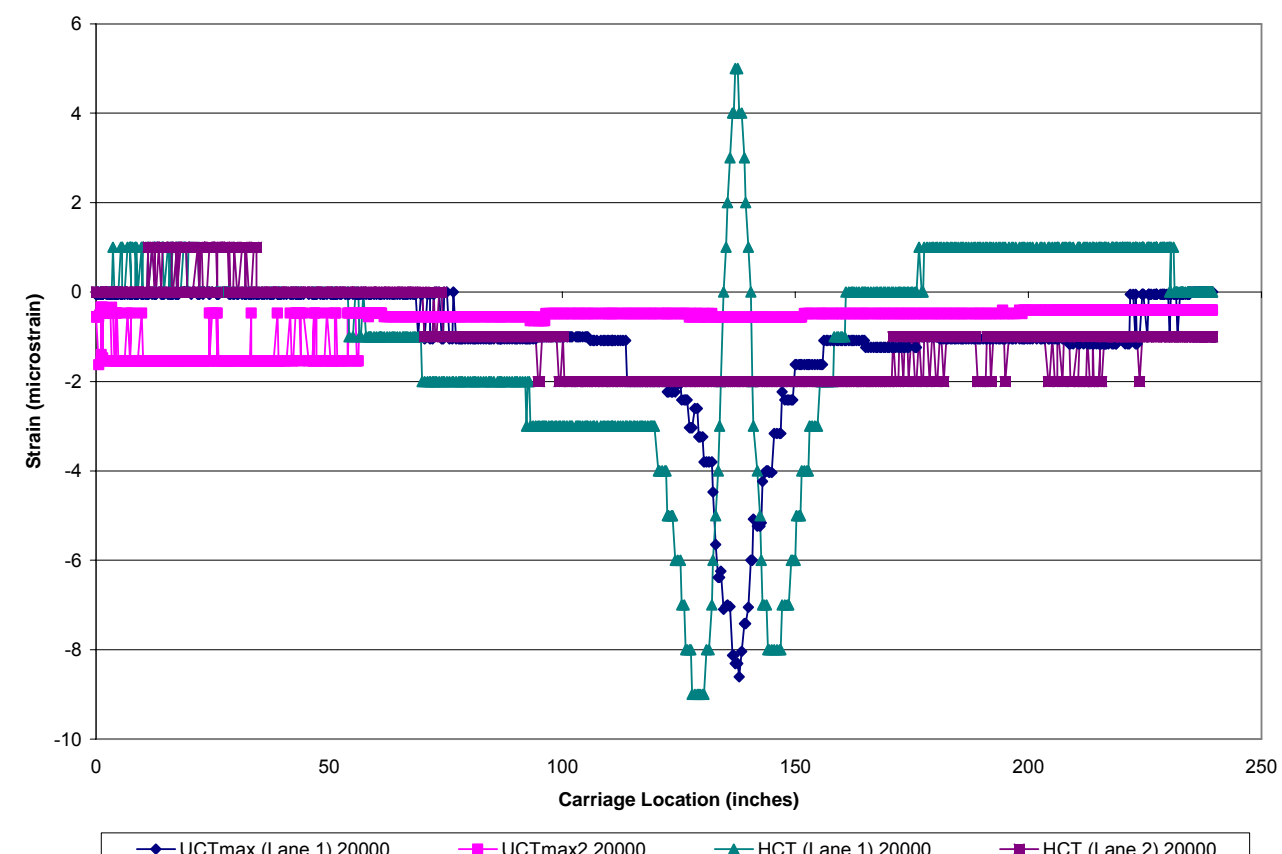

(a)

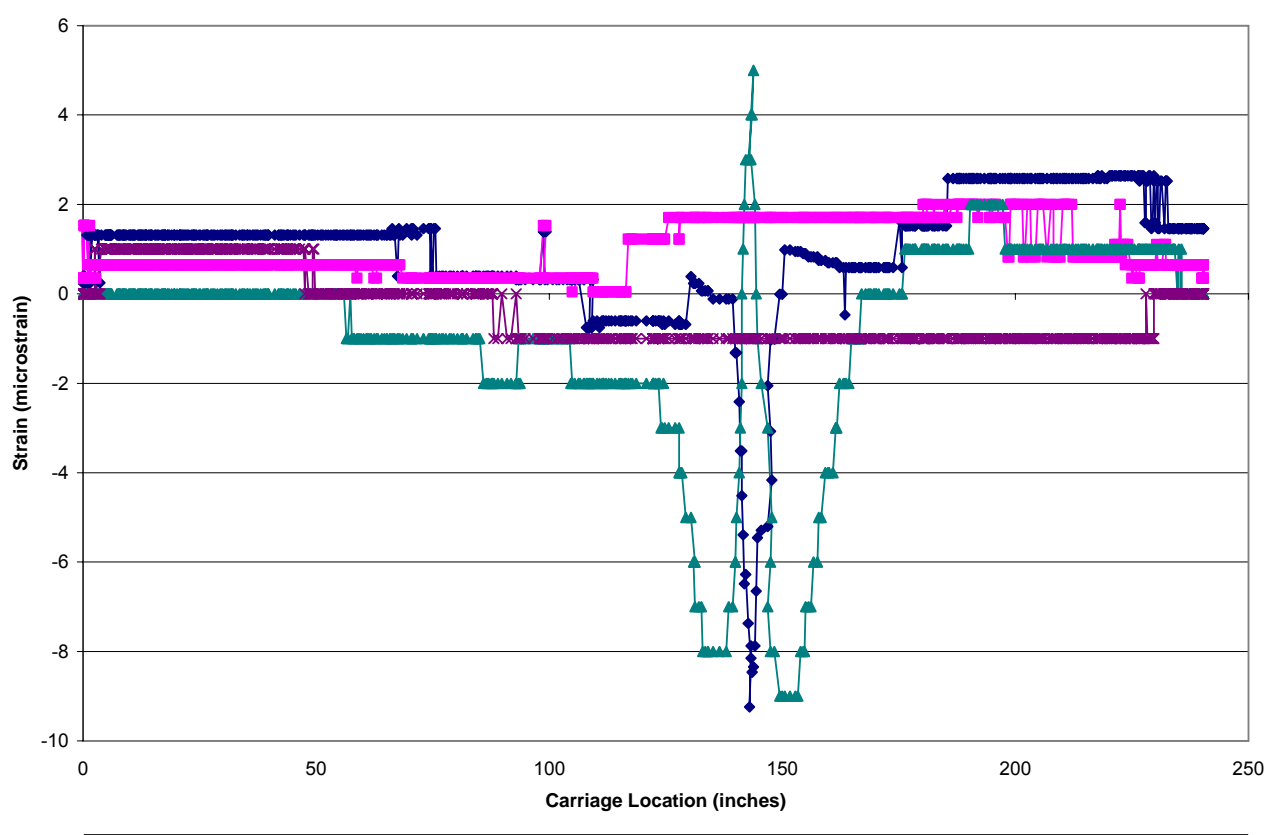

(b)

Figure B.37 Strain versus APT Carriage Location - Test Area 1 - Corner Location (a) 20,000 Load Applications (b) 300,000 Load Applications (c) 560,000 Load Applications (continued) 


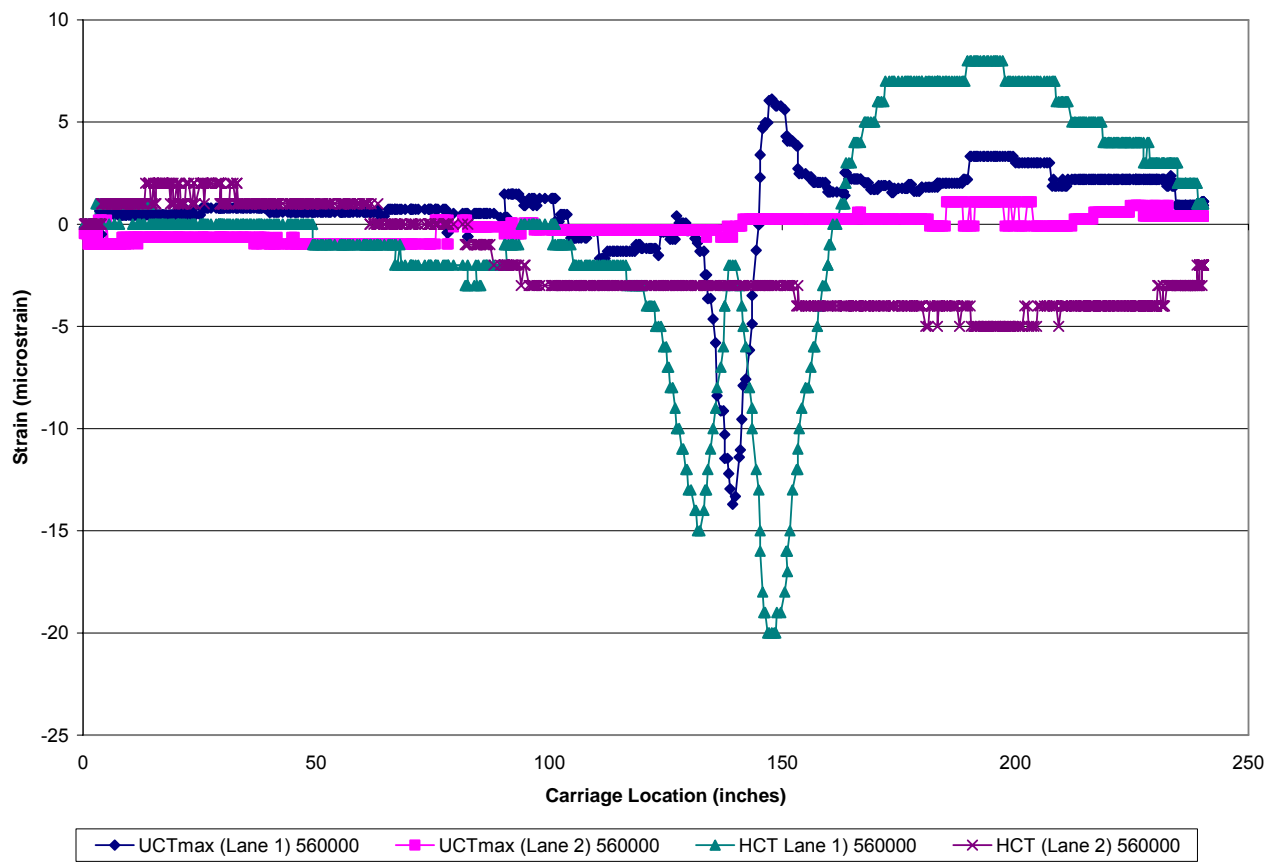

(c)

Figure B.37 Strain versus APT Carriage Location - Test Area 1 - Corner Location (a) 20,000 Load Applications (b) 300,000 Load Applications (c) 560,000 Load Applications 


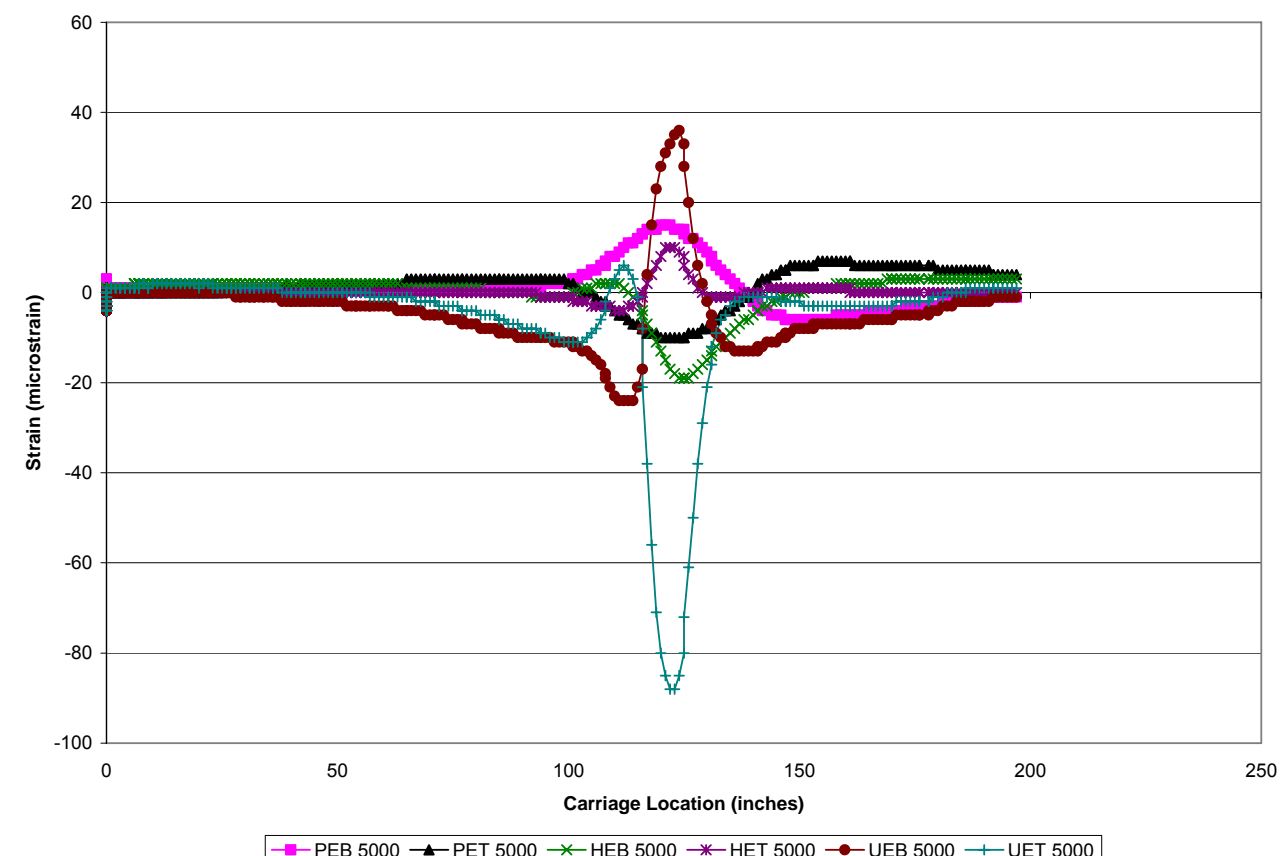

(a)

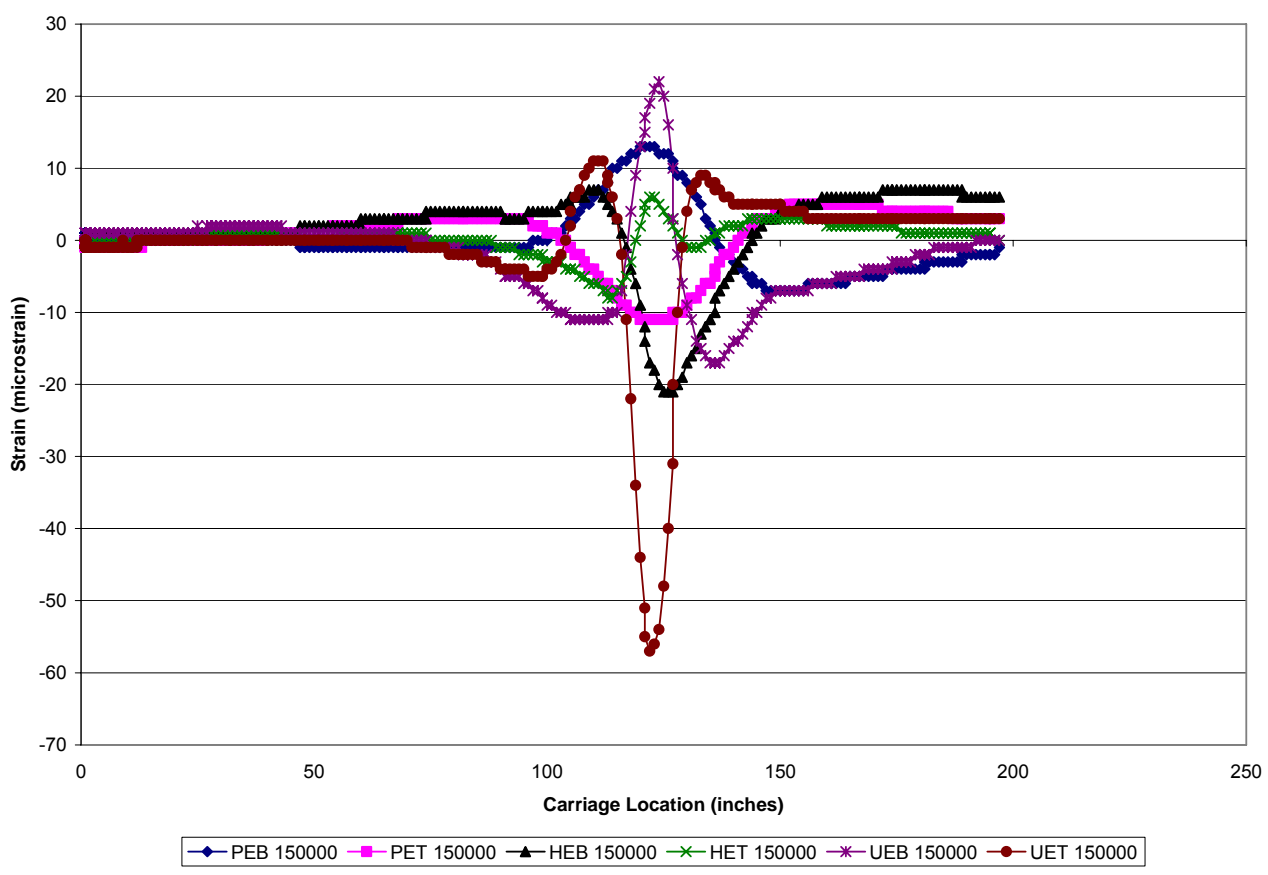

(b)

Figure B.38 Strain versus APT Carriage Location - Test Area 2 - Lane 1 - Edge Location (a) 5,000 Load Applications (b) 150,000 Load Applications (c) 275,000 Load Applications (continued) 


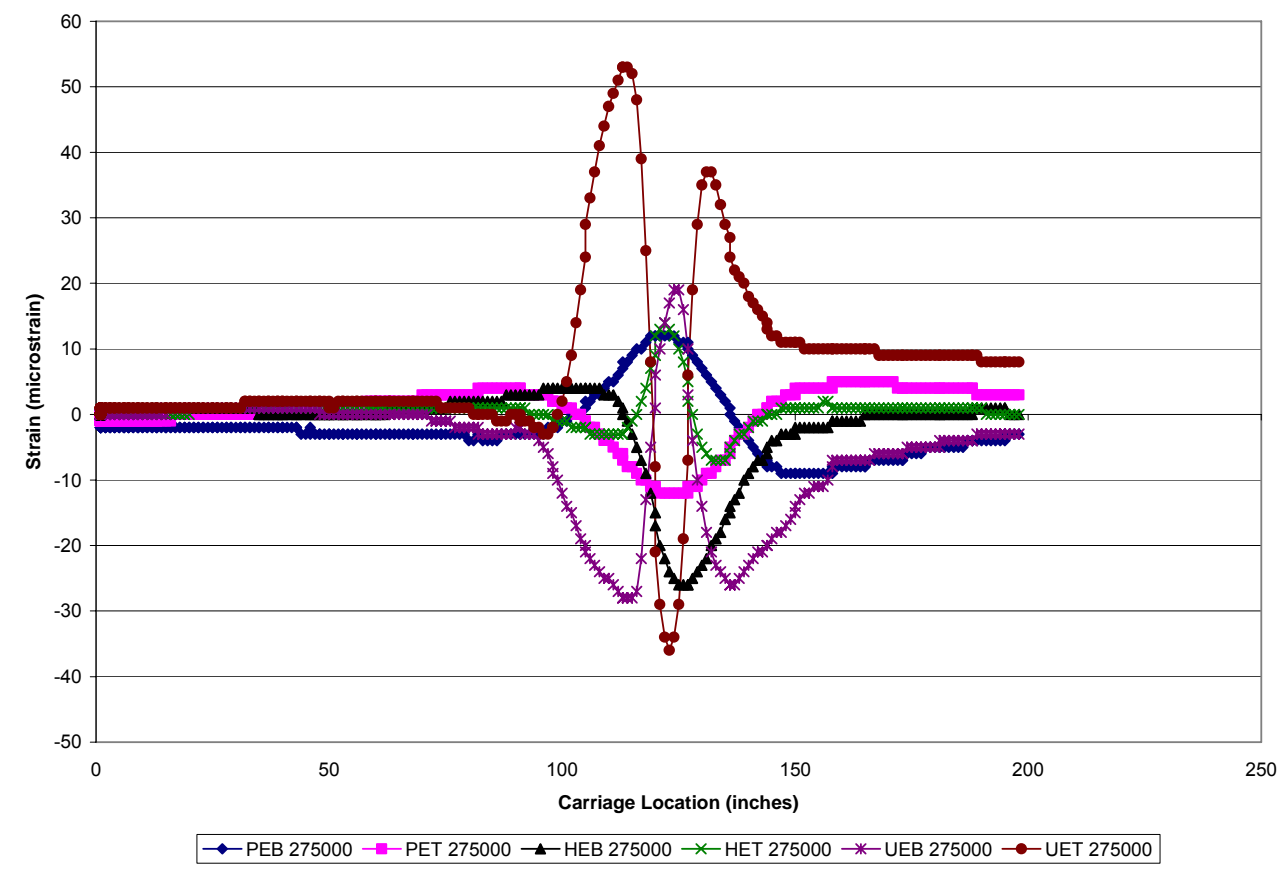

(c)

Figure B.38 Strain versus APT Carriage Location - Test Area 2 - Lane 1 - Edge Location (a) 5,000 Load Applications (b) 150,000 Load Applications (c) 275,000 Load Applications 


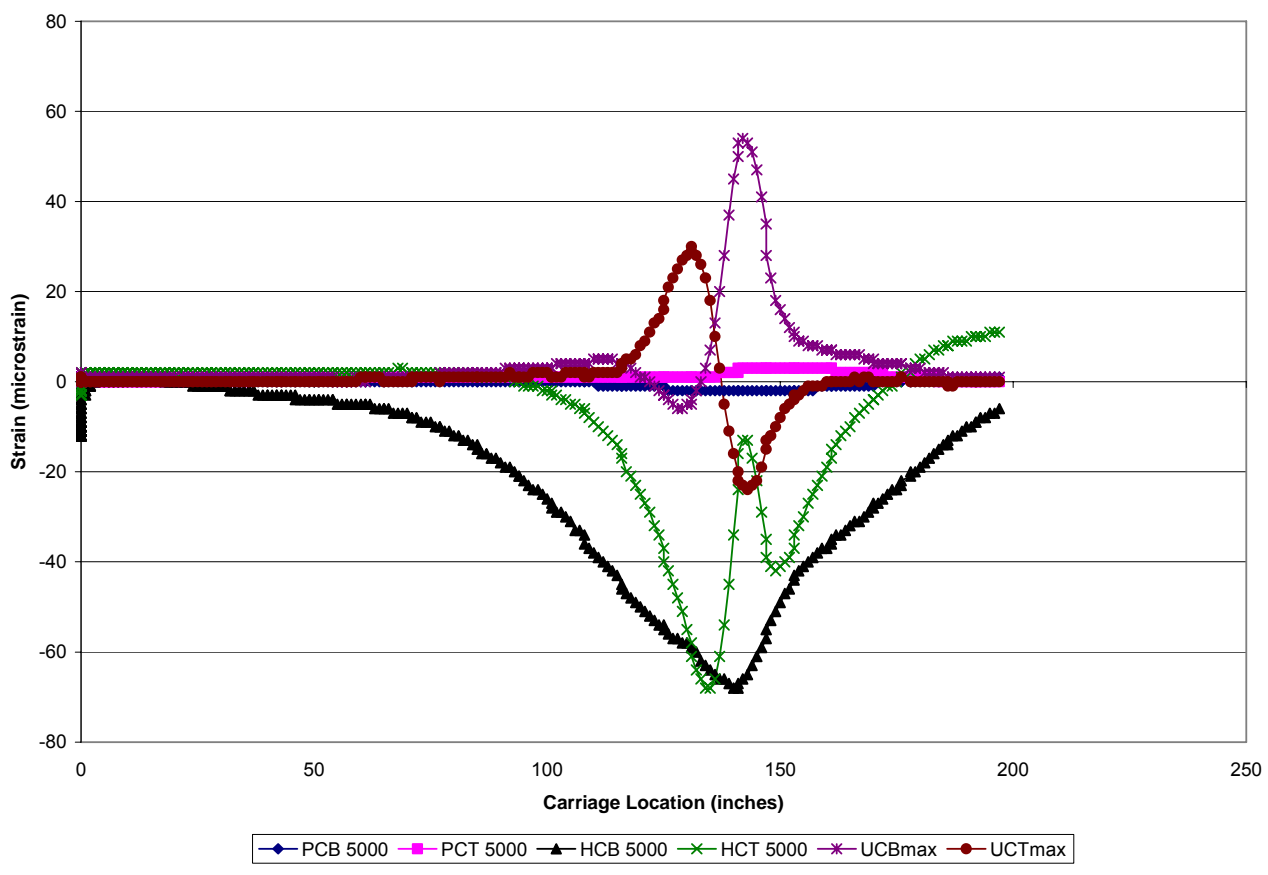

(a)

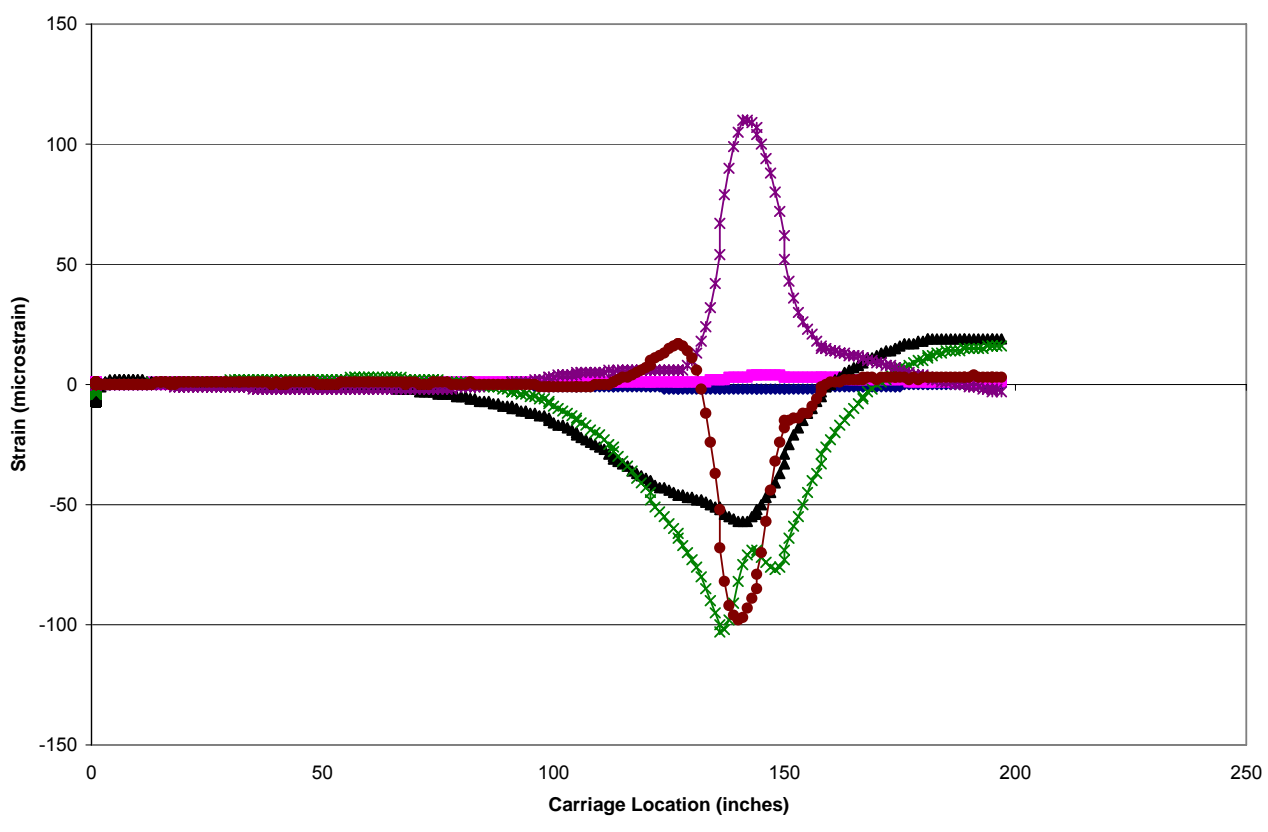

$\rightarrow-$ PCB $150000-$-PCT $150000 \rightarrow$ HCB $150000 *$ HCT $150000 \rightarrow$ UCBmax $150000 \rightarrow-$ UCTmax 150000

(b)

Figure B.39 Strain versus APT Carriage Location - Test Area 2 - Lane 1 Corner Location (a) 5,000 Load Applications (b) 150,000 Load Applications (c) 275,000 Load Applications (continued) 


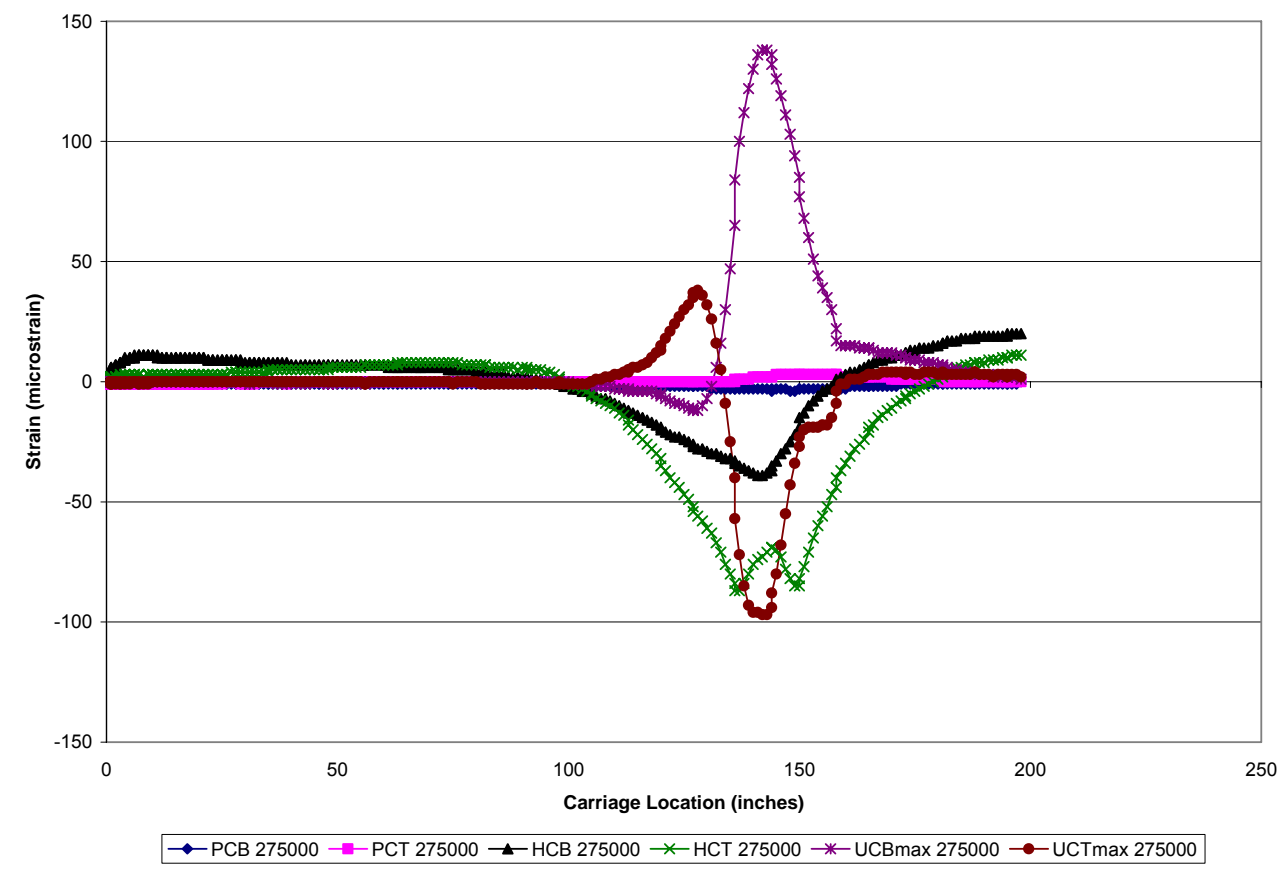

(c)

Figure B.39 Strain versus APT Carriage Location - Test Area 2 - Lane 1 Corner Location (a) 5,000 Load Applications (b) 150,000 Load Applications (c) 275,000 Load Applications 


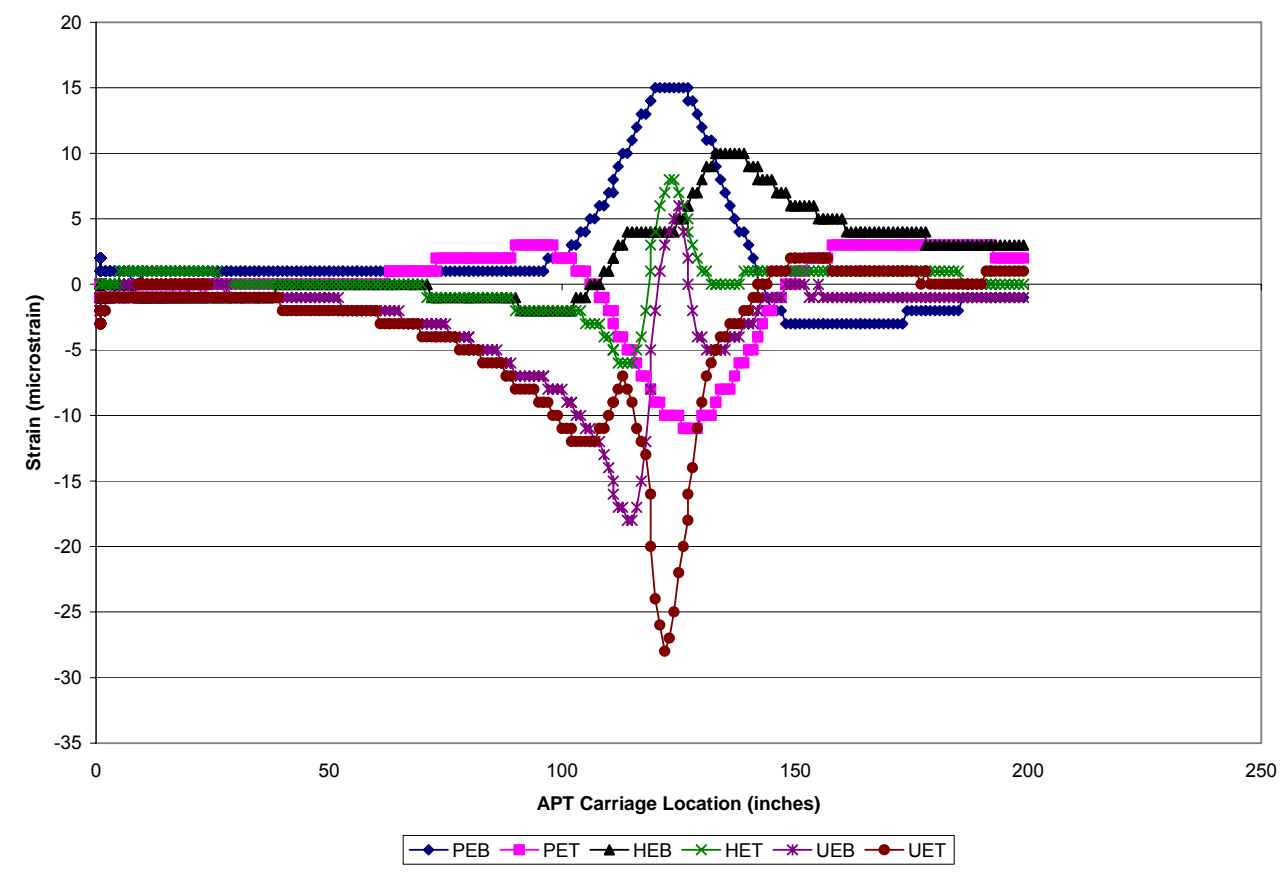

(a)

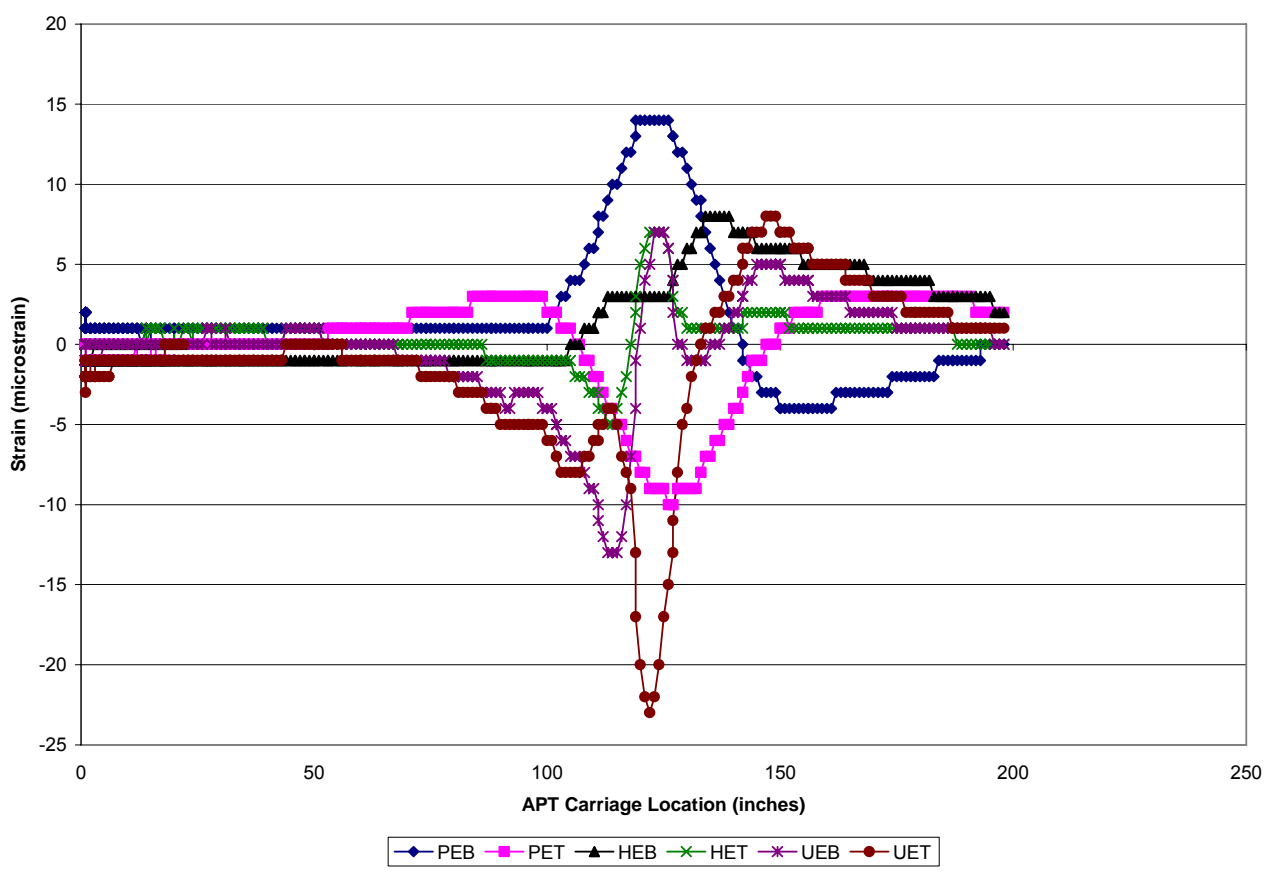

(b)

Figure B.40 Strain versus APT Carriage Location - Test Area 2 - Lane 2 - Edge Location (a) 5,000 Load Applications (b) 150,000 Load Applications (c) 275,000 Load Applications (continued) 


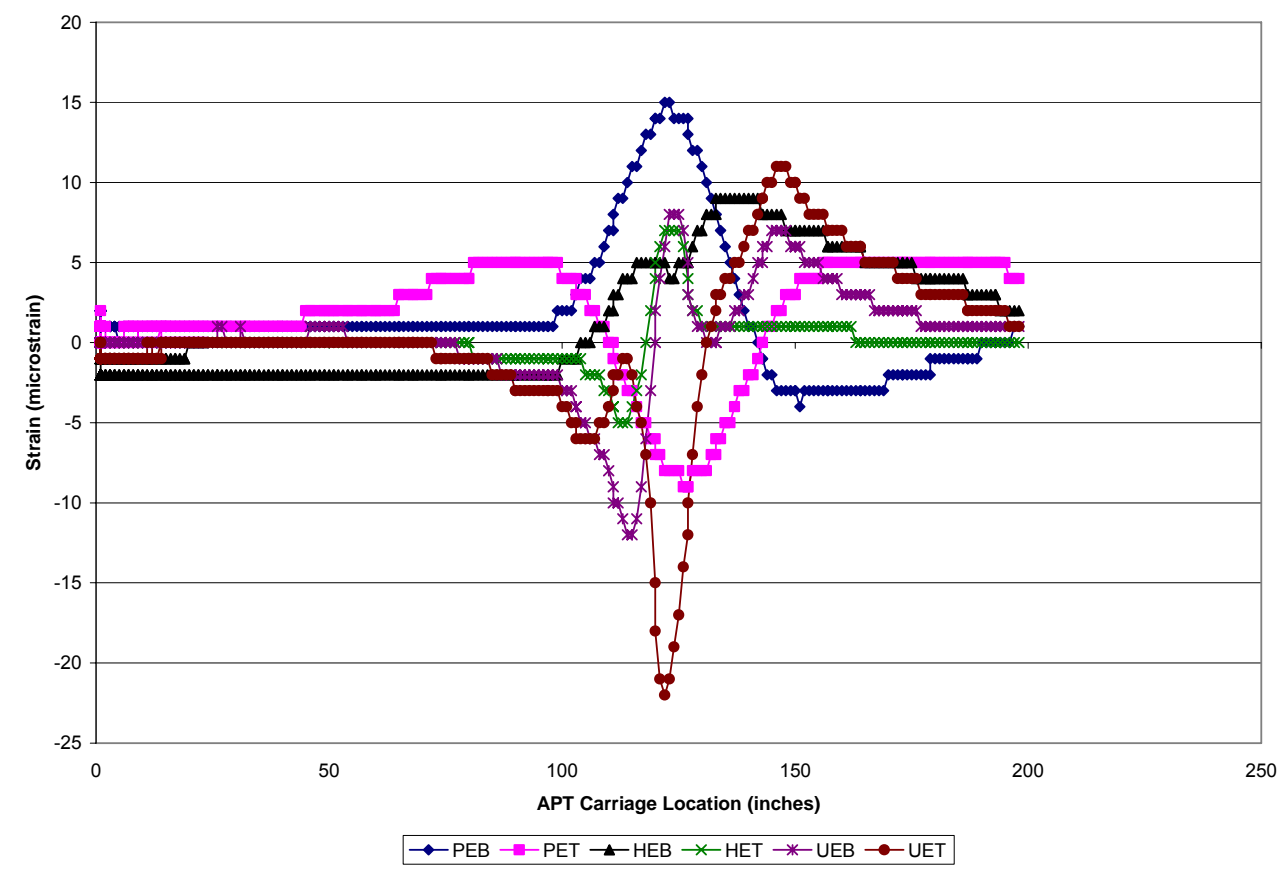

(c)

Figure B.40 Strain versus APT Carriage Location - Test Area 2 - Lane 2 - Edge Location (a) 5,000 Load Applications (b) 150,000 Load Applications (c) 275,000 Load Applications 


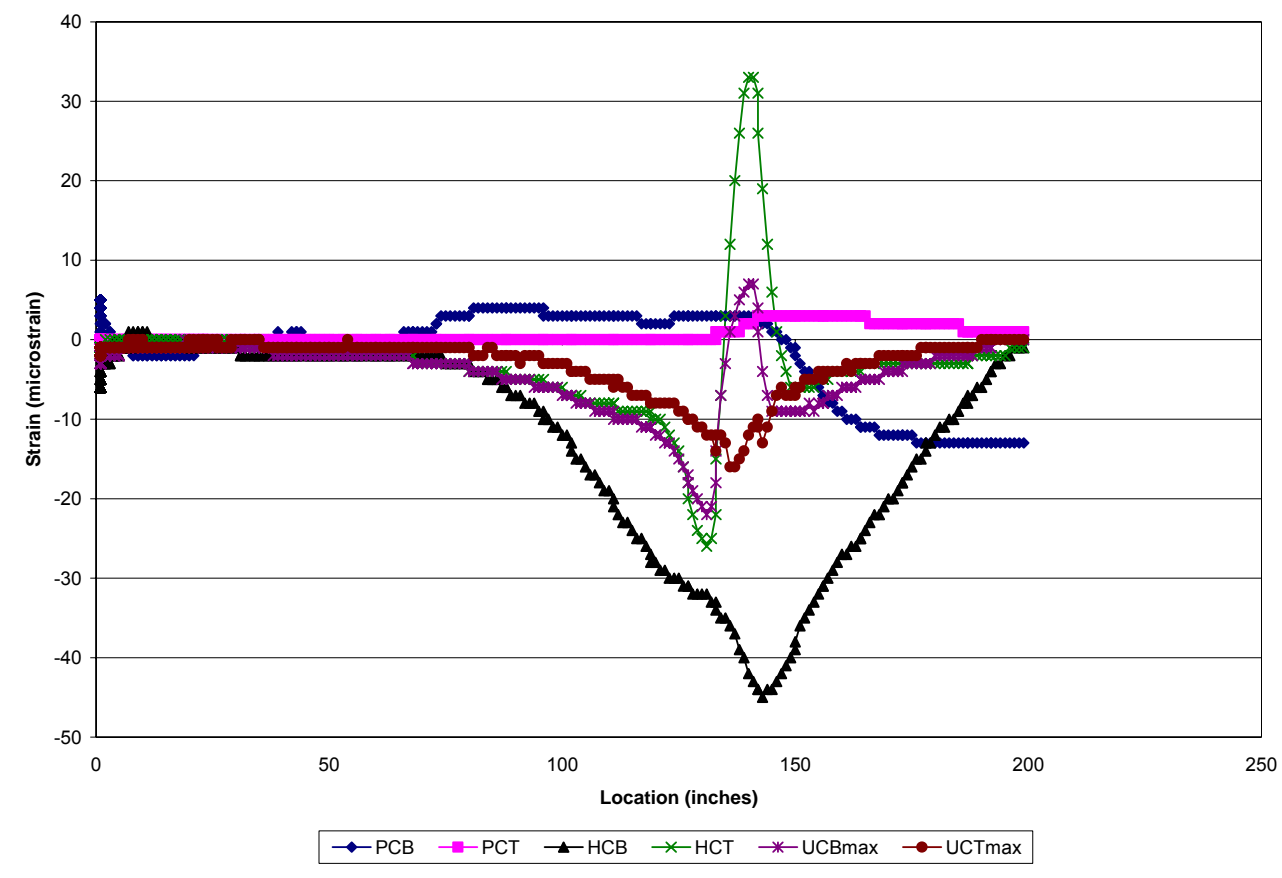

(a)

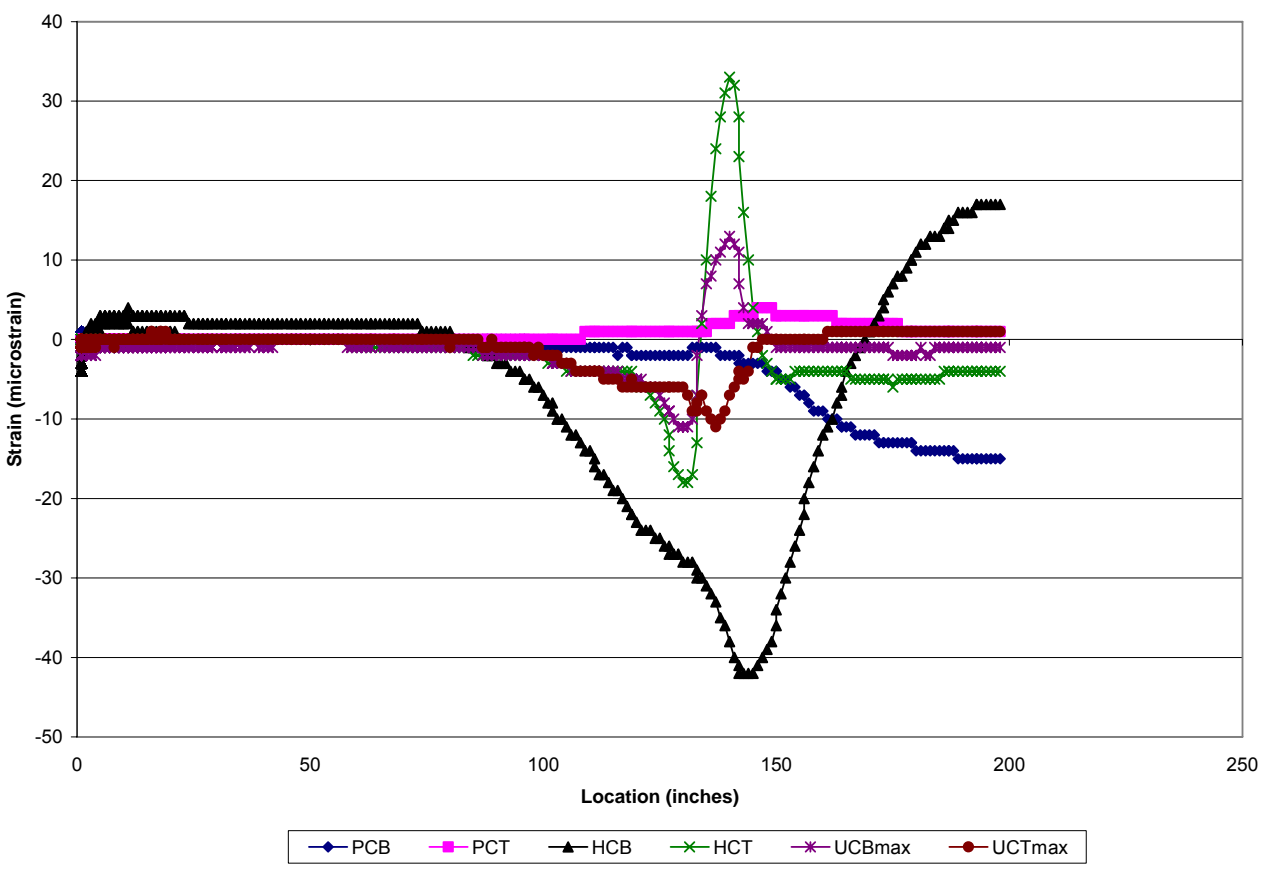

(b)

Figure B.41 Strain versus APT Carriage Location - Test Area 2 - Lane 2 Corner Location (a) 5,000 Load Applications (b) 150,000 Load Applications (c) 275,000 Load Applications (continued) 


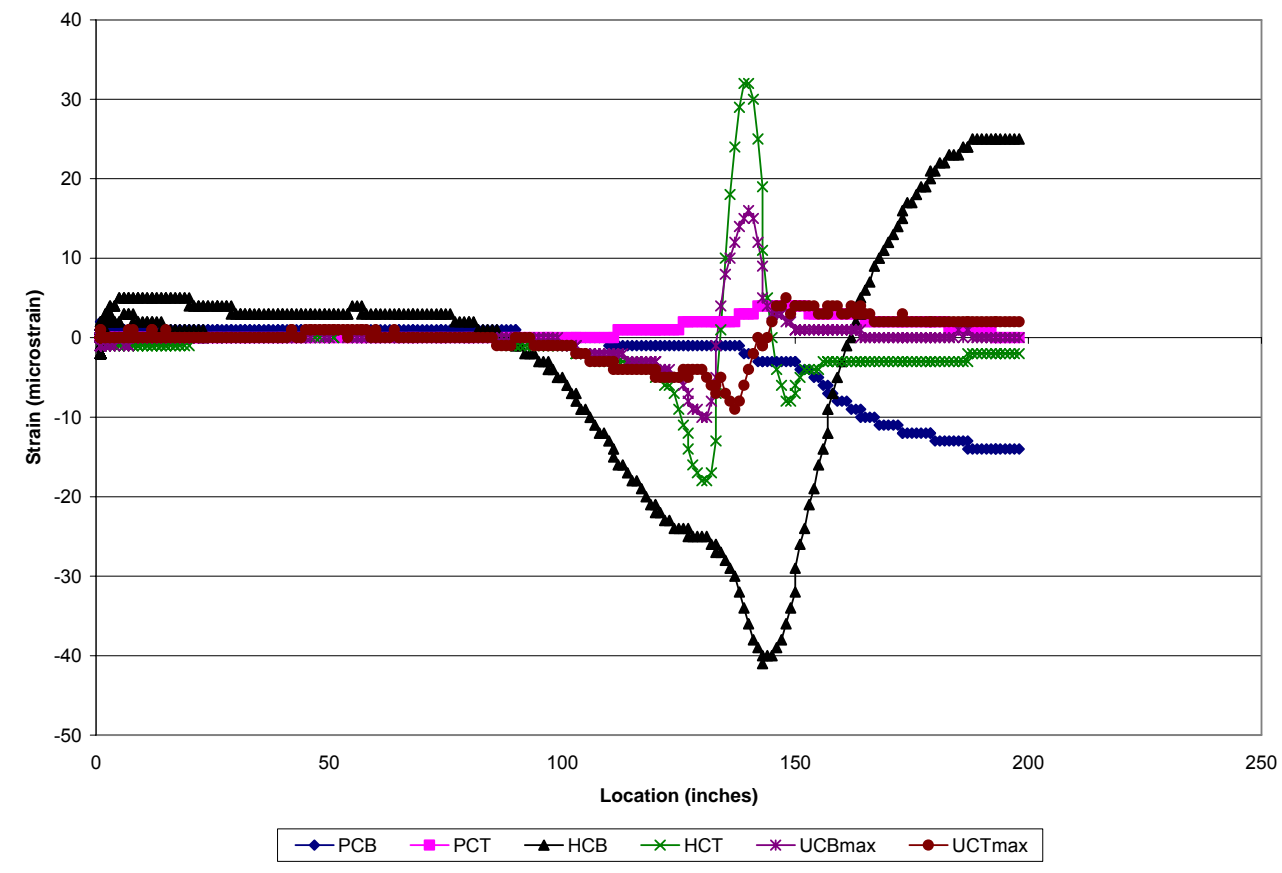

(c)

Figure B.41 Strain versus APT Carriage Location - Test Area 2 - Lane 2 Corner Location (a) 5,000 Load Applications (b) 150,000 Load Applications (c) 275,000 Load Applications 


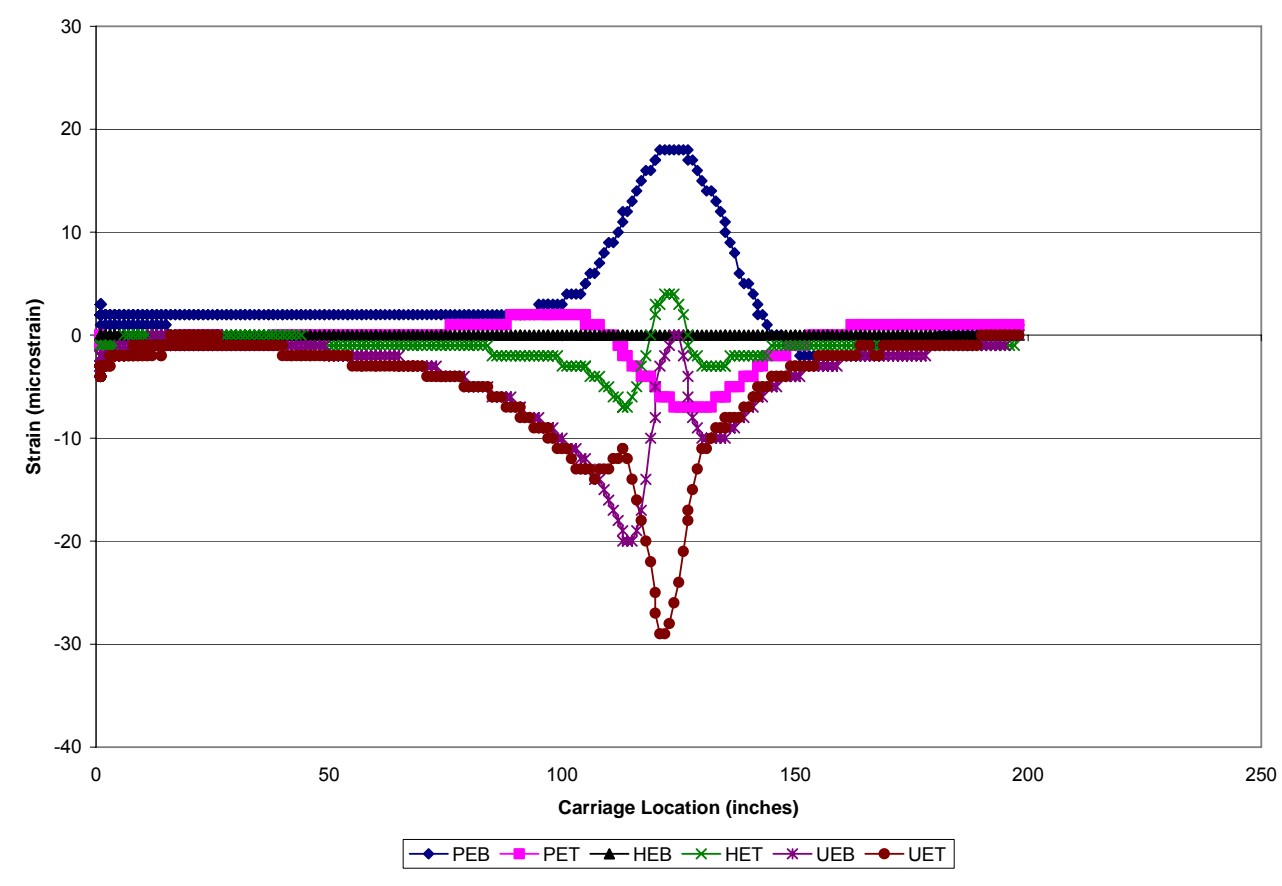

(a)

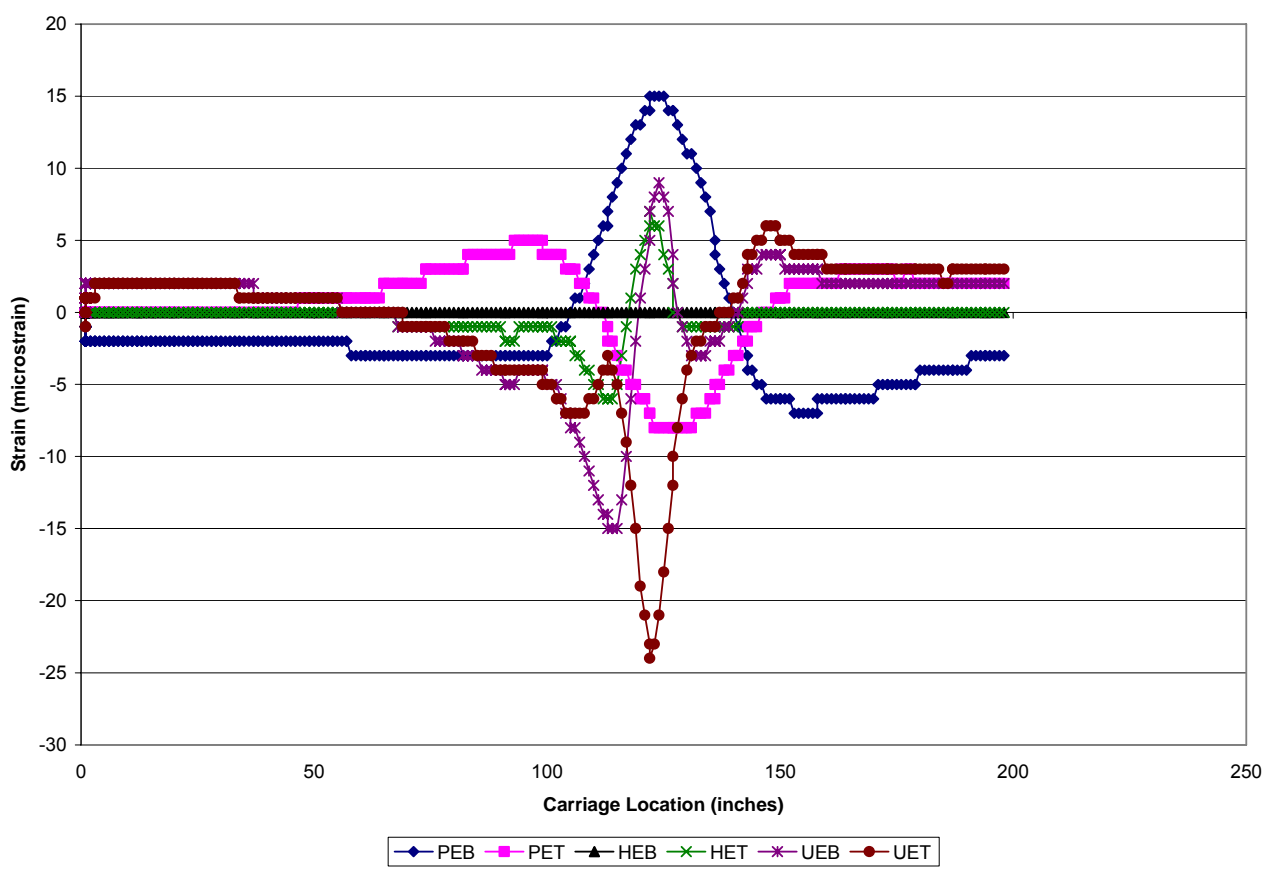

(b)

Figure B.42 Strain versus APT Carriage Location - Test Area 2 - Lane 3 - Edge Location (a) 5,000 Load Applications (b) 150,000 Load Applications (c) 275,000 Load Applications (continued) 


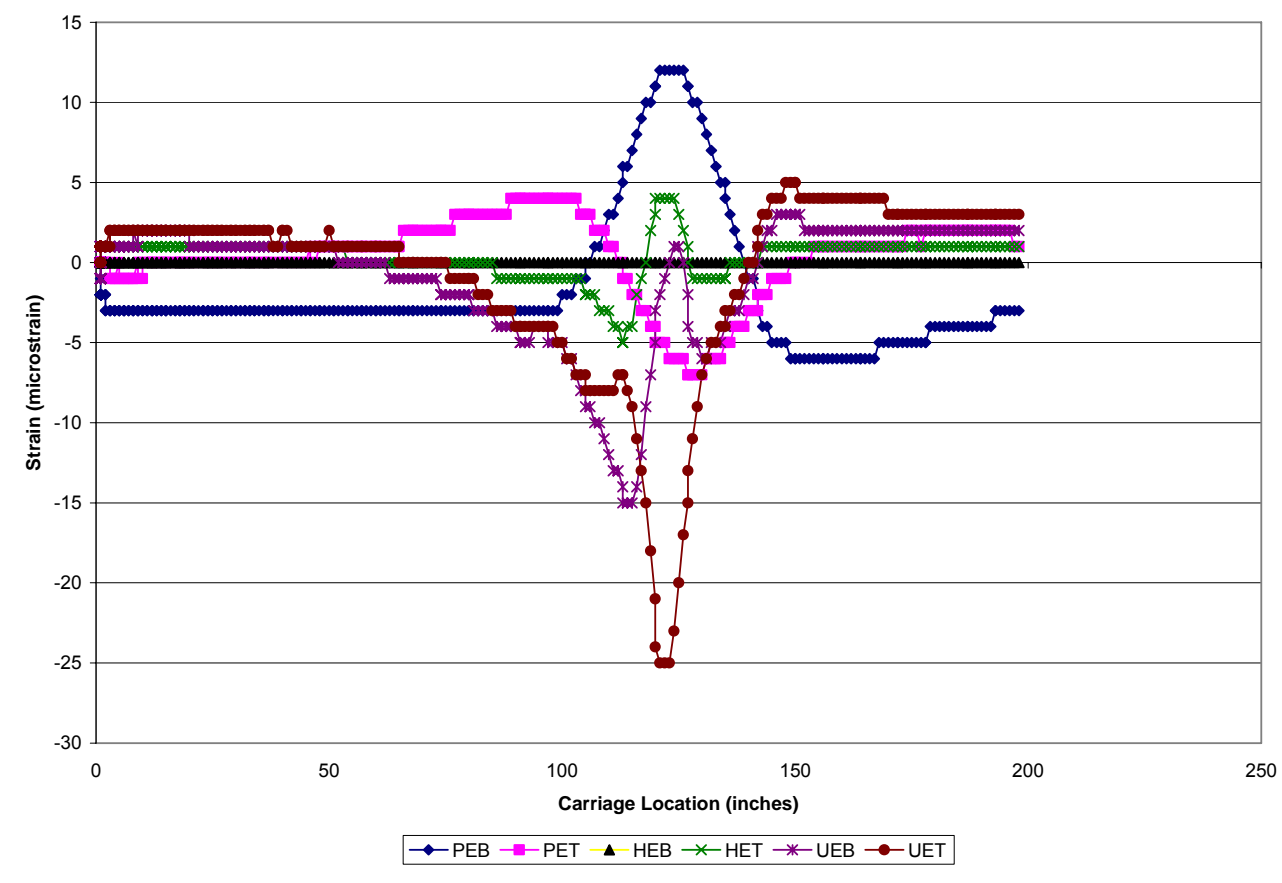

(c)

Figure B.42 Strain versus APT Carriage Location - Test Area 2 - Lane 3 - Edge Location (a) 5,000 Load Applications (b) 150,000 Load Applications (c) 275,000 Load Applications 


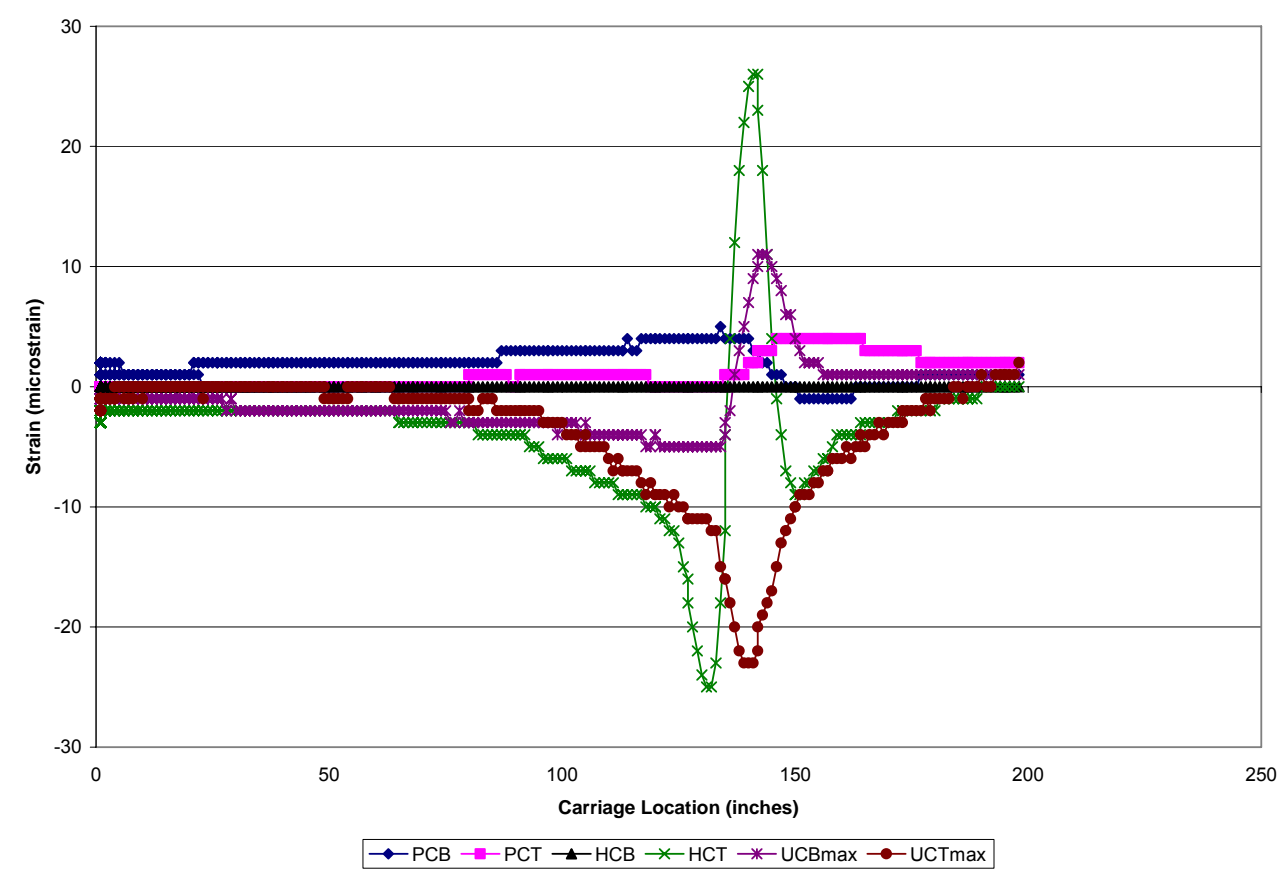

(a)

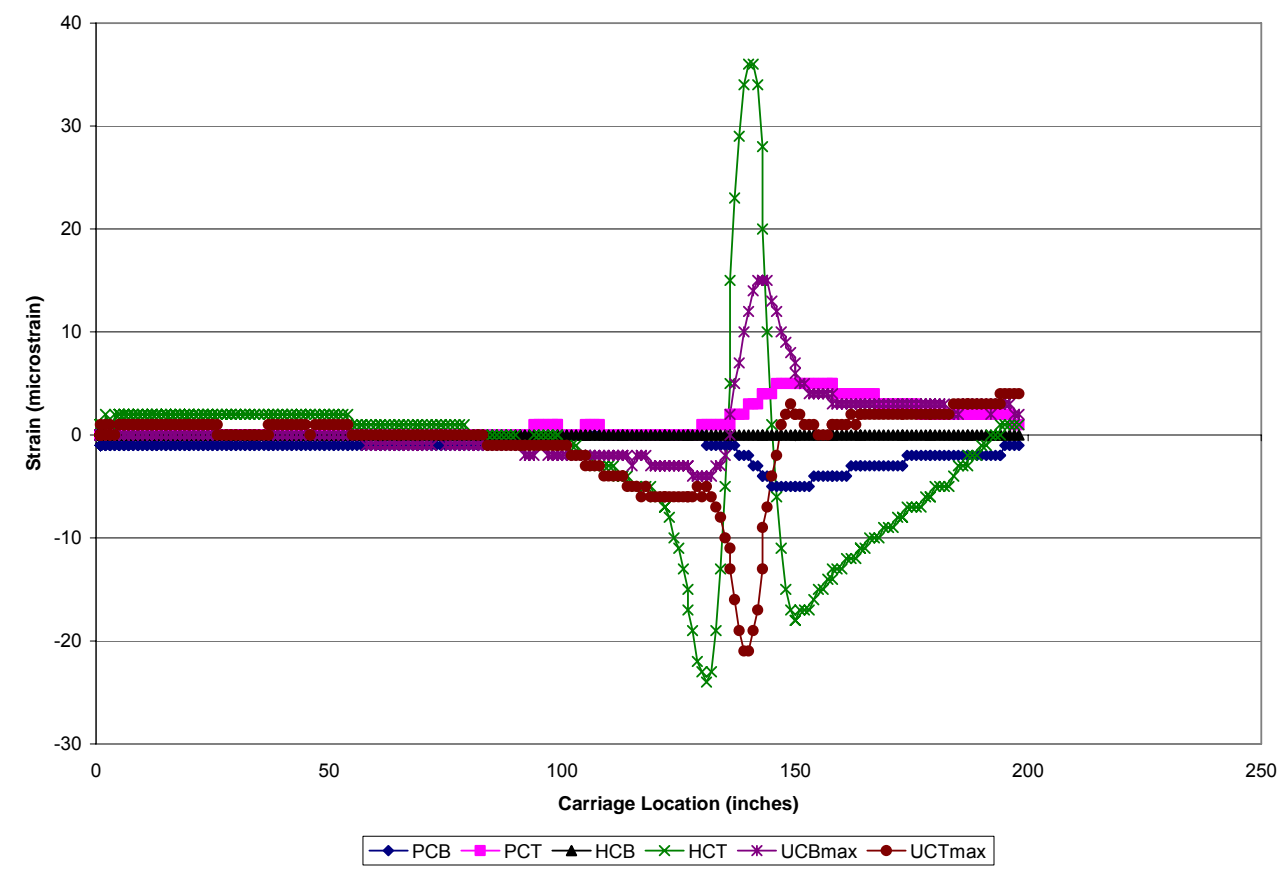

(b)

Figure B.43 Strain versus APT Carriage Location - Test Area 2 - Lane 3 Corner Location (a) 5,000 Load Applications (b) 150,000 Load Applications (c) 275,000 Load Applications (continued) 


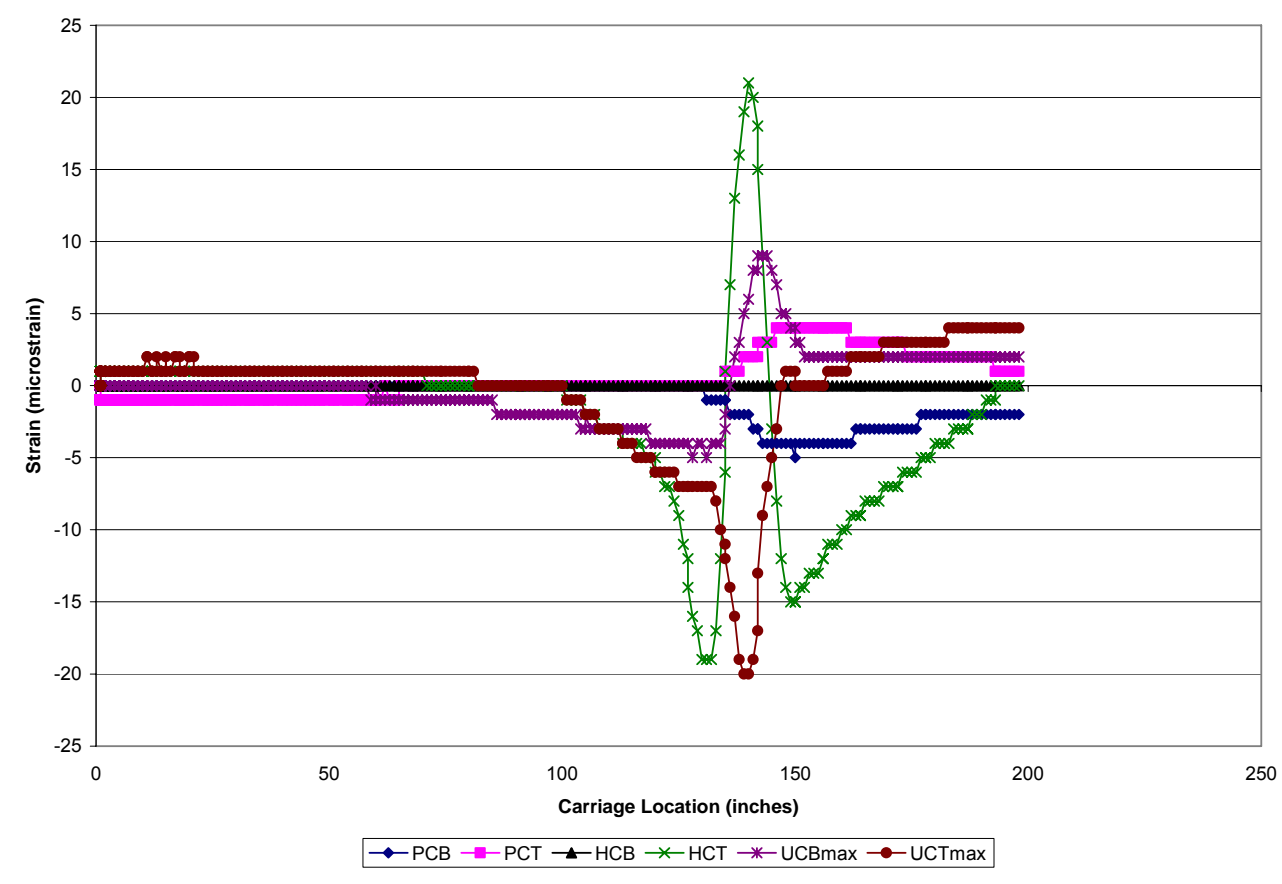

(c)

Figure B.43 Strain versus APT Carriage Location - Test Area 2 - Lane 3 Corner Location (a) 5,000 Load Applications (b) 150,000 Load Applications (c) 275,000 Load Applications 


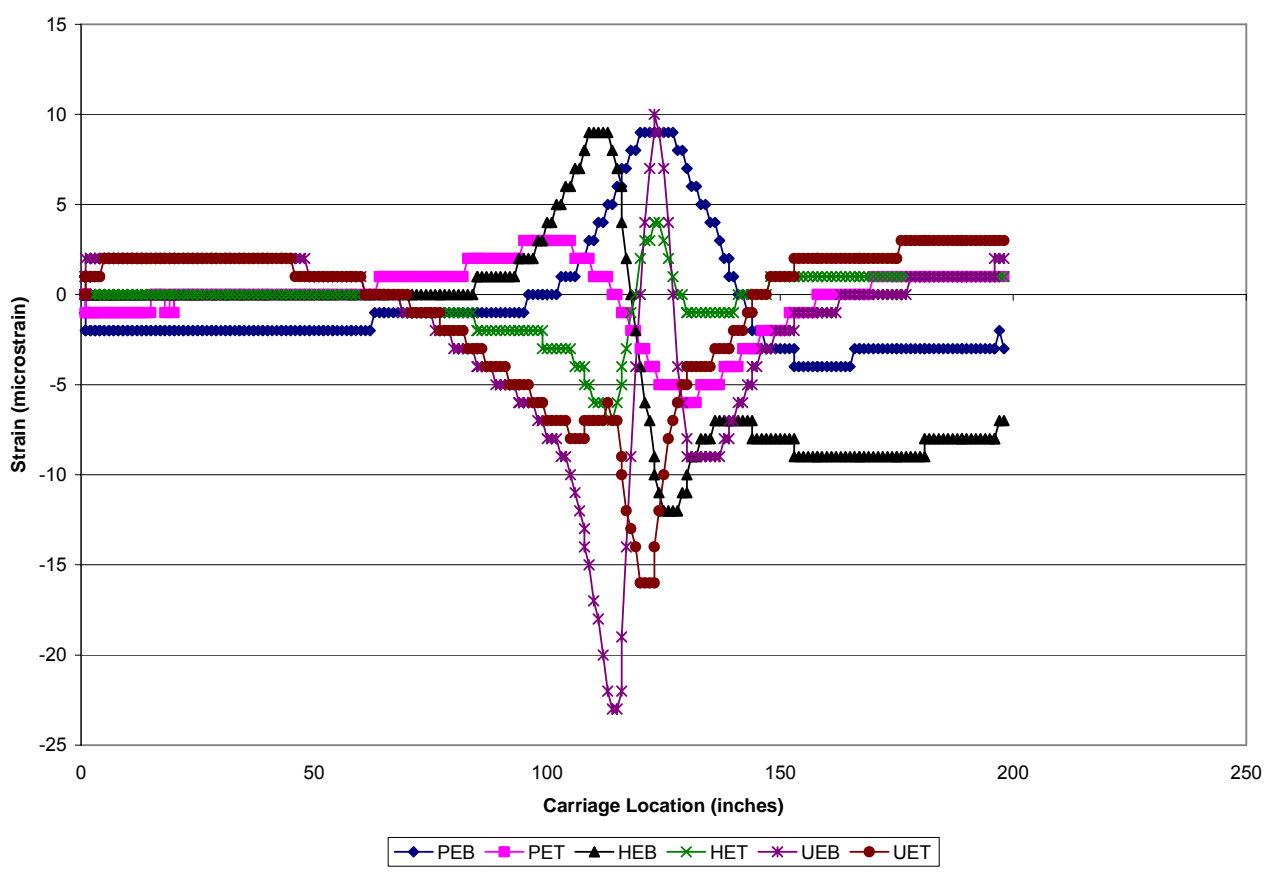

(a)

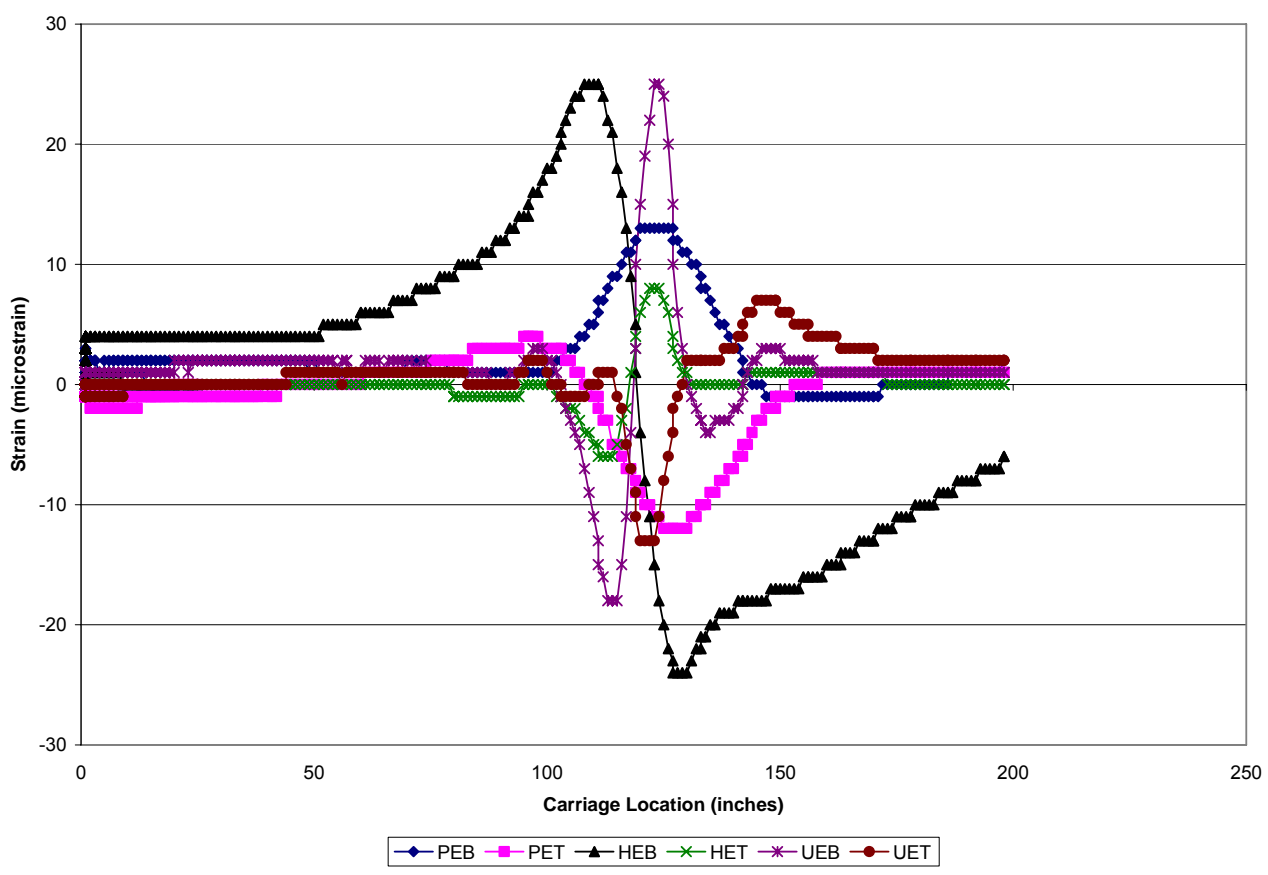

(b)

Figure B.44 Strain versus APT Carriage Location - Test Area 2 - Lane 4 - Edge Location (a) 3,500 Load Applications (b) 150,000 Load Applications (c) 275,000 Load Applications (continued) 


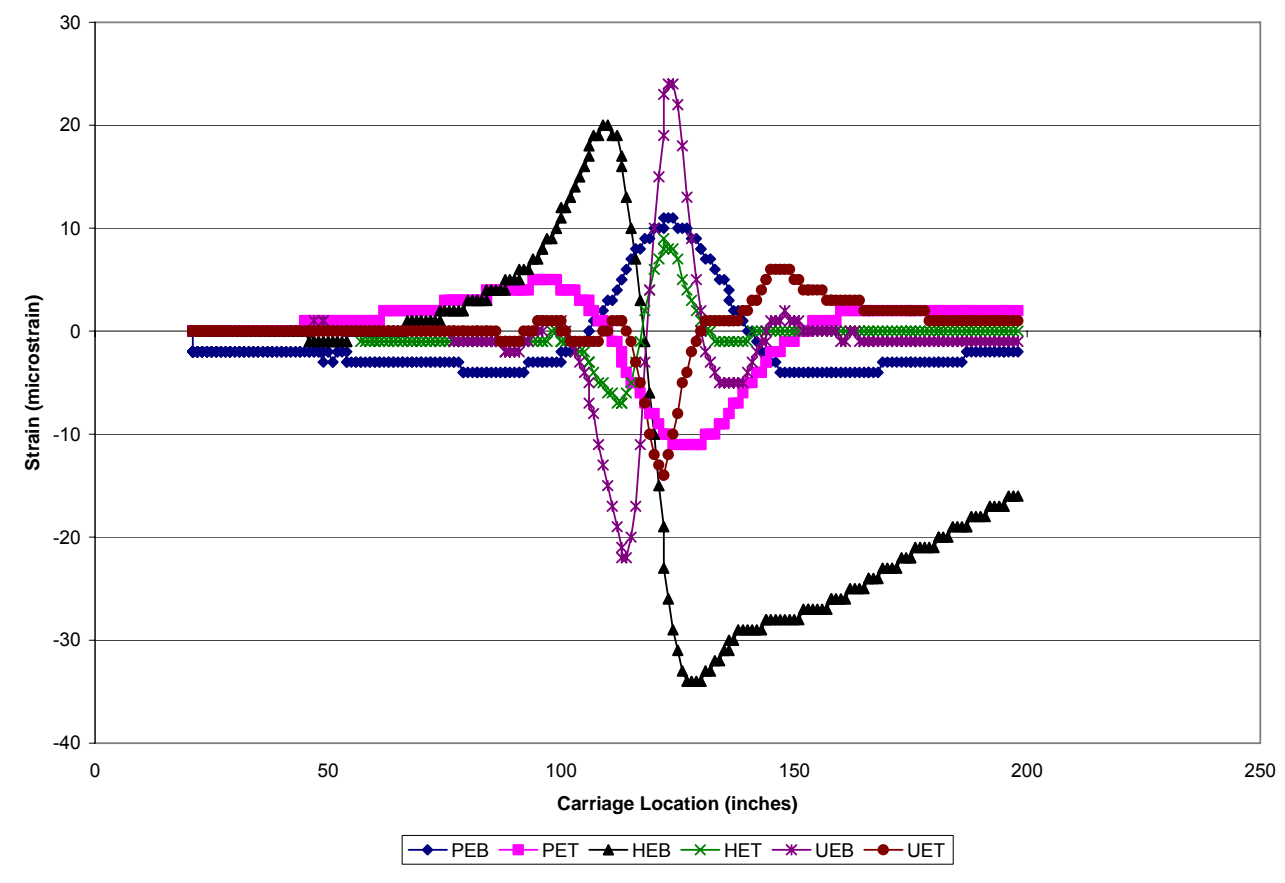

(c)

Figure B.44 Strain versus APT Carriage Location - Test Area 2 - Lane 4 - Edge Location (a) 3,500 Load Applications (b) 150,000 Load Applications (c) 275,000 Load Applications 


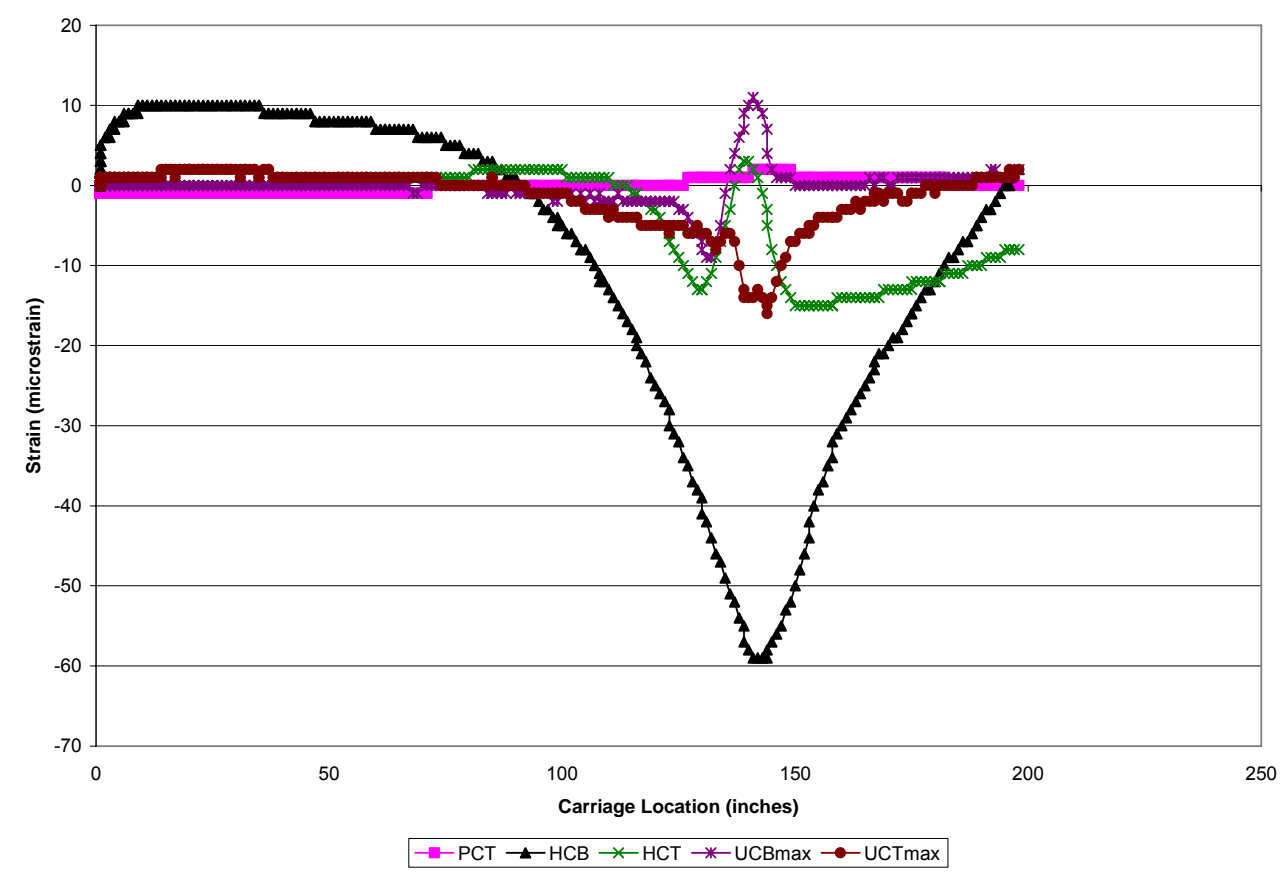

(a)

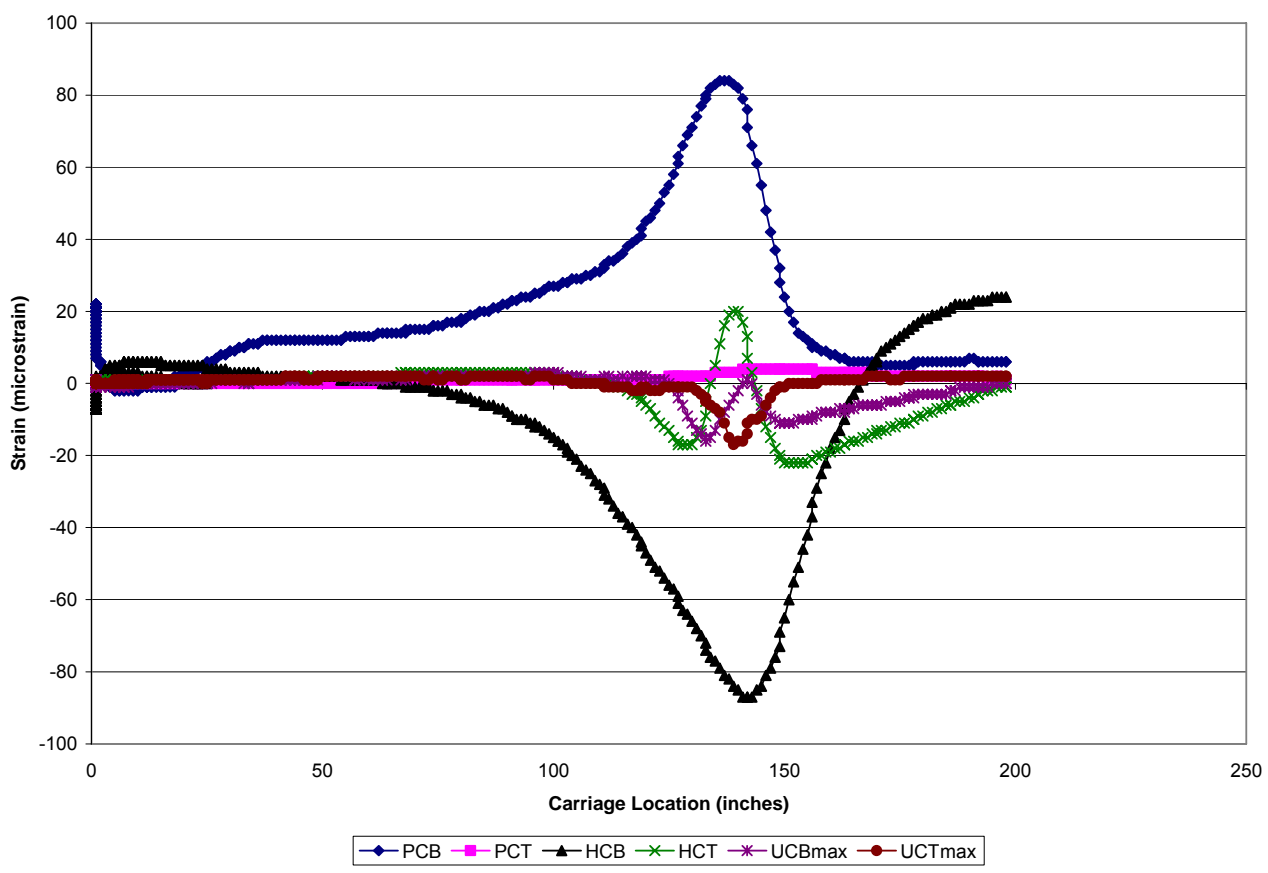

(b)

Figure B.45 Strain versus APT Carriage Location - Test Area 2 - Lane 4 Corner Location (a) 3,500 Load Applications (b) 150,000 Load Applications (c) 275,000 Load Applications (continued) 


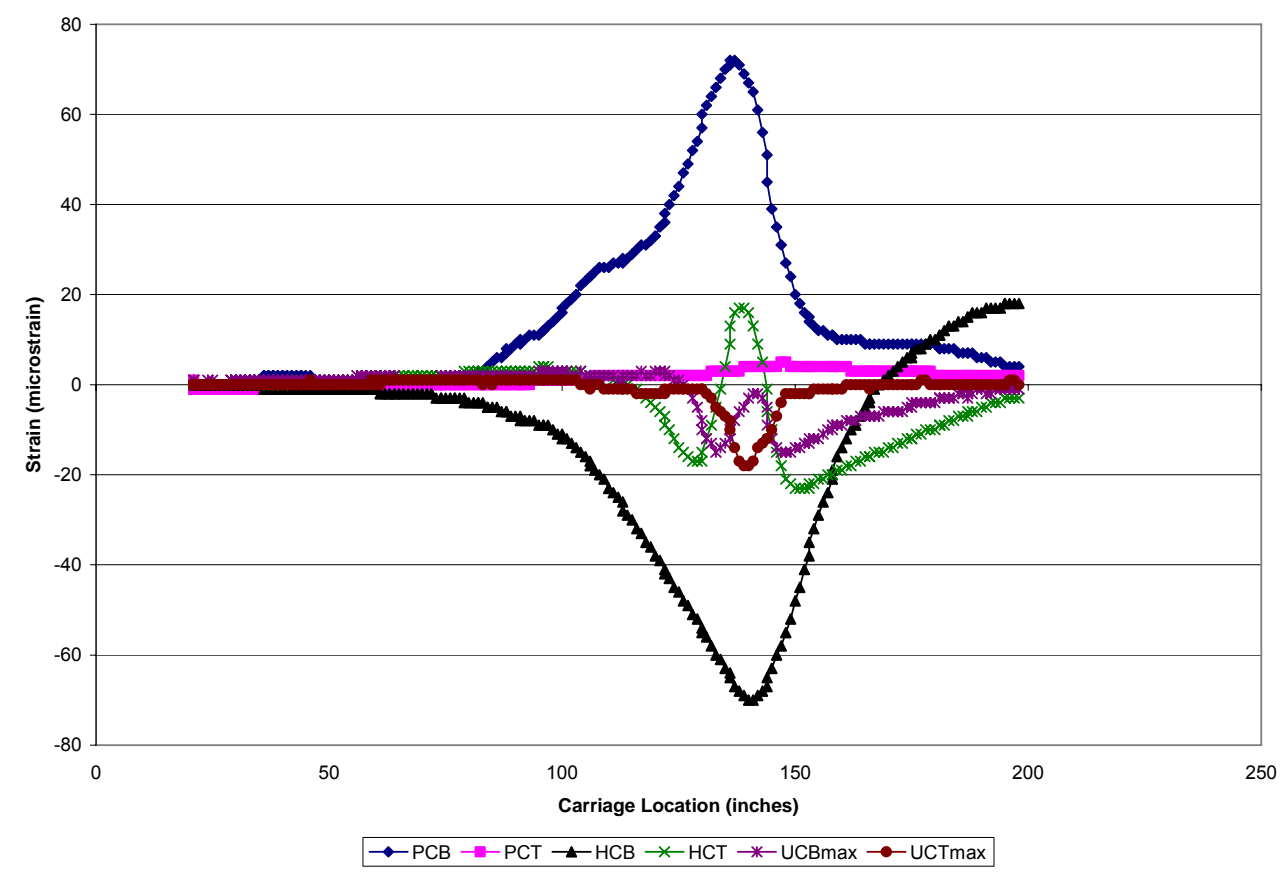

(c)

Figure B.45 Strain versus APT Carriage Location - Test Area 2 - Lane 4 Corner Location (a) 3,500 Load Applications (b) 150,000 Load Applications (c) 275,000 Load Applications 


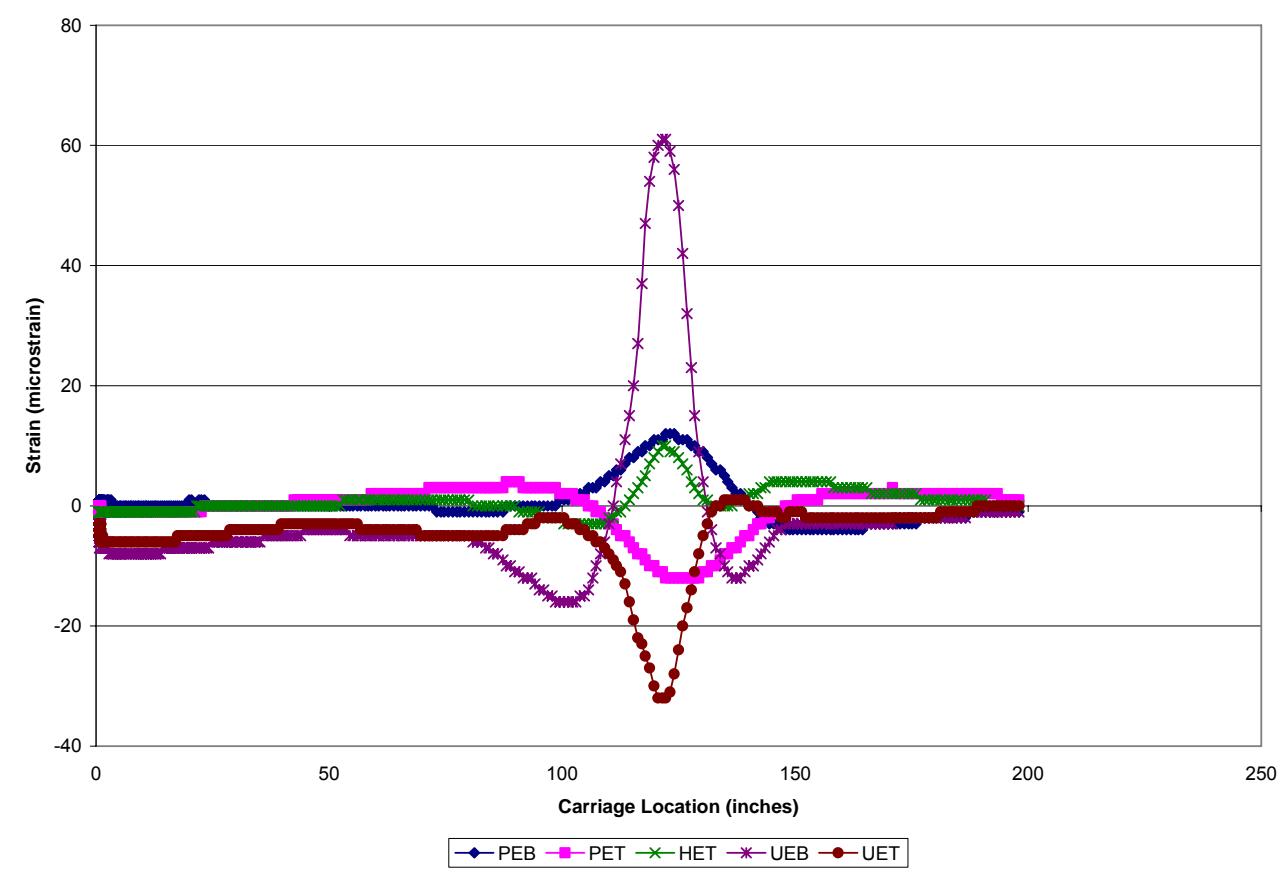

(a)

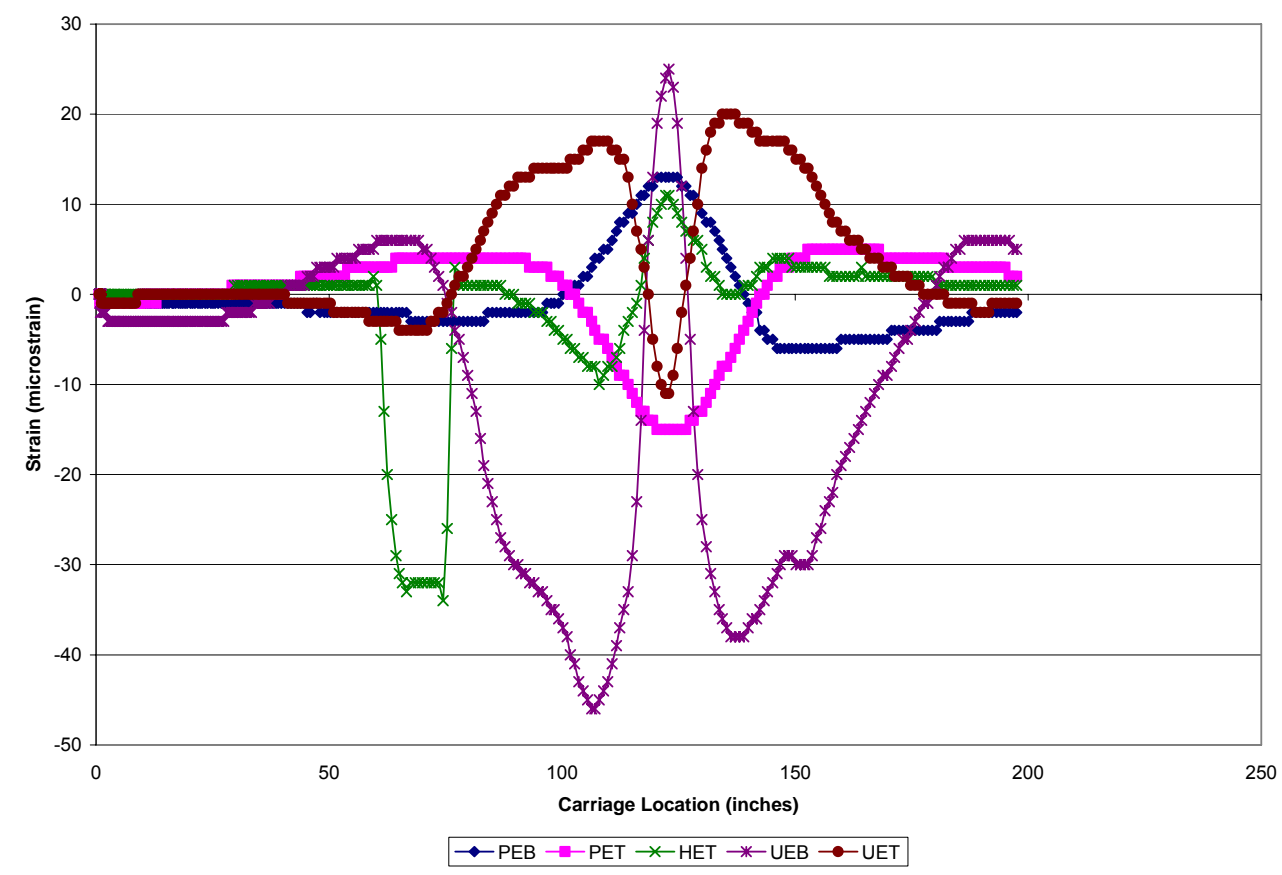

(b)

Figure B.46 Strain versus APT Carriage Location - Test Area 2 - Lane 5 - Edge Location (a) 5,000 Load Applications (b) 150,000 Load Applications (c) 177,000 Load Applications (continued) 


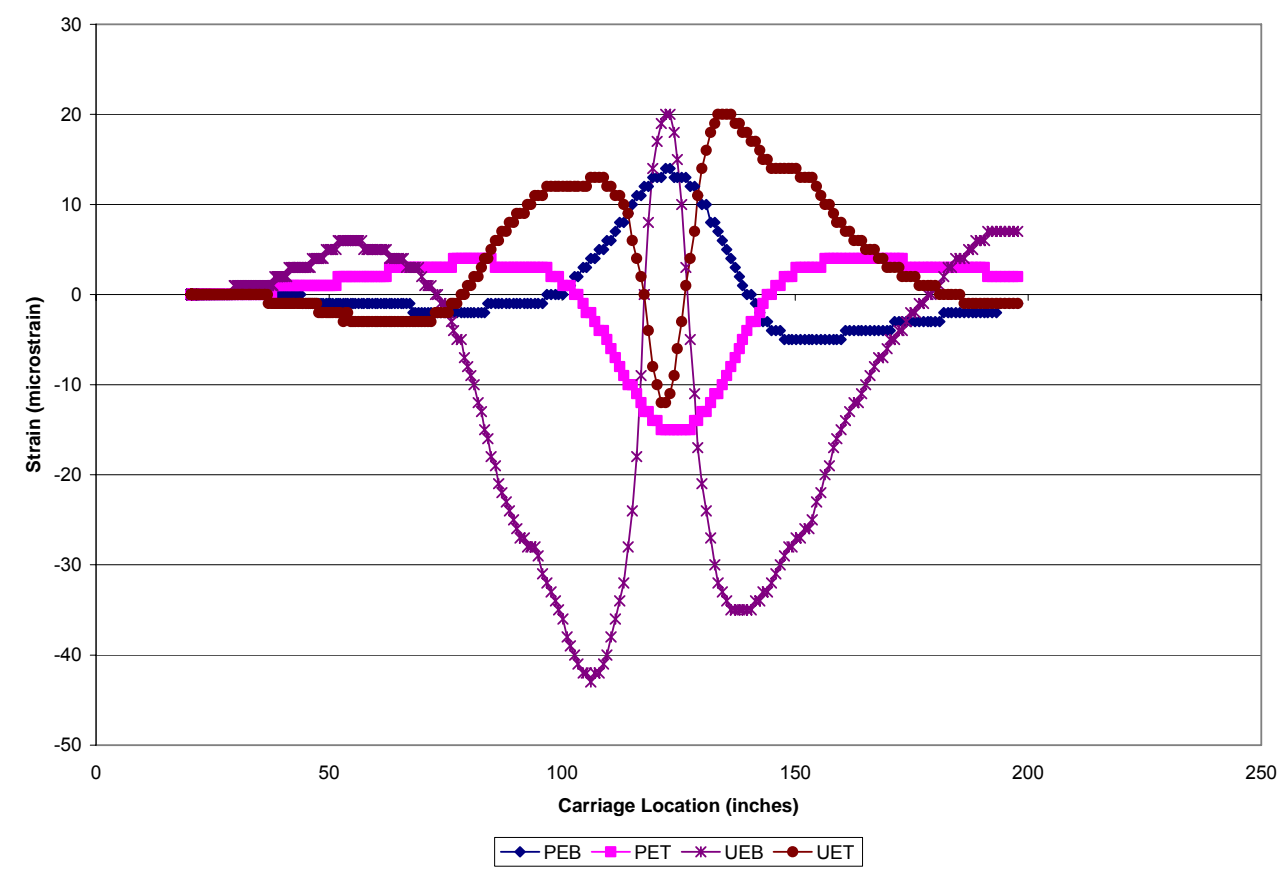

(c)

Figure B.46 Strain versus APT Carriage Location - Test Area 2 - Lane 5 - Edge Location (a) 5,000 Load Applications (b) 150,000 Load Applications (c) 177,000 Load Applications 


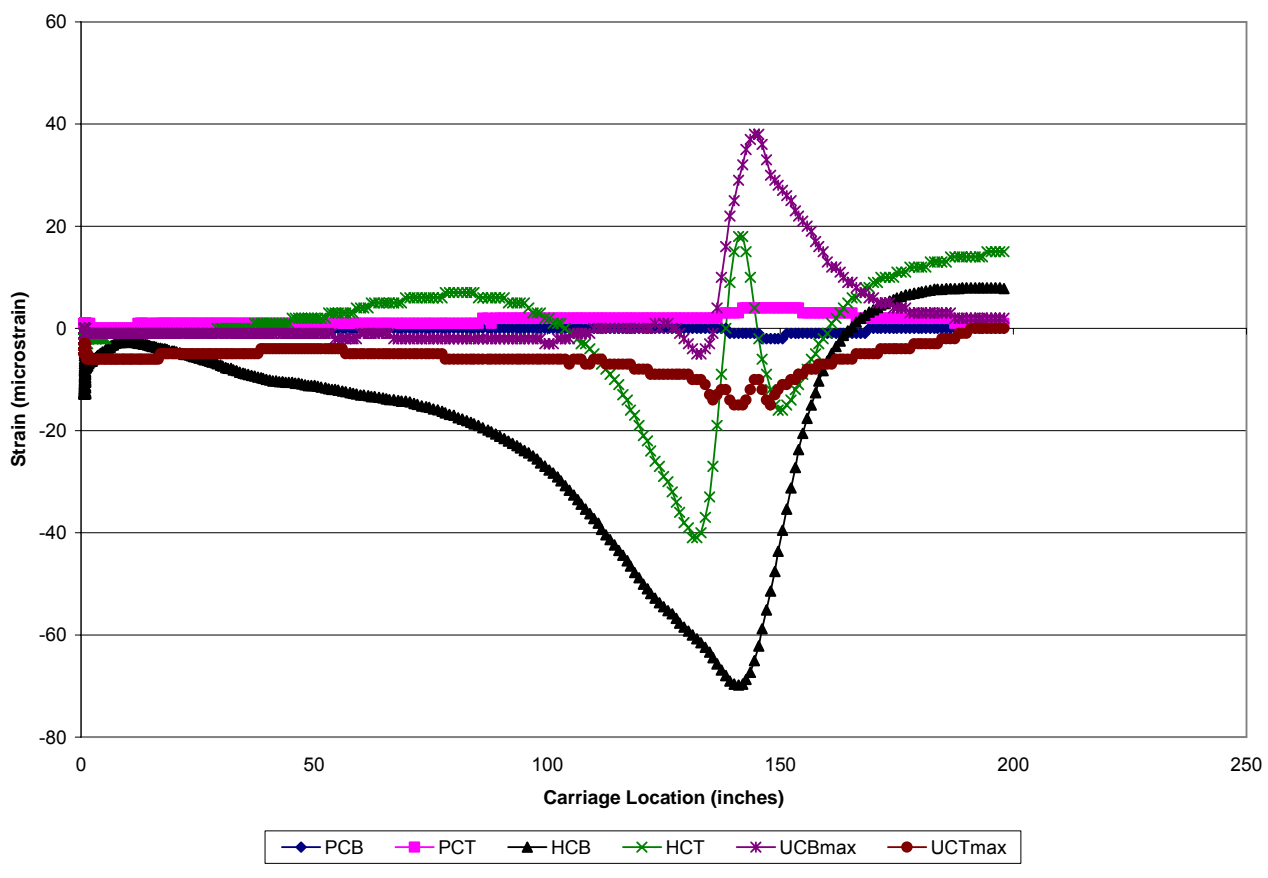

(a)

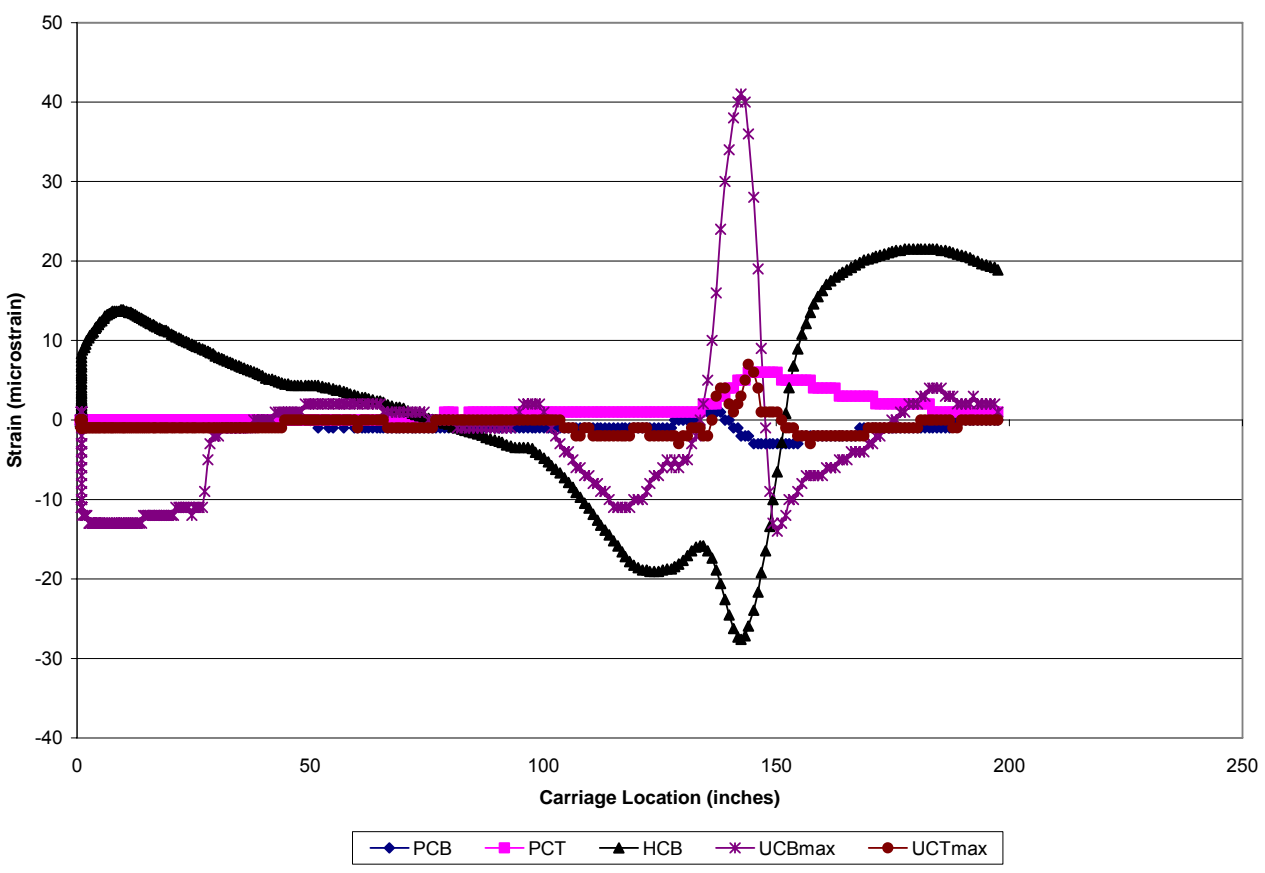

(b)

Figure B.47 Strain versus APT Carriage Location - Test Area 2 - Lane 5 Corner Location (a) 5,000 Load Applications (b) 150,000 Load Applications (c) 177,000 Load Applications (continued) 


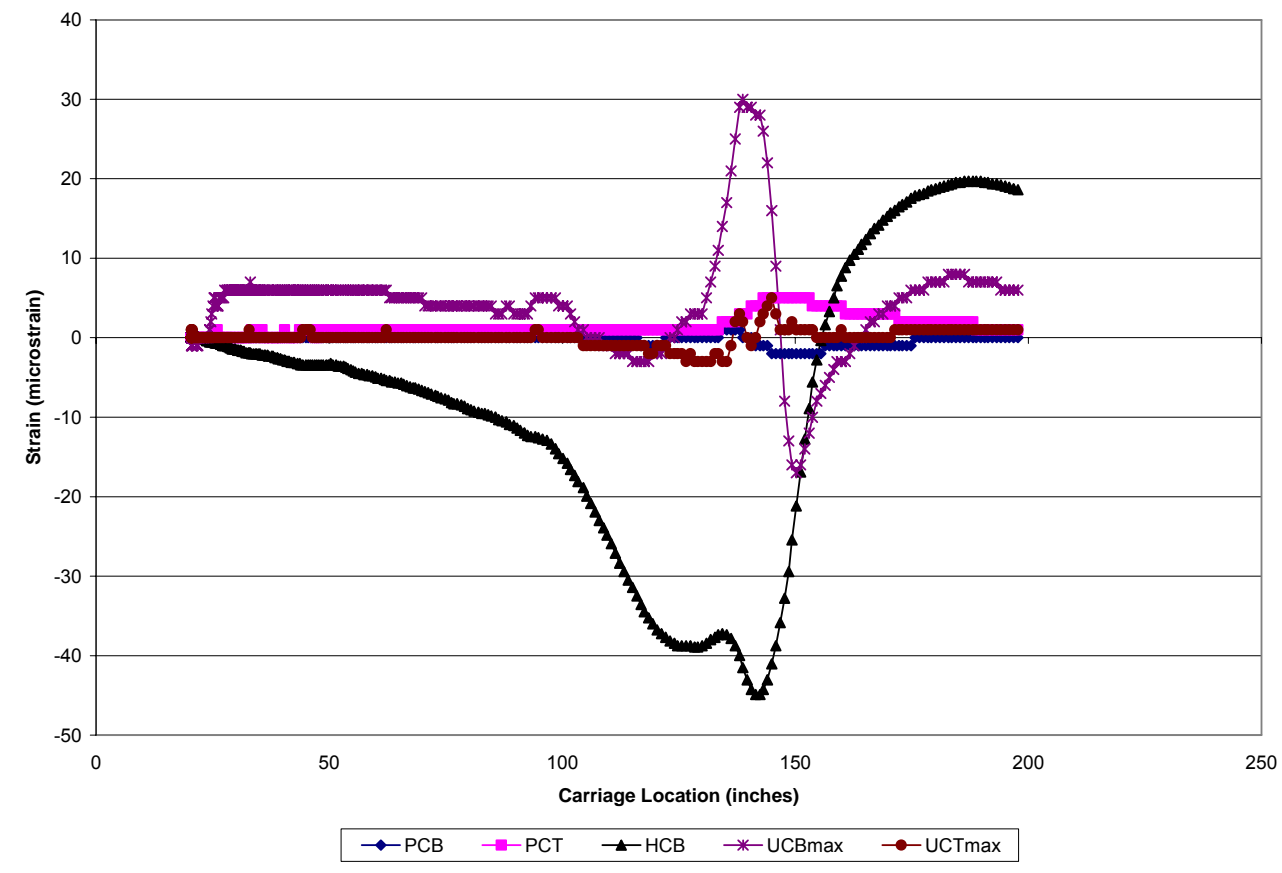

(c) 177,000 Load Applications

Figure B.47 Strain versus APT Carriage Location - Test Area 2 - Lane 5 Corner Location (a) 5,000 Load Applications (b) 150,000 Load Applications (c) 177,000 Load Applications 


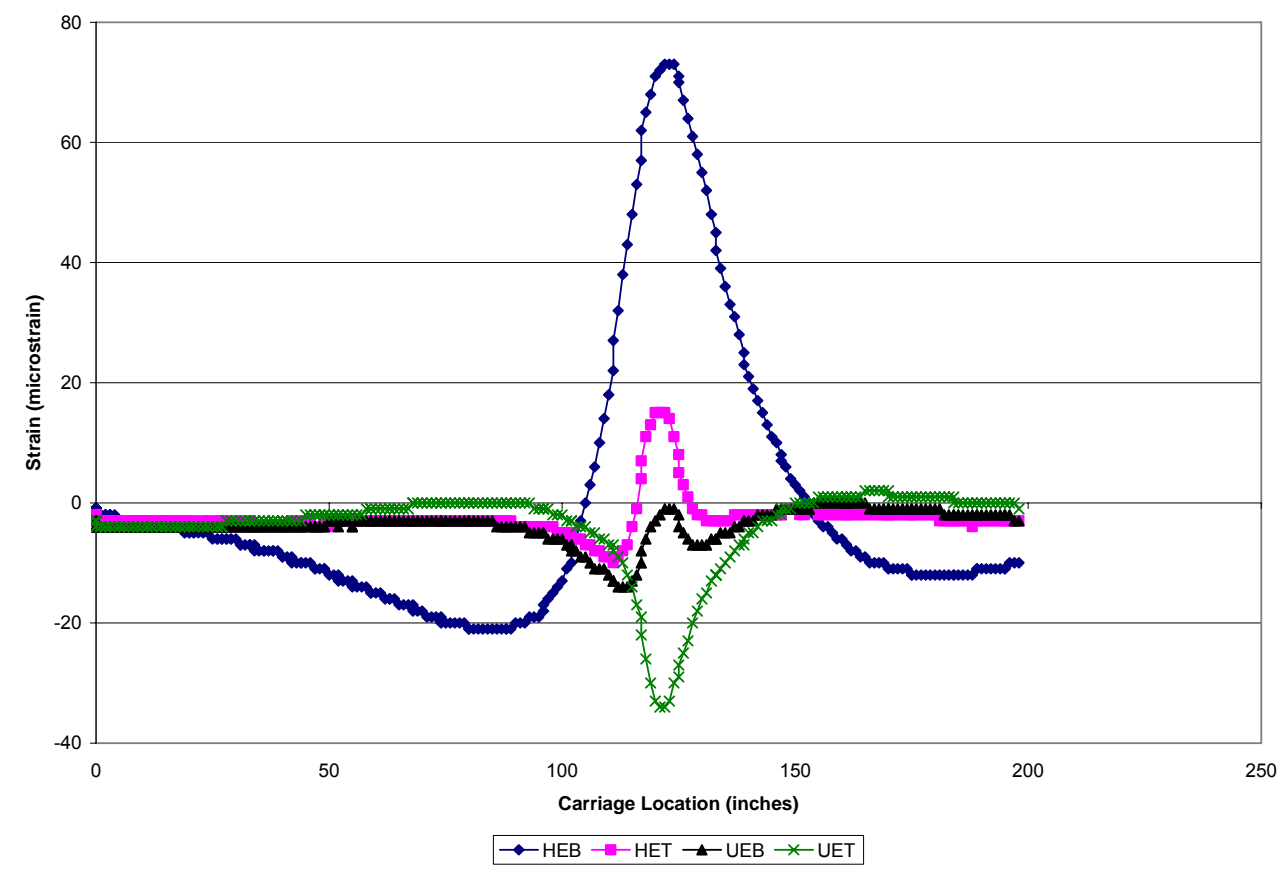

(a)

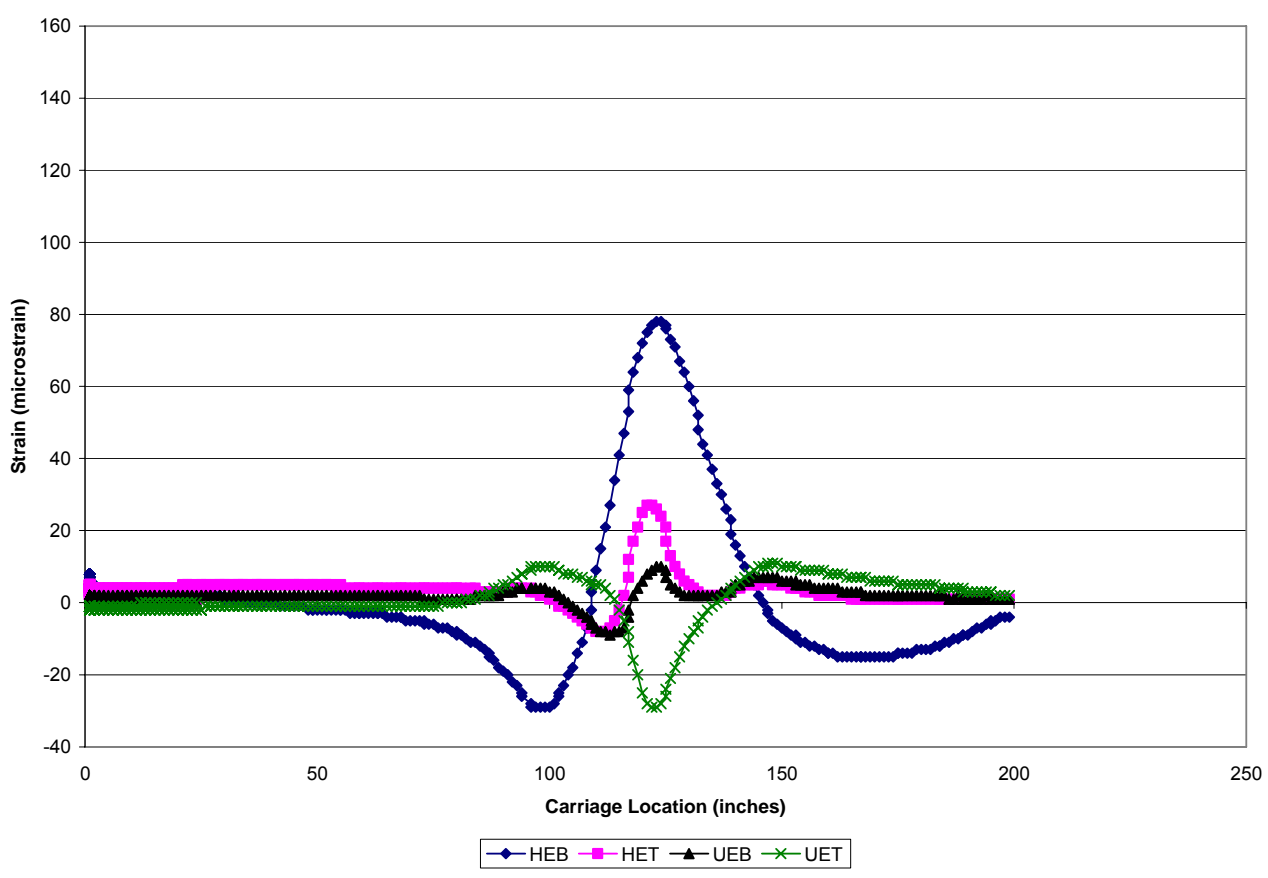

(b)

Figure B.48 Strain versus APT Carriage Location - Test Area 3 - Lane 1 - Edge Location (a) 0 Load Applications (b) 150,000 Load Applications (c) 275,000 Load Applications (continued) 


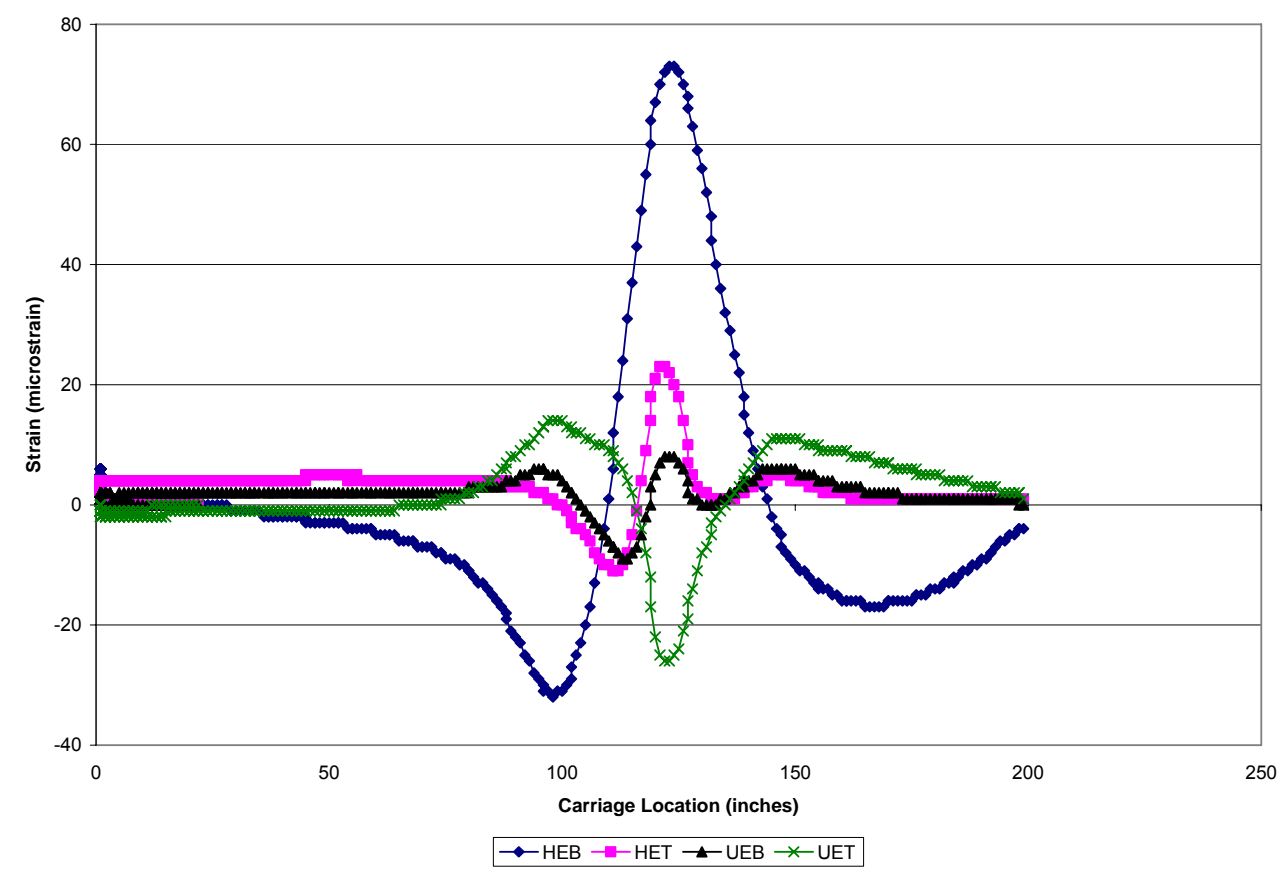

(c)

Figure B.48 Strain versus APT Carriage Location - Test Area 3 - Lane 1 - Edge Location (a) 0 Load Applications (b) 150,000 Load Applications (c) 275,000 Load Applications 


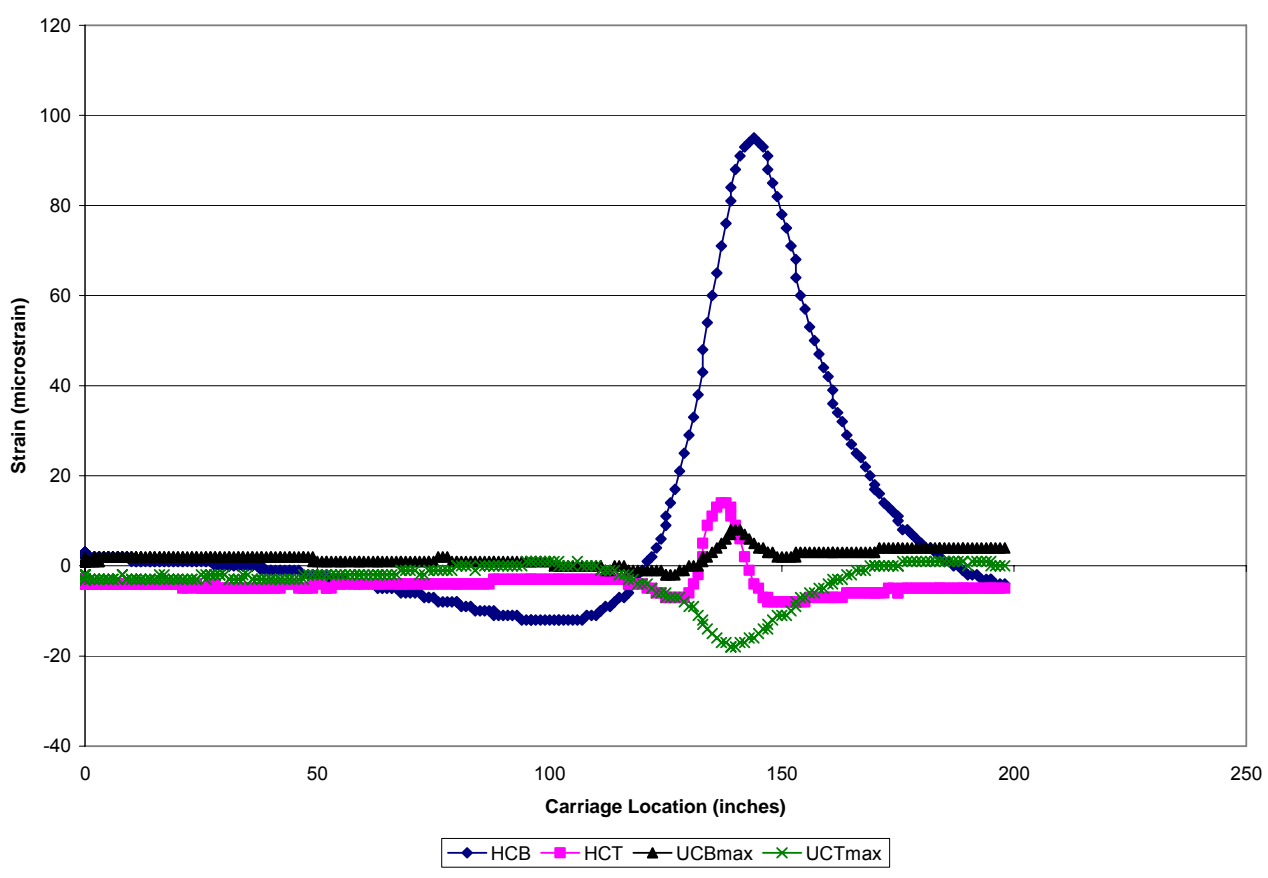

(a)

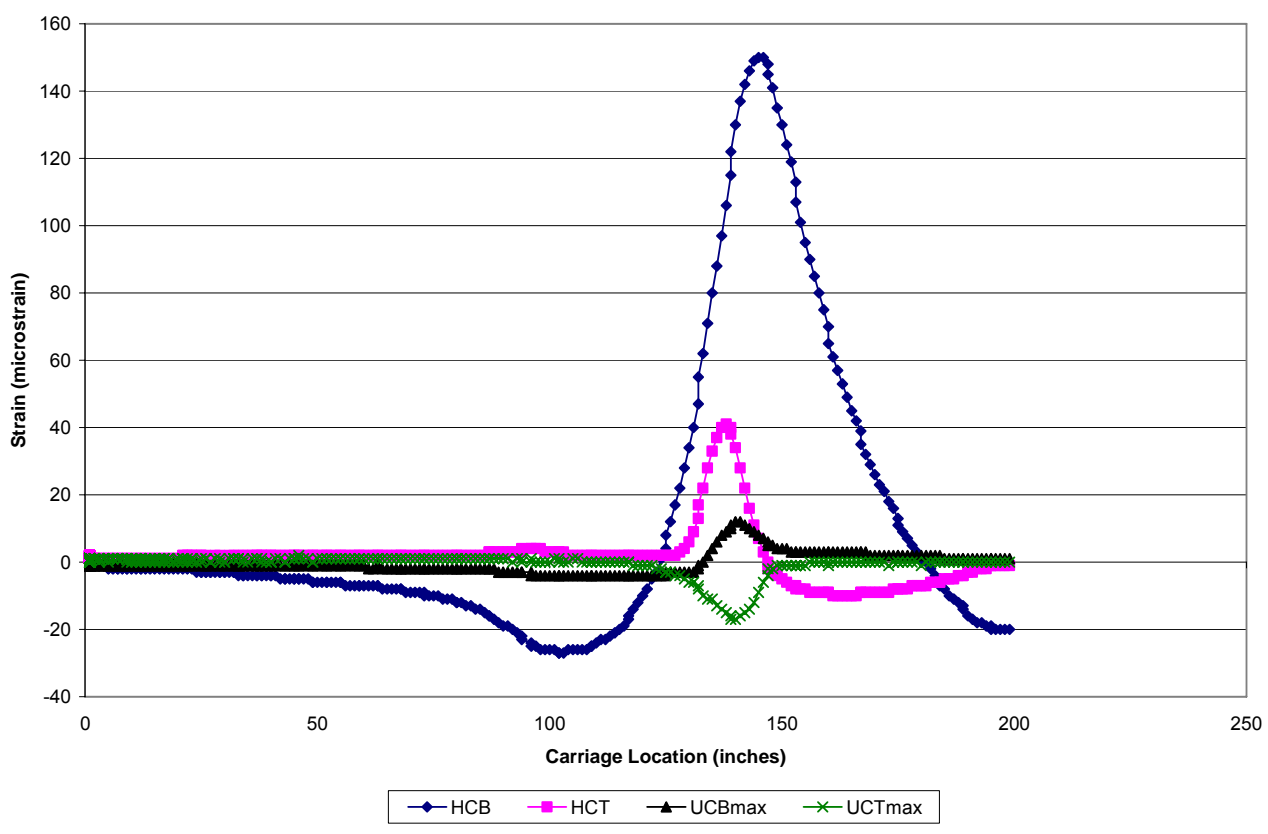

(b)

Figure B.49 Strain versus APT Carriage Location - Test Area 3 - Lane 1 Corner Location (a) 0 Load Applications (b) 150,000 Load Applications (c) 275,000 Load Applications (continued) 


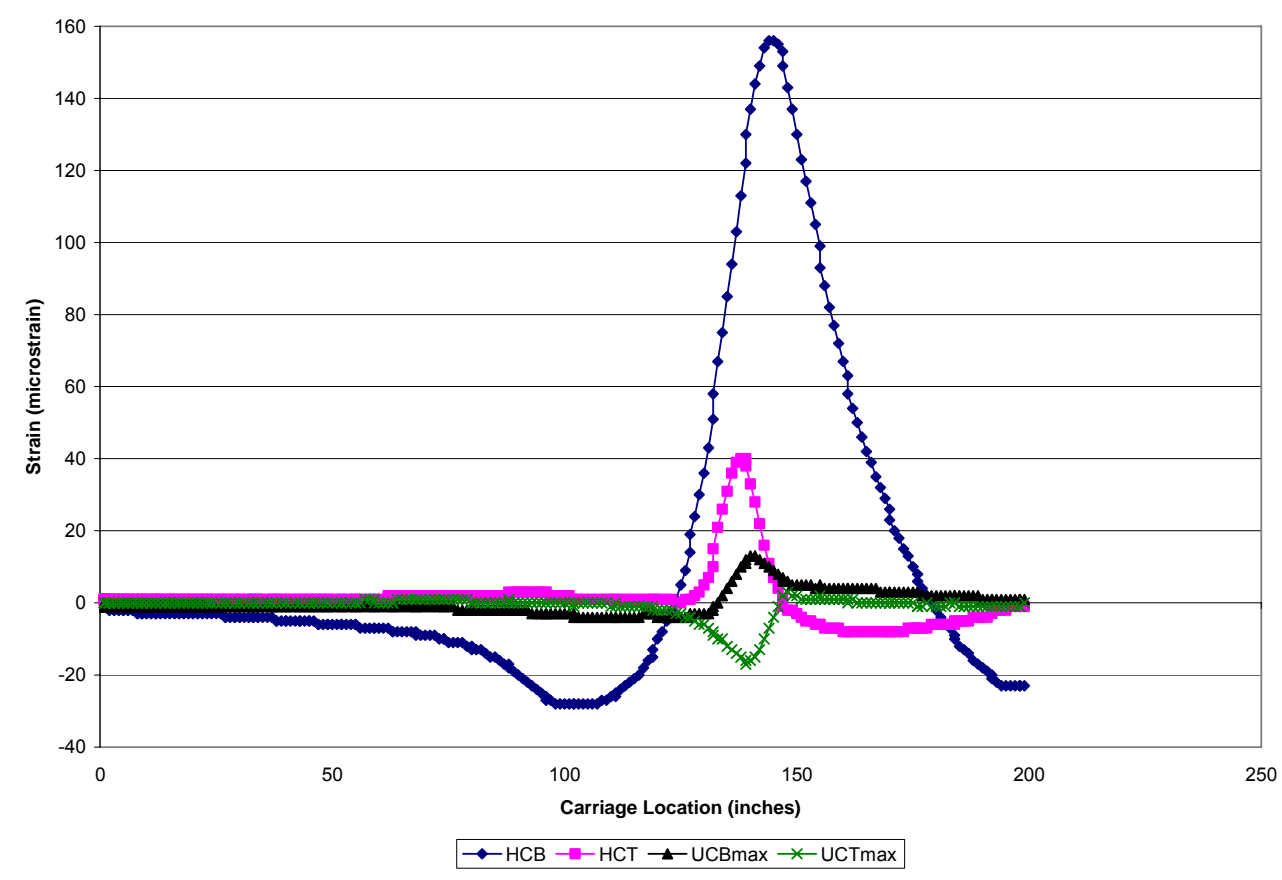

(c)

Figure B.49 Strain versus APT Carriage Location - Test Area 3 - Lane 1 Corner Location (a) 0 Load Applications (b) 150,000 Load Applications (c) 275,000 Load Applications 


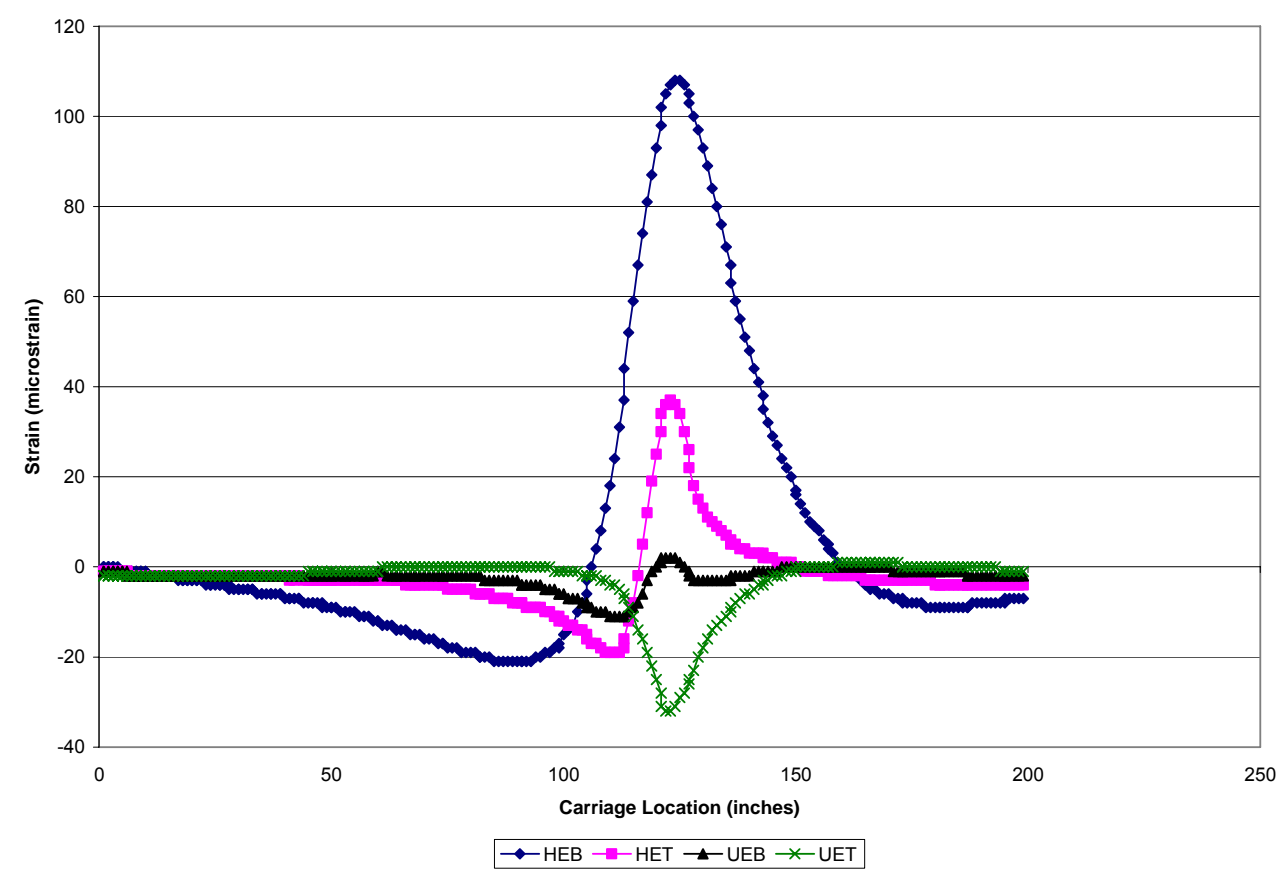

(a)

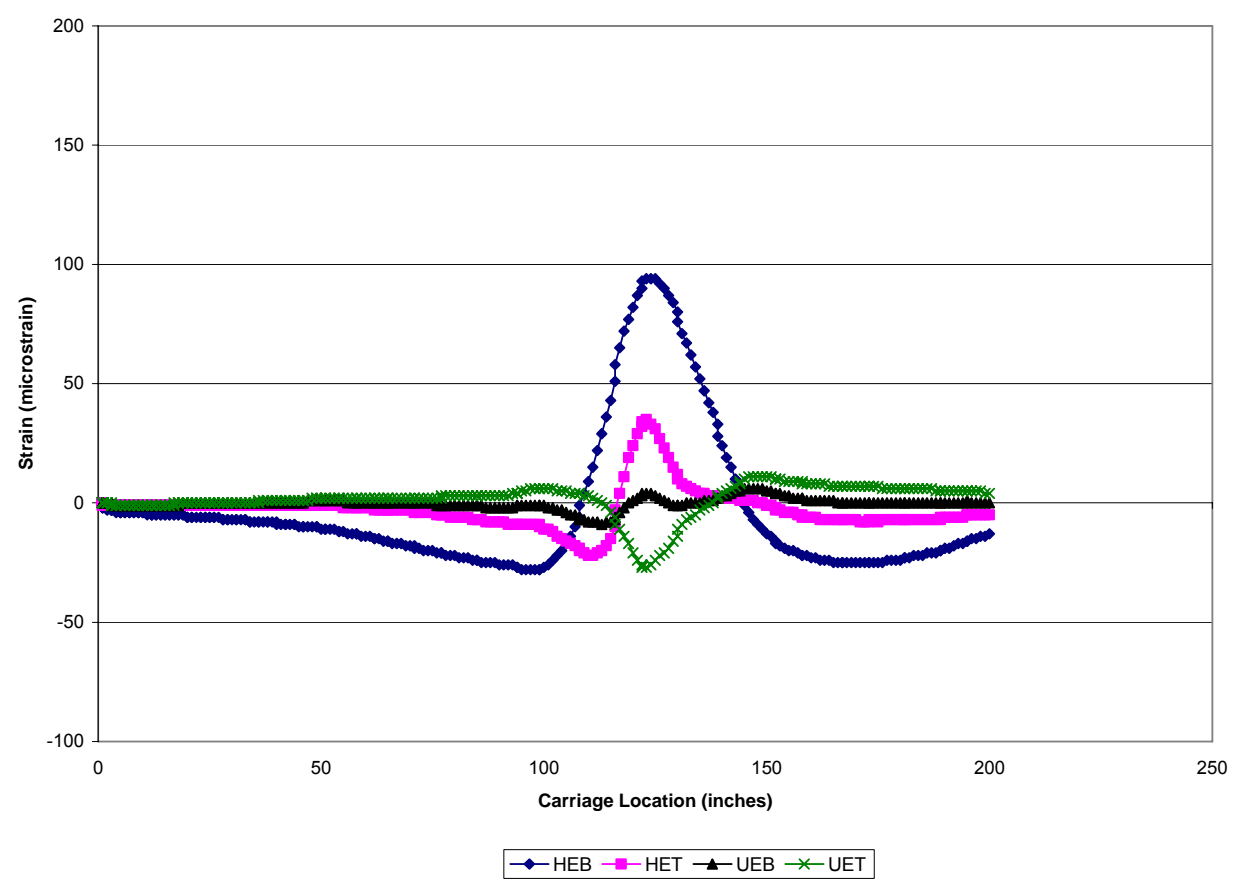

(b)

Figure B.50 Strain versus APT Carriage Location - Test Area 3 - Lane 2 - Edge Location (a) 0 Load Applications (b) 150,000 Load Applications (c) 275,000 Load Applications (continued) 


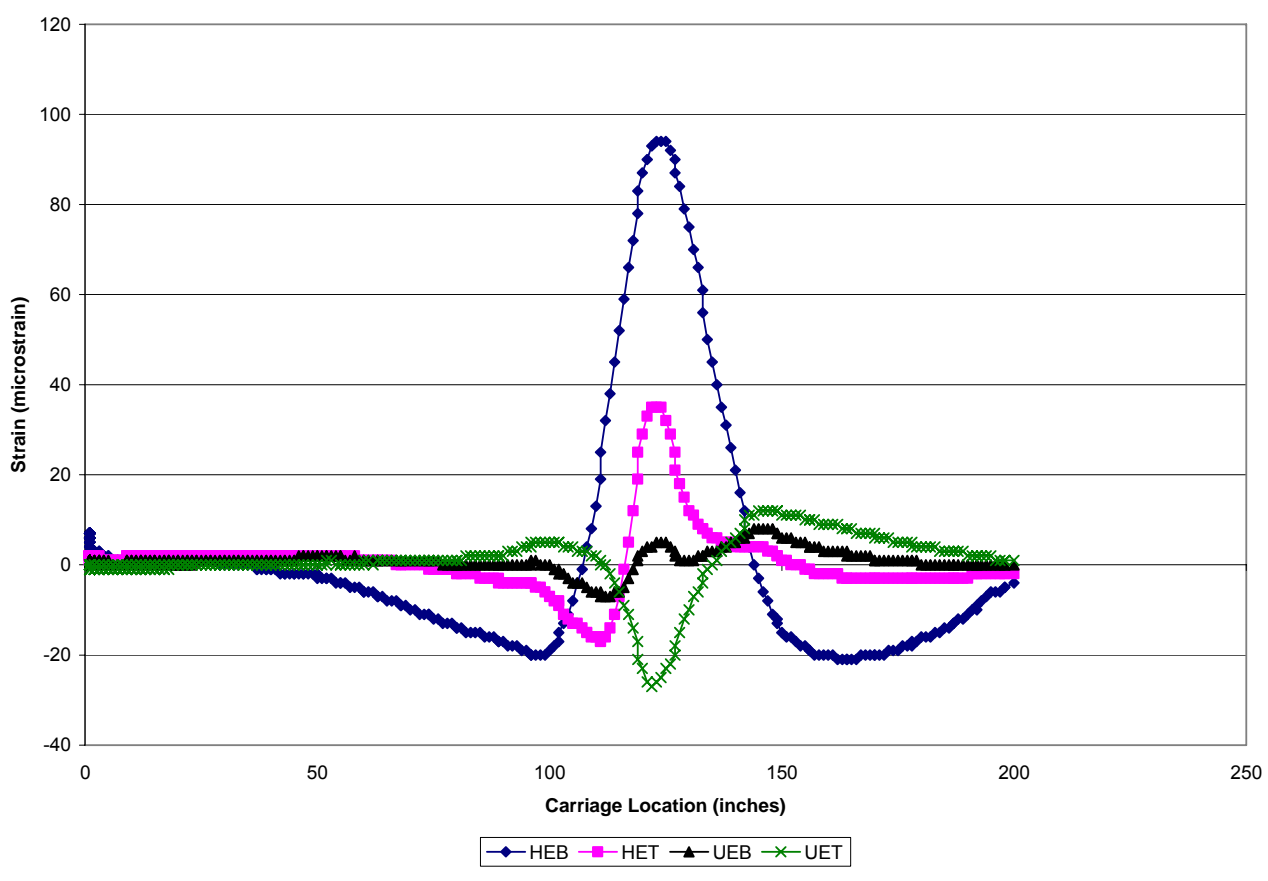

(c)

Figure B.50 Strain versus APT Carriage Location - Test Area 3 - Lane 2 - Edge Location (a) 0 Load Applications (b) 150,000 Load Applications (c) 275,000 Load Applications 


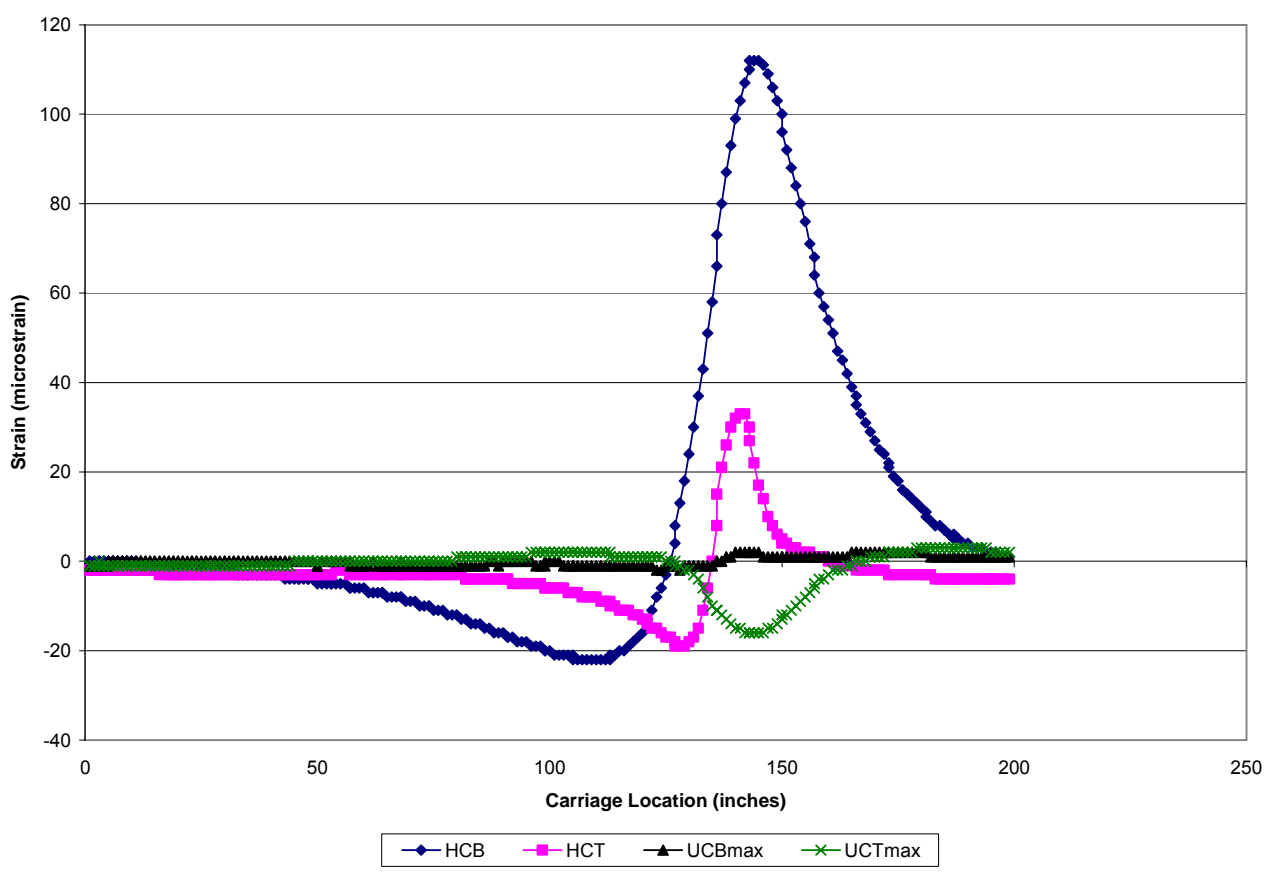

(a)

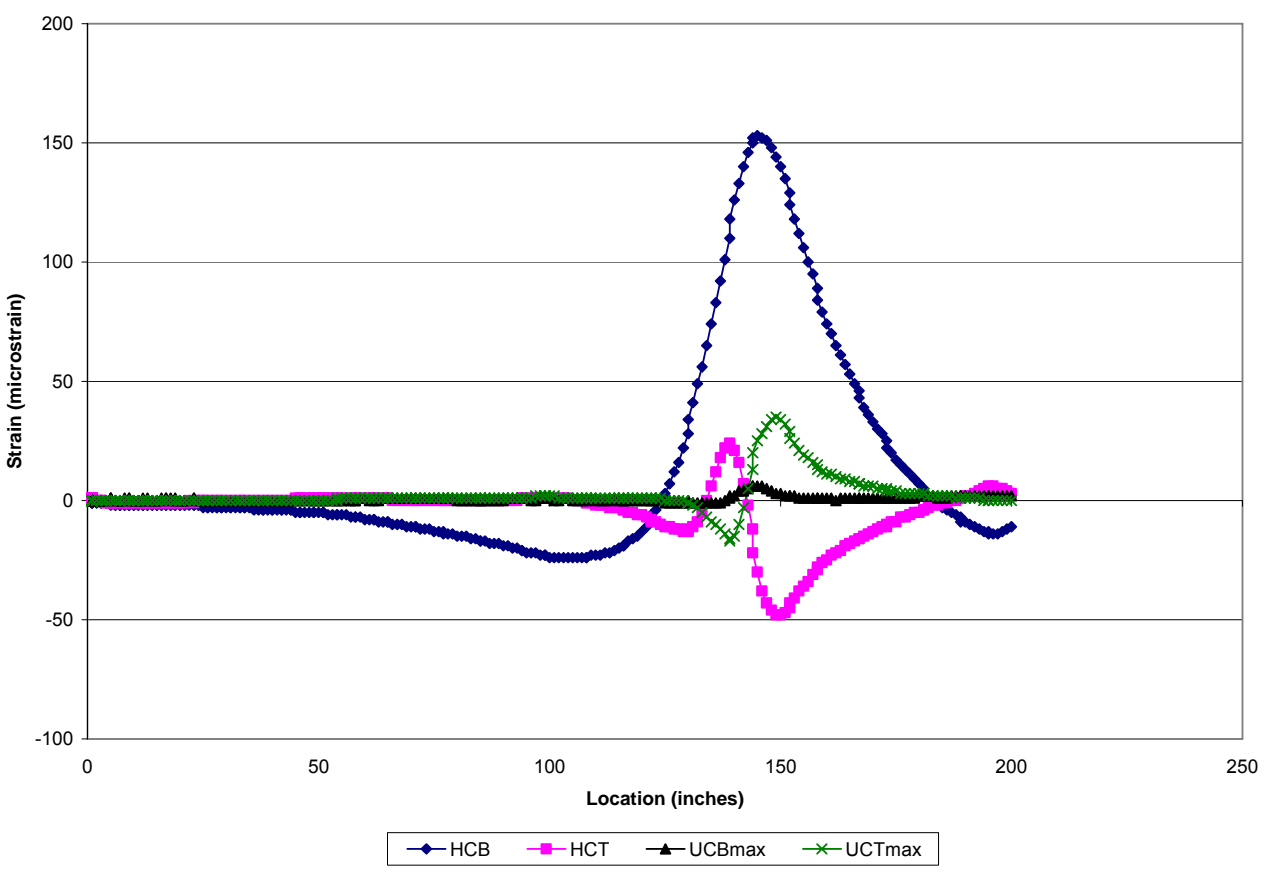

(b)

Figure B.51 Strain versus APT Carriage Location - Test Area 3 - Lane 2 Corner Location (a) 0 Load Applications (b) 150,000 Load Applications (c) 275,000 Load Applications (continued) 


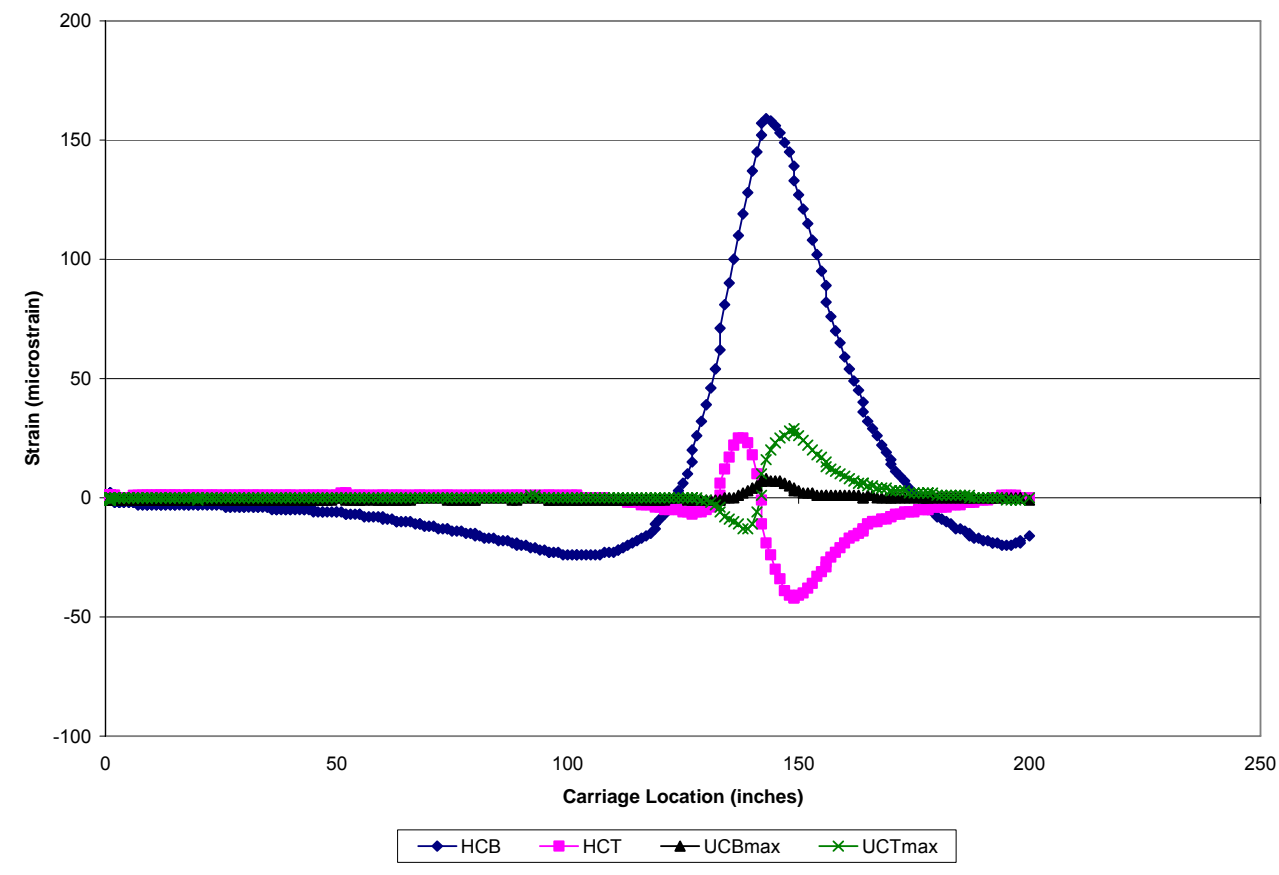

(c)

Figure B.51 Strain versus APT Carriage Location - Test Area 3 - Lane 2 Corner Location (a) 0 Load Applications (b) 150,000 Load Applications (c) 275,000 Load Applications 


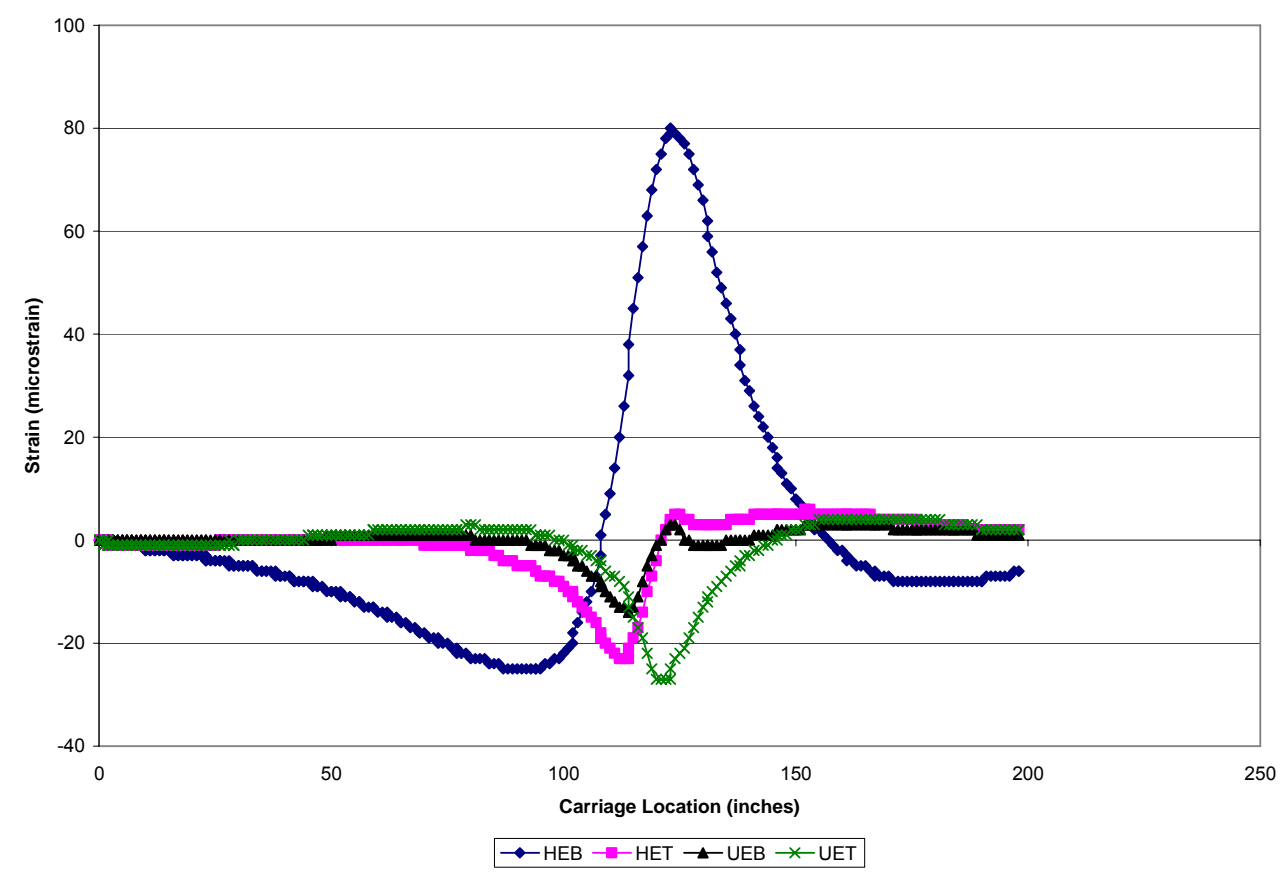

(a)

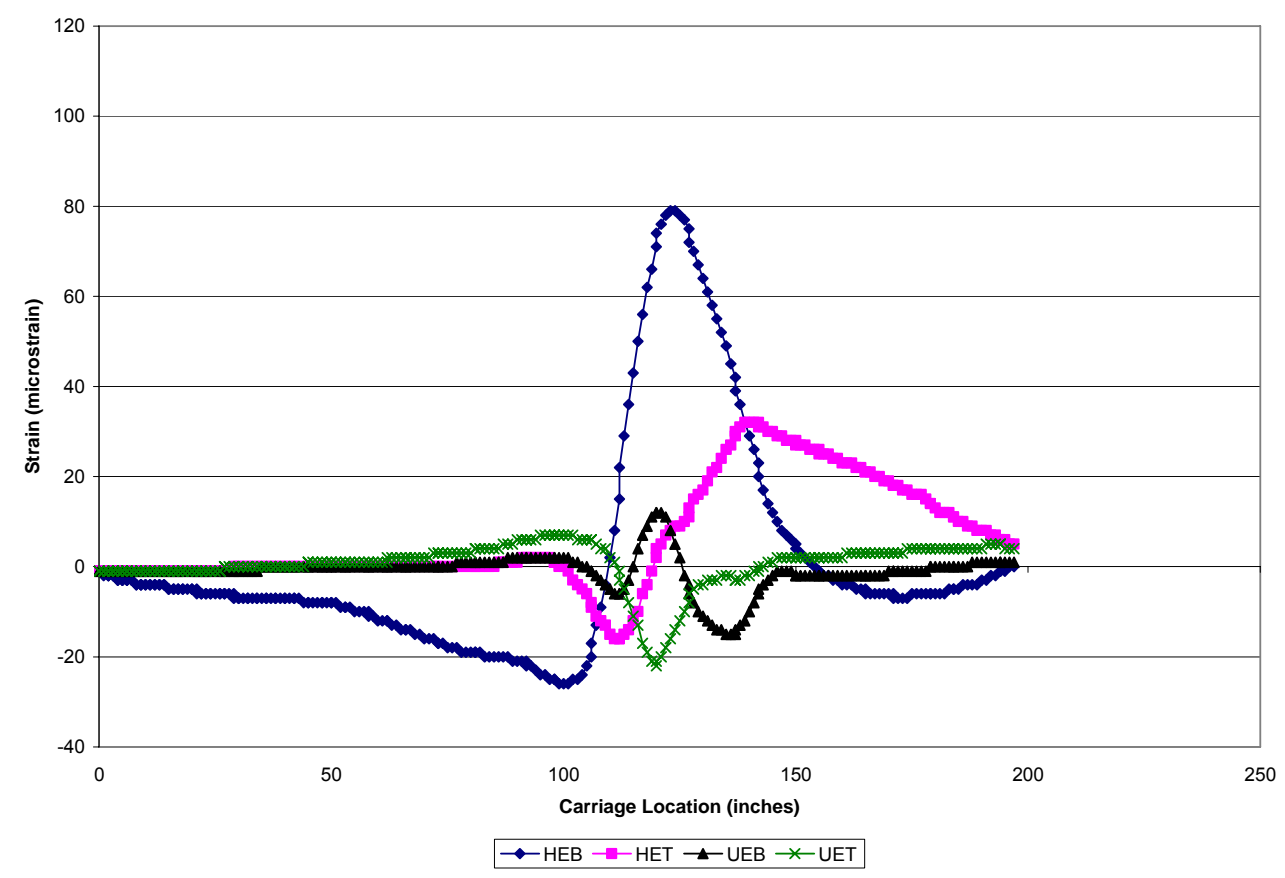

(b)

Figure B.52 Strain versus APT Carriage Location - Test Area 3 - Lane 3 - Edge Location (a) 0 Load Applications (b) 150,000 Load Applications (c) 275,000 Load Applications (continued) 


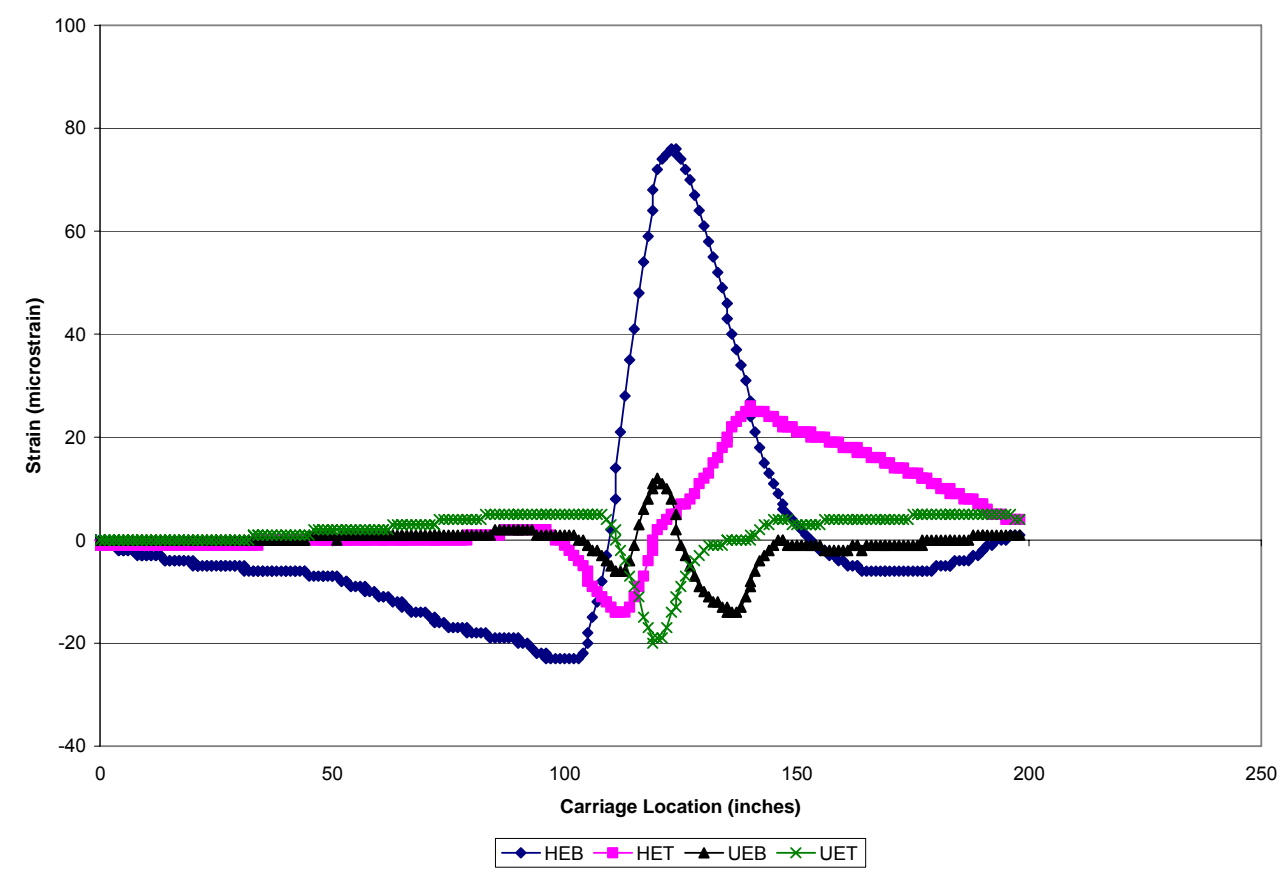

(c)

Figure B.52 Strain versus APT Carriage Location - Test Area 3 - Lane 3 - Edge Location (a) 0 Load Applications (b) 150,000 Load Applications (c) 275,000 Load Applications 


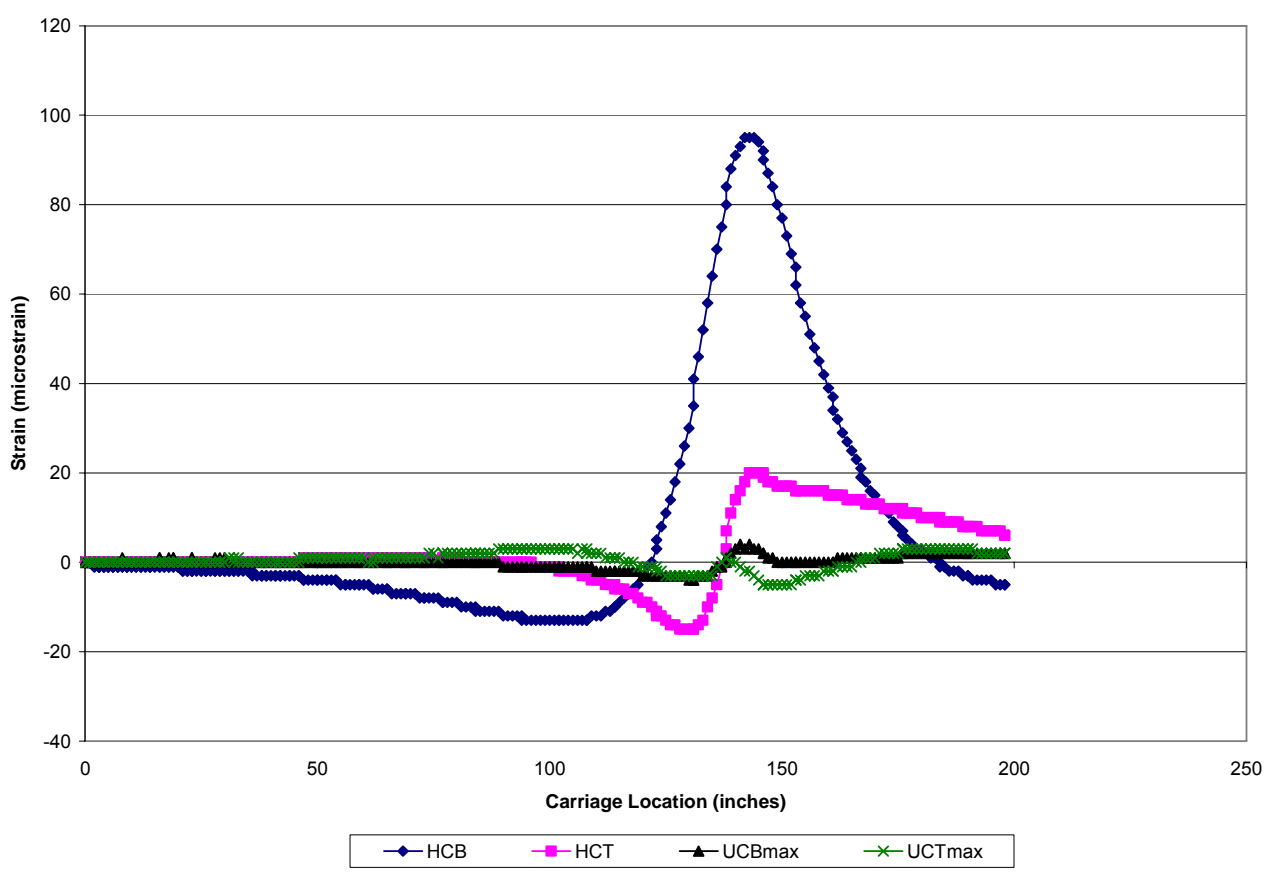

(a)

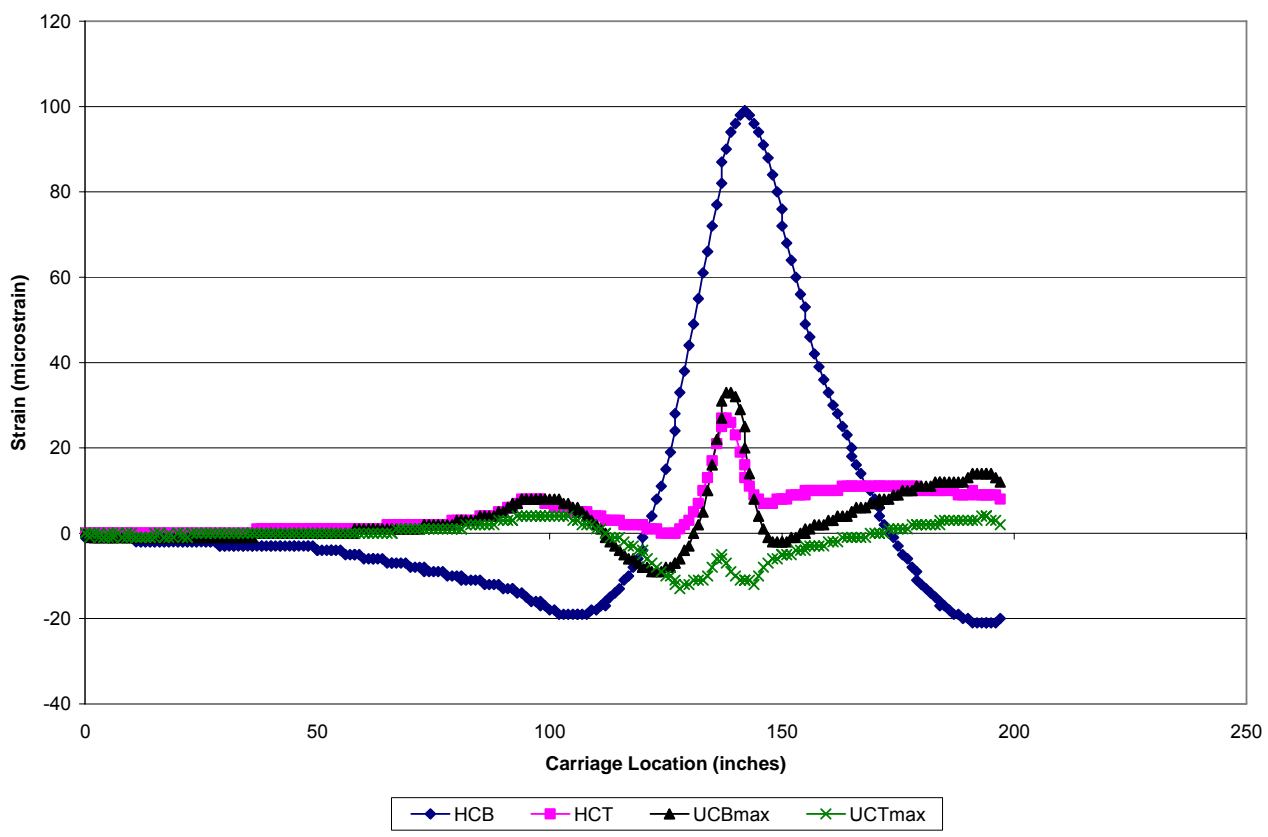

(b)

Figure B.53 Strain versus APT Carriage Location - Test Area 3 - Lane 3 Corner Location (a) 0 Load Applications (b) 150,000 Load Applications (c) 275,000 Load Applications (continued) 


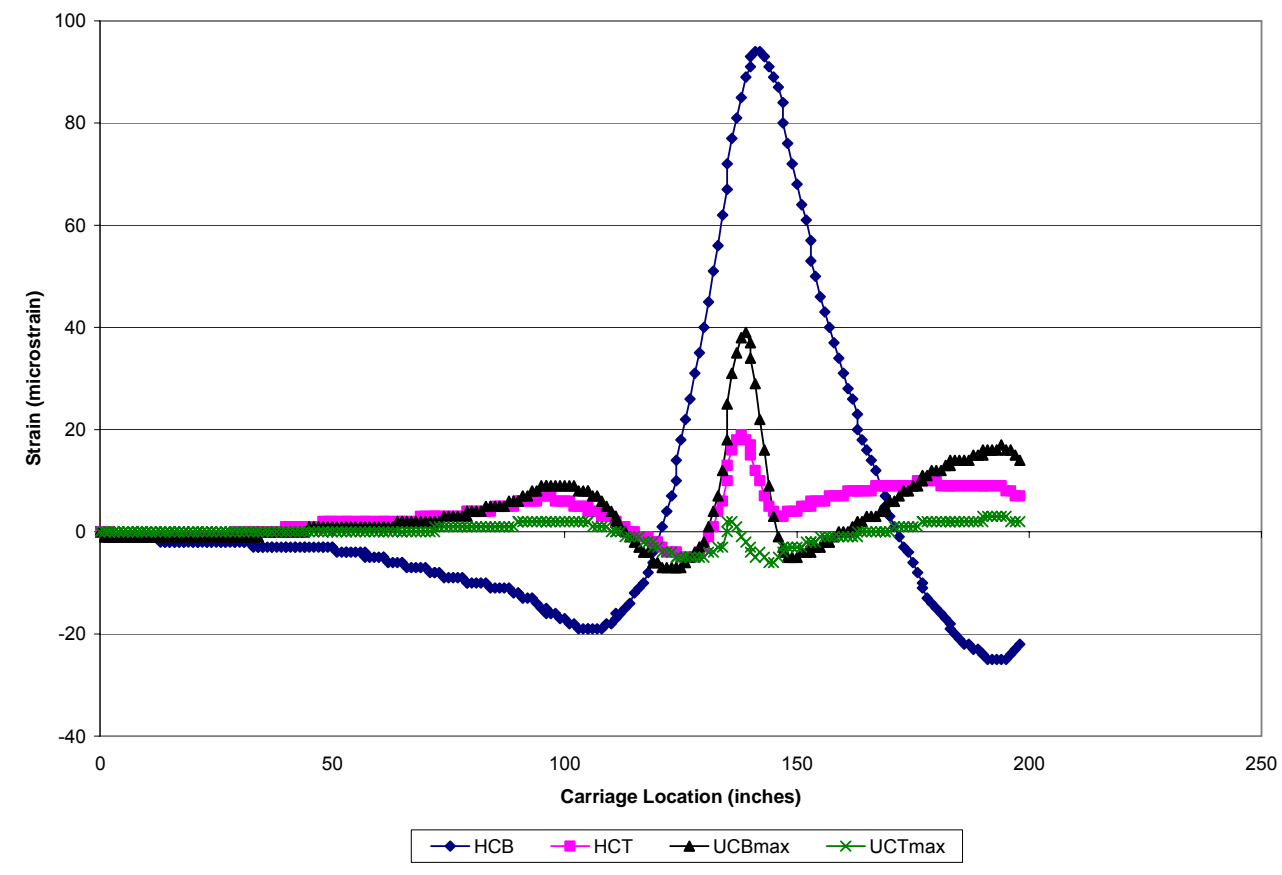

(c)

Figure B.53 Strain versus APT Carriage Location - Test Area 3 - Lane 3 Corner Location (a) 0 Load Applications (b) 150,000 Load Applications (c) 275,000 Load Applications 


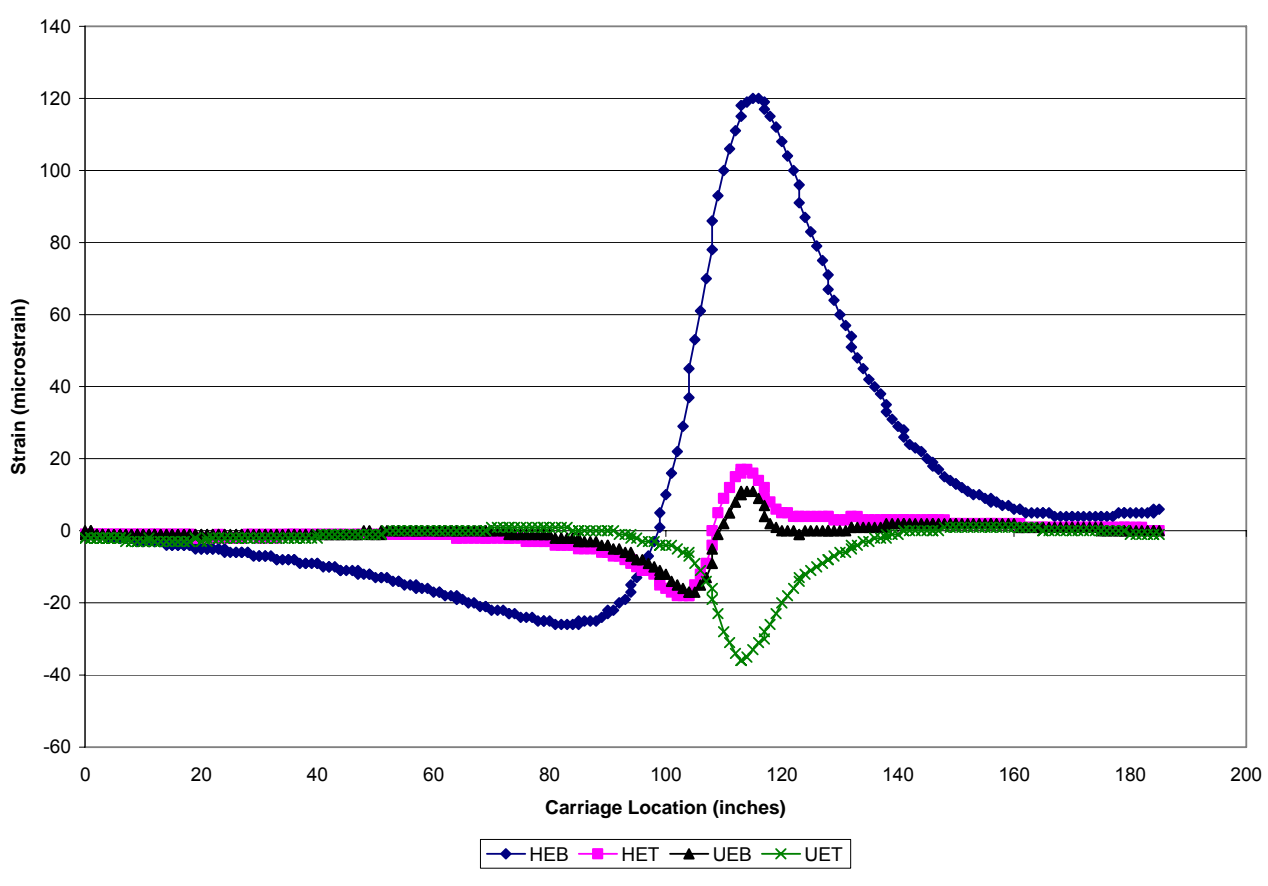

(a)

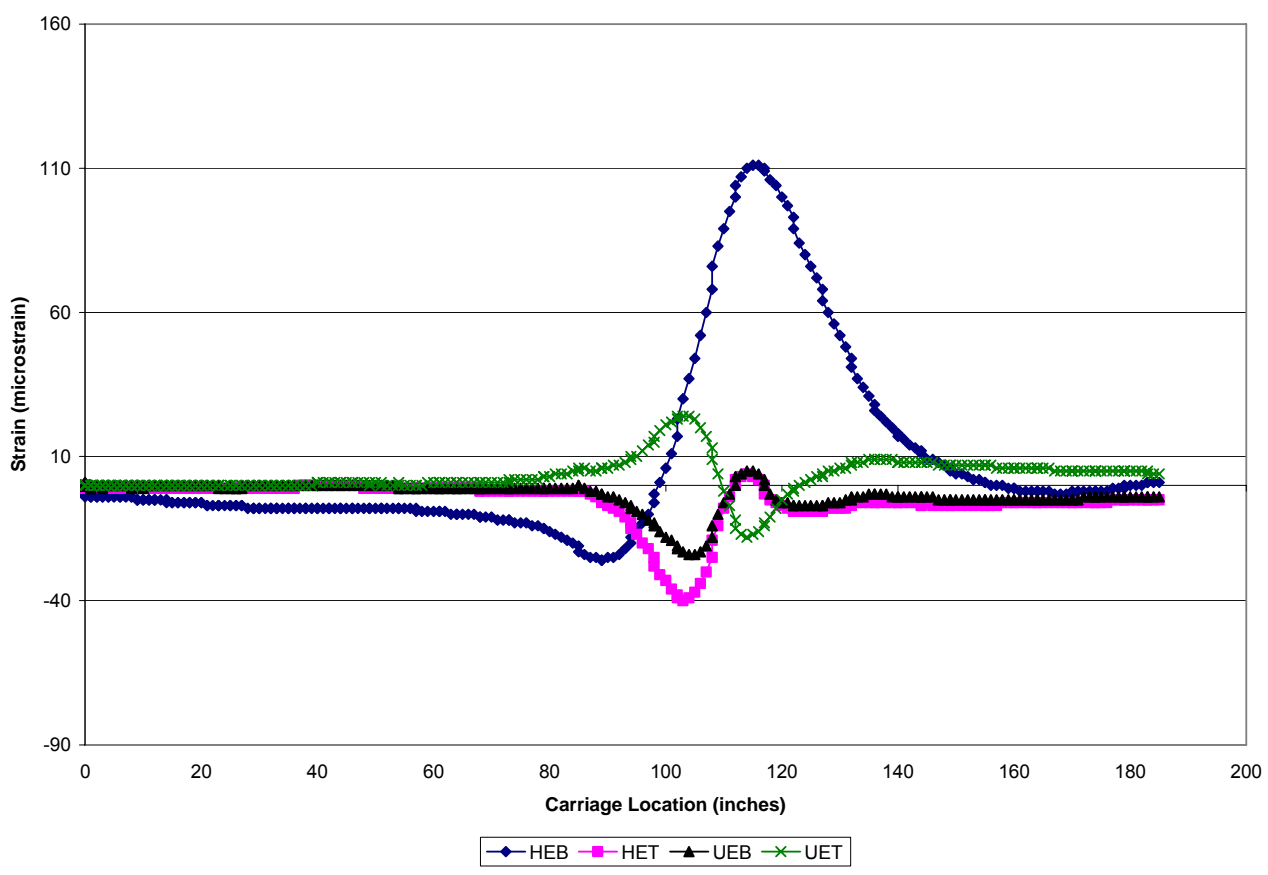

(b)

Figure B.54 Strain versus APT Carriage Location - Test Area 3 - Lane 4 - Edge Location (a) 0 Load Applications (b) 150,000 Load Applications (c) 275,000 Load Applications (continued) 


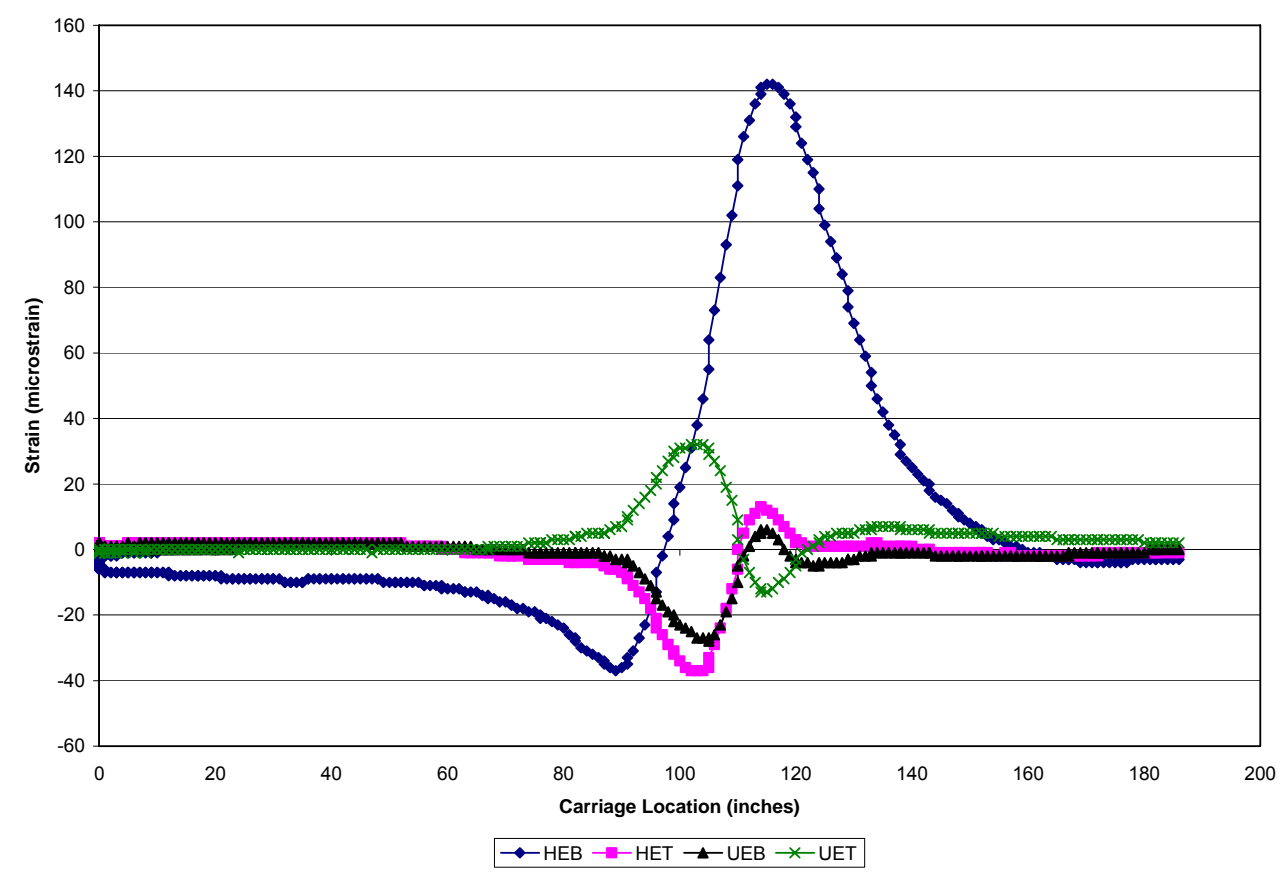

(c)

Figure B.54 Strain versus APT Carriage Location - Test Area 3 - Lane 4 - Edge Location (a) 0 Load Applications (b) 150,000 Load Applications (c) 275,000 Load Applications 


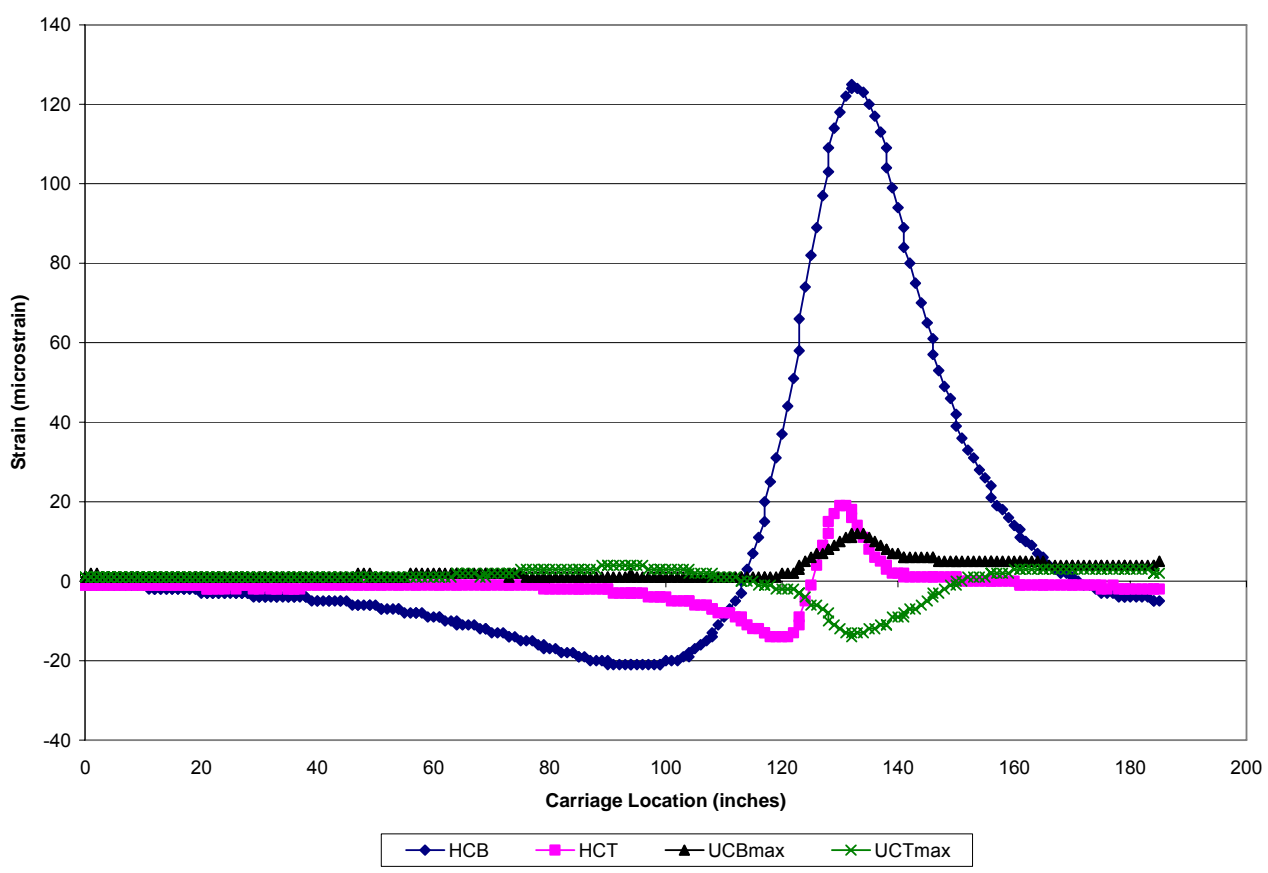

(a)

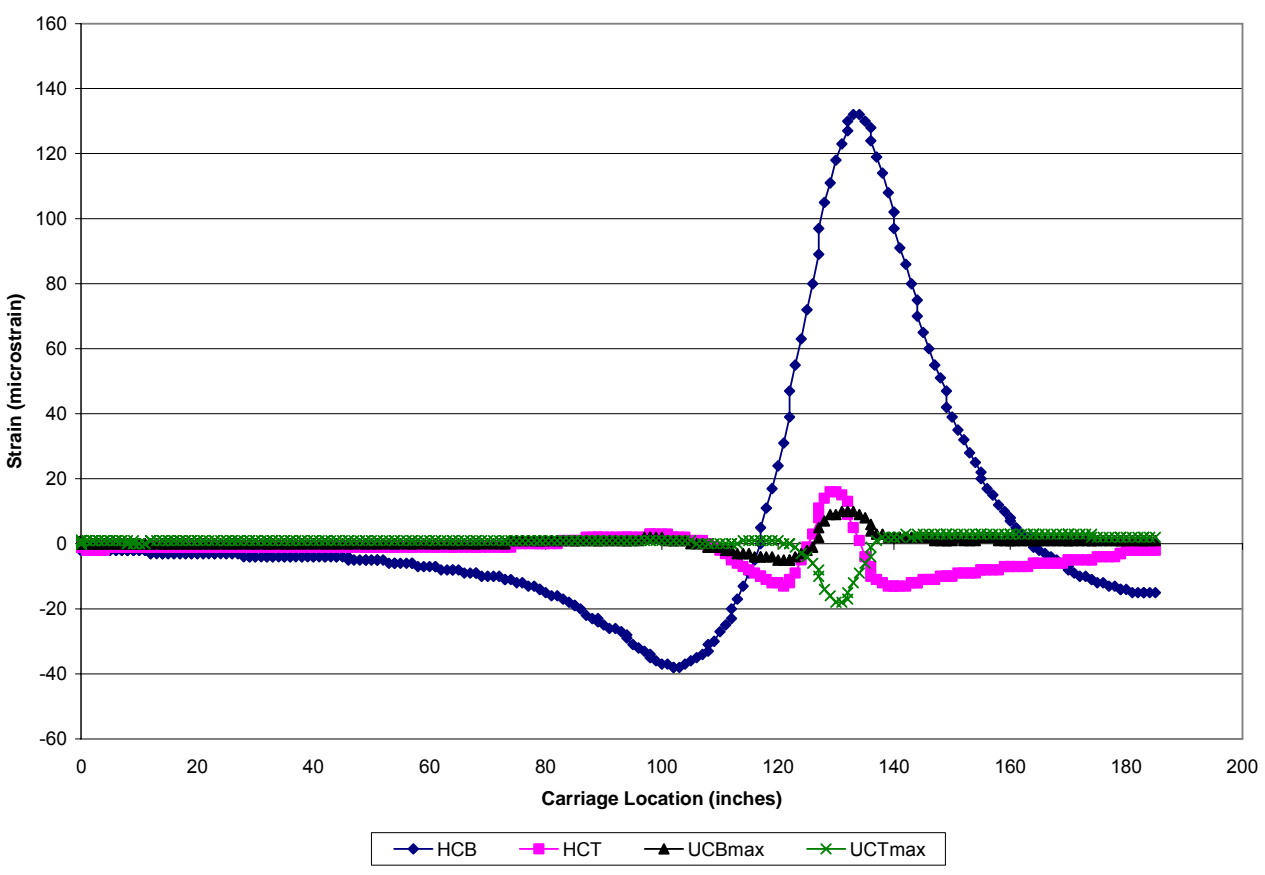

(b)

Figure B.55 Strain versus APT Carriage Location - Test Area 3 - Lane 4 Corner Location (a) 0 Load Applications (b) 150,000 Load Applications (c) 275,000 Load Applications (continued) 


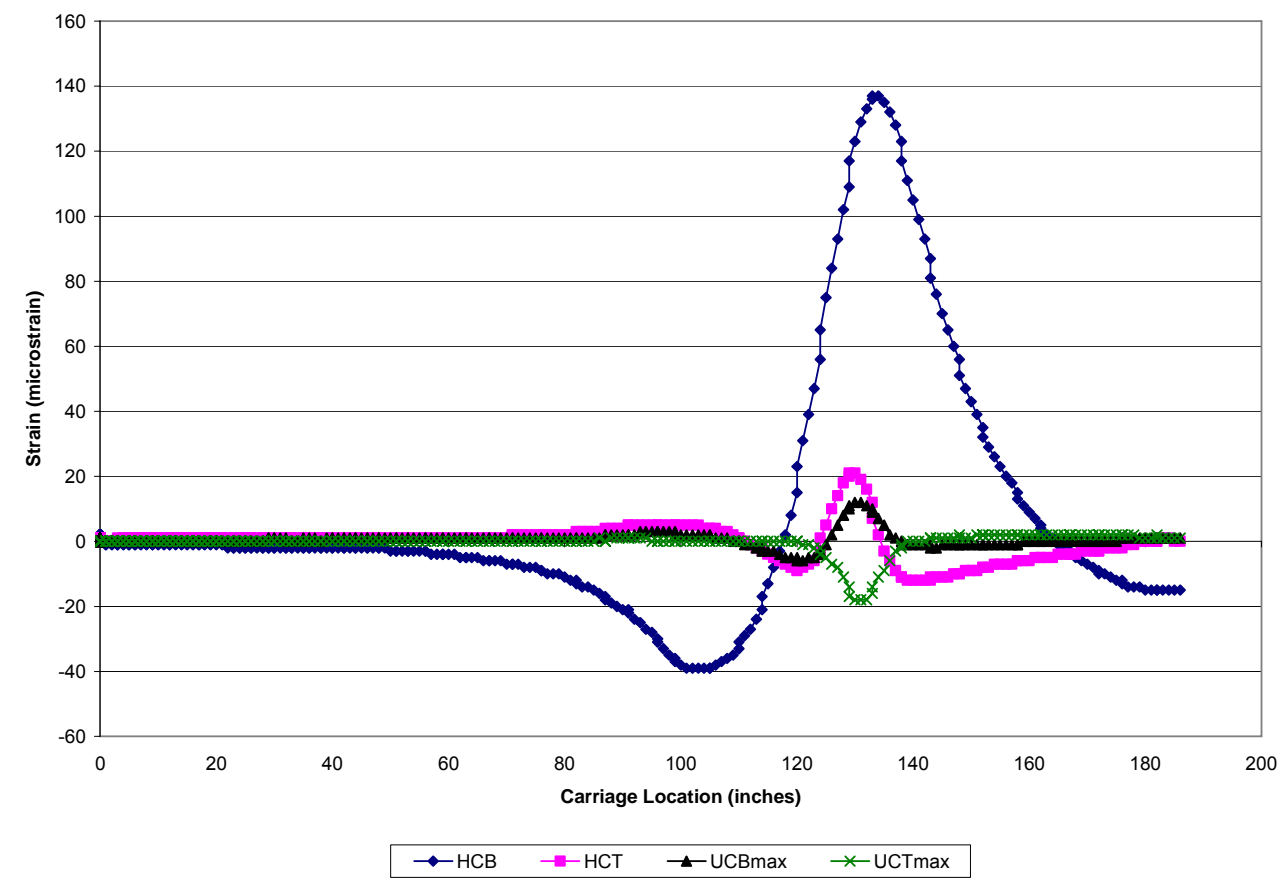

(c)

Figure B.55 Strain versus APT Carriage Location - Test Area 3 - Lane 4 Corner Location (a) 0 Load Applications (b) 150,000 Load Applications (c) 275,000 Load Applications 


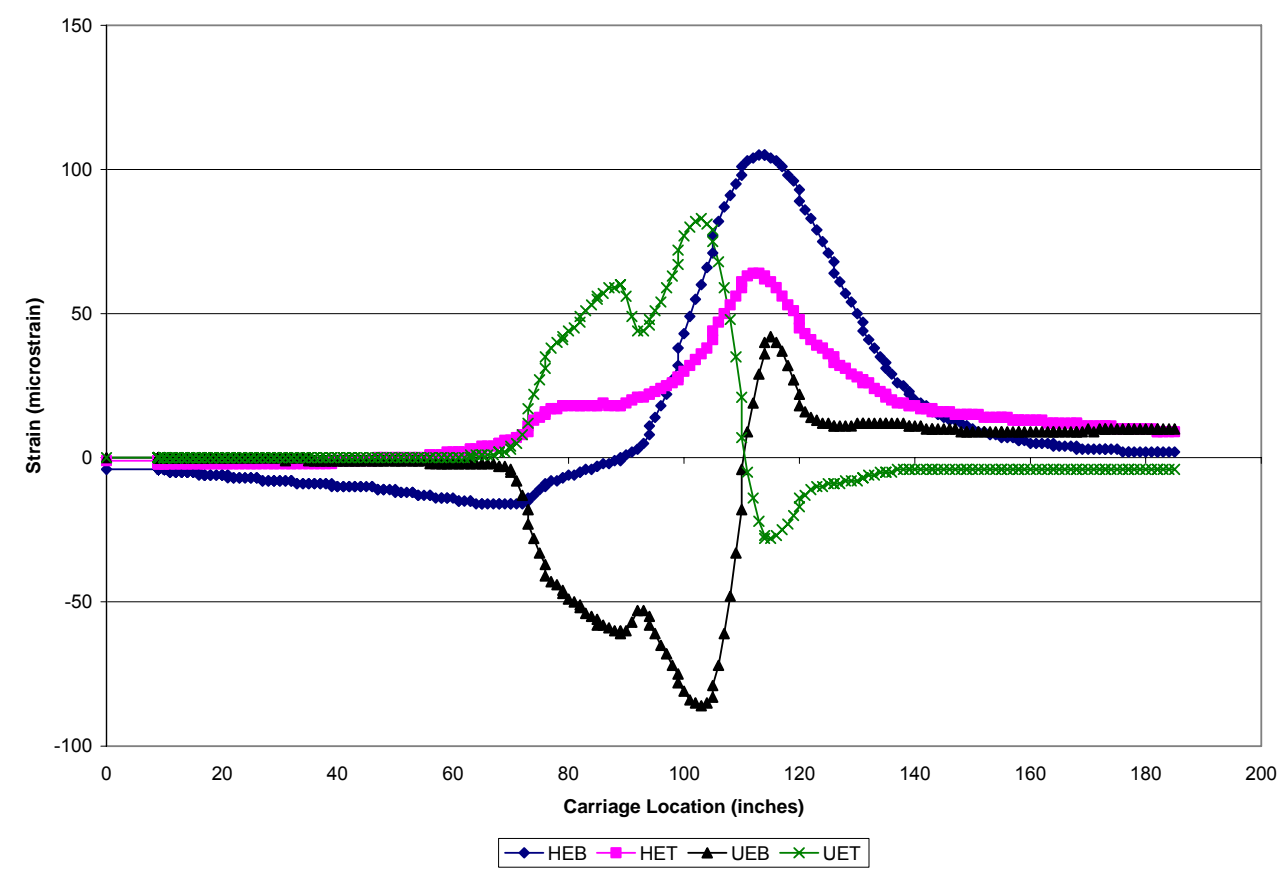

(a)

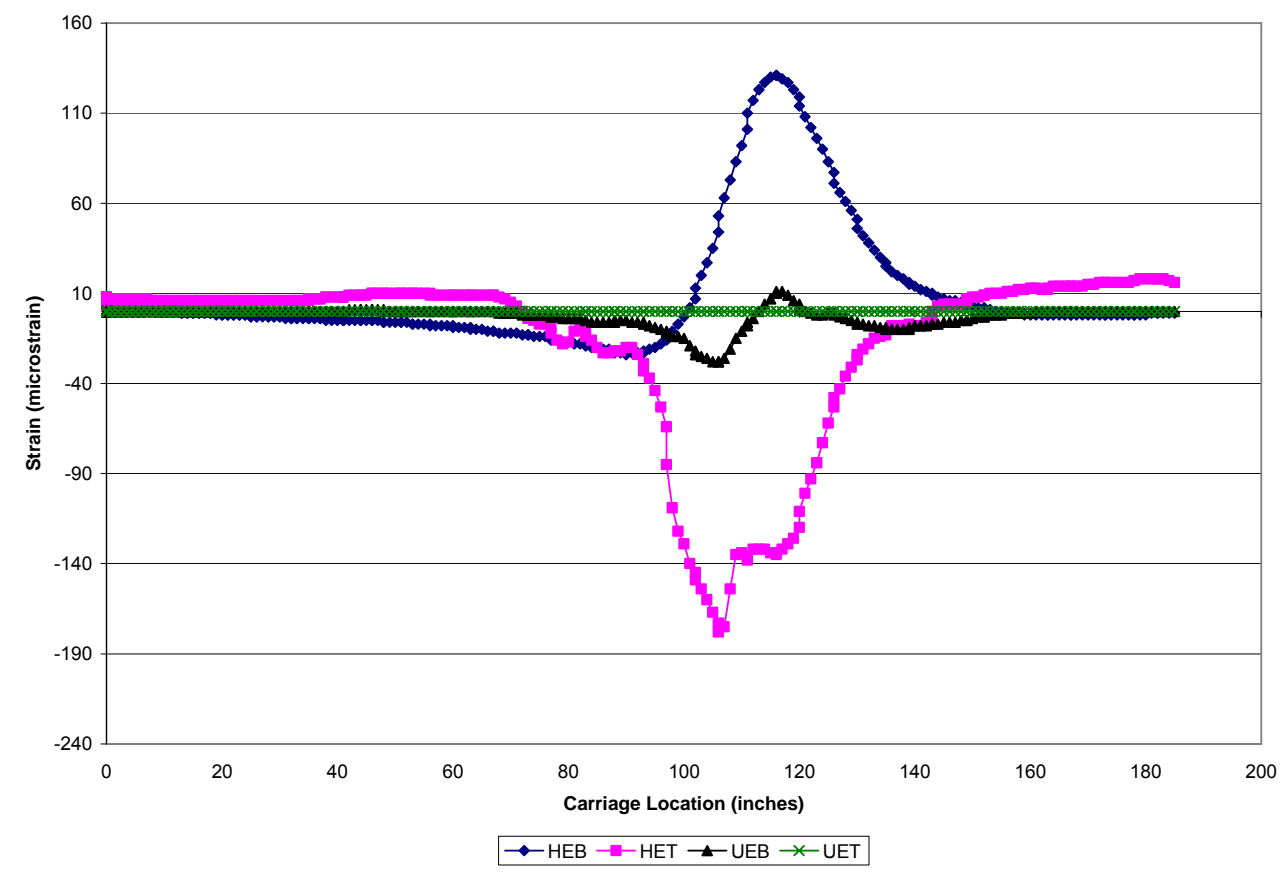

(b)

Figure B.56 Strain versus APT Carriage Location - Test Area 3 - Lane 5 - Edge Location (a) 0 Load Applications (b) 150,000 Load Applications (c) 275,000 Load Applications (continued) 


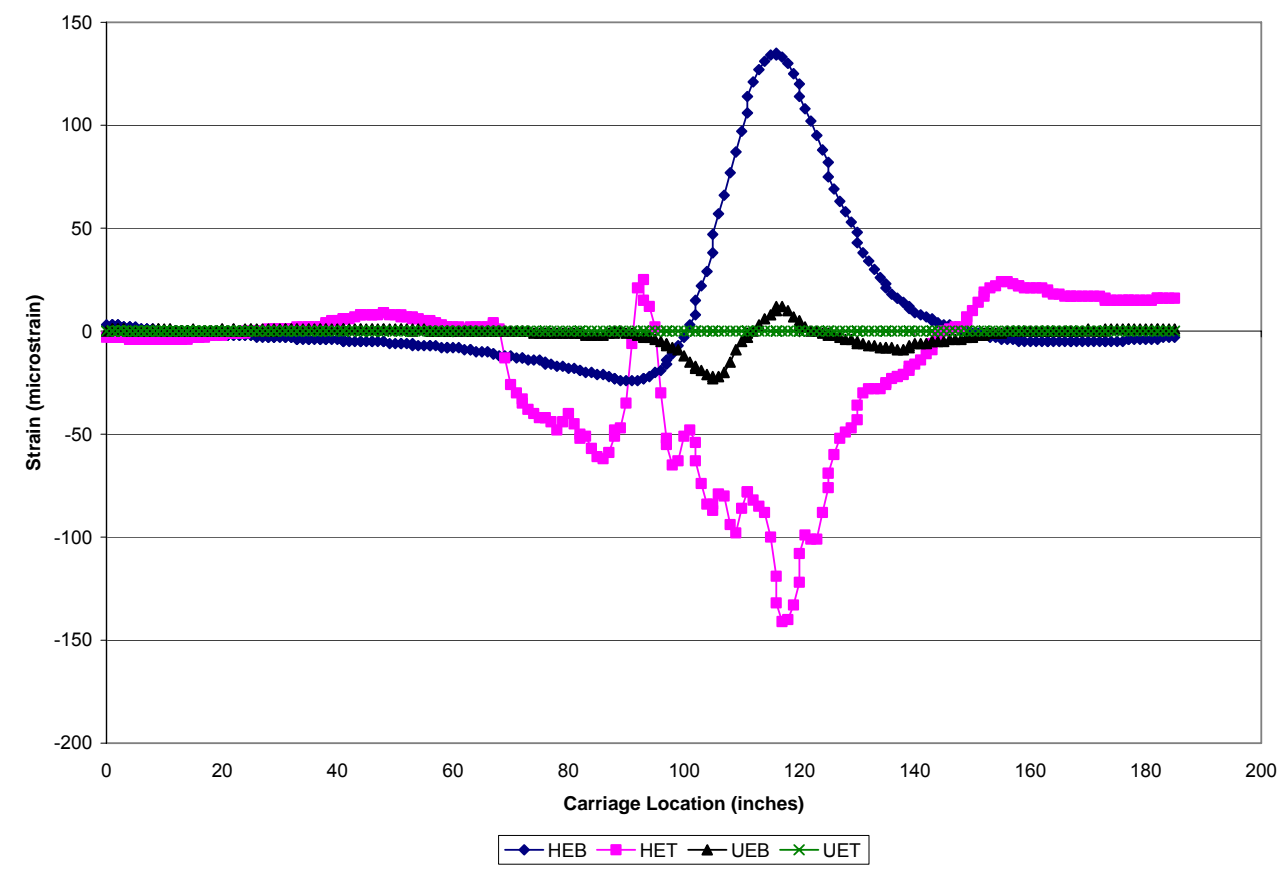

(c) 275,000 Load Applications

Figure B.56 Strain versus APT Carriage Location - Test Area 3 - Lane 5 - Edge Location (a) 0 Load Applications (b) 150,000 Load Applications (c) 275,000 Load Applications 


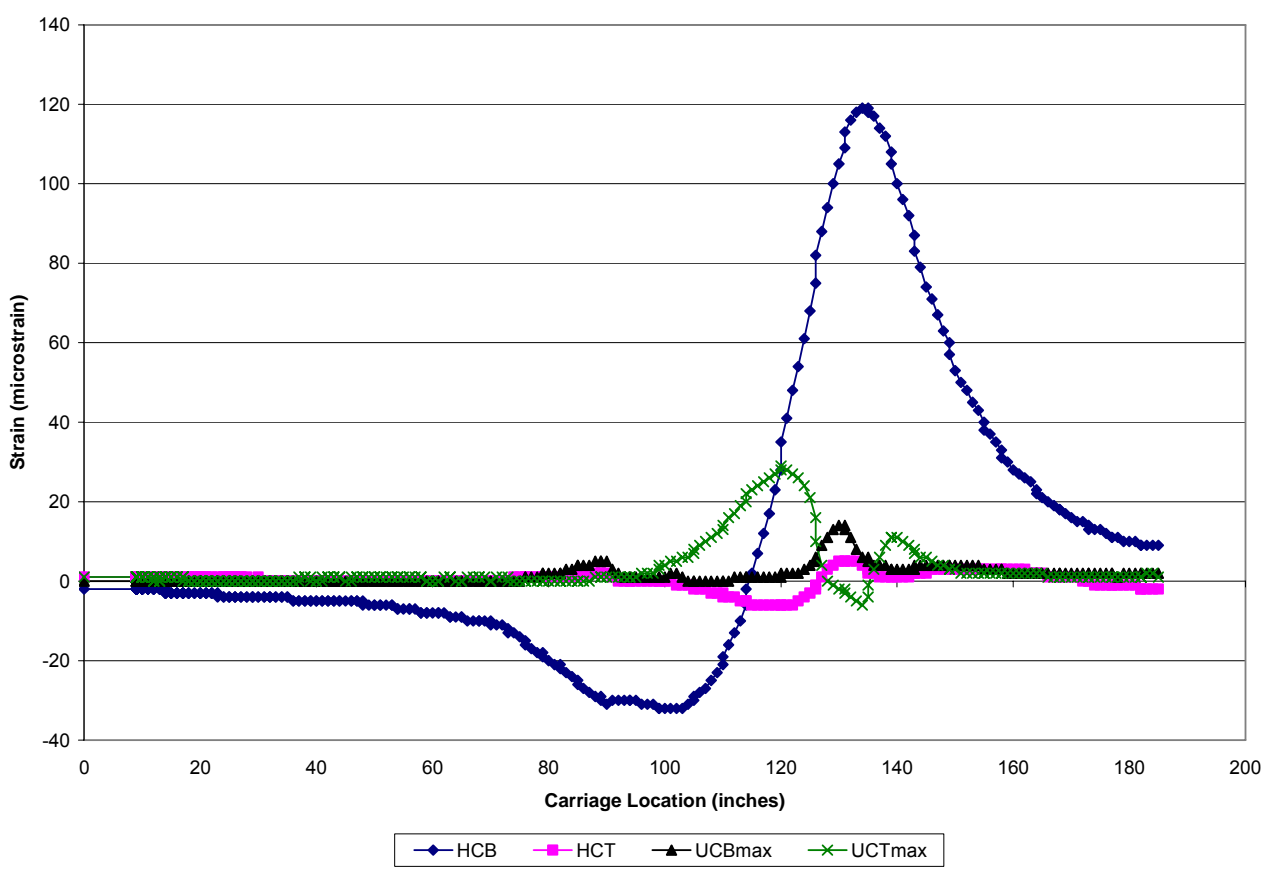

(a)

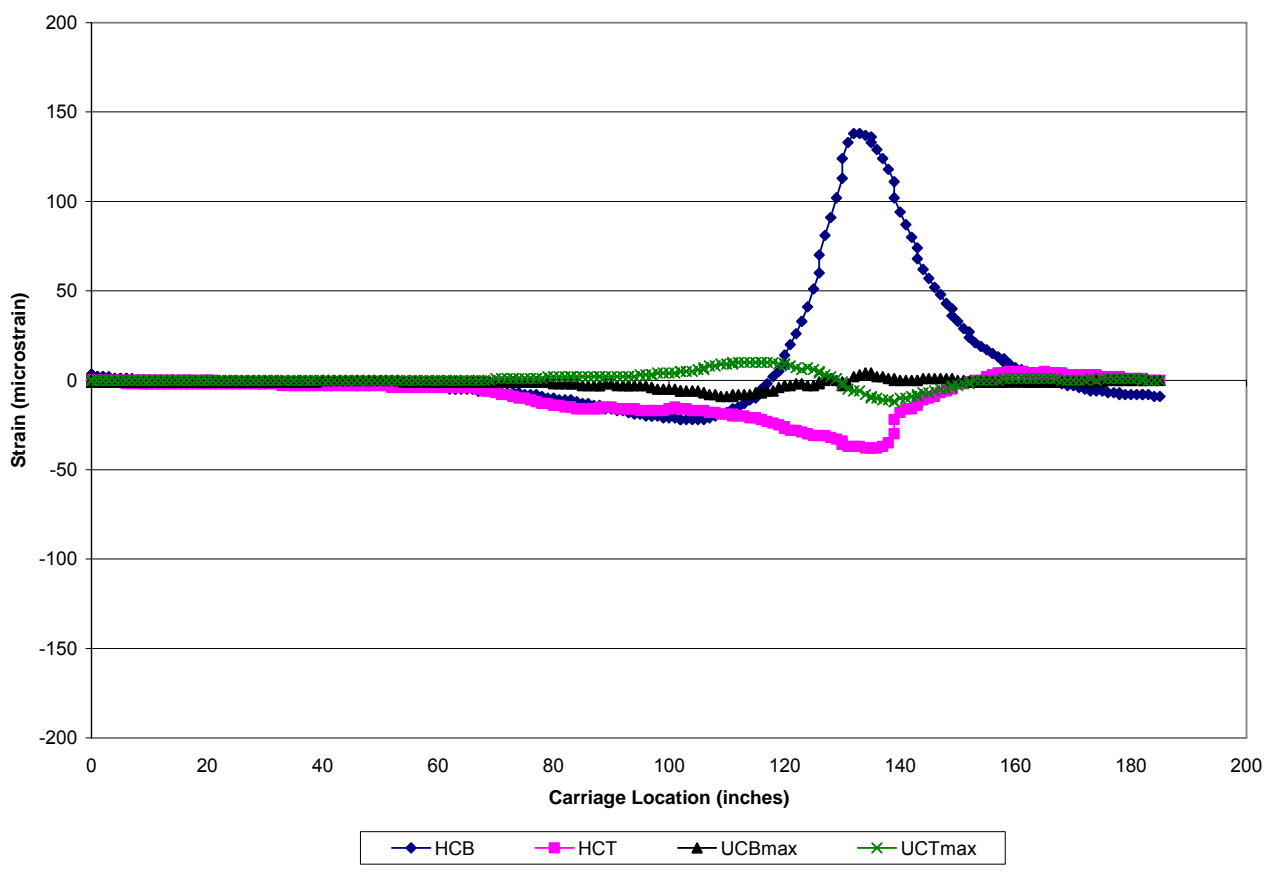

(b)

Figure B.57 Strain versus APT Carriage Location - Test Area 3 - Lane 5 Corner Location (a) 0 Load Applications (b) 150,000 Load Applications (c) 275,000 Load Applications (continued) 


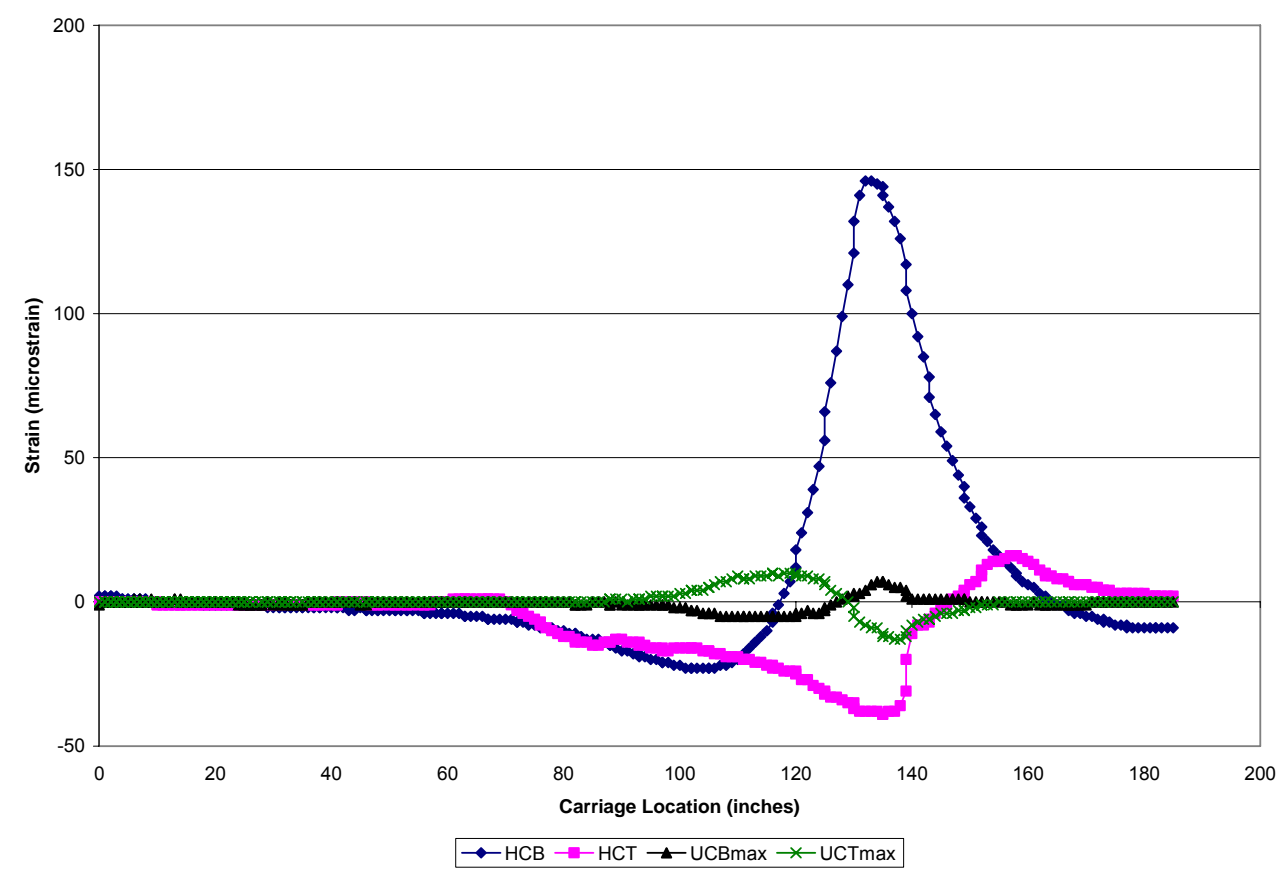

(c)

Figure B.57 Strain versus APT Carriage Location - Test Area 3 - Lane 5 Corner Location (a) 0 Load Applications (b) 150,000 Load Applications (c) 275,000 Load Applications 


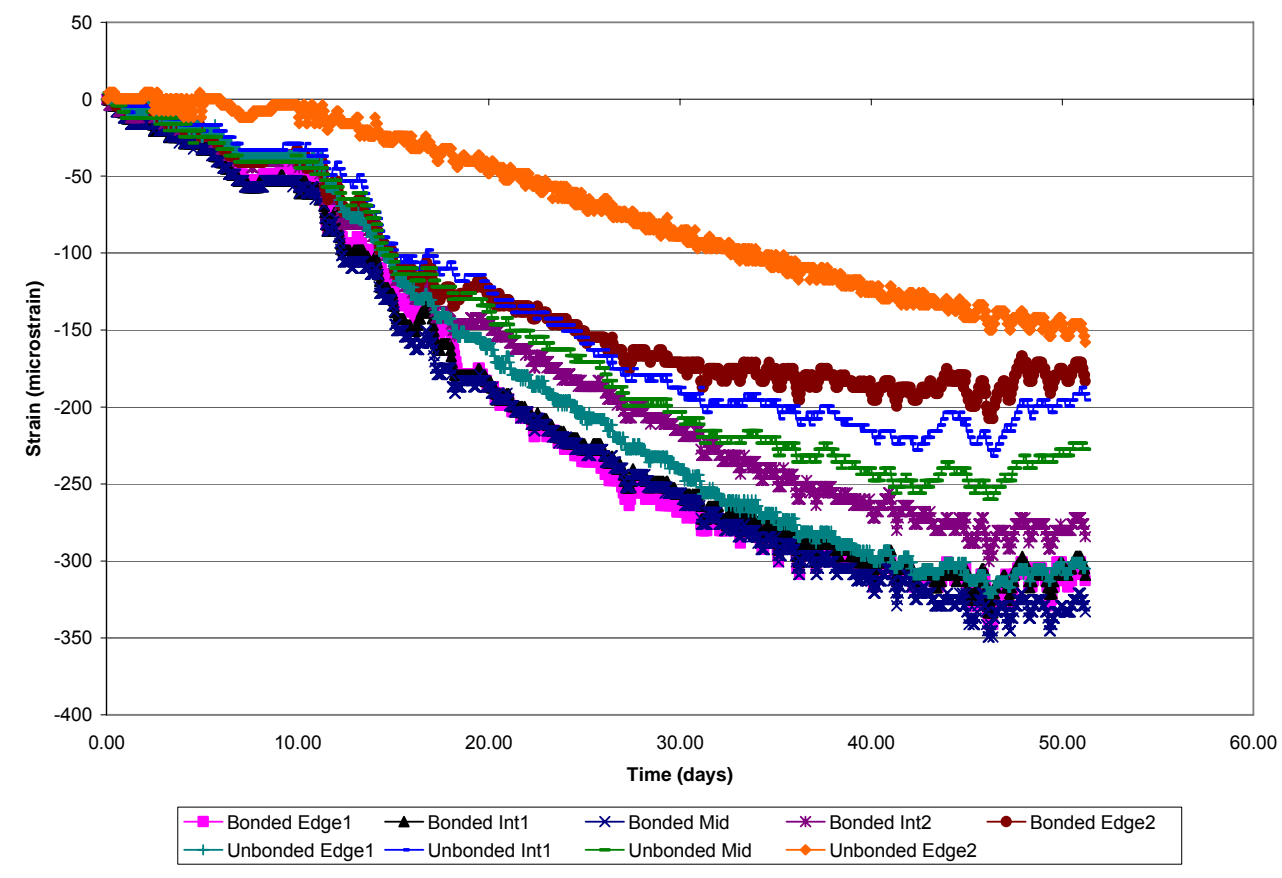

Figure B.58 Bonded and Unbonded Strains over Time - Test Area 1

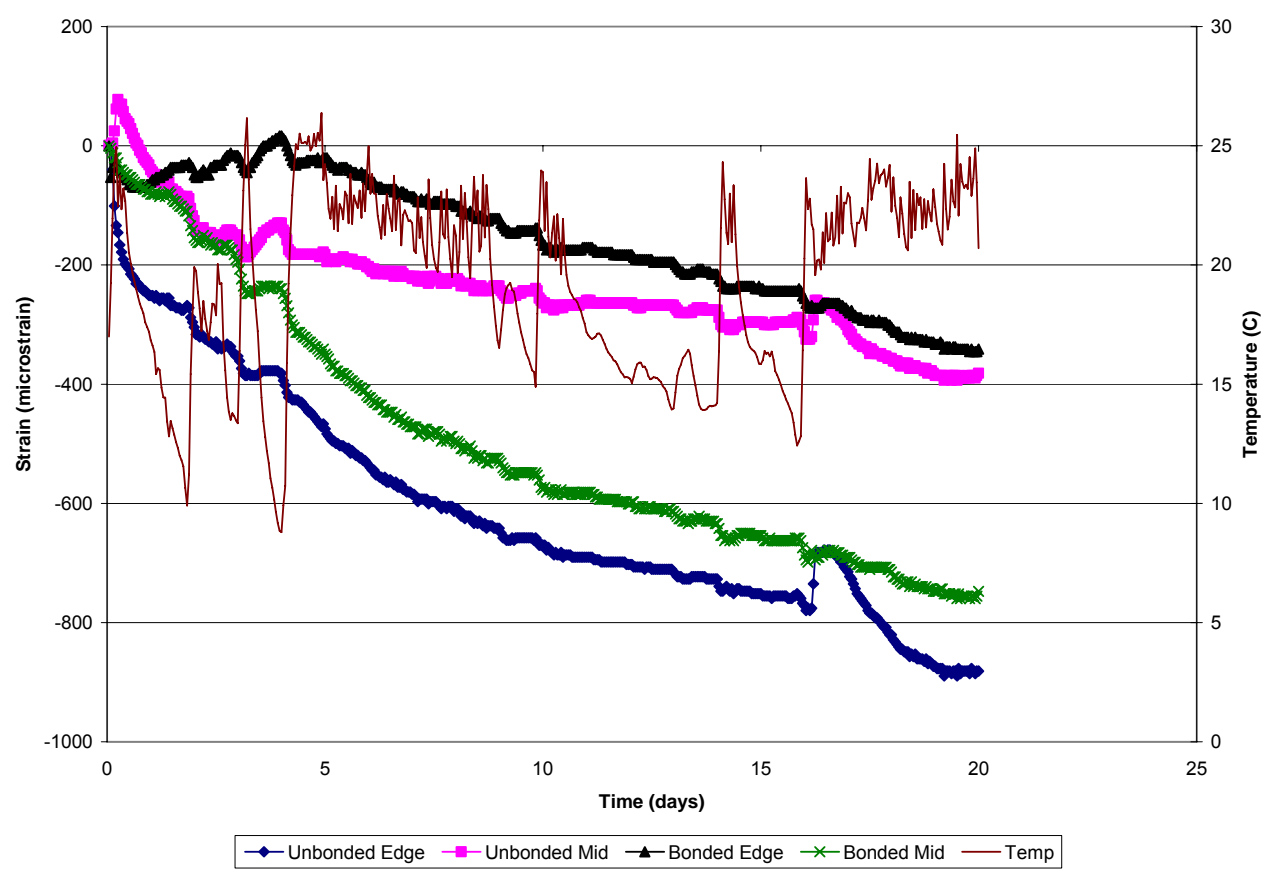

Figure B.59 Bonded and Unbonded Strains over Time - Test Area 2 - Lane 1 


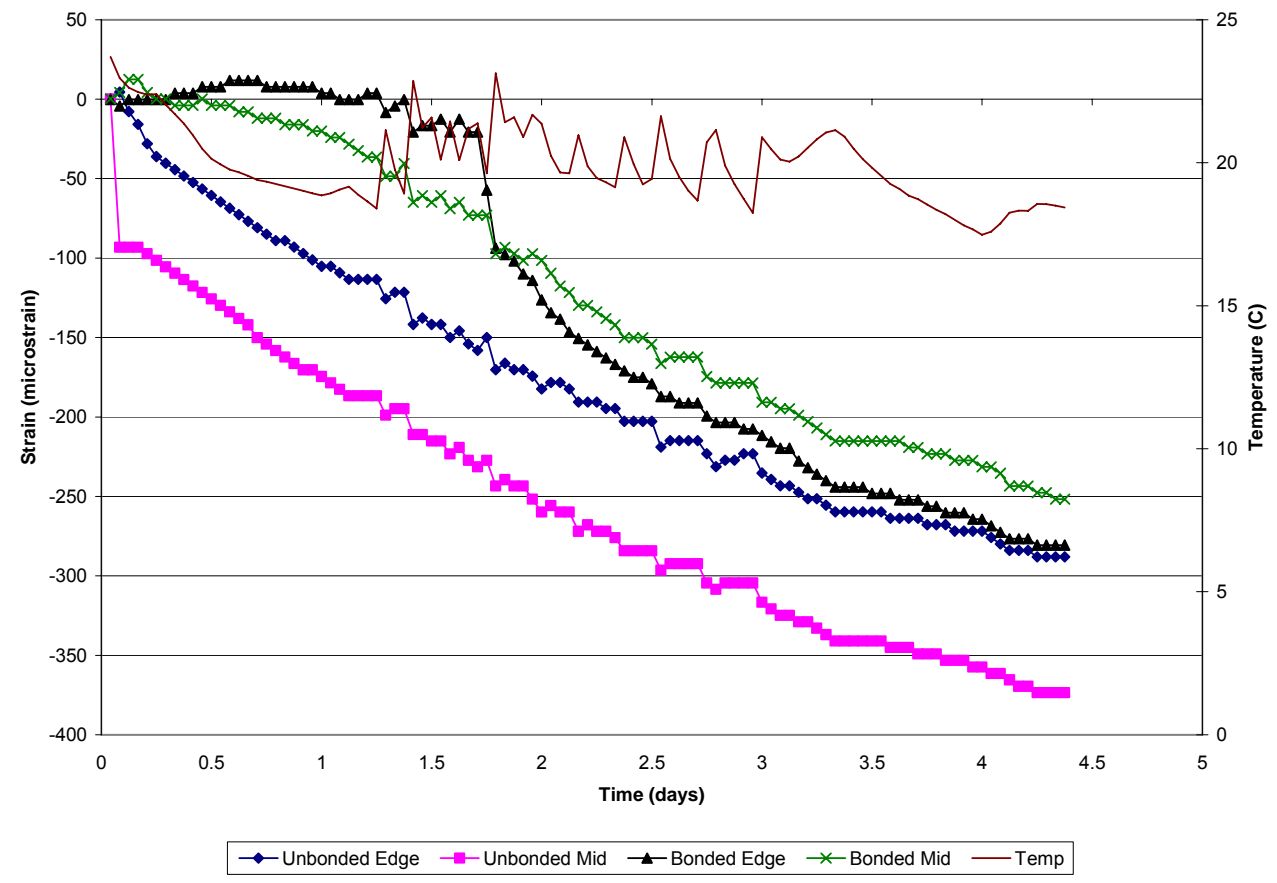

Figure B.60 Bonded and Unbonded Strains over Time - Test Area 2 - Lane 2

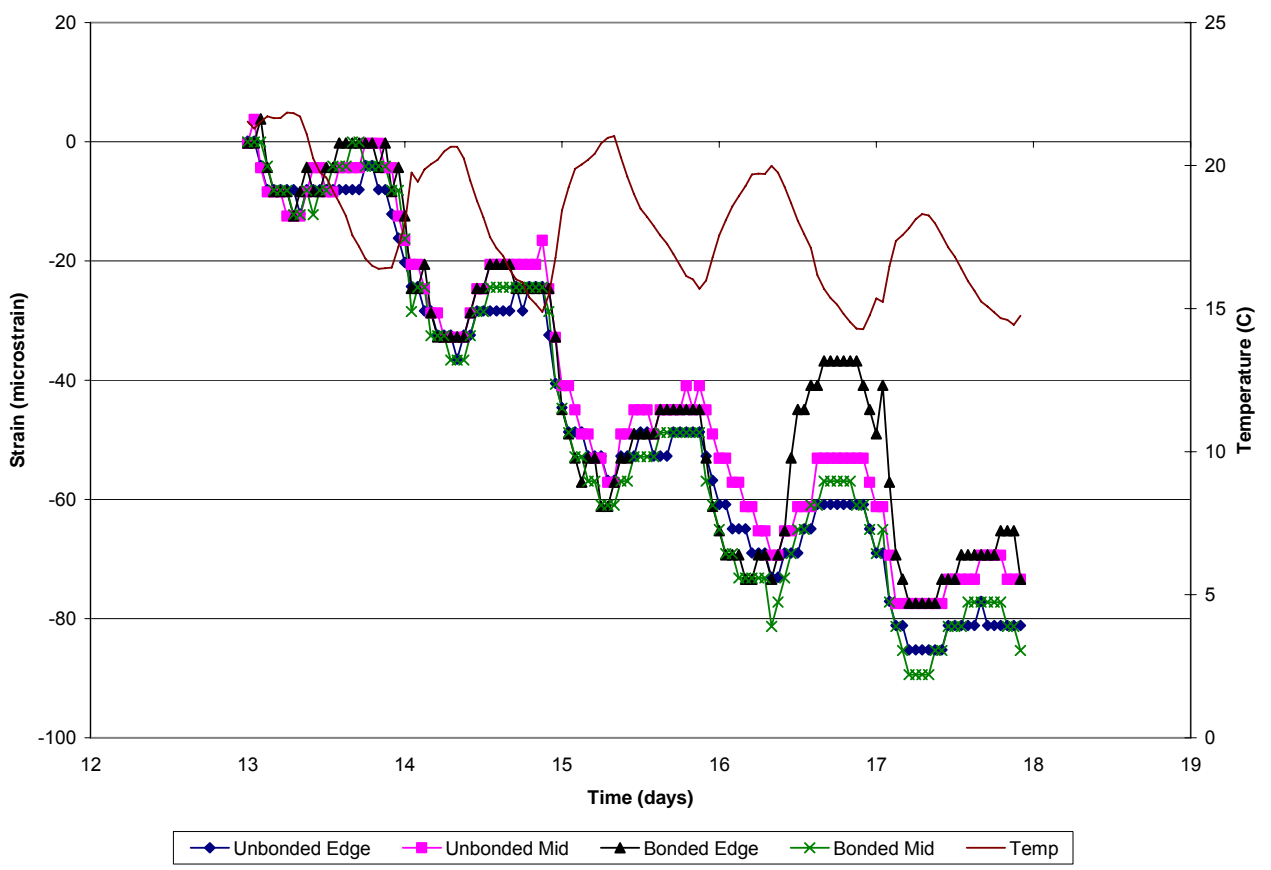

Figure B.61 Bonded and Unbonded Strains over Time - Test Area 2 - Lane 3 


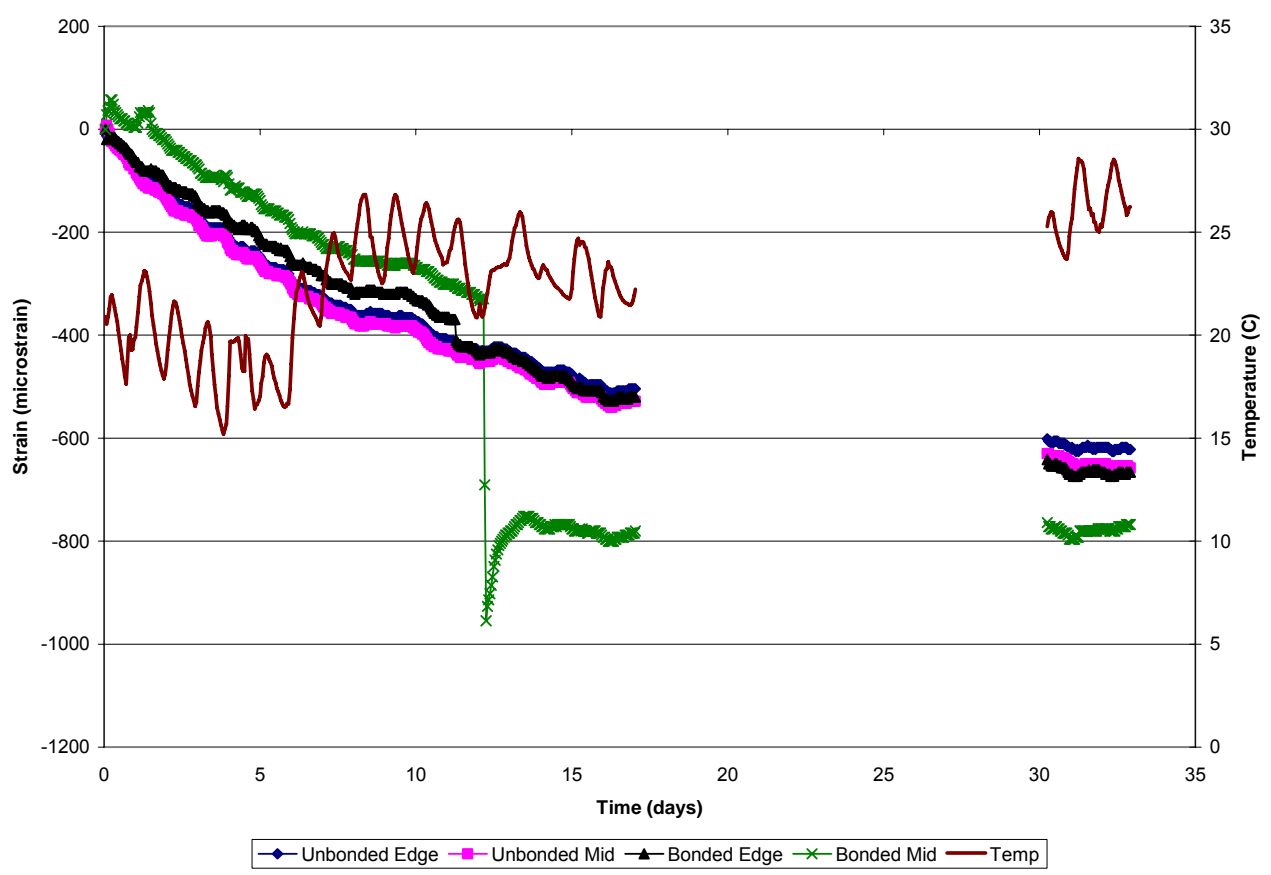

Figure B.62 Bonded and Unbonded Strains over Time - Test Area 2 - Lane 4

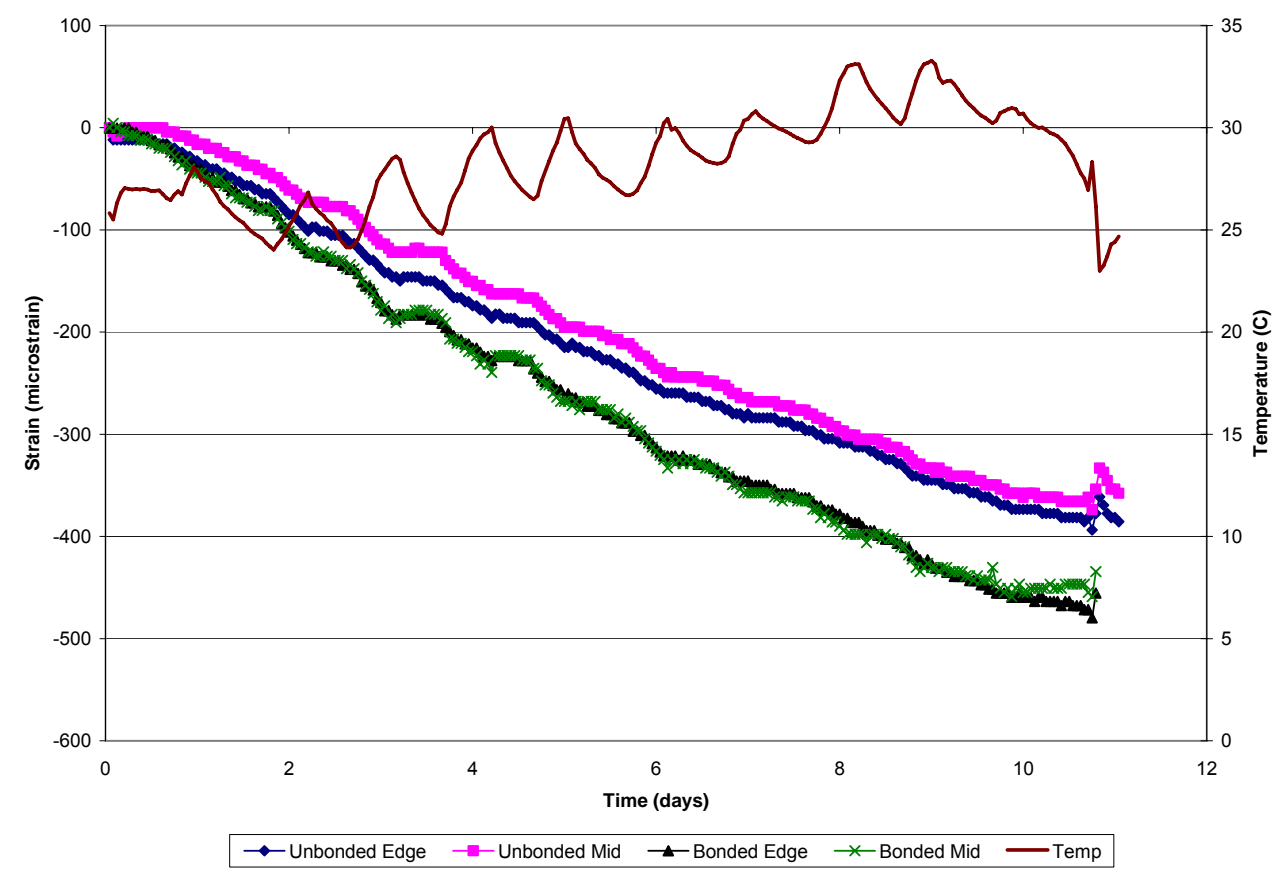

Figure B.63 Bonded and Unbonded Strains over Time - Test Area 2 - Lane 5 


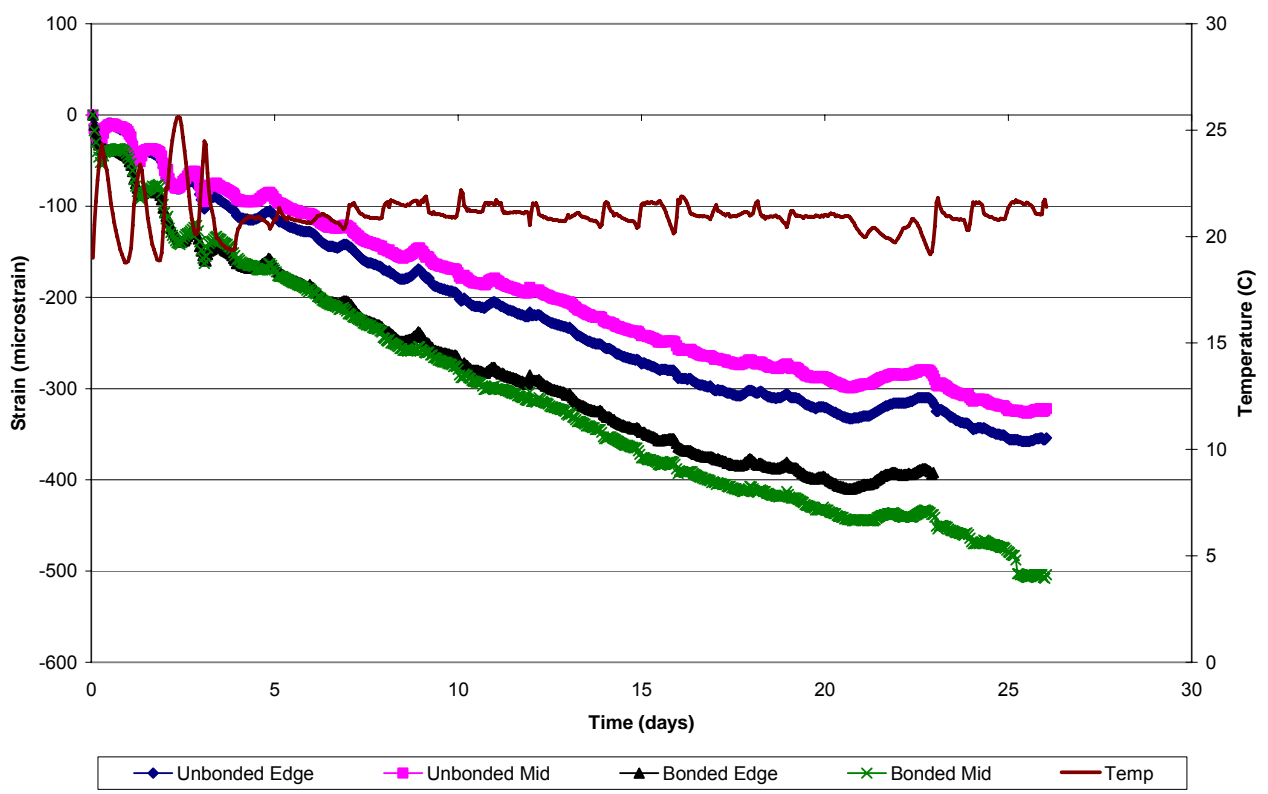

Figure B.64 Bonded and Unbonded Strains over Time - Test Area 3 - Lane 1

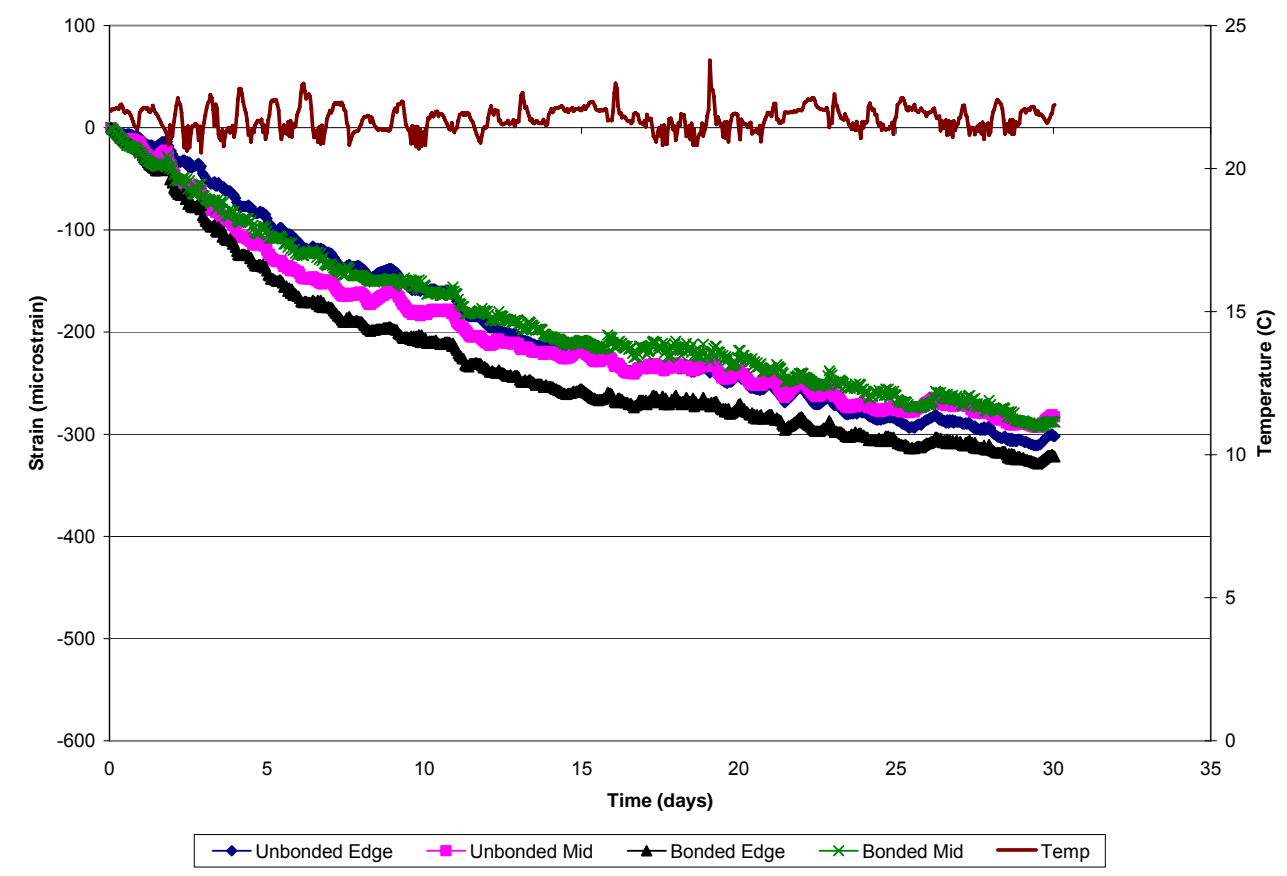

Figure B.65 Bonded and Unbonded Strains over Time - Test Area 3 - Lane 2 


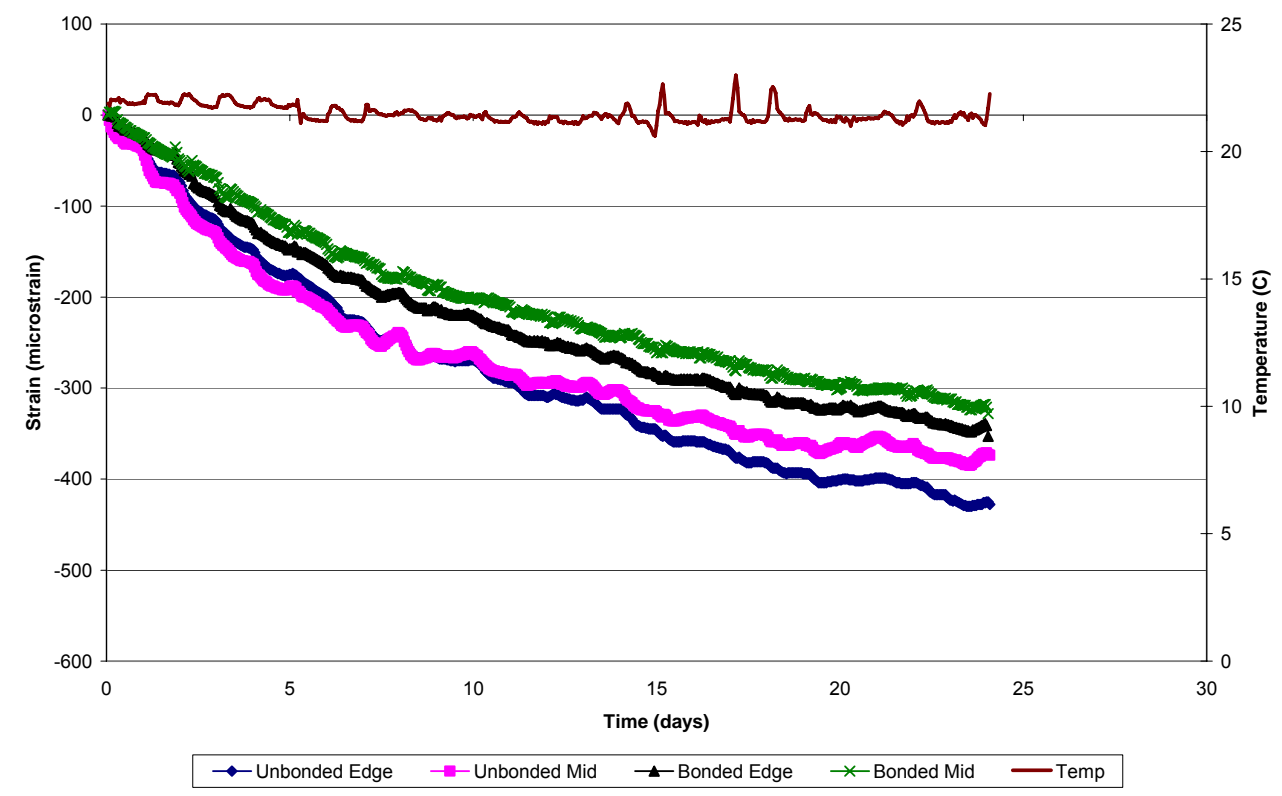

Figure B.66 Bonded and Unbonded Strains over Time - Test Area 3 - Lane 3

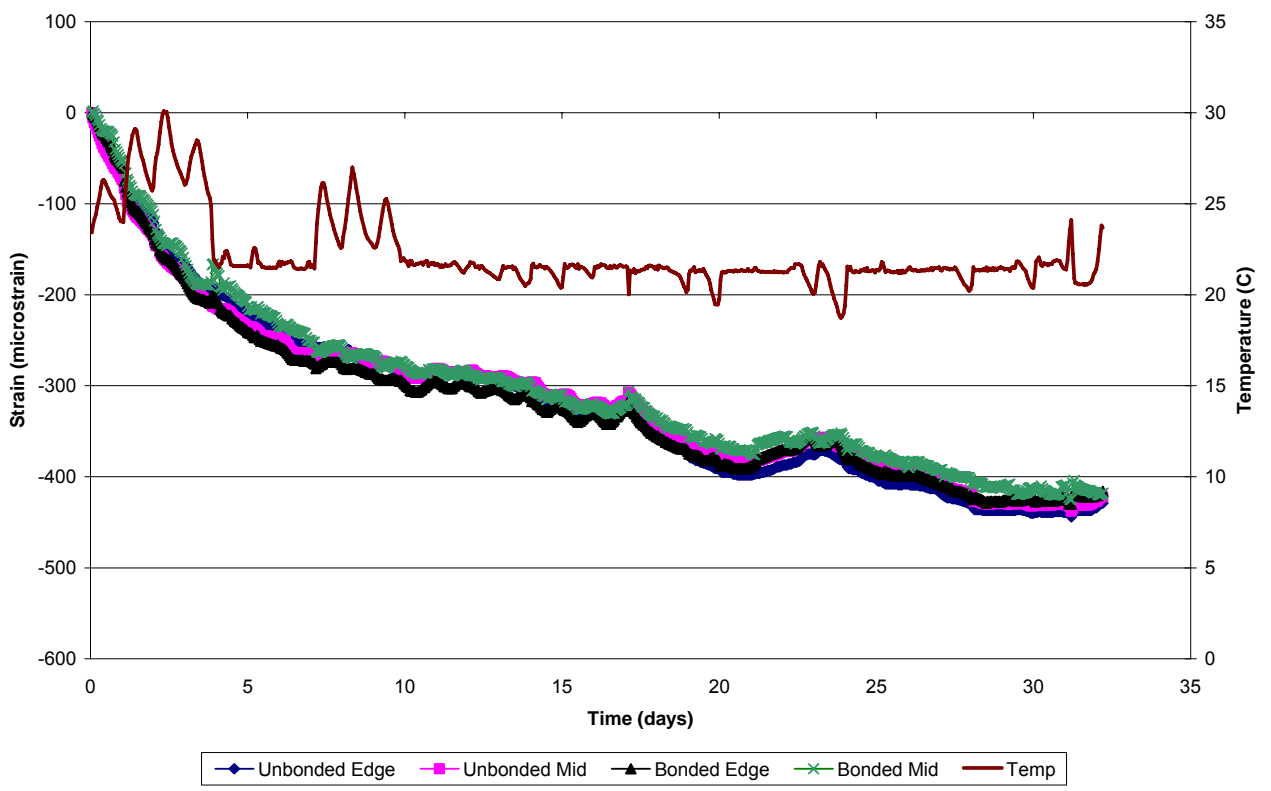

Figure B.67 Bonded and Unbonded Strains over Time - Test Area 3 - Lane 4 


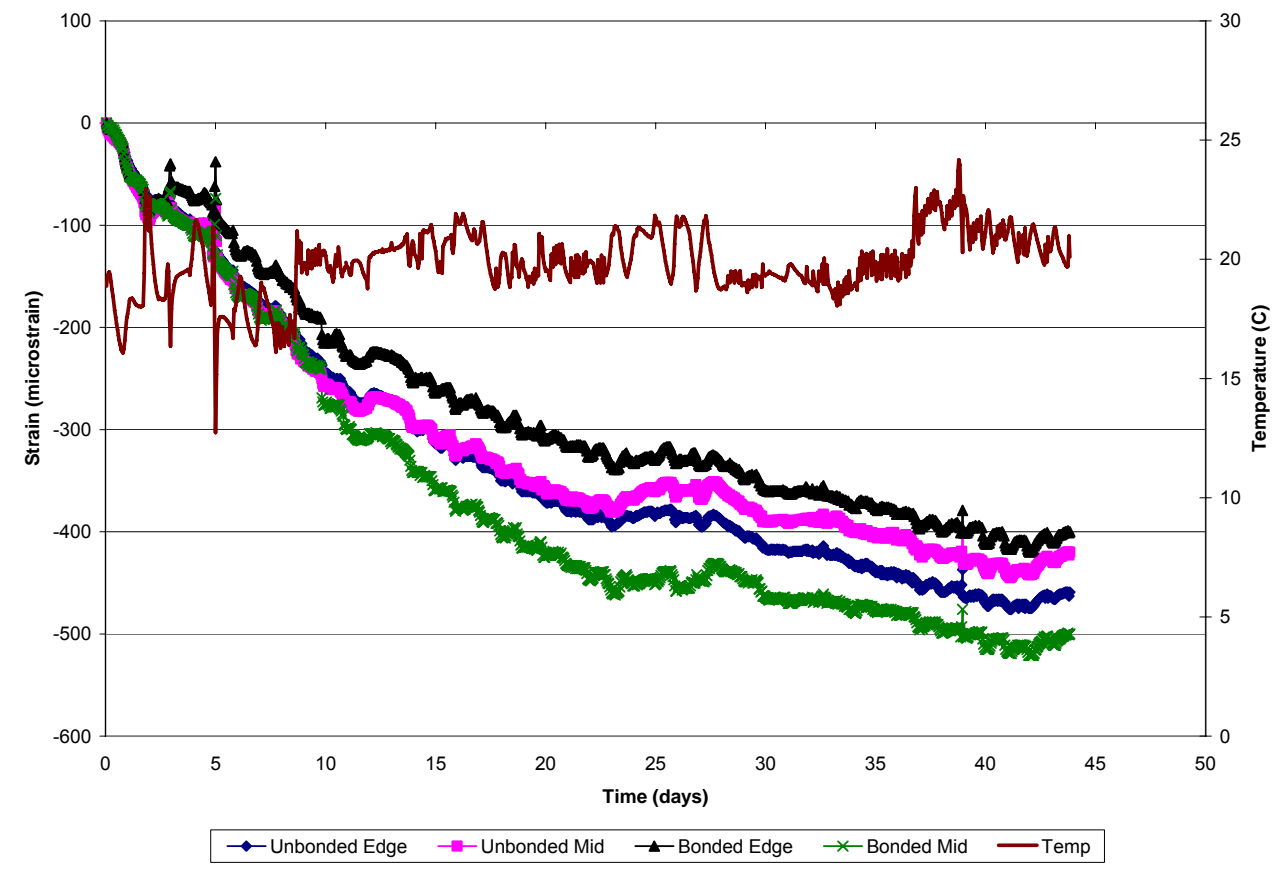

Figure B.68 Bonded and Unbonded Strains over Time - Test Area 3 - Lane 5 


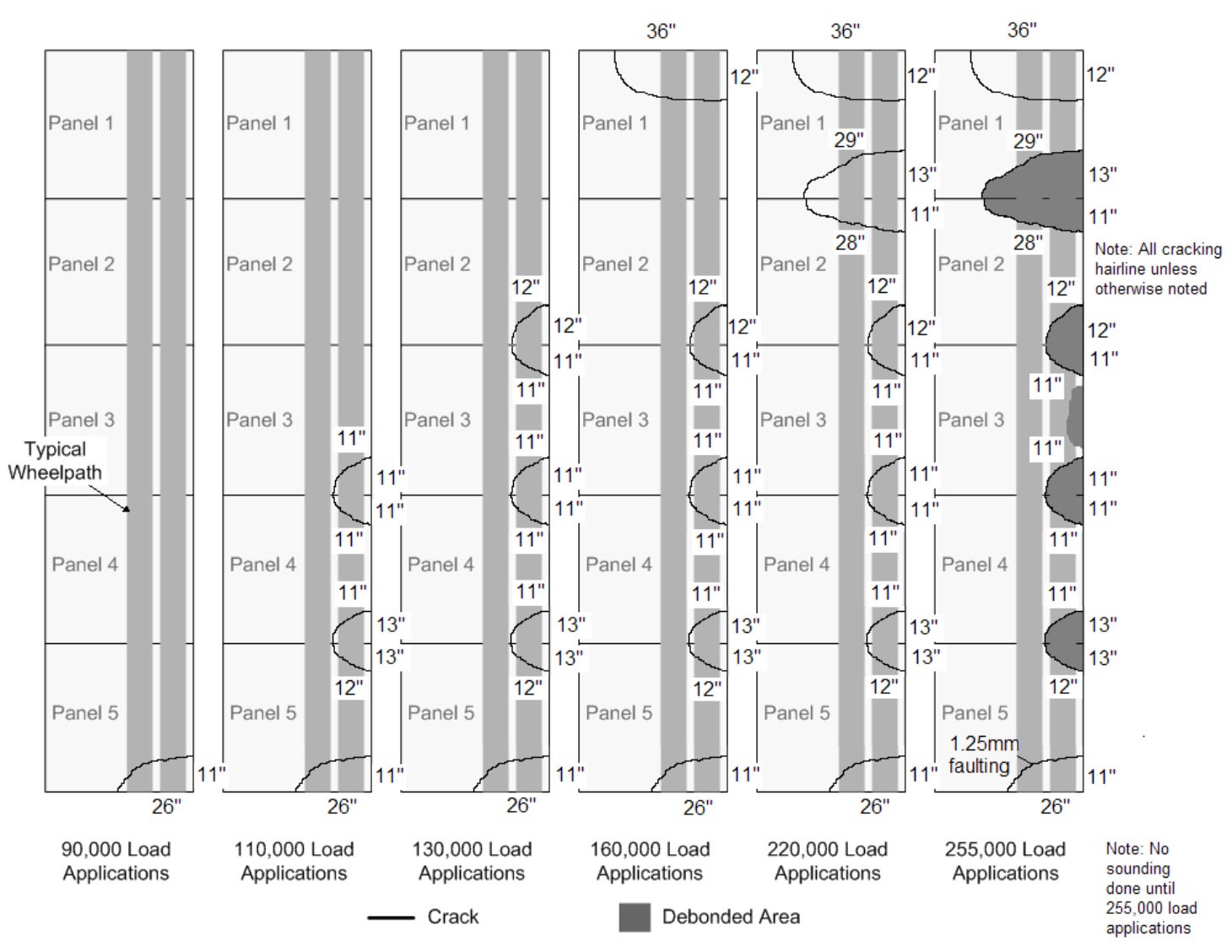

Figure B.69 Distress Map for Test Area 2 - Lane 1 


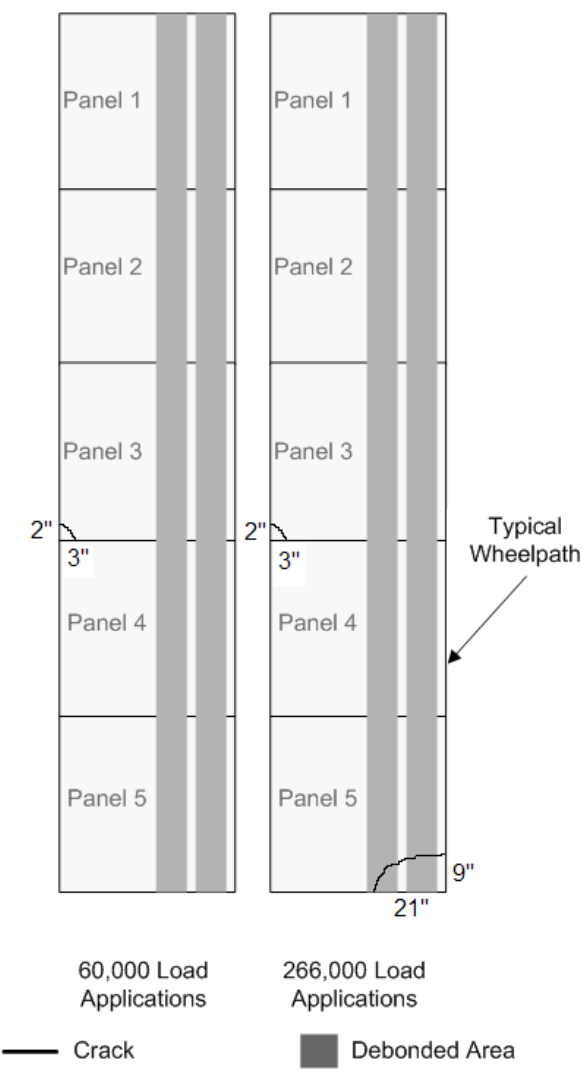

Figure B.70 Distress Map for Test Area 2 - Lane 2 


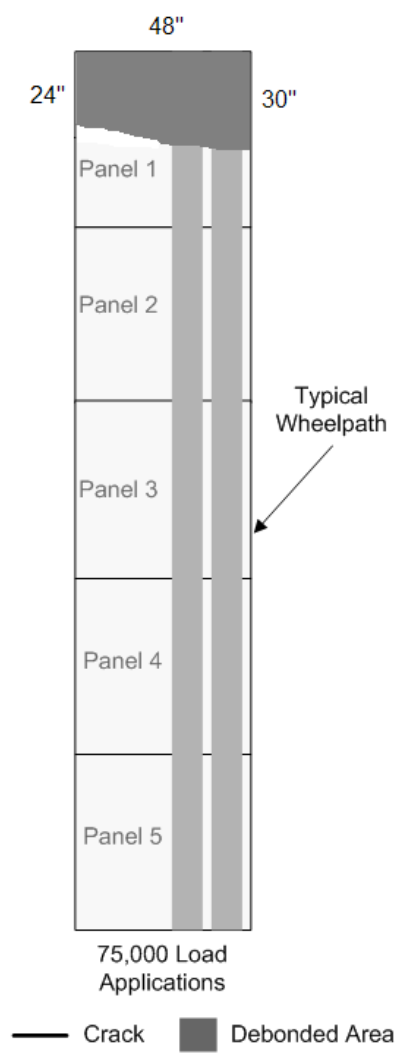

Figure B.71 Distress Map for Test Area 2 - Lane 3 


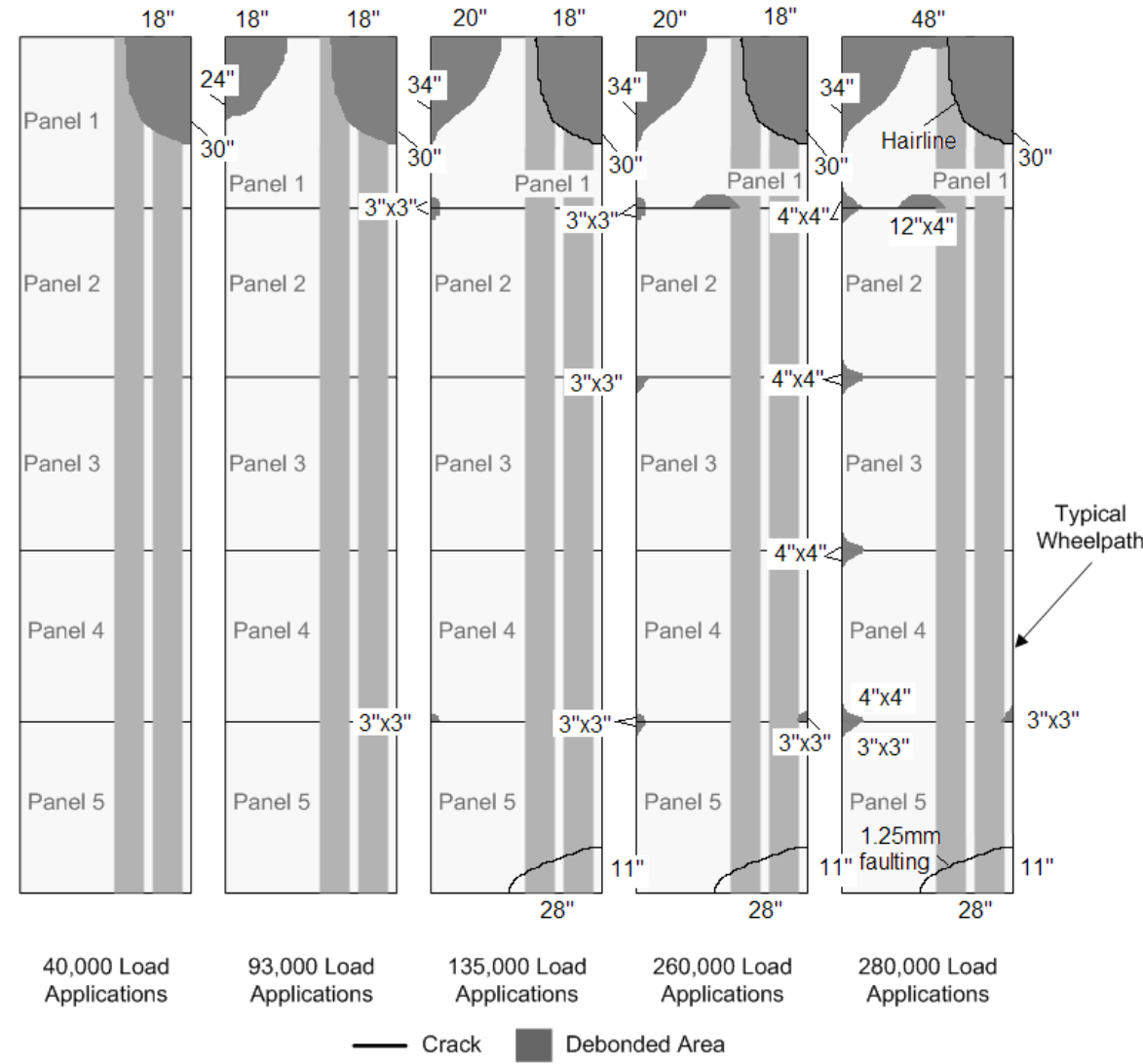

Figure B.72 Distress Map for Test Area 2 - Lane 4 


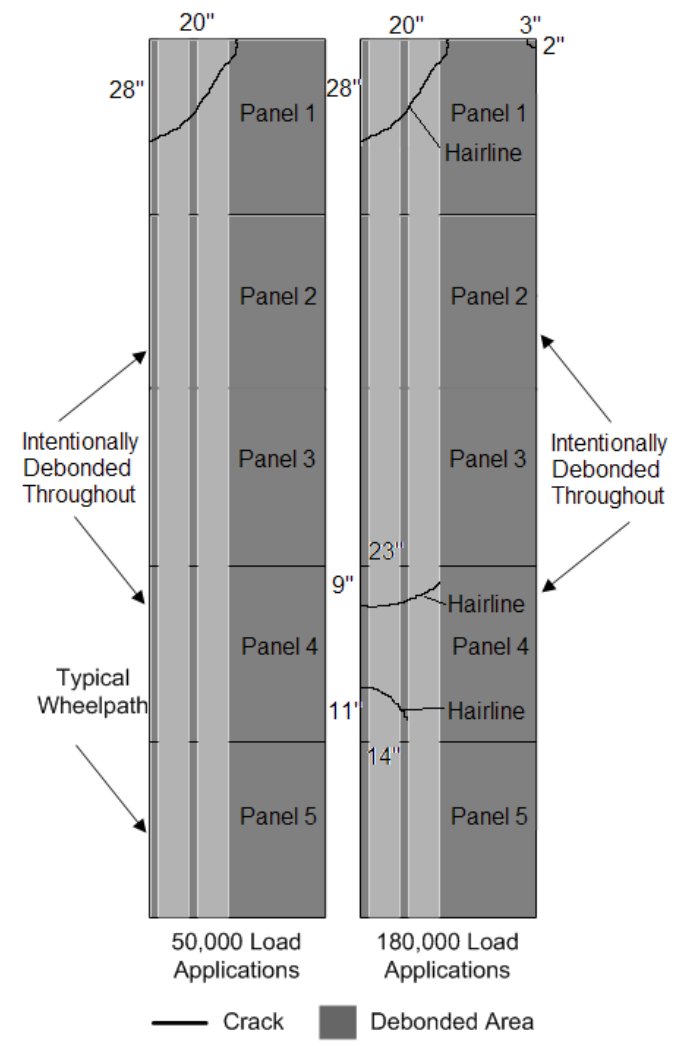

Figure B.73 Distress Map for Test Area 2 - Lane 5 


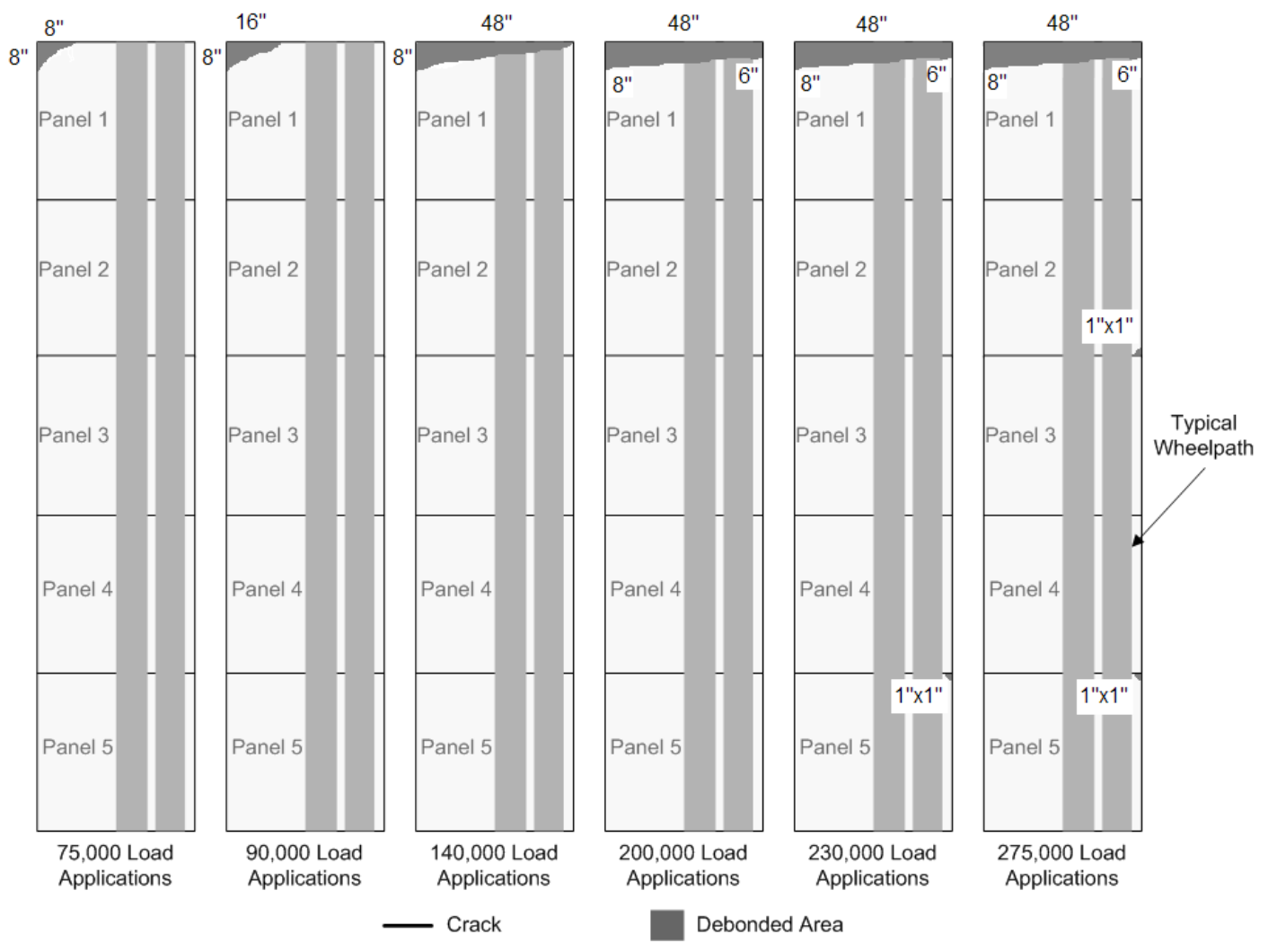

Figure B.74 Distress Map for Test Area 3 - Lane 1 


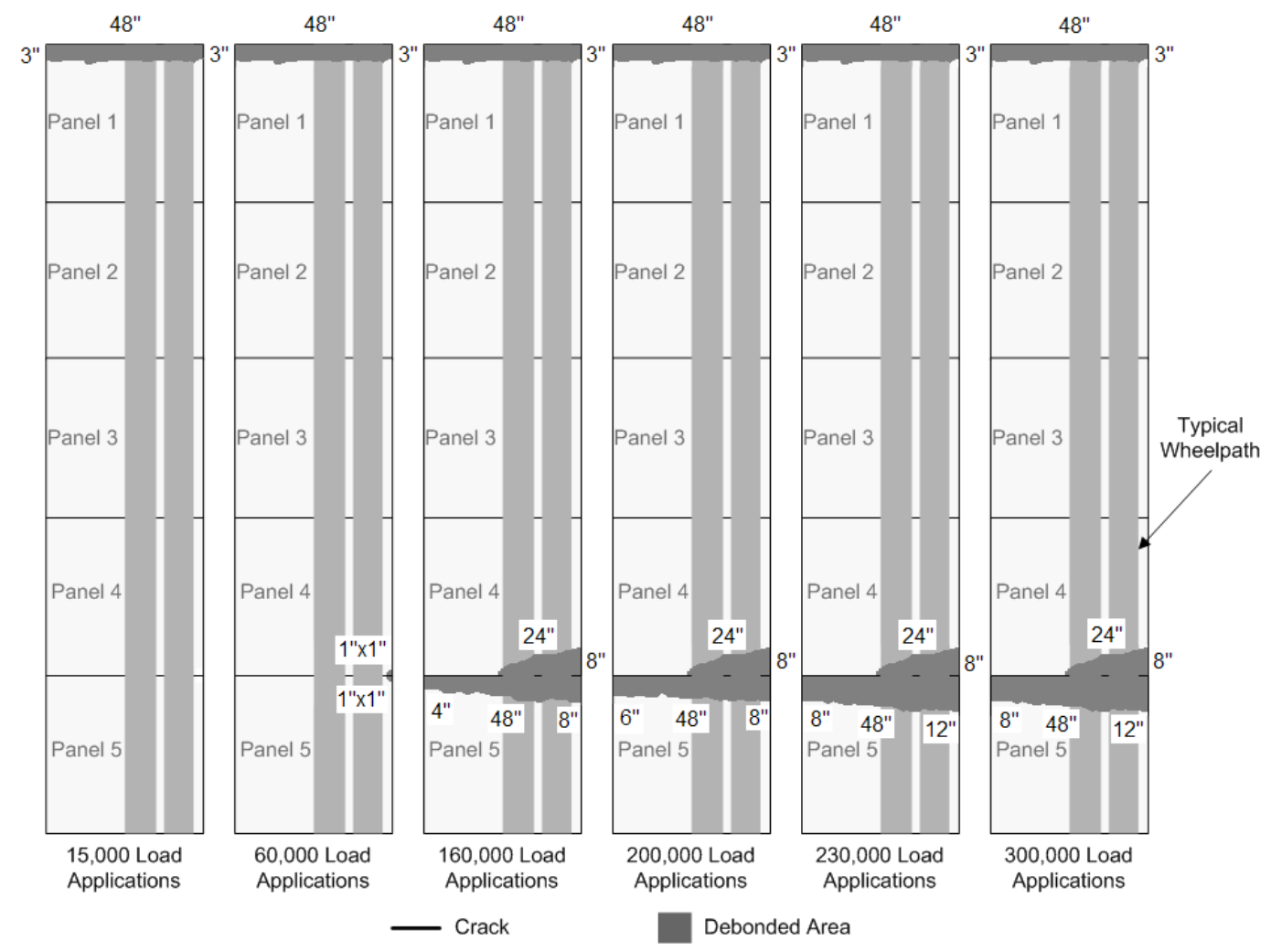

Figure B.75 Distress Map for Test Area 3 - Lane 2 


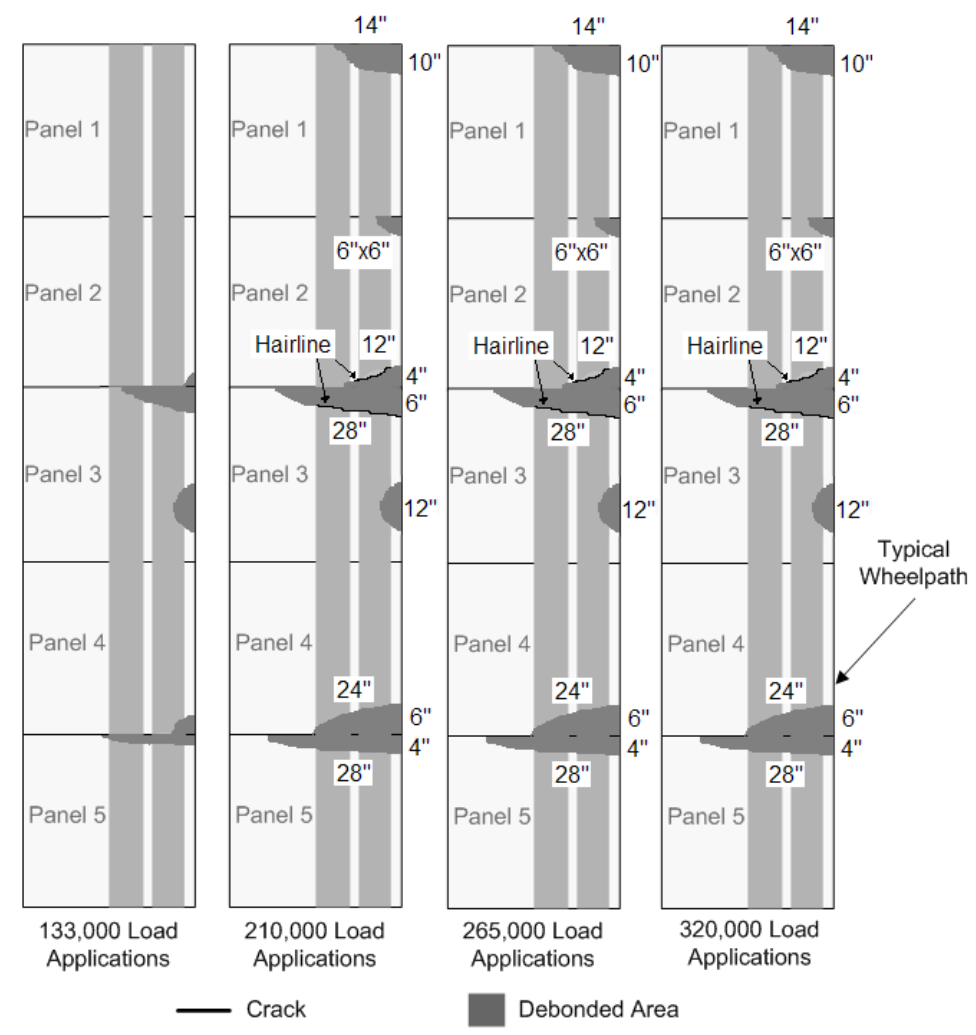

Figure B.76 Distress Map for Test Area 3 - Lane 3 


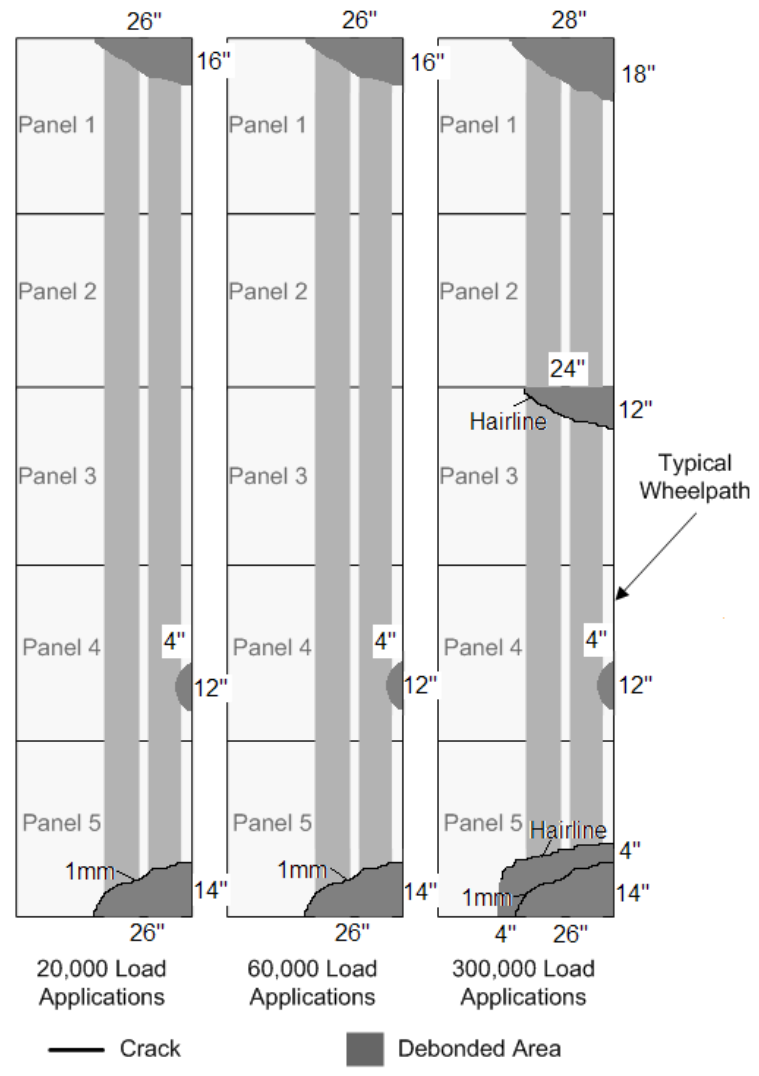

Figure B.77 Distress Map for Test Area 3 - Lane 4 


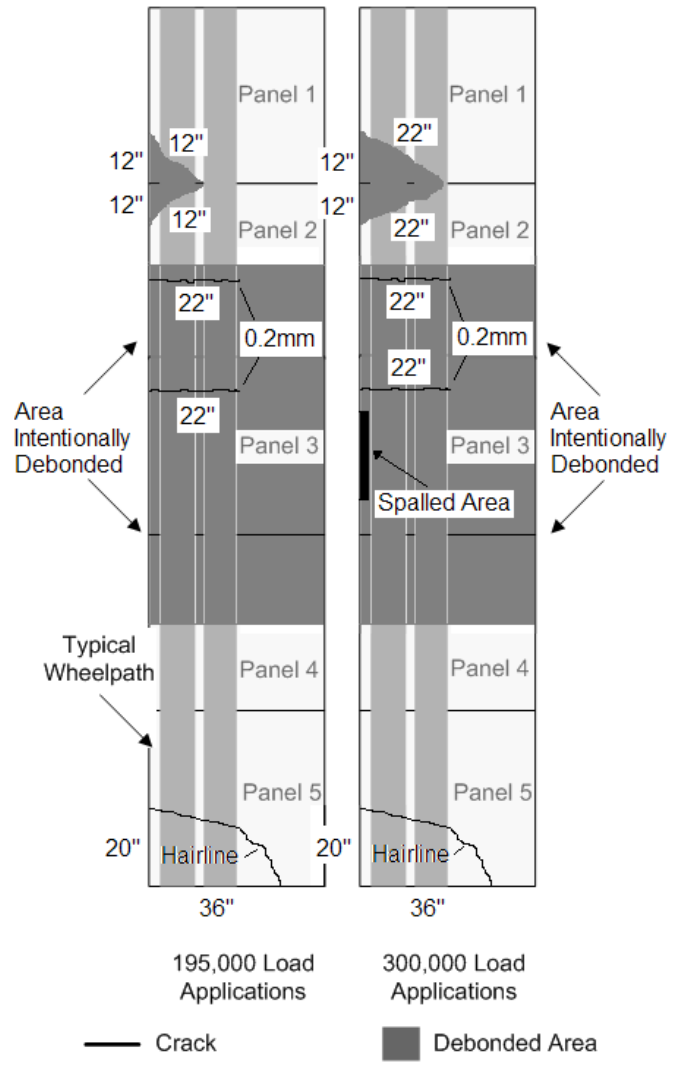

Figure B.78 Distress Map for Test Area 3 - Lane 5 


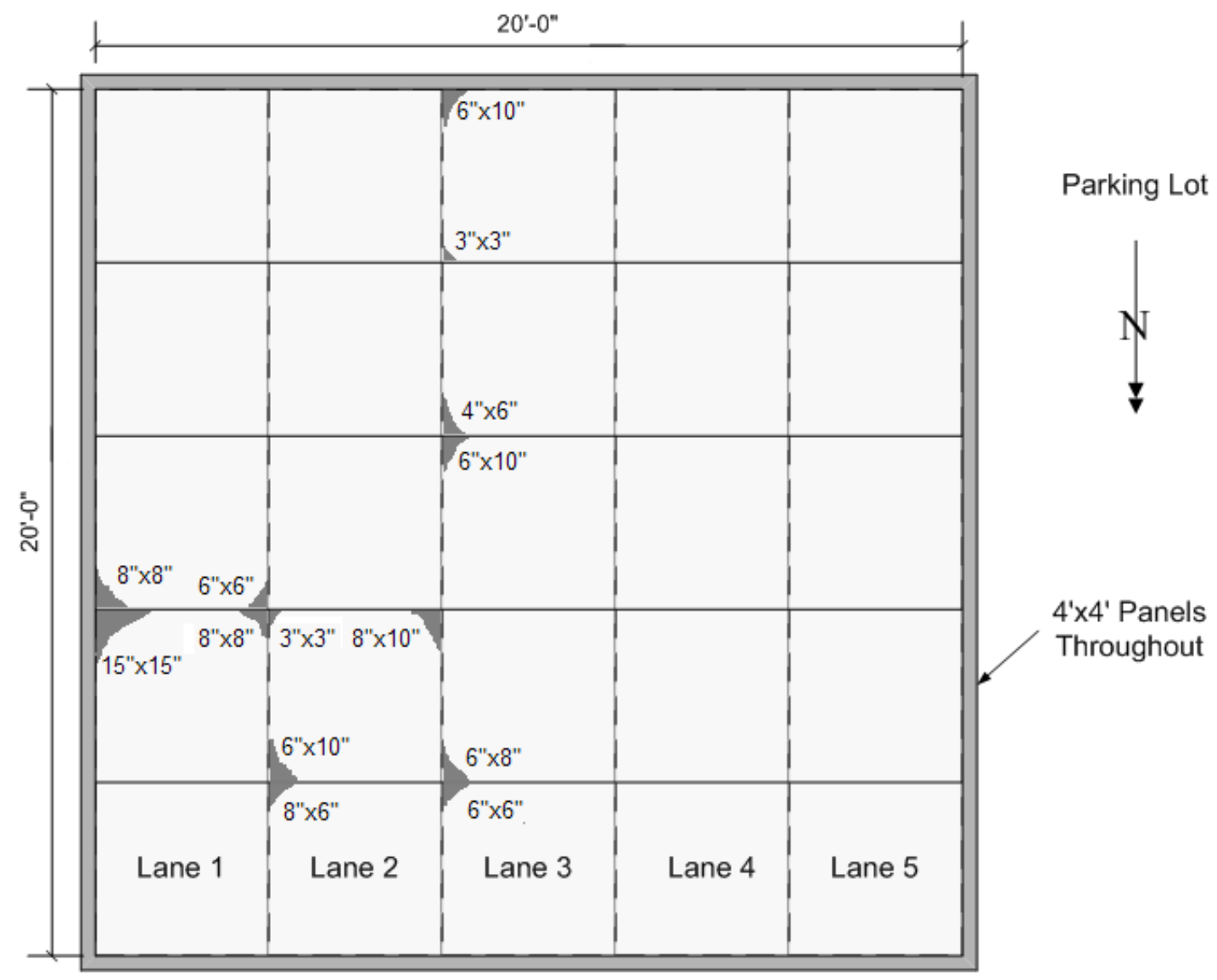

Figure B.79 Distress Map at 1 Year for Test Area 4 


\section{Appendix C. Strain Distribution Plots}

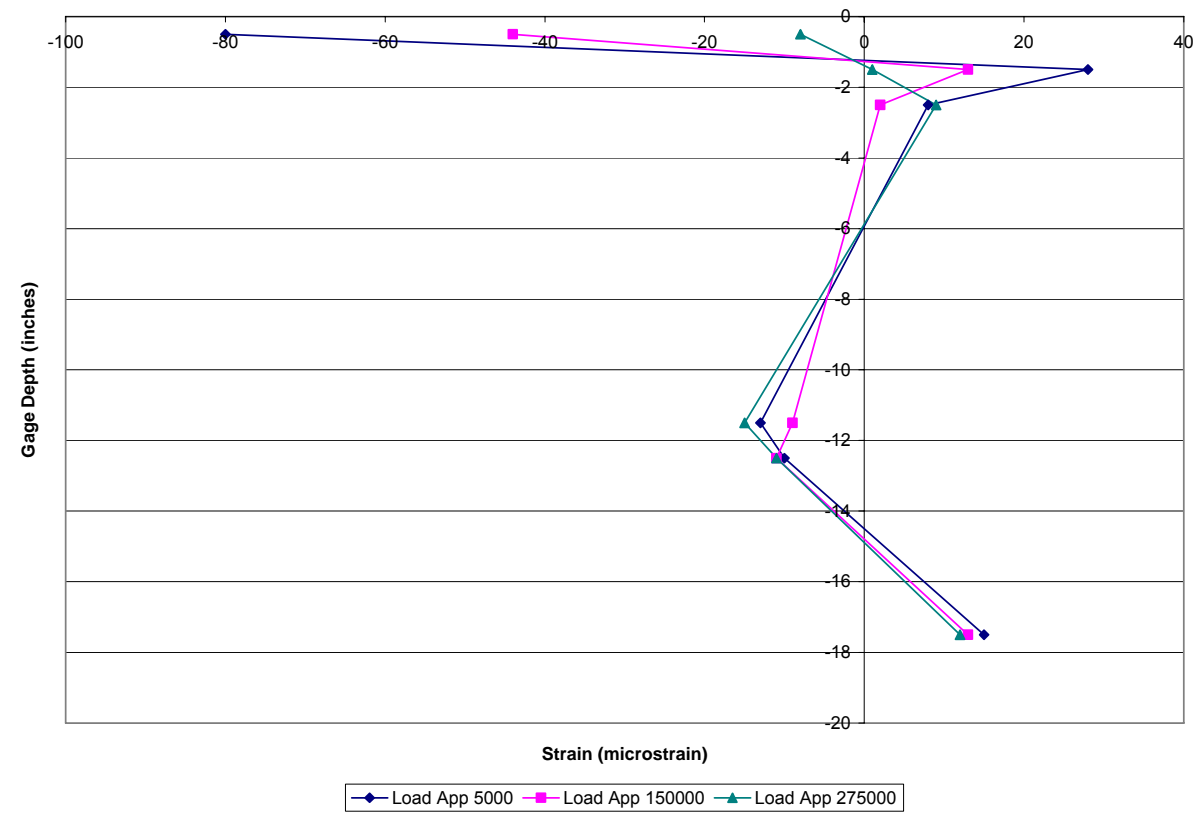

(a)

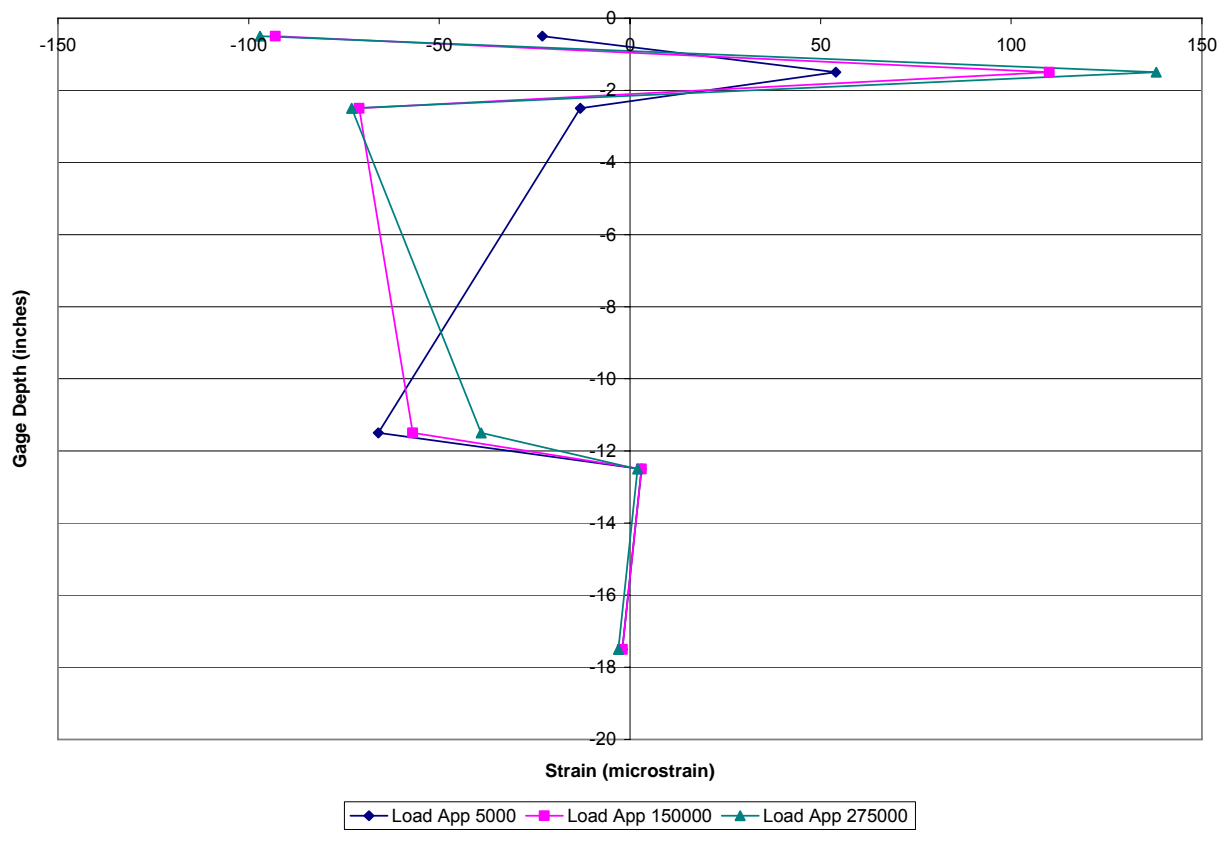

(b)

Figure C.1 Strain Distribution - Test Area 2 - Lane 1 (a) Edge (b) Corner 


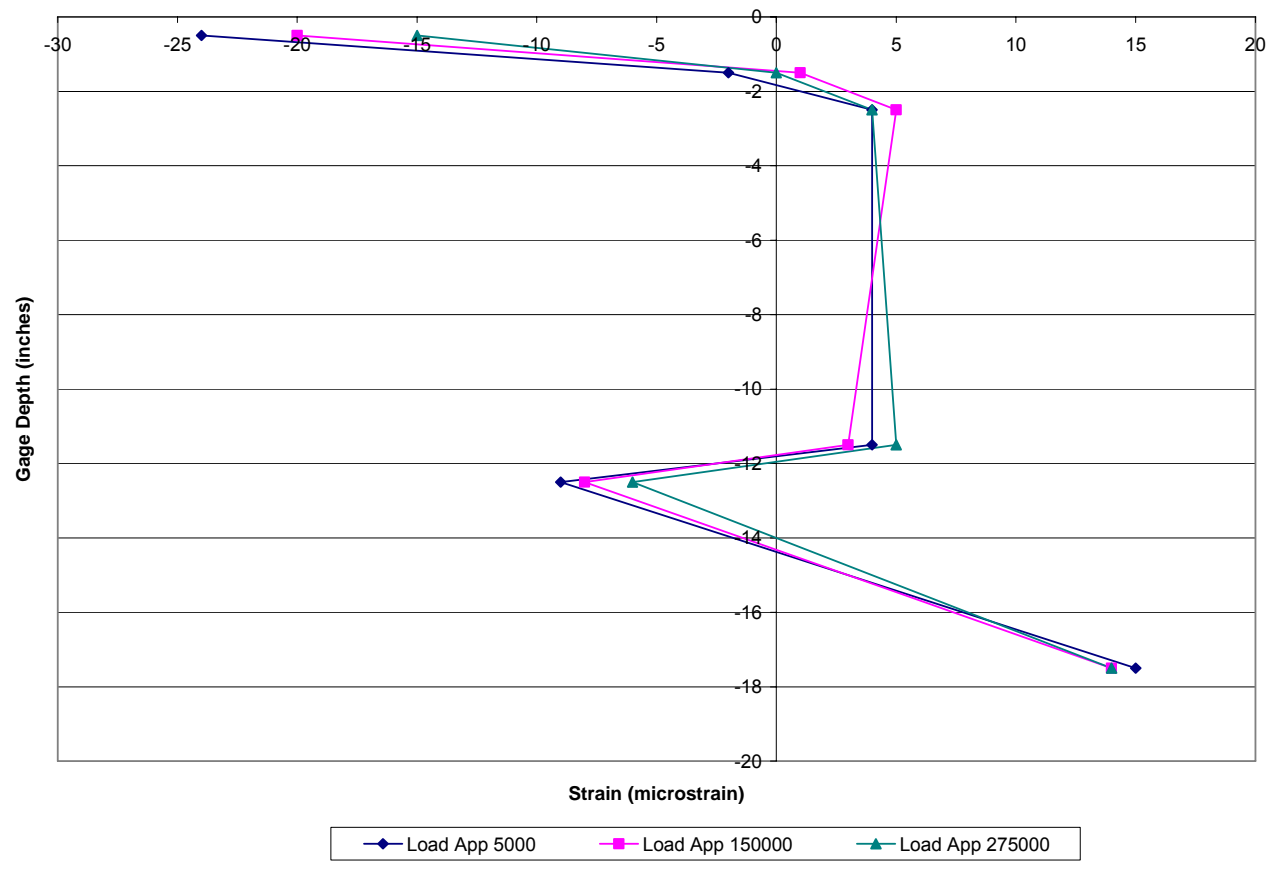

(a)

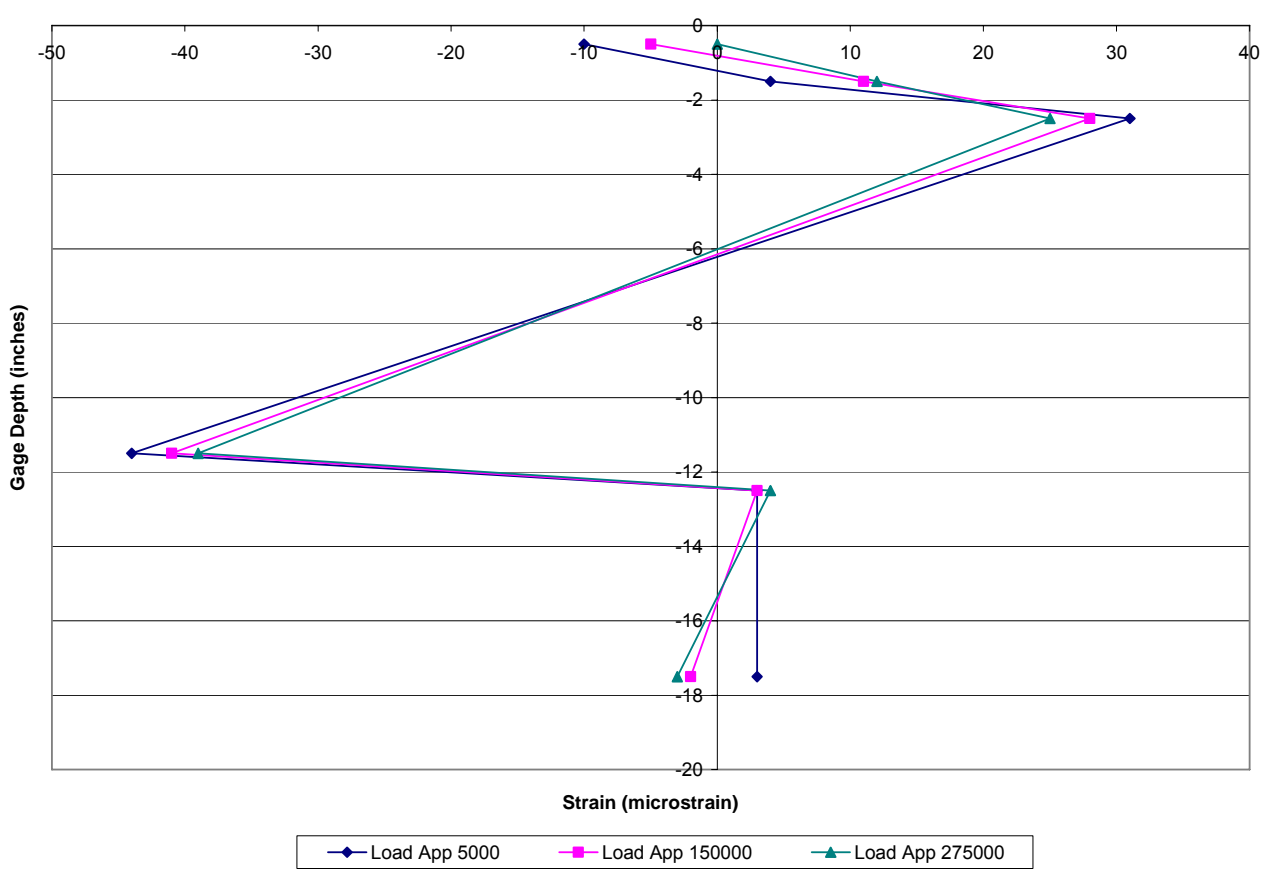

(b)

Figure C.2 Strain Distribution - Test Area 2 - Lane 2 (a) Edge (b) Corner 


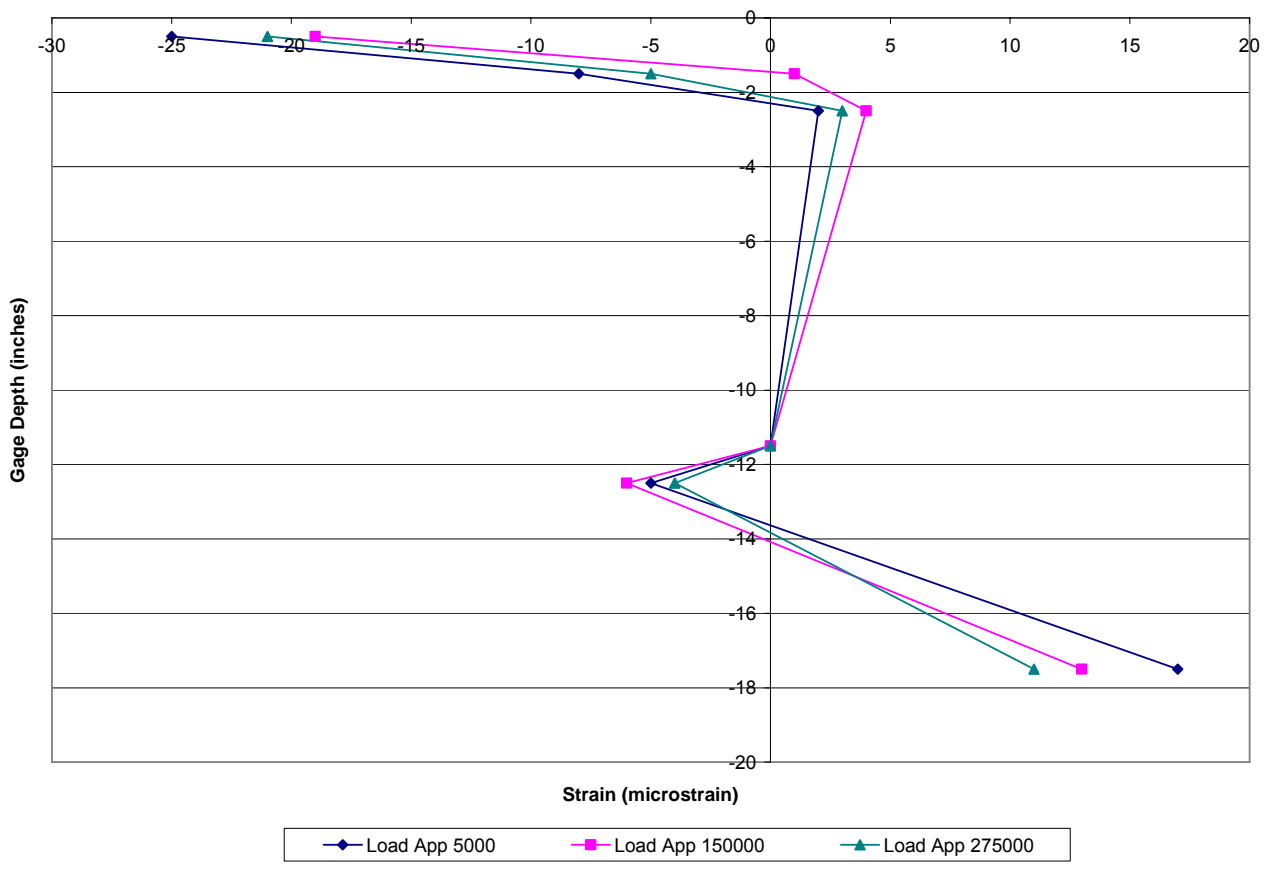

(a)

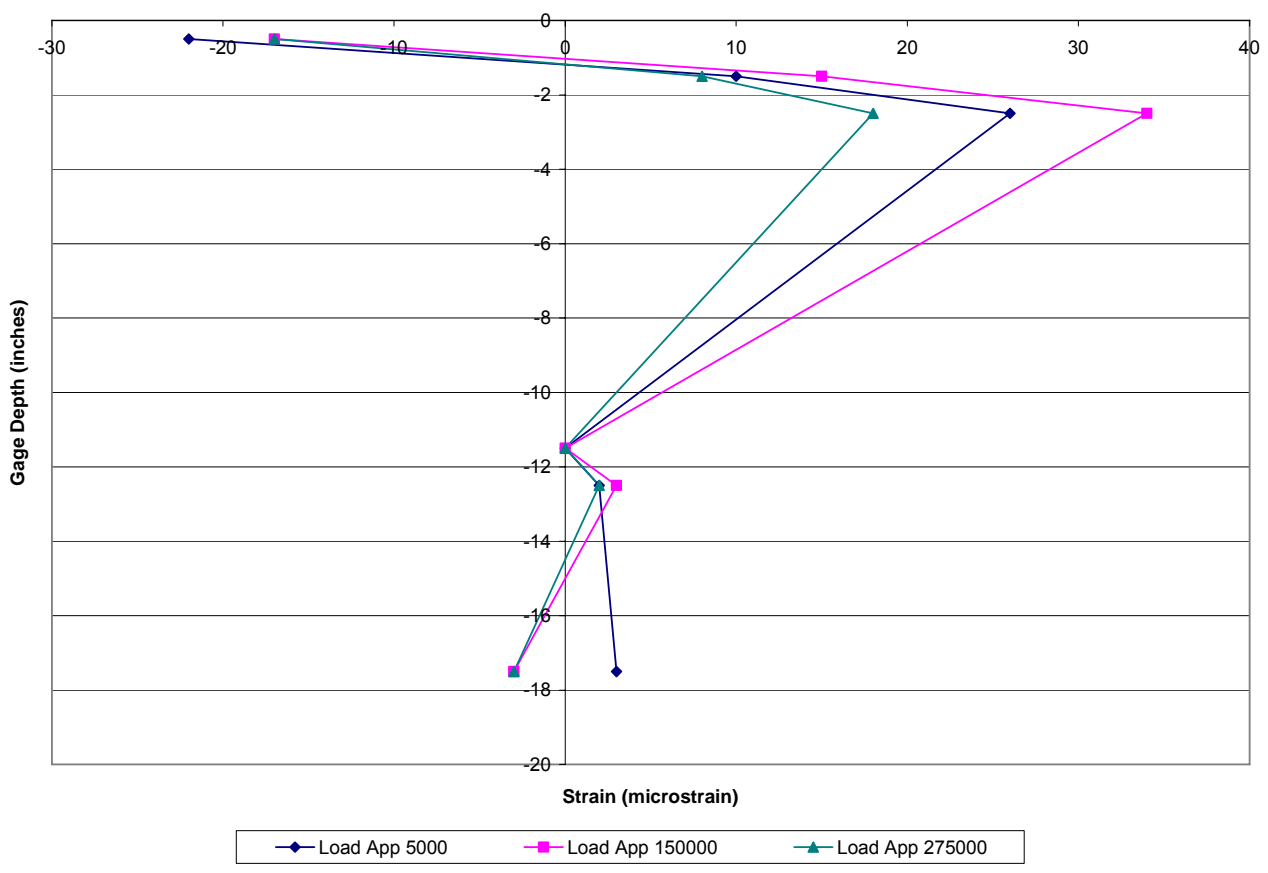

(b)

Figure C.3 Strain Distribution - Test Area 2 - Lane 3 (a) Edge (b) Corner 


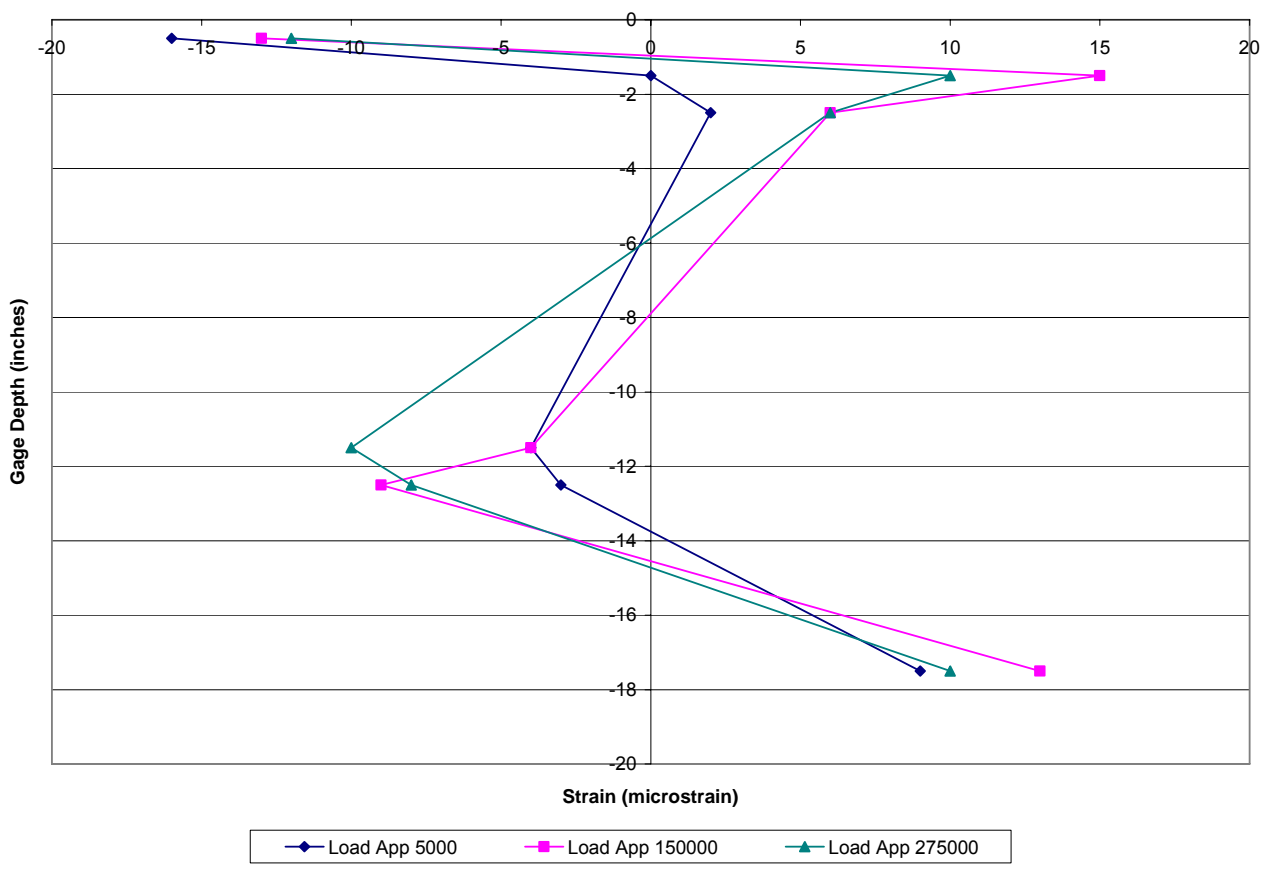

(a)

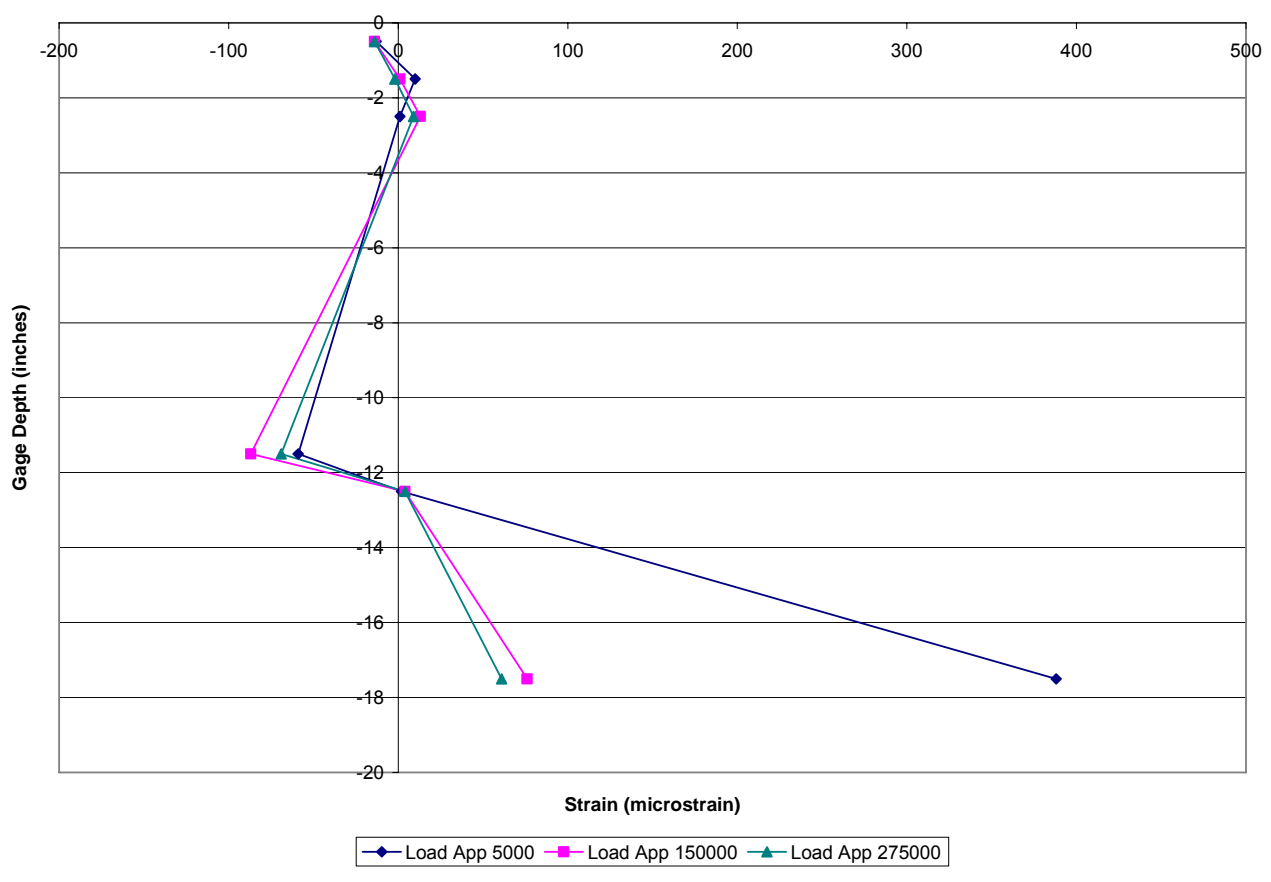

(b)

Figure C.4 Strain Distribution - Test Area 2 - Lane 4 (a) Edge (b) Corner 


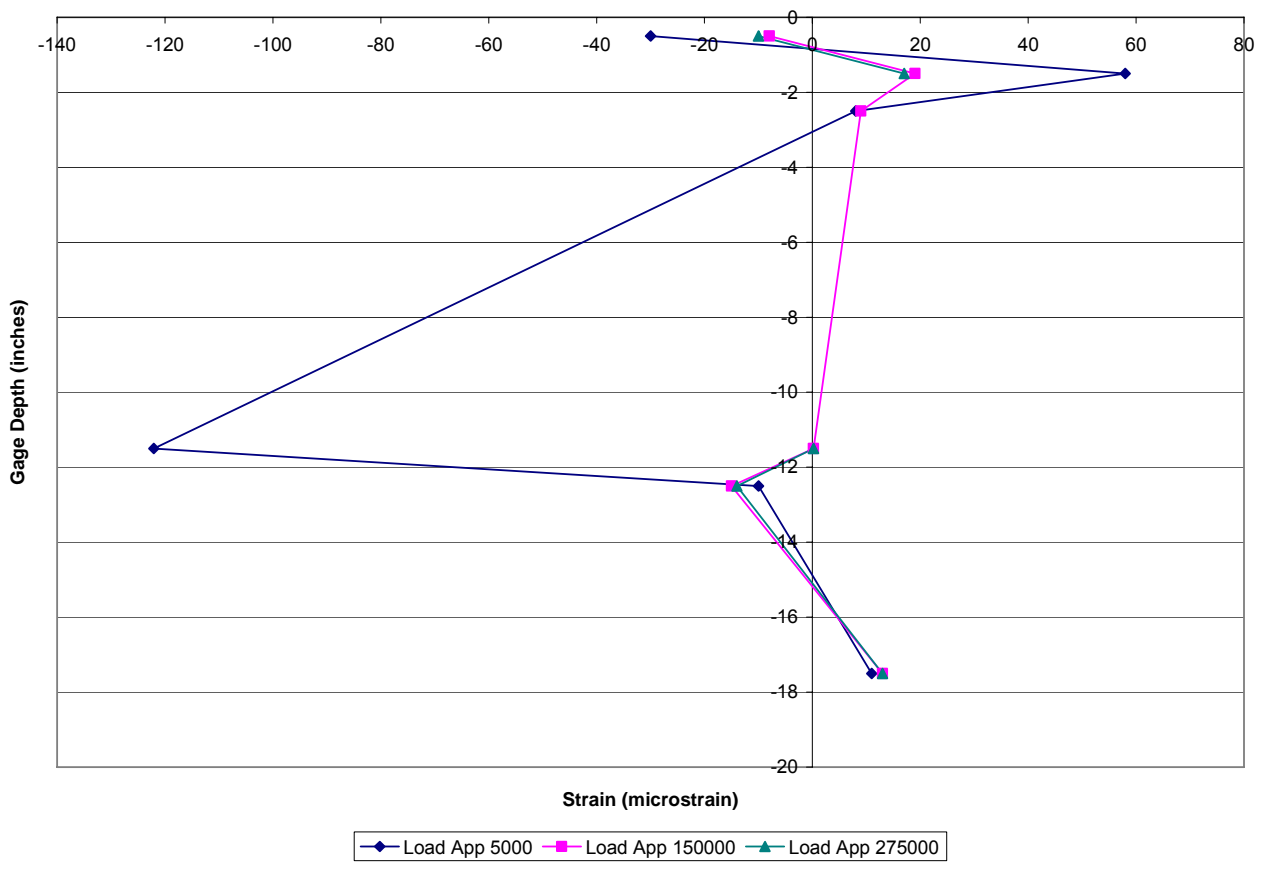

(a)

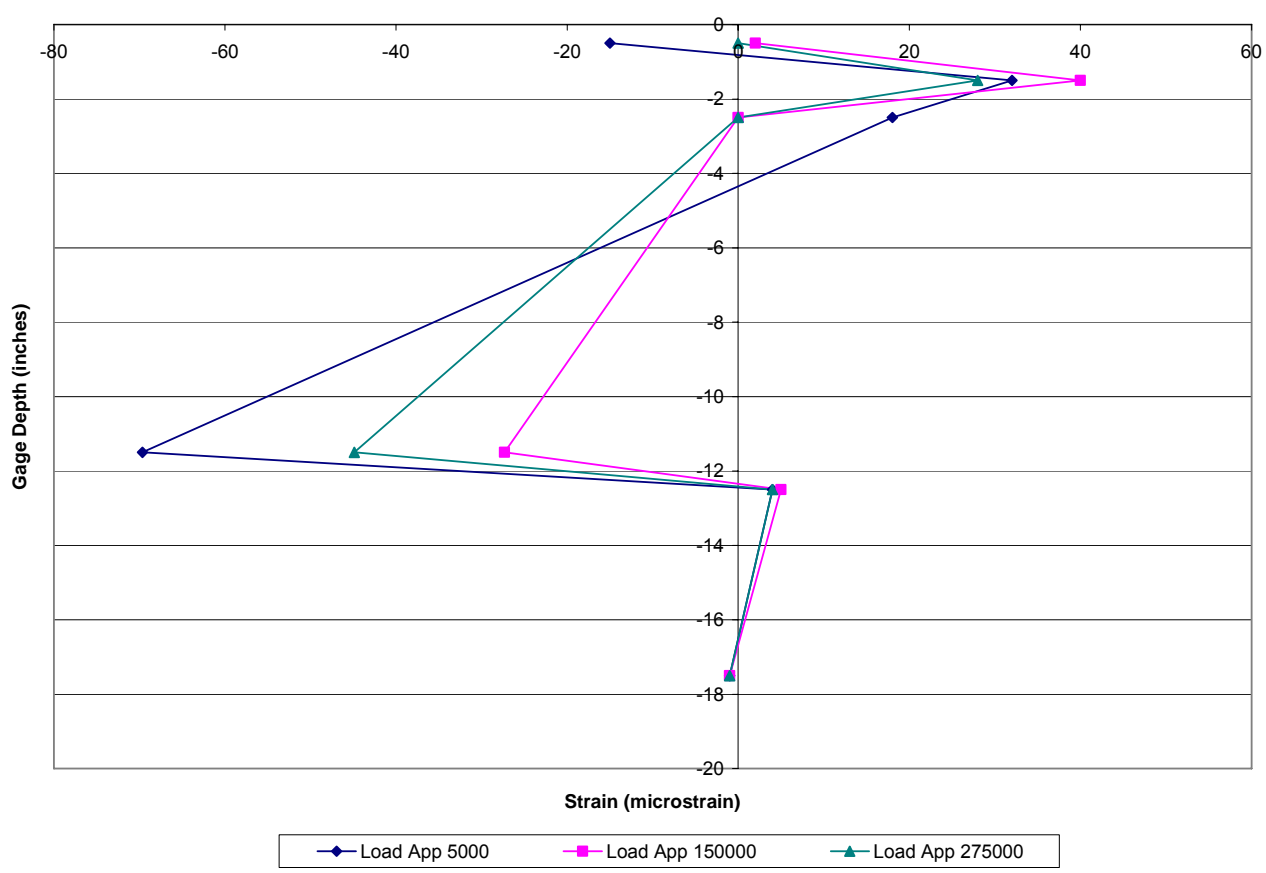

(b)

Figure C.5 Strain Distribution - Test Area 2 - Lane 5 (a) Edge (b) Corner 


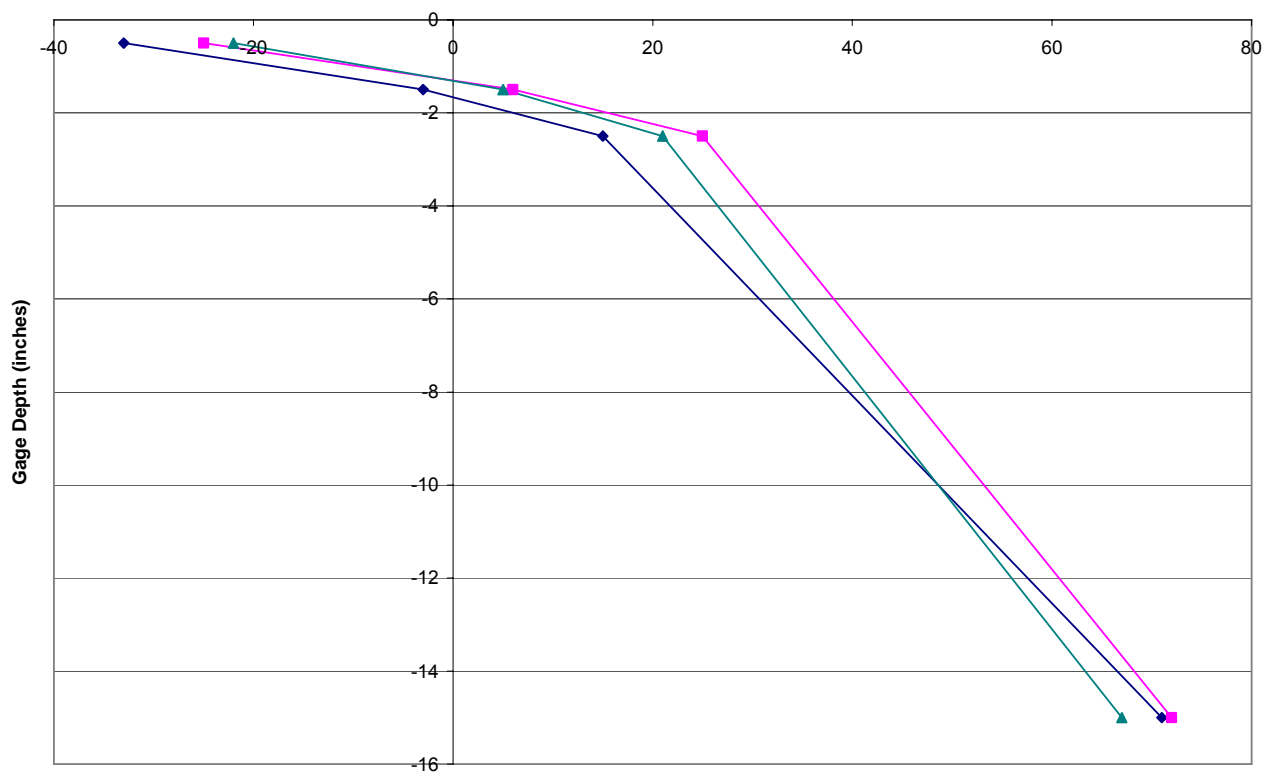

Strain (microstrain)

- - Load App 150000

(a)

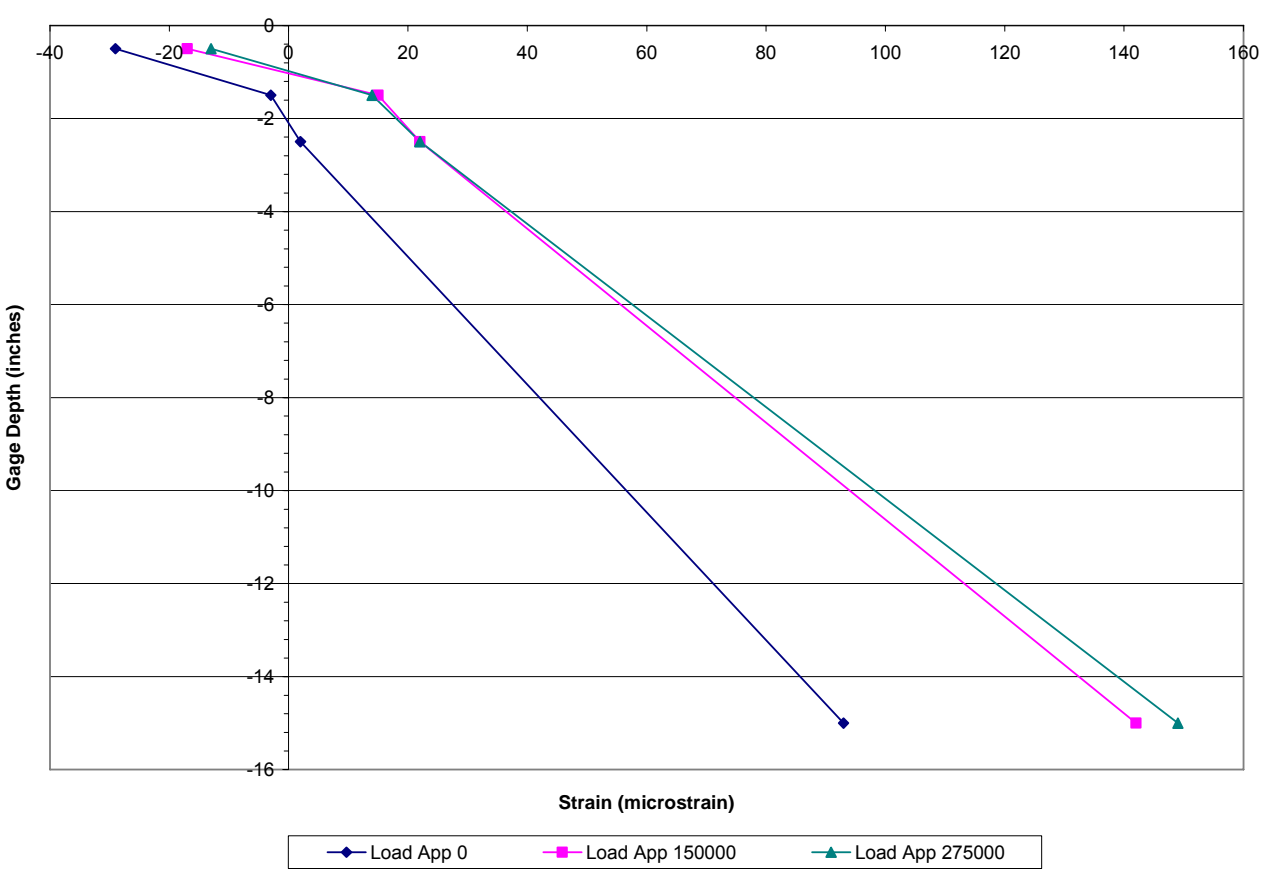

(b)

Figure C.6 Strain Distribution - Test Area 3 - Lane 1 (a) Edge (b) Corner 


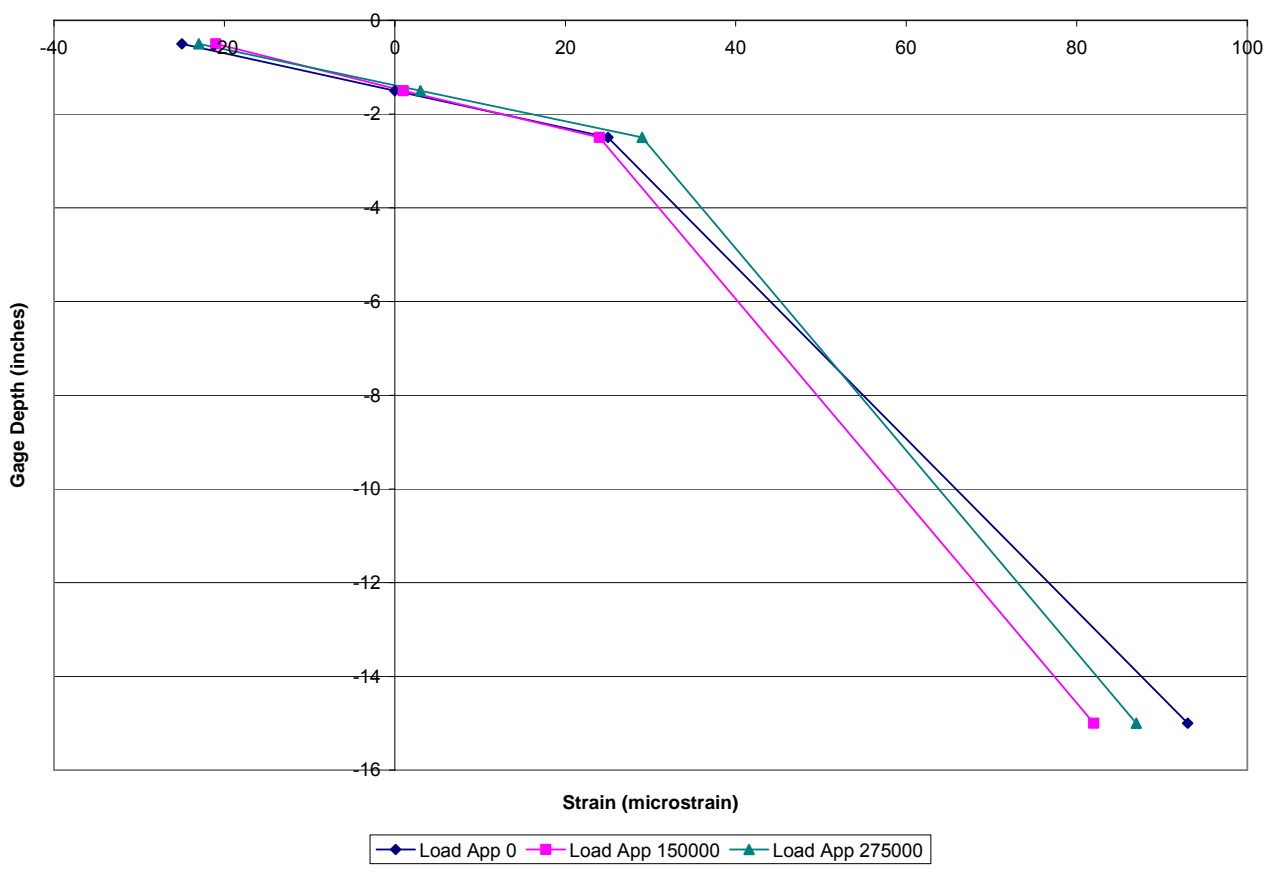

(a)

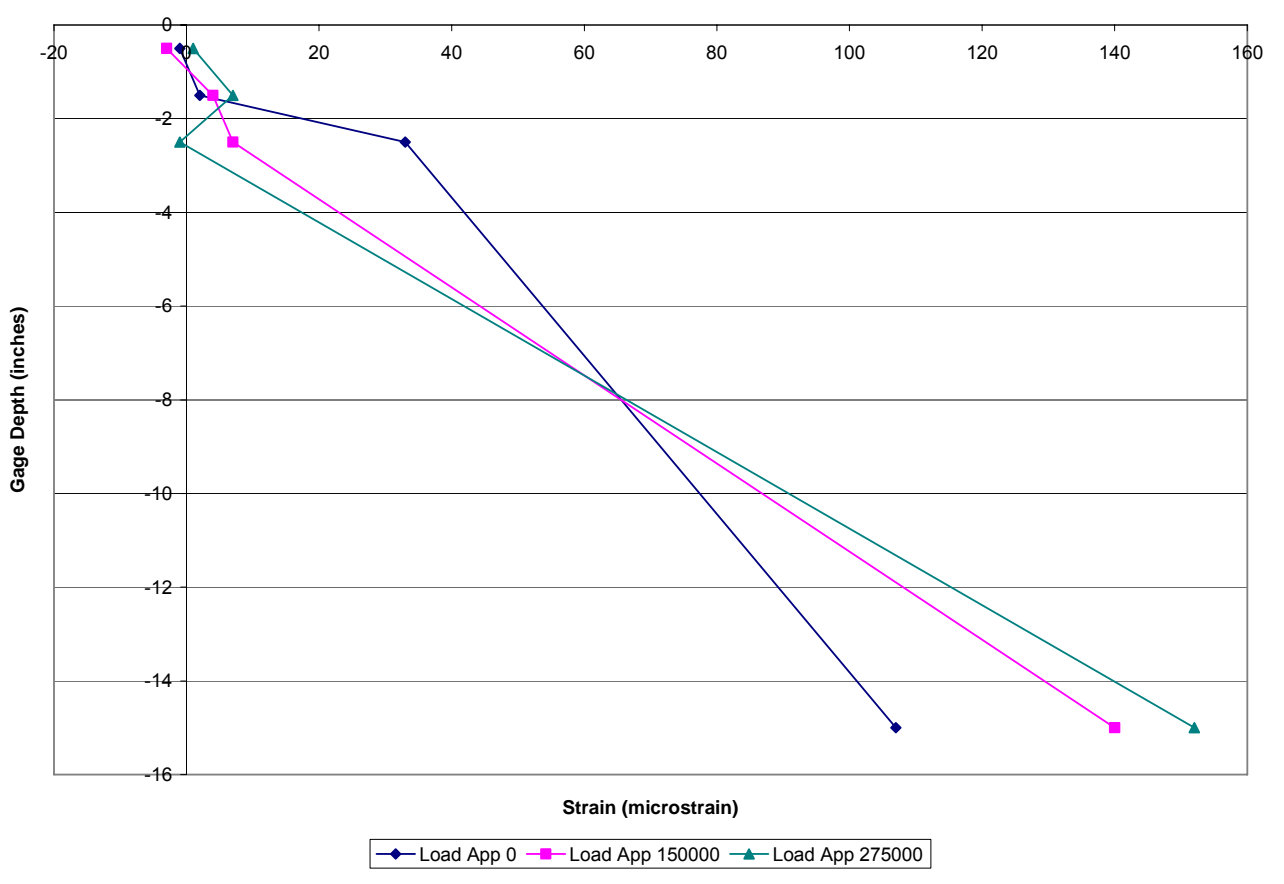

(b)

Figure C.7 Strain Distribution - Test Area 3 - Lane 2 (a) Edge (b) Corner 


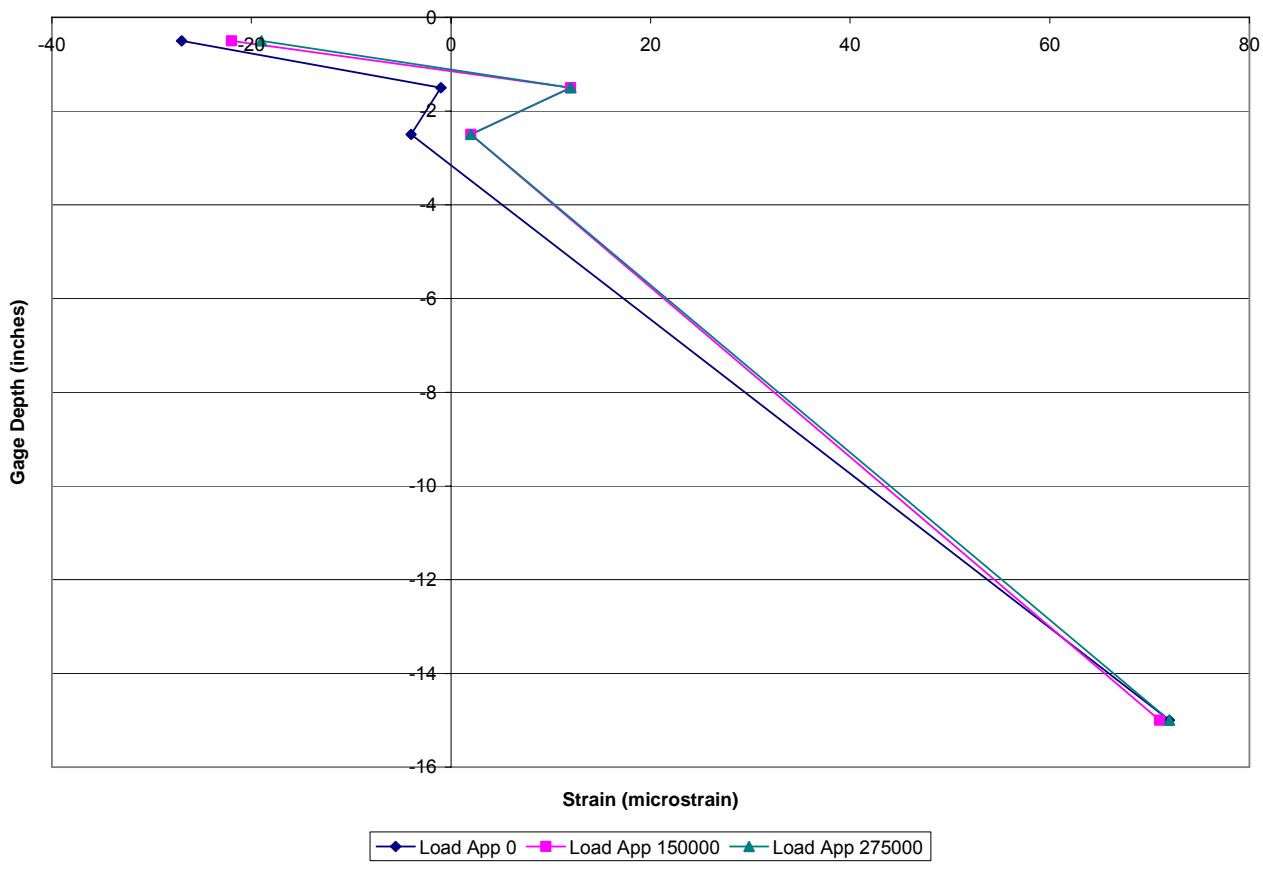

(a)

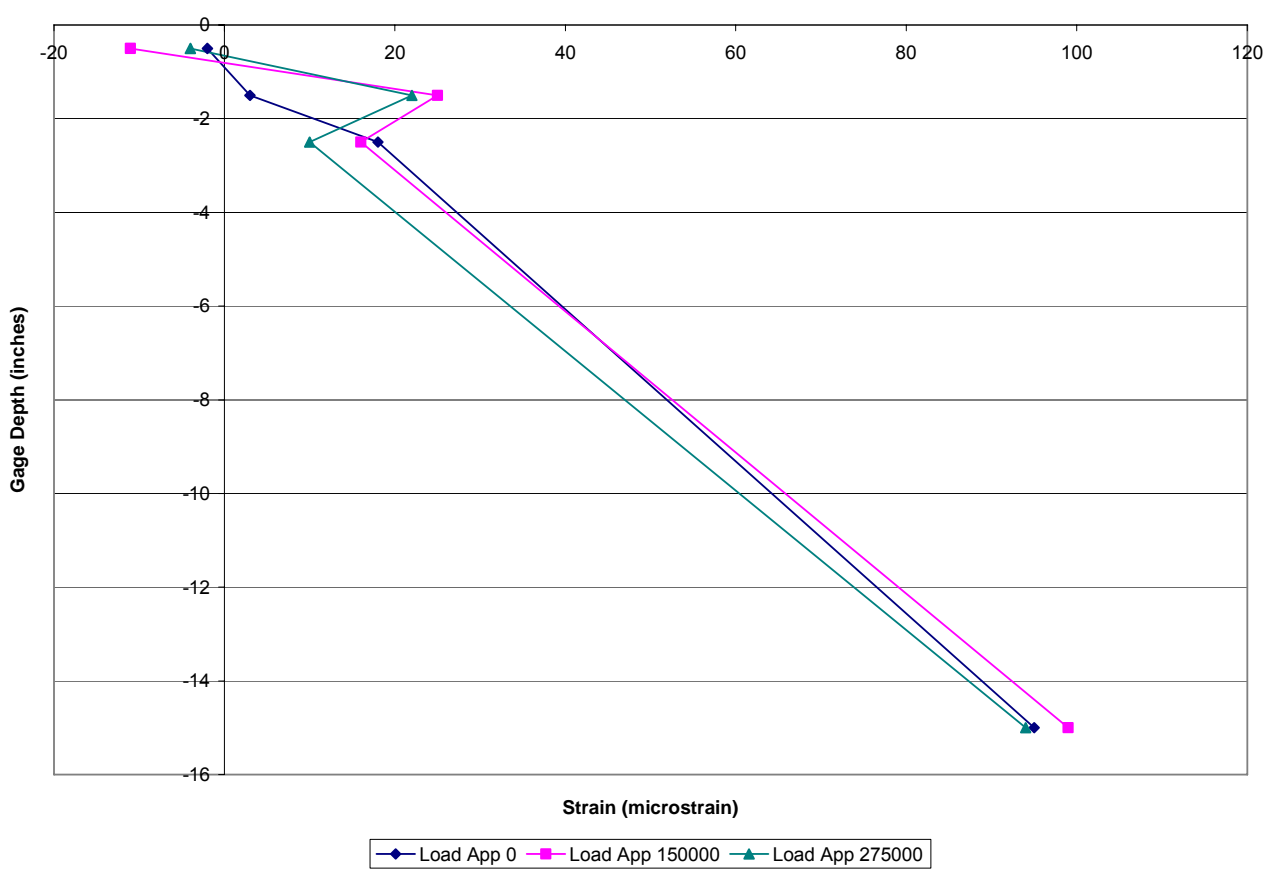

(b)

Figure C.8 Strain Distribution - Test Area 3 - Lane 3 (a) Edge (b) Corner 


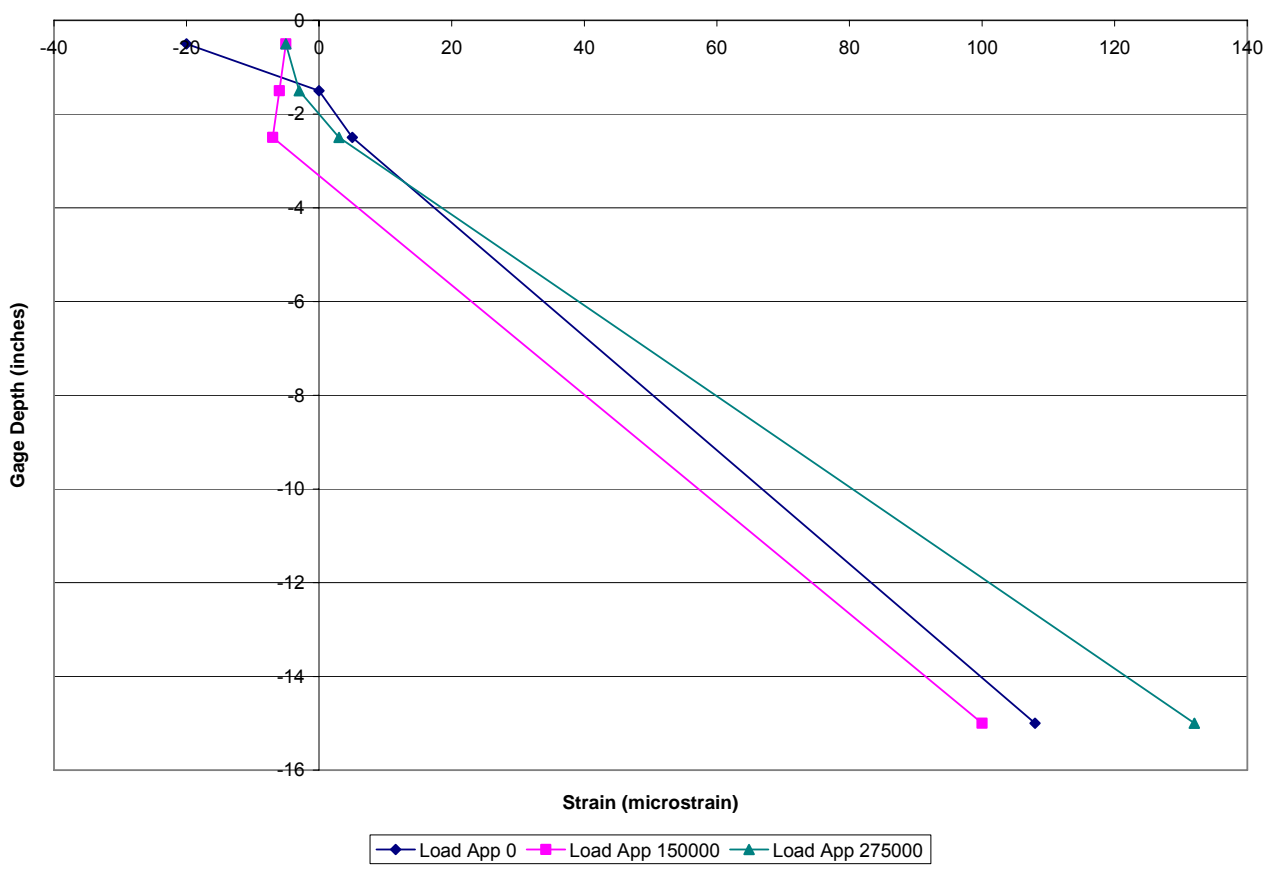

(a)

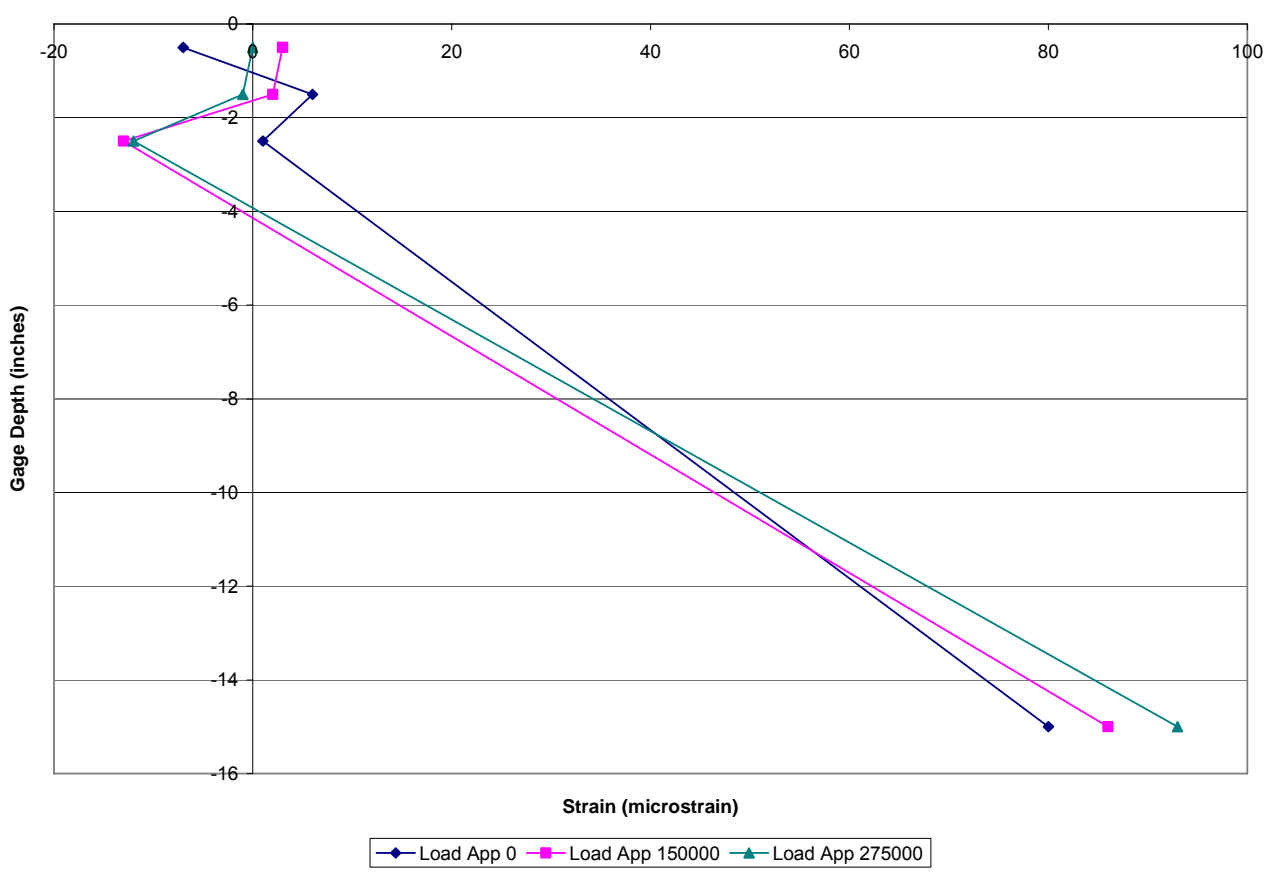

(b)

Figure C.9 Strain Distribution - Test Area 3 - Lane 4 (a) Edge (b) Corner 


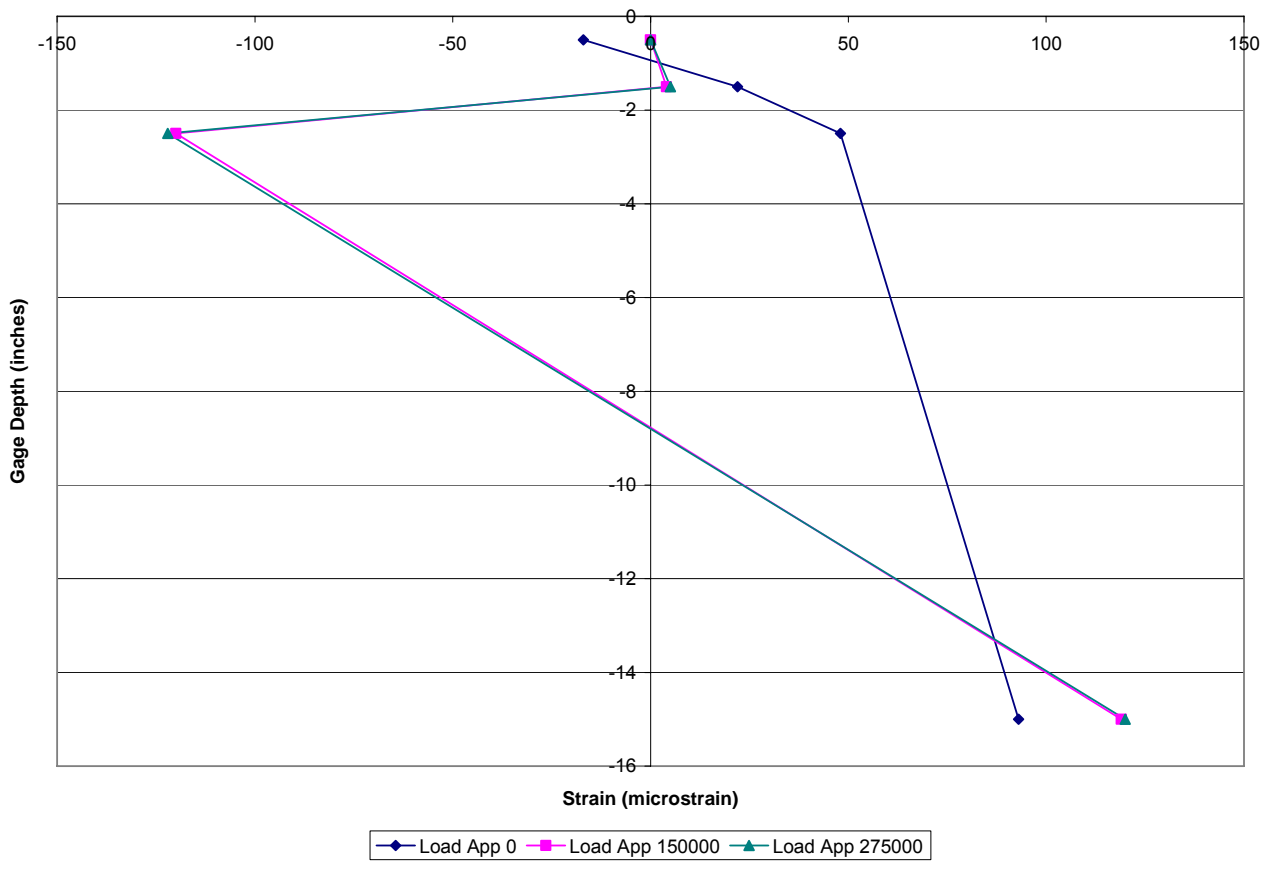

(a)

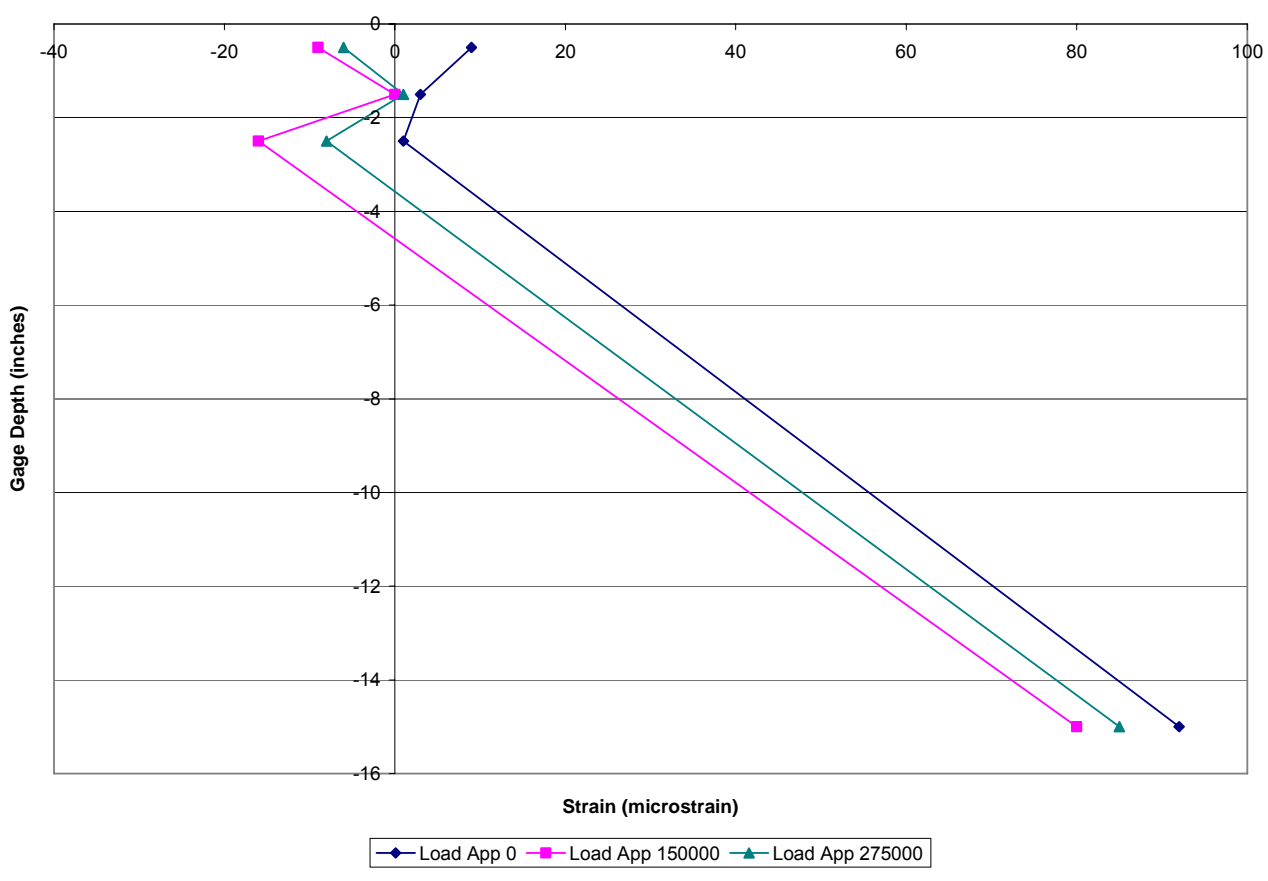

(b)

Figure C.10 Strain Distribution - Test Area 3 - Lane 5 (a) Edge (b) Corner 


\section{Appendix D. Life Cycle Cost Analysis}

Probabilistic Life Cycle Cost Analysis Worksheet

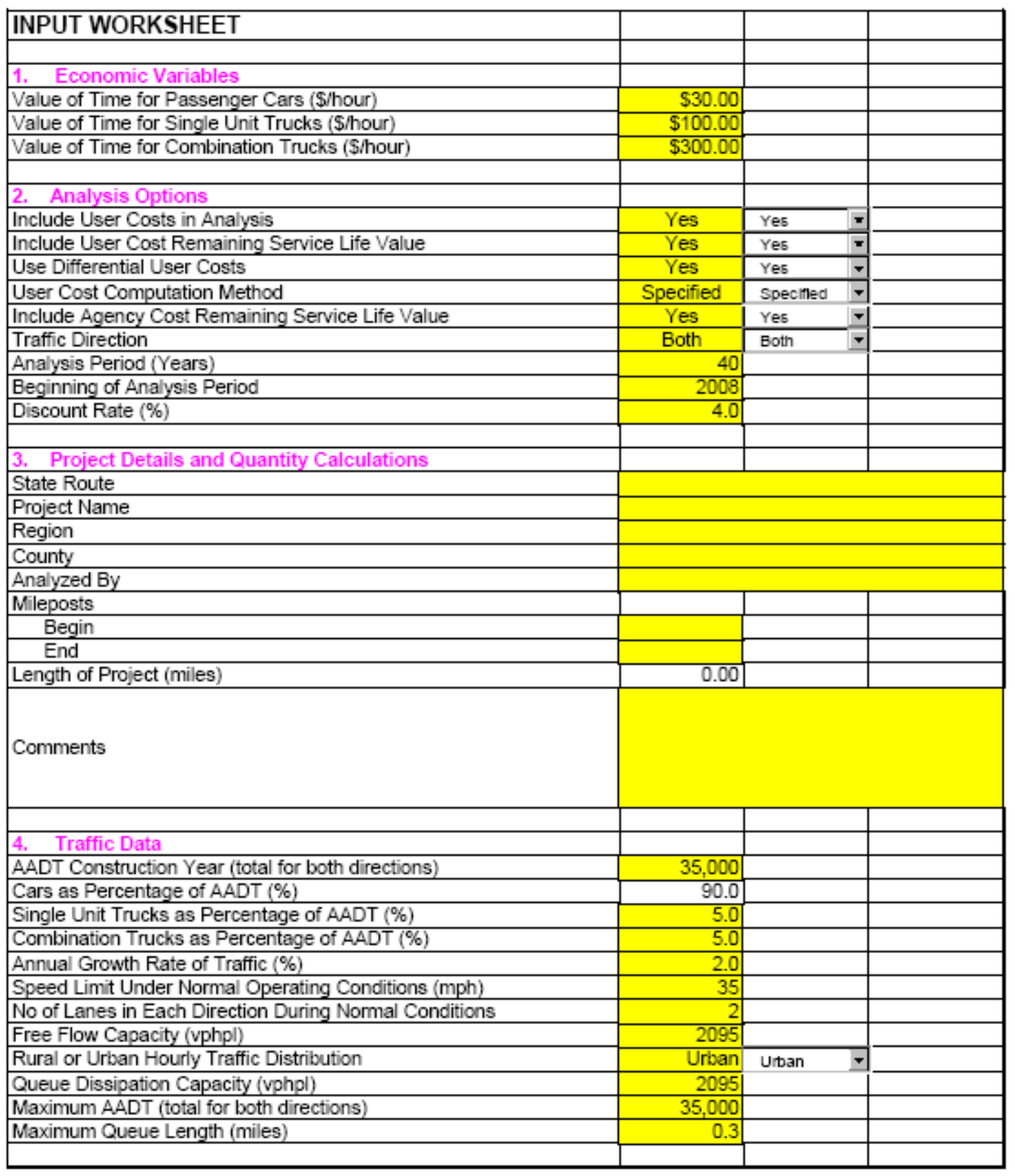


Probabilistic Life Cycle Cost Analysis Worksheet

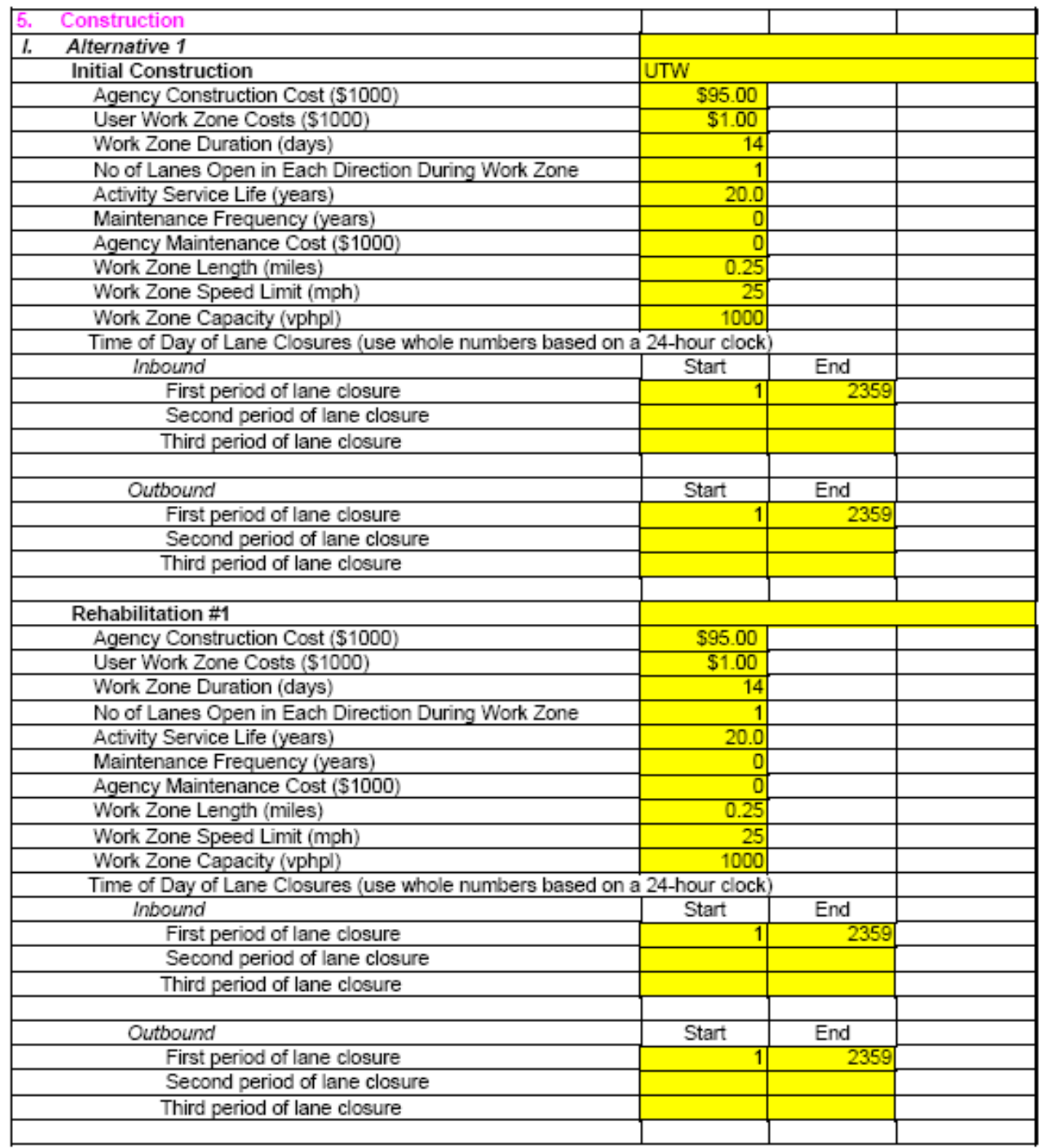


Probabilistic Life Cycle Cost Analysis Worksheet

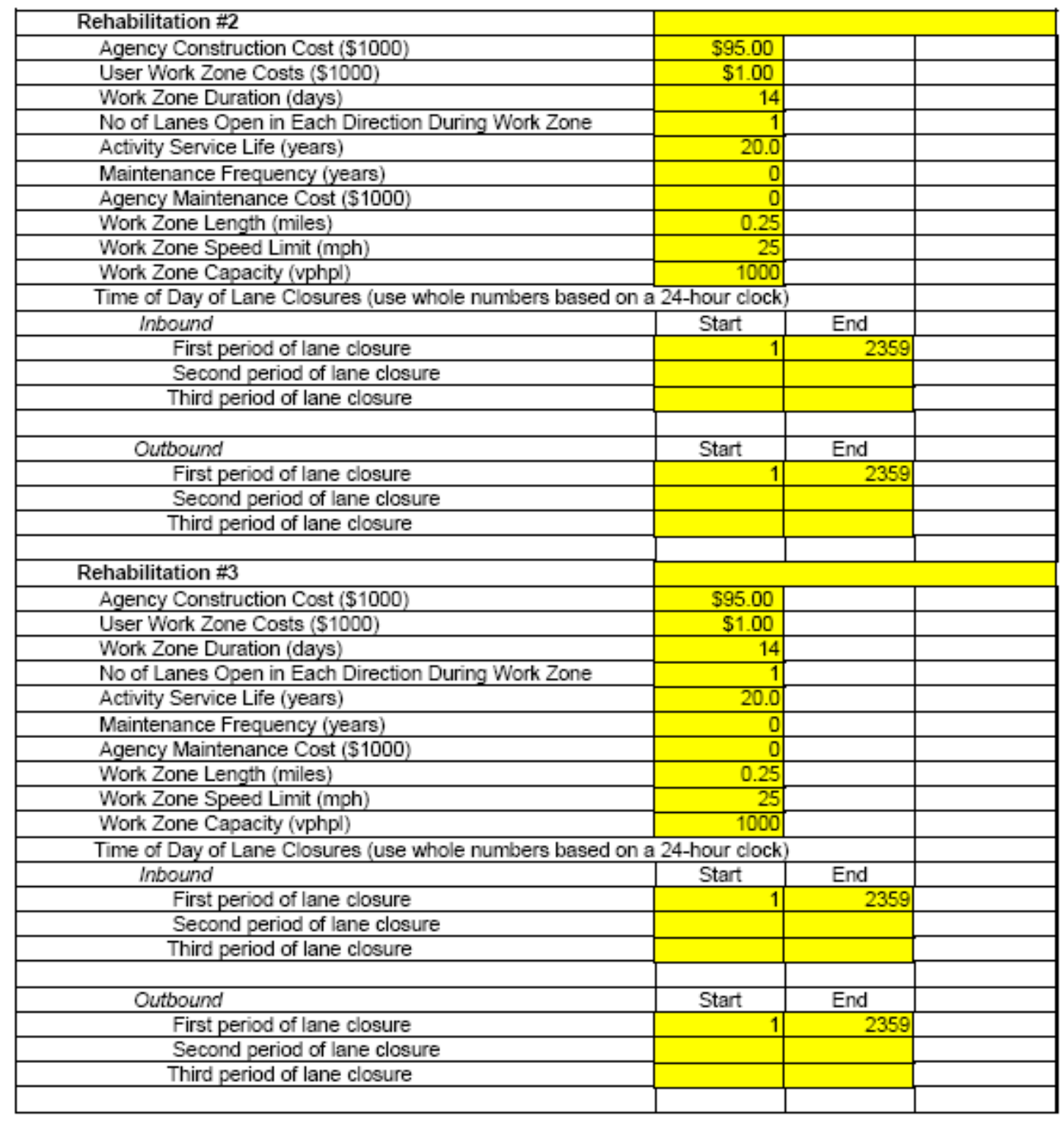


Probabilistic Life Cycle Cost Analysis Worksheet

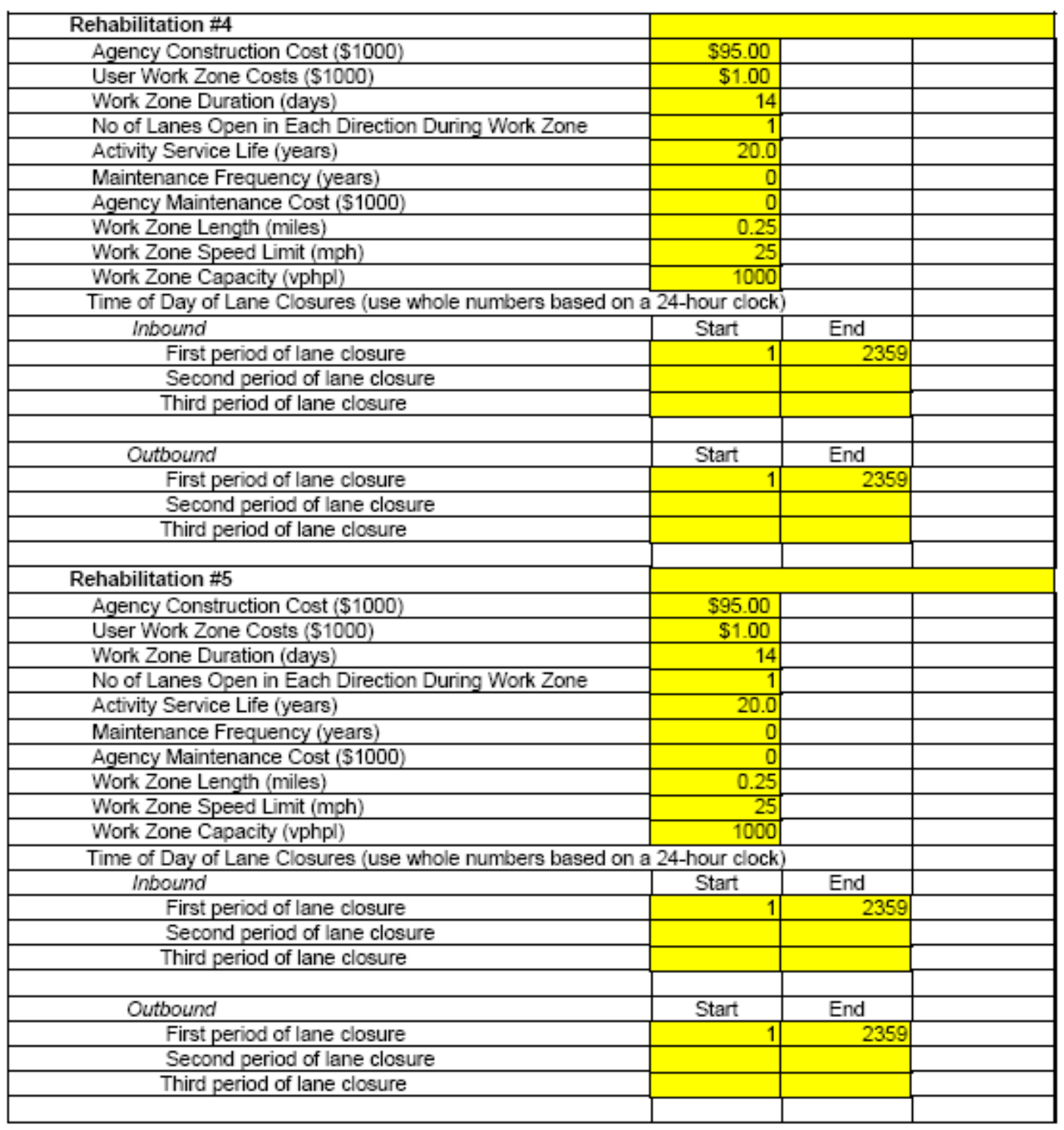


Probabilistic Life Cycle Cost Analysis Worksheet

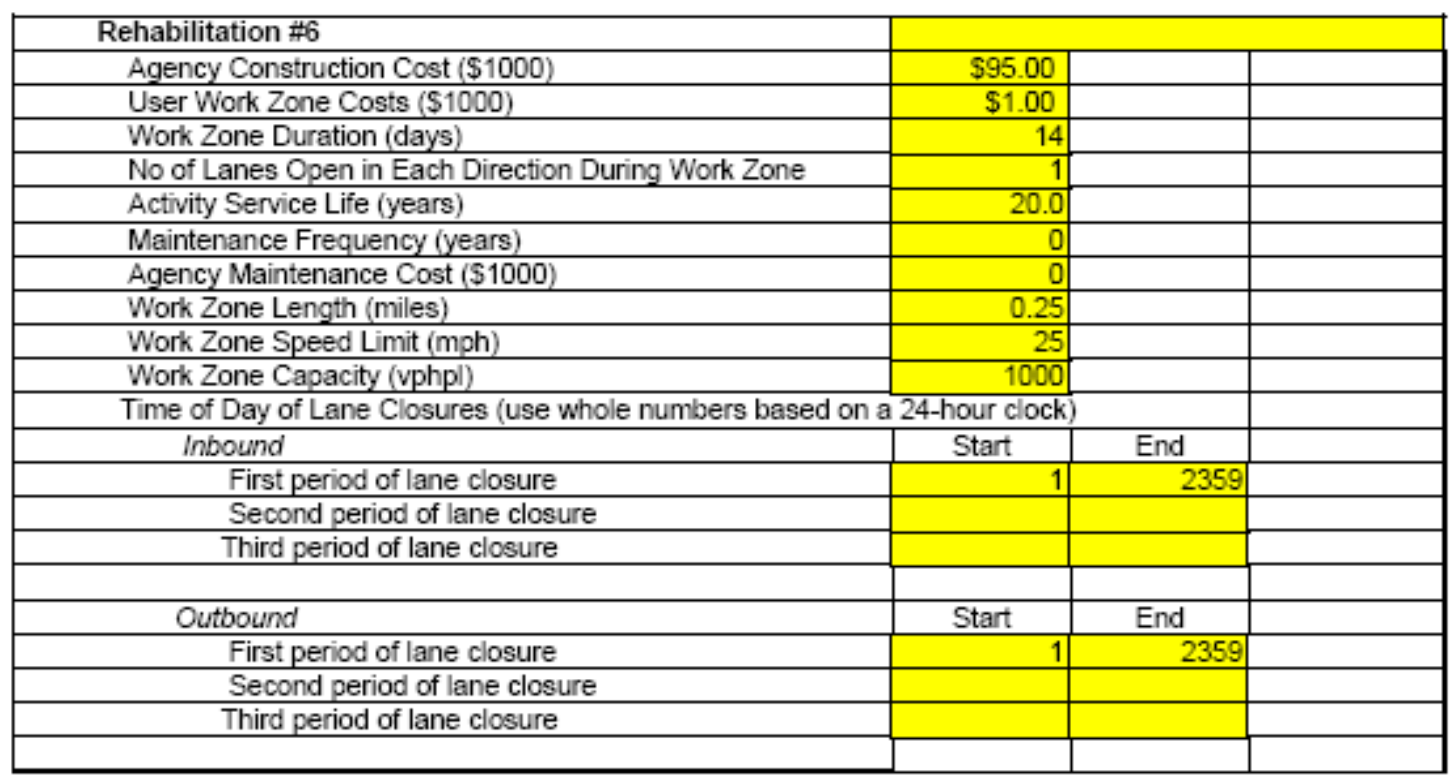




\section{Probabilistic Life Cycle Cost Analysis Worksheet}

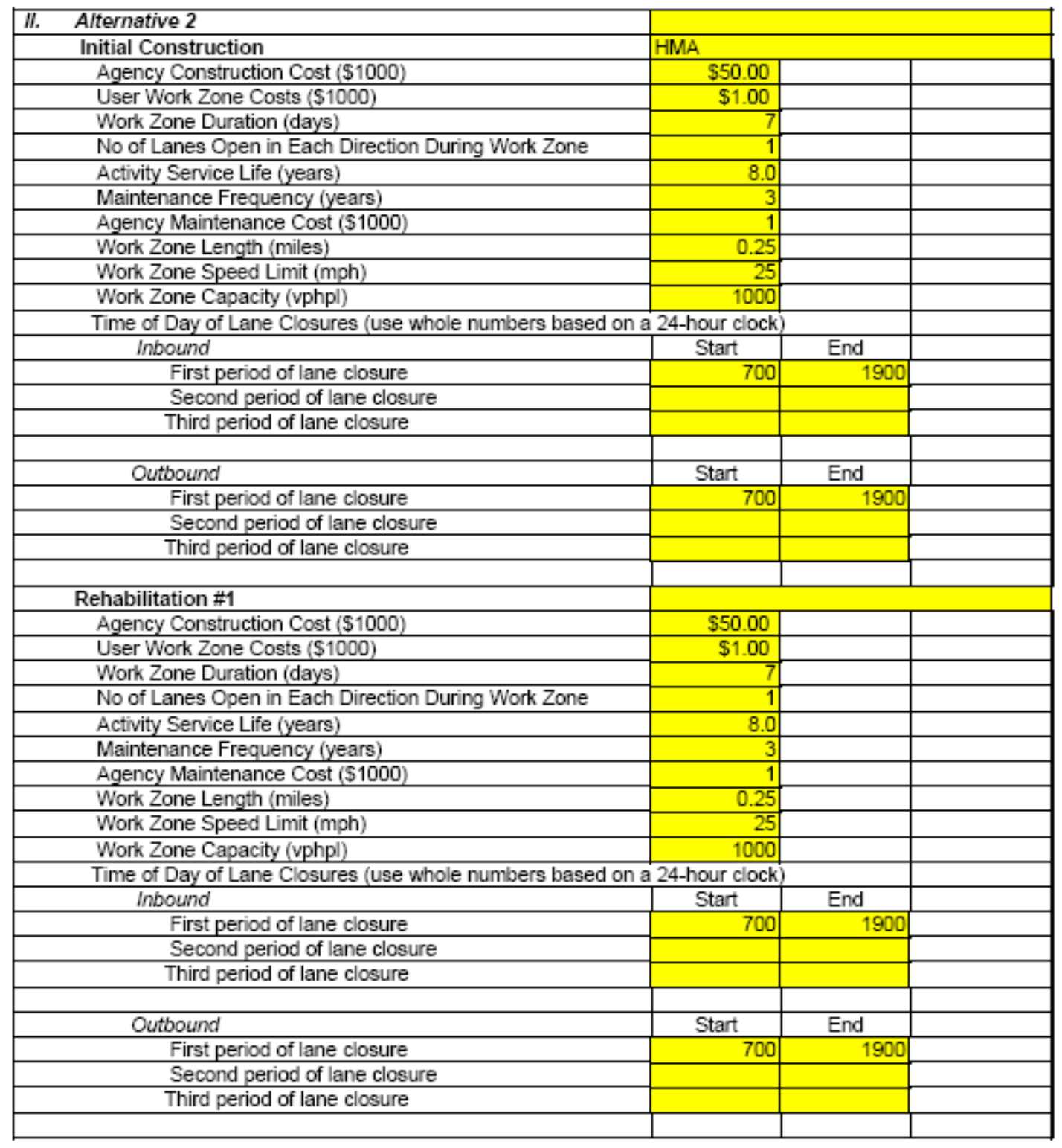




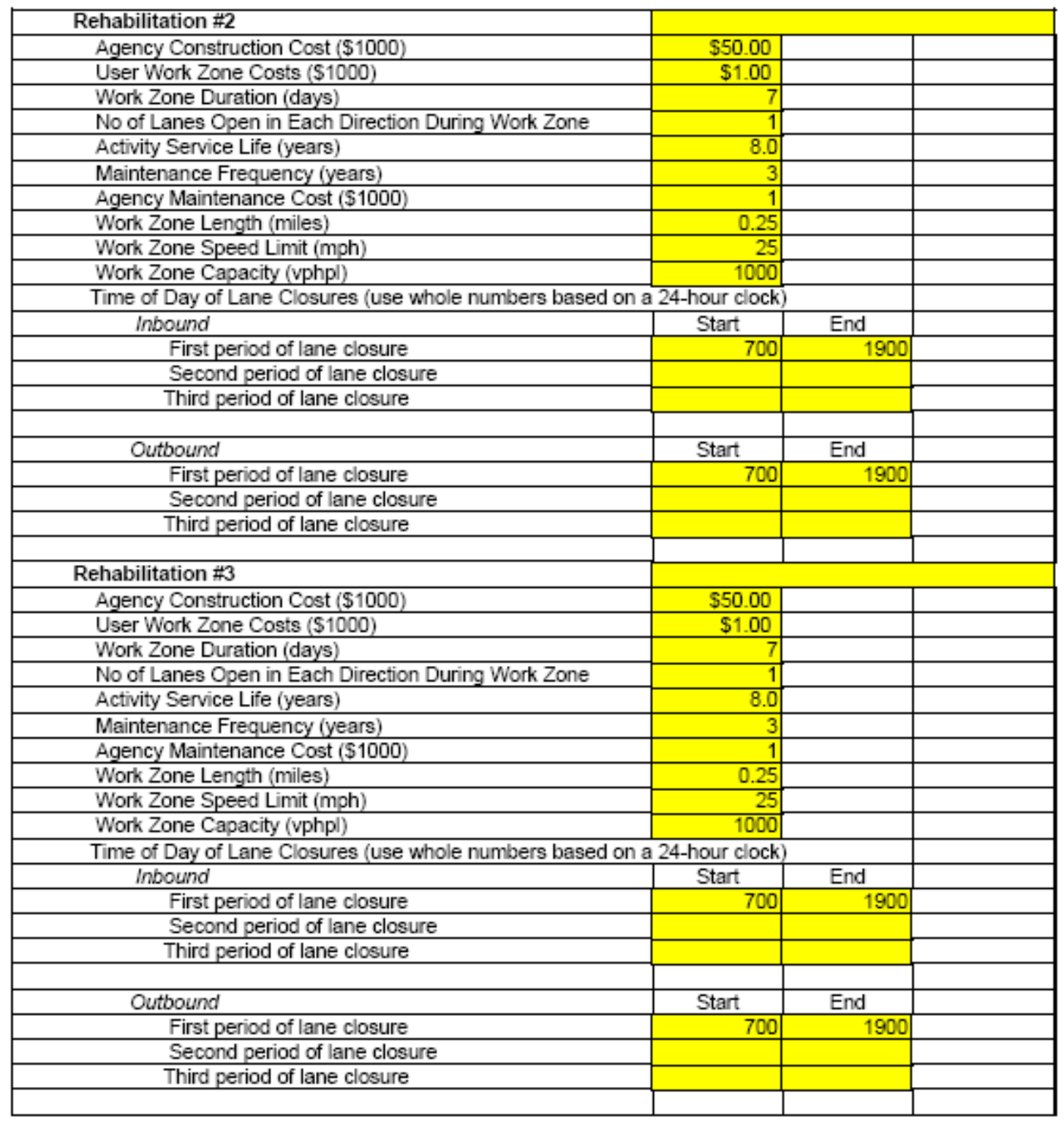


Probabilistic Life Cycle Cost Analysis Worksheet

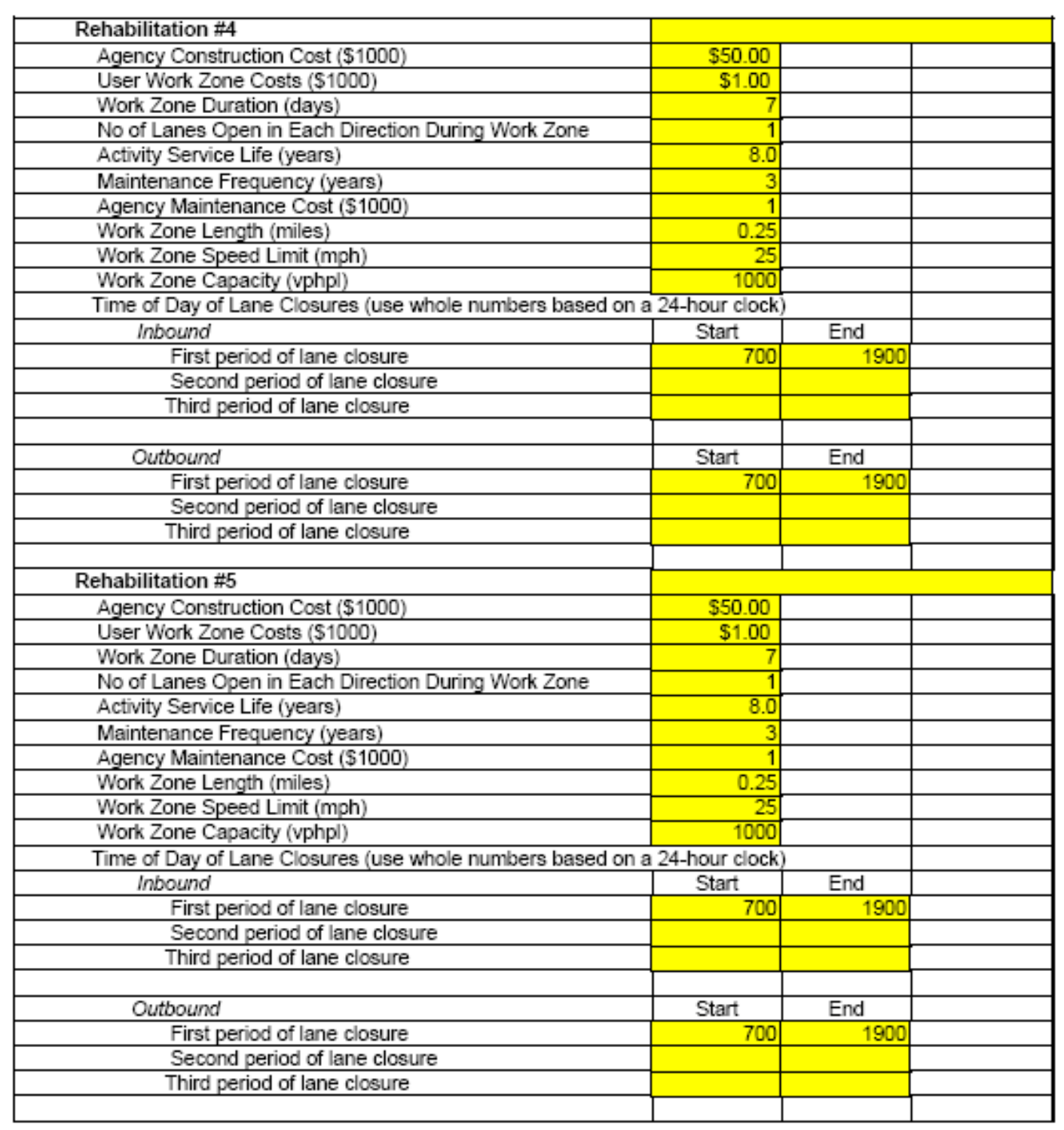




\section{Probabilistic Life Cycle Cost Analysis Worksheet}

\begin{tabular}{|c|c|c|c|}
\hline Rehabilitation \#6 & & & \\
\hline Agency Construction Cost (\$1000) & $\$ 50.00$ & & \\
\hline User Work Zone Costs $(\$ 1000)$ & $\$ 1.00$ & & \\
\hline Work Zone Duration (days) & 7 & & \\
\hline No of Lanes Open in Each Direction D & 1 & & \\
\hline Activity Service Life (years) & 8.0 & & \\
\hline Maintenance Frequency (years) & 3 & & \\
\hline Agency Maintenance Cost (\$1000) & 1 & & \\
\hline Work Zone Length (miles) & 0.25 & & \\
\hline Work Zone Speed Limit (mph) & 25 & & \\
\hline Work Zone Capacity (vphpl) & 1000 & & \\
\hline \multicolumn{4}{|c|}{ Time of Day of Lane Closures (use whole numbers based on a 24-hour clock) } \\
\hline Inbound & Start & End & \\
\hline First period of lane closure & 700 & 1900 & \\
\hline \multirow{2}{*}{\multicolumn{4}{|c|}{$\begin{array}{l}\text { Second period of lane closure } \\
\text { Third period of lane closure }\end{array}$}} \\
\hline & & & \\
\hline Outbound & Start & End & \\
\hline First period of lane closure & 700 & 1900 & \\
\hline Second period of lane closure & & & \\
\hline Third period of lane closure & & & \\
\hline
\end{tabular}

